UNIVERSIDAD POLITÉCNICA DE MADRID

ESCUELA TÉCNICA SUPERIOR DE INGENIEROS DE CAMINOS, CANALES Y PUERTOS

\title{
COMPORTAMIENTO DE PILARES DE HORMIGÓN ARMADO CONFINADOS CON MATERIALES COMPUESTOS SOMETIDOS A COMPRESIÓN CENTRADA
}

TESIS DOCTORAL

\author{
Ana de Diego Villalón \\ Ingeniero de Caminos, Canales y Puertos
}

Madrid, 2015 


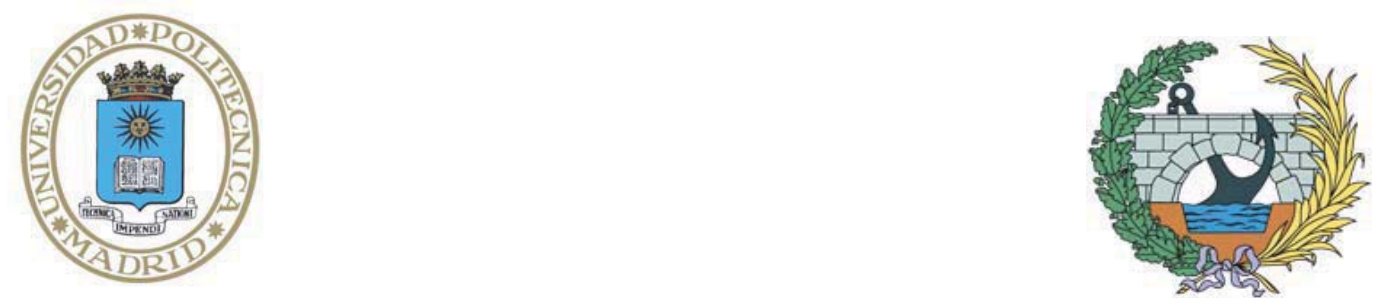

DEPARTAMENTO DE INGENIRÍA CIVIL. CONSTRUCCIÓN

ESCUELA TÉCNICA SUPERIOR DE INGENIEROS DE CAMINOS, CANALES Y PUERTOS

\title{
COMPORTAMIENTO DE PILARES DE HORMIGÓN ARMADO CONFINADOS CON MATERIALES COMPUESTOS SOMETIDOS A COMPRESIÓN CENTRADA
}

\section{TESIS DOCTORAL}

\author{
Ana de Diego Villalón \\ Ingeniero de Caminos, Canales y Puertos \\ Directores: \\ Ángel Arteaga Iriarte \\ Doctor Ingeniero de Caminos, Canales y Puertos \\ Jaime Fernández Gómez \\ Doctor Ingeniero de Caminos, Canales y Puertos
}

Madrid, 2015 



\title{
TESIS DOCTORAL
}

\section{COMPORTAMIENTO DE PILARES DE HORMIGÓN ARMADO CONFINADOS CON MATERIALES COMPUESTOS SOMETIDOS A COMPRESIÓN CENTRADA}

\author{
Autora: \\ Ana de Diego Villalón \\ Ingeniero de Caminos, Canales y Puertos
}

Tribunal nombrado por el Magnífico y Excelentísimo Sr. Rector de la Universidad Politécnica de Madrid, el día de de para juzgar la Tesis Doctoral arriba citada, compuesto de la siguiente manera:

Presidente:

Vocal:

Vocal:

Vocal:

Vocal Secretario:

Acuerda otorgarle la calificación de:

EL PRESIDENTE/A de de 



\section{Agradecimientos}

Quiero mostrar mi sincero agradecimiento a todas las personas que me han ayudado, animado y acompañado durante este largo camino y a las instituciones que han contribuido a la financiación de la investigación:

Al Dr. Ángel Arteaga Iriarte y al Dr. Jaime Fernández Gómez por haberme dado la oportunidad de realizar esta tesis doctoral, y por su entera disposición, apoyo y paciencia en la dirección de la misma.

A Cecilio López y a todo el personal de la nave de ensayos del Instituto Eduardo Torroja que han hecho posible y ameno el desarrollo del trabajo experimental: Gabriel Rentero, Javier Barroso, Rafa Soldado, Roberto, Javi, Carlos... Agradezco también a José Pedro Gutiérrez su gran ayuda para completar el programa de ensayos.

A mis compañeros durante estos años, con algunos he compartido muchas horas de trabajo, preocupación por las tesis que no se terminan... y con todos también buenos momentos: Daniel, Albert, Carlos, Miguel, Ramón, Rafa, Sonia, Javi, Vanesa, Luis, Pedro, Carmelo, Marta, Marcos, Filipe, Duc, Camille, los estudiantes de la École des Ponts, y Ricardo y Enrique en la UPM.

Agradezco muchísimo la ayuda de Albert Alzate y Daniel Cisneros, que han sido magníficos compañeros.

Al Gobierno de España y al Consejo Superior de Investigaciones Científicas, por la financiación de los proyectos de investigación BIA2013-49103-C2-1-R, FOM-738 y PIE 201460E049, al Colegio de Ingenieros de Caminos por la concesión de una ayuda para la realización de la tesis y a las empresas SIKA y NECSO por el suministro de material y colaboración en la investigación.

A Alberto y a toda mi familia, muy especialmente a mis padres. 


\section{Resumen}

En la actualidad muchas estructuras de hormigón armado necesitan ser reforzadas debido a diversas razones: errores en el proyecto o construcción, deterioro debido a efectos ambientales, cambios de uso o mayores requerimientos en los códigos.

Los materiales compuestos, también conocidos como polímeros reforzados con fibras (FRP), están constituidos por fibras continuas de gran resistencia y rigidez embebidas en un material polimérico. Los FRP se utilizan cada vez más en aplicaciones estructurales debido a sus excelentes propiedades (elevadas resistencia y rigidez específicas y resistencia a la corrosión).

Una de las aplicaciones más atractivas es el refuerzo de pilares mediante confinamiento para incrementar su resistencia y ductilidad. El confinamiento puede conseguirse pegando capas de FRP envolviendo el pilar en la dirección de los cercos (con las fibras orientadas en dirección perpendicular al eje del elemento).

Se han realizado numerosos estudios experimentales en probetas cilíndricas pequeñas confinadas con encamisados de FRP y sometidas a compresión axial, y se han propuesto varios modelos sobre el hormigón confinado con FRP. Es sabido que el confinamiento de pilares de sección no circular es menos eficiente. En una sección circular, el FRP ejerce una presión de confinamiento uniforme sobre todo el perímetro, mientras que en una sección rectangular la acción de confinamiento se concentra en las esquinas.

Esta tesis presenta los resultados de una investigación experimental sobre el comportamiento de probetas de hormigón de sección cuadrada confinadas con FRP y sometidas a compresión centrada. Se realizaron un total de 42 ensayos investigándose el comportamiento en las direcciones axial y transversal. Las variables del estudio incluyen: la resistencia del hormigón, el tipo de fibras (vidrio o carbono), la cuantía de refuerzo y el radio de curvatura de las esquinas. 
Los resultados de los ensayos realizados muestran que el confinamiento con FRP puede mejorar considerablemente la resistencia y ductilidad de pilares de hormigón armado de sección cuadrada con las esquinas redondeadas. La mejora conseguida es mayor en los hormigones de baja resistencia que en los de resistencia media. La deformación de rotura de la camisa de FRP es menor que la que se obtiene en ensayos de tracción normalizados del laminado, y la eficiencia del confinamiento depende en gran medida del radio de redondeo de las esquinas.

Los resultados se han comparado con los obtenidos según los modelos teóricos más aceptados. Hay dos parámetros críticos en el ajuste de los modelos: el factor de eficiencia de la deformación y el efecto de confinamiento en secciones no circulares. 


\begin{abstract}
Nowadays, many existing RC structures are in need of repair and strengthening for several reasons: design or construction errors, deterioration caused by environmental effects, change in use of the structures or revisions of code requirements.

Composite materials, also known as fibre reinforced polymers (FRP), are composed of high strength and stiffness continuous fibres embedded in a polymer material. FRP materials are being increasingly used in many structural applications due to their excellent properties (high strength- and stiffness-toweight ratio, good corrosion behaviour).

One of the most attractive applications of FRP is the confinement of concrete columns to enhance both strength and ductility. Concrete confinement can be achieved by bonding layers of hoop FRP around the column (fibres oriented perpendicular to the longitudinal axis).

Many experimental studies have been conducted on small-scale plain concrete specimens of circular cross-sections confined with FRP and subjected to pure axial compressive loading, and several design models have been proposed to describe the behaviour of FRP-confined concrete. It is widely accepted that the confinement of non-circular columns is less efficient than the confinement of circular columns. In a circular cross section, the jacket exerts a uniform confining pressure over the entire perimeter. In the case of a rectangular cross section, the confining action is mostly concentrated at the corners.

This thesis presents the results of a comprehensive experimental investigation on the behaviour of axially loaded square concrete specimens confined with FRP. A total of 42 compression tests were conducted, and the behaviour of the specimens in the axial and transverse directions were investigated. The parameters considered in this study are: concrete strength, type of fibres (glass or carbon), amount of FRP reinforcement and corner radius of the cross section.
\end{abstract}


The tests results indicate that FRP confinement can enhance considerably the compressive strength and ductility of RC square columns with rounded corners. The enhancement is more pronounced for low- than for normal-strength concrete. The rupture strain of the FRP jacket is lower than the ultimate strain obtained by standard tensile testing of the FRP material, and the confinement efficiency significantly depends on the corner radius.

The confined concrete behaviour was predicted according to the more accepted theoretical models and compared with experimental results. There are two key parameters which critically influence the fitting of the models: the strain efficiency factor and the effect of confinement in non-circular sections. 


\section{Índice}

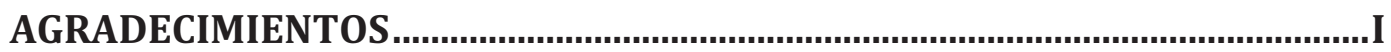

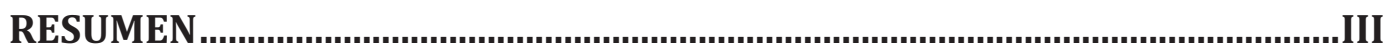

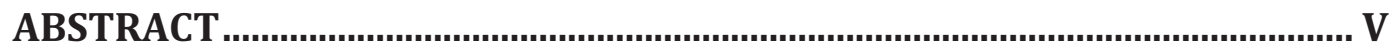

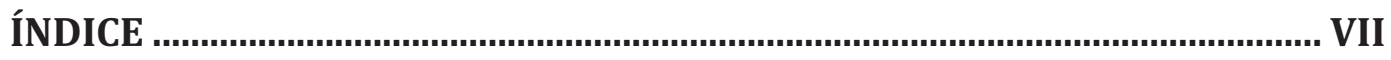

ÍNDICE DE FIGURAS .............................................................................. XIII

INDICE DE TABLAS

NOTACIÓN .................................................................................................... XXI

CAPÍTULO 1: INTRODUCCIÓN Y OBJETIVOS.................................................1

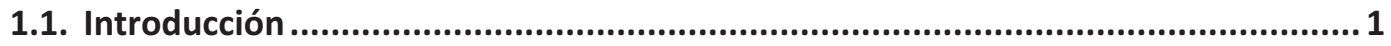

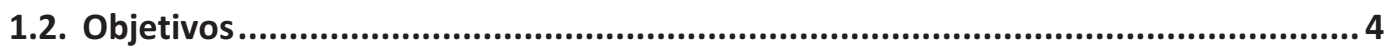

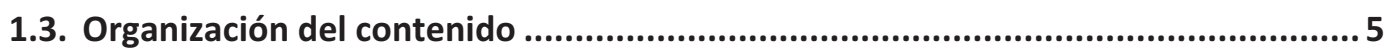

CAPÍTULO 2: ESTADO DEL CONOCIMIENTO .................................................. 7

2.1. Materiales compuestos. Propiedades ................................................................... 7

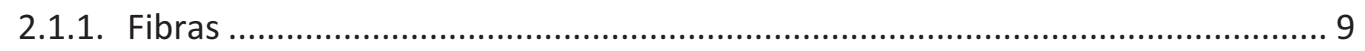

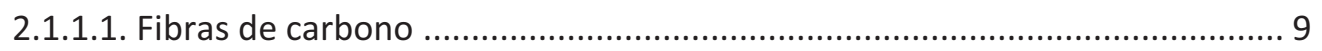

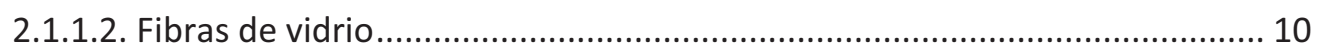

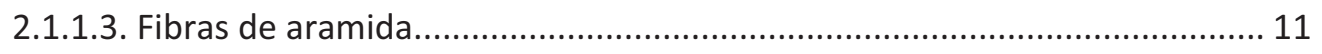

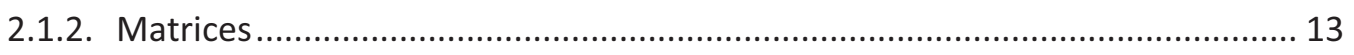

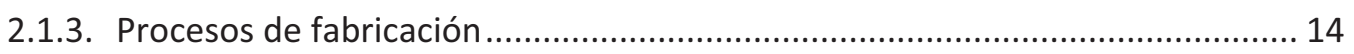

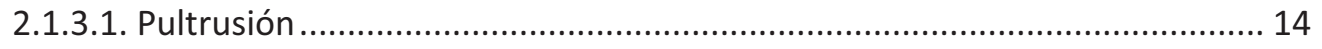

2.1.3.2. Moldeo por contacto manual .................................................................. 15

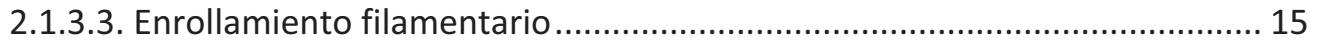


2.1.4. Formatos de FRP para refuerzo de estructuras ................................................. 16

2.1.4.1. Sistemas para moldeo manual en húmedo (wet layup) ..............................16

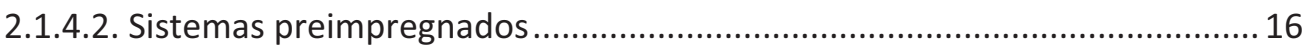

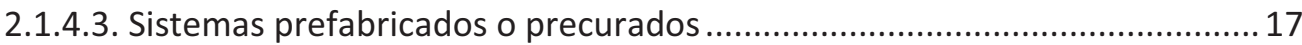

2.1.4.4. Sistemas insertados en el recubrimiento (NSM) ........................................ 17

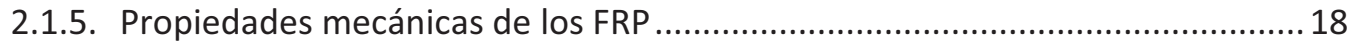

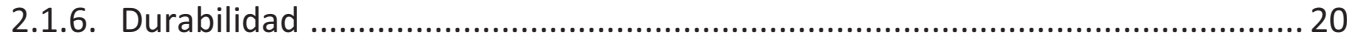

2.2. Utilización de polímeros reforzados con fibras (FRP) en estructuras de

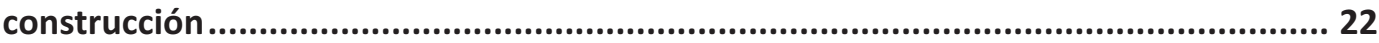

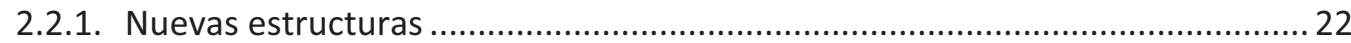

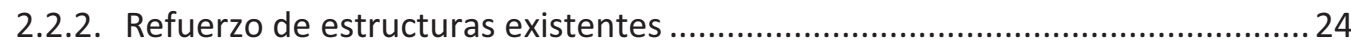

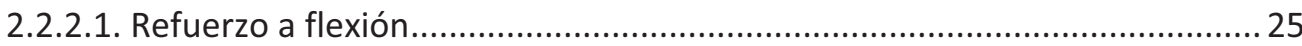

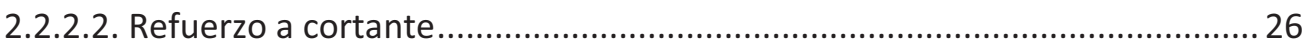

2.2.2.3. Refuerzo de pilares mediante confinamiento............................................... 27

2.3. Refuerzo de pilares de hormigón sometidos a compresión centrada .................. 27

2.3.1. Sistemas de refuerzo con materiales convencionales ..........................................2 28

2.3.1.1. Refuerzo de pilares con hormigón ................................................................ 28

2.3.1.2. Refuerzo de pilares con materiales metálicos ............................................... 29

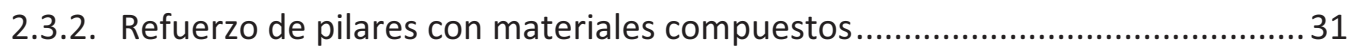

2.4. Comportamiento del hormigón confinado con FRP........................................... 36

2.4.1. Primeros estudios sobre confinamiento activo y hormigón confinado con acero

2.4.1.1. Modelo de Mander et al. (1988) ...................................................................... 38

2.4.2. Hormigón confinado con FRP. Estudios experimentales .................................... 41

2.4.2.1. Respuesta tensión-deformación. Modo de fallo........................................... 44

2.4.2.2. Deformación última efectiva...................................................................... 46

2.4.2.3. Influencia de la forma de la sección. Secciones cuadradas o rectangulares 53

2.4.3. Hormigón confinado con FRP. Modelos teóricos. ............................................55

2.4.3.1. Modelo de Spoelstra y Monti (1999) ...........................................................59

2.4.3.2. Modelo de Lam y Teng (2003) para pilares de sección circular ....................65

2.4.3.3. Modelo de Lam y Teng (2003) para pilares de sección rectangular ............68

2.4.3.4. Modelo de Pham y Hadi (2014) para pilares de sección rectangular ..........70 
CAPÍTULO 3: PROGRAMA EXPERIMENTAL. PARTE I

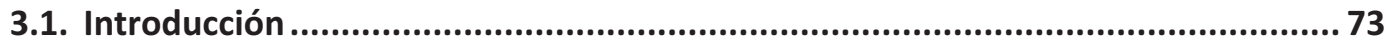

3.2. Descripción del plan de ensayos. Variables estudiadas ......................................... 74

3.3. Preparación de las probetas de hormigón.............................................................. 76

3.4. Materiales empleados en el refuerzo...............................................................79

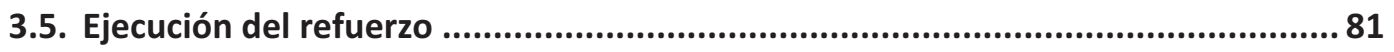

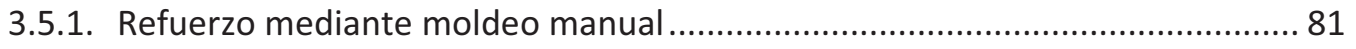

3.5.2. Refuerzo mediante camisas prefabricadas y mixtas .......................................... 83

3.6. Instrumentación y procedimiento de ensayo. .................................................... 84

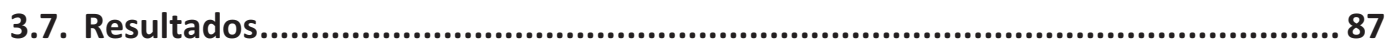

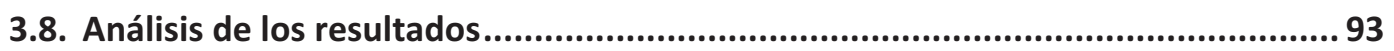

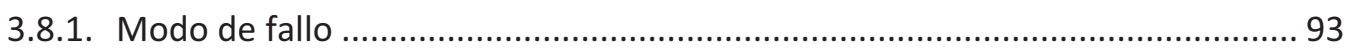

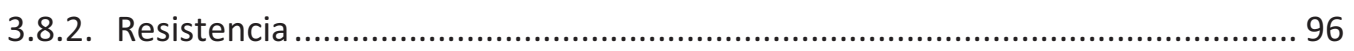

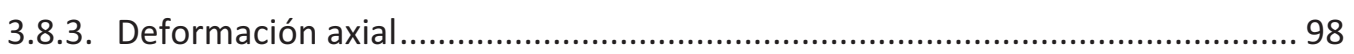

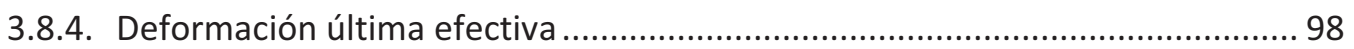

3.8.5. Comportamiento tensión-deformación ......................................................... 101

CAPÍTULO 4: PROGRAMA EXPERIMENTAL. PARTE II............................. 103

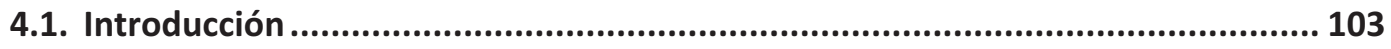

4.2. Descripción del plan de ensayos. Variables estudiadas ..................................... 104

4.3. Preparación de las probetas de hormigón.......................................................... 105

4.4. Materiales empleados en el refuerzo .............................................................. 107

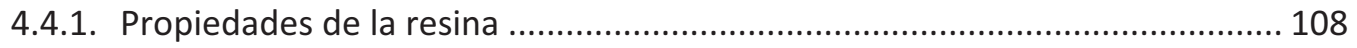

4.4.2. Propiedades de la fibra de carbono ............................................................... 108

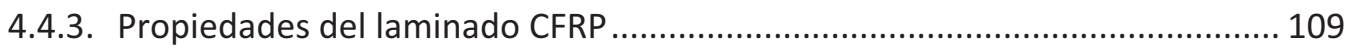

4.4.3.1. Ensayos de tracción del laminado CFRP ................................................. 109

4.5. Ejecución del refuerzo ...................................................................................... 113

4.6. Instrumentación y procedimiento de ensayo..................................................... 117

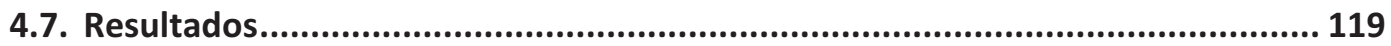

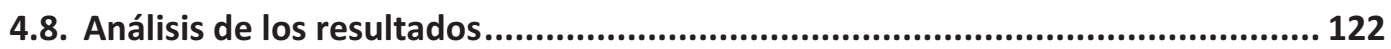




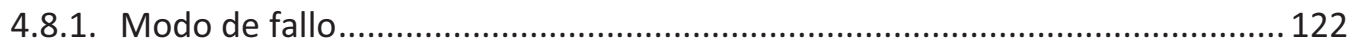

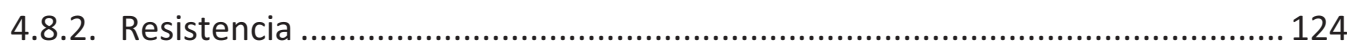

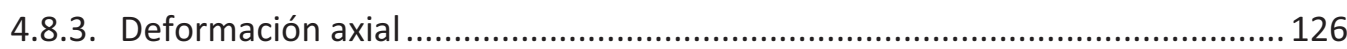

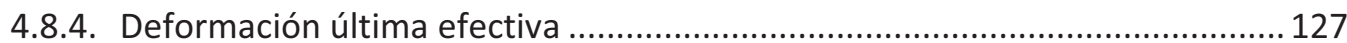

4.8.5. Comportamiento tensión-deformación........................................................ 129

\section{CAPÍTULO 5: ANÁLISIS DE LOS MODELOS DE CÁLCULO PROPUESTOS EN}

LAS GUÍAS .............................................................................................. 135

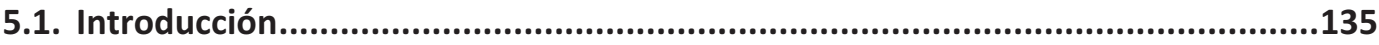

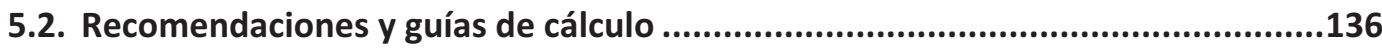

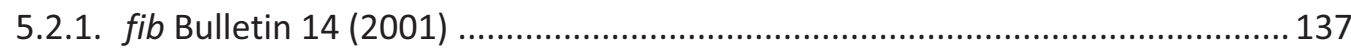

5.2.1.1. Diagrama tensión-deformación y ratio de confinamiento mínimo ............137

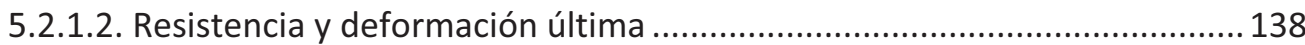

5.2.1.3. Deformación última efectiva del FRP ....................................................... 139

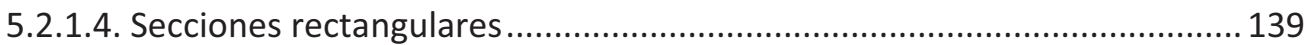

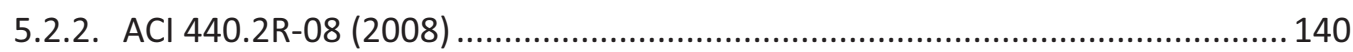

5.2.2.1. Diagrama tensión-deformación y ratio de confinamiento mínimo .............140

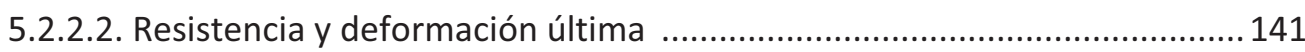

5.2.2.3. Deformación última efectiva del FRP ....................................................... 141

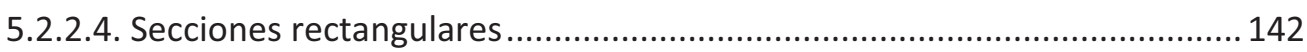

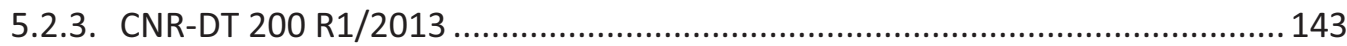

5.2.3.1. Diagrama tensión-deformación y ratio de confinamiento mínimo .............143

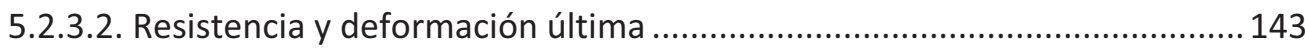

5.2.3.3. Deformación última efectiva del FRP ....................................................... 145

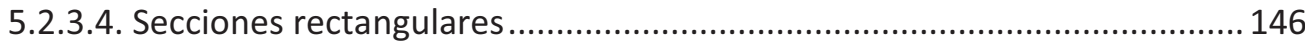

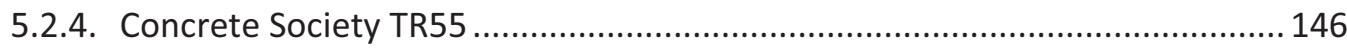

5.2.4.1. Diagrama tensión-deformación y ratio de confinamiento mínimo ............146

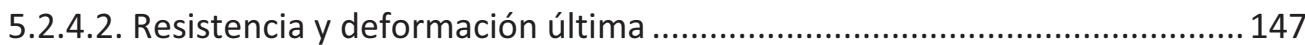

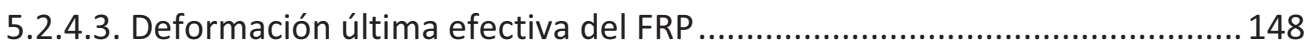

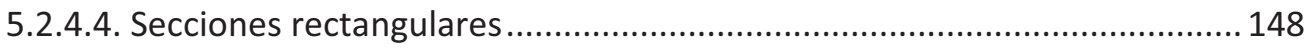

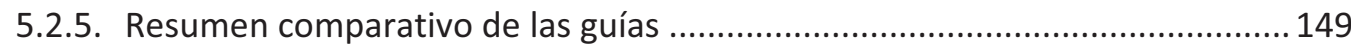


5.3. Comparación con los resultados experimentales ............................................. 152

5.3.1. Hormigones de baja resistencia ................................................................ 156

5.3.2. Deformación última efectiva del FRP ……………...................................... 157

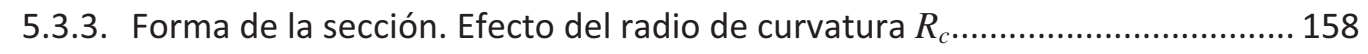

5.3.4. Diagrama tensión-deformación.................................................................. 159

5.3.5. Limitación de la deformación última del hormigón confinado ........................ 160

\section{CAPÍTULO 6: CONCLUSIONES Y LÍNEAS FUTURAS DE INVESTIGACIÓN 161}

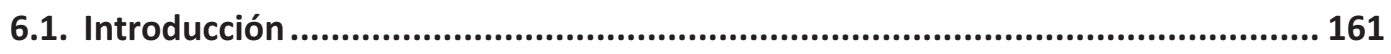

6.2. Conclusiones del estudio experimental...................................................... 161

6.3 Conclusiones derivadas de la comparación de los modelos de cálculo propuestos en las guías y los resultados experimentales ........................................................... 163

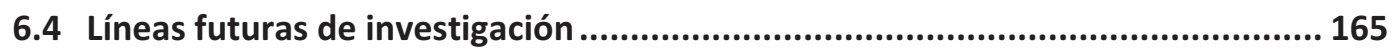

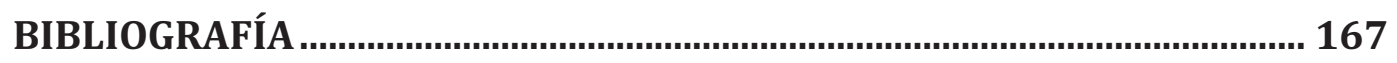

ANEJO A. RESULTADOS EXPERIMENTALES ….............................................

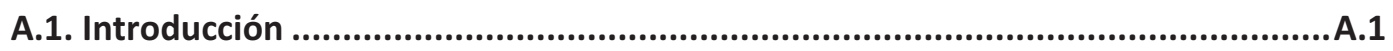

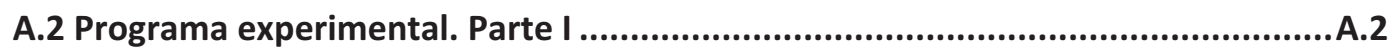

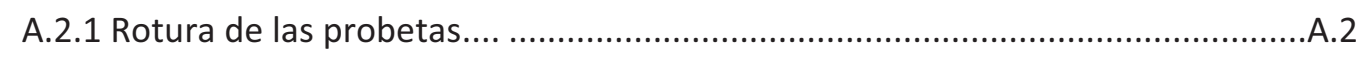

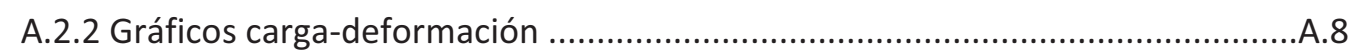

A.3 Programa experimental. Parte II ..................................................................

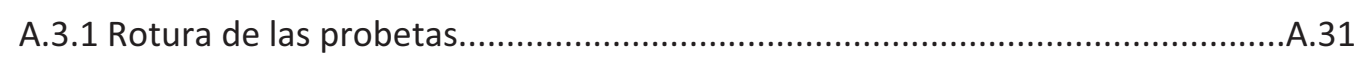

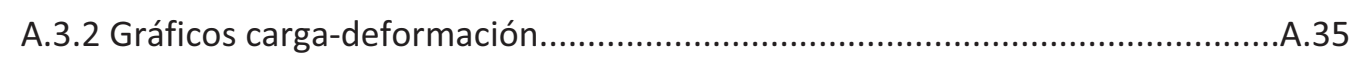




\section{Índice de figuras}

Figura 2.1 Proceso de fabricación de FRP mediante pultrusión

Figura 2.2 Sistema de refuerzo por moldeo manual (Cortesía de SIKA).

Figura 2.3 Sistema de refuerzo con elementos prefabricados (TR55, 2012)

Figura 2.4 Sistema de refuerzo con elementos NSM.

Figura 2.5 Curvas tensión-deformación del FRP y de la fibra y matriz que lo constituyen..

Figura 2.6 Diagrama tensión-deformación de diferentes FRP y acero.

Figura 2.7 Pasarela de Aberfeldy (Escocia, 1992)

Figura 2.8 Construcción del primer puente europeo de FRP (Oxfordshire, UK, 2002).......... 24

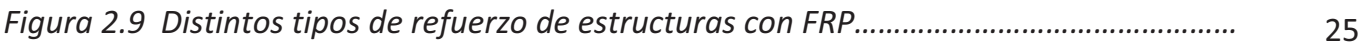

Figura 2.10 Refuerzo a flexión (Cortesía de SIKA)................................................................ 25

Figura 2.11 Modos de fallo de una viga reforzada con un laminado de FRP....................... 26

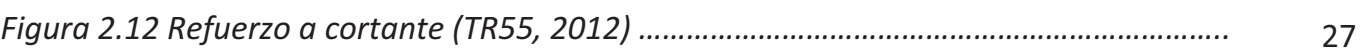

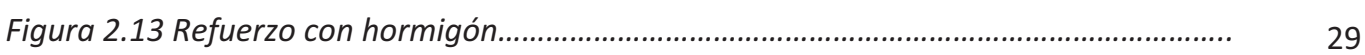

Figura 2.14 Refuerzo con angulares metálicos empresillados (izqda.) y camisa de acero (dcha.)......

Figura 2.15 Redondeo previo de esquinas (cortesía de SIKA) ..............................................

Figura 2.16 Aplicación de fibra de carbono mediante wrapping, enrollamiento filamentario y camisas prefabricadas.

Figura 2.17 Modelo tensión-deformación para hormigón confinado y sin confinar propuesto por Mander et al. (1988)

Figura 2.18 Núcleo de hormigón efectivamente confinado por cercos circulares (Mander et al. 1988).

Figura 2.19 Núcleo de hormigón efectivamente confinado por cercos rectangulares (Mander et al., 1988) .

Figura 2.20 Presión de confinamiento ejercida por el FRP.

Figura 2.21 Curvas tensión-deformación de probetas confinadas con FRP(Aire, 2002).....

Figura 2.22 Comportamiento tensión-deformación del hormigón confinado con FRP (TR55, 2012).

Figura 2.23 Modo de fallo habitual..

Figura 2.24 Ensayos de cupones planos y anillos (tomada de (Chen et al., 2009))......

Figura 2.25 Tensiones en la camisa de FRP.

Figura 2.26 Confinamiento en secciones rectangulares (efecto arco)

Figura 2.27 Obtención de la curva tensión-deformación del hormigón confinado con FRP (Jiang and Teng, 2007) .....

Figura 2.28 Procedimiento iterativo del modelo de Spoelstra y Monti... 
Figura 2.29 Curvas tensión axial deformación axial para hormigón confinado con acero, CFRP y GFRP, según modelo de Spoelstra y Monti..

Figura 2.30 Procedimiento cálculo de la tensión y deformación últimas............................... 64

Figura 2.31 Modelo tensión-deformación propuesto por Lam y Teng ................................. 66

Figura 2.32 Área de confinamiento efectivo en secciones rectangulares............................. 70

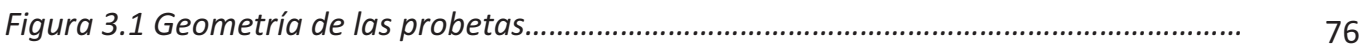

Figura 3.2 Moldes utilizados con molduras para redondeo de esquinas............................. 77

Figura 3.3 Fabricación del hormigón.................................................................................. 77

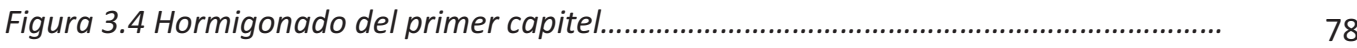

Figura 3.5 Hormigonado del fuste y probetas de control.................................................... 78

Figura 3.6 Hormigonado del segundo capitel...................................................................... 78

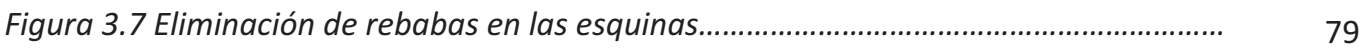

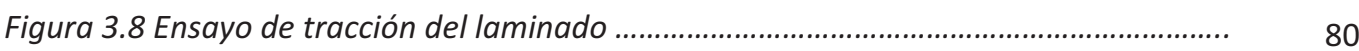

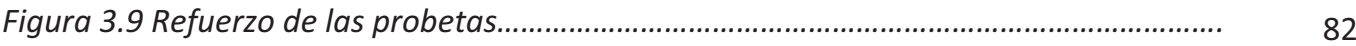

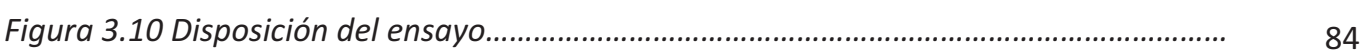

Figura 3.11 Instrumentación mediante captadores de desplazamiento y bandas extensométricas.

Figura 3.12 Deformación lateral en la probeta G_13_a ................................................... 87

Figura 3.13 Rotura de probeta sin reforzar ....................................................................... 87

Figura 3.14 Fallo por rotura del FRP (izqda.) y por despegue del solape (dcha.) ................. 88

Figura 3.15 Curvas tensión-deformación de las probetas reforzadas con fibra de carbono 90

Figura 3.16 Curvas tensión-deformación de las probetas reforzadas con fibra de vidrio... 92

Figura 3.17 Aspecto de las probetas reforzadas con carbono y vidrio en los instantes

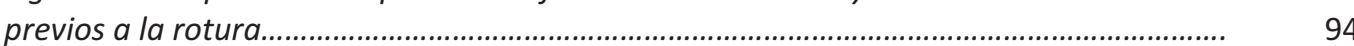

Figura 3.18 Fallo de probetas por despegue del solape....................................................... 94

Figura 3.19 Fallo de probetas por rotura del FRP................................................................... 95

Figura 3.20 Comparación de curvas tensión-deformación de probetas reforzadas con

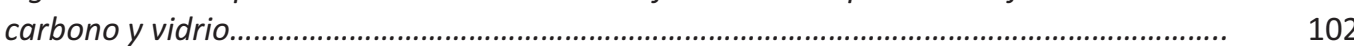

Figura 4.1 Izqda: Moldes utilizados. Dcha: Interior del molde con molduras en las esquinas.

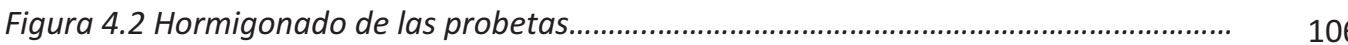

Figura 4.3 Redondeo de las esquinas y limpieza con aire a presión...................................... 107

Figura 4.4 Fibra de carbono y resina epoxi utilizados en el refuerzo.................................... 107

Figura 4.5 Ensayo de tracción del laminado CFRP............................................................... 111

Figura 4.6 Comportamiento tensión-deformación de las probetas ensayadas................... 112

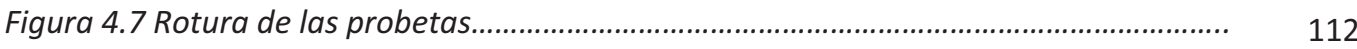

Figura 4.8 Corte de la fibra de carbono y mezclado de la resina.......................................... 115

Figura 4.9 Aplicación de fibra y resina sobre la probeta mediante wrapping...................... 116

Figura 4.10 Dispositivo de ensayo e instrumentación en probetas 0_a y 0_b...................... 117

Figura 4.11 Instrumentación en probetas reforzadas............................................................ 118 
Figura 4.12 Dispositivo de ensayo de las probetas reforzadas.

Figura 4.13 Modo de fallo típico en las probetas patrón (izquierda) y en las probetas reforzadas (derecha).

Figura 4.14 Curvas carga-deformación.

Figura 4.15 Rotura de las probetas sin reforzar 0_a y $0 \_b .$.

Figura 4.16 Rotura de las probetas reforzadas (1_20_b, 1_40_a, 2_20_b, 2_40_b, 3_20_by3_40_a).

Figura 4.17 Comportamiento tensión-deformación de todas las probetas ensayadas ......

Figura 4.18 Comportamiento tensión-deformación de probetas reforzadas con una capa

Figura 4.19 Comportamiento tensión-deformación de probetas reforzadas con 2 capas...

Figura 4.20 Comportamiento tensión-deformación de probetas reforzadas con 3 capas...

Figura 4.21 Comportamiento tensión-deformación de probetas con $R c=20 \mathrm{~mm}$.

Figura 4.22 Comportamiento tensión-deformación de probetas con $R c=40 \mathrm{~mm}$.

Figura 5.1 Diagrama tensión-deformación según modelo de Spoelstra y Monti.................. 138

Figura 5.2 Área efectivamente confinada en secciones rectangulares...

Figura 5.3 Vista en alzado de un elemento circular con refuerzo discontinuo con bandas de FRP.

Figura 5.4 Comparación del incremento de resistencia experimental y las predicciones de las guías.

Figura 5.5 Comparación del incremento de deformación axial experimental y las predicciones de las guías.

Figura A.1 Rotura de la probetas sin refuerzo ( $a$ y b)

Figura A.2 Rotura de las probetas C_8.8_a y C_8.8_b.

Figura A.3 Rotura de las probetas G_8.8_a y G_8.8_b

Figura A.4 Rotura de las probetas C_13_a y C_13_b

Figura A.5 Rotura de las probetas G_13_a y G_13_b.

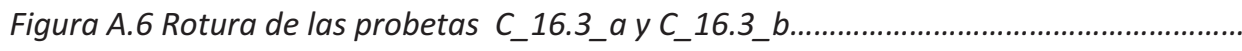

Figura A.7 Rotura de las probetas C_16.5_a, C_16.5_bYC_16.5_c.......

Figura A.8 Rotura de las probetas G_16.5_a, G_16.5_bY G_16.5_c.

Figura A.9 Rotura de las probetas C_16.7_a y C_16.7_b..

Figura A.10 Rotura de las probetas G_16.7_a y G_16.7_b.

Figura A.11 Rotura de las probetas C_17.5_a y C_17.5_b......

Figura A.12 Rotura de las probetas G_17.5_a y G_17.5_b.

Figura A.13 Rotura de las probetas C_26.4_a y C_26.4_b

Figura A.14 Curvas carga-deformación en la probeta 0_26.4_a..

Figura A.15 Curvas carga-deformación axial en la probeta $C$ _8.8_b.

Figura A.16 Curvas carga-deformación lateral en la probeta C_8.8_b.

Figura A.17 Curvas carga-deformación axial en la probeta G_8.8_b.

Figura A.18 Curvas carga-deformación lateral en la probeta G_8.8_b.

Figura A.19 Curvas carga-deformación axial en la probeta C_13_a... 
Figura A.20 Curvas carga-deformación lateral en la probeta C_13_a..

Figura A.21 Curvas carga-deformación axial en la probeta C_13_b...

Figura A.22 Curvas carga-deformación lateral en la probeta C_13_b................................. A.12

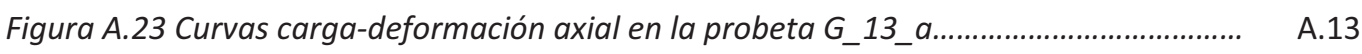

Figura A.24 Curvas carga-deformación lateral en la probeta G_13_a................................. A.13

Figura A.25 Curvas carga-deformación axial en la probeta $G_{\text {_ }} 13$ _b.................................... A.14

Figura A.26 Curvas carga-deformación lateral en la probeta $G_{-} 13$ _b................................. A.14

Figura A.27 Curvas carga-deformación axial en la probeta C_16.3_a................................. A.15

Figura A.28 Curvas carga-deformación lateral en la probeta C_16.3_a................................. A.15

Figura A.29 Curvas carga-deformación axial en la probeta C_16.3_b................................. A.16

Figura A.30 Curvas carga-deformación lateral en la probeta C_16.3_b............................... A.16

Figura A.31 Curvas carga-deformación axial en la probeta C_16.5_b................................ A.17

Figura A.32 Curvas carga-deformación lateral en la probeta C_16.5_b.............................. A.17

Figura A.33 Curvas carga-deformación axial en la probeta $C_{2} 16.5$ _c................................... A.18

Figura A.34 Curvas carga-deformación lateral en la probeta C_16.5_c.............................. A.18

Figura A.35 Curvas carga-deformación axial en la probeta $G_{\text {_ }} 16.5$ _b................................. A.19

Figura A.36 Curvas carga-deformación lateral en la probeta G_16.5_b.............................. A.19

Figura A.37 Curvas carga-deformación axial en la probeta G_16.5_c................................ A.20

Figura A.38 Curvas carga-deformación lateral en la probeta G_16.5_c................................. A.20

Figura A.39 Curvas carga-deformación axial en la probeta C_16.7_a................................ A.21

Figura A.40 Curvas carga-deformación lateral en la probeta C_16.7_a................................ A.21

Figura A.41 Curvas carga-deformación axial en la probeta C_16.7_b................................. A.22

Figura A.42 Curvas carga-deformación lateral en la probeta C_16.7_b............................... A.22

Figura A.43 Curvas carga-deformación axial en la probeta G_16.7_a................................. A.23

Figura A.44 Curvas carga-deformación lateral en la probeta G_16.7_a............................. A.23

Figura A.45 Curvas carga-deformación axial en la probeta G_16.7_b................................. A.24

Figura A.46 Curvas carga-deformación lateral en la probeta G_16.7_b............................. A.24

Figura A.47 Curvas carga-deformación axial en la probeta $C$ _17.5_a................................ A.25

Figura A.48 Curvas carga-deformación lateral en la probeta C_17.5_a............................... A.25

Figura A.49 Curvas carga-deformación axial en la probeta C_17.5_b................................. A.26

Figura A.50 Curvas carga-deformación lateral en la probeta C_17.5_b............................... A.26

Figura A.51 Curvas carga-deformación axial en la probeta G_17.5_a............................... A.27

Figura A.52 Curvas carga-deformación lateral en la probeta G_17.5_a............................. A.27

Figura A.53 Curvas carga-deformación axial en la probeta G_17.5_b................................. A.28

Figura A.54 Curvas carga-deformación lateral en la probeta G_17.5_b.............................. A.28

Figura A.55 Curvas carga-deformación axial en la probeta C_26.4_a................................. A.29

Figura A.56 Curvas carga-deformación lateral en la probeta C_26.4_a............................... A.29 
Figura A.57 Curvas carga-deformación axial en la probeta C_26.4_b.

Figura A.58 Curvas carga-deformación lateral en la probeta C_26.4_b...

Figura A.59 Rotura de las probetas 0_a y 0_b.....

Figura A.60 Rotura de las probetas 1_20_a y 1_20_b.

Figura A.61 Rotura de las probetas 1_40_a y 1_40_b.

Figura A.62 Rotura de las probetas 2_20_a y 2_20_b.

Figura A.63 Rotura de las probetas 2_40_a y 2_40_b.

Figura A.64 Rotura de las probetas 3_20_a y 3_20_b.

Figura A.65 Rotura de las probetas 3_40_a y 3_40_b.

Figura A.66 Curvas carga-deformación en la probeta 0_a.

Figura A.67 Curvas carga-deformación axial en la probeta $0 \_b$.

Figura A.68 Curvas carga-deformación lateral en la probeta $0 \_b$.

Figura A.69 Curvas carga-deformación axial en la probeta 1_20_a......

Figura A.70 Curvas carga-deformación lateral en la probeta 1_20_a.

Figura A.71 Curvas carga-deformación axial en la probeta 1_20_b.

Figura A.72 Curvas carga-deformación lateral en la probeta 1_20_b.

Figura A.73 Curvas carga-deformación axial en la probeta 1_40_a.

Figura A.74 Curvas carga-deformación lateral en la probeta 1_40_a.

Figura A.75 Curvas carga-deformación axial en la probeta 1_40_b.

Figura A.76 Curvas carga-deformación lateral en la probeta 1_40_b.

A.40

Figura A.77 Curvas carga-deformación axial en la probeta 2_20_a.

Figura A.78 Curvas carga-deformación lateral en la probeta 2_20_a.

Figura A.79 Curvas carga-deformación axial en la probeta 2_20_b.

Figura A.80 Curvas carga-deformación lateral en la probeta 2_20_b.

Figura A.81 Curvas carga-deformación axial en la probeta 2_40_a.

Figura A.82 Curvas carga-deformación lateral en la probeta 2_40_a.

Figura A.83 Curvas carga-deformación axial en la probeta 2_40_b.

Figura A.84 Curvas carga-deformación lateral en la probeta 2_40_b.

Figura A.85 Curvas carga-deformación axial en la probeta 3_20_a.

Figura A.86 Curvas carga-deformación lateral en la probeta 3_20_a.

Figura A.87 Curvas carga-deformación axial en la probeta 3_20_b.

Figura A.88 Curvas carga-deformación lateral en la probeta 3_20_b.

Figura A.89 Curvas carga-deformación axial en la probeta 3_40_a.

Figura A.90 Curvas carga-deformación lateral en la probeta 3_40_a.

Figura A.81 Curvas carga-deformación axial en la probeta 3_40_b. 


\section{Índice de tablas}

Tabla 2.1 Propiedades típicas de distintas fibras (Miravete, 2000)

Tabla 2.2 Comparación cualitativa de las propiedades de FRP constituidos por fibras de vidrio-E, aramida, y carbono (Meier, 1995)

Tabla 2.3 Propiedades mecánicas de dos sistemas de refuerzo con fibra de carbono de

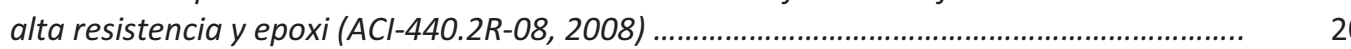

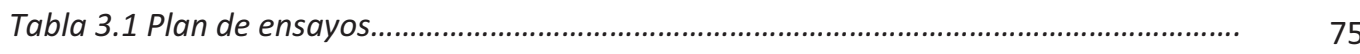

Tabla 3.2 Propiedades mecánicas de las fibras, suministradas por los fabricantes............. 80

Tabla 3.3 Propiedades mecánicas de los laminados................................................................

Tabla 3.4 Resumen de resultados experimentales................................................................ 89

Tabla 3.5 Resultados experimentales. Incremento de resistencia y deformación axial en probetas reforzadas con fibra de carbono.

Tabla 3.6 Resultados experimentales. Incremento de resistencia y deformación axial en probetas reforzadas con fibra de vidrio.

Tabla 3.7 Deformación última efectiva en probetas reforzadas con fibra de carbono........

Tabla 3.8 Deformación última efectiva en probetas reforzadas con fibra de vidrio............. 100

Tabla 4.1 Plan de ensayos........................................................................................................ 105

Tabla 4.2 Propiedades mecánicas de la resina epoxi............................................................ 108

Tabla 4.3 Propiedades de la fibra de carbono en seco........................................................... 109

Tabla 4.4 Propiedades del laminado carbono/epoxi suministradas por el fabricante......... 109

Tabla 4.5 Resultados de los ensayos de tracción del laminado.............................................. 113

Tabla 4.6 Resumen de resultados experimentales................................................................... 120

Tabla 4.7 Resultados experimentales. Incremento de resistencia. ..................................... 125

Tabla 4.8 Resultados experimentales. Deformación axial última. ......................................... 126

Tabla 4.9 Resultados experimentales. Deformación última efectiva. ................................... 128

Tabla 5.1 Ecuaciones para el cálculo de la resistencia y deformación última en las guías.. 150

Tabla 5.2 Ecuaciones para el cálculo de la resistencia y deformación última en las guías.. 154 


\section{Notación}

\section{Mayúsculas romanas}

$A_{g} \quad$ área total de la sección de hormigón

$A_{e}$ área de la sección de hormigón efectivamente confinada

$A_{s}$ sección de acero longitudinal

$A_{s t}$ sección de acero transversal

$D$ diámetro de la sección

$E_{c}$ módulo de deformación longitudinal del hormigón

$E_{f} \quad$ módulo de elasticidad en tracción del FRP

$E_{f i b}$ módulo de elasticidad en tracción de las fibras

$E_{m} \quad$ módulo de elasticidad en tracción de la matriz

$E_{s e c}$ módulo de deformación longitudinal secante del hormigón

$E_{2}$ pendiente del tramo lineal del modelo tensión-deformación del hormigón confinado con FRP

$R_{c} \quad$ radio de curvatura de las esquinas redondeadas

$T_{g} \quad$ temperatura de transición vítrea de los polímeros termoestables

$V_{f i b}$ fracción de volumen del FRP ocupado por las fibras

\section{Minúsculas romanas}

$b \quad$ lado de la sección en secciones cuadradas (lado mayor en secciones rectangulares)

$d$ lado menor de la sección en secciones rectangulares

$\mathrm{d}_{\mathrm{s}}$ diámetro de los cercos o de la espiral

$f_{c} \quad$ tensión de compresión en el hormigón

$f_{c o}$ resistencia a compresión del hormigón sin confinar

$f_{c c}$ resistencia a compresión del hormigón confinado

$f_{f} \quad$ resistencia a tracción del FRP

$f_{f i b}$ resistencia a tracción de las fibras

$f_{l} \quad$ máxima presión de confinamiento

$f_{m} \quad$ resistencia a tracción de la matriz

$f_{y} \quad$ tensión de plastificación del acero

$k_{\varepsilon} \quad$ factor de eficiencia de la deformación del FRP que tiene en cuenta la relación entre la deformación de rotura del FRP en la camisa y en ensayos de tracción del material

$k_{l} \quad$ factor de incremento de la resistencia en función de la presión lateral

$k_{2} \quad$ factor de incremento de la deformación última en función de la presión lateral

s separación entre cercos o paso de la espiral

$t$ espesor de FRP (o espesor neto de fibras cuando las propiedades del FRP se refieren al área nominal de fibras) 


\section{Minúsculas griegas}

$\alpha_{e}$ factor de forma de la sección rectangular confinada

$\alpha_{s}$ coeficiente que tiene en cuenta la separación entre cercos

$\gamma_{f}$ coeficiente parcial del material FRP

$\varepsilon_{c} \quad$ deformación axial en el hormigón

$\varepsilon_{c o}$ deformación axial del hormigón sin confinamiento cuando alcanza su resistencia a compresión $f_{c o}$

$\varepsilon_{c c} \quad$ deformación axial última del hormigón confinado

$\varepsilon_{j} \quad$ deformación en el FRP

$\varepsilon_{f}$ deformación última del FRP (obtenida en ensayos de tracción material)

$\varepsilon_{f u}$ deformación última efectiva del FRP (deformación de rotura del encamisado de FRP)

$\varepsilon_{l} \quad$ deformación lateral en el hormigón

$\varepsilon_{t}$ deformación axial correspondiente al punto de transición en la curva tensióndeformación del hormigón confinado con FRP

$\eta_{\mathrm{a}}$ coeficiente reductor de las propiedades del FRP según modo de aplicación y exposición (guía CNR)

$\kappa_{\mathrm{a}}$ factor de forma en el cálculo de la resistencia del hormigón confinado (modelo de Lam y Teng y ACl440 para secciones rectangulares)

$\kappa_{b} \quad$ factor de forma en el cálculo de la deformación del hormigón confinado (modelo de Lam y Teng y ACl440 para secciones rectangulares)

$\rho_{f} \quad$ cuantía geométrica de refuerzo de FRP

$\rho_{k} \quad$ ratio de rigidez del confinamiento

$\rho_{s g} \quad$ cuantía geométrica de acero longitudinal

$\rho_{s t} \quad$ cuantía geométrica de acero transversal

$\sigma_{j} \quad$ tensión en la camisa de FRP

$\sigma_{l} \quad$ presión de confinamiento

$\psi_{f}$ coeficiente reductor de la resistencia del FRP considerado en ACI440.2R-08 
CAPÍTULO 1

\section{INTRODUCCIÓN Y OBJETIVOS}

\subsection{Introducción}

Es conocida la necesidad cada vez más frecuente de rehabilitar, reparar y reforzar estructuras. Particularmente en los países desarrollados, que cuentan con un parque de estructuras envejecido, las labores de mantenimiento, rehabilitación y refuerzo están cobrando una gran atención, motivada por criterios económicos, de sostenibilidad y medio ambientales, que llevan a intentar alargar en lo posible la vida útil de las estructuras.

En este contexto, se entiende por refuerzo la modificación de una estructura, no necesariamente dañada, con el propósito de aumentar su capacidad portante o su estabilidad (GEHO-CEB, 1994). El refuerzo puede aplicarse a elementos horizontales (vigas, forjados o tableros de puentes) frente a solicitaciones de flexión (momentos positivos o negativos) o cortante; o a elementos verticales (pilares o pilas) sometidos predominantemente a compresión.

El refuerzo de estructuras es una actividad antigua en la construcción donde desde hace muchos años se han utilizado materiales como el acero o el hormigón. Junto a estos métodos tradicionales de refuerzo, aún válidos, se están desarrollando más recientemente nuevas técnicas que incluyen la utilización de materiales compuestos. 
En esta tesis se emplea el término materiales compuestos para designar a los materiales formados por fibras largas de gran resistencia embebidas en una matriz de resina polimérica, habitualmente conocidos por sus siglas en inglés FRP (Fibre Reinforced Polymers) o polímeros reforzados por fibras.

Estos materiales se empezaron a utilizar tras la segunda guerra mundial y han tenido un desarrollo muy amplio en industrias muy tecnológicas como la automoción, la aeronáutica o la espacial. En el campo de la construcción su introducción ha sido mucho más lenta por su elevado precio, pero aun así su uso se ha ido extendiendo, particularmente en aplicaciones de refuerzo de estructuras, debido a sus excelentes propiedades: gran resistencia, ligereza, durabilidad, etc.

Los laminados de FRP se empezaron a utilizar en el refuerzo de vigas a finales de los años 80 del siglo pasado, en base a las investigaciones llevadas a cabo en los laboratorios del EMPA (Suiza) y rápidamente se introdujeron en otros muchos países, destacando el amplio desarrollo en Estados Unidos, Canadá, Suiza, Italia, Suecia, Grecia, China y Japón; países donde se han creado importantes grupos de investigación.

Una de las aplicaciones más difundidas es el refuerzo mediante confinamiento de pilares de hormigón armado en estructuras existentes como puentes o edificios. El aumento de resistencia a compresión del hormigón cuando se encuentra confinado ha sido estudiado desde principios del siglo $X X$ y se ha aplicado al refuerzo de pilares mediante el zunchado con barras o el uso de presillas metálicas.

Las primeras investigaciones sobre confinamiento con FRP trataron de utilizar los modelos analíticos previamente desarrollados para el confinamiento con acero pero pronto se comprobó que se obtenían resultados inadecuados, debido al comportamiento elástico hasta rotura del FRP. Los modelos de confinamiento con acero suponen una presión de confinamiento constante, hipótesis que es válida para el acero una vez plastificado, pero no para los materiales compuestos, cuya acción de confinamiento se incrementa continuamente a medida que el hormigón se expande lateralmente hasta que se produce la rotura del refuerzo.

Esta diferencia ha llevado a la necesidad de renovar los estudios experimentales en probetas reforzadas con FRP y al planteamiento de nuevos modelos 
analíticos, unos y otros aún escasos hasta la fecha. Los estudios experimentales han demostrado que puede incrementarse considerablemente la resistencia a compresión y la deformación última del hormigón. A medida que el hormigón se comprime axialmente, su deformación lateral por efecto Poisson somete a la camisa de FRP a tensiones de tracción crecientes en la dirección de la fibra, y el fallo se produce habitualmente por la rotura de la misma. Se ha demostrado que esta rotura se produce para un valor de deformación última del FRP (que se denomina deformación última efectiva) mucho menor que la deformación última obtenida en ensayos de tracción normalizados del FRP.

En los últimos años se están proponiendo diferentes modelos teóricos, la mayoría de naturaleza empírica, calibrados a partir de un número más o menos reducido de resultados, casi siempre de ensayos de probetas cilíndricas de pequeño tamaño $(15 \times 30)$ fabricadas con hormigones de resistencia media (30 a $50 \mathrm{MPa}$ ). Estos modelos se han ido incorporando en las guías y recomendaciones de cálculo que se han publicado en los últimos años en diversos países. Algunos estudios que tratan de comparar los distintos modelos con una base de resultados experimentales más amplia recopilada de la literatura señalan la dispersión encontrada en los resultados y ponen de manifiesto especialmente la dificultad para predecir la deformación axial última.

Otro aspecto relevante es la influencia de la forma de la sección. La mayoría de los estudios experimentales se han llevado a cabo en secciones circulares. Los ensayos sobre probetas cuadradas o rectangulares son bastante más escasos, a pesar de que por su mayor uso estas secciones son las que hay que reforzar con más frecuencia, y muestran que el confinamiento es menos efectivo. Incluso algunas de las recomendaciones de cálculo publicadas inicialmente no consideraban la posibilidad de refuerzo con FRP de secciones cuadradas, aunque la experiencia posterior ha demostrado que también pueden conseguirse incrementos de resistencia notables. En cuanto al análisis teórico se trata en general de utilizar los modelos desarrollados para secciones circulares adaptándolos mediante la introducción en el cálculo de coeficientes reductores.

A falta de modelos analíticos seguros y de una experimentación que permita dar seguridad a las formulaciones empíricas, las incertidumbres existentes para el cálculo de refuerzo de pilares por confinamiento con FRP podrían sintetizarse en las siguientes: 
- La mayor parte de la experimentación se ha llevado a cabo sobre probetas pequeñas, en su mayor parte cilíndricas de $15 \times 30$. El comportamiento de elementos a escala natural es complicado por las necesidades de equipamiento que implica en los laboratorios, pero parece evidente que es necesaria la experimentación con elementos de dimensiones superiores que puedan disminuir las incertezas del uso en elementos reales.

- Los ensayos se han realizado mayoritariamente con hormigones de entre 30 y $50 \mathrm{MPa}$ de resistencia a compresión, que ahora son de uso habitual, pero con frecuencia el refuerzo debe llevarse a cabo sobre hormigones antiguos o defectuosos con resistencias muy inferiores.

- Se ha comprobado que la deformación de rotura del FRP en el pilar confinado es sensiblemente inferior a la que se alcanza en ensayos de tracción normalizados del mismo material. Sin embargo la dispersión de los resultados publicados en la literatura es muy grande. Como posibles causas del valor reducido de la deformación última efectiva se han señalado el estado triaxial de tensiones en el FRP, defectos de ejecución, la curvatura de las fibras, etc. Este es un punto esencial para el ajuste de los modelos de cálculo que aún no se ha resuelto.

- La experimentación con secciones cuadradas es muy limitada hasta la fecha. El confinamiento es menos efectivo, y suelen emplearse para el cálculo modelos desarrollados para secciones circulares en los que se introducen coeficientes reductores, para los que también se han hecho distintas propuestas.

\subsection{Objetivos}

Con este trabajo se pretende disminuir las incertidumbres indicadas anteriormente sobre el comportamiento bajo compresión centrada de pilares de hormigón armado de sección cuadrada reforzados externamente con materiales compuestos (FRP).

Los objetivos principales son:

- Hacer una revisión del estado actual del conocimiento sobre el comportamiento del hormigón confinado con FRP, incluyendo los 
estudios experimentales y teóricos, prestando especial atención a las modelos de cálculo más relevantes.

- Con base en el análisis del estado del conocimiento, definir y realizar un programa experimental sobre probetas de hormigón de sección cuadrada y a una escala más representativa que contribuya a mejorar la adecuación de los modelos al caso real. Los objetivos específicos del programa experimental son, en primer lugar estudiar el efecto del confinamiento en hormigones de baja resistencia y verificar en su caso la validez de los modelos; y en segundo lugar estudiar la influencia de diversas variables (la rigidez del FRP, la cuantía de refuerzo y el radio de curvatura en las esquinas) en el comportamiento del hormigón confinado.

- Analizar los modelos propuestos en las principales guías de cálculo publicadas, y verificar su validez en un rango más amplio de parámetros utilizando para ello la base experimental desarrollada en esta tesis doctoral.

\subsection{Organización del contenido}

Este documento consta de 6 capítulos y un anejo.

Tras la introducción y presentación de los objetivos de la tesis, en el capítulo 2 se expone el estado del conocimiento. Dicho capítulo está dividido en cuatro partes, que tratan sobre: los materiales compuestos; su uso en estructuras; los sistemas de refuerzo de pilares sometidos a compresión centrada (recrecidos con hormigón armado, empresillados metálicos y encamisados de FRP); y los principales aspectos del comportamiento del hormigón confinado con FRP.

En los capítulos 3 y 4 se presentan las dos fases del programa experimental realizado y sus resultados. Se han ensayado probetas de sección cuadrada de $150 \times 150 \mathrm{~mm}^{2}$ y altura de $600 \mathrm{~mm}$ que pueden ser consideradas como una escala intermedia entre la escala natural y la habitual en los estudios hasta la fecha (probetas de $300 \mathrm{~mm}$ de altura). En la primera fase se han estudiado pilares con hormigones de baja resistencia con refuerzos de distinta rigidez empleando fibras de vidrio o carbono. En la segunda fase se han ensayado probetas de resistencia media estudiando el efecto de la cuantía de refuerzo y el radio de redondeo de las esquinas de la sección. 
En el capítulo 5 se analizan los principales modelos adoptados por las guías de cálculo más representativas publicadas hasta la fecha y se comparan los resultados obtenidos en las fases experimentales con las formulaciones existentes, lo que lleva a obtener las conclusiones derivadas del estudio que se presentan en el último capítulo junto con las posibles líneas de investigación futura.

Finalmente se incluyen las referencias bibliográficas y un anejo con los resultados experimentales. 
CAPÍTULO 2

\section{ESTADO DEL CONOCIMIENTO}

\subsection{Materiales compuestos. Propiedades}

Se define como material compuesto (Hull and Clyne, 1996) aquel que:

- Consta de dos o más materiales físicamente distintos y separables mecánicamente.

- Puede fabricarse mezclando los distintos materiales de tal forma que la dispersión de un material en el otro pueda hacerse de manera controlada para alcanzar unas propiedades óptimas.

- Sus propiedades son, en algunos aspectos específicos, superiores a las de los componentes por separado.

Aunque esta definición incluye una gran diversidad de materiales (entre los materiales de construcción el hormigón armado es el ejemplo más habitual), en este trabajo se utiliza el término material compuesto para referirse a los polímeros reforzados con fibras, conocidos habitualmente por sus siglas en inglés como FRP (Fibre Reinforced Polymers).

Los FRP están constituidos por dos fases: fibras y matriz. En aplicaciones estructurales se emplean fibras largas continuas, que son las responsables de las propiedades resistentes. Son materiales altamente anisótropos, con valores 
muy diferentes de resistencia y módulo elástico en las distintas direcciones dependiendo de cómo estén orientadas las fibras, lo cual permite diseñar un material introduciendo resistencia y rigidez donde realmente se necesita. Los FRP están formados por el apilamiento de una serie de capas o láminas (que se denomina laminado), y en cada lámina las fibras se disponen en la dirección que se requiera. La matriz es un polímero con buena resistencia a ataques químicos, que envuelve a las fibras configurando geométricamente el elemento, transmite los esfuerzos entre las fibras y las protege de posibles daños mecánicos o ambientales.

Los FRP han comenzado a utilizarse como materiales de construcción debido a que poseen ciertas propiedades que hacen que su uso pueda resultar potencialmente ventajoso frente a materiales tradicionales como el hormigón o el acero. Entre estas propiedades pueden citarse:

- Gran ligereza y buenas características mecánicas, destacando sus elevadas resistencia y rigidez específicas y buena resistencia a la fatiga. Esto se traduce en economía y facilidad de transporte y puesta en obra, reduciéndose los plazos y costes de ejecución, sin olvidar la reducción de cargas muertas o, en el caso de aplicaciones en refuerzo de estructuras, la mínima modificación que supone en las dimensiones del elemento reforzado.

- Resistencia a la corrosión y al ataque de agentes ambientales, una ventaja importante en aplicaciones costeras, marinas y en general en todos aquellos ambientes que sean agresivos, siendo el mantenimiento prácticamente nulo.

- Poseen una baja conductividad térmica y no producen interferencias con campos electro-magnéticos, lo que les hace insustituibles en algunas aplicaciones.

- Presentan gran libertad de formas y diseños, y existe la posibilidad de moldeo en grandes piezas, por lo que en ocasiones de difícil ejecución con materiales tradicionales, se puede contemplar su utilización sin ningún tipo de limitaciones desde el punto de vista de proceso de fabricación. Eligiendo el tipo de fibra y la matriz, el porcentaje de refuerzo y la orientación de las fibras, puede diseñarse el material con las características que requiera cada aplicación. 
Estos materiales surgieron en la segunda mitad del siglo $\mathrm{XX}$ y desde entonces han experimentado un importante desarrollo en industrias como la aeronáutica, naval o automovilística, siendo sus superiores propiedades bien conocidas. Su introducción en el campo de la construcción se ha realizado más lentamente debido a su elevado coste, al escaso conocimiento y experiencia por parte de los técnicos, y sobre todo a la falta de normativa y guías de diseño y construcción adecuadas, elaboradas sobre una base experimental firme. Sólo cuando la capacidad de producción industrial ha permitido disponer de materiales en cantidad y precio adecuados se ha planteado su empleo en la construcción, empezando por aquellos casos en los que la utilización de productos caros se ve compensada por otros factores económicos tales como la reducción de la mano de obra, la rapidez en la ejecución, la reducción de molestias a los usuarios, o por cuestiones técnicas como ambientes muy agresivos o necesidad de evitar interferencias electromagnéticas.

\subsubsection{Fibras}

En aplicaciones en construcción se utilizan habitualmente tres tipos de fibra: vidrio, carbono y aramida. Dependiendo del tipo de fibra los materiales compuestos suelen denominarse GFRP (polímero reforzado con fibra de vidrio), CFRP (polímero reforzado con fibra de carbono) o AFRP (polímero reforzado con fibra de aramida).

La elección del tipo de fibra para formar el material compuesto va a depender de las necesidades requeridas en el diseño: módulo elástico, resistencia última, así como de su durabilidad en medios agresivos (aunque ésta se ve modificada por el recubrimiento mediante resinas sintéticas), y respuesta bajo cargas sostenidas.

\subsubsection{Fibras de carbono}

Las fibras de carbono se fabrican mediante pirólisis controlada de un material precursor con alto contenido de carbono. El poliacrilonitrilo (PAN) es el precursor más comúnmente utilizado, seguido del alquitrán. En el procesado del PAN para obtener fibra de carbono se pueden distinguir las siguientes etapas: 
a) Estabilización: un filamento de copolímero de poliacrilonitrilo es estirado y pasado a través de un horno de oxidación a baja temperatura $\left(200-300^{\circ}\right)$ para adquirir estabilidad dimensional.

b) Carbonización: la estructura interna del polímero se convierte a una temperatura más alta $\left(800^{\circ} \mathrm{C}\right)$ en lazos de anillos hexagonales de carbono continuo.

c) Grafitización: calentamiento a más altas temperaturas, por encima de $2000^{\circ} \mathrm{C}$, con lo que el tamaño de los cristales de carbono aumenta y mejora la orientación de los cristales de la fibra.

d) Tratamiento de superficie: finalmente la fibra pasa a través de una cámara de tratamiento de superficie para promover la adhesión de la fibra.

Mediante la selección de un proceso de fabricación adecuado se puede controlar la disposición y el alineamiento de las capas de grafito, con lo que las propiedades físicas se pueden optimizar para adecuarlas a los requerimientos de la aplicación. Como ejemplo, las fibras basadas en PAN pueden ser grafitizadas para obtener la mayor rigidez, aunque con una resistencia relativamente baja, o bien para obtener la máxima resistencia. En la Tabla 2.1 se muestran las propiedades de estas fibras junto con las de las fibras de vidrio y aramida.

Las fibras de carbono de alto módulo y alta resistencia tienen un diámetro comprendido entre las 7 y las $8 \mu \mathrm{m}$. Son casi completamente frágiles, y experimentan una recuperación del $100 \%$ cuando se cargan por debajo del límite de rotura. Los módulos transversal y de cortadura son mucho más pequeños que el longitudinal, y dependen de la estructura estratificada.

Las fibras de carbono son las más utilizadas en aplicaciones de refuerzo de estructuras, debido a sus mejores propiedades (ver Tabla 2.2), ya que además su mayor desventaja, que es el alto coste, no es un factor determinante porque la cantidad de material empleada es pequeña.

\subsubsection{Fibras de vidrio}

Existen varios procedimientos de producción de fibras de vidrio, que se basan en general en el estiramiento a muy alta temperatura, por tracción mecánica o por 
acción de fluidos en movimiento, de una veta o vena de vidrio fundido y su inmediata solidificación. En todos los métodos de fabricación se distinguen las siguientes fases: composición-fusión, fibrado y ensimado. El diámetro de las fibras de vidrio está comprendido entre 3 y 25 micras.

Las fibras de vidrio son las más utilizadas en construcción debido a que son las más baratas. Hay diferentes tipos de fibra de vidrio disponibles, siendo el más común el vidrio-E, y el más caro, pero con mayor resistencia, el vidrio R. Las fibras de vidrio se caracterizan por su elevada resistencia, moderados módulo de elasticidad y densidad, y su baja conductividad térmica. A diferencia del carbono y la aramida, las propiedades de las fibras de vidrio son isótropas, consecuencia de la estructura tridimensional del vidrio.

Las fibras de vidrio se utilizan a menudo en aplicaciones estructurales en las que el factor peso no es crítico, (tienen menor relación resistencia /peso que otras fibras) y que pueden tolerar mayores deformaciones derivadas del comparativamente más bajo módulo de elasticidad.

Se utilizan en la fabricación de barras de FRP para armado del hormigón, secciones estructurales pultruídas de FRP, hojas de FRP para refuerzo sísmico y tubos de FRP fabricados por enrollamiento filamentario.

\subsubsection{Fibras de aramida}

Las fibras de aramida, conocidas por el nombre comercial de Kevlar, se fabrican a partir de poliamidas aromáticas mediante un procedimiento de extrusión e hilado. Las propiedades de las fibras pueden ser modificadas según el procedimiento de fabricación, por ejemplo añadiendo aditivos al solvente, variando las condiciones de hilado o utilizando tratamientos térmicos después del hilado. Se distinguen dos tipos de fibra de aramida en función de su rigidez: fibras de bajo módulo (en torno a 60 GPa), y fibras de alto módulo (120 GPa).

Las fibras de aramida se caracterizan por su elevada resistencia a tracción y al impacto, moderado módulo de elasticidad y reducida densidad. Se utilizan en menor grado que las anteriores en aplicaciones en construcción por su elevado coste relativo, dificultad de procesado y absorción de humedad.

En la Tabla 2.1 se resumen las propiedades físicas de las fibras de carbono, vidrio y aramida y en la Tabla 2.2 se presenta una comparación entre las 
propiedades de los materiales compuestos constituidos por dichas fibras (Meier, 1995).

Tabla 2.1 Propiedades típicas de distintas fibras (Miravete, 2000)

\begin{tabular}{|c|c|c|c|}
\hline Tipo de fibra & $\begin{array}{c}\text { Módulo elástico } \\
{[\mathrm{GPa}]}\end{array}$ & $\begin{array}{c}\text { Resistencia a } \\
\text { tracción [GPa] }\end{array}$ & $\begin{array}{c}\text { Densidad } \\
{\left[\mathrm{gr}_{\mathrm{cm}}{ }^{3}\right]}\end{array}$ \\
\hline Carbono & $2.6-5$ & 1.75 \\
\hline Alta resistencia & 230 & $2.1-2.7$ & $1.8-1.9$ \\
\hline Alto módulo & 390 & 3.4 & 2,5 \\
\hline Vidrio & 72.5 & $3.4-4.4$ & 2,5 \\
\hline Vidrio-E & 85 & & 1,4 \\
\hline Vidrio - R & 60 & 1.92 & 1,4 \\
\hline Aramida & 128 & $2.94-3.6$ & \\
\hline Bajo módulo & \multicolumn{5}{|c|}{} \\
\hline Alto módulo & & & \\
\hline
\end{tabular}

Tabla 2.2 Comparación cualitativa de las propiedades de FRP constituidos por fibras de vidrio-E, aramida, y carbono (Meier, 1995)

\begin{tabular}{|c|c|c|c|}
\hline Características & Aramida & Carbono & Vidrio- $E$ \\
\hline Resistencia a tracción & Muy buena & Muy buena & Muy buena \\
\hline Resistencia a compresión & Inadecuada & Muy buena & Buena \\
\hline Módulo elástico & Bueno & Muy bueno & Adecuado \\
\hline Comportamiento a largo plazo & Bueno & Muy bueno & Adecuado \\
\hline Resistencia a la fatiga & Buena & Excelente & Adecuada \\
\hline Resistencia a los álcalis & Buena & Muy buena & Inadecuada \\
\hline Densidad & Excelente & Buena & Adecuada \\
\hline Coste & Adecuado & Adecuado & Muy bueno \\
\hline
\end{tabular}




\subsubsection{Matrices}

La matriz del FRP cumple las siguientes funciones:

- unir las fibras entre sí

- proteger las fibras de la abrasión y del deterioro por la acción del medio ambiente

- separar las fibras y dispersarlas dentro del FRP

- transferir las fuerzas entre las fibras individuales

- ser química y térmicamente compatible con las fibras.

Mientras que las fibras aportan la resistencia y la rigidez del FRP, la matriz es esencial para transferir las fuerzas entre las fibras individuales. Esta transferencia se logra a través de las tensiones de cortadura que se desarrollan en la matriz entre las fibras. Por consiguiente, la calidad de la adherencia entre las fibras y la matriz es un factor clave a la hora de obtener buenas propiedades mecánicas.

Hasta el momento en aplicaciones estructurales se han utilizado de manera prácticamente exclusiva resinas de tipo termoestable. Estos polímeros tienen generalmente buena resistencia química y propiedades de relajación y fluencia reducidas en comparación con las resinas termoplásticas, así como buena estabilidad térmica a temperaturas de servicio. Sin embargo al elevarse la temperatura por encima de cierto umbral, que se denomina temperatura de transición vítrea $T_{g}$, los polímeros termoestables se degradan de manera irreversible perdiendo rigidez y su capacidad para soportar cargas. El procedimiento de curado es importante para alcanzar las propiedades óptimas de los polímeros termoestables. Muchos de ellos pueden polimerizar a temperatura ambiente pero el material suele ser expuesto a una temperatura relativamente alta en un curado final destinado a minimizar cualquier curado posterior y cambios de propiedades durante la vida en servicio.

Recientemente se está investigando el uso de resinas termoplásticas para algunos usos específicos, como por ejemplo, barras de FRP para armar el hormigón, ya que las fabricadas con resinas termoestables no pueden ser dobladas en obra.

Las resinas epoxi, poliéster y viniléster son las resinas más comunes en los FRP. Se trata de polímeros termoestables con buena resistencia química. Las 
matrices de poliéster son los polímeros más ampliamente utilizados en la fabricación de FRP para construcción, debido a su coste relativamente bajo y a la facilidad de proceso. Las resinas de viniléster dan un mayor grado de protección a las fibras frente a ataques químicos, por lo que se usan por ejemplo en armaduras de fibra de vidrio. Las resinas epoxi tienen un coste más elevado pero mejores propiedades, son muy versátiles y pueden formularse con un variado rango de propiedades para utilizarlas como matrices de los FRP y también como adhesivos estructurales. Tienen una excelente resistencia a la corrosión y menor retracción que poliéster y viniléster. Los epoxis con curado a temperatura ambiente tienen usualmente una temperatura de transición vítrea $T_{g}$ entre 50 y $65^{\circ} \mathrm{C}$ (TR55, 2012), aunque pueden formularse resinas con valores superiores. El valor de $T_{g}$ de un adhesivo o resina que forma parte de un sistema de refuerzo debería ser al menos $15^{\circ} \mathrm{C}$ superior a la máxima temperatura de servicio (TR55, 2012).

En el refuerzo de estructuras se emplea mayoritariamente resina epoxi junto con fibra de carbono, mientras que en la fabricación de armaduras, paneles o perfiles se emplea poliéster o viniléster con fibra de vidrio.

\subsubsection{Procesos de fabricación}

Existe una gran variedad de procesos de fabricación de materiales compuestos (Miravete, 2000), pero los FRP que se utilizan en estructuras de construcción se fabrican principalmente por dos métodos: pultrusión y moldeo por contacto a mano. El enrollamiento filamentario es un proceso no muy común, pero una variante de este método se ha utilizado en algunas ocasiones para reforzar pilares existentes.

\subsubsection{Pultrusión}

La pultrusión es un proceso automático y continuo con el que se obtienen elementos de sección constante de alta calidad con un alto contenido en fibra, normalmente alrededor del $65 \%$. Se fabrican mediante pultrusión las armaduras de FRP, perfiles con todo tipo de formas, laminados para esfuerzo de estructuras, etc.

En la Figura 2.1 se observa el esquema de una máquina de pultrusión. Las fibras de refuerzo, en forma de hilo, tejido, etc., están en unas bobinas al comienzo de 
la línea. El proceso consiste en tirar de las fibras, que se encuentran enrolladas en bobinas al comienzo de la línea de pultrusión, hacerlas pasar por un baño de resina para impregnarlas y a continuación por una zona de conformado donde son distribuidas y preformadas con la forma de la sección del molde. Después entran en el molde, que tiene la forma de la sección que se pretende obtener, y en él se polimeriza la resina con la aplicación de un proceso térmico y de presión, enfriándose a continuación a temperatura ambiente mediante aire o agua. Durante todo el proceso el perfil se mueve continuamente gracias al mecanismo de tirado, y finalmente se corta automáticamente a la longitud que se desee.

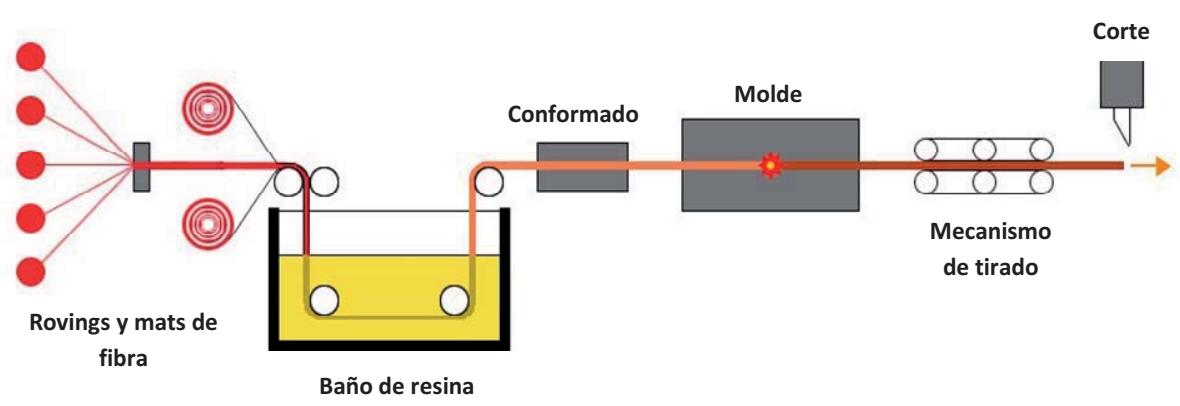

Figura 2.1 Proceso de fabricación de FRP mediante pultrusión

\subsubsection{Moldeo por contacto manual}

El moldeo por contacto manual, también conocido como hand layup o wet layup, es el método más senillo y tradicional para fabricar materiales compuestos. Aunque existen variantes, básicamente consiste en ir disponiendo manualmente sobre un molde la fibra, orientada en la dirección que se requiera, y la resina en sucesivas capas utilizando rodillos para lograr la impregnación de la fibra, eliminación de aire y compactación.

En el caso de refuerzo de estructuras, fibra y resina se aplican sobre el elemento a reforzar, fabricándose el material compuesto in situ una vez que se produce el curado de la resina, normalmente a temperatura ambiente.

\subsubsection{Enrollamiento filamentario}

En este proceso los refuerzos en forma de hilos (rovings) o bandas de fibra impregnada se enrollan a gran velocidad sobre un mandril rotatorio. Mientras el 
mandril gira el sistema de alimentación de fibra impregnada en resina avanza longitudinalmente. La velocidad de avance se sincroniza con la de giro del mandril para controlar de manera precisa el ángulo de enrollado.

Con este sistema se fabrican piezas de simetría cilíndrica como depósitos, tuberías y tubos que posteriormente se rellenan de hormigón para construir pilares. En algunas ocasiones se ha utilizado una variante de este método para reforzar pilares existentes, enrollando directamente la fibra sobre el pilar de hormigón.

\subsubsection{Formatos de FRP para refuerzo de estructuras}

Dentro de los materiales FRP utilizados en refuerzo de estructuras cabe distinguir diferentes formatos, que se describen a continuación.

\subsubsection{Sistemas para moldeo manual en húmedo (wet layup)}

Consisten en hojas o tejidos de fibra en seco unidireccionales o multidireccionales. Esta fibra se aplica sobre el elemento a reforzar junto con una resina de baja viscosidad que se utiliza para saturar la fibra y adherirla a la superficie de hormigón. El curado de la resina y formación del FRP se produce in situ, normalmente a temperatura ambiente.

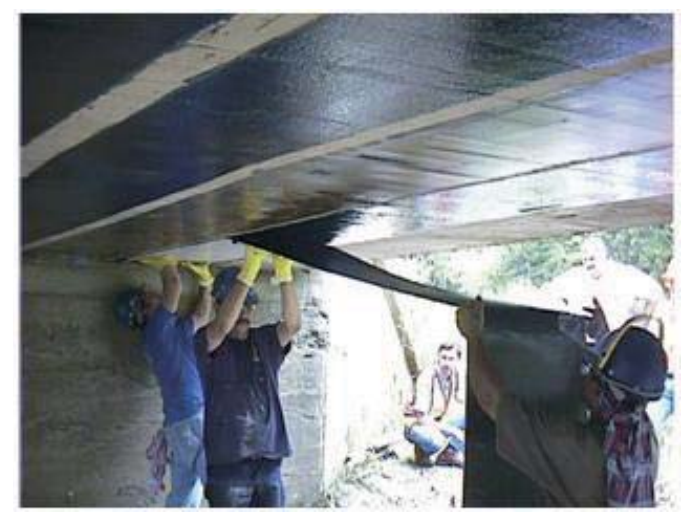

Figura 2.2 Sistema de refuerzo por moldeo manual (Cortesía de SIKA)

\subsubsection{Sistemas preimpregnados}

Consisten en hojas o tejidos de fibra unidireccionales o multidireccionales, similares a los anteriores, pero que han sido preimpregnados con la resina en 
fábrica. Estas hojas o tejidos contienen ya la resina parcialmente curada, y se disponen sobre la superficie de hormigón. Dependiendo del sistema puede requerirse aplicar más resina o no, y una vez aplicados sobre el elemento a reforzar se finaliza el curado de la resina, usualmente con la aportación de calor.

\subsubsection{Sistemas prefabricados o precurados}

Son elementos de FRP ya prefabricados, que se pegan sobre la superficie de hormigón mediante un adhesivo. Los más comunes son los laminados FRP formados por fibra de carbono unidireccional y resina epoxi que se fabrican por pultrusión. Los laminados disponibles comercialmente suelen tener un espesor del orden de 1 a $1.5 \mathrm{~mm}$ (que incluye fibra y resina) y diferentes anchuras, de entre 50 y $150 \mathrm{~mm}$.

A este grupo pertenecen también los encamisados prefabricados que se utilizan para reforzar pilares.

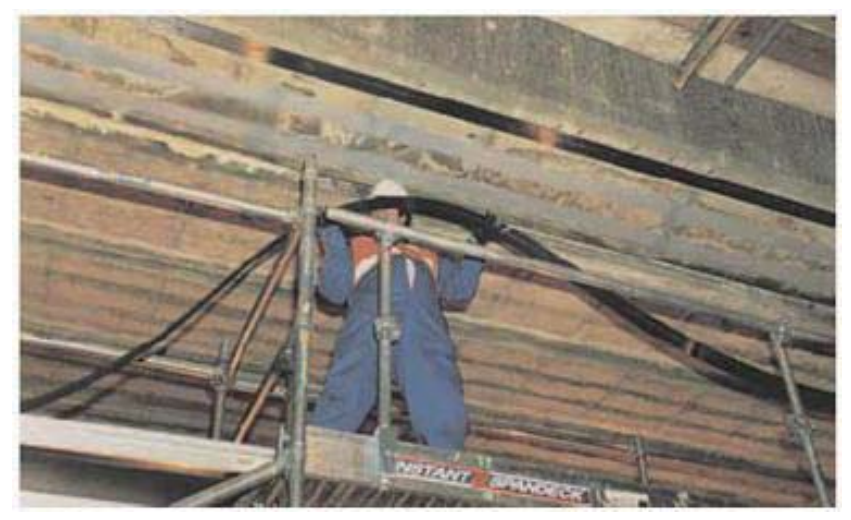

Figura 2.3 Sistema de refuerzo con elementos prefabricados (TR55, 2012)

\subsubsection{Sistemas insertados en el recubrimiento (NSM)}

Se trata una variante del sistema anterior. Son también elementos prefabricados por pultrusión (barras o laminados), pero que en lugar de pegarse externamente en la estructura a reforzar se insertan en el recubrimiento. Se realizan rozas en el hormigón, se rellenan con resina y se introduce la barra o laminado de FRP. Estos sistemas se conocen habitualmente como NSM, que son las siglas en inglés de Near Surface Mounted (Figura 2.4). 


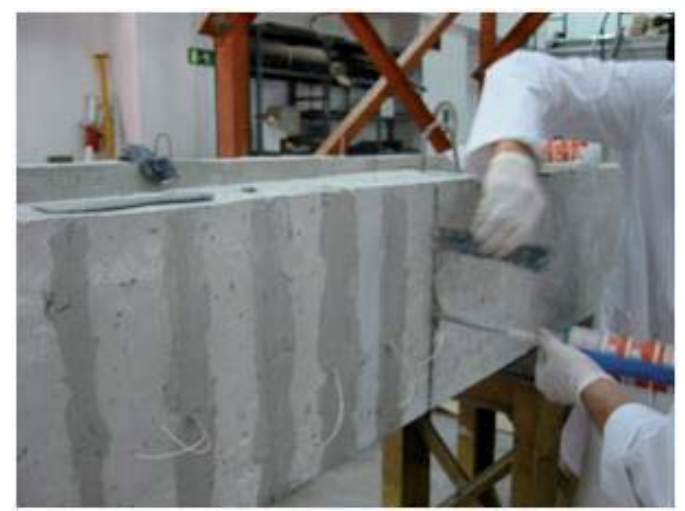

Figura 2.4 Sistema de refuerzo con elementos NSM

\subsubsection{Propiedades mecánicas de los FRP}

La capacidad de carga y la rigidez de los FRP vienen determinadas por las fibras mientras que la matriz hace posible la transferencia de carga entre las fibras y las protege de daños ambientales. Habitualmente se emplean fibras con valores elevados de resistencia y rigidez mientras que la deformación de rotura es menor que la de la matriz.

En la Figura 2.5 se muestra el comportamiento tensión-deformación en tracción de la fibra, la matriz, y el correspondiente material compuesto. El FRP tiene un valor de rigidez intermedio entre los correspondientes de la fibra y la matriz, y la deformación de rotura es la misma que la de la fibra. El comportamiento es elástico lineal hasta que se alcanza la rotura, que es repentina y frágil.

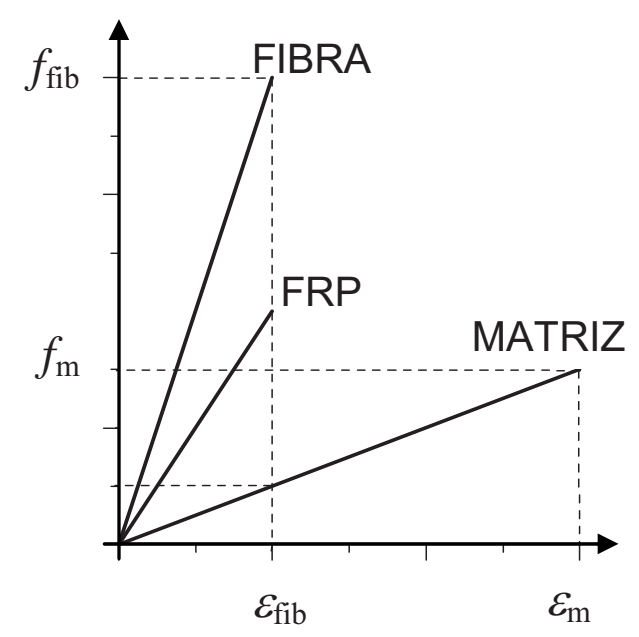

Figura 2.5 Curvas tensión-deformación del FRP y de la fibra y matriz que lo constituyen. 
En los FRP unidireccionales, que son los más empleados en refuerzo de estructuras, las propiedades mecánicas en la dirección de las fibras pueden obtenerse de manera aproximada a partir de las propiedades de la fibra y la matriz y su fracción volumétrica utilizando lo que se conoce como regla de las mezclas. Así, el módulo de elasticidad $E_{f}$ y la resistencia $f_{f}$ del FRP en la dirección de las fibras se obtienen mediante:

$$
\begin{aligned}
& E_{f}=V_{f i b} \cdot E_{f i b}+\left(1-V_{f i b}\right) \cdot E_{m} \\
& f_{f}=V_{f i b} \cdot f_{f i b}+\left(1-V_{f i b}\right) \cdot f_{m}
\end{aligned}
$$

siendo $V_{f i b}$ la cuantía volumétrica de fibras (relación entre el volumen de fibras y el volumen total de material compuesto), $E_{f i b}$ y $E_{m}$ los módulos de elasticidad de la fibra y de la matriz respectivamente, y $f_{f i b}$ y $f_{m}$ la resistencia a tracción de las fibras y de la matriz, respectivamente.

La regla de las mezclas es sólo válida para las propiedades en el sentido de la fibra, no en el sentido transversal, y en cualquier caso es una aproximación. Está basada en la hipótesis de adherencia perfecta entre fibras y matriz. En materiales compuestos unidireccionales da una estimación razonable del módulo de elasticidad, pero no tanto de la resistencia. Para obtener las propiedades reales del FRP han de realizarse ensayos del material.

Debido a que la resistencia a tracción y rigidez de un FRP unidireccional depende fundamentalmente de las fibras, es habitual referir estas propiedades del FRP al área neta de fibras de la sección, excluyendo el área ocupada por la resina. En laminados prefabricados donde el espesor es constante y la proporción fibra/resina es controlada, suelen darse las propiedades referidas al área total de la sección del laminado (incluyendo fibras y resina). En cambio, en sistemas de moldeo manual que incluyen tejidos unidireccionales de fibra seca manufacturados y resina aplicada in situ, lo normal es referir las propiedades al área neta de fibra. En sistemas moldeados también podrían darse las propiedades respecto a un área nominal de laminado, aunque no coincidirá con el espesor real aplicado en obra donde la cantidad de resina que se aplica es difícil de controlar y no es uniforme en el laminado. Ambas opciones son válidas, pero obviamente los cálculos deben hacerse de manera consistente utilizando las propiedades referidas de una u otra manera. 
En la Tabla 2.3 se dan las que podrían considerarse propiedades típicas de un tejido unidireccional de fibra de carbono en seco (referidas al espesor neto de fibra) y de un laminado prefabricado carbono/epoxi. En la Figura 2.6 se muestran diagramas tensión-deformación de diferentes FRP y del acero.

Tabla 2.3 Propiedades mecánicas de dos sistemas de refuerzo con fibra de carbono de alta resistencia y epoxi (ACl-440.2R-08, 2008)

\begin{tabular}{|c|c|c|}
\hline $\begin{array}{c}\text { Tipo de } \\
\text { material }\end{array}$ & Tejido unidireccional & $\begin{array}{c}\text { Laminado prefabricado } \\
\text { unidireccional }\end{array}$ \\
\hline Espesor $[\mathrm{mm}]$ & 0,33 & 1,27 \\
\hline$f_{f}\left[\mathrm{~N} / \mathrm{mm}^{2}\right]$ & 3792 & 2620 \\
\hline$\varepsilon_{f}[\%]$ & 1,6 & 1,5 \\
\hline$E_{f}\left[\mathrm{~N} / \mathrm{mm}^{2}\right]$ & 227527 & 151724 \\
\hline
\end{tabular}

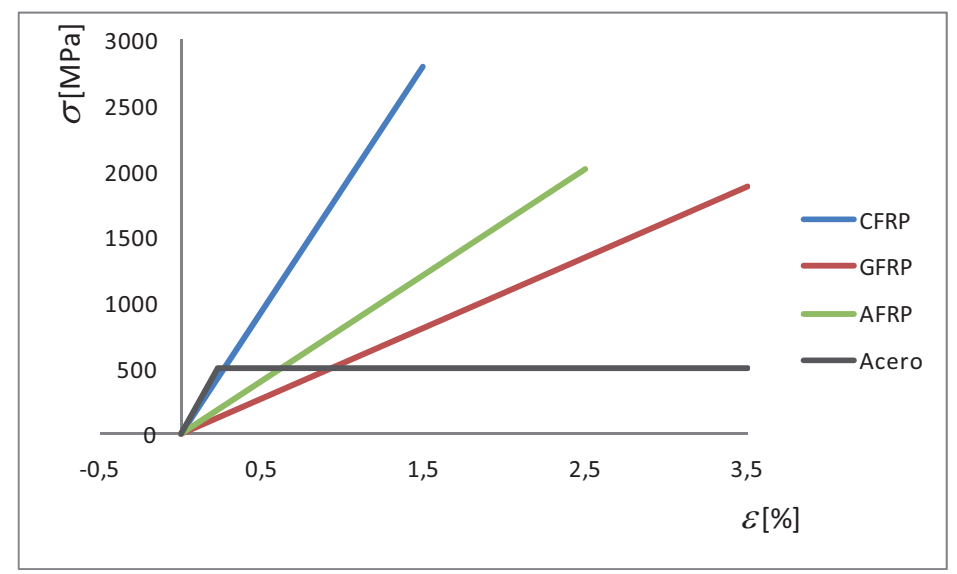

Figura 2.6 Diagrama tensión-deformación de diferentes FRP y acero

\subsubsection{Durabilidad}

Los FRP son en general materiales con muy buenas condiciones de durabilidad y resistentes a la corrosión. Sin embargo pueden sufrir cierta degradación de sus propiedades a largo plazo en determinados ambientes agresivos o condiciones de carga. Para tener en cuenta esto, las normativas y guías de cálculo publicadas proponen factores reductores para obtener los valores de cálculo de las propiedades mecánicas de los FRP. Estos factores tienen en cuenta, en función del tipo de material y exposición, la posible degradación de propiedades a largo plazo debido a condiciones ambientales (alcalinidad, humedad, 
temperatura) o modo de carga (fatiga, fluencia). Dentro de los FRP los sistemas carbono/epoxi, que son los más habituales en refuerzo de estructuras existentes, son los que presentan mejor durabilidad.

Las fibras de carbono y aramida tienen una excelente resistencia a ataques de tipo químico. La mayoría de las fibras de vidrio son atacadas por los álcalis, pero no por los ácidos. Existen fibras de vidrio álcali-resistentes formuladas para su uso en ambientes alcalinos. Las fibras de aramida pueden absorber humedad.

Las radiaciones ultravioleta no afectan a las fibras de carbono ni de vidrio. Las de aramida pueden cambiar de color y reducir su resistencia, aunque el efecto es muy pequeño cuando las fibras están embebidas en resina. Sobre las resinas puede producirse fragilización y erosión superficial, que podría facilitar la penetración de humedad o agentes agresivos. Para evitarlo, en las aplicaciones donde el refuerzo vaya a estar expuesto directamente a la luz solar se recomienda normalmente aplicar una pintura protectora.

Las fibras de vidrio y aramida no son conductoras, pero las de carbono sí. Las fibras de carbono no deberían colocarse en contacto directo con el acero para prevenir que se forme un par galvánico. La conductividad de la fibra de carbono debe tenerse en cuenta en otras circunstancias, por ejemplo no debe cortarse la fibra en ambientes con riesgo eléctrico.

Las fibras, especialmente las de carbono, resisten muy bien las altas temperaturas. Las de vidrio tienen menor resistencia, y las de aramida no deben emplearse por encima de $200^{\circ} \mathrm{C}$. En todos los casos la resistencia térmica viene limitada por las resinas y adhesivos. Debe considerarse la temperatura de transición vítrea $\left(T_{g}\right)$ de la resina empleada, ya que al superarse esta temperatura la resina se degrada de manera irreversible, y no es capaz de transmitir los esfuerzos entre las fibras. En situaciones donde el fuego sea un condicionante importante (por ejemplo túneles o espacios cerrados) debe también considerarse al elegir la resina la generación de humos y su posible toxicidad. 


\subsection{Utilización de polímeros reforzados con fibras (FRP) en estructuras de construcción}

\subsubsection{Nuevas estructuras}

Los materiales compuestos han comenzado a utilizarse en obra nueva en determinados elementos y aplicaciones donde presentan propiedades ventajosas frente a los materiales tradicionales. Así se utilizan redondos de FRP en lugar de la armadura de acero en aplicaciones donde el acero tenga serios problemas como corrosión, magnetismo o densidad demasiado elevada. También se han empleado en ocasiones cables y tendones con fibra de carbono o aramida debido a sus elevados módulo y resistencia específicos, excelentes comportamiento a fatiga y resistencia a la corrosión y bajo coeficiente de expansión térmica.

Su introducción en forma de perfiles estructurales como alternativa a los elementos de hormigón o acero se está realizando de manera más lenta, y aunque son numerosas ya las aplicaciones en todo el mundo, en muchos casos se trata de proyectos de carácter demostrativo o proyectos singulares que por algún motivo especial requieren la utilización de estos materiales.

Los perfiles de FRP copian inicialmente las formas habituales de los perfiles metálicos, lo cual facilita de alguna forma en una primera fase el uso de los nuevos materiales, pero es necesario avanzar en la búsqueda de nuevas tipologías que permitan sacar provecho adecuadamente a sus propiedades y que muestren las ventajas potenciales sobre otros materiales. Lo mismo ocurre con las uniones de los perfiles, utilizándose inicialmente uniones atornilladas similares a las de estructuras metálicas. Las perforaciones en los perfiles de FRP cortan las fibras y generan puntos débiles con concentraciones de tensiones, por lo que se tiende al uso de uniones adhesivas, pero hay que estudiar cómo afectan a las propiedades del adhesivo las condiciones de aplicación en obra, posible envejecimiento, etc.

Junto con el elevado precio del material, que supone un obstáculo más difícil de salvar en estructuras nuevas que en su uso como refuerzo, el riesgo de incendio es otro aspecto que está frenando la introducción de los perfiles de FRP, sobre todo en edificación, debido a la pérdida de propiedades de las matrices usuales 
a temperaturas relativamente bajas y al desconocimiento, por falta de estudios, del comportamiento conjunto del material compuesto.

El desarrollo de aplicaciones en obra civil, concretamente pasarelas peatonales y puentes de pequeñas luces ha sido mayor. En 1992 se construyó en Aberfeldy (Escocia) la primera pasarela peatonal con materiales compuestos (Figura 2.7), y desde entonces se han construido numerosas pasarelas en todo el mundo.

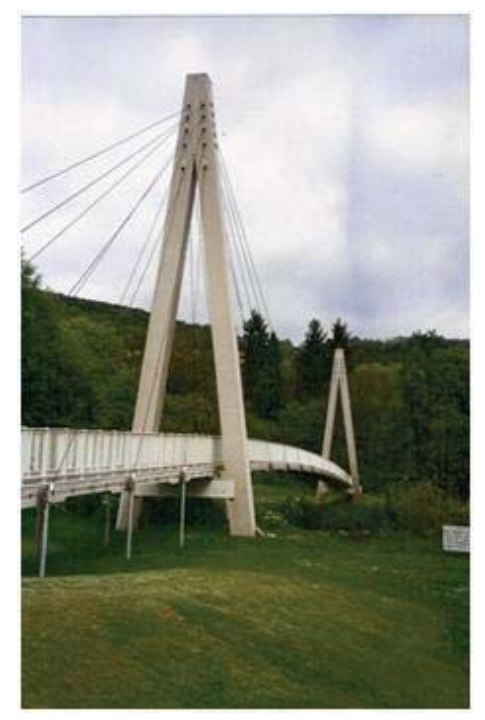

Figura 2.7 Pasarela de Aberfeldy (Escocia, 1992)

También están construyéndose en los últimos años un número creciente de nuevos puentes, bien enteramente de FRP o como estructuras híbridas de FRP combinado con materiales tradicionales. En el caso de puentes nuevos híbridos, los FRP sustituyen a los materiales tradicionales, hormigón o acero, en componentes como cables exteriores, vigas y tableros. Las nuevas estructuras "all-composite", especialmente superestructuras de puentes, están construidas exclusivamente con FRP, aunque los estribos y pilas normalmente son de materiales tradicionales. En estas estructuras son evidentes las diferencias entre concepciones de puentes tradicionales con una simple sustitución del material y los primeros pasos hacia concepciones adaptadas al nuevo material, con formas alveolares o elementos tipo sándwich (Figura 2.8). 

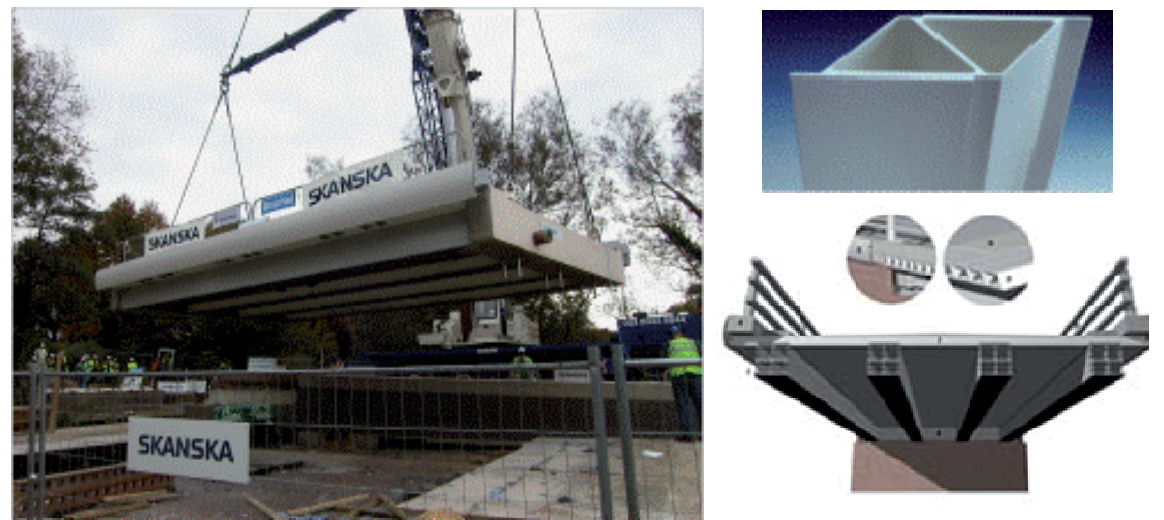

Figura 2.8 Construcción del primer puente europeo de FRP (Oxfordshire, UK, 2002)

\subsubsection{Refuerzo de estructuras existentes}

El refuerzo de estructuras de hormigón es el campo de la construcción donde más rápidamente y con mayor éxito se están aplicando los materiales compuestos debido sobre todo a su resistencia a la corrosión y a su ligereza que se traduce en facilidad y ahorro en el transporte y puesta en obra.

La utilización de FRP surge como alternativa al encolado exterior de chapas de acero, técnica de refuerzo utilizada habitualmente y de probada eficacia que conlleva sin embargo ciertos inconvenientes y limitaciones: corrosión del acero que deteriora la adherencia entre el refuerzo y la estructura, elevado peso de las chapas que dificulta su manejo e instalación y limitación de la longitud de las chapas siendo necesaria la ejecución de juntas.

El empleo de FRP elimina estos inconvenientes. Además de su resistencia a la corrosión, se presentan en forma de rollos con la longitud deseada y su bajo peso permite aplicar los refuerzos con gran facilidad y rapidez, con pocos operarios y $\sin$ necesidad de medios auxiliares pesados, reduciendo las molestias ocasionadas a los usuarios y permitiendo en algunos casos mantener la estructura en servicio mientras se repara. Además reducen el peso muerto sobre la estructura y en el caso de refuerzos, dado el reducido espesor del laminado la pérdida de gálibo es mínima.

Los FRP normalmente se adhieren externamente a todo tipo de elementos estructurales en refuerzos a flexión, cortante y confinamiento (Figura 2.9). 


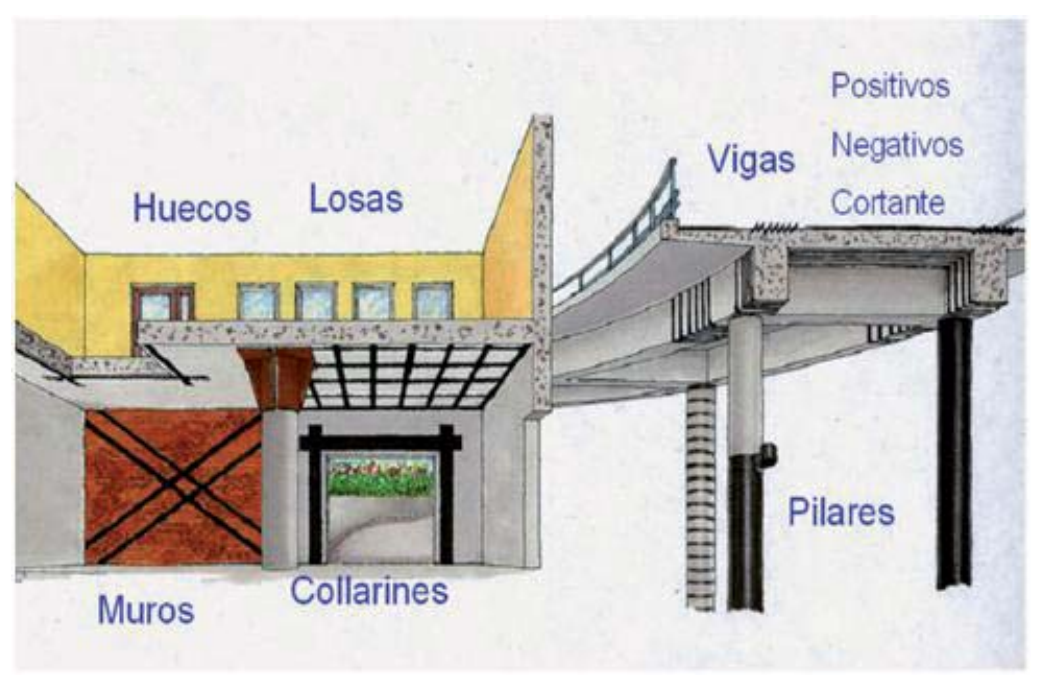

Figura 2.9 Distintos tipos de refuerzo de estructuras con FRP

\subsubsection{Refuerzo a flexión}

Los refuerzos a flexión se pegan en las zonas de tracción, con la dirección de las fibras paralela a aquella de mayores tensiones de tracción (eje del elemento) (Figura 2.10). Pueden utilizarse tanto laminados prefabricados como tejidos unidireccionales.

El procedimiento de cálculo, recogido en las guías de cálculo existentes, se basa en los mismos principios que el de los refuerzos con chapas de acero, considerando el comportamiento elástico lineal del FRP y analizando todos los posibles modos de fallo de la estructura reforzada (Figura 2.11).
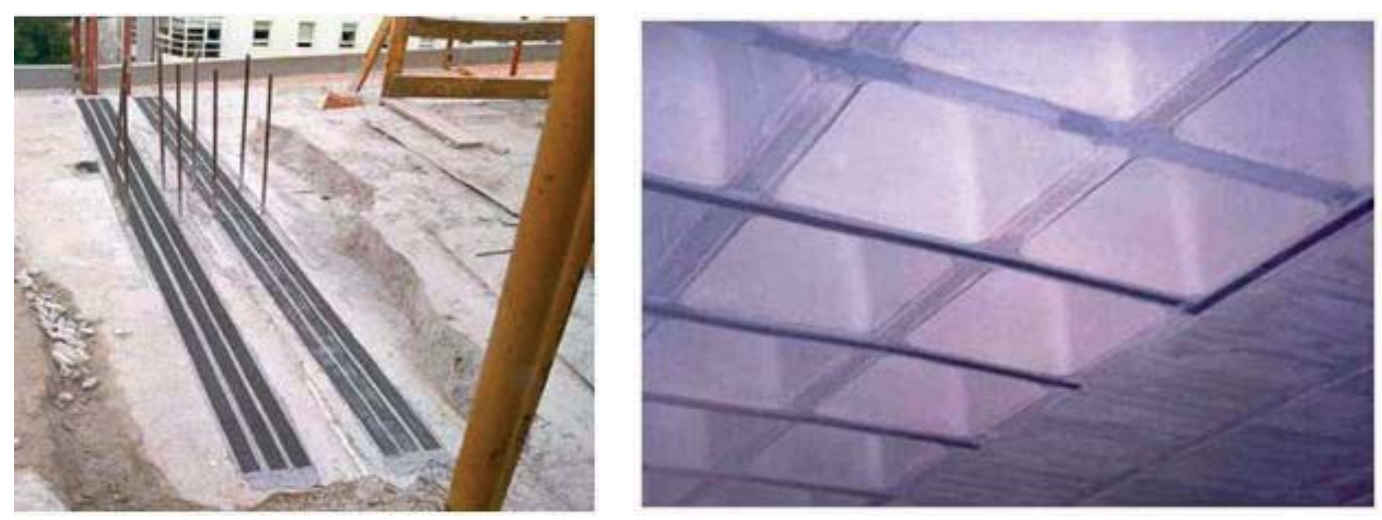

Figura 2.10 Refuerzo a flexión (Cortesía de SIKA) 


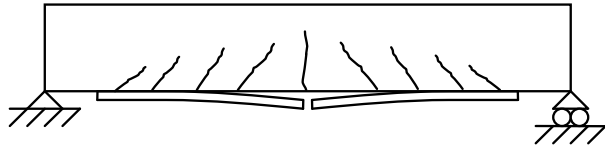

(a) Rotura del laminado

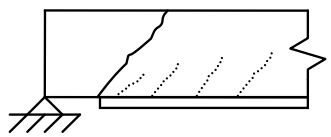

(c) Fallo a cortante

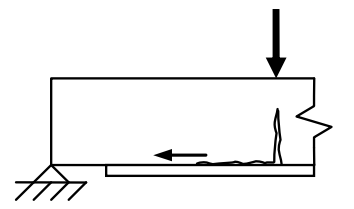

(f) Despegue intermedio a partir de una fisura de flexión

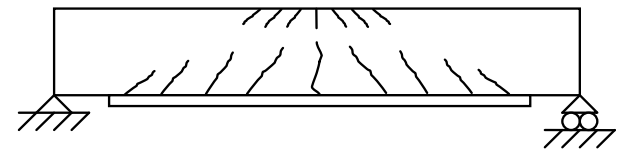

(b) Agotamiento del hormigón

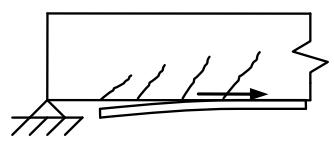

(e) Despegue del laminado en el extremo

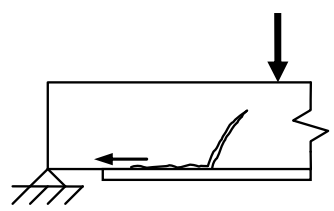

(g) Despegue intermedio a partir de una fisura por flector-cortante

Figura 2.11 Modos de fallo de una viga reforzada con un laminado de FRP

El modo de fallo más característico se origina de una forma completamente repentina por pérdida de la adherencia entre el laminado de FRP y el hormigón, y ha sido objeto de múltiples trabajos de investigación.

\subsubsection{Refuerzo a cortante}

Los materiales compuestos se utilizan también en el refuerzo a cortante de vigas de hormigón armado. Los FRP pueden aplicarse según distintas configuraciones aplicados bien sobre las caras laterales del elemento, o en forma de $\mathrm{U}$, o envolviendo completamente la sección en los casos en que es posible. Suelen emplearse tejidos de fibra ya que al ser flexibles se adaptan con facilidad a la forma de la sección a reforzar, aunque también existen laminados prefabricados comerciales con forma de $L$ para refuerzo a cortante (Figura 2.12).

El cálculo del refuerzo a cortante exige la comprobación de múltiples modos de fallo asociados, que exigen análisis independientes. El modo de fallo típico, a no ser que el refuerzo envuelva completamente la sección, está provocado por el despegue del FRP, y en los refuerzos a cortante además la longitud de anclaje suele ser muy limitada. En las guías publicadas se proponen procedimientos de cálculo, generalmente basados en la limitación de la deformación efectiva del refuerzo. 


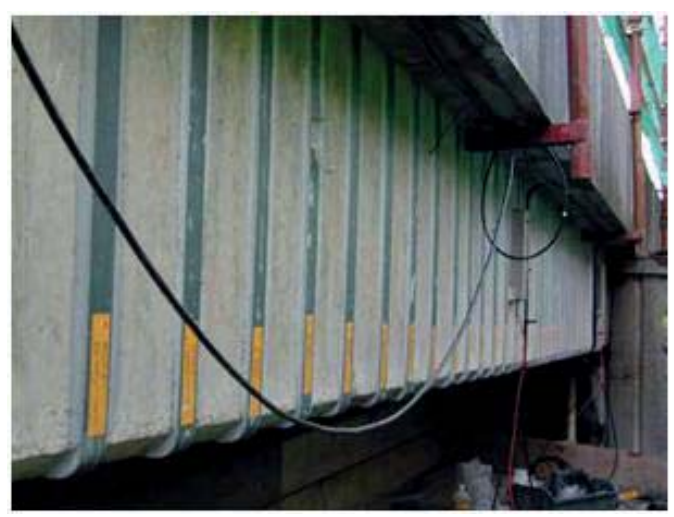

Figura 2.12 Refuerzo a cortante (TR55, 2012)

\subsubsection{Refuerzo de pilares mediante confinamiento}

El uso de FRP en el refuerzo de pilares de hormigón armado por confinamiento, objeto de esta tesis, es una técnica que se está extendiendo en los últimos años debido a sus múltiples ventajas. En el apartado 2.3.3. se describe ampliamente su utilización.

\subsection{Refuerzo de pilares de hormigón sometidos a compresión centrada}

El fallo de pilares por compresión simple, o con muy pequeña excentricidad, se ha señalado como causa principal de derrumbamientos generalizados de estructuras (Calavera, 2005). Los pilares poseen además muy escasa capacidad de aviso previa a la rotura. La forma habitual de rotura consiste en una fisuración muy fina $(0,05$ a $0,15 \mathrm{~mm})$ paralela a la directriz del soporte y que no coincide en general con las armaduras. Estas fisuras son difíciles de ver y aparecen muy poco antes de la rotura, al alcanzarse el $85-90 \%$ de la capacidad resistente del pilar. Todo ello pone de manifiesto la importancia que tienen las intervenciones en pilares de hormigón armado dentro del campo del refuerzo estructural.

Entre las causas más comunes que motivan la necesidad de reforzar los pilares, y en general las estructuras de hormigón armado, están las siguientes:

- Errores en el proyecto o en la ejecución que pueden dar lugar a bajas de resistencia del hormigón de la estructura y/o falta de cuantía de acero. 
- Aumento previsto de las cargas por cambio de uso u otras circunstancias, como por ejemplo aumento del número de plantas del edificio, cambios en la configuración estructural por supresión de pilares, apertura de huecos en forjados, posible adaptación a nuevas normativas, etc.

- Daños por unas deficientes condiciones de durabilidad de la estructura.

- Afección por acciones accidentales (fuego, impactos, explosiones, seísmos...).

Existen diferentes sistemas de refuerzo de pilares de hormigón armado (ACHE, en prensa). Atendiendo a la forma de trabajo cabe distinguir entre refuerzos por sustitución, que son aquellos que se proyectan para soportar todas las cargas, y refuerzos por colaboración, que tienen por finalidad incrementar la resistencia de los elementos existentes, ya sea aumentando la sección del soporte, o simplemente mejorando su resistencia a través del confinamiento.

A continuación se describen los métodos de refuerzo de pilares de hormigón armado mediante materiales convencionales y mediante materiales compuestos.

\subsubsection{Sistemas de refuerzo con materiales convencionales}

En función del material empleado, cabe distinguir entre refuerzos con hormigón y refuerzos con materiales metálicos.

\subsubsection{Refuerzo de pilares con hormigón}

Consiste en recrecer la sección existente mediante un encamisado de hormigón (Figura 2.13), que puede trabajar por sustitución del pilar existente, conformando con él una sección compuesta o bien cumpliendo la función de dotar de confinamiento al pilar original. La camisa de hormigón se arma habitualmente mediante barras de acero pasivo convencional. La camisa debe tener un espesor mínimo, del orden de 70 a 100 mm, para disponer la armadura y realizar el hormigonado correctamente. Pueden emplearse hormigones convencionales, limitando el tamaño máximo de los áridos, aunque en la actualidad se recurre habitualmente a hormigones autocompactantes, que evitan la necesidad de vibrado, rellenan perfectamente los pequeños espacios y mejoran la adherencia al hormigón existente. 
Los pasos a seguir para ejecutar un encamisado de hormigón son los siguientes (ACHE, en prensa):

1 Saneado o preparación previa del hormigón existente.

2 Aumento de rugosidad del hormigón antiguo.

3 Achaflanado de las aristas del pilar existente.

4 Conexión mediante horquillas y pasadores.

5 Montaje de las armaduras.

6 Hormigonado de la camisa, por vertido, o como hormigón proyectado.
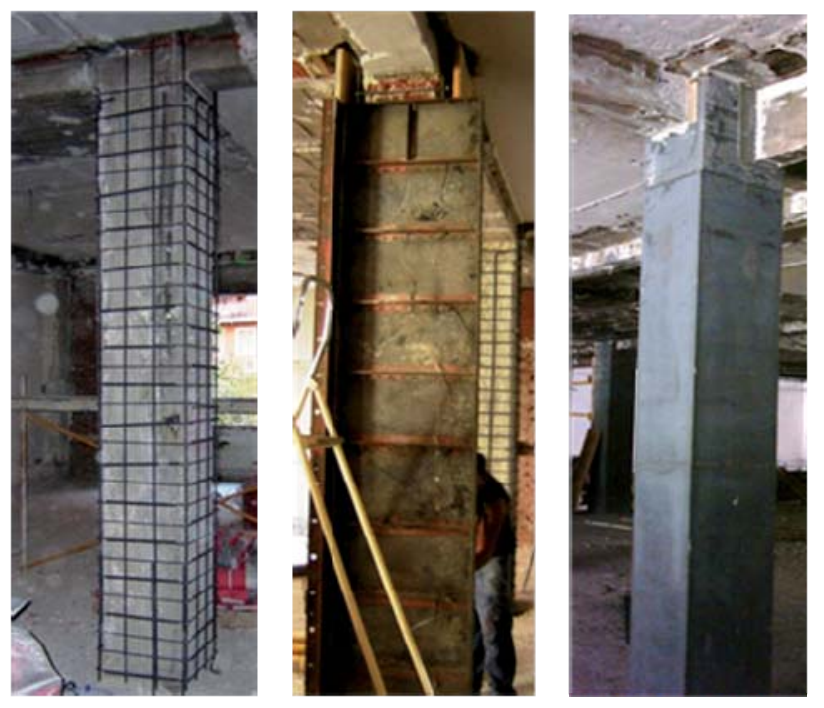

Figura 2.13 Refuerzo con hormigón

El principal inconveniente de este método de refuerzo es el elevado tiempo de ejecución y puesta en servicio, así como el incremento notable de la sección. Tiene la ventaja de que las labores de ejecución son similares a las que construcción de un pilar nuevo, por lo que no se requiere mano de obra especializada, aunque sí es importante que el control de calidad de la ejecución sea intenso.

\subsubsection{Refuerzo de pilares con materiales metálicos}

Se han planteado diferentes técnicas de refuerzo con elementos metálicos. La más empleada es el uso de angulares y presillas, que se utiliza en soportes de sección cuadrada, fundamentalmente, o rectangular. Consiste en colocar en cada una de las cuatro esquinas un angular metálico y posteriormente soldar 
entre ellos unas presillas metálicas, como se observa en la fotografía de la izquierda de la Figura 2.14.

Lo más común es dimensionarlos como refuerzos por sustitución, y asegurar la transferencia de toda la carga al refuerzo en el caso de que se produzca el fallo del pilar existente.

La ejecución de un refuerzo con angulares y presillas metálicas, aunque no requiere mano de obra especializada, es un trabajo delicado que requiere un control de calidad intenso por parte de los técnicos responsables. Deben realizarse las siguientes tareas ( $\mathrm{ACHE}$, en prensa):

1 Saneado o preparación previa del hormigón existente.

2 Colocación de los angulares metálicos.

3 Soldado de las presillas.

4 Colocación de capitel y basamento en los extremos del soporte.

5 Ejecución de zona de transferencia.

6 Protección frente al fuego en el caso de ser necesaria.

Un refuerzo con angulares y presillas también puede utilizarse para zunchar el núcleo de hormigón y conseguir un incremento de resistencia y ductilidad por confinamiento ( $\mathrm{ACHE}$, en prensa). En este caso las presillas hay que disponerlas muy próximas entre sí, y hay que garantizar el contacto pleno entre el hormigón del soporte y el acero del refuerzo sin que quede ningún hueco u holgura.

También puede reforzarse por confinamiento con un encamisado de chapa continua, que se ejecuta envolviendo al soporte con chapas de acero y soldando los bordes libres de éstas (fotografía de la derecha de la Figura 2.14). En el caso de secciones cuadradas, pueden emplearse como camisas dos perfiles en $\mathrm{U} o$ dos chapas de acero dobladas en forma de L. El espacio entre el encamisado y el soporte original se rellena con resinas epoxi o con morteros de cemento o con hormigón. En la práctica este tipo de refuerzo ha dejado de utilizarse por las mejores propiedades de los FRP en refuerzos por confinamiento. 

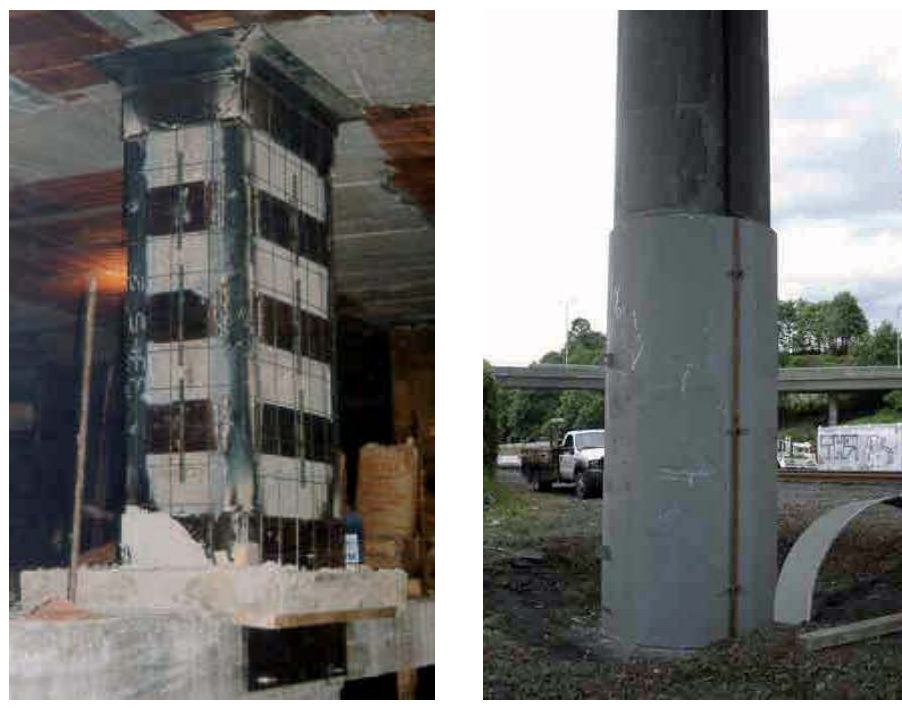

Figura 2.14 Refuerzo con angulares metálicos empresillados (izqda.) y con camisa de acero (dcha.)

\subsubsection{Refuerzo de pilares con materiales compuestos}

Los FRP se utilizan en el refuerzo de pilares de puentes y de edificios para conferirles mayor resistencia y ductilidad mediante el confinamiento de la sección de hormigón. Las primeras aplicaciones significativas de refuerzo de pilares con FRP se hicieron en zonas sísmicas, ya que un confinamiento adecuado incrementa la ductilidad. Pero el confinamiento es también efectivo en zonas no sísmicas donde deba aumentarse la capacidad de carga axial de los pilares (por ejemplo en pilares deteriorados o en los que la resistencia del hormigón sea baja, o en puentes o estructuras que vayan a ensancharse o a incrementar las cargas de servicio).

En este trabajo no se trata el refuerzo frente a sismo ni esfuerzos horizontales (fib, 2006), sino que se limita al refuerzo de pilares sometidos a compresión centrada o con excentricidades de carga muy reducidas. En estos casos el refuerzo consiste en disponer una camisa de FRP, que puede cubrir el pilar totalmente o bien parcialmente en forma de anillos, con las fibras en sentido perpendicular al eje, y el refuerzo se basa exclusivamente en la acción de confinamiento, es decir el refuerzo de FRP no tiene en sí mismo ninguna resistencia a compresión, sino que somete al núcleo de hormigón a un estado triaxial de tensiones que mejora sus propiedades resistentes. 
La acción de confinamiento puede ser activa o pasiva. En los refuerzos pasivos, que son los más habituales, la presión de confinamiento es resultado de la reacción de la camisa contra la expansión lateral de la sección transversal del pilar al ser comprimida axialmente. En los refuerzos activos las fibras se ponen en tensión previamente a la puesta en servicio, bien pretensándolas al ser envueltas alrededor del pilar o bien inyectando un mortero expansivo o resina epoxi a presión entre la camisa y el pilar. La presión de confinamiento comienza a desarrollarse así antes de que ocurra ninguna expansión en el pilar.

Frente a los refuerzos con materiales convencionales, como el recrecido con hormigón o los empresillados metálicos, el refuerzo de pilares con FRP presenta las siguientes ventajas:

- Facilidad y rapidez de ejecución, con mínimas interrupciones en el servicio de la estructura.

- Prácticamente no se modifican las dimensiones del pilar ni se aumenta el peso propio.

- Resistencia a la corrosión.

La principal desventaja, sobre todo respecto al refuerzo con hormigón, es el comportamiento en caso de incendio. Dado que las resinas que forman la matriz o el adhesivo pierden sus propiedades cuando se sobrepasa su temperatura de transición vítrea $T_{g}$, el refuerzo con FRP se recomienda para casos en los que en situación accidental de fuego se garantice que las cargas de cálculo en el pilar son inferiores a la resistencia de cálculo en situación de incendio. En caso contrario, debe disponerse una protección con el fin de mantener durante el tiempo de evacuación la temperatura por debajo del valor de $T_{g}$.

La ejecución del refuerzo consta básicamente de dos pasos: preparación del soporte de hormigón existente y aplicación de la camisa de material compuesto. En caso de ser necesario se aplicaría sobre el refuerzo una protección frente al fuego.

\section{1) Preparación del soporte}

La superficie de hormigón debe de estar saneada, limpia y seca antes de aplicar el material compuesto. Las partes de hormigón dañadas o deterioradas deben quitarse y restituirse con un hormigón, mortero o resina adecuados. 
A diferencia de lo que ocurre en los refuerzos a flexión o a cortante con materiales compuestos, en el refuerzo de soportes mediante confinamiento no es crítica la adherencia entre el soporte y el refuerzo (de hecho no es necesario que exista esta adherencia, aunque por el modo de ejecución habitualmente el encamisado queda pegado al soporte). Lo que sí es crítico es la buena adherencia en la zona de solape, que exista pleno contacto del encamisado con el soporte y que la fibra envuelva el pilar de manera ajustada, sin ninguna holgura. Para ello deberá prepararse la superficie de hormigón para que no queden huecos ni aristas.

Como ya se ha mencionado, en pilares cuadrados o rectangulares, y en general en todas las secciones que presenten esquinas, éstas deben redondearse (Figura 2.15). El redondeo de las esquinas es fundamental por dos razones: para evitar la rotura prematura de las fibras en las esquinas, y para aumentar la efectividad del confinamiento.
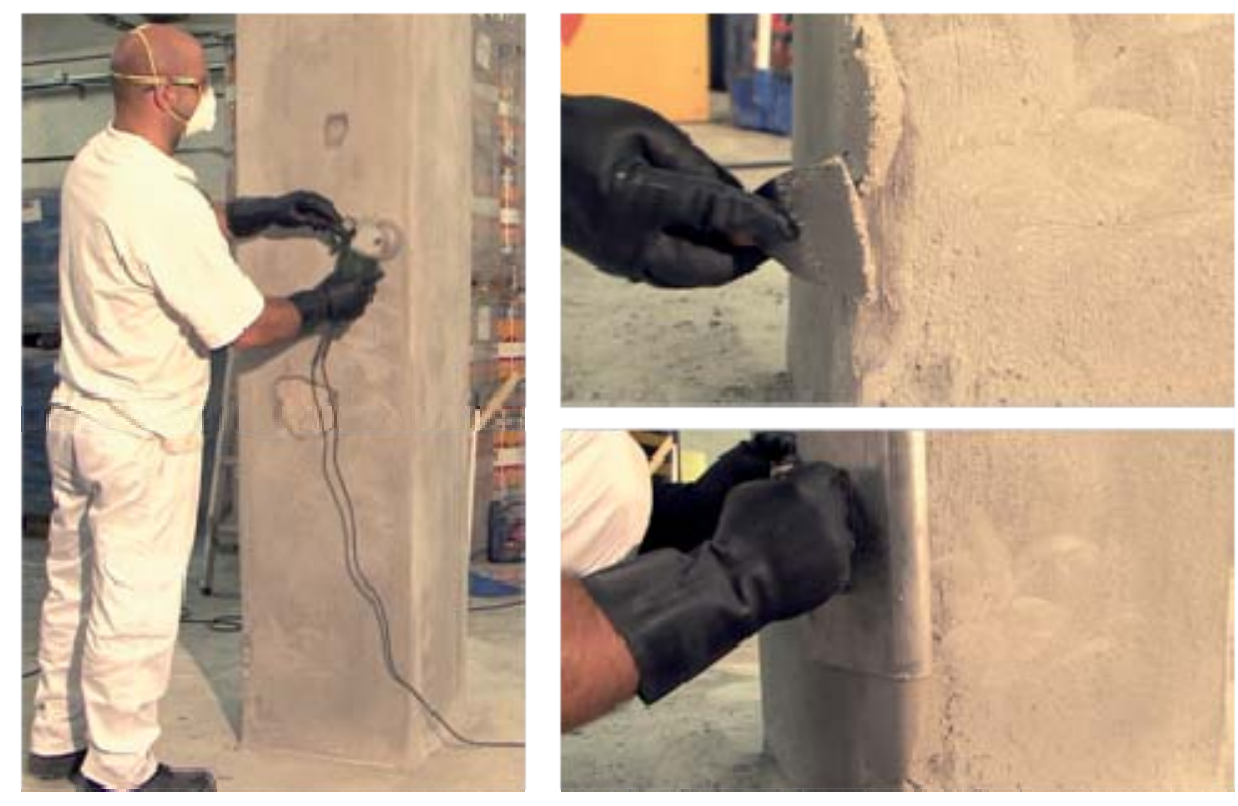

Figura 2.15 Redondeo previo de esquinas (cortesía de SIKA)

Cuanto mayor sea el radio de redondeo se obtendrá mayor efectividad del refuerzo, como se verá en los capítulos siguientes, aunque este valor está limitado por el recubrimiento que tenga el pilar original. Si no se lleva a cabo el redondeo de las esquinas la efectividad del refuerzo puede ser nula.

En el caso de que los recubrimientos de las armaduras existentes en las esquinas del soporte sean reducidos o nulos, impidiendo el picado para la 
ejecución de dicho redondeo, será preciso garantizar el mismo mediante el recrecido de la sección.

\section{2) Aplicación de la camisa de material compuesto}

Atendiendo a cómo se forma la camisa de material compuesto pueden distinguirse tres técnicas de refuerzo: refuerzo mediante moldeo por contacto a mano (más conocido como wrapping), refuerzo por enrollamiento filamentario, y refuerzo con camisas prefabricadas (Figura 2.16).
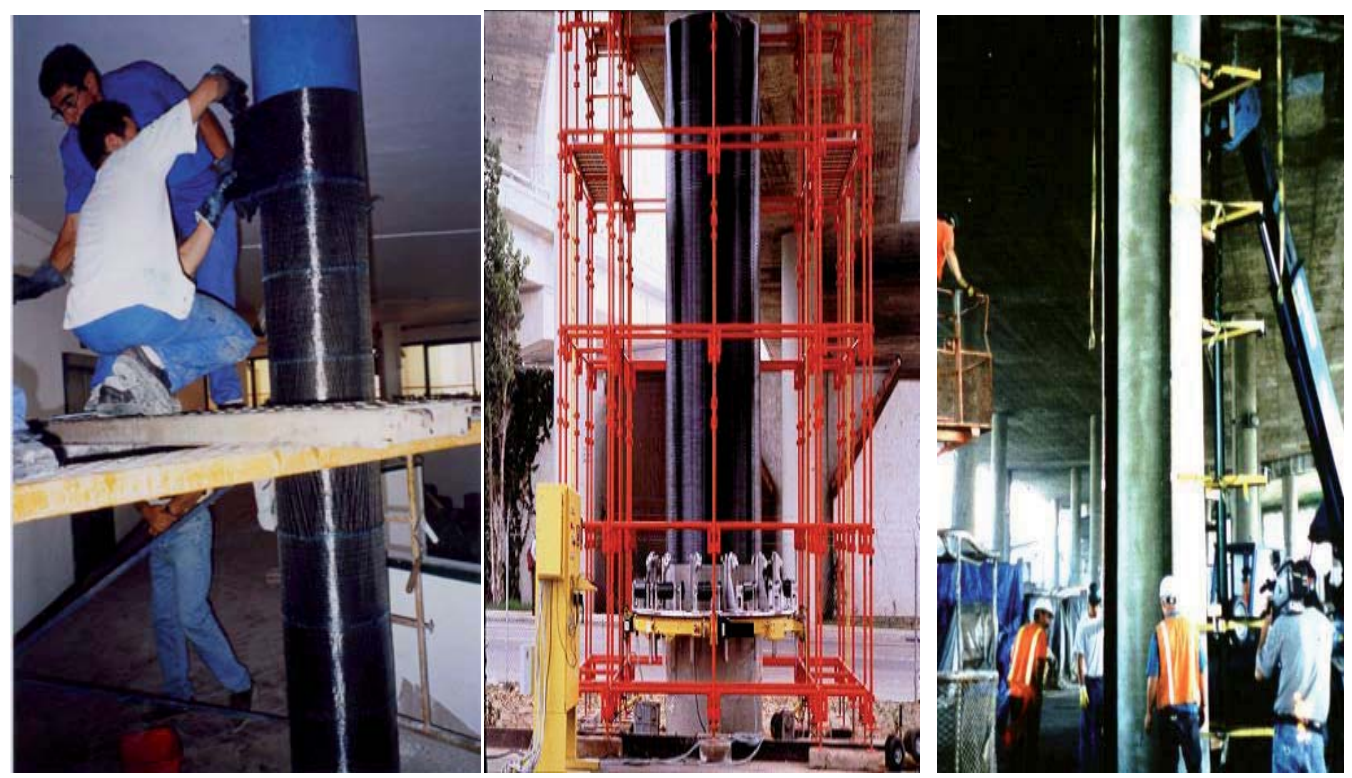

Figura 2.16 Aplicación de fibra de carbono mediante wrapping, enrollamiento filamentario y camisas prefabricadas

La aplicación del material compuesto sobre el soporte de hormigón se lleva a cabo en la mayoría de las aplicaciones mediante moldeo por contacto a mano o wrapping. Con este término en inglés se conoce la técnica que consiste en impregnar en la resina hojas de fibra unidireccional o tejidos y aplicarlos manualmente sobre el pilar envolviendo el perímetro de la sección. El material compuesto se forma in situ alrededor del pilar cuando cura la resina. También puede hacerse aplicando una capa de resina sobre la superficie del pilar, colocando a continuación sobre ella la fibra seca y finalmente otra capa de resina encima. En todo caso, al terminar de envolver la sección se continúa en una longitud de solape adicional. Es muy importante asegurar que la longitud de solape en cada capa sea suficiente, de modo que no se produzca el fallo de la unión en la zona solapada, sino que se alcance la rotura de la fibra. El valor 
mínimo de la longitud de solape deberá indicarlo el fabricante del material de refuerzo.

El wrapping es el método de confinamiento más comúnmente utilizado debido a su facilidad de aplicación y la flexibilidad para adaptarse a distintas geometrías y dimensiones del elemento a reforzar. Las primeras aplicaciones conocidas se realizaron en Japón a mediados de la década de 1980.

Un método de refuerzo parecido, pero muy poco utilizado, es el enrollamiento filamentario, o bobinado automático, en el que una máquina impregna las fibras continuas en un baño de resina antes de enrollarlas alrededor del pilar fabricando una camisa de espesor, porcentaje de fibras y orientación de las mismas controlados. Se obtiene así una camisa de mayor calidad y con mayor porcentaje de fibras. Sin embargo requiere una inversión importante en la máquina de bobinado y es difícil adaptarse a distintas formas de la sección.

También puede formarse el encamisado con elementos prefabricados, bien dos piezas que se pegan entre sí al colocarlas sobre el pilar, o en una sola pieza con una abertura longitudinal que permite abrirla y envolver el pilar. Para que el confinamiento sea efectivo es esencial que pilar y camisa estén en contacto, lo que se asegura bien pegándola con adhesivos o inyectando algún material de relleno en el espacio entre el núcleo de hormigón y la camisa. En algunas ocasiones se ha planteado pretensar la camisa mediante la inyección por ejemplo de un mortero expansivo para lograr un confinamiento activo.

El refuerzo con elementos prefabricados presenta también limitaciones en cuanto a formas y tamaños de la sección, y no está indicado si no hay que reforzar un número elevado de pilares con la misma geometría. Sí se ha utilizado en algunos casos en pilares cuadrados o rectangulares en los que se quiere modificar la forma de la sección para aumentar la eficacia del confinamiento. Se colocan camisas circulares o elípticas que sirven también como encofrado y se hormigona el espacio entre la sección cuadrada o rectangular original y la camisa.

Al igual que en el wrapping, en el refuerzo con elementos prefabricados existen normalmente una o más uniones verticales en la camisa de FRP. Cuando se utiliza una camisa prefabricada de una sola pieza con una abertura vertical, o bien se fabrica ya la camisa con la longitud de solape apropiada que se pega con adhesivo, o se pega sobre la unión una banda adicional de FRP (en esta 
banda vertical las fibras han de estar orientadas horizontalmente, en la misma dirección que en la camisa). Estas uniones deben diseñarse y ejecutarse de modo que el fallo de la unión no sea nunca el que provoque el fallo del elemento reforzado, sino que se aproveche en el mayor grado posible la resistencia del FRP.

\subsection{Comportamiento del hormigón confinado con FRP}

En este apartado se presenta una revisión del estado del conocimiento sobre el comportamiento del hormigón confinado, con especial énfasis en los estudios sobre hormigón confinado con FRP en secciones rectangulares.

Cuando se produce el fallo por compresión axial de un pilar de hormigón armado, el hormigón se fisura, y la deformación lateral aumenta sustancialmente. Si esta deformación lateral se restringe confinando lateralmente el hormigón, ya sea mediante presión hidráulica, cercos o espirales de acero, o una camisa de FRP, la resistencia y ductilidad del hormigón pueden incrementarse significativamente.

$\mathrm{Si}$ el hormigón se confina lateralmente mediante una presión que es independiente de su deformación lateral, el confinamiento se denomina activo. Por el contrario, los cercos o espirales de acero o las camisas de FRP, a no ser que la fibra sea inicialmente pretensada, generan una presión de confinamiento que depende de la deformación lateral del hormigón, y este confinamiento se denomina pasivo.

\subsubsection{Primeros estudios sobre confinamiento activo y hormigón confinado con acero}

En 1906 Considère (Considère, 1906) ya reconoció el efecto beneficioso de presiones laterales (confinamiento activo) en la resistencia y deformación del hormigón. En 1928 Richart et al. (Richart et al., 1928) ensayaron probetas cilíndricas sometidas a diferentes intensidades de presión lateral, aplicando dicha presión de forma independiente de la deformación axial (confinamiento activo). Sus ensayos mostraron que la presencia de la presión lateral uniforme conducía a un incremento de resistencia uniaxial de la probeta confinada respecto a la probeta sin confinar que era función del valor de la presión aplicada: 


$$
f_{c c}=f_{c o}+k_{1} \sigma_{l}
$$

siendo:

$f_{c c}:$ resistencia a compresión con confinamiento

$f_{c o}$ : resistencia uniaxial a compresión sin confinar

$k_{1}$ : coeficiente de efectividad determinado experimentalmente

$\sigma_{l}:$ presión de confinamiento lateral

La ecuación anterior ha sido utilizada después por varios investigadores para expresar el incremento de resistencia en función del ratio de confinamiento, definido como la relación entre la máxima presión de confinamiento $f_{l}$ y la resistencia del hormigón sin confinar $f_{c o}$ :

$$
\frac{f_{c c}}{f_{c o}}=1+k_{1}\left(\frac{f_{l}}{f_{c o}}\right)
$$

Mientras que el incremento en la deformación última suele expresarse como:

$$
\frac{\varepsilon_{c c}}{\varepsilon_{c o}}=1+k_{2}\left(\frac{f_{l}}{f_{c o}}\right)
$$

asumiéndose generalmente $\varepsilon_{C O}=0.002$.

Richart et al. obtienen como valor medio en sus ensayos $k_{1}=4.1$ y $k_{2}=5 k_{1}$.

Los mismos autores (Richart et al., 1929) realizaron un año después ensayos sobre cilindros confinados con espirales continuas de acero (confinamiento pasivo), confirmándose el mismo resultado obtenido para confinamiento activo, si el paso de la espiral era suficientemente pequeño causando una presión lateral equivalente. La constante $k_{1}$ había sido previamente evaluada por Considère (Considère, 1906) como 4.8, y más tarde revisada a 4.2. Talbot (Talbot, 1906) había publicado que el valor de esta constante variaba entre 2.8 y 4.0 dependiendo de las proporciones de la mezcla y de los materiales utilizados en el elemento de hormigón. Balmer (Balmer, 1949) encontró que la misma constante variaba entre 4.5 y 7.0 , con un valor medio de 5.6, correspondiendo los valores más altos a las presiones laterales más bajas. Newman y Newman 
(Newman and Newman, 1969) demostraron que la efectividad del confinamiento es menos pronunciada para presiones laterales elevadas y propusieron una expresión no lineal para el incremento de resistencia como una función de la presión de confinamiento:

$$
k_{1}=3.7\left(f_{l} / f_{c o}\right)^{-0.14}
$$

La necesidad de reforzar estructuras de hormigón provocó después que el efecto del confinamiento en la capacidad resistente y de deformación se estudiara más en profundidad, tanto experimental como teóricamente. Se han desarrollado varios modelos para el confinamiento de hormigón con acero. En 1971 Kent y Park (Kent and Park, 1971) propusieron un modelo tensión-deformación consistente en una rama ascendente definida por una parábola de segundo grado y una rama descendente en línea recta. En este modelo el efecto del confinamiento se incluía en la pendiente de la rama descendente. Park et al. (Park et al., 1982) revisaron el modelo para introducir el incremento de resistencia, suponiendo que el efecto del confinamiento era proporcional a la cuantía volumétrica y a la tensión de plastificación de los cercos. Otros modelos fueron propuestos por Sheik y Uzumeri (Sheikh and Uzumeri, 1980, Sheikh and Uzumeri, 1982), Ahmad y Shah (Ahmad and Shah, 1982) y Mander et al. (Mander et al., 1988). Sheik y Uzumeri introducen un coeficiente de efectividad del confinamiento que depende de la configuración de los cercos de refuerzo. Otro modelo de aplicación general fue presentado después por Saatcioglu y Razvi (Saatcioglu and Razvi, 1992), quienes sugirieron el siguiente coeficiente basándose en los datos de los ensayos de Richart et al. de $1928: k_{1}=6.7 f_{l}^{-0.17}$.

Se expone a continuación el modelo de Mander, por ser el modelo más aceptado para el confinamiento con acero en el hormigón armado, y porque más tarde se tomó como punto de partida para el estudio del confinamiento con FRP.

\subsubsection{Modelo de Mander et al. (1988)}

Mander et al. (Mander et al., 1988) ensayaron a compresión axial pilares de hormigón armado de sección circular, cuadrada y rectangular con diferentes configuraciones de armadura longitudinal y transversal. Con base en los resultados experimentales desarrollaron un modelo empírico para describir la respuesta tensión-deformación del hormigón confinado con armadura transversal sometido a compresión axial. 
Para describir la curva tensión-deformación (Figura 2.17) utilizan la ecuación propuesta por Popovics (Popovics, 1973):

$$
f_{c}=\frac{f_{c c} \cdot x \cdot r}{r-1+x^{r}}
$$

donde

$$
x=\frac{\varepsilon_{c}}{\varepsilon_{c o}} ; \quad r=\frac{E_{c}}{E_{c}-E_{s e c}} ; \quad E_{s e c}=\frac{f_{c c}}{\varepsilon_{c c}}
$$

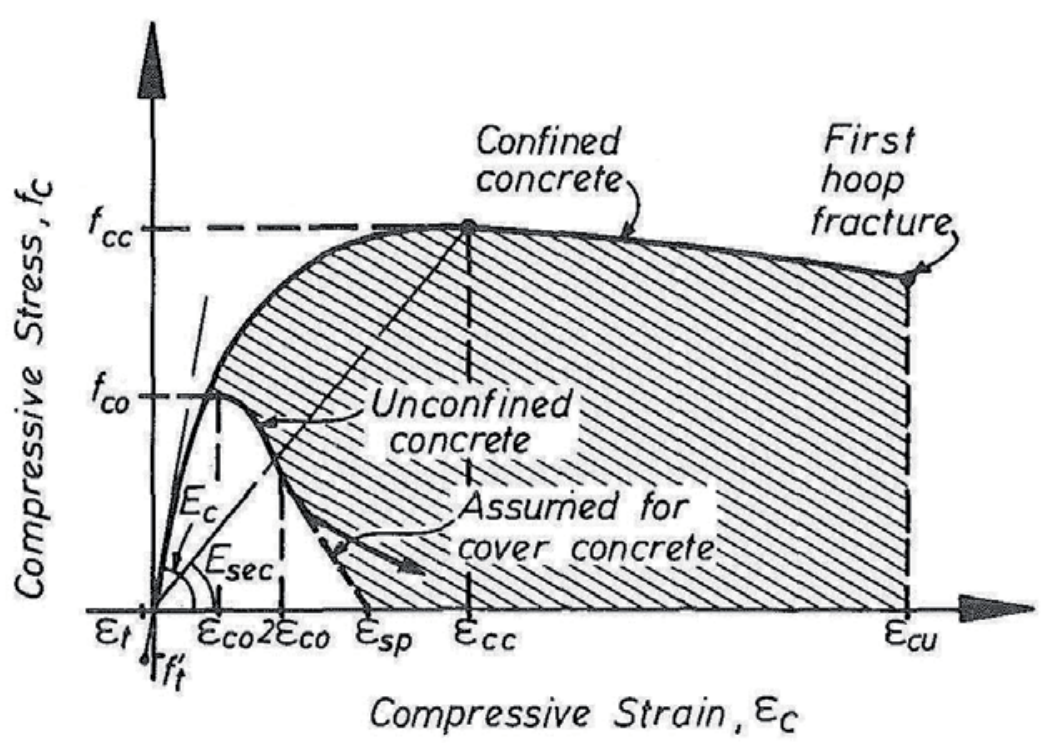

Figura 2.17 Modelo tensión-deformación para hormigón confinado y sin confinar propuesto por Mander et al. (1988)

El modelo se basa en la hipótesis de que el hormigón está sometido a una presión de confinamiento constante que es función de la cuantía de acero transversal $\rho_{\mathrm{st}}$ y su tensión de plastificación $f_{\mathrm{y}}$ :

$$
f_{l}=\frac{1}{2} \alpha_{s} \rho_{s t} f_{y} \quad \text { con } \quad \rho_{s t}=\frac{4 A_{s t}}{s d_{s}}
$$

donde

$\alpha_{s}=$ coeficiente que considera la separación entre cercos,

$s=$ separación entre cercos o paso de la espiral, 
$A_{\mathrm{st}}=$ sección de acero transversal,

$d_{s}=$ diámetro de los cercos de acero o de la espiral.

La presión que ejerce la armadura transversal sobre el hormigón no es uniforme sino que se concentra en los cercos y por efecto arco (Figura 2.18) disminuye al alejarse de los mismos. Para tener en cuenta este efecto y calcular la presión de confinamiento real o efectiva $f_{l}$ Mander adoptó el coeficiente $\alpha_{s}$, que fue originalmente propuesto por Sheikh y Uzumeri (1982) (Sheikh and Uzumeri, 1982), que para el caso de cercos circulares viene dado por:

$$
\alpha_{s}=\frac{\left(1-\frac{s^{\prime}}{2 \cdot d_{s}}\right)}{1-\rho_{c c}}
$$

siendo $\rho_{c c}$ la relación entre el área de armadura longitudinal y el área del núcleo de hormigón.

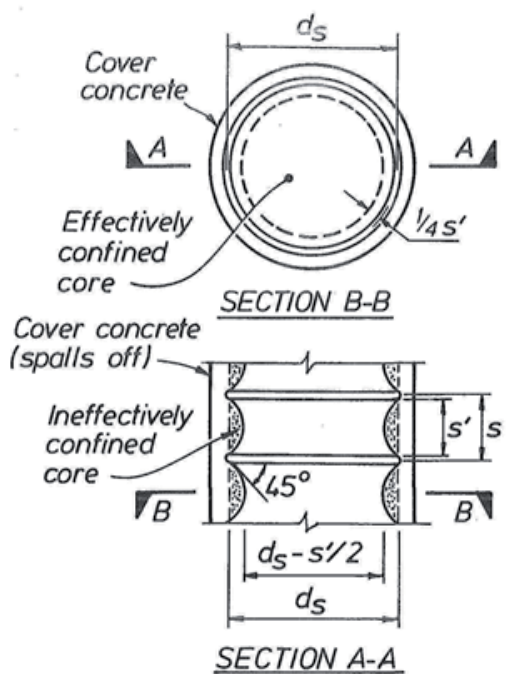

Figura 2.18 Núcleo de hormigón efectivamente confinado por cercos circulares (Mander et al., 1988))

El modelo es aplicable a hormigón confinado con armadura transversal tanto circular como rectangular introduciendo en la formulación el concepto de factor de forma o coeficiente reductor de la efectividad del confinamiento para secciones rectangulares. En las secciones rectangulares se asume de nuevo que el confinamiento se desarrolla por efecto arco en forma de parábolas de 
segundo grado que cortan a los lados de la sección a $45^{\circ}$, y que sólo el núcleo de hormigón delimitado por estas parábolas está confinado (Figura 2.19).

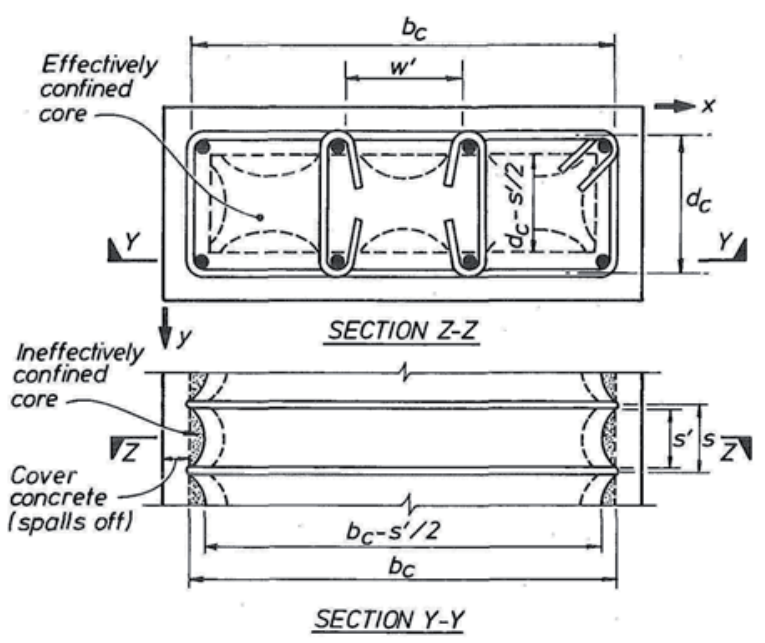

Figura 2.19 Núcleo de hormigón efectivamente confinado por cercos rectangulares (Mander et al., 1988)

La resistencia a compresión del hormigón confinado $f_{c c}$ y la correspondiente deformación $\varepsilon_{c c}$ se expresan en función de la presión lateral de confinamiento efectiva $f_{l}$ mediante las siguientes expresiones:

$$
\begin{gathered}
\frac{f_{c c}}{f_{c o}}=2.254 \sqrt{1+7.94 \frac{f_{l}}{f_{c o}}}-2 \frac{f_{l}}{f_{c o}}-1.254 \\
\varepsilon_{c c}=\varepsilon_{c o}\left[1+5\left(\frac{f_{c c}}{f_{c o}}-1\right)\right]
\end{gathered}
$$

En las ecuaciones anteriores la deformación del hormigón sin confinar $\varepsilon_{c o}$ se toma usualmente igual a 0.002 .

El modelo de Mander ha tenido gran aceptación convirtiéndose probablemente en el modelo de confinamiento más ampliamente utilizado, y en él se han basado muchos estudios llevados a cabo sobre confinamiento con FRP.

\subsubsection{Hormigón confinado con FRP. Estudios experimentales}

El uso de FRP para el confinamiento de pilares se inició a comienzos de los años 80 , aunque anteriormente Kurt (Kurt, 1978) había ya sugerido, aunque sin mucho éxito, el uso de tubos de PVC rellenos de hormigón. Fardis y Khalili 
(Fardis and Khalili, 1981, Fardis and Khalili, 1982) investigaron el comportamiento de cilindros de hormigón encamisados con GFRP consiguiendo incrementos sustanciales de resistencia y ductilidad.

Desde entonces se han realizado una gran cantidad de estudios para investigar el comportamiento de pilares de hormigón confinados con FRP en forma de espirales, wraps y tubos. Estas investigaciones han corroborado que los FRP son materiales adecuados para confinar el hormigón que pueden mejorar la resistencia y ductilidad de los pilares, y han estudiado la influencia de diversas variables como la resistencia del hormigón (Berthet et al., 2005, Li, 2006, H.M. Mohamed, 2010, Xiao et al., 2010), el tipo de fibra (Xiao and Wu, 2003, Ozbakkaloglu, 2013), su orientación (Vincent and Ozbakkaloglu, 2013), la rigidez del FRP (Harries and Kharell, 2002, Jiang and Teng, 2007), adherencia hormigón-camisa, longitud del encamisado (Pham et al., 2015), el tamaño del elemento (Elsanadedy et al., 2012), esbeltez del pilar (Pan et al., 2006), forma de la sección (Mirmiran et al., 1998), radio de curvatura, etc.

Estos trabajos experimentales han dado lugar a la formulación de diversos modelos de comportamiento, que proponen expresiones para el cálculo del incremento de resistencia y de deformación del hormigón en función de la resistencia inicial y de la presión de confinamiento aplicada por el FRP. En el caso de cilindros confinados con camisas de FRP que cubran toda la superficie del hormigón con las fibras orientadas en el sentido de la circunferencia, la presión de confinamiento lateral $\sigma_{l}$ puede evaluarse, aplicando condiciones de equilibrio en la Figura 2.20., por la regla de los tubos de pared delgada:

$$
\sigma_{l}=\frac{1}{2} \rho_{f} \sigma_{j}=\frac{1}{2} \rho_{f} E_{f} \varepsilon_{j=l} \quad \text { con } \quad \rho_{f}=\frac{4 t}{D}
$$

donde

$\rho_{f}=$ cuantía volumétrica de FRP

$\sigma_{j}=$ tensión en la camisa de FRP

$E_{f}=$ módulo de elasticidad del FRP en la dirección perpendicular al eje del pilar

$\varepsilon_{j=l}=$ deformación circunferencial en la camisa de FRP $\varepsilon_{j}$ (tomada igual a la deformación lateral en el hormigón $\varepsilon_{\ell}$ ) 
$t=$ espesor de la camisa de FRP

$D=$ diámetro de la camisa de FRP

La presión de confinamiento $\sigma_{l}$ ejercida por la camisa en cada instante se calcula así en función de la tensión existente en el FRP $\sigma_{j}=E_{f} \varepsilon_{j}$.

La presión de confinamiento máxima $f_{l}$ viene dada por:

$$
f_{l}=\frac{1}{2} \rho_{f} E_{f} \varepsilon_{f u}
$$

Donde $\varepsilon_{f u}$ es la deformación máxima alcanzada en la camisa de FRP en el momento de la rotura, que se denomina deformación última efectiva.
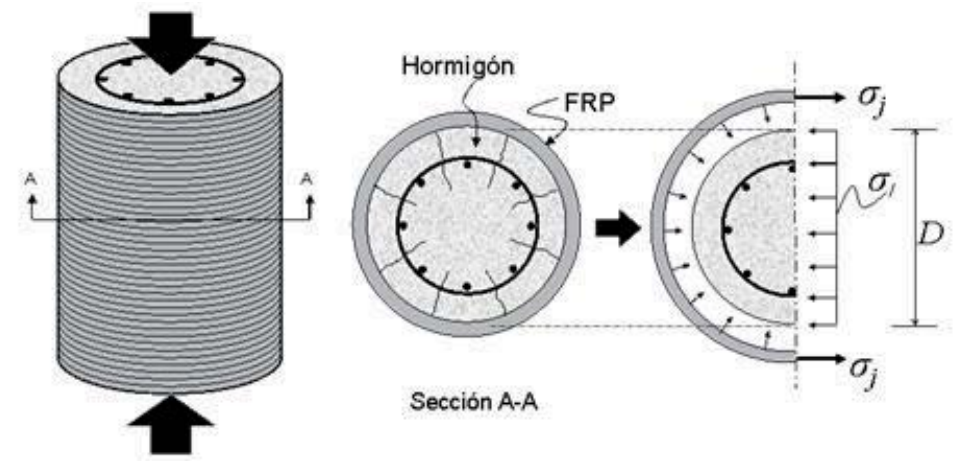

Figura 2.20 Presión de confinamiento ejercida por el FRP

Muchos de los modelos han sido deducidos y calibrados a partir de un número más o menos reducido de resultados, casi siempre correspondientes a ensayos de probetas cilíndricas de pequeño tamaño $(15 \times 30)$ fabricadas con hormigones de 30 a 50 MPa de resistencia a compresión. En Wu y Wei 2015 (Wu and Wei, 2015) puede consultarse una base datos reciente bastante extensa de probetas circulares pequeñas. En la actualidad siguen proponiéndose nuevos modelos y se han realizado algunos estudios que señalan importantes diferencias en las predicciones de los mismos cuando se aplican a un conjunto más amplio de resultados experimentales recogidos en la literatura, probablemente debido a que los investigadores utilizaron resultados experimentales limitados con diferentes rangos de parámetros en sus estudios. Todo ello pone de manifiesto la necesidad de seguir investigando en este campo. 
La mayoría de los estudios experimentales se han llevado a cabo en secciones circulares. Los ensayos sobre probetas cuadradas o rectangulares son escasos, a pesar de que por su mayor uso estas secciones son las que hay que reforzar con más frecuencia, y muestran que el confinamiento es menos efectivo. En cuanto al análisis teórico se trata en general de utilizar los modelos desarrollados para probetas cilíndricas aplicando coeficientes reductores.

También se han realizado ensayos sobre probetas con secciones tanto circulares como no circulares de tamaño más parecido al real (dimensión mínima $300 \mathrm{~mm}$ ), aunque estos estudios han sido muy limitados debido al coste elevado y a la falta de equipamiento de ensayo con capacidad de carga suficiente. Esto ha conducido a que en la mayoría de los modelos disponibles no se haya tenido en cuenta efectos como el tamaño de la sección, la relación entre los lados de la sección en secciones rectangulares, la presencia de armadura longitudinal y su posible efecto perjudicial o la contribución de la armadura interna de acero.

En los siguientes subapartados se describe el comportamiento del hormigón confinado con FRP, y se revisa en detalle el estado del conocimiento sobre dos aspectos que se han identificado como claves en este comportamiento y en el ajuste de los modelos: la deformación última efectiva del FRP y la influencia de la forma de la sección del pilar en la eficacia del confinamiento.

\subsubsection{Respuesta tensión-deformación. Modo de fallo}

Los ensayos publicados sobre probetas de hormigón confinado con FRP muestran que las curvas tensión-deformación tienen una forma característica que puede observarse en la Figura 2.21.

Inicialmente el comportamiento es similar al del hormigón sin confinar ya que para valores pequeños de carga, la deformación transversal en el hormigón es muy pequeña y el FRP ejerce una presión de confinamiento muy limitada. Sin embargo, al incrementarse la tensión axial y alcanzarse una deformación de compresión próxima a la correspondiente a la tensión pico del hormigón sin confinar, típicamente 0,002 , el material está muy fisurado y el ratio de deformación transversal del hormigón también se incrementa reduciéndose la rigidez del hormigón. Esta expansión transversal activa el efecto de confinamiento del FRP. En este estado, y siempre que haya un nivel de confinamiento suficiente, la respuesta tensión-deformación se convierte en aproximadamente lineal con una pendiente que depende de la rigidez del FRP 
en el sentido de los cercos. Si la rigidez del confinamiento es baja, el comportamiento tensión-deformación resultante puede tener una rama descendente, de manera que la carga pico es mayor que la carga última correspondiente a la deformación axial máxima. Si la rigidez del confinamiento es alta, el comportamiento tensión-deformación resultante tiene una rama ascendente, de manera que la carga última corresponde a la deformación axial máxima (Figura 2.22). Algunos investigadores han propuesto, basándose en ensayos, diferentes criterios sobre el nivel de confinamiento mínimo para que la segunda rama de la curva tensión-deformación sea monótona creciente.

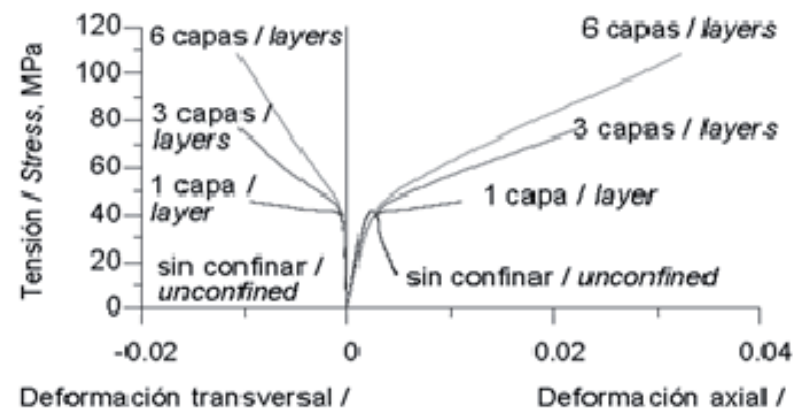

Figura 2.21 Curvas tensión-deformación de probetas confinadas con FRP (Aire, 2002)

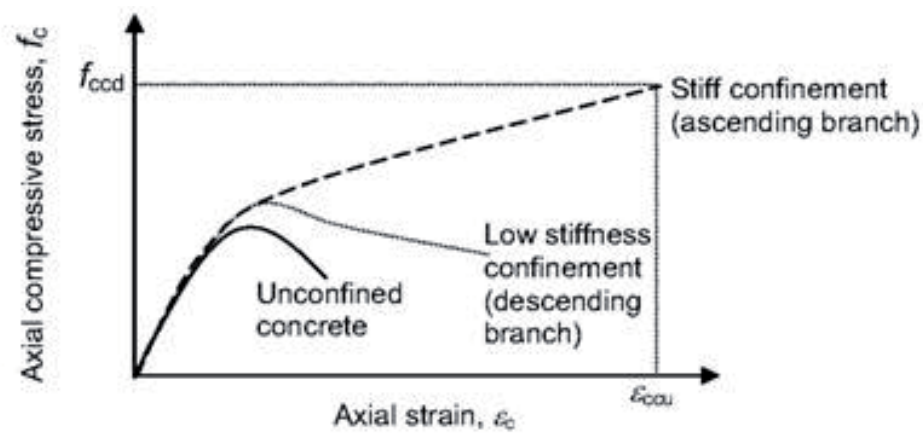

Figura 2.22 Comportamiento tensión-deformación del hormigón confinado con FRP

(TR55, 2012)

A medida que el hormigón se comprime, la camisa de FRP está sometida a tensiones de tracción crecientes en la dirección de la fibra, y el fallo se produce habitualmente por la rotura de la misma, como se muestra en la Figura 2.23, siempre que al aplicar el refuerzo se haya dispuesto una longitud de solape suficiente. Un aspecto muy importante es que los estudios experimentales han 
mostrado que esta rotura se produce para un valor de deformación última de la fibra (que se denomina deformación última efectiva) mucho menor que la deformación última obtenida en ensayos de tracción normalizados del material FRP.

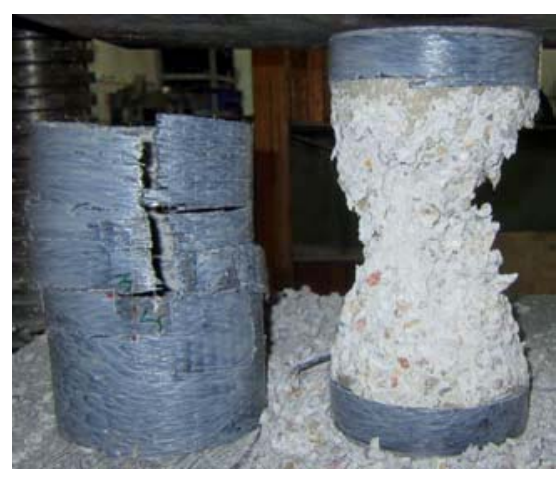

Figura 2.23 Modo de fallo habitual

\subsubsection{Deformación última efectiva}

La resistencia última del hormigón confinado con FRP está condicionada por la deformación última efectiva, que es aquella alcanzada en el FRP en el momento en que se produce la rotura de la camisa. Los estudios experimentales han mostrado que esta deformación última efectiva $\varepsilon_{f u}$ es mucho menor que la deformación última $\varepsilon_{f}$ obtenida en ensayos de tracción normalizados del FRP, que en adelante será referida como deformación de tracción última del material.

Para caracterizar el comportamiento a tracción del material FRP determinando su resistencia a tracción, módulo de elasticidad y deformación de tracción última, existen dos tipos de ensayos (Figura 2.24): ensayos de cupones planos (ASTM, 2008b, UNE-EN-ISO, 1997), y ensayos de probetas en forma de anillo (ASTM, 2008a). El ensayo de cupones planos es con mucho el más habitual, y es el que suelen realizar los fabricantes para obtener las propiedades de sus productos. EI ensayo de probetas en forma de anillo es el que se utiliza para tuberías de plástico, o plástico reforzado, y dada su similitud con la forma de trabajar de los encamisados de FRP, ha sido utilizado por algunos investigadores precisamente tratando de profundizar en las causas de que la deformación última efectiva sea menor que la deformación última del material. Sin embargo en un trabajo de Chen et al. (2009) (Chen et al., 2009) se considera más representativo el ensayo de cupones planos debido a que en los ensayos tipo anillo, muchos fallos se 
producen en la zona del FRP que está junto a la unión de los dos semianillos (punto $\mathrm{C}$ de la Figura 2.24.b).

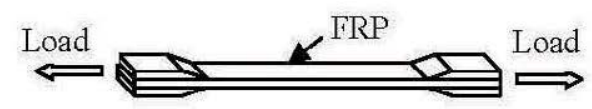

(a) Flat coupon test

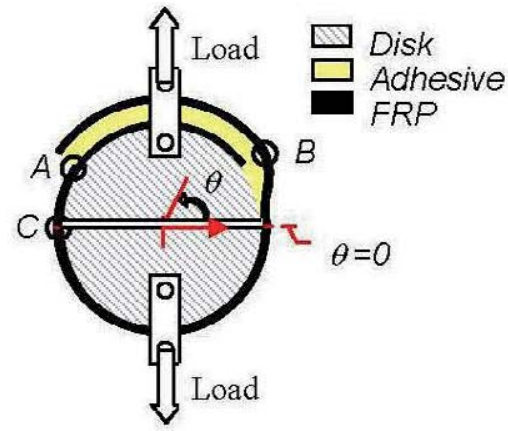

(b) Split disk test

Figura 2.24 Ensayos de cupones planos y anillos (tomada de (Chen et al., 2009))

En cuanto a las posibles causas del valor reducido de la deformación última efectiva se han señalado las siguientes:

- el estado triaxial de tensiones de la camisa de FRP (Figura 2.25)

- mala calidad en la ejecución del refuerzo con deficiencias en la alineación de las fibras, existencia de huecos, bordes mal redondeados 0 protuberancias locales donde las fibras pueden dañarse.

- la forma curva de la camisa, especialmente en esquinas con radios de curvatura pequeños.

- deformación no homogénea y fisuración del hormigón que pueden conducir a concentraciones locales de tensiones a las que es muy sensible el FRP.

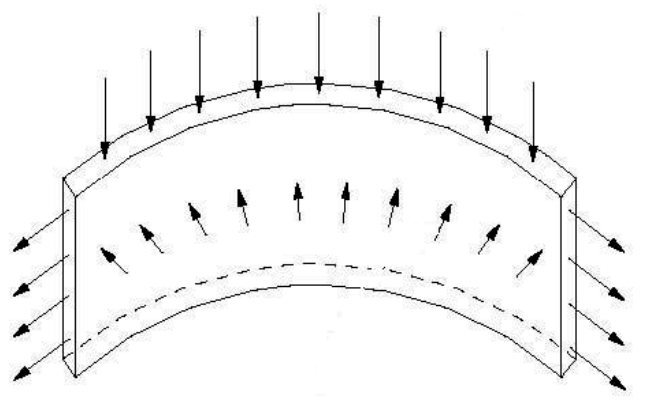

Figura 2.25 Tensiones en la camisa de FRP (fib, 2001) 
En el año 2001 la guía fib (fib, 2001) ya indicaba que para el cálculo deberían tomarse valores apropiados de la deformación última efectiva, y que dado que los datos disponibles hasta el momento eran limitados, los valores de $\varepsilon_{f u}$ deberían justificarse experimentalmente. Desde entonces se han llevado a cabo un gran número de ensayos de hormigón confinado con FRP, y llama la atención la gran dispersión existente en los datos de deformación de rotura del FRP medida en la camisa. Por ejemplo en Xiao y Wu (2000) (Xiao and Wu, 2000) se indican unas deformaciones de fallo de aproximadamente $50-80 \%$ de las obtenidas en cupones planos, pero De Lorenzis y Tepfers (2003) (De Lorenzis and Tepfers, 2003) mostraron, con base en una revisión global de ensayos en probetas circulares confinadas con FRP, que las deformaciones de rotura oscilaban entre más de 1.0 y menos de 0.1 de la deformación media obtenida en ensayos del FRP. De manera similar, en un estudio más reciente Sadeghian y Fam (2014) (Sadeghian and Fam, 2014) obtienen del análisis de una base de datos formada por 454 probetas cilíndricas valores que oscilan entre 1.22 y 0.12 , con un valor medio de 0.67. De acuerdo con Lam y Teng (2004) (Lam and Teng, 2004) el ratio entre deformación de rotura en wrapping y en cupones planos está en el rango de 58-91\%. Todos estos resultados ponen de manifiesto la dificultad para predecir la deformación última efectiva y la necesidad de seguir investigando. Se citan a continuación algunos estudios que han tratado específicamente este tema.

Pessiki et al. (Pessiki et al., 2001) en un programa experimental sobre probetas de sección circular y cuadrada, a pequeña y gran escala, encuentran importantes diferencias entre la deformación efectiva última y la obtenida en ensayos de tracción, e introducen el término factor de eficiencia de la deformación $k_{\varepsilon}$ que tiene en cuenta las discrepancias entre las propiedades del FRP obtenidas en cupones e in situ en la camisa. Este factor de eficiencia de deformaciones lo descomponen en dos, un factor $k_{\varepsilon 1}$ de localización de la deformación, y un factor $k_{\varepsilon 2}$ que denominan de propiedades in situ:

$$
\begin{gathered}
k_{\varepsilon}=k_{\varepsilon_{1}} \cdot k_{\varepsilon_{2}} \\
k_{\varepsilon_{1}}=\frac{\varepsilon_{f u}}{\varepsilon_{j r}} ; k_{\varepsilon_{2}}=\frac{\varepsilon_{j r}}{\varepsilon_{f}}
\end{gathered}
$$

siendo:

$\varepsilon_{f u}$ : deformación media en el perímetro de la camisa 
$\varepsilon_{j r}:$ deformación de rotura in situ

$\varepsilon_{j}$ : deformación de rotura en ensayos de tracción sobre cupones planos

$k_{\varepsilon l}$ tiene en cuenta que la deformación en la camisa no es uniforme a lo largo de todo el perímetro de la sección. Si la camisa estuviera despegada del núcleo de hormigón y no hubiera fricción entre las dos superficies la deformación a lo largo del perímetro sí sería uniforme y el factor $k_{\varepsilon l}$ sería igual a la unidad. En $k_{\varepsilon l}$ influirían las zonas localizadas con una mayor deformación en el FRP, por ejemplo cuando el FRP cruza una fisura. La adherencia entre la camisa y el núcleo de hormigón, sin embargo, permite que las tensiones en el FRP se transfieran al hormigón reduciendo así la deformación media en la camisa.

El factor $k_{\varepsilon 2}$ puede deberse a: existencia de fibras no alineadas o dañadas durante su manejo, inclusión de deformaciones residuales durante la fabricación de la camisa o mayor probabilidad de puntos débiles en el FRP al haber mayor cantidad de material en la camisa que en los cupones.

Lam y Teng (Lam and Teng, 2003b) analizan resultados de ensayos publicados en la literatura obteniendo un coeficiente de relación entre la deformación última en la camisa y en el ensayo del material de 0.586 para fibra de carbono (52 probetas reforzadas mediante wrapping) y 0.624 para fibra de vidrio (9 probetas), si bien resaltan la gran dispersión en los resultados analizados y recomiendan la realización de un pequeño número de ensayos (tres, por ejemplo) sobre cilindros de hormigón confinados con FRP para determinar el factor de eficiencia de un determinado FRP en aplicaciones de confinamiento. Harries y Carey (2003)(Harries and Carey, 2003) obtienen también a partir de una base de datos de 251 ensayos un valor de 0.58 para el coeficiente $k_{\varepsilon}$.

Lam y Teng (Lam and Teng, 2004) también realizan un estudio encaminado a esclarecer las causas, que incluye tres tipos de ensayos: ensayos de compresión de cilindros de hormigón confinados con CFRP y GFRP, y ensayos de tracción de probetas de FRP de tipo cupón plano (ASTM, 2008b, UNE-EN-ISO, 1997), y de tipo anillo (ASTM, 2008a). La rotura en las probetas de FRP con forma de anillo se produce a una deformación muy inferior a la obtenida en el ensayo de cupones planos (la relación entre deformaciones últimas es de 0.68 para el carbono y 0.85 para el vidrio), lo que puede interpretarse como que la curvatura en las fibras reduce sensiblemente su resistencia a tracción. En cuanto a la relación entre la deformación última en los ensayos sobre cilindros y sobre 
cupones, obtuvieron valores medios de 0.581 para el carbono ( 9 probetas) y 0.669 para el vidrio (6 probetas), valores muy cercanos a los obtenidos previamente por los mismos autores a partir de ensayos de la literatura (Lam and Teng, 2003b). Del estudio de los resultados de los tres tipos de ensayos concluyen que la deformación de rotura que se mide en las camisas de las probetas confinadas se ve afectada por al menos tres factores: la curvatura de la camisa, la deformación no uniforme del hormigón fisurado y la existencia de una zona de solape en la que las deformaciones medidas son más bajas que las deformaciones medidas en otros sitios. El primer factor es sensible al tipo de FRP y produce una disminución de su capacidad de deformación, mientras que los otros dos factores producen una distribución de deformaciones en la camisa no uniforme. Los autores indican la limitación de su estudio al tratarse de probetas pequeñas (152 mm de diámetro) y la necesidad de realizar ensayos en probetas a gran escala donde el efecto de la curvatura y del solape puede ser menor y en cambio incrementarse el efecto de la deformación no uniforme del hormigón y otros factores no considerados en su estudio, como la influencia de fibras no alineadas, deformaciones residuales o mayor posibilidad de puntos débiles en el FRP.

Un ensayo similar al ring splitting test fue utilizado por Yang et al. (Yang et al., 2001) para investigar el efecto del radio de curvatura en la resistencia a tracción del CFRP, obteniendo para un radio de curvatura de $50.8 \mathrm{~mm}$ una resistencia media de sólo el $66 \%$ de la resistencia obtenida en ensayo a tracción de cupones planos, y valores inferiores al reducirse el radio de curvatura.

A la vista de estas investigaciones también los modelos teóricos, como se verá más adelante, han ido incorporando el concepto de deformación última efectiva, que no se había tenido en cuenta en la mayoría de los modelos. Por ejemplo en (Matthys et al., 2005) se revisa el modelo inicial de Toutanji (Toutanji, 1999) considerando un valor de $k_{\varepsilon}=0.6$ para la relación entre la deformación última efectiva y la deformación última del material en ensayos de tracción. Este valor de $k_{\varepsilon}=0.6$ lo obtienen a partir de resultados experimentales propios y de otros autores sobre probetas cilíndricas. Xiao y Wu (Xiao and Wu, 2003), a partir de las observaciones de sus propios ensayos, sugieren tomar como deformación de rotura del FRP el $50 \%$ del valor obtenido en los ensayos de tracción del FRP. A partir de los resultados citados del trabajo de Lam y Teng (Lam and Teng, 2003b) sobre ensayos de la literatura se justifica también en la guía de cálculo 
de $\mathrm{ACl}(\mathrm{ACl}-440.2 \mathrm{R}-08,2008)$ un coeficiente de eficiencia de la deformación $k_{\varepsilon}=0.55$.

La disminución de la deformación de rotura al disminuir el radio de curvatura del FRP tiene especial importancia en caso de secciones cuadradas y rectangulares con las esquinas redondeadas. Es conocido que el confinamiento en secciones rectangulares es menos efectivo, y se atribuye a la no uniformidad de la presión de confinamiento alrededor de la sección, porque ésta se concentra en las esquinas. Como se verá a continuación en el apartado 2.4.2.3 habitualmente este efecto se tiene en cuenta en los modelos teóricos a través de un coeficiente reductor de eficiencia debido a la forma de la sección, de manera similar a como se hace con el confinamiento con acero. Sin embargo, rara vez se ha considerado en los modelos el hecho de que además en las secciones rectangulares la deformación última efectiva del FRP pueda ser menor.

Los estudios experimentales sobre probetas cuadradas o rectangulares son mucho más escasos que sobre probetas cilíndricas, y además muy pocos han abordado el estudio de la deformación de rotura del FRP.

Wang y Wu (Wang and Wu, 2008) realizaron ensayos sobre secciones cuadradas para ver el efecto del radio de curvatura de las esquinas en la deformación de rotura del FRP, encontrando que al incrementarse el radio de curvatura generalmente aumentaba la deformación de rotura. Pham y Hadi (Pham and Hadi, 2014) encontraron lo mismo al analizar una base de datos de ensayos de secciones cuadradas y rectangulares recopilada de la literatura. Se supone que la deformación de rotura depende del ratio entre el radio de curvatura y la longitud del lado (podría ser $2 R_{c} / b$ o $2 R_{c} / d$ siendo $b$ y $d$ la longitud de los lados mayor y menor de la sección). Wu y Wei 2010 investigaron los efectos de la relación entre lados $(b / d)$ en la deformación de rotura del FRP, encontrando que cuando la relación entre lados variaba entre 1 y 2, la deformación de rotura del FRP era muy similar. La deformación de rotura se mantenía en un cierto valor para probetas con diferente longitud del lado largo pero la misma longitud del lado corto y las mismas propiedades de los materiales (resistencia del hormigón sin confinar, $\mathrm{n}^{\circ}$ de capas y radio de curvatura). Los autores supusieron que la deformación de rotura del FRP es función de la relación entre el radio de curvatura y la longitud del lado más corto $\left(2 R_{c} / d\right)$. 
Pham y Hadi (Pham and Hadi, 2014) estudiaron la base de datos recopilada de la literatura, y a partir de un número reducido de ensayos, que eran aquellos en los que se indicaba la deformación de rotura del FRP en las esquinas, obtuvieron una ecuación para obtener el factor de eficiencia da la deformación $k_{\varepsilon}$ (relación entre deformación real de rotura del FRP en la camisa y deformación de rotura en cupones planos) en función de un parámetro $\mathrm{A}$, en el que incluyen la relación entre el $R_{c}$ y el lado corto, y el ratio de rigidez del confinamiento $\rho_{k}$.

$$
k_{\varepsilon}=0.5+0.0642 \ln A
$$

con

$$
A=\frac{2 R_{c}}{d \rho_{k}}
$$

El ratio de confinamiento $\rho_{k}$ lo habían definido Teng et al. (Teng et al., 2009) para una sección circular en función de su diámetro $D$, el espesor $t$ y módulo elástico $E_{f}$ del FRP y las propiedades del hormigón sin confinar :

$$
\rho_{k}=\frac{2 t E_{f}}{\left(\frac{f c o}{\varepsilon_{c o}}\right) D}
$$

En el caso de una sección rectangular Pham y Hadi reemplazan $D / 2$ por el radio de las esquinas:

$$
\rho_{\mathrm{k}}=\frac{t E_{f}}{\left(\frac{f_{c o}}{\varepsilon_{c o}}\right) R_{c}}
$$

De los datos analizados obtienen que el factor $k_{\varepsilon}$ varía entre 0.4 y 0.7 , por lo que recomiendan que el factor de eficiencia de la deformación que se adopte esté en este rango.

Como se ve, los distintos investigadores proponen valores diferentes, y siempre sujetos a una importante incertidumbre, para la deformación última efectiva del FRP, definida por el coeficiente $k_{\varepsilon}$. Este coeficiente es un punto no resuelto hasta la fecha y esencial para el ajuste y calibración de los modelos de cálculo, ya que dependiendo del valor que se adopte los resultados pueden ser muy distintos, anulando los esfuerzos hechos en la obtención de modelos fenomenológicamente bien desarrollados. 


\subsubsection{Influencia de la forma de la sección. Secciones cuadradas o rectangulares}

La mayoría de los estudios teóricos y experimentales sobre confinamiento con FRP se han ocupado de pilares de sección circular. Las investigaciones sobre secciones cuadradas o rectangulares han mostrado que el confinamiento es mucho menos efectivo. En algunos estudios incluso se afirma que el incremento de resistencia que se consigue es despreciable aunque sí puede aumentarse la deformación axial última. Sin embargo otras guías y estudios permiten evaluar el efecto beneficioso del confinamiento, generalmente basándose en formulaciones creadas para secciones circulares que se modifican mediante un "factor de eficiencia" debido a la forma de la sección o "factor de forma" que pretende tener en cuenta la geometría de la sección y su efecto en la presión de confinamiento, que no se aplica uniformemente como en el caso de secciones circulares.

El factor de forma $\alpha_{e}$ más aceptado es el basado en el efecto arco, utilizado habitualmente en el confinamiento con acero, que considera que solamente el área de hormigón contenida por las cuatro parábolas de segundo grado que cortan a los lados a $45^{\circ}$ está plenamente confinada, mientras que en el resto de la sección el confinamiento es despreciable. Dicho coeficiente se obtiene como la relación entre el área confinada y el área total de hormigón (Figura 2.26):

$$
\alpha_{e}=1-\frac{b^{2}+d^{2}}{3 A_{g}\left(1-\rho_{s g}\right)}
$$

siendo $b^{\prime}$ y $d^{\prime}$ la distancia entre dos esquinas redondeadas: $b^{\prime}=b-2 R_{c}$; $d^{\prime}=d-2 R_{c} ;$ y $\rho_{s g}=A_{s} / A_{g}$ es la cuantía de acero longitudinal.

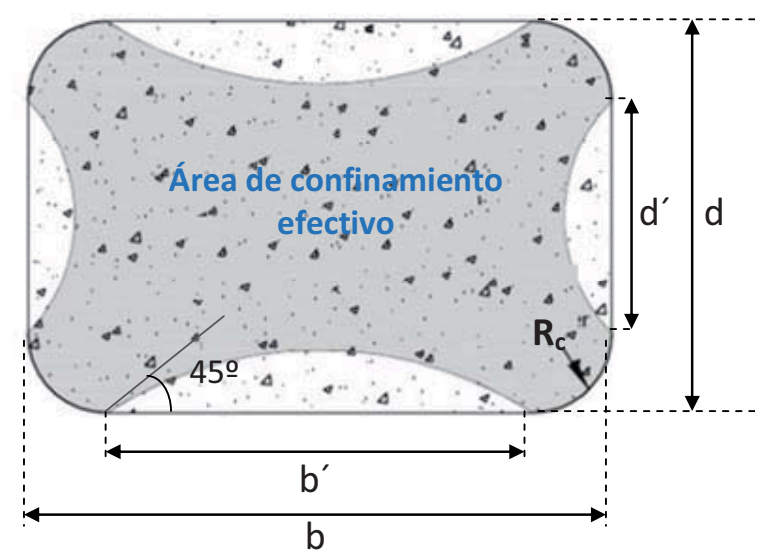

Figura 2.26 Confinamiento en secciones rectangulares (efecto arco) 
Aunque el coeficiente derivado del efecto arco es el más comúnmente utilizado, algunos autores han hecho diferentes propuestas para el cálculo de $\alpha_{e}$.

Rochette y Labossière (Rochette and Labossière, 2000) ensayaron probetas de sección circular, cuadrada y rectangular encontrando que el efecto del confinamiento estaba directamente relacionado con la forma de la sección para una cuantía de refuerzo dada, que las esquinas debían redondearse siempre para evitar la rotura prematura de las fibras y que el ratio entre el radio de la esquina y el lado de la sección podía utilizarse para estimar el efecto del confinamiento.

Los ensayos publicados en la literatura muestran que el radio de curvatura con que se redondean las esquinas afecta significativamente a la efectividad del confinamiento, y varios investigadores sitúan la rotura del FRP en las esquinas de la sección, o cerca de ellas (Rochette and Labossière 2000, Chaallal et al. 2003, Wang et al. 2012; Hadi et al. 2013).

Mirmiran et al. (Mirmiran et al., 1998) ensayaron tubos de FRP rellenos de hormigón de pequeño tamaño con sección circular y cuadrada encontrando que el confinamiento era menos efectivo en las cuadradas. Para considerar el efecto de la forma de la sección proponían reemplazar el ratio de confinamiento $f_{l} / f_{c o}$ de probetas circulares por un ratio de confinamiento modificado definido como:

$$
M C R=\left(\frac{2 R_{c}}{b}\right) \frac{f_{l}}{f_{c o}}
$$

donde $R_{c}$ es el radio de curvatura de las esquinas, $b$ el lado de la sección de hormigón, y $f_{l}$ es la presión de confinamiento sobre un pilar circular equivalente de diámetro igual a $b$. Para valores de $M C R$ menores de 0.15 no era esperable mejora en la resistencia. Esta propuesta es equivalente a definir el coeficiente $\alpha_{e}$ como:

$$
\alpha_{e}=\frac{2 R_{c}}{b}
$$

Con esta expresión se obtienen valores de $\alpha_{e}$ mucho más reducidos que con el factor de forma habitual basado en el efecto arco, y más influenciados por el valor del radio de curvatura con el que se redondean las esquinas.

Karam y Tabbara (Karam and Tabbara, 2004) proponen el siguiente coeficiente de efectividad para secciones rectangulares: 


$$
\alpha_{e}=\frac{R_{c}}{d / 2} \frac{1}{2}\left(1+\frac{d / 2}{b / 2}\right)
$$

siendo $b$ la longitud del lado mayor del rectángulo y $d$ la del lado menor. Nótese que $\alpha_{e}=1$ para secciones circulares, mientras que para secciones cuadradas de lado $b$ se obtiene la misma expresión que propuso Mirmiran (Mirmiran et al., 1998).

Karam y Tabbara (Karam and Tabbara, 2004) realizan también un análisis mediante elementos finitos de las tensiones en pilares de hormigón confinados con FRP, investigando secciones cuadradas y rectangulares con radio de curvatura variable en las esquinas y comparándolas con secciones circulares. Los resultados muestran un incremento en las tensiones en las esquinas con radios de curvatura más pequeños, una localización de la rotura en las esquinas causado por este incremento de tensiones y una disminución de la eficiencia del confinamiento al aumentar la relación entre los lados del rectángulo $b / d$, y al disminuir los radios de curvatura. Mediante el método numérico calculan los coeficientes de efectividad para valores típicos de dimensiones de la sección y de $R_{c}$, obteniendo resultados muy similares a los que se obtienen mediante la expresión anterior.

\subsubsection{Hormigón confinado con FRP. Modelos teóricos.}

El efecto beneficioso de la presión de confinamiento sobre la resistencia y deformación última del hormigón es conocido desde hace mucho tiempo, y en el caso de confinamiento con acero son numerosas las investigaciones realizadas y se han desarrollado modelos y formulaciones que explican satisfactoriamente su comportamiento.

Los primeros estudios sobre confinamiento con FRP trataron de aplicar directamente los modelos desarrollados previamente para el acero (Saadatmanesh et al., 1994, Fardis and Khalili, 1982), pero pronto se comprobó que no eran válidos. En el caso de confinamiento con acero, tan pronto como el hormigón comienza a fisurarse, la deformación lateral crece repentinamente y los cercos plastifican. A partir de ese punto la presión de confinamiento aplicada sobre el hormigón es constante.

Debido a su comportamiento elástico hasta rotura, los materiales compuestos, a diferencia del acero, ejercen una acción de confinamiento sobre el hormigón continuamente creciente al incrementarse la expansión lateral del elemento 
confinado, que a su vez se ve afectada por el aumento de la presión de confinamiento.

A la vista de este diferente comportamiento, se han propuesto en los últimos años varios modelos específicos para el confinamiento de hormigón con FRP, la mayoría de naturaleza empírica. Los modelos suelen clasificarse en dos categorías, según estén orientados al cálculo ((Fardis and Khalili, 1982, Samaan et al., 1998, Miyauchi et al., 1997, Saafi et al., 1999, Toutanji, 1999, Xiao and Wu, 2003, Lam and Teng, 2003b, Youssef et al., 2007, Wu et al., 2007) o al análisis (Mirmiran and Shahawy, 1996, Spoelstra and Monti, 1999, Fam and Rizkalla, 2001, Marques et al., 2004, Teng et al., 2007a, Jiang and Teng, 2007, Binici, 2005, Becque et al., 2003, Harries and Kharell, 2002).

En los modelos orientados al cálculo la resistencia a compresión, la deformación última del hormigón y su respuesta tensión-deformación se obtienen mediante ecuaciones basadas directamente en la interpretación de resultados de ensayos. Este tipo de modelos son los que se han ido incorporando en las guías y recomendaciones de cálculo publicadas en los distintos países.

En los modelos orientados al análisis las curvas tensión-deformación se generan mediante un procedimiento incremental. Suele utilizarse como base un modelo de confinamiento activo (es decir, la presión de confinamiento se aplica externamente y permanece constante mientras que se incrementa la tensión axial) para evaluar la tensión y deformación del hormigón para cada valor de la presión de confinamiento. La interacción entre el hormigón y el FRP que lo confina se tienen en cuenta explícitamente mediante condiciones de equilibrio y compatibilidad de desplazamientos. Estos modelos se basan en la hipótesis de que la tensión y deformación axial del hormigón confinado con FRP para una deformación lateral dada son los mismos que en un hormigón confinado activamente con una presión de confinamiento constante e igual a la que aporta la camisa de FRP. Como resultado de esta hipótesis, la curva tensióndeformación del hormigón confinado con FRP puede obtenerse mediante el siguiente procedimiento (Jiang and Teng, 2007) (Figura 2.27):

1) Para una deformación axial dada, se obtiene la correspondiente deformación lateral de acuerdo con la relación deformación lateraldeformación axial. 
2) Mediante equilibrio de fuerzas y compatibilidad de desplazamientos entre el hormigón y el FRP, se calcula la correspondiente presión lateral de confinamiento ejercida por el FRP.

3) Se utilizan los valores de deformación axial y presión de confinamiento obtenidos en los pasos anteriores para, mediante el modelo de confinamiento activo, evaluar la correspondiente compresión axial, con lo cual se obtiene un punto de la curva tensión-deformación del hormigón confinado con FRP.

4) Se repiten los pasos anteriores para generar la curva tensióndeformación completa.

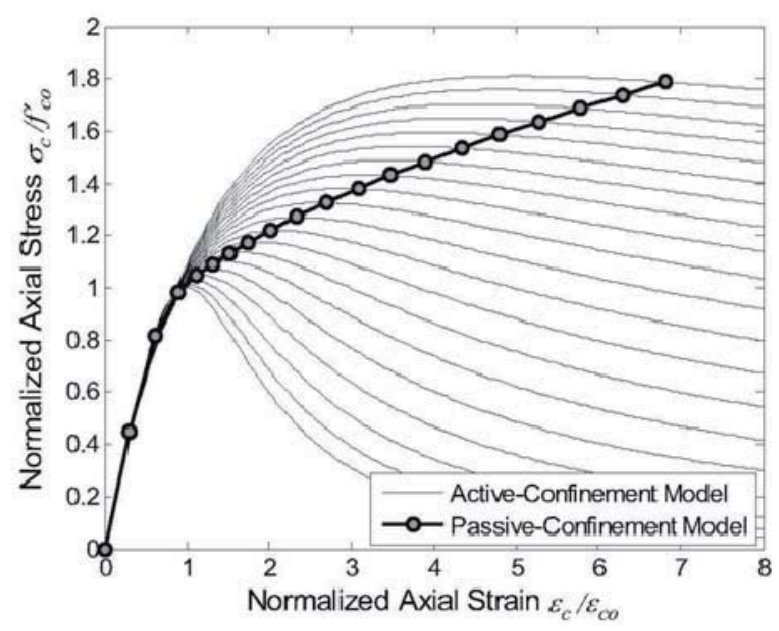

Figura 2.27 Obtención de la curva tensión-deformación del hormigón confinado con FRP (Jiang and Teng, 2007)

Se han propuesto diversos modelos orientados al análisis de este tipo en los que generalmente se parte del modelo de Mander como modelo de confinamiento activo.

En Jiang y Teng (Jiang and Teng, 2007) puede encontrarse una revisión de los principales modelos analíticos propuestos hasta entonces, y se propone una revisión de un modelo anterior de los autores (Teng et al., 2007a) que ha mostrado encontrarse entre los que mejor se ajustan a los resultados experimentales (Ozbakkaloglu, 2013). Posteriormente en Teng et al. (Teng et al., 2014) se propone un modelo basado en los anteriores para el caso de confinamiento con FRP y con acero (tiene en cuenta el confinamiento de la armadura de acero transversal), aunque para ello utilizan una base de datos muy 
limitada. La complejidad del procedimiento incremental hace que todos estos modelos no se consideren adecuados para el cálculo, pero sí para incorporarlos en métodos de análisis numérico mediante elementos finitos.

Recientemente Dong et al. (Dong et al., 2015) han propuesto un modelo analítico verificado con datos experimentales, y con él han realizado un estudio paramétrico para evaluar el efecto de la resistencia del hormigón, la rigidez del FRP y la deformación de rotura del FRP. Basándose en el modelo analítico han desarrollado fórmulas para el cálculo de la resistencia y deformación últimas. Estas fórmulas se expresan en función de la rigidez del confinamiento y la deformación de rotura, que en opinión de los autores son los parámetros fundamentales y deberían tenerse en cuenta de manera separada. De hecho, indican que las fórmulas existentes que no tienen en cuenta de manera separada la deformación de rotura son incorrectas.

Comparativamente existen pocos modelos para secciones rectangulares: Restrepo y De Vino, (Mirmiran et al., 1998), Campione y Miraglia, (Lam and Teng, 2003b), (Wu and Wang, 2009), (Toutanji et al., 2010), (Wu and Wei, 2010), (Wu and Zhou, 2010) (Pham and Hadi, 2014). Se han propuesto algunos modelos que tratan de manera unificada las secciones circulares y rectangulares.

La mayoría de los modelos existentes para secciones rectangulares son similares a los de secciones circulares en los que se introduce un factor de forma para tener en cuenta que la presión de confinamiento a lo largo del perímetro de la sección no es uniforme. La presión de confinamiento en estos casos se calcula como la que actuaría sobre una sección circular con un diámetro equivalente. Las diferencias entre estos modelos radican en el factor de forma y la definición del diámetro equivalente para secciones rectangulares.

A continuación en los siguientes subapartados se exponen con mayor detenimiento, a modo de síntesis del estado del conocimiento, los modelos que se consideran de mayor interés, por su mayor uso o por su mejor comprensión del fenómeno del confinamiento:

- el modelo de Spoelstra y Monti (1999), como ejemplo de modelo analítico, recogido además en la guía de cálculo publicada por la fib; 
- el modelo de Lam y Teng (2003) (Lam and Teng, 2003b), modelo orientado al cálculo basado en una base de datos experimental de la literatura. Se trata seguramente del modelo con más aceptación que además ha sido adoptado con ligeras modificaciones por guías internacionales de cálculo como (ACl-440.2R-08, 2008) y la segunda edición del TR55 (2004). Posteriormente los mismos autores presentan en 2009 (Teng et al., 2009) una revisión del modelo basándose en resultados de nuevos ensayos realizados por el grupo (Lam and Teng, 2004, Jiang and Teng, 2007, Lam et al., 2006, Teng et al., 2007b) y un estudio paramétrico con un modelo orientado al análisis que también habían desarrollado (Jiang and Teng, 2007, Teng et al., 2007a). Esta última versión del modelo no se expone en este capítulo, pero ha sido adoptada por la 3a edición del TR55 en 2012 (TR55, 2012) que se analiza en el capítulo 5.

- el modelo para secciones rectangulares propuesto por Lam y Teng (Lam and Teng, 2003a), adoptado también por la guía de ACI-440.2R-08.

- el modelo de Pham y Hadi (2014) para pilares de sección rectangular.

\subsubsection{Modelo de Spoelstra y Monti (1999)}

Parten del modelo de Mander (Mander et al., 1988) para hormigón confinado con acero, expuesto en el apartado 2.4.1.1, que está basado a su vez en la fórmula de Popovics (Popovics, 1973). Como ya se ha indicado, aunque algunos investigadores intentaron aplicar el modelo de Mander al confinamiento con materiales compuestos, este modelo no es aplicable directamente al caso del FRP ya que está basado en un valor constante de la presión de confinamiento a lo largo de la historia de carga, hipótesis válida para el acero plastificado pero no para el FRP.

Spoelstra y Monti (Spoelstra and Monti, 1999) proponen un cálculo iterativo que combina el modelo de Popovics-Mander (ecuaciones [2.6 a 2.9]) con el modelo de Pantazopoulou y Mills (Pantazopoulou and Mills, 1995) que expresa la deformación circunferencial como una función de la deformación axial. Según este modelo, para hormigón sin confinar, la tensión uniaxial $f_{c}$ del hormigón bajo una deformación axial $\varepsilon_{c}$ viene dada por:

$$
f_{c}=E_{s e c} \cdot \varepsilon_{c}
$$




$$
E_{s e c}=E_{c} \frac{1}{1+\beta \varepsilon_{A}}=E_{c} \frac{1}{1+2 \beta \varepsilon_{l}}
$$

Adoptándose en la última ecuación la hipótesis de simetría radial $\left(\varepsilon_{A}=2 \varepsilon_{l}\right)$ que permite introducir la dependencia de la deformación lateral $\varepsilon_{\text {l }}$.

La deformación del área $\varepsilon_{A}$ se toma como una medida del daño interno debido a la fisuración, que reduce el módulo secante $E_{s e c}$ a partir del módulo tangente inicial $E_{c}$.

$\beta$ es una constante propiedad del hormigón que se expone más adelante.

Según el convenio de signos utilizado $\varepsilon_{c}$ y $f_{c}$ son negativos (compresiones) y $\varepsilon_{A}$ y $\varepsilon_{l}$ (expansiones) son positivos.

La variación de la deformación lateral sin restricción $\varepsilon_{l}$ bajo la deformación axial impuesta $\varepsilon_{c}$ se evalúa con una fórmula deducida experimentalmente, que bajo la hipótesis de simetría radial se expresa:

$$
\varepsilon_{l}=-v \varepsilon_{c}-\frac{1}{2}(1-2 v) \alpha \varepsilon_{c o}\left(\frac{\left\langle\varepsilon_{l i m}-\varepsilon_{c}\right\rangle}{\varepsilon_{l i m}-\alpha \varepsilon_{c o}}\right)^{2}
$$

donde:

$v$ : coeficiente de Poisson

$\varepsilon_{\text {lim }} \approx-0.001$ : deformación axial límite a partir de la cual comienzan a aparecer microfisuras

$\alpha \varepsilon_{c o}$ : deformación axial para una deformación volumétrica nula, $\varepsilon_{v}=\varepsilon_{A}+\varepsilon_{c}=0$ siendo $\alpha=$ 0.9-1.0 para hormigón sin confinar y $\varepsilon_{c o} \approx-0.002$ : deformación para el pico de tensión $f_{\text {co }}$.

Los corchetes de McAuley, definidos como $\langle x\rangle=0,5(x+|x|)$ indican que el término al cuadrado se considera sólo cuando $\varepsilon_{c}<\varepsilon_{\text {lim }}$.

Pantazopoulou y Mills proponían evaluar la constante $\beta$ a partir del porcentaje en volumen de pasta y de la relación agua-cemento. Sin embargo Spoelstra y Monti creen más conveniente en este caso expresarla en función de las propiedades mecánicas del hormigón sin confinar, como $f_{c o}, \varepsilon_{c o}$ y $E_{c}$. Dado que $\beta$ es una 
constante, es decir, independiente de $\varepsilon_{c}$, proponen evaluarla a partir de la ecuación [2.20 b] con $\varepsilon_{c}=\varepsilon_{c o}$ :

$$
\beta=\frac{\frac{E_{C}}{E_{\text {seco }}}-1}{2 \varepsilon_{l o}}
$$

Donde:

$$
E_{\text {seco }}=\frac{f_{c o}}{\varepsilon_{c o}}
$$

$$
\varepsilon_{l o}=-v \varepsilon_{c o}-\left(\frac{1}{2}-v\right) \alpha \varepsilon_{c o}\left(\frac{\left\langle\varepsilon_{l i m}-\varepsilon_{c o}\right\rangle-\varepsilon_{c o}}{\varepsilon_{l i m}-\alpha \varepsilon_{c o}}\right)^{2}
$$

siendo $\varepsilon_{l o}$ la deformación lateral del hormigón correspondiente a $\varepsilon_{c o}$. Así $\beta$ depende sólo de las propiedades del hormigón sin confinar $f_{c o}, \varepsilon_{c o}, E_{c}, v$ y $\alpha$. Tomando $\alpha=1$, la constante $\beta$ se convierte en:

$$
\beta=\frac{1}{\varepsilon_{c o}}-\frac{E_{c}}{f_{c o}}=\frac{E_{c}}{\left|f_{c o}\right|}-\frac{1}{\left|\varepsilon_{c o}\right|}
$$

y admitiendo $\varepsilon_{c o}=-0.002$ y $E_{c}=5700 \sqrt{\left|f_{c o}\right|}(\mathrm{MPa})$ :

$$
\beta=\frac{5700}{\sqrt{\left|f_{c o}\right|}}-500 \quad\left(f_{c o} \text { en MPa }\right)
$$

Las ecuaciones [2.20 a y b] se pueden escribir como:

$$
\begin{aligned}
& E_{s e c}\left(\varepsilon_{c}, f_{l}\right)=\frac{f_{c}\left(\varepsilon_{c}, f_{l}\right)}{\varepsilon_{c}} \\
& \varepsilon_{l}\left(\varepsilon_{c}, f_{l}\right)=\frac{E_{c}-E_{s e c}\left(\varepsilon_{c}, f_{l}\right)}{2 \beta E_{s e c}\left(\varepsilon_{c}, f_{l}\right)}
\end{aligned}
$$

y unidas en una ecuación:

$$
\varepsilon_{l}\left(\varepsilon_{c}, f_{l}\right)=\frac{E_{c} \varepsilon_{c}-f_{c}\left(\varepsilon_{c}, f_{l}\right)}{2 \beta E f_{c}\left(\varepsilon_{c}, f_{l}\right)}
$$

donde se pone explícitamente la dependencia de los valores $f_{c}$ y $\varepsilon_{l}$ de la deformación axial $\varepsilon_{c}$ y la presión de confinamiento $f_{l}$.

Una vez que se calcula $\varepsilon_{l}$ mediante [2.29], puede obtenerse la deformación en la camisa $\varepsilon_{j}$ (por ejemplo para el caso de cilindros de hormigón cargados axialmente es simplemente $\varepsilon_{j}=\varepsilon_{l}$ ), junto con su tensión $f_{j}=E_{f} \cdot \varepsilon_{j}$, siendo $E_{f}$ el 
módulo de elasticidad del material compuesto de la camisa. La presión de confinamiento correspondiente $f_{l}$ puede evaluarse como

$$
f_{l}=\frac{1}{2} \rho_{f} f_{j}=\frac{1}{2} \rho_{f} E_{f} \varepsilon_{j=l} ; \quad \text { con } \quad \rho_{f}=\frac{4 t}{d}
$$

Este valor actualizado de $f_{l}$ puede utilizarse para una nueva estimación de $\varepsilon_{l}$ mediante [2.28], dando lugar a un procedimiento iterativo (Figura 2.28) hasta que $f_{l}$ converja a un valor estable.

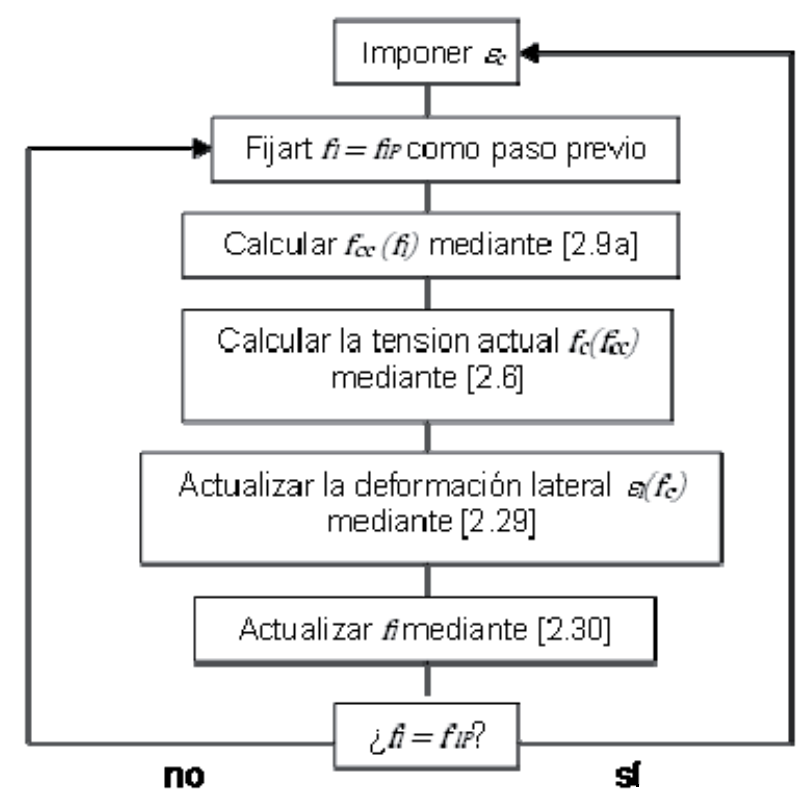

Figura 2.28 Procedimiento iterativo del modelo de Spoelstra y Monti

Todo el procedimiento se repite para cada $\varepsilon_{c}$, sobre la curva tensión-deformación completa (Figura 2.27). Esta última puede considerarse como una curva que cruza a una familia de curvas de Mander, cada una perteneciente al nivel de presión de confinamiento correspondiente a la deformación lateral en cada momento. Las características de tensión-deformación del mecanismo de confinamiento se tienen en cuenta explícitamente, mientras que la deformación lateral del hormigón se obtiene implícitamente a través del procedimiento iterativo. Todos los ensayos numéricos han mostrado que la convergencia es muy rápida para valores razonables de los parámetros. 


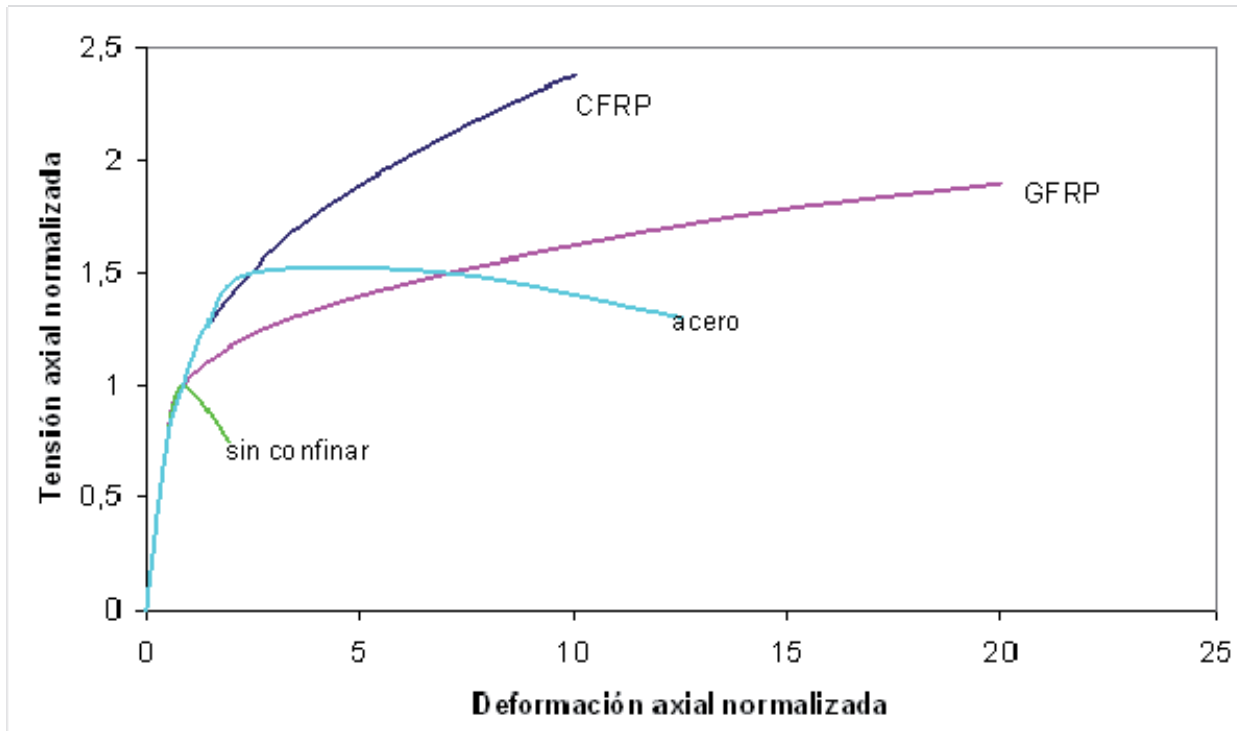

Figura 2.29 Curvas tensión axial deformación axial para hormigón confinado con acero, CFRP y GFRP, según modelo de Spoelstra y Monti

Independientemente de la respuesta tensión-deformación completa, las coordenadas de la tensión y deformación últimas pueden obtenerse directamente de la presión de confinamiento ejercida por la camisa en el momento último de la siguiente manera (ver Figura 2.30):

1. La presión de confinamiento última viene dada por:

$$
f_{l}=\frac{1}{2} \rho_{f} f_{f}=\frac{2 t f_{f}}{D}
$$

2. Los parámetros del modelo de confinamiento de Mander correspondientes a $f_{l}$ son:

$$
\begin{gathered}
f^{\prime}{ }_{c c}=f_{c o}\left(2,254 \sqrt{1+7,94 \frac{f_{l}}{f_{c o}}}-2 \frac{f_{l}}{f_{c o}}-1,254\right) \\
\varepsilon^{\prime}{ }_{c c}=\varepsilon_{c o}\left[1+5\left(\frac{f_{c c}}{f_{c o}}-1\right)\right]
\end{gathered}
$$

3. El módulo secante último se obtiene de [2.20 b]:

$$
E_{s e c, u}=\frac{E_{c}}{1+2 \beta \varepsilon_{j u}}=\frac{E_{c}}{1+2 \beta f_{j u} / E_{f}}
$$


4. La intersección de la línea recta con pendiente $E_{\text {sec,u }}$ en la Figura 2.30. y con la curva de Mander en el instante último da la tensión y deformación últimas en el hormigón:

$$
\begin{aligned}
& \varepsilon_{c c}=\varepsilon^{\prime}{ }_{c c}\left[\frac{E_{c c}\left(E_{c}-E_{s e c, u}\right)}{E_{s e c, u}\left(E_{c}-E_{c c}\right)}\right]^{1-E_{c c} / E_{c}} \\
& f_{c c}=E_{s e c, u} \varepsilon_{c c}
\end{aligned}
$$

donde $E_{c c}=f^{\prime}{ }_{c c} / \varepsilon^{\prime}{ }_{c c}$.

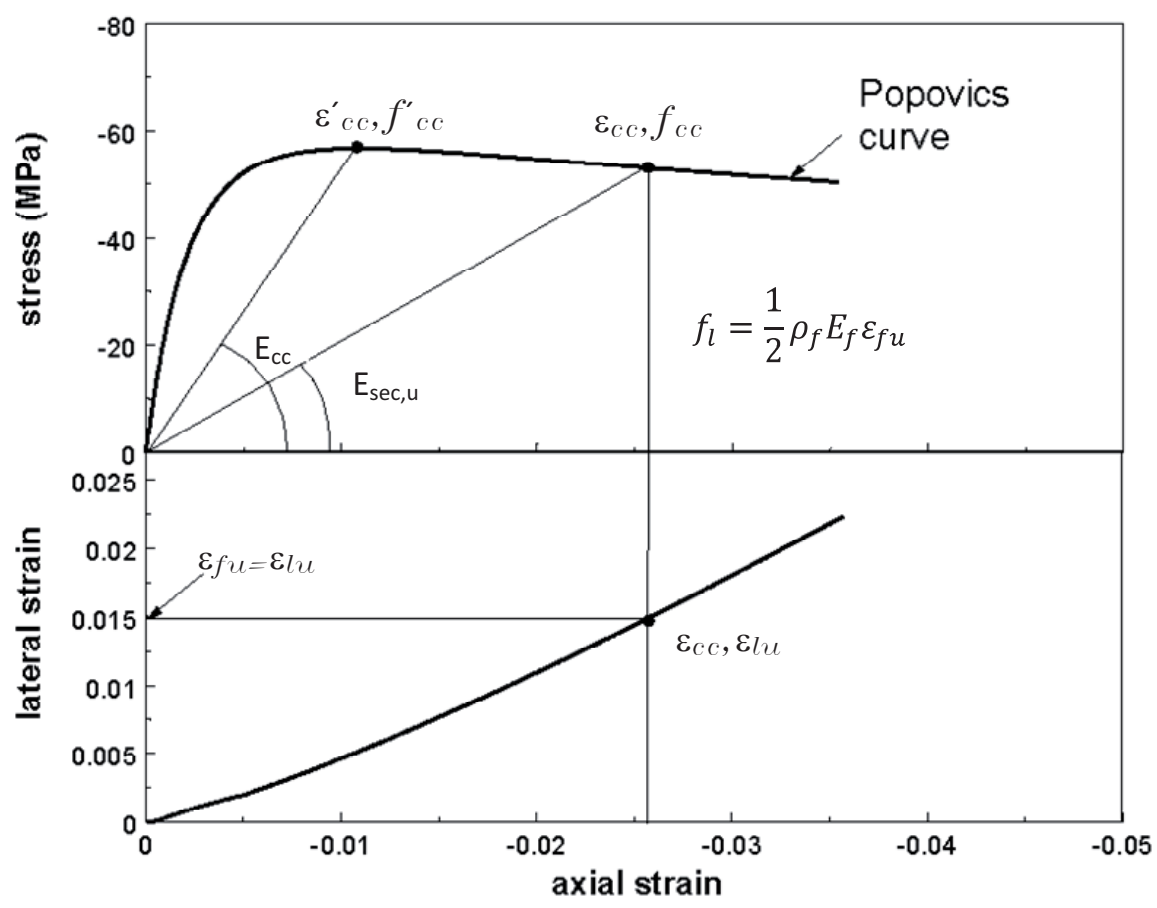

Figura 2.30 Procedimiento de cálculo de la tensión y deformación últimas

Spoelstra y Monti proponen también unas fórmulas aproximadas para obtener la tensión y deformación últimas, obtenidas mediante análisis de regresión basándose en que los resultados experimentales muestran que ambas tienen una dependencia directa de la deformación última de la camisa $\varepsilon_{f u}$, la máxima presión de confinamiento $f_{l}$ y el módulo del hormigón $E_{c}$, mientras que dependen inversamente de la resistencia del hormigón sin confinar $f_{c o}$. Estas ecuaciones son: 


$$
\begin{aligned}
& f_{c c}=f_{c o}\left(0,2+3 \sqrt{\bar{f}_{l}}\right) \\
& \varepsilon_{c c}=\varepsilon_{c o}\left(2+1,25 \bar{E}_{c} \varepsilon_{f u} \sqrt{\bar{f}_{l}}\right)
\end{aligned}
$$

donde los valores normalizados de la máxima presión de confinamiento y del módulo tangente del hormigón son:

$$
\bar{f}_{l}=\frac{f_{l}}{f_{c o}} \quad ; \quad \bar{E}_{c}=\frac{E_{c}}{f_{c o}}
$$

Para el caso en que no exista confinamiento $\left(f_{l}=0\right)$ se obtienen los parámetros del hormigón sin confinar con $\varepsilon_{c c}=0.004$ (con $\varepsilon_{c o}=0.002$ ) y $f_{c c}$ igual al $20 \%$ de la resistencia sin confinar.

\subsubsection{Modelo de Lam y Teng (2003) para pilares de sección circular}

Lam y Teng (Lam and Teng, 2003b) proponen un modelo tensión-deformación para confinamiento de hormigón con FRP, a partir del análisis de observaciones y resultados de una base de datos experimental recopilada de la literatura.

La base de datos está formada por 76 probetas de sección circular sin armadura interna. La resistencia del hormigón está entre 26.2 y $55.2 \mathrm{MPa}$, el diámetro de las probetas entre 100 y $200 \mathrm{~mm}$, e incluye refuerzos con fibra de carbono, vidrio y aramida. En 52 probetas las propiedades del FRP las habían obtenido los investigadores mediante ensayos de cupones planos, mientras que en las restantes se utilizaron las propiedades dadas por los fabricantes.

El modelo se basa en las siguientes hipótesis:

a) La curva tensión deformación está formada por una primera rama parabólica y una segunda rama lineal (Figura 2.31).

b) La pendiente inicial de la parábola viene dada por el módulo de elasticidad del hormigón sin confinar $E_{c}$.

c) La parte no lineal de la primera rama se ve en parte afectada por la presencia de la camisa de FRP.

d) El encuentro entre la primera rama parabólica y la segunda rama lineal es suave, sin cambio de pendiente en la unión de ambas. 
e) La segunda rama lineal termina en el punto definido por la resistencia a compresión $f_{c c}$ y la deformación axial última $\varepsilon_{c c}$ del hormigón confinado.

Estas hipótesis están de acuerdo con las observaciones de ensayos de probetas de hormigón confinadas con una cantidad de FRP suficiente, es decir, con un ratio de confinamiento $f_{l} / f_{c o}$ no menor de 0.07 . Lam y Teng indican que el confinamiento suficiente así definido no garantiza una curva tensión-deformación monótona ascendente pero aseguran que puede esperarse alguna ganancia de resistencia, y que incluso, si la cantidad de confinamiento de FRP es insuficiente para mejorar la resistencia, puede esperarse una significativa mejora de la ductilidad de la respuesta tensión-deformación. Esta definición del ratio de confinamiento mínimo está basada en los resultados de ensayos disponibles.

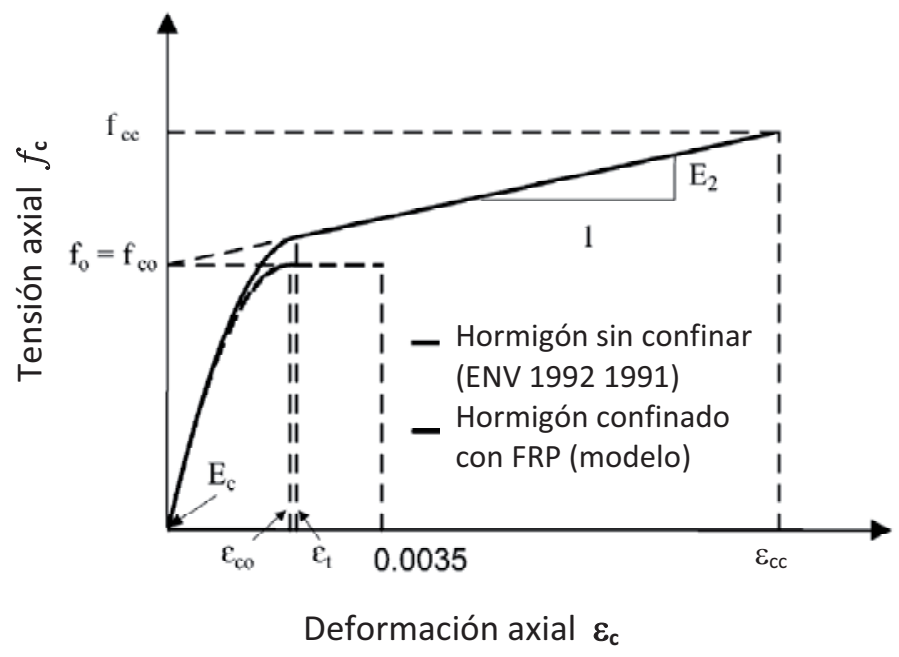

Figura 2.31 Modelo tensión-deformación propuesto por Lam y Teng

Asumen de manera simplificada que el punto de corte entre la segunda rama lineal y el eje de tensiones $\left(f_{0}\right)$ es igual a la resistencia del hormigón sin confinar $f_{c o}$ dado que del análisis de los resultados experimentales de la literatura se obtiene un valor igual a 1.09 para la relación $f_{o} / f_{\text {co }}$.

Así, el modelo tensión deformación para probetas circulares vendría dado por:

$$
\begin{array}{r}
f_{c}=E_{c} \varepsilon_{c}-\frac{\left(E_{c}-E_{2}\right)^{2}}{4 f_{c o}} \varepsilon_{c}^{2}\left(0 \leq \varepsilon_{c} \leq \varepsilon_{t}\right) \\
f_{c}=f_{c o}+E_{2} \varepsilon_{c} \\
\quad\left(\varepsilon_{t} \leq \varepsilon_{c} \leq \varepsilon_{c c}\right)
\end{array}
$$


donde $f_{c} \quad$ y $\varepsilon_{c}$ son la tensión axial y deformación axial del hormigón confinado, $E_{c}$ es el módulo de elasticidad del hormigón sin confinar, $\varepsilon_{t}$ es la deformación axial correspondiente al punto de transición, y $E_{2}$ es la pendiente de la segunda rama lineal.

$\varepsilon_{t}$ y $E_{2}$ vienen dados por:

$$
\begin{gathered}
\varepsilon_{t}=\frac{2 f_{c o}}{E_{c}-E_{2}} \\
E_{2}=\frac{f_{c c}-f_{c o}}{\varepsilon_{c c}}
\end{gathered}
$$

La resistencia del hormigón confinado se calcula según la ecuación de Richart (Richart et al., 1928) :

$$
f_{c c}=f_{c o}+k_{1} f_{l}
$$

Para $k_{1}$ obtienen un valor de 3.3 si se calcula la presión de confinamiento $f_{l}$ a partir del valor de la deformación última efectiva del FRP en la camisa, es decir:

$$
f_{l}=\frac{2 t E_{f} \varepsilon_{f u}}{D} \quad \text { con } \quad \varepsilon_{f u}=k_{\varepsilon} \varepsilon_{f}
$$

Este valor de $k_{1}=3.3$ concuerda con el que habían propuesto previamente los autores (Lam and Teng, 2002) de $k_{1}=2$ en el que la presión de confinamiento se calculaba teniendo en cuenta el valor de deformación última del material $\varepsilon_{f}$ en lugar de $\varepsilon_{f u}$.

En cuanto a la deformación axial última, viene dada por:

$$
\frac{\varepsilon_{c c}}{\varepsilon_{c o}}=1.75+k_{2} \frac{f_{l}}{f_{c o}}\left(\frac{\varepsilon_{f u}}{\varepsilon_{c o}}\right)^{0.45}
$$

tomando la deformación axial del hormigón sin confinar $\varepsilon_{c o}=0.002$ y el factor de mejora de la deformación $k_{2}$ igual a 12. 


\subsubsection{Modelo de Lam y Teng (2003) para pilares de sección rectangular}

En (Lam and Teng, 2003a) los autores extienden el modelo anterior al caso de pilares de sección rectangular. Utilizan para ello una base de datos de ensayos recopilada de la literatura que completan con una serie de ensayos propios. La base de datos de la literatura está formada por 58 ensayos de probetas de sección cuadrada o rectangular de hormigón sin armadura interna (en algunos casos los datos de un ensayo son el valor promedio de dos probetas iguales). La longitud del lado de la sección oscila entre 152 y 203 mm, y la resistencia del hormigón sin confinamiento entre 22.6 y $43.9 \mathrm{MPa}$. Incluye refuerzos con fibra de carbono de alto módulo, carbono de alta resistencia, vidrio y aramida. En la mayoría de las probetas el ratio de confinamiento es bajo, por lo que Lam y Teng completan la base de datos realizando un programa experimental. Este programa incluye 10 probetas cuadradas de $150 \times 150 \mathrm{~mm}^{2}$ de sección y 2 rectangulares de $150 \times 225 \mathrm{~mm}^{2}$, todas de $600 \mathrm{~mm}$ de altura, sin armadura interna y reforzadas con fibra de carbono. La resistencia del hormigón sin confinar estaba comprendida entre 24 y $41.5 \mathrm{MPa}$.

El modelo que proponen para secciones rectangulares es el mismo que habían propuesto para confinamiento uniforme, pero modificando las ecuaciones de cálculo de la resistencia y deformación última.

Para la resistencia a compresión $f_{c c}$ se propone una modificación de la ecuación [2.40] introduciendo un factor de forma $\kappa_{a}$ :

$$
\frac{f_{c c}}{f_{c o}}=1+k_{1} \kappa_{a} \frac{f_{l}}{f_{c o}}
$$

Donde $\kappa_{a} f_{l} / f_{c o}$ sería el ratio de confinamiento efectivo.

Análogamente para obtener la deformación axial última se introduce en la ecuación [2.42] un factor de forma $\kappa_{b}$ diferente de $\kappa_{a}$ :

$$
\frac{\varepsilon_{c c}}{\varepsilon_{c o}}=1.75+k_{2} \kappa_{b} \frac{f_{l}}{f_{c o}}\left(\frac{\varepsilon_{f u}}{\varepsilon_{c o}}\right)^{0.45}
$$

En las ecuaciones [2.43] y [2.44], $f_{l}$ es la presión de confinamiento en un pilar circular equivalente que se define como aquel que tiene por diámetro $D$ la longitud de la diagonal de la sección rectangular: 


$$
D=\sqrt{b^{2}+d^{2}}
$$

Los factores de forma propuestos $\kappa_{a}$ y $\kappa_{b}$ dependen de dos parámetros, el área efectivamente confinada (factor $\alpha_{e}$ ) y la relación entre las dimensiones de los lados del rectángulo:

$$
\begin{aligned}
\kappa_{a} & =\left(\frac{d}{b}\right)^{2} \alpha_{e} \\
\kappa_{b} & =\sqrt{\frac{b}{d}} \alpha_{e}
\end{aligned}
$$

En el caso de secciones cuadradas el valor de ambos factores es igual al de $\alpha_{e}$, que es la relación entre el área efectivamente confinada y el área total de la sección de hormigón. Para calcularlo proponen una modificación al coeficiente comúnmente utilizado basado en que área confinada es aquella encerrada por las parábolas que cortan a los lados con una pendiente de $45^{\circ}$ (ecuación 2.16). Esta suposición no es válida para secciones rectangulares con una relación $b / d$ elevada, pues las parábolas se superpondrían y se podría obtener para $\alpha_{e}$ un valor negativo.

Lam y Teng proponen considerar para el cálculo del área confinada que las parábolas cortan a los lados de la sección con una pendiente igual a la de la diagonal adyacente (Figura 2.32). En consecuencia, para secciones rectangulares, el coeficiente $\alpha_{e}$ viene dado por:

$$
\alpha_{e}=\frac{1-\left((d / b)\left(b-2 R_{c}\right)^{2}+(b / d)\left(d-2 R_{c}\right)^{2} /\left(3 A_{g}\right)\right)-\rho_{s g}}{1-\rho_{s g}}
$$

siendo $b$ y $d$ las dimensiones del lado mayor y menor del rectángulo respectivamente.

Nótese que en el caso particular de sección cuadrada la diagonal forma con los lados $45^{\circ}$, y el coeficiente $\alpha_{e}$ resultante coincide con el factor de forma más comúnmente aceptado. 


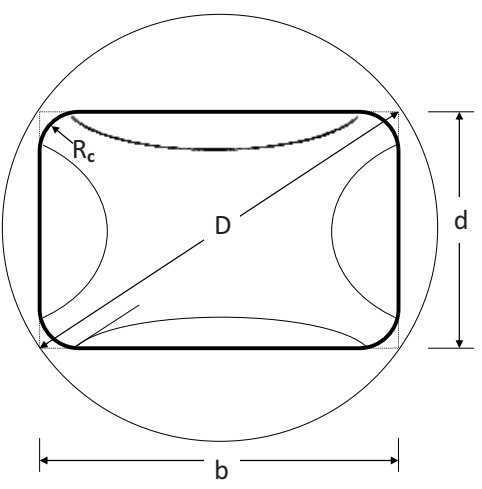

Figura 2.32 Área de confinamiento efectivo en secciones rectangulares.

\subsubsection{Modelo de Pham y Hadi (2014) para pilares de sección rectangular}

Proponen un modelo para calcular la resistencia del hormigón confinado con FRP en secciones rectangulares con las esquinas redondeadas. Para ello utilizan una base de datos recopilada de la literatura formada por 190 probetas rectangulares, con la longitud de los lados de la sección entre 79 y $305 \mathrm{~mm}$, y la relación entre los lados entre 1 y 2.7 . Se trata en su mayoría de probetas sin armadura interna, reforzadas con fibras carbono, vidrio y aramida. La resistencia del hormigón sin confinar está entre 18.3 y $55.2 \mathrm{MPa}$.

Consideran los resultados de ensayos en los que se obtiene una segunda rama ascendente (probetas con suficiente confinamiento) y proponen obtener la resistencia del hormigón confinado mediante la siguiente ecuación:

$$
\frac{f_{c c}}{f_{c o}}=0.68+3.91 \frac{k_{c} f_{l}}{f_{c o}}
$$

Donde $k_{c}$ es un factor que tiene en cuenta el efecto de la esquina (Pham and Hadi, 2013) definido como la relación entre la longitud de las 4 esquinas redondeadas y el perímetro de la sección:

$$
k_{c}=\frac{\pi R_{c}}{b+d-R_{c}(4-\pi)}
$$

y $f_{l}$ es la presión de confinamiento nominal que se obtiene con:

$$
f_{l}=\frac{t E_{f} \varepsilon_{f u}}{R_{c}}
$$


El cálculo de $f_{l}$ mediante la ecuación anterior se basa en la hipótesis de la membrana para formular el comportamiento del hormigón confinado con FRP en secciones rectangulares. Siempre que se cumpla que la relación entre el radio de curvatura $R_{c}$ y el espesor de la camisa $t$ sea mayor de 20 (Calladine, 1983), puede asumirse que la presión de confinamiento se concentra sólo en las esquinas de la sección.

El modelo es válido para los casos en que el confinamiento sea suficiente de manera que se cumpla

$$
\frac{k_{c} f_{l}}{f_{c o}} \geq 0,15
$$

En cuanto a la deformación última efectiva del FRP en las esquinas, ésta depende del ratio entre el radio de curvatura de la esquina y la longitud del lado más corto, y del ratio de rigidez del confinamiento, y puede calcularse mediante la ecuación [2.13] (ver apartado 2.4.2.2). 



\section{CAPÍTULO 3}

\section{PROGRAMA EXPERIMENTAL. PARTE I}

\subsection{Introducción}

En la revisión del estado del conocimiento presentada en el capítulo anterior se ha encontrado que existen dos conceptos clave, aún no resueltos, que determinan el comportamiento del hormigón confinado con FRP sometido a compresión centrada: la deformación última efectiva del FRP y la acción de confinamiento en secciones no circulares.

La mayoría de los estudios experimentales realizados hasta el momento han sido sobre probetas cilíndricas de pequeño tamaño fabricadas con hormigones de entre 30 y $50 \mathrm{MPa}$, y los modelos de cálculo existentes se han basado en estos resultados. Los estudios sobre probetas cuadradas o rectangulares, más escasos, muestran una reducción importante de la efectividad del confinamiento. En cuanto al análisis teórico suelen emplearse los modelos desarrollados para sección circular incluyendo en el cálculo coeficientes reductores por el efecto de la forma de la sección.

Dado que la base experimental disponible es reducida y que el rango de parámetros considerados en los ensayos es muy limitado, se plantea en esta Tesis Doctoral la realización de un programa de ensayos con el objeto de investigar el comportamiento del hormigón confinado con FRP en probetas de 
sección cuadrada. El programa experimental incluye dos fases, que se exponen en este capítulo y en el siguiente.

El objetivo del los trabajos incluidos en este capítulo es estudiar el comportamiento del confinamiento en hormigones de baja resistencia viendo la influencia de la deformación última efectiva del FRP y la forma de la sección.

\subsection{Descripción del plan de ensayos. Variables estudiadas}

Se han ensayado a compresión centrada 26 probetas prismáticas de sección cuadrada de hormigón armado reforzadas con FRP y 2 probetas patrón sin refuerzo externo.

Dada la falta de resultados disponibles en la literatura sobre confinamiento de hormigones de baja resistencia, que sin embargo pueden encontrarse en la rehabilitación de estructuras antiguas, se han empleado en este estudio hormigones con valores de resistencia a compresión bajos (entre 10 y $25 \mathrm{MPa}$ aproximadamente).

De las 26 probetas 15 se han reforzado con fibra de carbono y 11 con fibra de vidrio, para evaluar el posible diferente comportamiento en cuanto a aumento de capacidad de carga o ductilidad.

Se han empleado tres métodos de refuerzo diferentes:

- moldeo manual o wrapping, que es el procedimiento de refuerzo más común.

- aplicación de una camisa de FRP prefabricada con inyección de un mortero para rellenar el hueco entre el pilar original y la camisa.

- un método mixto en el que se aplica una camisa prefabricada y sobre ella una capa de fibra adicional mediante moldeo manual.

En principio se consideró utilizar en algunas de las probetas del programa experimental el refuerzo con camisas prefabricadas para tratar de conseguir un confinamiento activo mediante la inyección del mortero. Sin embargo se plantearon dificultades en la ejecución y esto no fue posible, por lo que se inyectó el mortero rellenando el hueco, pero sin llegar a tensionar la camisa. En consecuencia, las probetas reforzadas por wrapping, camisa prefabricada o 
método mixto pueden considerarse equivalentes, ya que el tipo y cantidad de fibra son los mismos en los tres procesos de fabricación. En el comportamiento del hormigón confinado no se observaron diferencias, salvo que en alguna probeta con camisa prefabricada se produjo el fallo prematuro por despegue del solape, como se describe más adelante en este capítulo. Por esta razón no se considera el método de refuerzo como una variable en el estudio, si bien en el apartado de resultados se indica cómo se ha reforzado cada probeta.

Las variables estudiadas son por lo tanto el tipo de fibra de refuerzo (vidrio o carbono) y la resistencia del hormigón. En la Tabla 3.1 se muestra el plan de ensayos. En la nomenclatura de las probetas la primera letra indica el tipo de fibra empleado en el refuerzo ( $C$ para carbono y $G$ para vidrio) y a continuación se indica la resistencia a compresión del hormigón. De cada tipo se han ensayado dos o tres probetas, que se designarán en adelante con la nomenclatura anterior seguida de las letras $\mathrm{a}, \mathrm{b}$ o c.

Tabla 3.1 Plan de ensayos

\begin{tabular}{|c|c|c|c|}
\hline Fibra de refuerzo & $f_{c o} \quad[M P a]$ & Tipo de probeta & $N^{\circ}$ de probetas \\
\hline Sin refuerzo & 26.4 & 0_26.4 & 2 \\
\hline \multirow{7}{*}{ Carbono } & 8.8 & C_8.8 & 2 \\
\hline & 13.0 & C_13 & 2 \\
\hline & 16.3 & C_16.3 & 2 \\
\hline & 16.5 & C_16.5 & 3 \\
\hline & 16.7 & C_16.7 & 2 \\
\hline & 17.5 & C_17.5 & 2 \\
\hline & 26.4 & C_26.4 & 2 \\
\hline \multirow{5}{*}{ Vidrio } & 8.8 & G_8.8 & 2 \\
\hline & 13.0 & G_13 & 2 \\
\hline & 16.5 & G_16.5 & 3 \\
\hline & 16.7 & G_16.7 & 2 \\
\hline & 17.5 & G_17.5 & 2 \\
\hline
\end{tabular}




\subsection{Preparación de las probetas de hormigón}

Las probetas están formadas por un tramo central de sección cuadrada de $150 \mathrm{x}$ $150 \mathrm{~mm}^{2}$ y $600 \mathrm{~mm}$ de longitud, y dos capiteles en los extremos de 400x400x140 $\mathrm{mm}^{3}$ (ver Figura 3.1). Los capiteles simulan la conexión del pilar con las losas superior e inferior o la cimentación, y sirven para prevenir en el ensayo roturas prematuras en los extremos.

La sección correspondiente al pilar tiene las esquinas redondeadas con un radio de curvatura de $25 \mathrm{~mm}$. Para ello se pegan en las esquinas del molde unas molduras de madera con la sección pertinente (Figura 3.2).

Como ya se ha mencionado, a diferencia de lo que ocurre en los refuerzos a flexión o a cortante con materiales compuestos, en el refuerzo de soportes mediante confinamiento no es necesaria la adherencia entre el soporte de hormigón y el encamisado de FRP, pero sí es fundamental que exista pleno contacto entre ambos, y hay que preparar la superficie de hormigón para que no queden huecos ni esquinas o aristas. El redondeo de las esquinas del pilar evita la rotura prematura de las fibras y aumenta la efectividad del confinamiento.

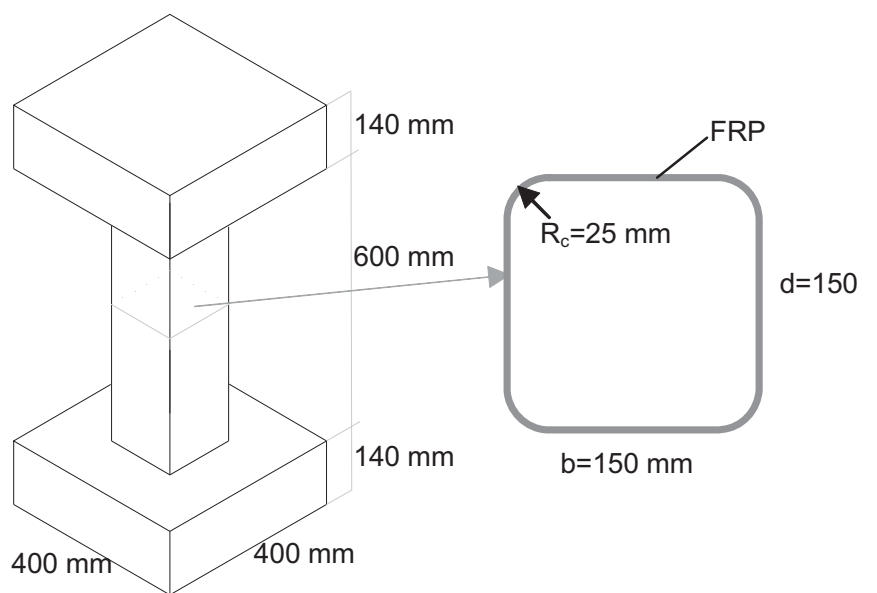

Figura 3.1 Geometría de las probetas

El valor de la resistencia a compresión del hormigón $f_{c o}$ se obtuvo para cada amasada mediante el ensayo a 28 días de dos probetas cilíndricas normalizadas, obteniéndose como valor medio el que se ha indicado en la Tabla 3.1.

La armadura longitudinal está formada por cuatro barras corrugadas de acero de $6 \mathrm{~mm}$ de diámetro y límite elástico $500 \mathrm{~N} / \mathrm{mm}^{2}$, y los cercos, de $6 \mathrm{~mm}$ de 
diámetro, se han dispuesto cada $100 \mathrm{~mm}$. El recubrimiento de hormigón es de 18 $\mathrm{mm}$.

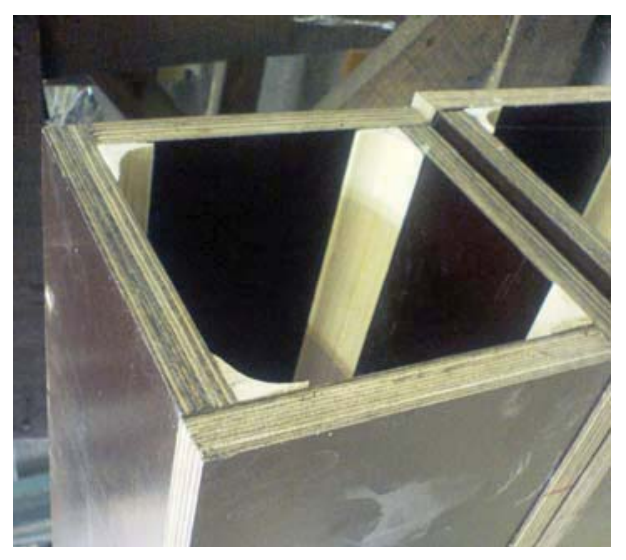

Figura 3.2 Moldes utilizados con molduras para redondeo de esquinas

Las probetas se hormigonan en vertical en tres fases, como se observa en las Figuras 3.3 a 3.6. En primer lugar se hormigona un capitel, después se coloca el molde del fuste y se hormigona éste, y finalmente se da la vuelta a la probeta y se hormigona el segundo capitel.
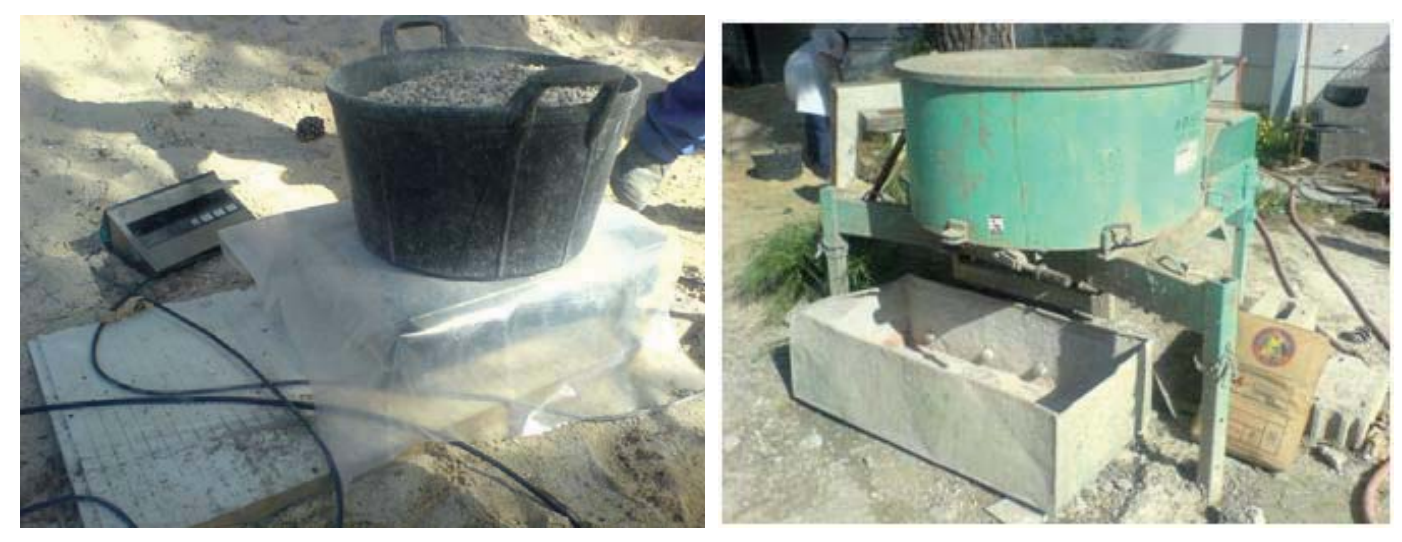

Figura 3.3 Fabricación del hormigón 

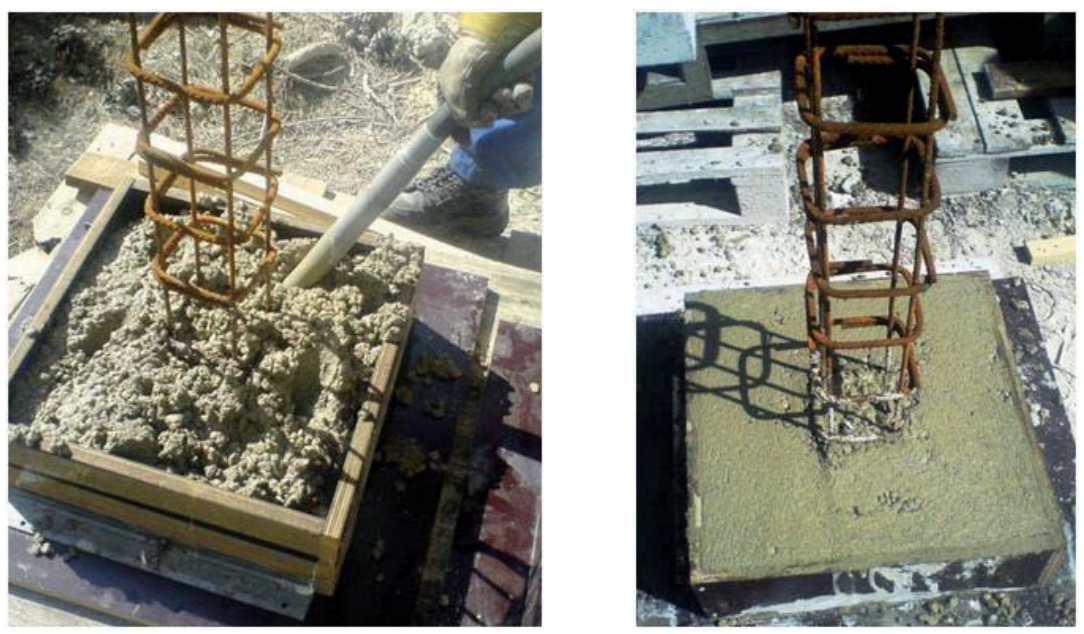

Figura 3.4 Hormigonado del primer capitel
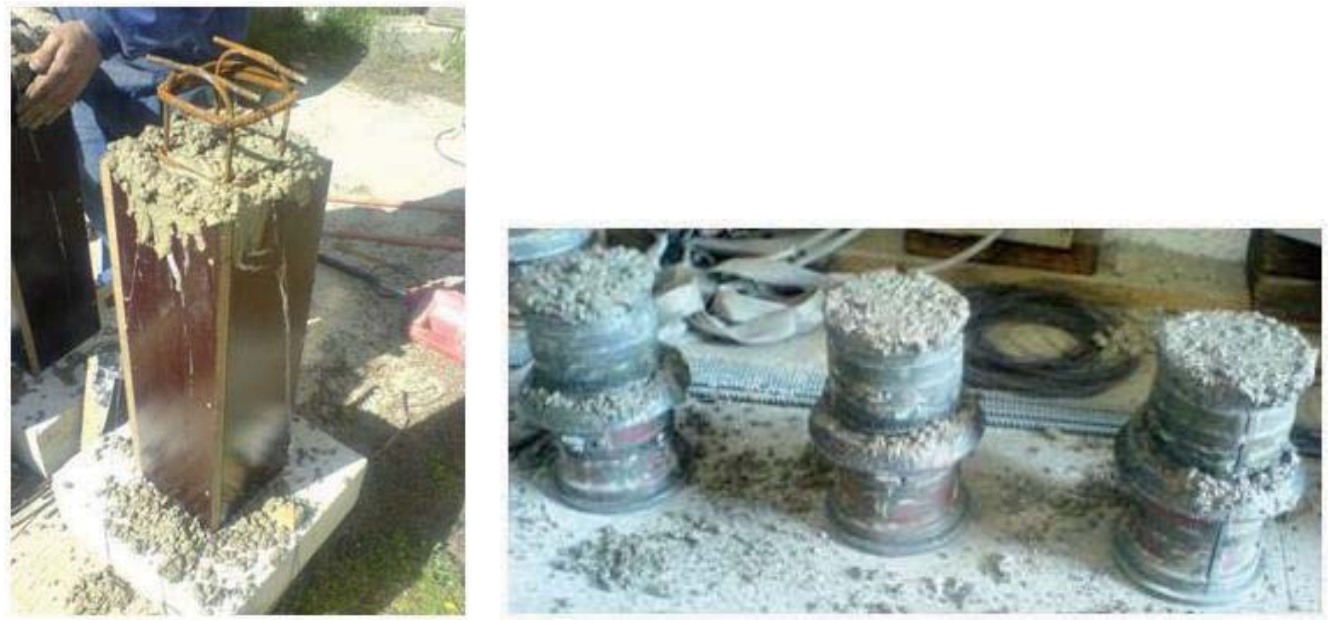

Figura 3.5 Hormigonado del fuste y probetas de control
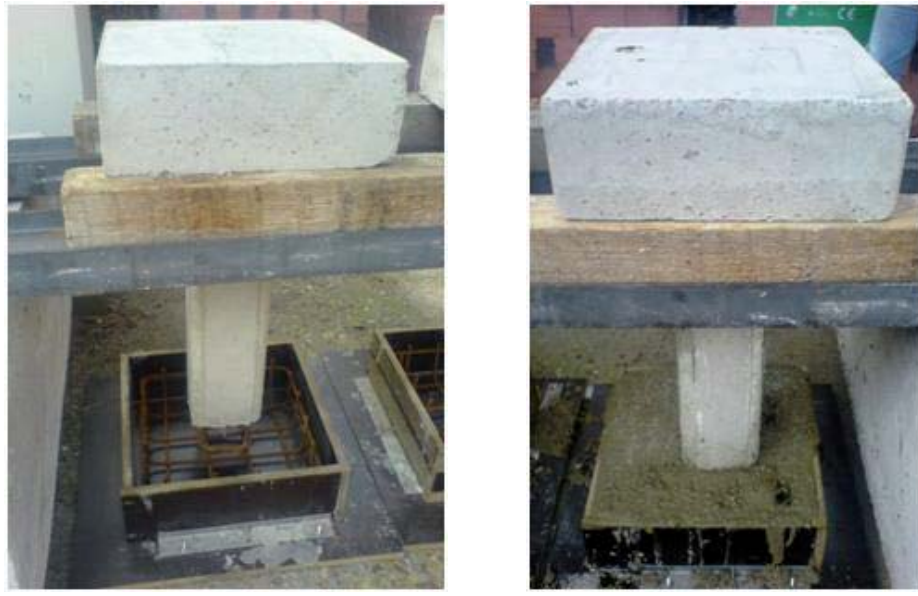

Figura 3.6 Hormigonado del segundo capitel 
Para preparar la superficie del hormigón antes del refuerzo sólo fue necesario eliminar con una radial las rebabas existentes en la zona de unión de las molduras que se habían dispuesto en las esquinas, con el fin de dejar una superficie lisa sin aristas (Figura 3.7). A continuación se limpiaron las probetas con aire a presión para eliminar el polvo.

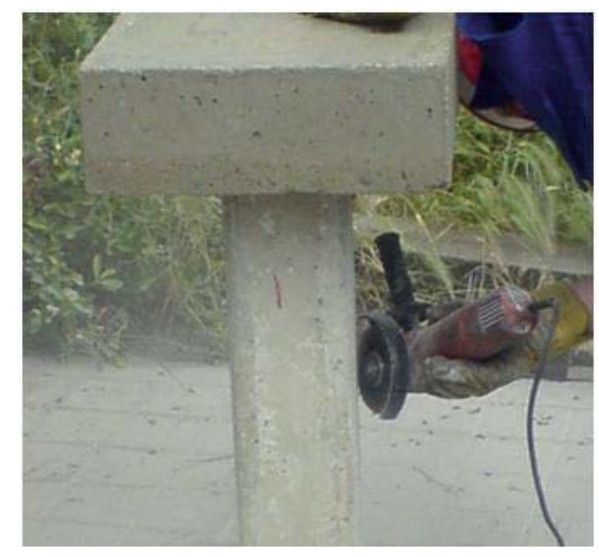

Figura 3.7 Eliminación de rebabas en las esquinas

\subsection{Materiales empleados en el refuerzo}

Se han empleado dos tipos de fibra en el refuerzo: carbono y vidrio.

Las probetas tipo $\mathrm{C}$ se han reforzado con tejido unidireccional de fibra de carbono, y las tipo $\mathrm{G}$ con tejido unidireccional de fibra de vidrio. Las propiedades de las fibras suministradas por el fabricante se dan en la Tabla 3.2. La resina epoxi utilizada, según los datos suministrados por el fabricante, tiene una densidad de $1100 \mathrm{~kg} / \mathrm{m}^{3}$, una resistencia a tracción de $75 \mathrm{MPa}$ y un módulo elástico de 3,2 GPa.

Por problemas en la disponibilidad de la fibra de carbono, en dos probetas (las de la serie C_26,4) se ha empleado material de un fabricante distinto. Las propiedades de la fibra se dan también en la Tabla 3.2. Se denomina carbono ${ }^{1}$ el empleado en la mayoría de las probetas, y carbono ${ }^{2}$ el empleado en la serie C_26.4. La resina epoxi aplicada con el carbono ${ }^{2}$ tiene una densidad de 1300 $\mathrm{kg} / \mathrm{m}^{3}$, una resistencia a tracción de $30 \mathrm{MPa}$ y un módulo de 4,5 GPa. 
Tabla 3.2 Propiedades mecánicas de las fibras, suministradas por los fabricantes

\begin{tabular}{|c|c|c|c|c|}
\hline Fibra & $\begin{array}{c}\text { Resistencia a } \\
\text { tracción [MPa] }\end{array}$ & $\begin{array}{c}\text { Módulo } \\
\text { elástico [GPa] }\end{array}$ & $\begin{array}{c}\text { Deformación } \\
\text { última }\end{array}$ & $\begin{array}{c}\text { Espesor neto } \\
\text { de fibra [mm] }\end{array}$ \\
\hline Carbono $^{1}$ & 3800 & 242 & 0.015 & 0.333 \\
\hline Carbono $^{2}$ & 4000 & 240 & 0.015 & 0.293 \\
\hline Vidrio & 2600 & 70 & 0.037 & 0.4 \\
\hline
\end{tabular}

Las propiedades mecánicas en tracción en la dirección longitudinal de la fibra (resistencia y módulo de elasticidad) de los laminados empleados se han obtenido también mediante ensayos de tracción de cupones planos (Figura 3.8). El espesor medio de los laminados era de $1.2 \mathrm{~mm}$ en el carbono ${ }^{1}, 1 \mathrm{~mm}$ en el carbono $^{2}$ y $1.3 \mathrm{~mm}$ en el vidrio. Dado que la cantidad de resina es difícil de controlar en la fabricación in situ de laminados, y como las propiedades resistentes dependen fundamentalmente de la cantidad de fibra que posea, se ha considerado para el cálculo de la tensión de tracción y el módulo de elasticidad el área neta de fibra la sección (ver Tabla 3.3).

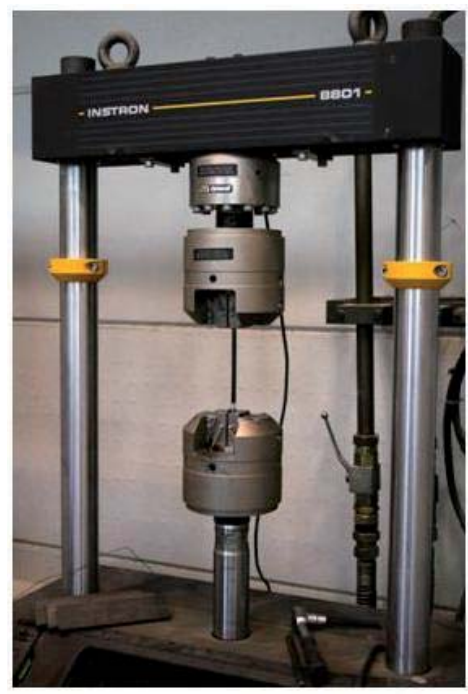

Figura 3.8 Ensayo de tracción del laminado

Los ensayos se realiza siguiendo las indicaciones de la norma UNE-EN ISO 5274 Plásticos. Determinación de las propiedades en tracción. Parte 4: Condiciones de ensayo para plásticos compuestos isotrópicos y ortotrópicos reforzados con fibras (UNE-EN-ISO, 1997). La preparación de las probetas con el pegado de los talones en los extremos y el procedimiento de ensayo es el mismo que se describe con más detalle en el apartado 4.4.3.1. 
En la Tabla 3.3 se dan los valores medios obtenidos en los ensayos para los tres laminados ensayados. Los valores de resistencia y módulo elástico de la tabla están referidos al espesor neto de fibra.

Tabla 3.3 Propiedades mecánicas de los laminados

\begin{tabular}{|c|c|c|c|c|}
\hline Laminado & $\begin{array}{c}\text { Resistencia a } \\
\text { tracción [MPa] }\end{array}$ & $\begin{array}{c}\text { Deformación } \\
\text { última [\%] }\end{array}$ & $\begin{array}{c}\text { Módulo elástico } \\
{[\mathrm{MPa}]}\end{array}$ & $\begin{array}{c}\text { Espesor neto } \\
\text { de fibra [mm] }\end{array}$ \\
\hline Carbono $^{1}$ & 2977 & 1.5 & 200175 & 0.333 \\
\hline Carbono $^{2}$ & 2447 & 1.28 & 191041 & 0.293 \\
\hline Vidrio & 2283 & 3.4 & 66602 & 0.4 \\
\hline
\end{tabular}

Los valores obtenidos en el laminado carbono ${ }^{2}$ son sensiblemente inferiores a las propiedades dadas por el fabricante. Una posible explicación es que debido a la configuración del tejido, en el que la urdimbre está formada por mechas muy anchas de fibra, se aprecia que las fibras no están perfectamente alineadas.

\subsection{Ejecución del refuerzo}

\subsubsection{Refuerzo mediante moldeo manual}

Transcurridos al menos 28 días después de su fabricación se ejecuta el refuerzo de las probetas por moldeo manual en húmedo, siguiendo el procedimiento indicado por el fabricante del material.

Después de limpiar las probetas con aire a presión para eliminar cualquier resto de polvo se comprueba que el soporte está seco y sin aristas, huecos ni protuberancias que puedan dañar la fibra.

A continuación se efectúa el refuerzo, como se muestra en la Figura 3.9. 

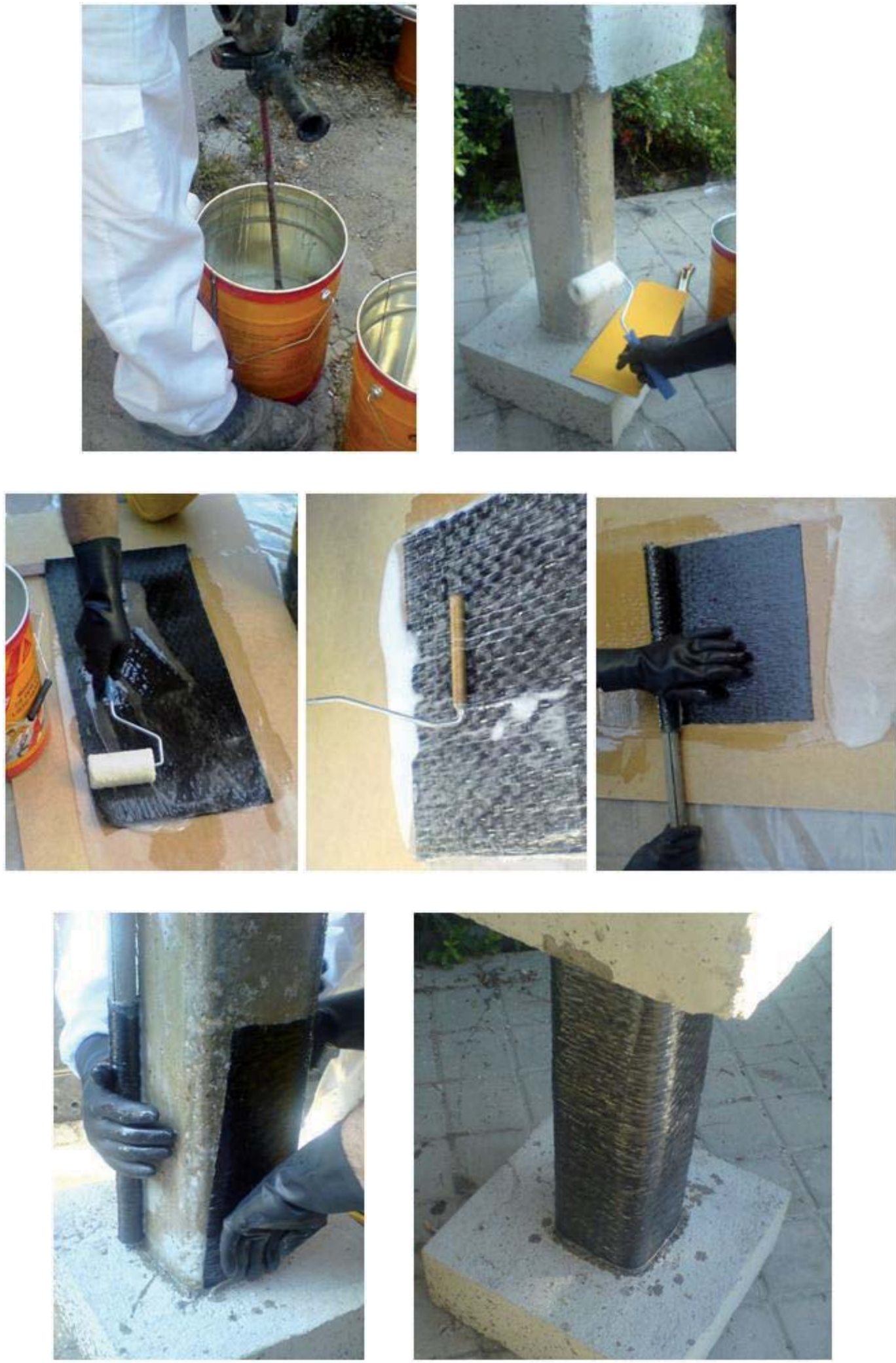

Figura 3.9 Refuerzo de las probetas 
El refuerzo se realiza disponiendo toda la fibra en dirección perpendicular al eje del pilar, en lo que se denomina orientación a $0^{\circ}$, mediante los siguientes pasos:

- Se cortan con unas tijeras los trozos de tejido de fibra con las dimensiones adecuadas para envolver el perímetro de la sección y disponer un solape en la dirección de la fibra de $100 \mathrm{~mm}$. En la dirección longitudinal de la probeta se dispone una banda de tejido a continuación de otra, no es necesario el solape.

- Se mezclan los dos componentes de la resina epoxi con una batidora eléctrica a baja velocidad siguiendo las instrucciones del fabricante hasta conseguir una mezcla completamente homogénea. Se trata de una resina de baja viscosidad, adecuada para impregnar tejidos de gramaje elevado como los que se han utilizado.

- Se aplica mediante rodillo una primera capa de resina sobre la probeta de hormigón a reforzar.

- Se impregna el tejido aplicando sobre él resina con un rodillo de pintor pasando a continuación un rodillo metálico ranurado sobre el tejido en la dirección de la fibra para favorecer su impregnación.

- Se coge el tejido impregnado y se aplica sobre el soporte de hormigón envolviendo la probeta. A continuación se pasa de nuevo el rodillo ranurado presionando ligeramente lo que ayuda a ajustar el tejido sobre el hormigón sin que queden huecos.

Las probetas reforzadas se mantienen en interior a temperatura ambiente (entre 17 y $22^{\circ} \mathrm{C}$ ) durante al menos 7 días para que cure por completo la resina epoxi antes de ensayarlas.

\subsubsection{Refuerzo mediante camisas prefabricadas y mixtas}

Los refuerzos mediante camisas prefabricadas y mixtas fueron realizados por la empresa NECSO, y no se dispone de fotos del proceso de ejecución.

En primer lugar se fabrican las camisas mediante un proceso de moldeo manual como el que se ha descrito en el apartado anterior, pero en lugar de aplicar la resina y la fibra sobre la probeta de hormigón se hace sobre un molde con la misma forma. Se trata de camisas de una sola pieza, con una abertura longitudinal y una zona de solape de $100 \mathrm{~mm}$ que queda sin pegar para permitir después abrir la camisa y colocarla envolviendo la probeta. Se colocan dos 
válvulas en la camisa, una en la zona superior y otra en la zona inferior, que permitirán después inyectar el mortero.

Después de que se produce el curado de la resina, las camisas se desmoldan y se colocan envolviendo las probetas de hormigón. La zona de solape se pega con resina epoxi. Transcurridos 7 días desde el pegado del solape se procede a la inyección de un mortero fluido de retracción compensada que rellena el hueco entre el núcleo de hormigón y la camisa. Para ello se sellan las uniones de la camisa con la probeta en los extremos, y la inyección se realiza por la válvula inferior hasta que el mortero sobrante sale por la válvula superior.

En las camisas mixtas se realiza el mismo proceso que en las prefabricadas y finalmente se aplica encima una capa de refuerzo por el método de moldeo manual, disponiéndose la mitad de la fibra en cada fase, de modo que la cuantía de refuerzo total es la misma.

\subsection{Instrumentación y procedimiento de ensayo.}

Las probetas se ensayan a compresión centrada en una prensa INSTRON de $1000 \mathrm{kN}$ de capacidad de carga.

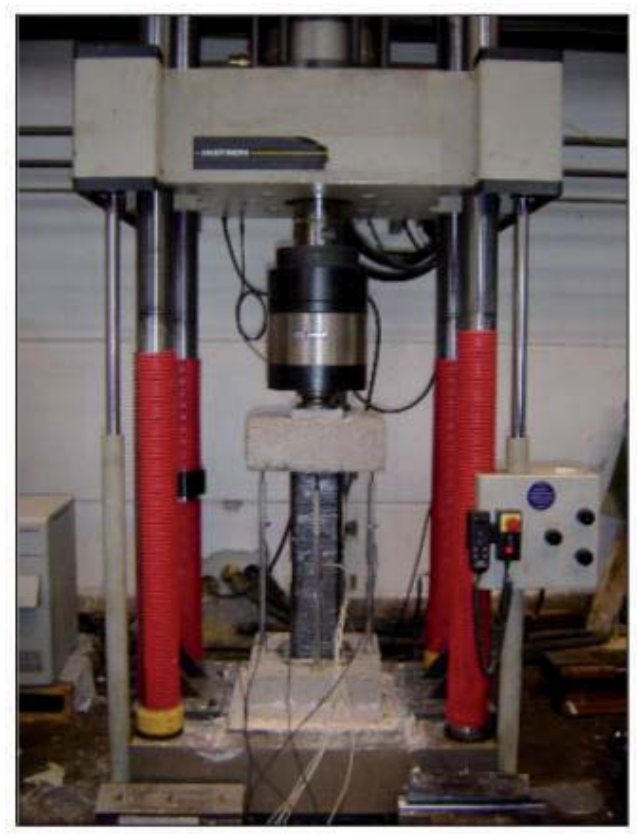

Figura 3.10 Disposición del ensayo 
La carga se aplica sobre una placa de acero de $150 \times 150 \times 20 \mathrm{~mm}^{3}$ centrada en la cabeza de la probeta coincidiendo con la sección del pilar. Al colocar las probetas en la prensa se aplica una fina capa de escayola en los dos extremos (entre el extremo inferior y la base de la prensa y entre el extremo superior y la placa de aplicación de la carga) con el fin de nivelar la probeta y eliminar las irregularidades de las superficies extremas.

La carga del ensayo se controla en desplazamiento con velocidad constante de aproximadamente $2 \mathrm{~mm} / \mathrm{min}$ hasta que se produce la rotura.

En el ensayo de las probetas 0_26.4_b, C_8.8_a, G_8.8_a, C_16.5_a y G_16.5_a únicamente se registró la carga aplicada y el desplazamiento del pistón de la prensa. Las restantes probetas se han instrumentado con el fin de medir su comportamiento tensión-deformación tanto en el sentido axial como transversal.

Para medir la deformación axial del pilar se utilizan cuatro captadores de desplazamiento de $5 \mathrm{~mm}$ de rango y $0.001 \mathrm{~mm}$ de precisión. Estos se colocan entre los capiteles, a $160 \mathrm{~mm}$ del eje del pilar, centrados con cada cara (Figura 3.11). Con el fin de verificar las lecturas de los captadores, en dos probetas (C_26.4_a y b) se pegaron además sobre la camisa de FRP cuatro bandas extensométricas en el centro de cada cara en sentido axial. Se comprobó que las medidas de captadores y bandas eran muy similares, de manera que la deformación media de las 4 caras prácticamente coincidía. El inconveniente de las bandas es que para cargas elevadas, próximas a la rotura, la deformación axial es importante y pueden formarse arrugas en la camisa de FRP provocando el fallo en la lectura de la banda extensométrica, mientras que con los captadores se recoge la lectura hasta el final del ensayo. Se decidió realizar en todas las probetas la medición con los cuatro captadores de desplazamiento.

Para medir las deformaciones transversales se han utilizado bandas extensométricas pegadas en la mitad de la altura de la probeta sobre la camisa de FRP. Las bandas se colocan en dirección perpendicular al eje del pilar, es decir, en el sentido longitudinal de las fibras. Se pegan en la sección central de cada probeta cuatro bandas, una en el centro de cada cara. Además en once probetas se pegó una banda extensométrica en una esquina. En el Anejo A se detalla la instrumentación empleada en cada probeta. Las lecturas de los transductores y las bandas, así como de la carga aplicada, se graban de manera continua durante los ensayos. Las bandas extensométricas empleadas para 
medir la deformación del FRP son FLA-5-5 de Tokyo Sokki, con una longitud de medida de $5 \mathrm{~mm}$.
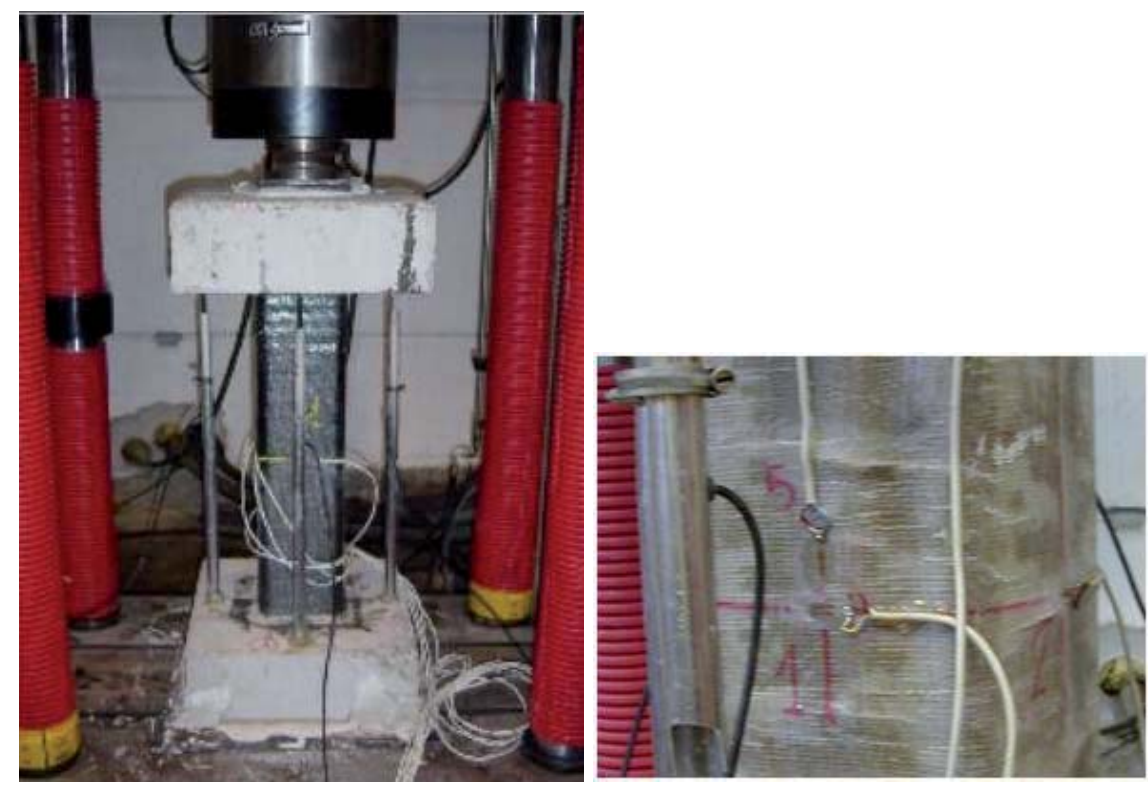

Figura 3.11 Instrumentación mediante captadores de desplazamiento y bandas extensométricas

En la probeta G_13_a se pegaron 7 bandas transversales con el fin de comprobar si había diferencia de deformaciones a lo largo del perímetro de la sección. En el gráfico de la Figura 3.12 se muestran las deformaciones medidas por las 7 bandas frente a la carga aplicada. Las medidas de todas las bandas fueron similares hasta la fase final del ensayo. Al alcanzarse el $85 \%$ de la carga última dos bandas extensométricas (situadas en el centro de una cara y en una esquina) registraron un repentino incremento de las deformación lateral, pero las bandas restantes continúan con medidas similares. No se observa por lo tanto relación entre la posición de las bandas y la deformación, sino que parece que la deformación lateral es aproximadamente uniforme, y que para valores de carga cercanos a la rotura se producen incrementos de deformación locales, que seguramente están provocados por la deformación no uniforme del hormigón fisurado. 


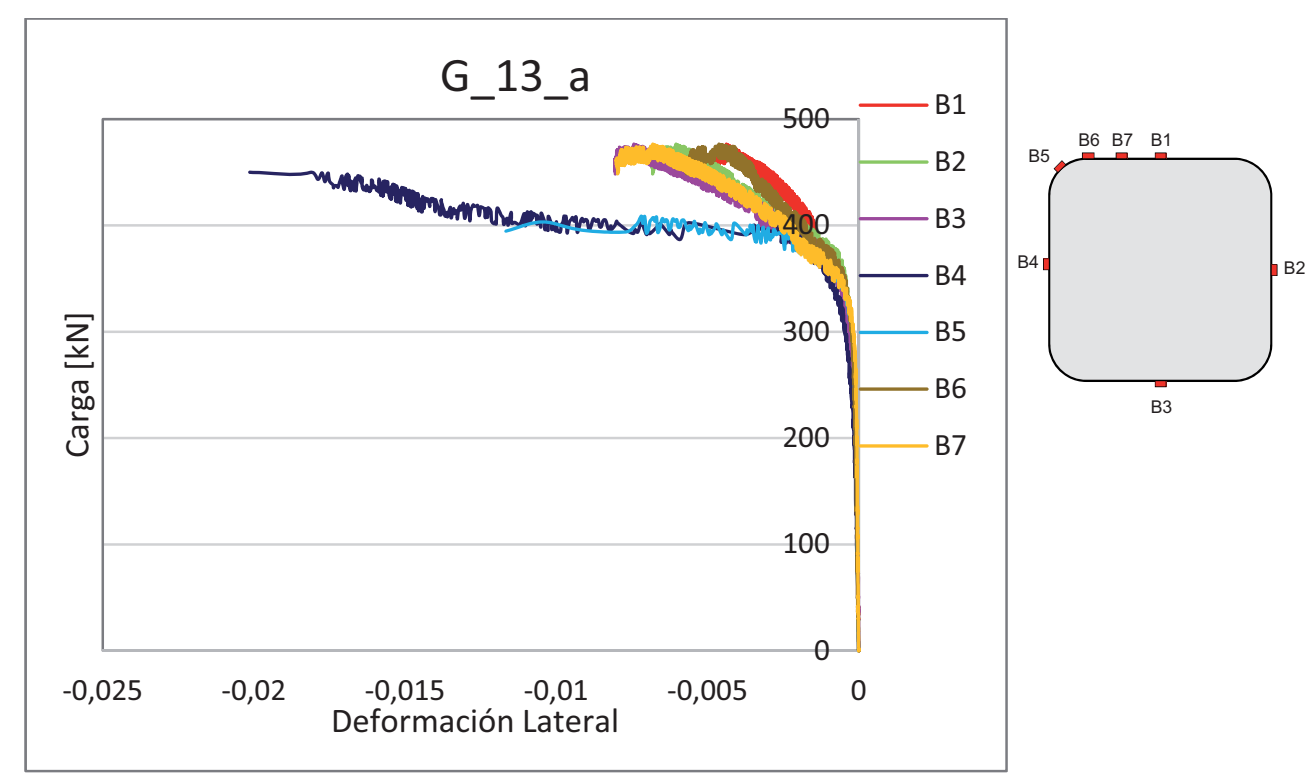

Figura 3.12 Deformación lateral en la probeta G_13_a

\subsection{Resultados}

En la Figura 3.13 se muestra el fallo típico de una probeta de hormigón armado sin reforzar.
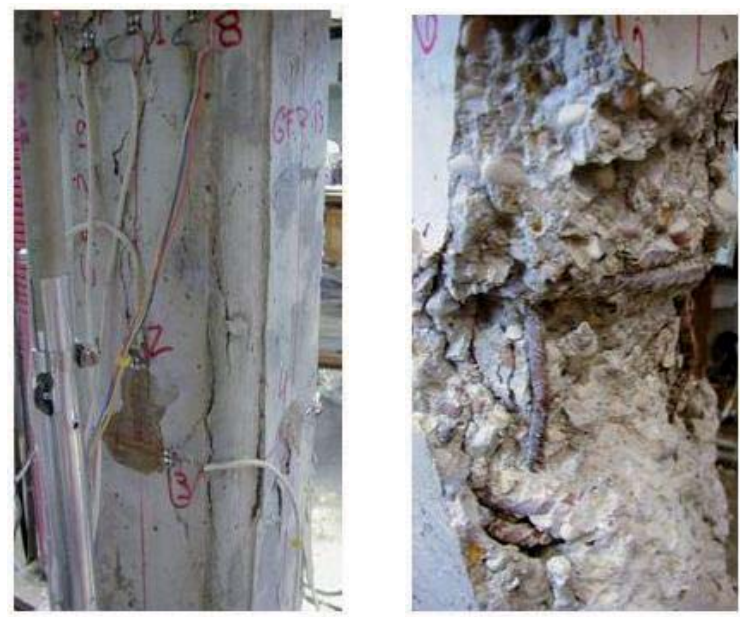

Figura 3.13 Rotura de probeta sin reforzar

En cuanto a las probetas reforzadas con FRP, en 23 de las 26 probetas ensayadas se ha producido el fallo por la rotura repentina de la camisa (Figura 3.14 izquierda). En 3 probetas se ha producido una rotura prematura debida al despegue del solape de los refuerzos (Figura 3.14 derecha). Estos modos de fallo se analizan en el apartado 3.8.1. 


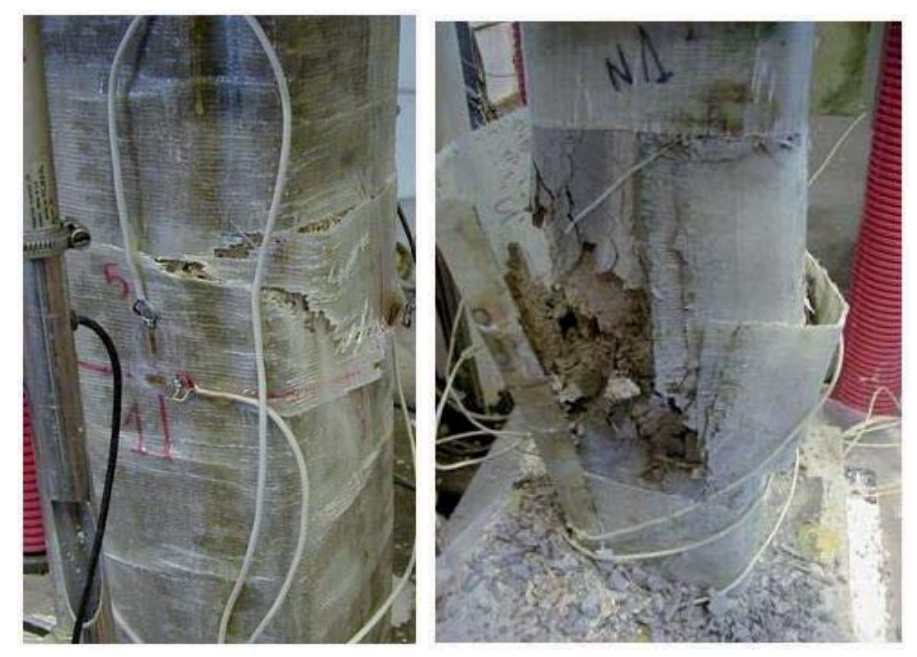

Figura 3.14 Fallo por rotura del FRP (izqda.) y por despegue del solape (dcha.)

En la Tabla 3.4 se muestra un resumen de los resultados de los ensayos. Se marcan con un asterisco los casos en los que hubo fallo debido al solape. Se indica para cada probeta:

- El método de refuerzo empleado: wrapping (W), camisas prefabricadas $(P)$ o método mixto $(M)$.

- La carga máxima alcanzada $Q_{\text {máx}}$

- Resistencia a compresión $f_{c c}$. Se ha calculado restando de la carga última la contribución de la armadura longitudinal (área de las cuatro barras por su tensión de plastificación), y dividiendo el resultado por el área de la sección neta de hormigón.

- Máxima deformación axial de compresión $\varepsilon_{c c}$. Se da el valor promedio de las medidas en las cuatro caras de la probeta.

- Deformación lateral última o deformación última efectiva $\left(\varepsilon_{f u}\right)$, es decir, deformación medida en la fibra en el momento de la rotura de la camisa. Este valor es también el promedio de las lecturas de las cuatro caras. 
Tabla 3.4 Resumen de resultados experimentales

\begin{tabular}{|c|c|c|c|c|c|}
\hline Probeta & $\begin{array}{c}\text { Método de } \\
\text { refuerzo }\end{array}$ & $Q_{\text {máx }}[\mathrm{kN}]$ & $f_{c c}[M P a]$ & $\mathcal{E}_{c c}$ & $\varepsilon_{f u}$ \\
\hline 0_26.4_a & - & 503 & 20.43 & 0.001980 & - \\
\hline 0_26.4_b & - & 576 & 23.77 & - & - \\
\hline C_8.8_a & $\mathrm{W}$ & 542 & 22.23 & - & - \\
\hline C_8.8_b & $\mathrm{M}$ & 518 & 21.12 & 0.017247 & -0.003335 \\
\hline G_8.8_a & $\mathrm{W}$ & 479 & 19.35 & - & - \\
\hline G_8.8_b & $\mathrm{P}$ & 543 & 22.27 & 0.029789 & -0.005142 \\
\hline C_13_a & $\mathrm{W}$ & 570 & 23.47 & 0.041213 & -0.004476 \\
\hline C_13_b & $\mathrm{M}$ & 559 & 23.00 & 0.027590 & -0.003564 \\
\hline G_13_a & $\mathrm{W}$ & 476 & 19.22 & 0.035846 & -0.006583 \\
\hline G_13_b & $\mathrm{M}$ & 522 & 21.30 & 0.021774 & -0.008339 \\
\hline C_16.3_a & $\mathrm{P}$ & 763 & 32.33 & 0.023237 & -0.006346 \\
\hline C_16.3_b & $\mathrm{P}$ & 722 & 30.43 & 0.023842 & -0.004992 \\
\hline C_16.5_a & $\mathrm{W}$ & 675 & 28.29 & - & - \\
\hline C_16.5_b* & $\mathrm{P}$ & 514 & 20.94 & 0.006162 & -0.000741 \\
\hline C_16.5_c & $\mathrm{P}$ & 679 & 28.49 & 0.019744 & -0.005258 \\
\hline G_16.5_a & $\mathrm{W}$ & 601 & 24.89 & - & - \\
\hline G_16.5_b & $\mathrm{P}$ & 618 & 25.70 & 0.020563 & -0.012608 \\
\hline G_16.5_c & $\mathrm{M}$ & 567 & 23.34 & 0.021969 & -0.008787 \\
\hline C_16.7_a & $\mathrm{W}$ & 693 & 29.11 & 0.023994 & -0.004653 \\
\hline C_16.7_b & $\mathrm{M}$ & 713 & 30.04 & 0.025845 & -0.004098 \\
\hline G_16.7_a & $\mathrm{W}$ & 586 & 24.22 & 0.024338 & -0.010430 \\
\hline G_16.7_b & $\mathrm{P}$ & 631 & 26.29 & 0.022226 & -0.006433 \\
\hline C_17.5_a & $\mathrm{W}$ & 621 & 25.83 & 0.028580 & -0.004062 \\
\hline C_17.5_b* & $\mathrm{P}$ & 470 & 18.93 & 0.011821 & -0.001671 \\
\hline G_17.5_a & $\mathrm{W}$ & 593 & 24.57 & 0.029347 & -0.009835 \\
\hline G_17.5_b* & $\mathrm{P}$ & 548 & 22.48 & 0.015902 & -0.006045 \\
\hline C_26.4_a & $\mathrm{W}$ & 994 & 42.90 & 0.015083 & -0.006410 \\
\hline C_26.4_b & $\mathrm{W}$ & 924 & 39.70 & 0.011792 & -0.006635 \\
\hline
\end{tabular}

* Probetas con fallos en el solape 
Valores positivos de deformación indican compresión y valores negativos tracción. En algún caso, cuando la medida de alguna banda extensométrica en la fase final del ensayo no refleja el comportamiento de la sección sino un efecto local, no se ha considerado su lectura para obtener la deformación media, sino la lectura de las tres bandas restantes. Esto ocurre debido a que cuando el valor de la carga aplicada se acerca a la carga última, se forman una especie de arrugas en la camisa, como puede apreciarse en la Figura 3.17, y si coincide la formación de una arruga con la localización de una banda extensométrica, ésta puede medir deformaciones muy elevadas que no se corresponden con la deformación transversal de la sección.

En las gráficas de la Figura 3.15 se representan la carga de compresión aplicada frente a la deformación axial y la deformación lateral medidas en las probetas reforzadas con fibra de carbono y en la Figura 3.16 las curvas correspondientes a las probetas reforzadas con fibra de vidrio. La deformación axial, de compresión, se representa con valores positivos, y la deformación lateral, de tracción, con valores negativos. Los valores de deformación axial y lateral representados son el valor medio de los cuatro captadores de desplazamiento o las cuatro bandas extensométricas situados en las cuatro caras de la sección.

En algunos gráficos se observan ciclos de carga-descarga, originados por problemas en el control del ensayo, por lo que se procedió a la descarga de las probetas y se cargó de nuevo. La envolvente de estas curvas presenta un comportamiento similar al esperado si no se hubieran producido las descargas.

En el Anejo A se muestran las gráficas con todas las medidas de bandas extensométricas y captadores de desplazamiento utilizados en los ensayos.

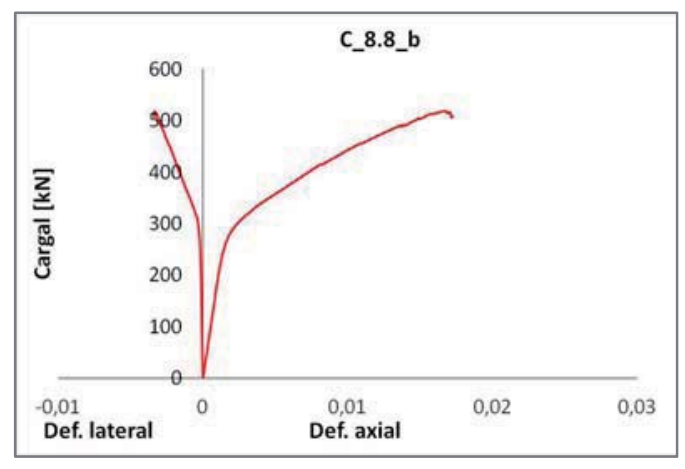

Figura 3.15 Curvas carga-deformación de las probetas reforzadas con carbono 

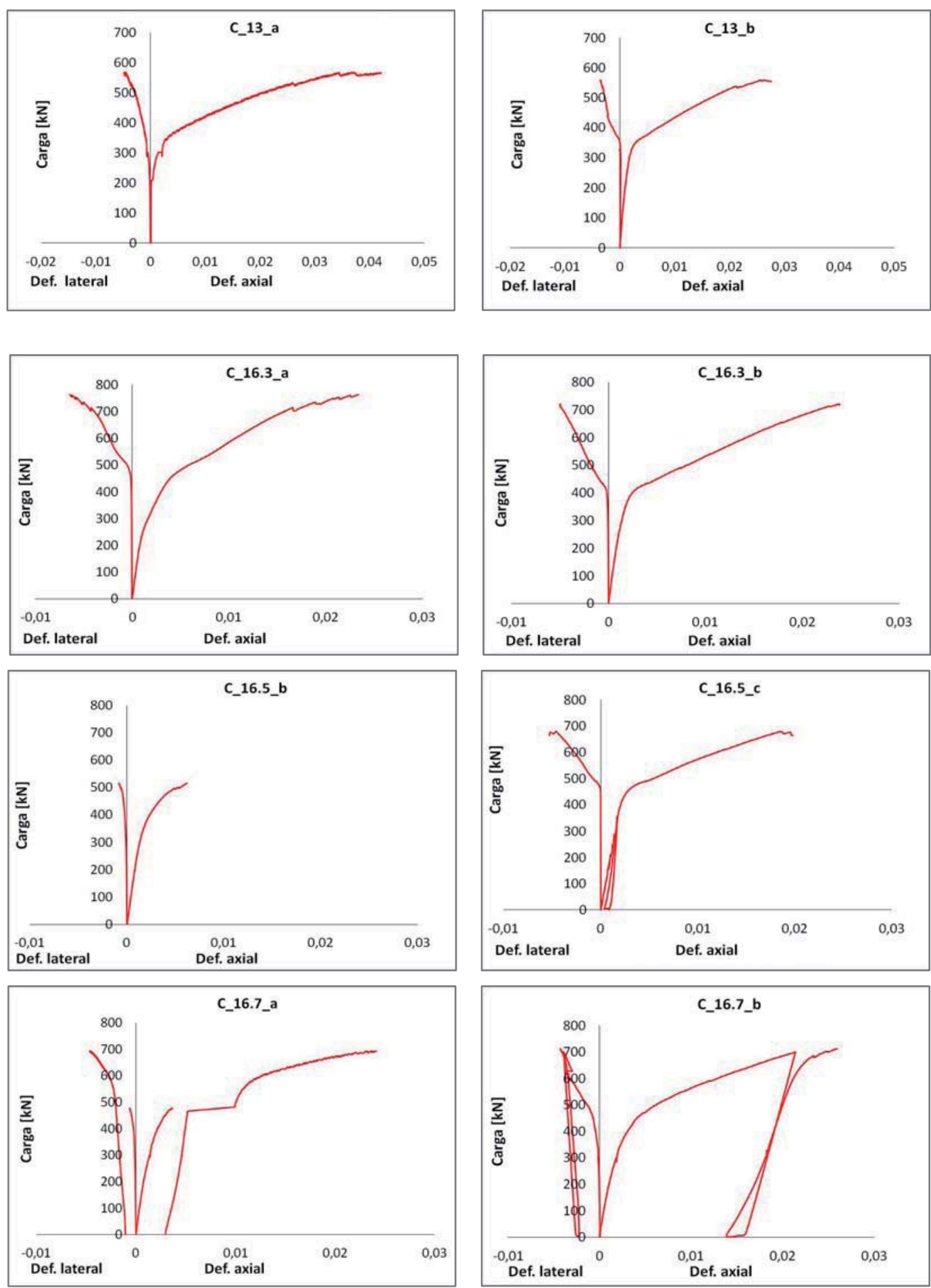

Figura 3.15 (cont.) Curvas carga-deformación de las probetas reforzadas con carbono 

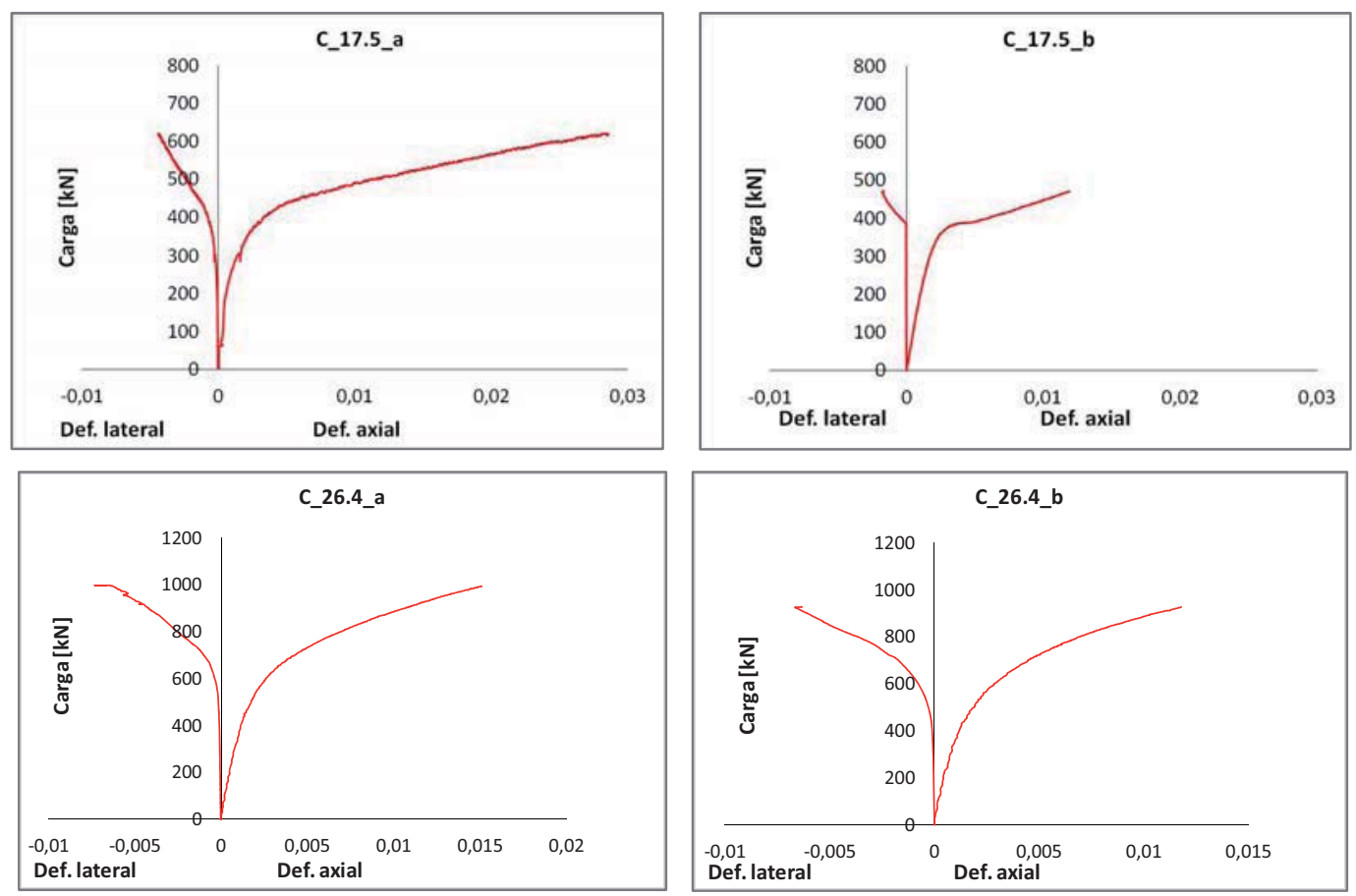

Figura 3.15 (cont.) Curvas carga-deformación de las probetas reforzadas con carbono
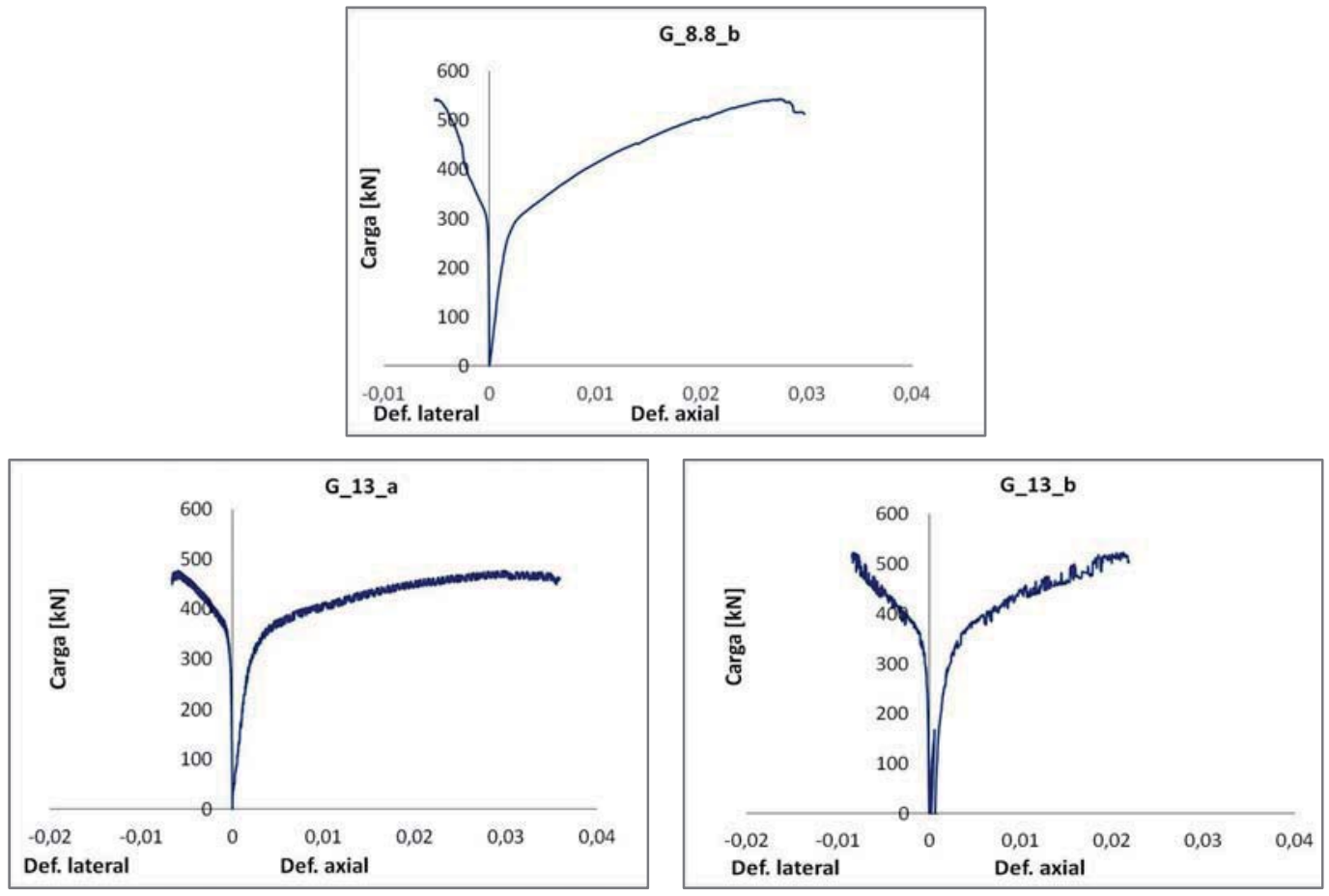

Figura 3.16 Curvas carga-deformación de las probetas reforzadas con vidrio 

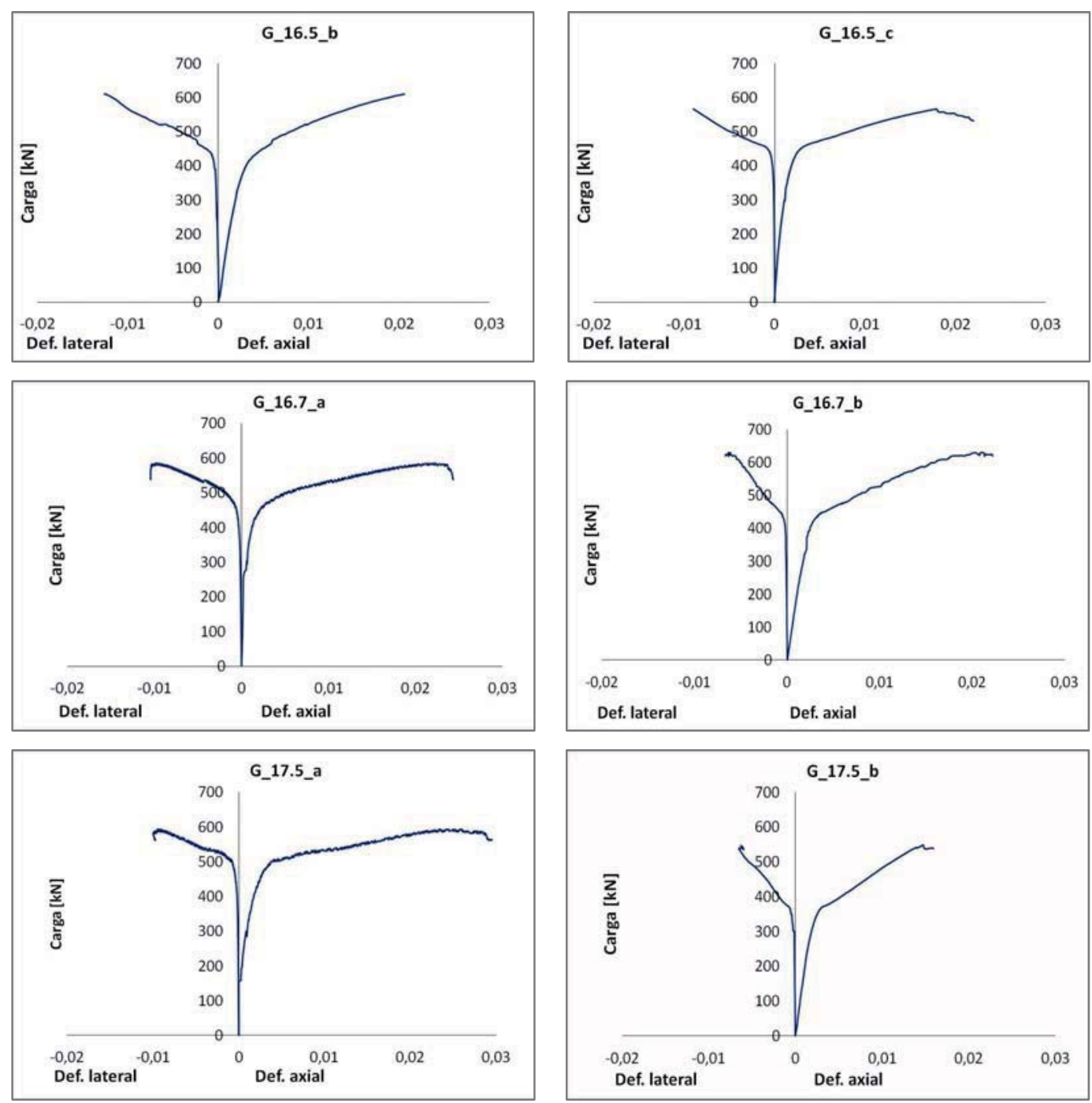

Figura 3.16 (cont.) Curvas carga-deformación de las probetas reforzadas con vidrio

\subsection{Análisis de los resultados}

\subsubsection{Modo de fallo}

En el Anejo A se incluyen fotografías mostrando la rotura de todas las probetas ensayadas.

El modo de fallo de las probetas sin refuerzo de FRP es el habitual de los soportes de hormigón armado sometidos a compresión. Durante el ensayo no se observan signos de deterioro hasta que aparecen fisuras aproximadamente verticales para valores de carga próximos a los de rotura. Después se produce el fallo por desprendimiento del recubrimiento de hormigón y el pandeo de las armaduras (Figura 3.13). 

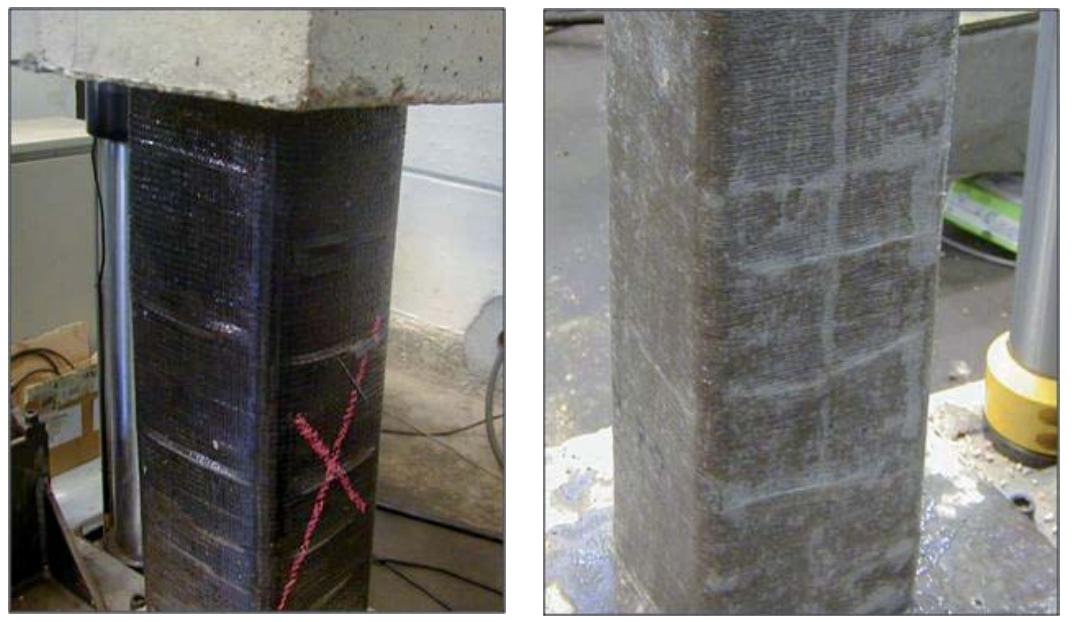

Figura 3.17 Aspecto de las probetas reforzadas con carbono y vidrio en los instantes previos a la rotura
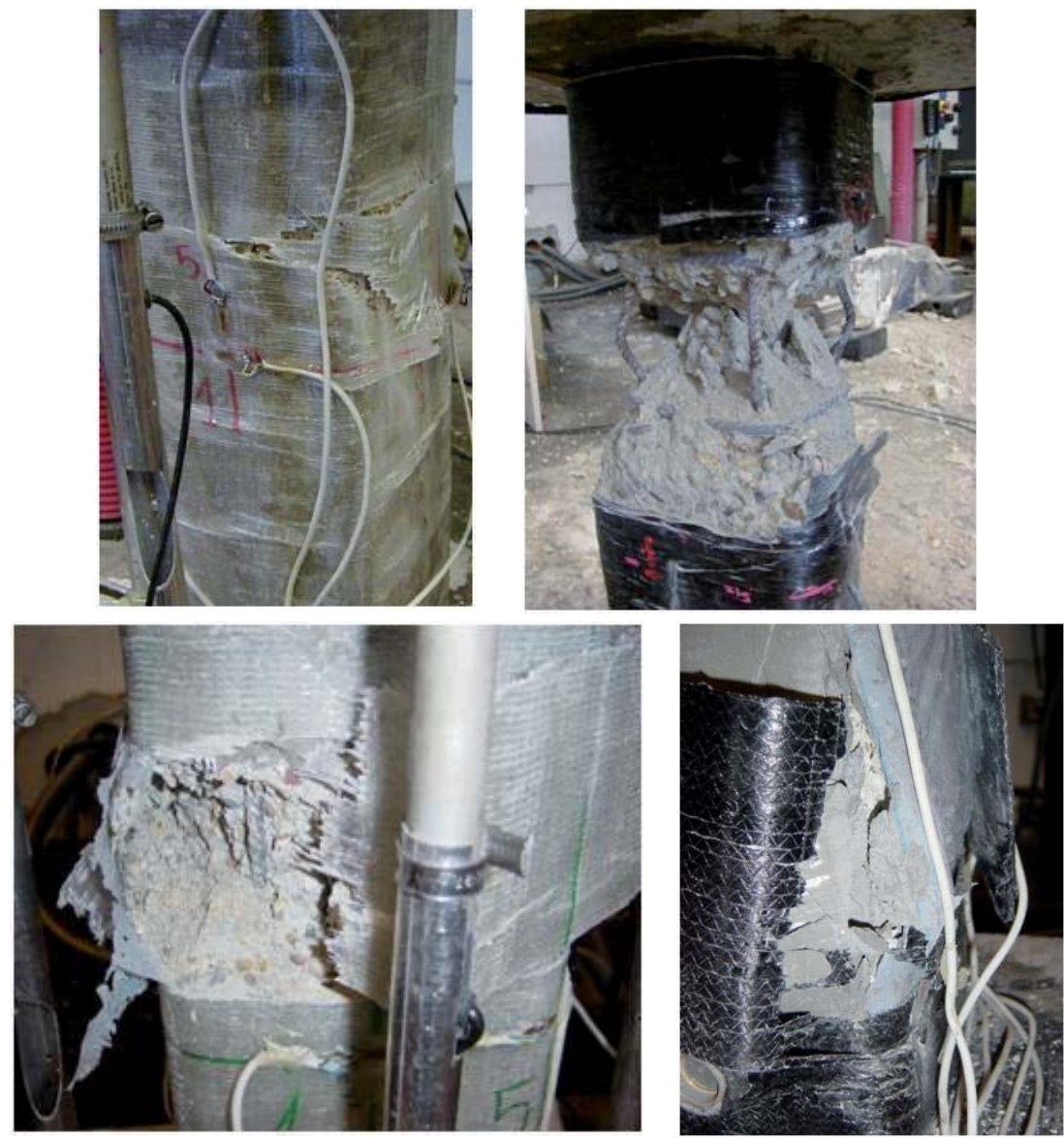

Figura 3.18 Fallo de probetas por rotura del FRP

Como se ha mencionado, en la mayoría de las probetas reforzadas con FRP, el fallo se produce debido a la rotura de las fibras de la camisa a tracción. Se trata 
de un fallo repentino, con muy poca capacidad de aviso. Instantes antes de la rotura se oyen pequeños ruidos y se observan algunas "arrugas" en la camisa cuando ya la deformación de compresión es significativa. Estas arrugas son más visibles en las camisas de vidrio, en las cuales se observan zonas más claras donde se ha producido el despegue entre la camisa y el núcleo de hormigón (Figura 3.17). Los pequeños ruidos pueden ser debidos precisamente al despegue de la camisa en estas zonas. Finalmente se produce la rotura instantánea de las camisas, generalmente en la zona central de las probetas según se muestra en las fotografías (Figura 3.18). En muchos casos la rotura se produce cerca de las esquinas, concretamente en la zona de transición entre el lado recto y la esquina redondeada.

Tras la rotura se observa el hormigón prácticamente desecho y en algunos casos la armadura longitudinal pandeada. Debido a que la rotura se produce de manera repentina y explosiva, no puede determinarse si el pandeo de la armadura se había iniciado antes de la rotura de la camisa, o es consecuencia de ésta. El fallo de las probetas reforzadas con vidrio y con carbono es similar, pero en el caso de las camisas de carbono hay menos señales de aviso previas a la rotura, y ésta es más violenta. Este es el modo de fallo típico y esperado en las probetas reforzadas con encamisados de FRP.

En 3 probetas (C_16.5_b, C_17.5_b y G_17.5_b), que se habían reforzado con camisas prefabricadas, el fallo se ha producido de manera prematura debido al despegue del solape de la camisa, sin que llegue a alcanzarse la rotura de las fibras (Figura 3.19). El despegue se produce de manera repentina sin ninguna señal de aviso.

En la Tabla 3.4 se indica para cada probeta reforzada el método empleado (wrapping, camisa prefabricada o método mixto). La única diferencia encontrada en el comportamiento de las probetas en relación con el método de refuerzo es la existencia de estos fallos relacionados con el solape. Al examinar las probetas tras la rotura prematura se observó que la longitud de la zona solapada era de alrededor de $80-85 \mathrm{~mm}$, menor de los $100 \mathrm{~mm}$ que se habían previsto. Es probable que aunque las camisas se fabriquen con las dimensiones adecuadas, su rigidez dificulte su colocación envolviendo el pilar y por este motivo no se consiguiera la longitud de solape requerida. También se encontraron en la zona de solape algunos restos del mortero inyectado lo que indicaría pequeñas zonas con falta de adherencia en el solape. El fallo prematuro parece por tanto debido a dificultades en el proceso de refuerzo. Las restantes probetas reforzadas con 
elementos prefabricados se comportaron bien, de manera análoga a las probetas reforzadas por moldeo manual o por el método mixto.

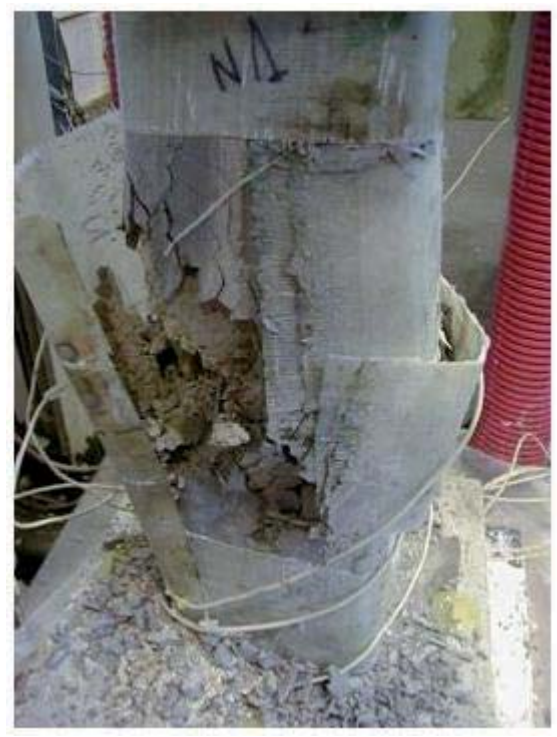

Figura 3.19 Fallo de probetas por despegue del solape

\subsubsection{Resistencia}

En las Tablas 3.5 y 3.6 se muestran para las probetas reforzadas con fibra de carbono y vidrio respectivamente la resistencia a compresión y su relación con la resistencia del hormigón sin confinar $f_{c o}$ obtenida en la rotura de probetas cilíndricas normalizadas. Se dan los valores obtenidos en cada probeta, y el valor medio de probetas iguales. Las tres probetas con fallos por despegue del solape no se han considerado para obtener los promedios.

Los resultados muestran que mediante el confinamiento con FRP puede incrementarse muy notablemente la resistencia de pilares de hormigón de baja resistencia, aun tratándose de secciones cuadradas. El incremento de resistencia es mayor cuanto menor es la resistencia del hormigón sin confinar, y es ligeramente superior en las probetas reforzadas con fibra de carbono que en las de vidrio (a pesar de que el espesor neto de fibra es menor en las camisas de carbono que en las de vidrio). 
Tabla 3.5 Resultados experimentales. Incremento de resistencia y deformación axial en probetas reforzadas con fibra de carbono

\begin{tabular}{|c|c|c|c|c|c|c|c|c|}
\hline Probeta & \multicolumn{2}{|c|}{$f_{c c}[\mathrm{MPa}]$} & \multicolumn{2}{|c|}{$f_{c c} l f_{c o}$} & \multicolumn{2}{|c|}{$\boldsymbol{\varepsilon}_{C C}$} & \multicolumn{2}{|c|}{$\boldsymbol{\varepsilon}_{c c} / \boldsymbol{\varepsilon}_{c O}$} \\
\hline C_8.8_a & 22.2 & \multirow{2}{*}{21.7} & 2.53 & \multirow{2}{*}{2.46} & - & \multirow{2}{*}{0.017247} & - & \multirow{2}{*}{8.6} \\
\hline C_8.8_b & 21.1 & & 2.40 & & 0.017247 & & 8.6 & \\
\hline C_13_a & 23.5 & \multirow{2}{*}{23.2} & 1.81 & \multirow{2}{*}{1.79} & 0.041213 & \multirow{2}{*}{0.034401} & 20.6 & \multirow{2}{*}{17.2} \\
\hline C_13_b & 23.0 & & 1.77 & & 0.027590 & & 13.8 & \\
\hline C_16.3_a & 32.3 & \multirow{2}{*}{31.4} & 1.98 & \multirow{2}{*}{1.93} & 0.023237 & \multirow{2}{*}{0.023540} & 11.6 & \multirow{2}{*}{11.8} \\
\hline C_16.3_b & 30.4 & & 1.87 & & 0.023842 & & 11.9 & \\
\hline C_16.5_a & 28.3 & \multirow{3}{*}{28.4} & 1.71 & \multirow{3}{*}{1.72} & - & \multirow{3}{*}{0.019744} & - & \multirow{3}{*}{9.9} \\
\hline C_16.5_b* & 20.9 & & 1.27 & & 0.006162 & & - & \\
\hline C_16.5_c & 28.5 & & 1.73 & & 0.019744 & & 9.9 & \\
\hline C_16.7_a & 29.1 & \multirow{2}{*}{29.6} & 1.74 & \multirow{2}{*}{1.77} & 0.023994 & \multirow{2}{*}{0.024920} & 12.0 & \multirow{2}{*}{12.5} \\
\hline C_16.7_b & 30.0 & & 1.80 & & 0.025845 & & 12.9 & \\
\hline C_17.5_a & 25.8 & \multirow{2}{*}{25.8} & 1.48 & \multirow{2}{*}{1.48} & 0.028580 & \multirow{2}{*}{0.028580} & 14.3 & \multirow{2}{*}{14.3} \\
\hline C_17.5_b* & 18.9 & & 1.08 & & 0.011821 & & - & \\
\hline C_26.4_a & 42.9 & \multirow{2}{*}{41.3} & 1.63 & \multirow{2}{*}{1.56} & 0.015083 & \multirow{2}{*}{0.013438} & 7.5 & \multirow{2}{*}{6.7} \\
\hline C_26.4_b & 39.7 & & 1.50 & & 0.011792 & & 5.9 & \\
\hline
\end{tabular}

* Probetas con fallos en el solape, no consideradas en los valores medios

Tabla 3.6 Resultados experimentales. Incremento de resistencia y deformación axial en probetas reforzadas con fibra de vidrio

\begin{tabular}{|c|c|c|c|c|c|c|c|c|}
\hline Probeta & \multicolumn{2}{|c|}{$f_{c c}[\mathrm{MPa}]$} & \multicolumn{2}{|c|}{$f_{c c} l f_{c o}$} & \multicolumn{2}{|c|}{$\boldsymbol{\varepsilon}_{C C}$} & \multicolumn{2}{|c|}{$\boldsymbol{\varepsilon}_{C C} / \boldsymbol{\varepsilon}_{C O}$} \\
\hline G $8.8 \mathrm{a}$ & 19.3 & 200 & 2.20 & 227 & - & 709200 & - & 110 \\
\hline G 8.8 b & 22.3 & 20.0 & 2.53 & 2.01 & 0.029789 & ט. & 14.9 & (19.0 \\
\hline G 13 a & 19.2 & & 1.48 & & 0.035846 & & 17.9 & \\
\hline $\mathrm{G} 13 \mathrm{~b}$ & 21.3 & & 1.64 & & 0.021774 & & 10.9 & \\
\hline G 16.5 a & 24.9 & & 1.51 & & - & & - & \\
\hline G $16.5 b$ & 25.7 & 24.6 & 1.56 & 1.49 & 0.020563 & 0.021266 & 10.3 & 10.6 \\
\hline G $16.5 \mathrm{c}$ & 23.3 & & 1.41 & & 0.021969 & & 11.0 & \\
\hline G 16.7 a & 24.2 & & 1.45 & & 0.024338 & & 12.2 & \\
\hline G $16.7 b$ & 26.3 & & 1.57 & & 0.022226 & & 11.1 & \\
\hline G $17.5 \mathrm{a}$ & 24.6 & 040 & 1.40 & & 0.029347 & & 14.7 & \\
\hline $\mathrm{G} 17.5 \mathrm{~b}^{*}$ & 22.5 & $2+.0$ & 1.28 & 1.70 & 0.015902 & ודל של & 8.0 & 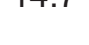 \\
\hline
\end{tabular}

*Probeta con fallos en el solape, no considerada en los valores medios 


\subsubsection{Deformación axial}

En las Tablas 3.5 y 3.6 se muestran también los valores de deformación axial última $\varepsilon_{c c}$ en las probetas reforzadas con fibra de carbono y de vidrio respectivamente, y su relación con la deformación del hormigón sin confinar, considerando el valor $\varepsilon_{c o}=0.002$. Se dan los valores de deformación axial obtenidos en cada probeta (promedio de las cuatro caras), y el valor medio de probetas iguales.

El incremento de deformación axial con el refuerzo de FRP es muy elevado. El valor medio de la relación $\varepsilon_{c c} / \varepsilon_{c o}$ es ligeramente mayor en las probetas reforzadas con vidrio (12.9) que en las de carbono (11.7). El número de ensayos y la dispersión de los resultados no permiten establecer conclusiones sobre la relación entre el incremento de deformación axial conseguido con el refuerzo y la resistencia del hormigón sin reforzar.

En cualquier caso es importante señalar que en la práctica deben evitarse valores elevados de deformación de compresión en el hormigón, ya que aunque el FRP se encuentre lejos de la rotura, el hormigón estará muy fisurado y el pilar sería incapaz de resistir esfuerzos transversales. Las guías de cálculo publicadas, como se verá en el capítulo 5 , imponen limitaciones a la deformación axial del hormigón. Por ejemplo la guía $\mathrm{ACl}$ (ACl-440.2R-08, 2008) la limita al 0.01 para prevenir una fisuración excesiva del hormigón.

En los resultados experimentales publicados en la literatura es habitual la gran dispersión en los datos de deformación axial última. Como consecuencia de la forma habitual de las curvas tensión axial- deformación axial (Figuras 3.15 y 3.16), en la parte final de los ensayos, a valores relativamente pequeños de incremento de resistencia corresponden incrementos elevados de deformación axial. Esto explica en parte esta dispersión, y la dificultad en el ajuste de los modelos.

\subsubsection{Deformación última efectiva}

En la Tabla 3.8 se dan los valores de deformación lateral última $\left(\varepsilon_{f u}\right)$ o deformación última efectiva en las probetas reforzadas con fibra de carbono, y en la Tabla 3.9 los datos de las probetas reforzadas con fibra de vidrio. Los valores que se dan en las tablas son el promedio de las lecturas de las bandas extensométricas situadas en la sección central en las cuatro caras en el momento en que se produce el fallo de la probeta. En algunas probetas se ha medido además la deformación en las esquinas, pero no se ha encontrado que sea diferente a la de los centros de las caras. Se da también el valor medio de 
probetas iguales, excluyendo las tres probetas en las que hubo un fallo prematuro por despegue del solape.

En todas las probetas la deformación última efectiva es muy inferior a la deformación de rotura del material FRP obtenida en los ensayos de tracción de cupones planos realizados sobre los laminados. Este hecho se refleja en la mayoría de los estudios experimentales publicados, como se ha visto en el capítulo 2. En las tablas se muestra también la relación entre la deformación última efectiva y deformación última del material $\left(\varepsilon_{f u} / \varepsilon_{f}\right)$, lo que suele denominarse factor de eficiencia de la deformación $k_{\varepsilon}$.

Tabla 3.7 Deformación última efectiva en probetas reforzadas con fibra de carbono

\begin{tabular}{|c|c|c|c|c|c|c|c|c|}
\hline Probeta & \multicolumn{2}{|c|}{$\boldsymbol{\varepsilon}_{f u}$} & \multicolumn{2}{|c|}{$\varepsilon_{f u} / \varepsilon_{f}$} & \multicolumn{2}{|c|}{$\varepsilon_{f \text { máx }}$} & \multicolumn{2}{|c|}{$\boldsymbol{\varepsilon}_{f \text { máx }} / \boldsymbol{\varepsilon}_{f}$} \\
\hline C_8.8_a & - & \multirow{2}{*}{-0.003335} & - & \multirow{2}{*}{0.22} & - & \multirow{2}{*}{-0.003749} & - & \multirow{2}{*}{0.25} \\
\hline C_8.8_b & -0.003335 & & 0.22 & & -0.003749 & & 0.25 & \\
\hline C_13_a & -0.004476 & \multirow{2}{*}{-0.004476} & 0.30 & \multirow{2}{*}{0.30} & -0.005289 & \multirow{2}{*}{-0.004983} & 0.35 & \multirow{2}{*}{0.33} \\
\hline C_13_b* & -0.003564 & & 0.24 & & -0.004676 & & 0.31 & \\
\hline C_16.3_a & -0.006346 & \multirow{2}{*}{-0.005669} & 0.42 & \multirow{2}{*}{0.38} & -0.007712 & \multirow{2}{*}{-0.007035} & 0.51 & \multirow{2}{*}{0.47} \\
\hline C_16.3_b & -0.004992 & & 0.33 & & -0.006357 & & 0.42 & \\
\hline C_16.5_a & - & \multirow{3}{*}{-0.005258} & - & \multirow{3}{*}{0.35} & - & \multirow{3}{*}{-0.007790} & - & \multirow{3}{*}{0.52} \\
\hline C_16.5_b* & -0.000741 & & 0.05 & & -0.001266 & & 0.08 & \\
\hline C_16.5_c & -0.005258 & & 0.35 & & -0.007790 & & 0.52 & \\
\hline C_16.7_a & -0.004653 & \multirow{2}{*}{-0.004376} & 0.31 & \multirow{2}{*}{0.29} & -0.005597 & \multirow{2}{*}{-0.006100} & 0.37 & \multirow{2}{*}{0.41} \\
\hline C_16.7_b & -0.004098 & & 0.27 & & -0.006603 & & 0.44 & \\
\hline C_17.5_a & -0.004062 & \multirow{2}{*}{-0.004062} & 0.27 & \multirow{2}{*}{0.27} & -0.004982 & \multirow{2}{*}{-0.004982} & 0.33 & \multirow{2}{*}{0.33} \\
\hline C_17.5_b* & -0.001671 & & 0.11 & & -0.002927 & & 0.20 & \\
\hline C_26.4_a & -0.006410 & \multirow{2}{*}{-0.006523} & 0.49 & \multirow{2}{*}{0.50} & -0.008330 & \multirow{2}{*}{-0.008880} & 0.65 & \multirow{2}{*}{0.69} \\
\hline C_26.4_b & -0.006635 & & 0.51 & & -0.009430 & & 0.74 & \\
\hline Valor medio & & & & 0.33 & & & & 0.43 \\
\hline
\end{tabular}

*Probetas con fallos en el solape, no consideradas en los valores medios

En las probetas reforzadas con fibra de carbono, el factor de eficiencia $k_{\varepsilon}$ oscila entre 0.22 y 0.51 , con un valor medio de 0.33 . Aunque el limitado número de ensayos no permite extraer conclusiones respecto a la posible relación entre el valor de $k_{\varepsilon}$ y la resistencia del hormigón sin confinar $f_{c o}$, en los resultados se aprecia un valor $k_{\varepsilon}$ más reducido para el hormigón de resistencia más baja (8.8 $\mathrm{MPa}$ ), y mayor $k_{\varepsilon}$ para el hormigón de mayor resistencia (26.4 MPa). Para los 
hormigones intermedios (entre 13 y $17.5 \mathrm{MPa}$ ) no se aprecia variación en el valor de $k_{\varepsilon}$.

Tabla 3.8 Deformación última efectiva en probetas reforzadas con fibra de vidrio

\begin{tabular}{|c|c|c|c|c|c|c|c|c|}
\hline Probeta & \multicolumn{2}{|c|}{$\boldsymbol{\varepsilon}_{f u}$} & \multicolumn{2}{|c|}{$\boldsymbol{\varepsilon}_{f u} / \boldsymbol{\varepsilon}_{f}$} & \multicolumn{2}{|c|}{$\varepsilon_{f \text { máx }}$} & \multicolumn{2}{|c|}{$\boldsymbol{\varepsilon}_{f \operatorname{máx}} / \boldsymbol{\varepsilon}_{f}$} \\
\hline G_8.8_a & - & \multirow{2}{*}{-0.005142} & - & \multirow{2}{*}{0.15} & - & \multirow{2}{*}{-0.007996} & - & \multirow{2}{*}{0.24} \\
\hline G_8.8_b & -0.005142 & & 0.15 & & -0.007996 & & 0.24 & \\
\hline G_13_a & -0.006583 & \multirow{2}{*}{-0.007461} & 0.19 & \multirow{2}{*}{0.22} & -0.008268 & \multirow{2}{*}{-0.009679} & 0.24 & \multirow{2}{*}{0.28} \\
\hline G_13_b & -0.008339 & & 0.25 & & -0.011090 & & 0.33 & \\
\hline G_16.5_a & - & \multirow{3}{*}{-0.010697} & - & \multirow{3}{*}{0.31} & - & \multirow{3}{*}{-0.021925} & - & \multirow{3}{*}{0.6} \\
\hline G_16.5_b & -0.012608 & & 0.37 & & -0.027179 & & 0.8 & \\
\hline G_16.5_c & -0.008787 & & 0.26 & & -0.016670 & & 0.49 & \\
\hline G_16.7_a & -0.010430 & \multirow{2}{*}{-0.008431} & 0.31 & \multirow{2}{*}{0.25} & -0.016860 & \multirow{2}{*}{-0.015800} & 0.50 & \multirow{2}{*}{0.46} \\
\hline G_16.7_b & -0.006433 & & 0.19 & & -0.014740 & & 0.43 & \\
\hline G_17.5_a & -0.009835 & \multirow{2}{*}{-0.009835} & 0.29 & \multirow{2}{*}{0.29} & -0.014102 & \multirow{2}{*}{-0.014102} & 0.41 & \multirow{2}{*}{0.41} \\
\hline G_17.5_b* & -0.006045 & & 0.18 & & -0.010774 & & 0.32 & \\
\hline Valor medio & & & & 0.24 & & & & 0.41 \\
\hline
\end{tabular}

${ }^{*}$ Probetas con fallos en el solape, no consideradas en los valores medios

En las probetas reforzadas con fibra de vidrio, el factor de eficiencia $k_{\varepsilon}$ oscila entre 0.15 y 0.37 , con un valor medio de 0.24 , siendo menor para los hormigones de resistencia más baja, aunque el número de datos es muy limitado. El valor de $k_{\varepsilon}$ obtenido es ligeramente menor en las probetas reforzadas con vidrio que con carbono.

Al analizar las lecturas de las bandas extensométricas que miden la deformación transversal en las cuatro caras de las probetas, se observan lecturas diferentes, sobre todo para valores de carga cercanos a la rotura. El valor de deformación lateral última $\varepsilon_{f u}$ que se da en las columnas 2 y 3 de las Tablas 3.7 y 3.8 es el valor medio de las cuatro lecturas, pero algunas bandas extensométricas en los momentos previos a la rotura miden valores muy superiores debido a concentraciones de tensiones locales. Se añade en las columnas 4 y 5 de las tablas el valor máximo medido por alguna de las bandas extensométricas $\varepsilon_{\text {mmáx }}$, así como la relación con $\varepsilon_{f}$. El valor promedio de $\varepsilon_{\text {máx }} / \varepsilon_{f}$ es 0.43 para las probetas reforzadas con carbono y 0.41 para las probetas reforzadas con vidrio.

Como posibles causas del valor reducido de la deformación última efectiva se han señalado el estado triaxial de tensiones del FRP en las camisas, defectos de 
ejecución, la curvatura de las fibras y también deformación no homogénea y fisuración del hormigón.

En el apartado 2.4.2.2. se revisaron algunos trabajos encontrados en la literatura que ponen de manifiesto la gran dispersión existente en los datos publicados sobre la deformación de rotura efectiva. Así, en una recopilación de ensayos de probetas cilíndricas llevada a cabo por De Lorenzis y Tepfers (De Lorenzis and Tepfers, 2003) se encontraba que ésta oscilaba entre más de 1 y menos de 0.1 de la deformación media obtenida en ensayos de FRP, y en un reciente estudio de Sadeghian y Fam (Sadeghian and Fam, 2014) de una base de datos de 454 probetas cilíndricas, se obtienen valores entre 1.22 y 0.12 , con un valor medio de $k_{\varepsilon}=0.67$. Otros autores encuentran también valores medios similares, en torno a 0.6, del análisis de ensayos propios y de la literatura( (Harries and Carey, 2003), (Lam and Teng, 2003b, Lam and Teng, 2004)), y con base en estas investigaciones sobre probetas de sección circular algunas guías internacionales han propuesto utilizar en el cálculo un factor de eficiencia de la deformación en torno a 0.55 o 0.6 .

Los valores de $k_{\varepsilon}$ obtenidos en el presente estudio experimental son bastante inferiores a los valores propuestos en las guías. Esto podría ser debido a la forma cuadrada de la sección y también a que se trata de hormigones con resistencia a compresión muy baja, ya que la mayoría de los ensayos de la literatura se han realizado sobre probetas cilíndricas fabricadas con hormigones de entre 30 y $50 \mathrm{MPa}$.

Uno de los objetivos de la segunda parte del programa experimental desarrollado en esta tesis, que se expone en el capítulo 4, es precisamente profundizar en este tema, para lo cual se han ensayado probetas de sección cuadrada pero con hormigones de resistencia normal (alrededor de $40 \mathrm{MPa}$ ).

En el capítulo 5 de esta tesis se analizan más en detalle los resultados experimentales obtenidos en las dos partes del programa experimental, en relación con las propuestas de las guías de cálculo sobre la deformación última efectiva.

\subsubsection{Comportamiento tensión-deformación}

En las Figuras 3.14 y 3.15 se han mostrado las curvas carga deformación axial y carga deformación lateral de las probetas ensayadas. Se observa el 
comportamiento típico del hormigón confinado con FRP descrito en el apartado 2.4.2.1. En todos los casos las curvas tienen una forma monótona creciente. En la primera parte de las curvas el comportamiento es similar al del hormigón sin confinar, ya que la deformación transversal del hormigón es muy pequeña y la camisa prácticamente no entra en tensión y no confina al hormigón. Al incrementarse la carga y superarse la deformación de compresión correspondiente a la tensión pico del hormigón sin confinar (en torno a 0.002), el núcleo de hormigón se fisura, la expansión lateral crece y activa el efecto del confinamiento del FRP. Tras una zona de transición, la respuesta tensión deformación se convierte en aproximadamente lineal con una pendiente mayor cuanto mayor es la rigidez del FRP.

En la Figura 3.20 se muestran las curvas tensión-deformación correspondientes a las probetas con resistencia $f_{c o}$ comprendida entre 16.3 y $17.5 \mathrm{MPa}$ (no se incluyen las probetas con fallo por despegue del solape). Se representan en color rojo las probetas reforzadas con fibra de carbono y en azul las reforzadas con fibra de vidrio. Se aprecia que la segunda rama de las curvas tiene una mayor pendiente en las reforzadas con carbono (mayor rigidez del encamisado) que en las de vidrio.

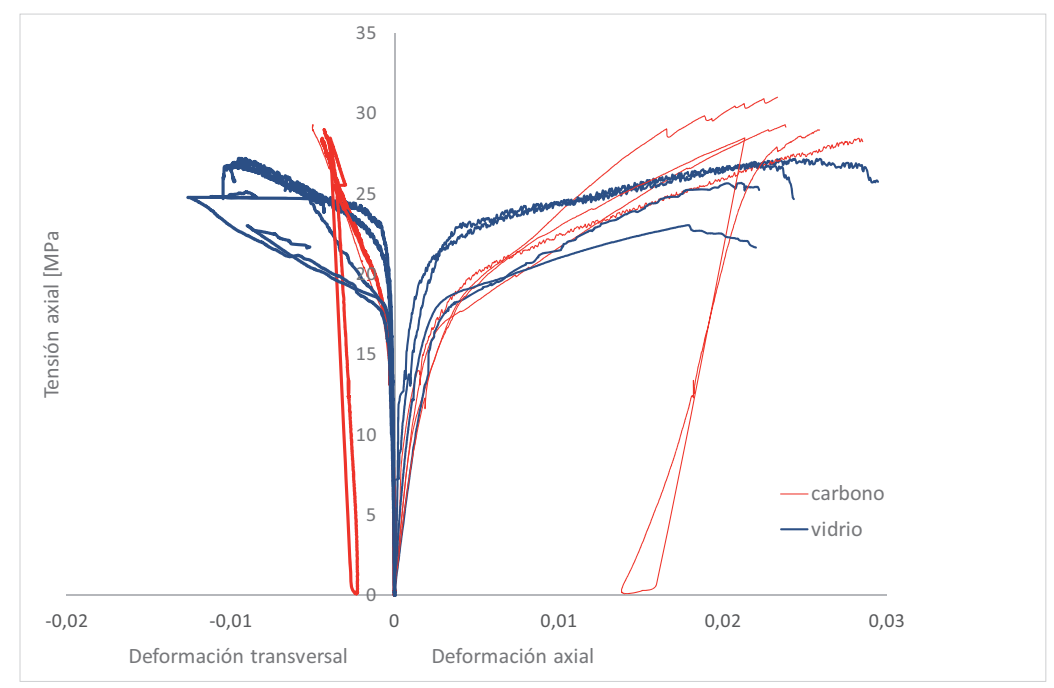

Figura 3.20 Comparación de curvas tensión-deformación de probetas reforzadas con carbono y vidrio 


\section{CAPÍTULO 4}

\section{PROGRAMA EXPERIMENTAL. PARTE II}

\subsection{Introducción}

En este capítulo se presenta la segunda parte del programa experimental, llevada a cabo sobre probetas de sección cuadrada fabricadas con hormigones de resistencia media. Con el objetivo de profundizar en la investigación de la deformación última efectiva y de la influencia de la forma de la sección, y a la vista de los resultados obtenidos en la primera parte del estudio, se incluyen como variables en esta segunda parte:

- el radio de curvatura $R_{c}$ con el que se redondean las esquinas. En los ensayos de la parte I el radio de curvatura era igual en todas las probetas. Es conocido que al aumentar el radio de redondeo se mejora la efectividad del confinamiento, y en los modelos de cálculo el valor de $R_{c}$ se tiene en cuenta para obtener el factor de forma $\alpha_{e}$. Se pretende estudiar también la posible relación entre el radio de curvatura y el coeficiente de efectividad de la deformación $k_{\varepsilon}$, ya que como se vio en el capítulo 2, la curvatura de las fibras en la camisa se ha sugerido como causa del valor reducido de la deformación última efectiva.

- la cuantía de refuerzo. Todas las probetas se refuerzan con fibra de carbono, pero con tres cuantías diferentes: 1, 2 y 3 capas de fibra. En los 
ensayos realizados en la primera parte, con hormigones de muy baja resistencia, el ratio $f_{1} / f_{c o}$ era en todos los casos elevado, $y$ las probetas mostraron el comportamiento tensión-deformación típico con una segunda rama ascendente. Algunos investigadores han propuesto diferentes criterios, generalmente basándose en ensayos de probetas cilíndricas, sobre el nivel de confinamiento mínimo necesario para asegurar este comportamiento. Con los ensayos de esta segunda parte del programa experimental se pretende estudiar la influencia de la forma de la sección en la forma de las curvas tensión-deformación.

\subsection{Descripción del plan de ensayos. Variables estudiadas}

En esta fase se han ensayado a compresión centrada 14 probetas prismáticas de hormigón de sección cuadrada: 2 probetas patrón de hormigón sin reforzar y 12 probetas de hormigón reforzadas con CFRP (polímero reforzado con fibras de carbono). Las probetas no llevan armadura interna. La técnica de refuerzo empleada consiste en la aplicación manual de fibras y resinas sobra las probetas (moldeo por contacto a mano o wrapping).

Como se ha indicado las variables estudiadas son:

- el radio de curvatura con el que se redondean las esquinas de la probeta antes de aplicar el refuerzo $R_{c}$. Al incrementar el radio de redondeo se incrementa significativamente el valor del factor de forma $\alpha_{e}$ utilizado para incluir en los modelos la pérdida de efectividad del confinamiento respecto a una sección circular. Se han elegido dos valores de $R_{c}: 20$ y $40 \mathrm{~mm}$. Teniendo en cuenta que las probetas ensayadas tienen una sección cuadrada de $150 \times 150 \mathrm{~mm}^{2}$, el correspondiente factor de forma $\alpha_{e}$ obtenido según la propuesta más aceptada que lo define como la relación entre el área que se considera efectivamente confinada incluida entre las parábolas a $45^{\circ}$ construidas sobre los lados (Figura 2.26) y el área total sería $\alpha_{e}=0.636$ para $R_{c}=20 \mathrm{~mm}$ y $\alpha_{e}=0.845$ para $R_{c}=40 \mathrm{~mm}$.

- la cuantía de refuerzo. Se han reforzado probetas con 1, 2 y 3 capas de fibra de carbono. El material utilizado tiene un espesor nominal de fibra 
de $0.129 \mathrm{~mm}$, por lo que las cuantías de refuerzo definidas como $\rho_{f}=\frac{2 t(b+d)}{b d}$ en el estudio son: $0.0034,0.0068$ y 0.0103 .

En la Tabla 4.1 se muestra el plan de ensayos. En la nomenclatura del tipo de probeta el primer dígito indica el número de capas de refuerzo $(0,1,2$ o 3) seguido del radio de curvatura de las esquinas $R_{c}$ en $\mathrm{mm}$ (20 o 40). De cada tipo se han ensayado dos probetas, que se designarán en adelante con la nomenclatura indicada seguida de las letra $a$ o $b$.

Tabla 4.1 Plan de ensayos

\begin{tabular}{|c|c|c|c|}
\hline $\begin{array}{c}\text { Cuantía de refuerzo } \\
\left(n^{\circ} \text { capas }\right)\end{array}$ & $R_{c}[\mathrm{~mm}]$ & Tipo de probeta & $N^{\circ}$ de probetas \\
\hline 0 & - & 0 & 2 \\
\hline \multirow{2}{*}{1} & 20 & 1_20 & 2 \\
\cline { 2 - 4 } & 40 & 1_40 & 2 \\
\hline \multirow{2}{*}{2} & 20 & 2_20 & 2 \\
\cline { 2 - 4 } & 40 & 2_40 & 2 \\
\hline \multirow{2}{*}{3} & 20 & 3_20 & 2 \\
\cline { 2 - 4 } & 40 & 3_40 & 2 \\
\hline
\end{tabular}

\subsection{Preparación de las probetas de hormigón}

Se fabrican 14 probetas prismáticas de sección cuadrada de $150 \times 150 \mathrm{~mm}^{2}$ y 600 mm de longitud. Para determinar la resistencia a compresión del hormigón se ensayan probetas cilíndricas normalizadas obteniéndose una resistencia media a 28 días de $41 \mathrm{MPa}$.

En el interior de los moldes de las probetas prismáticas se incorporan en las esquinas unas molduras de madera de forma triangular con el fin de facilitar el posterior redondeo de las esquinas que es necesario realizar antes de reforzarlas (Figura 4.1).

En la Figura 4.2 se muestra el hormigonado de las probetas, que se realiza en vertical. 

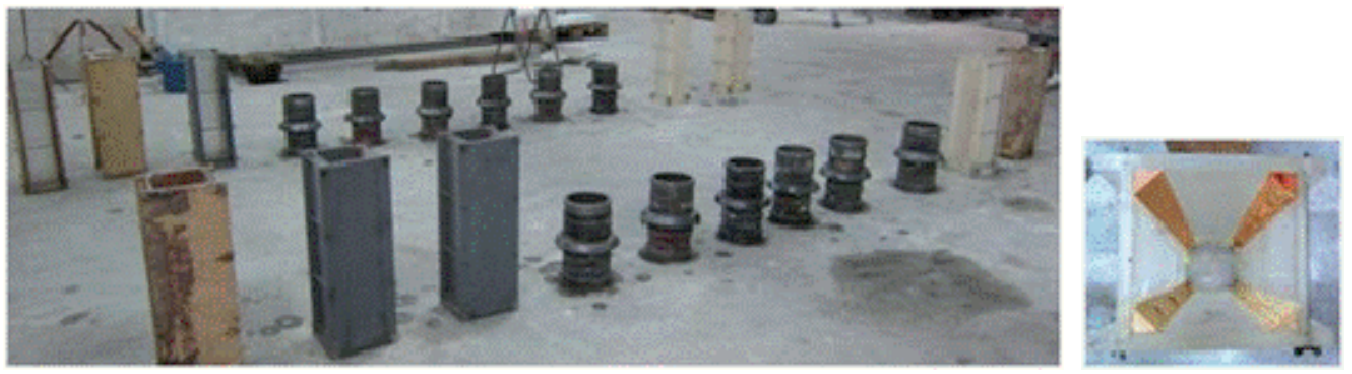

Figura 4.1 Izqda: Moldes utilizados. Dcha: Interior del molde con molduras en las esquinas
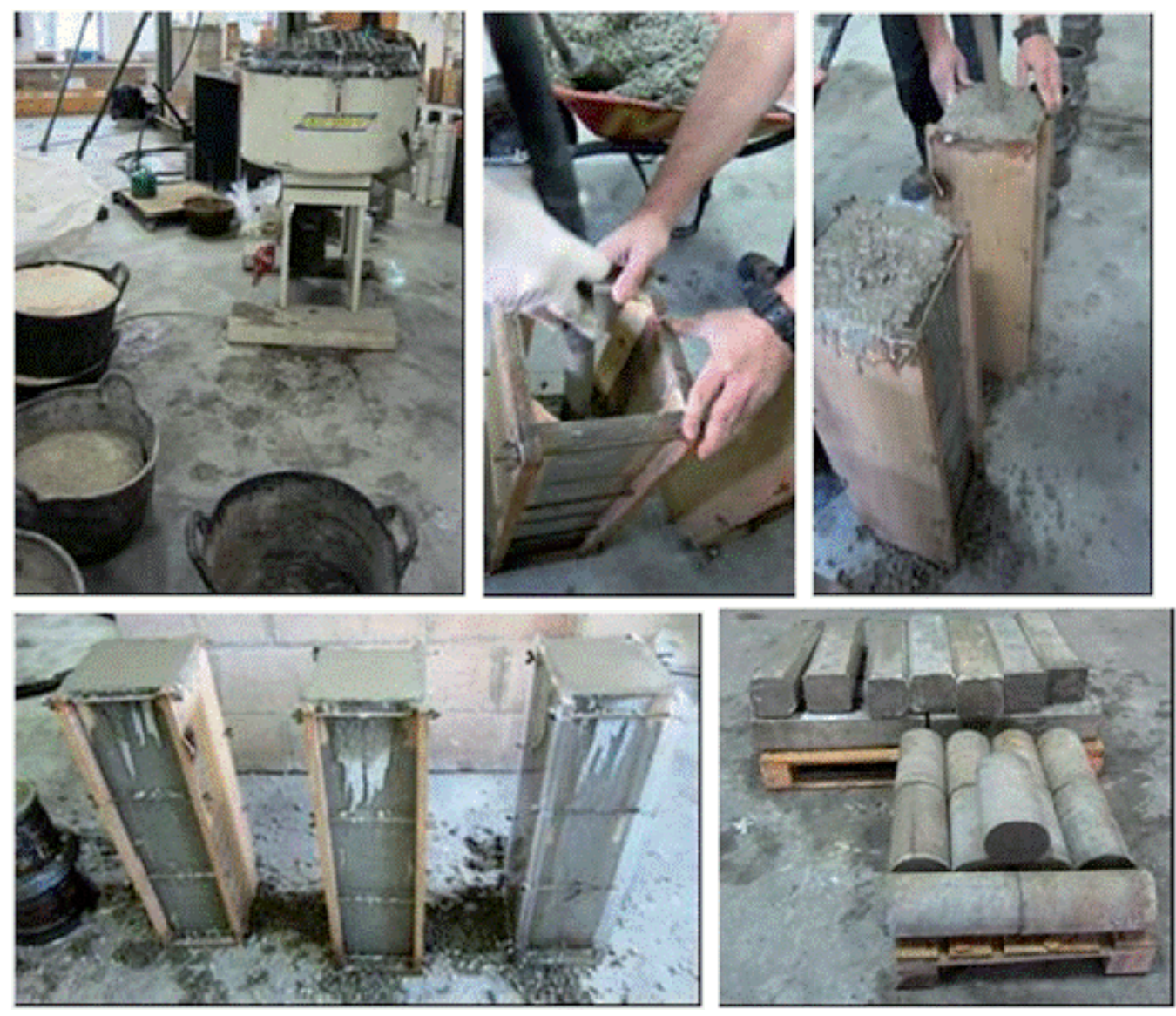

Figura 4.2 Hormigonado de las probetas.

Como ya se ha mencionado, a diferencia de lo que ocurre en los refuerzos a flexión o a cortante con materiales compuestos, en el refuerzo de soportes mediante confinamiento no es crítica la adherencia entre el soporte y el refuerzo (de hecho no es necesario que exista esta adherencia, aunque por el modo de 
ejecución habitualmente el encamisado queda pegado al soporte). Lo que sí es crítico es que exista pleno contacto del encamisado con el soporte y hay que preparar la superficie de hormigón para que no queden huecos ni aristas. En las probetas fabricadas sólo fue necesario realizar el redondeo de las esquinas, que se hizo 21 días después del hormigonado. El redondeo, con valores del radio de curvatura de 20 y $40 \mathrm{~mm}$, se efectuó con una radial, como se observa en la Figura 4.3. A continuación las probetas se limpiaron con aire a presión para eliminar todo el polvo.
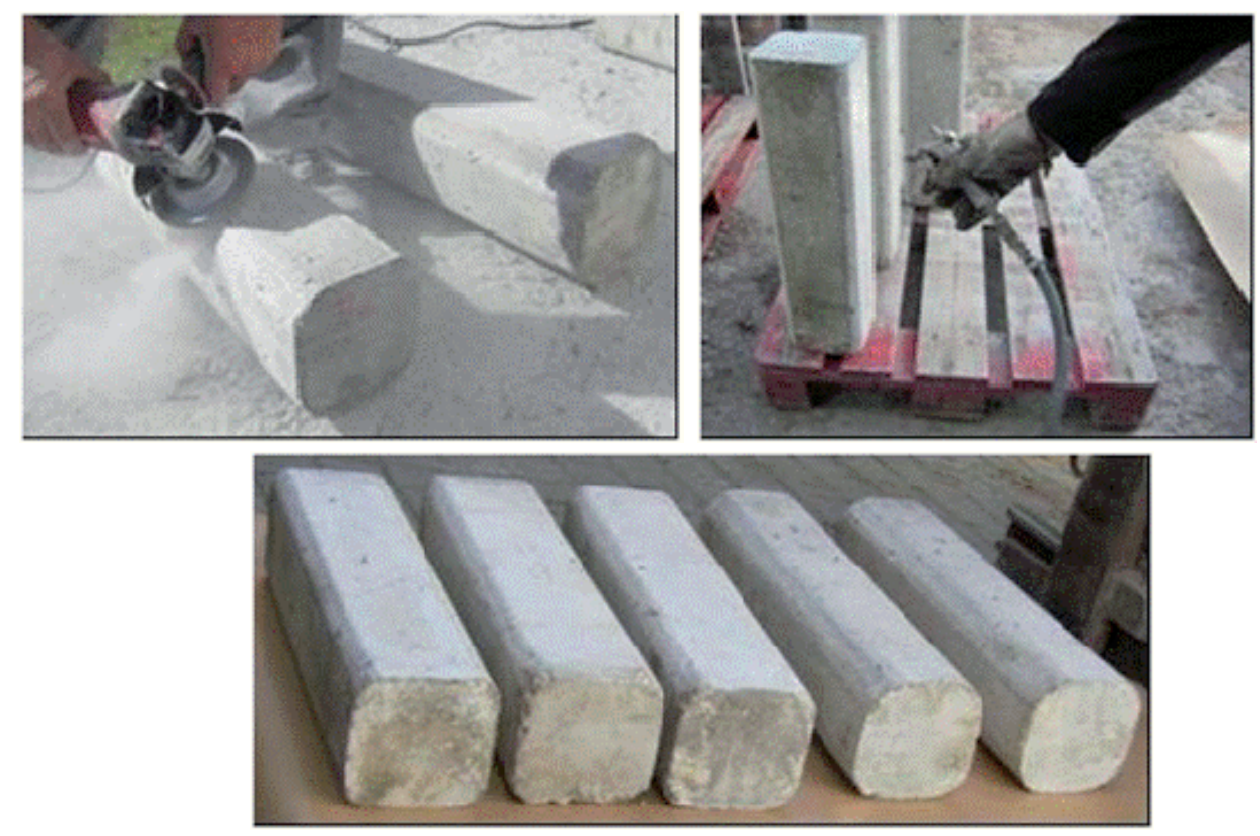

Figura 4.3 Redondeo de las esquinas y limpieza con aire a presión.

\subsection{Materiales empleados en el refuerzo}

Los materiales empleados en el refuerzo son tejido unidireccional de fibra carbono y resina epoxi (Figura 4.4).
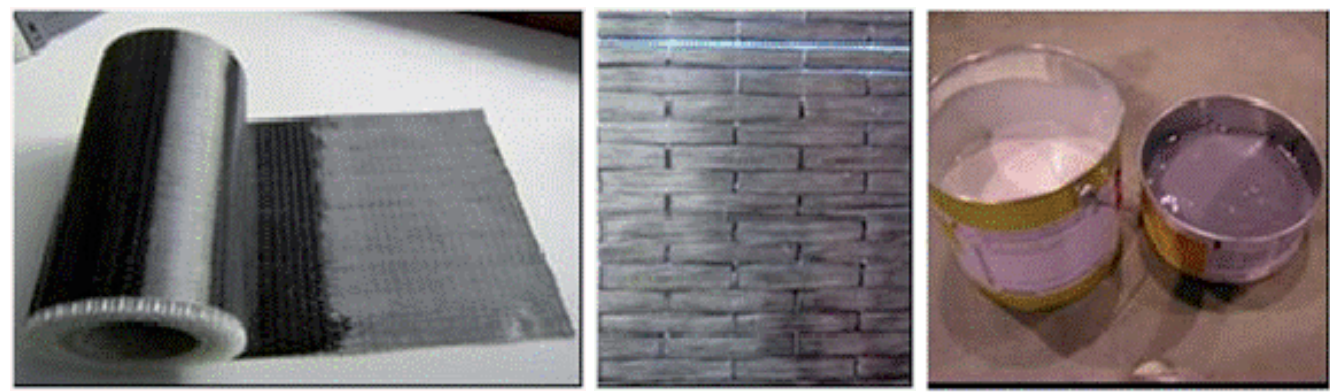

Figura 4.4 Fibra de carbono y resina epoxi utilizados en el refuerzo. 


\subsubsection{Propiedades de la resina}

La resina es de tipo epoxi, bicomponente, de viscosidad media, que permite un fácil mezclado y aplicación sobre superficies verticales. Es la resina que suministra el fabricante para la aplicación de tejidos de bajo gramaje por proceso seco, que se describe en el apartado 4.5.

En la Tabla 4.2 se indican las propiedades mecánicas de la resina epoxi, obtenidas de la hoja de datos del producto que proporciona el fabricante. La densidad de la resina es $1.30 \mathrm{~kg} / \mathrm{l}$. El fabricante da como temperatura de servicio el intervalo entre $-40^{\circ} \mathrm{C}$ y $+45^{\circ} \mathrm{C}$, y como limitaciones en las condiciones de aplicación indica que tanto la temperatura del soporte como la temperatura ambiente deben estar entre $+10^{\circ} \mathrm{C} \mathrm{y}+35^{\circ} \mathrm{C}$, la humedad del soporte ha de ser menor o igual del $4 \%$, y ha de tenerse cuidado con la condensación, la temperatura durante la aplicación debe ser al menos $3{ }^{\circ} \mathrm{C}$ superior al punto de rocío. El curado de la resina se produce a temperatura ambiente, y el tiempo estimado para el curado antes de entrar en carga es de 7 días a $10^{\circ} \mathrm{C}, 5$ días a $23^{\circ} \mathrm{C}$ y 2 días a $35^{\circ} \mathrm{C}$.

Tabla 4.2 Propiedades mecánicas de la resina epoxi

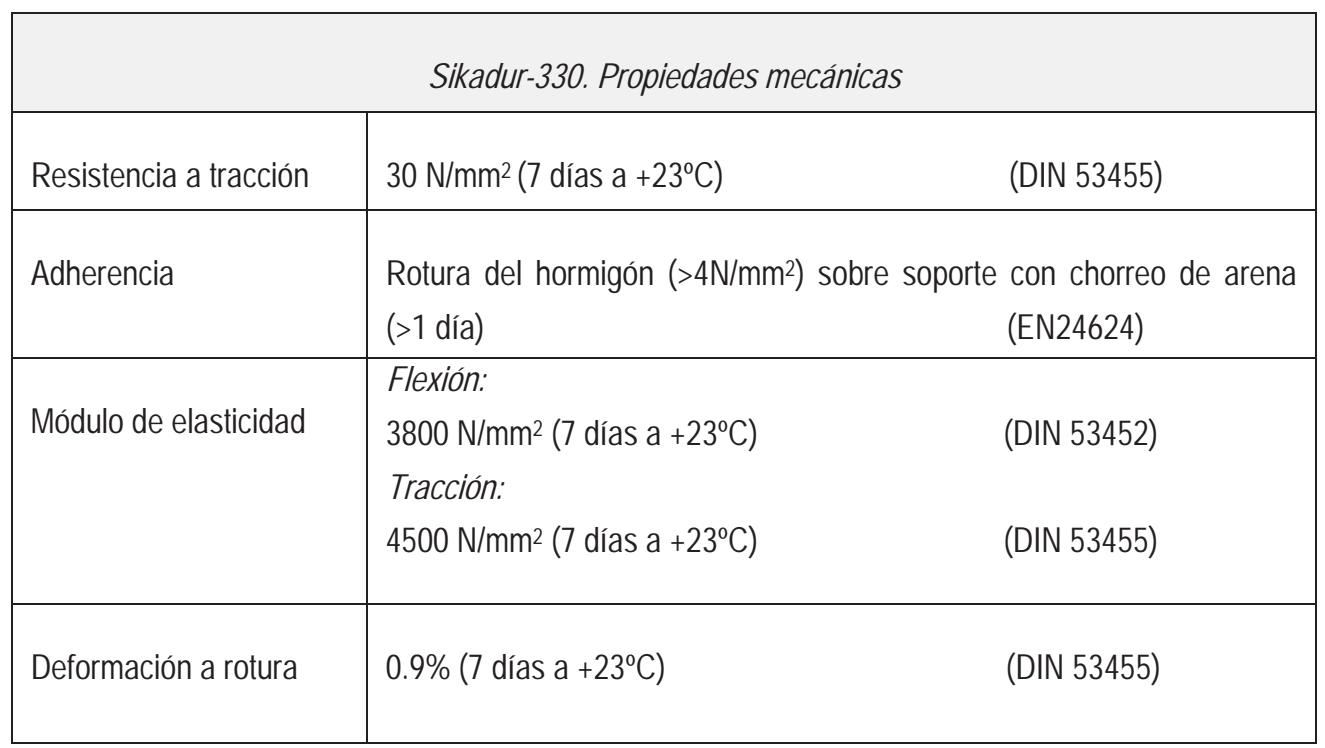

\subsubsection{Propiedades de la fibra de carbono}

Se ha empleado tejido de fibra de carbono unidireccional que se presenta en rollos de $300 \mathrm{~mm}$ de anchura y $50 \mathrm{~m}$ de longitud. Es un tejido muy flexible que permite su adaptación a la geometría del soporte a reforzar y puede cortarse 
fácilmente con tijeras la cantidad que se precise. La fibra de carbono tiene una densidad de $1.82 \mathrm{~g} / \mathrm{cm}^{3}$, y el tejido empleado tiene un peso de $235 \mathrm{~g} / \mathrm{m}^{2}$, lo que corresponde a un espesor del tejido de $0.129 \mathrm{~mm}$. Es decir, el espesor neto de fibra es de $0.129 \mathrm{~mm}$ por cada capa de tejido. El fabricante da en la hoja del producto las propiedades de la fibra en seco que se indican en la Tabla 4.3.

Tabla 4.3 Propiedades de la fibra de carbono en seco

\begin{tabular}{|c|c|}
\hline \multicolumn{2}{|c|}{ SikaWrap-230 C. Propiedades de la fibra en seco (ISO 10618) } \\
\hline Módulo elástico & Valor mínimo $230000 \mathrm{~N} / \mathrm{mm}^{2}$ \\
\hline Resistencia a tracción & Valor mínimo $4000 \mathrm{~N} / \mathrm{mm}^{2}$ \\
\hline Alargamiento a rotura & $1.7 \%$ \\
\hline
\end{tabular}

\subsubsection{Propiedades del laminado CFRP}

Las características mecánicas del laminado carbono/epoxi en la dirección longitudinal de la fibra suministradas por el fabricante se recogen en la Tabla 4.4. Los valores de resistencia y módulo elástico de la tabla están referidos al espesor neto de fibra.

Además se han realizado ensayos de tracción que se describen a continuación en el siguiente subapartado.

Tabla 4.4 Propiedades del laminado carbono/epoxi suministradas por el fabricante

\begin{tabular}{|c|c|}
\hline \multicolumn{2}{|c|}{$\begin{array}{c}\text { SikaWrap-230 C. Propiedades del laminado (EN 2561) } \\
\text { (1 capa, 27 muestras por serie de ensayo) }\end{array}$} \\
\hline $\begin{array}{c}\text { Espesor del laminado } \\
\text { (nominal) }\end{array}$ & $0.129 \mathrm{~mm}$ \\
\hline Módulo elástico & $\begin{array}{c}\text { Valor medio } 225000 \mathrm{~N} / \mathrm{mm}^{2} \\
\text { Valor característico } 220000 \mathrm{~N} / \mathrm{mm}^{2}\end{array}$ \\
\hline Resistencia a tracción & Valor medio $3500 \mathrm{~N} / \mathrm{mm}^{2}$ \\
& Valor característico $3200 \mathrm{~N} / \mathrm{mm}^{2}$ \\
\hline
\end{tabular}

\subsubsection{Ensayos de tracción del laminado CFRP}

Con el fin de verificar la caracterización de las propiedades mecánicas en tracción (resistencia y módulo de elasticidad) del laminado carbono/epoxi se realizó una serie de ensayos siguiendo las indicaciones de la norma UNE-EN ISO 527-4 Plásticos. Determinación de las propiedades en tracción. Parte 4: 
Condiciones de ensayo para plásticos compuestos isotrópicos y ortotrópicos reforzados con fibras (UNE-EN-ISO, 1997).

Para ello se fabricó un laminado con una capa del tejido unidireccional de fibra de carbono y la resina epoxi, teniendo un espesor aproximado de $0.8 \mathrm{~mm}$. De este laminado se cortaron las probetas o cupones objeto de ensayo, de forma rectangular, con una longitud de $250 \mathrm{~mm}$ y una anchura de $17 \mathrm{~mm}$. En UNE-EN ISO 527-4 se recomienda una anchura de $25 \mathrm{~mm}$, mientras que en la norma $D$ 3039/D 3039M-00 Standard Test Method for Tensile Properties of Polymer Matrix Composite Materials (ASTM, 2008b) se recomienda para materiales unidireccionales como el ensayado una anchura de $15 \mathrm{~mm}$ y la misma longitud. El valor de la anchura de $17 \mathrm{~mm}$ se eligió de manera que se incluyera un número entero de haces de fibras (ver en la fotografía central de la Figura 4.4 un detalle de la trama del tejido), con el fin de facilitar el cortado de las probetas y a su vez que la cantidad de fibra fuera uniforme en la longitud de la probeta y entre distintas probetas.

Los extremos de las probetas se reforzaron pegando talones del mismo material CFRP con una longitud de $50 \mathrm{~mm}$, de manera que la distancia libre entre talones es de $150 \mathrm{~mm}$. El objeto de los talones es tratar de evitar que en los ensayos se produzca deslizamiento o rotura en las mordazas.

Los ensayos se realizan en una prensa INSTRON 8801 con capacidad de 100 kN (Figura 4.5). La probeta se sujeta en sus extremos entre las mordazas de la prensa dejando una longitud libre entre mordazas de $150 \mathrm{~mm}$. Para la determinación de la deformación de las probetas se utiliza un extensómetro INSTRON con una longitud de referencia de $50 \mathrm{~mm}$.

El ensayo se realiza con control en desplazamiento, de acuerdo a UNE-EN ISO $527-4$, a una velocidad de $2 \mathrm{~mm} / \mathrm{min}$ hasta alcanzar la rotura.

Durante el ensayo se registran de manera continua la carga de tracción aplicada, el desplazamiento de la prensa y el incremento de la longitud de referencia medido con el extensómetro. 

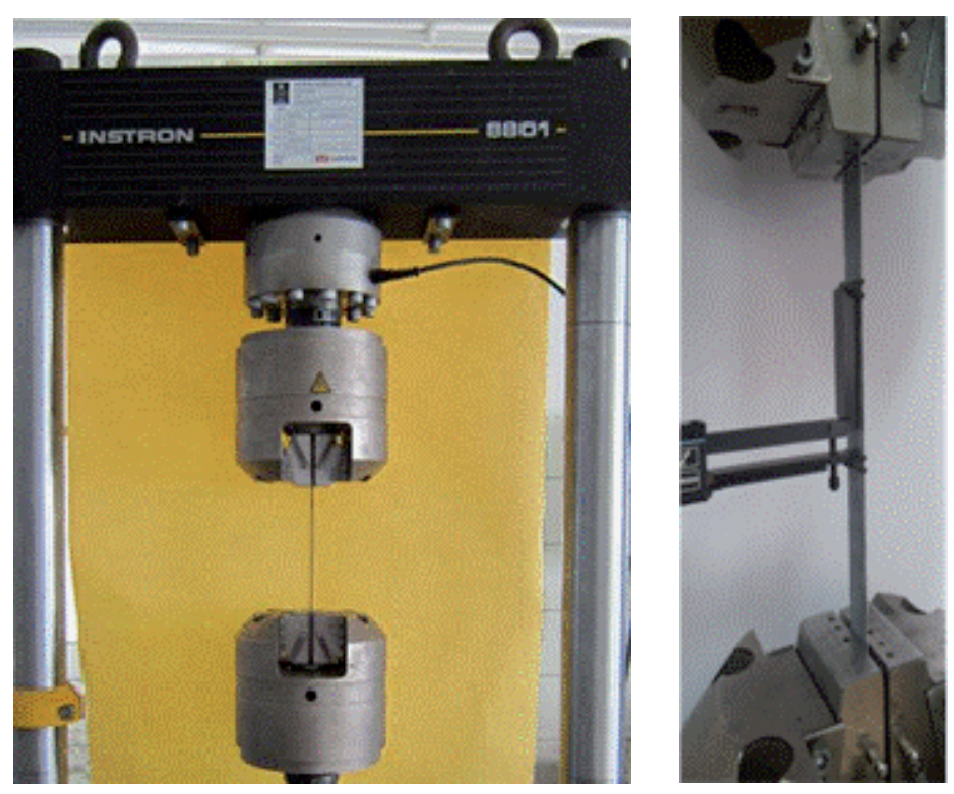

Figura 4.5 Ensayo de tracción del laminado CFRP.

Dado que la cantidad de resina es difícil de controlar en la fabricación in situ de laminados, y como las propiedades resistentes de un laminado carbono/epoxi dependen fundamentalmente de la cantidad de fibra que posea, se ha considerado para el cálculo de la tensión de tracción y el módulo de elasticidad el área neta de fibra la sección.

En la Figura 4.6 se recogen los gráficos tensión-deformación obtenidos en los ensayos. Se realizaron 7 ensayos, pero en uno de ellos se obtuvo una rotura en la zona de agarre de la mordaza, por lo que este resultado se desechó. En las probetas 2 y 3 no se representa la curva completa del ensayo, pues en la parte final no se obtuvo la medida del extensómetro. El comportamiento de los laminados es elástico lineal hasta que se produce la rotura de manera repentina (Figuras 4.6 y 4.7 ). 


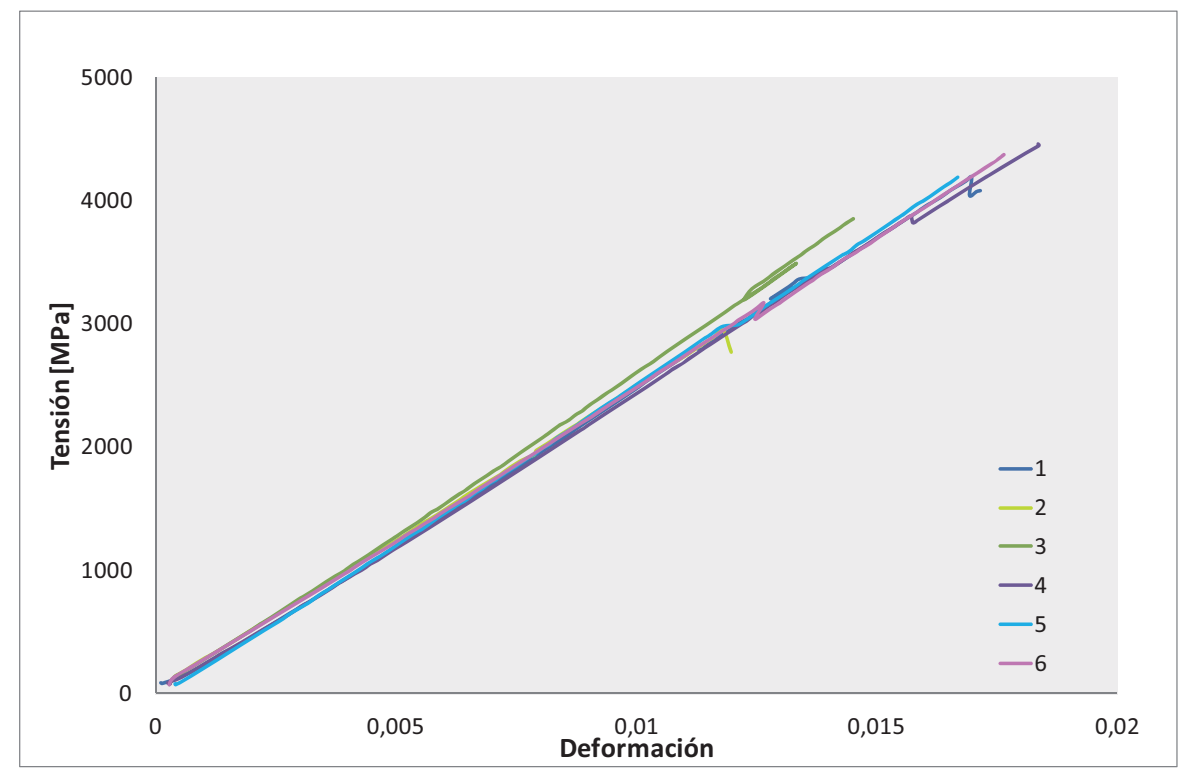

Figura 4.6 Comportamiento tensión-deformación de las probetas ensayadas.
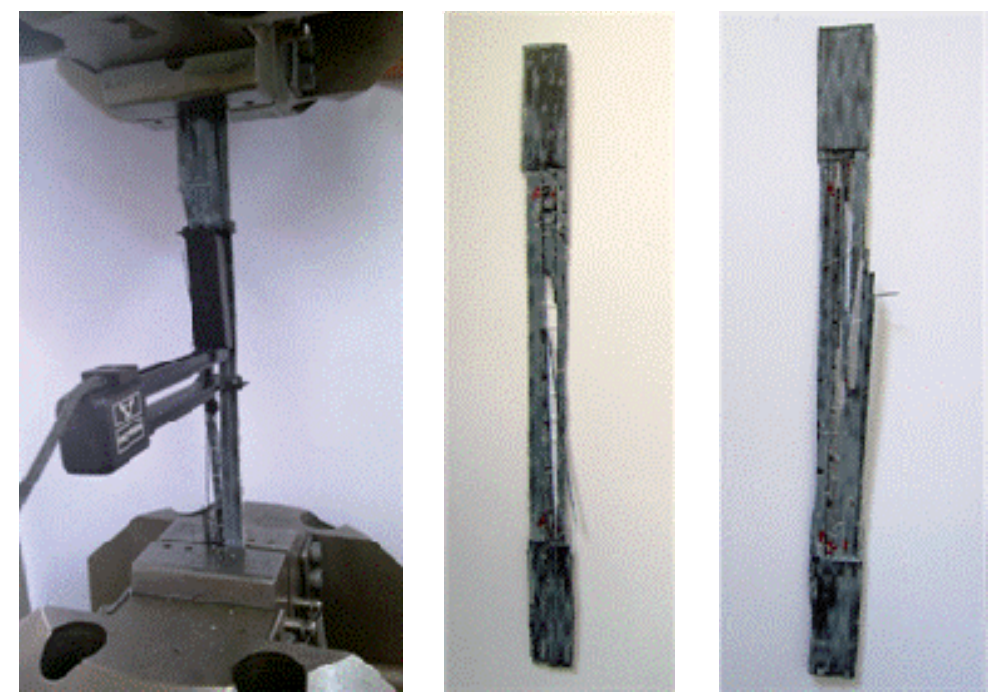

Figura 4.7 Rotura de las probetas

En la Tabla 4.5 se muestra para cada probeta ensayada el valor de la carga última, la resistencia a tracción, la deformación última (excepto en las probetas $n^{\circ} 2$ y $n^{\circ} 3$, en que no se pudo medir) y el módulo de elasticidad obtenido en cada probeta. Se indican también los valores medios y coeficientes de variación correspondientes. Los valores de resistencia y módulo se refieren al espesor neto de fibra. 
La tensión de rotura se ha calculado dividiendo el valor máximo de la carga por el área neta de fibra de la sección transversal de la probeta.

El módulo de elasticidad en tracción se ha calculado, conforme a la norma ISO 527-1, sobre la base de dos valores de deformación especificados:

$$
E_{f}=\frac{\sigma_{2}-\sigma_{1}}{\varepsilon_{2}-\varepsilon_{1}}
$$

Donde $\sigma_{1}$ y $\sigma_{2}$ son los valores de tensión medidos para los valores de deformación $\varepsilon_{1}=0.0005$ y $\varepsilon_{2}=0.0025$ respectivamente.

Tabla 4.5 Resultados de los ensayos de tracción del laminado

\begin{tabular}{|c|c|c|c|c|}
\hline Probeta & $\begin{array}{c}\text { Carga } \\
\text { última }[\mathrm{N}]\end{array}$ & $\begin{array}{c}\text { Resistencia a tracción } \\
f_{f}[\mathrm{MPa}]\end{array}$ & $\begin{array}{c}\text { Deformación última } \\
\boldsymbol{\varepsilon}_{f}[\%]\end{array}$ & $\begin{array}{c}\text { Módulo elástico } \\
E_{f}[\mathrm{MPa}]\end{array}$ \\
\hline 1 & 9210 & 4187 & 1.699 & 229789 \\
\hline 2 & 8159 & 3709 & - & 239277 \\
\hline 3 & 8848 & 4023 & - & 245257 \\
\hline 4 & 9796 & 4454 & 1.835 & 227082 \\
\hline 5 & 9278 & 4218 & 1.807 & 243993 \\
\hline 6 & 9619 & 4373 & 1.765 & 236109 \\
\hline $\begin{array}{c}\text { Valor } \\
\text { medio }\end{array}$ & 9152 & 4161 & 1.776 & 236918 \\
\hline V (\%) & 6.43 & 6.43 & 3.33 & 3.12 \\
\hline
\end{tabular}

\subsection{Ejecución del refuerzo}

Transcurridos al menos 28 días después de la fabricación de las probetas se ejecuta el refuerzo de las mismas. El método de refuerzo empleado es el moldeo por contacto a mano o wrapping que consiste en aplicar sobre la probeta el tejido unidireccional de fibra de carbono y la resina, formándose in situ el material compuesto sobre el sustrato de hormigón cuando cura la resina. Dentro del proceso de refuerzo por moldeo manual existen ciertas variantes, según el fabricante y el tipo de material. En este caso, el fabricante recomienda para el tejido utilizado, que es de gramaje bajo, lo que denomina método seco, que el tejido se coloque directamente sobre la resina aplicada previamente sobre el hormigón. Los tejidos de mayor gramaje, como los empleados en la primera 
parte del programa experimental, deben impregnarse con la resina antes de aplicarlos sobre el soporte (método húmedo). En el método húmedo se emplean resinas de baja viscosidad, mientras que en el seco son resinas de viscosidad media.

Antes de iniciar el refuerzo se limpian las probetas con aire a presión para eliminar cualquier resto de polvo. Se comprueba que el hormigón está limpio y seco, y que no existen en la superficie de las probetas imperfecciones como huecos, rebabas o aristas que pudieran dificultar el ajuste del refuerzo o dañar la fibra. El refuerzo se lleva a cabo en los siguientes pasos (Figuras 4.8 y 4.9):

- Se cortan con unas tijeras los trozos de tejido de fibra de carbono que se van a utilizar con las dimensiones adecuadas. La longitud de las bandas cortadas es la necesaria para envolver el perímetro de la sección y disponer un solape en la dirección de la fibra de $100 \mathrm{~mm}$ (valor mínimo de longitud de solape recomendado por el fabricante). En la dirección longitudinal de la probeta se dispone una banda de tejido a continuación de otra, no es necesario el solape.

- Se mezclan los dos componentes de la resina epoxi con una batidora eléctrica a baja velocidad siguiendo las instrucciones del fabricante hasta conseguir una mezcla completamente homogénea.

- Se aplica mediante rodillo una primera capa de resina sobre la probeta de hormigón a reforzar.

- Se coloca una capa de tejido sobre la resina embebiendo el tejido en la misma y envolviendo la probeta.

- Se presiona el tejido contra el hormigón pasando un rodillo ranurado especial para impregnación en la dirección de la fibra hasta conseguir que la resina salga por los huecos del tejido de manera que éste quede impregnado y se ajuste perfectamente a la superficie del hormigón sin que queden huecos. En la zona de solape de tejido se aplica también una capa de resina (entre tejido y tejido) y se pasa el rodillo de impregnación.

- Se aplica una segunda capa de resina o capa de cierre, antes de que comience la polimerización de la primera capa. 
- En las probetas que se refuerzan con varias capas de fibra se repite el procedimiento. Los solapes se distribuyen a lo largo de la sección de manera que no coincidan en el mismo lado.

- Las probetas reforzadas se mantienen en interior a temperatura ambiente (ente 17 y $20^{\circ} \mathrm{C}$ ) durante al menos 7 días para que cure por completo la resina epoxi antes de ensayarlas.

Toda la fibra se orienta en dirección perpendicular al eje del pilar, en lo que se denomina orientación a $0^{\circ}$. Se refuerzan 12 probetas en toda su longitud con 1, 2 o 3 capas de fibra, de acuerdo con el plan de ensayos mostrado en la Tabla 4.1. Además en los extremos de cada probeta se aplica un zunchado adicional de $100 \mathrm{~mm}$ de ancho con dos capas de fibra con el fin de evitar fallos locales en las cabezas y que la rotura se produzca en la zona central. Es decir, de los $600 \mathrm{~mm}$ que tiene de alto la probeta, los $400 \mathrm{~mm}$ centrales están reforzados con $n$ capas de fibra $(n=1,2$ o 3$)$ y los $100 \mathrm{~mm}$ de cada extremo llevan $(n+2)$ capas de refuerzo.

En las probetas control de hormigón sin reforzar también se han confinado los extremos con dos capas de fibra, en este caso de $150 \mathrm{~mm}$ de anchura, quedando en la parte central de estas probetas $300 \mathrm{~mm}$ sin refuerzo (Figura 4.10).
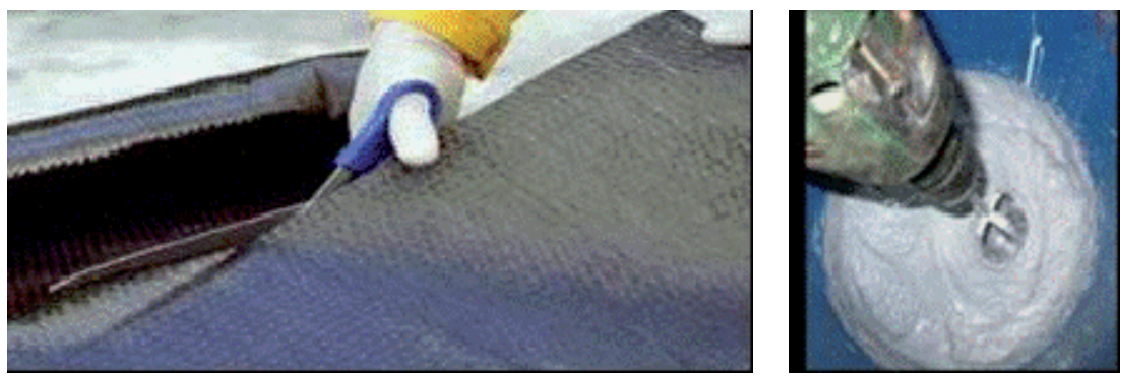

Figura 4.8 Corte de la fibra de carbono y mezclado de la resina. 

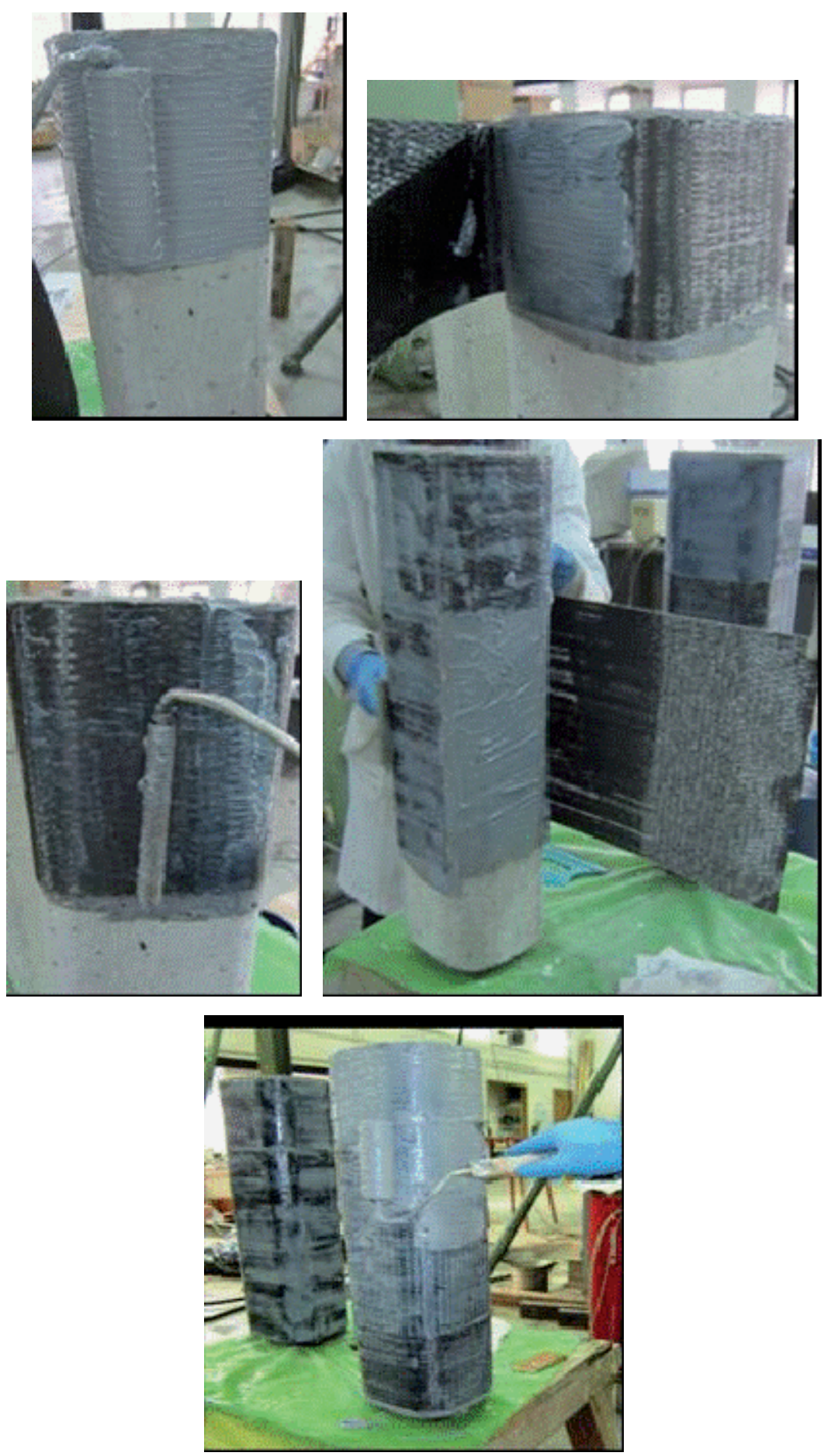

Figura 4.9 Aplicación de fibra y resina sobre la probeta mediante wrapping. 


\subsection{Instrumentación y procedimiento de ensayo.}

Las probetas se han instrumentado con el fin de medir su comportamiento tensión-deformación. En todas las probetas se ha medido la deformación axial y transversal en la zona central en las cuatro caras.

En las dos probetas de la serie 0, de hormigón sin reforzar (Figura 4.10), la deformación lateral se mide con cuatro bandas extensométricas, pegadas una en el centro de cada cara. Para medir la deformación axial en la probeta 0_a se utilizaron cuatro captadores de desplazamiento colocados en la zona central sobre una longitud de medida de $150 \mathrm{~mm}$. Sin embargo durante el ensayo, al irse dañando la probeta, tres de los captadores se desprendieron y no midieron bien, por lo que en la probeta 0_b la deformación axial se midió con cuatro bandas extensométricas en lugar de captadores. Las bandas extensométricas son de tipo PL60 de Tokyo Sokki, con una longitud de medida de $60 \mathrm{~mm}$.
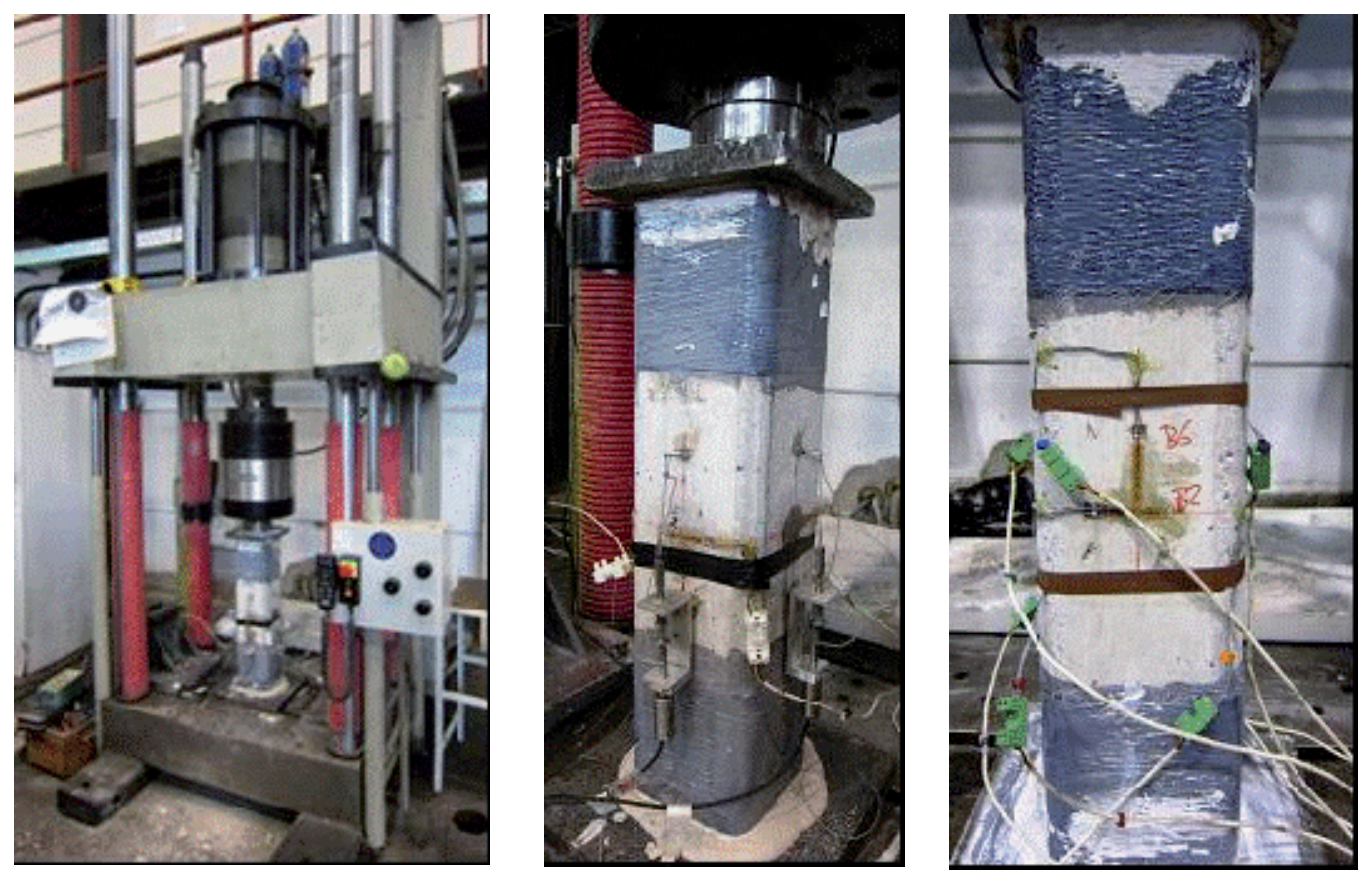

Figura 4.10 Dispositivo de ensayo e instrumentación en probetas 0_a y 0_b

En las probetas reforzadas la deformación lateral se mide también con cuatro bandas extensométricas pegadas sobre la camisa de FRP, y para la deformación axial se utilizan cuatro bandas y cuatro captadores de desplazamiento sobre una 
longitud de medida de $150 \mathrm{~mm}$ (Figura 4.11). En este caso se utilizan bandas FLA-5-5 de Tokyo Sokki, con una longitud de medida de $5 \mathrm{~mm}$.

Las lecturas de los captadores de desplazamiento y las bandas, así como de la carga aplicada, se graban de manera continua durante el ensayo.
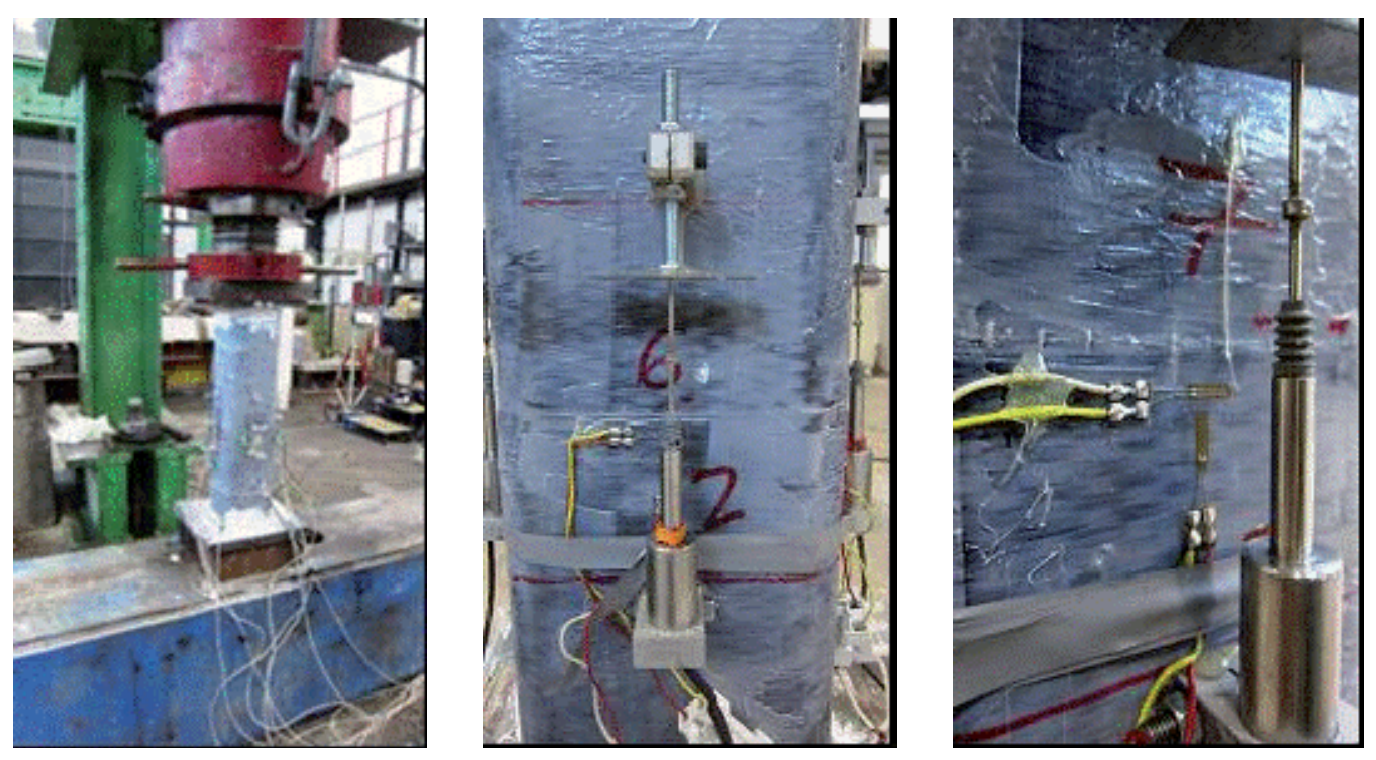

Figura 4.11 Instrumentación en probetas reforzadas

Las probetas se ensayan a compresión centrada. Las probetas sin refuerzo se han ensayado en una prensa INSTRON de $1000 \mathrm{kN}$ de capacidad de carga (Figura 4.10). Las reforzadas se ensayaron en un pórtico metálico mediante un gato hidráulico de $2700 \mathrm{kN}$ de capacidad (Figura 4.12). En ambos casos el ensayo se controla en desplazamiento con velocidad constante de aproximadamente $2 \mathrm{~mm} / \mathrm{min}$ hasta que se produce la rotura. 

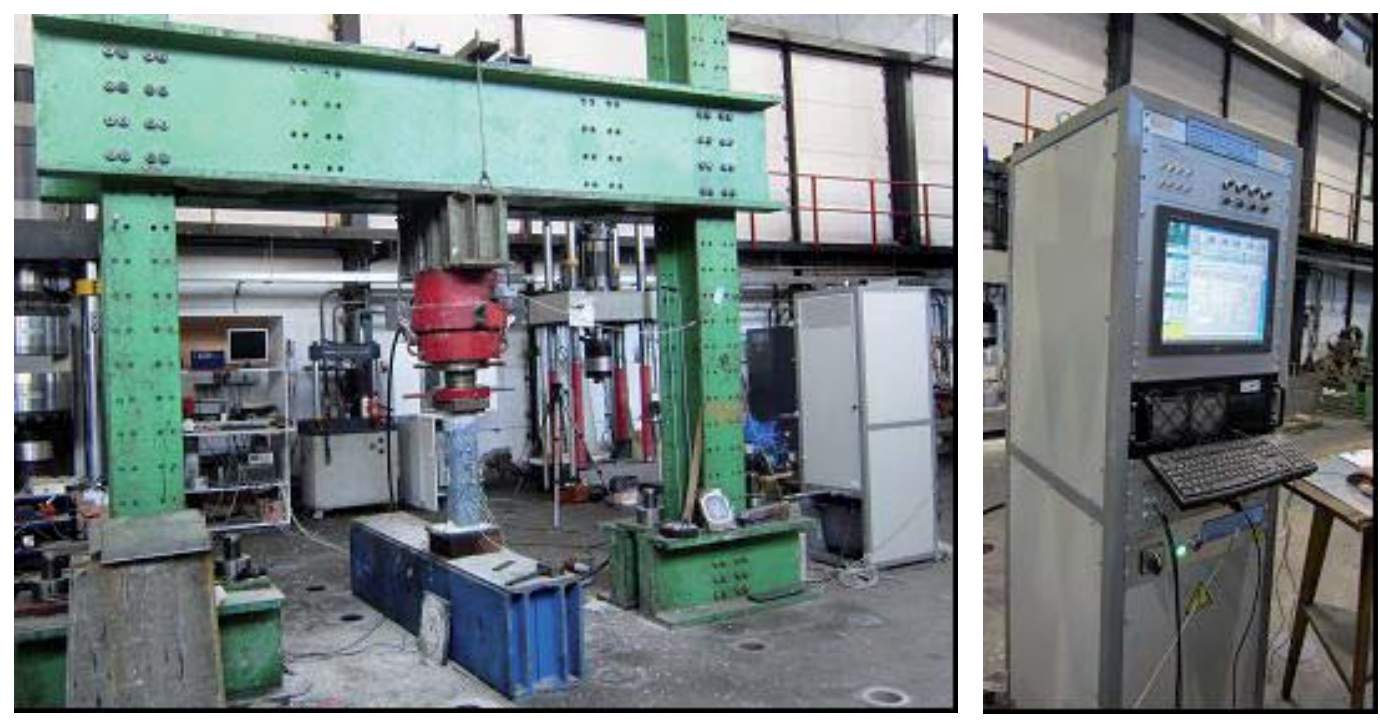

Figura 4.12 Dispositivo de ensayo de las probetas reforzadas

\subsection{Resultados}

En la Figura 4.13 (izquierda) se observa el fallo típico de las probetas patrón de la serie 0 , sin refuerzo externo de fibra (únicamente el zunchado de fibra en los extremos). Todas las probetas reforzadas fallaron debido a la rotura de la camisa de carbono (Figura 4.13 derecha).
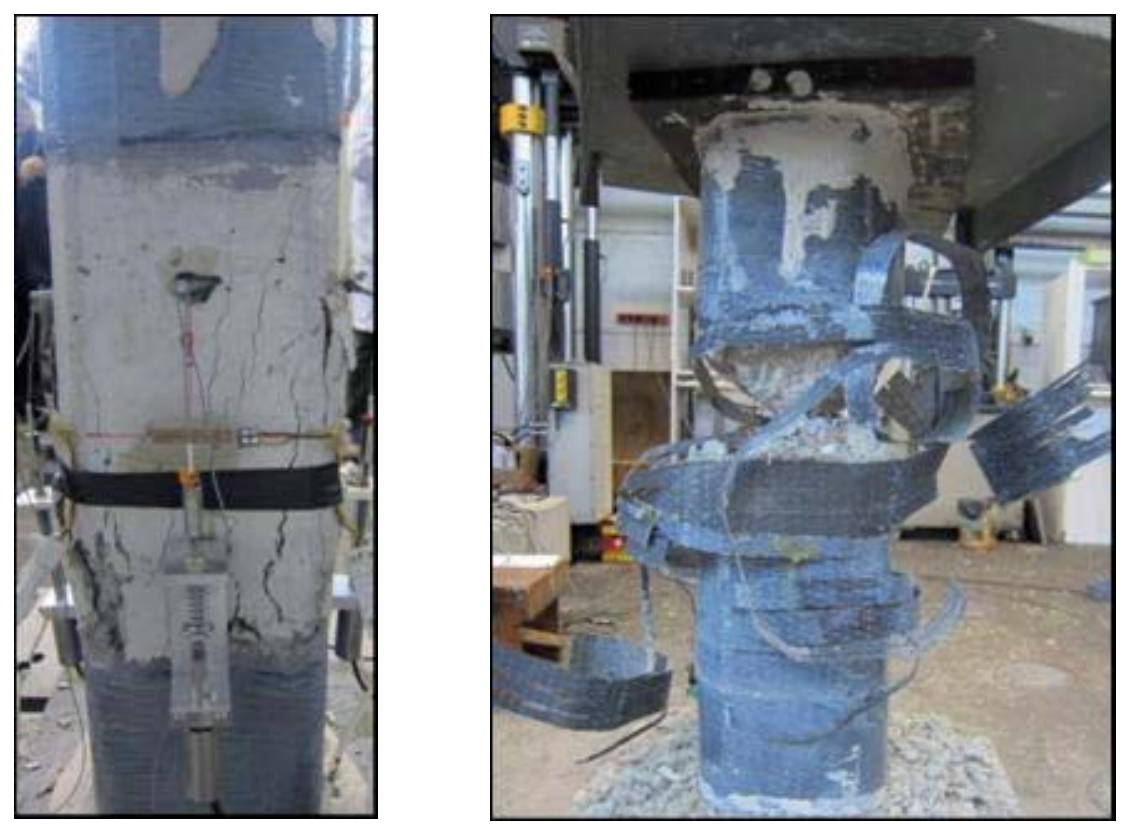

Figura 4.13 Modo de fallo típico en las probetas patrón (izquierda) y en las probetas reforzadas (derecha) 
En la Tabla 4.6 se muestra un resumen de los resultados obtenidos en los ensayos de las 14 probetas. Se indica para cada ensayo:

- La carga máxima alcanzada $Q_{m a ́ x}$

- Resistencia a compresión $f_{c c}\left(f_{c o}\right.$ en el caso de las probetas de la serie 0 sin refuerzo), calculada dividiendo la carga máxima por el área de la sección $A_{c}$.

- Máxima deformación axial de compresión $\varepsilon_{c c}\left(\varepsilon_{c o}\right.$ para las probetas sin reforzar). Es el promedio de los valores medidos en las cuatro caras.

- Deformación lateral última de las probetas reforzadas o deformación última efectiva $\varepsilon_{f u}$, es decir, deformación medida en la fibra en el momento de la rotura de la camisa. Este valor es también el promedio de las lecturas de las cuatro caras.

La deformación axial, de compresión, se representa con valores positivos, y la deformación lateral, de tracción, con valores negativos.

Tabla 4.6 Resumen de resultados experimentales

\begin{tabular}{|c|c|c|c|c|c|c|}
\hline $\begin{array}{l}N^{\circ} \text { de capas } \\
\text { de refuerzo }\end{array}$ & $R_{c}[\mathrm{~mm}]$ & Probeta & $\begin{array}{l}Q_{\operatorname{máx}} \\
{[\mathrm{kN}]}\end{array}$ & $\begin{array}{c}f_{c c} \\
{[\mathrm{MPa}]}\end{array}$ & $\varepsilon_{c c}$ & $\varepsilon_{f u}$ \\
\hline \multirow{2}{*}{0} & & 0_a & 791 & 35.72 & - & - \\
\hline & & 0_b & 782 & 35.29 & 0.002138 & - \\
\hline \multirow{4}{*}{1} & \multirow{2}{*}{20} & 1_20_a & 914 & 41.24 & 0.008077 & -0.010020 \\
\hline & & 1_20_b & 993 & 44.83 & 0.005748 & -0.009442 \\
\hline & \multirow{2}{*}{40} & 1_40_a & 1108 & 52.46 & 0.010660 & -0.013630 \\
\hline & & 1_40_b & 1088 & 51.49 & 0.007554 & -0.009526 \\
\hline \multirow{4}{*}{2} & \multirow{2}{*}{20} & 2_20_a & 1140 & 51.43 & 0.008257 & -0.008558 \\
\hline & & 2_20_b & 1306 & 58.93 & 0.019480 & -0.009110 \\
\hline & \multirow[t]{2}{*}{40} & 2_40_a & 1626 & 76.97 & 0.021137 & -0.012297 \\
\hline & & 2_40_b & 1586 & 75.08 & 0.018328 & -0.011456 \\
\hline \multirow{4}{*}{3} & \multirow{2}{*}{20} & 3_20_a & 1864 & 84.13 & 0.020885 & -0.013163 \\
\hline & & 3_20_b & 1621 & 73.17 & 0.015539 & -0.008561 \\
\hline & \multirow{2}{*}{40} & 3_40_a & 1998 & 94.59 & 0.013533 & -0.011224 \\
\hline & & 3_40_b & 1956 & 92.58 & 0.015506 & -0.010858 \\
\hline
\end{tabular}

En las gráficas de la Figura 4.14 se representan la carga de compresión aplicada frente a la deformación axial y la deformación transversal medidas en la sección 
media de la probeta. Los valores de deformación axial y transversal representados son el valor medio de las cuatro bandas extensométricas o cuatro captadores de desplazamiento situados en las cuatro caras de la sección. Únicamente en la probeta 0_b, la deformación axial representada es sólo la medida en una cara, ya que en las restantes hubo error en la medida. En cada gráfica se representan los resultados de las dos probetas iguales (a y b) que se han ensayado de cada tipo.

Durante el ensayo de algunas de las probetas (1_40_a, 2_40_b y 3_40_b), debido a problemas con los equipos de aplicación de carga, se realizó la descarga de las probetas y se cargó de nuevo. En los gráficos tensióndeformación se aprecian estos ciclos de carga-descarga, y cómo la envolvente de los mismos representa un comportamiento similar al esperado si no se hubieran producido las descargas.

En el Anejo A se muestran las gráficas con todas las medidas de bandas extensométricas y captadores de desplazamiento utilizados en los ensayos.
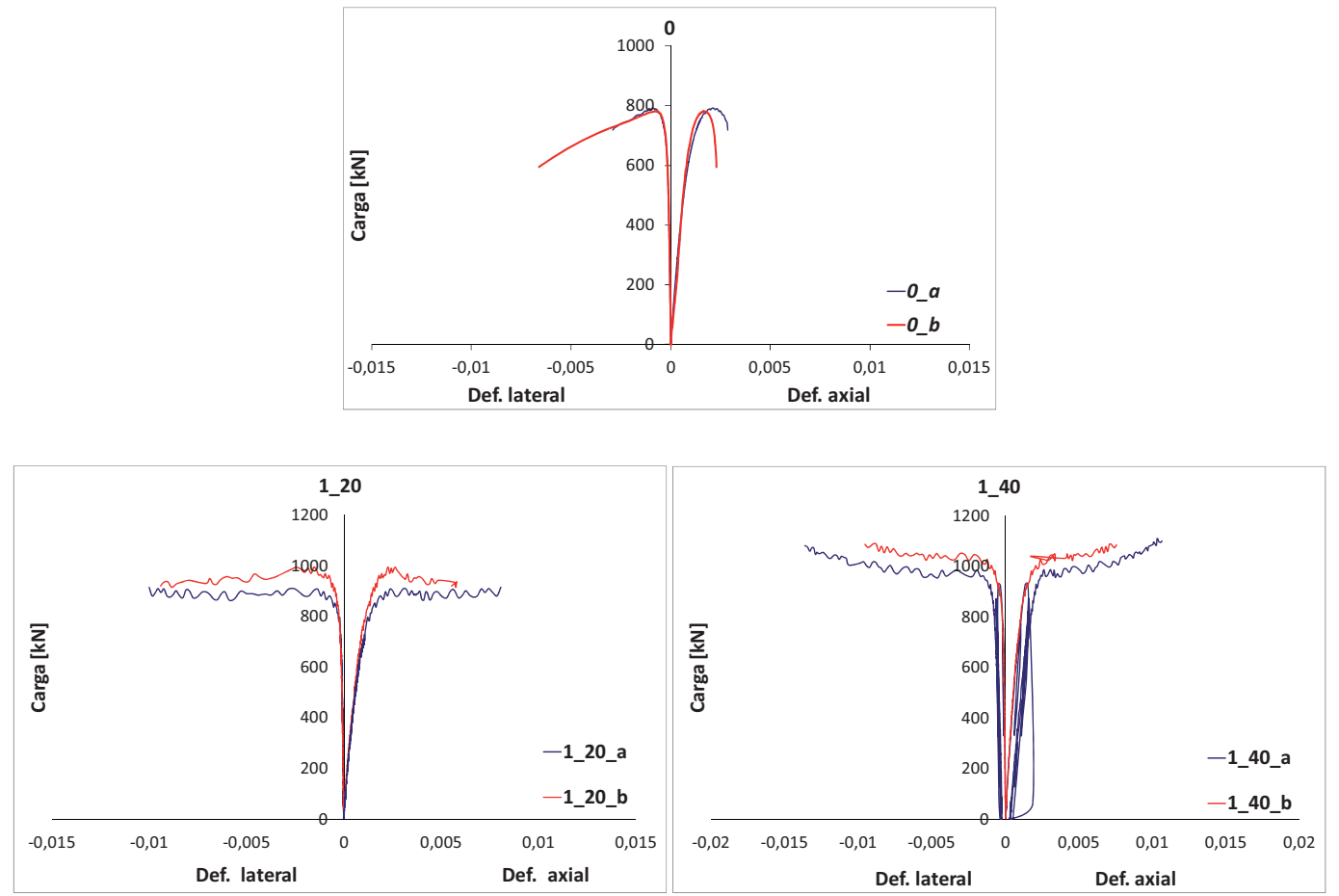

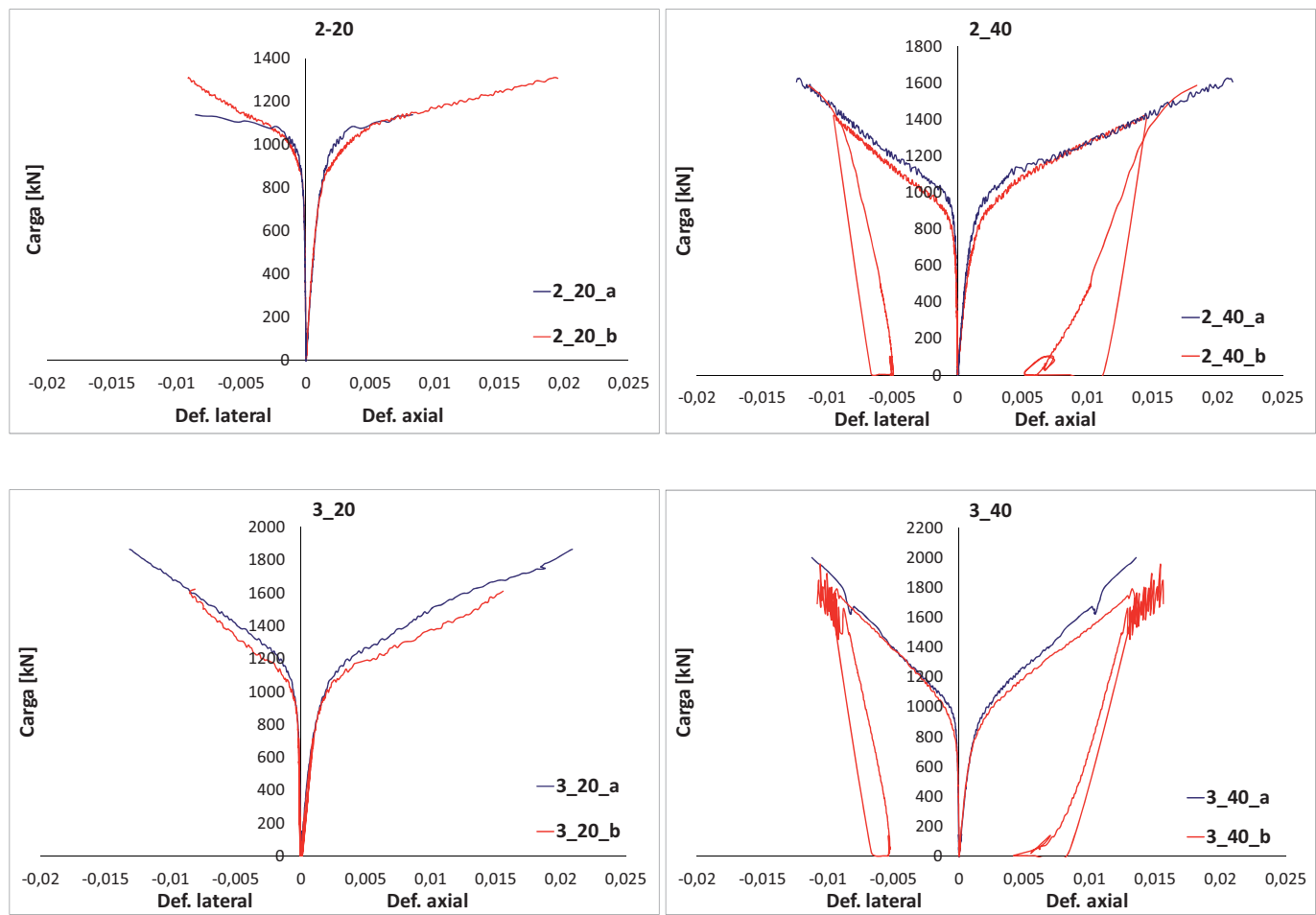

Figura 4.14 Curvas carga-deformación

\subsection{Análisis de los resultados}

\subsubsection{Modo de fallo}

En el anejo A se muestran fotografías de las roturas de todas la probetas ensayadas.

En las dos probetas patrón de la serie 0 , sin refuerzo externo de fibra, se produce el modo de fallo característico del hormigón sometido a compresión (Figura 4.15). Estas probetas se habían reforzado únicamente con un zunchado de fibra en los extremos para evitar fallos locales en los extremos. La rotura se produce en la zona central de las probetas y se inicia con fisuras aproximadamente verticales, que sólo son visibles cuando la carga es ya elevada, próxima a la de rotura. 

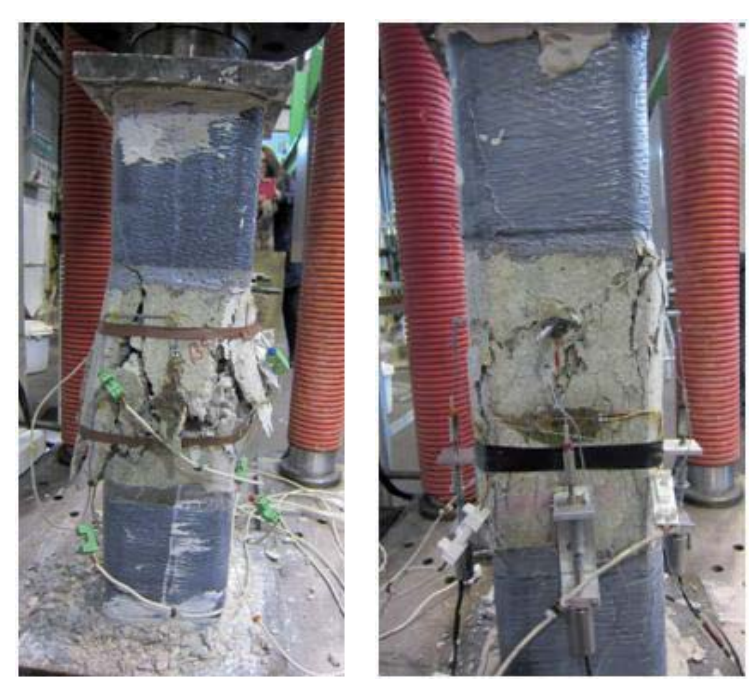

Figura 4.15 Rotura de las probetas sin reforzar $0 \_a$ y $0 \_b$

En las probetas reforzadas externamente con CFRP, el fallo se produjo por la rotura del encamisado de fibra de carbono, con frecuencia cerca de las esquinas de la sección. Hasta alcanzarse niveles de carga muy próximos a la rotura, no se observa ningún tipo de daño o deterioro en la probeta. Únicamente en los instantes previos a la rotura se oyen algunos pequeños sonidos tipo "clic" probablemente debidos a la rotura de algunas fibras y de repente se produce el fallo repentino y explosivo con rotura de la camisa en la zona central. Las probetas quedan partidas en dos trozos. En la zona central, donde rompe la camisa, el hormigón se encuentra prácticamente desecho. En los extremos, donde se habían aplicado dos capas adicionales de FRP no se observan signos de daño.

El fallo en las probetas de las series 1, 2 y 3 fue del mismo tipo, si bien al aumentar el $n^{\circ}$ de capas de refuerzo la rotura es aún más violenta. No se observan diferencias en el modo de fallo de las probetas con distinto radio de redondeo de las esquinas.

En la Figura 4.16 se muestran fotografías de la rotura de las probetas reforzadas (se muestra una probeta de cada serie). 

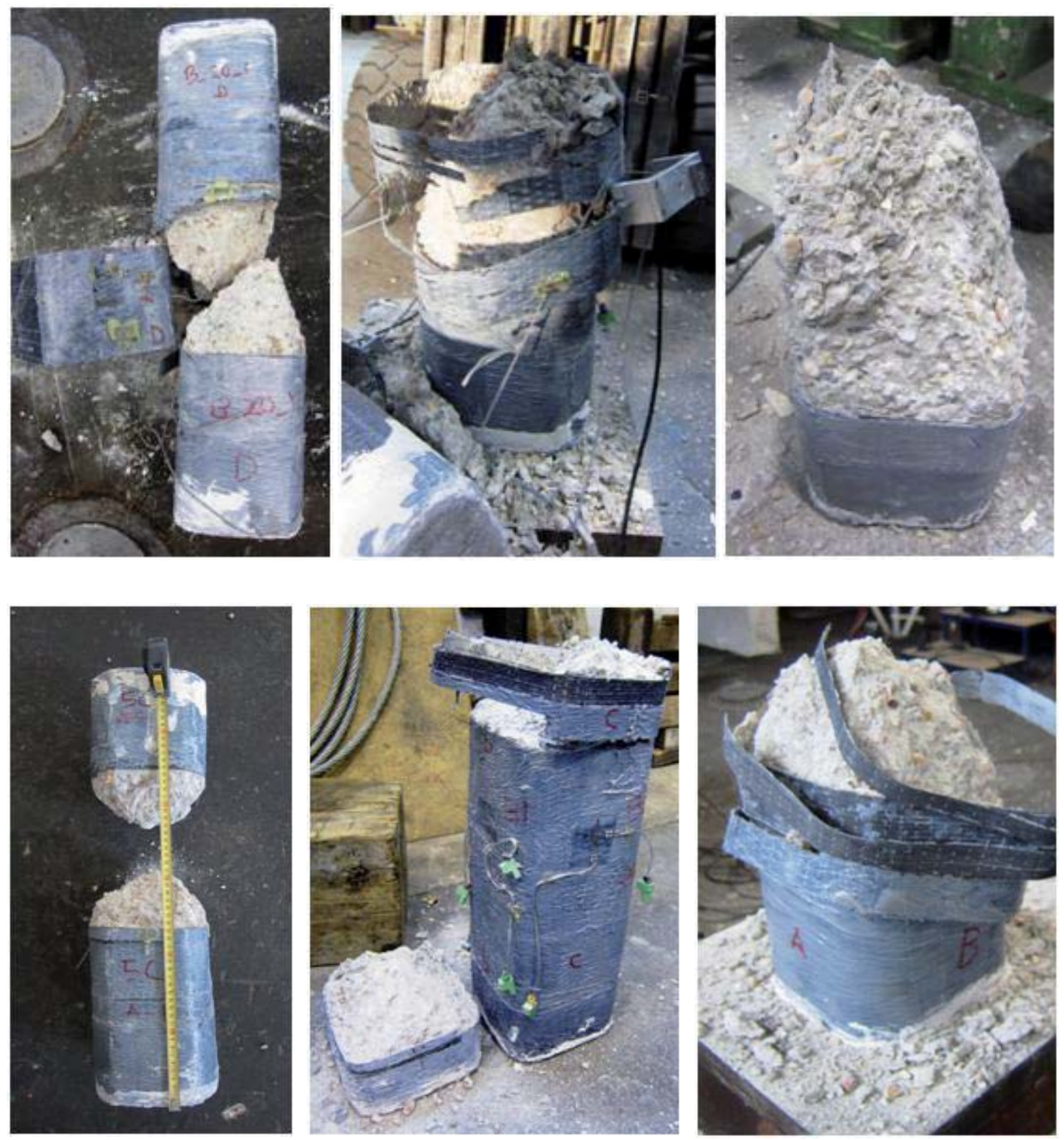

Figura 4.16 Rotura de las probetas reforzadas (1_20_b, 1_40_a, 2_20_b, 2_40_b, 3_20_b y 3_40_a)

\subsubsection{Resistencia}

En la Tabla 4.7 se indica para cada probeta reforzada, la resistencia a compresión $f_{c c}$, y su relación con la resistencia de las probetas patrón (valor medio de las dos probetas control de la serie 0 , es decir $35.5 \mathrm{MPa}$ ). Se dan los valores individuales obtenidos en cada probeta, y el valor medio de las 2 probetas iguales. Se incluye también la relación entre la resistencia de las probetas reforzadas con respecto a la resistencia del hormigón sin confinar $f_{c o}=41 \mathrm{MPa}$ obtenida en la rotura de las probetas cilíndricas normalizadas. 
Tabla 4.7 Resultados experimentales. Incremento de resistencia.

\begin{tabular}{|c|c|c|c|c|c|c|}
\hline Probeta & \multicolumn{2}{|c|}{$f_{c c} \quad[\mathrm{MPa}]$} & \multicolumn{2}{|c|}{$f_{c c} / f_{\text {patrón }}$} & \multicolumn{2}{|c|}{$f_{c c} / f_{c o}$} \\
\hline 0_a & 35.7 & \multirow{2}{*}{35.5} & 1.01 & \multirow{2}{*}{1.00} & 0.87 & \multirow{2}{*}{0.87} \\
\hline 0_b & 35.3 & & 0.99 & & 0.86 & \\
\hline 1_20_a & 41.2 & \multirow{2}{*}{43.0} & 1.16 & \multirow{2}{*}{1.21} & 1.01 & \multirow{2}{*}{1.05} \\
\hline 1_20_b & 44.8 & & 1.26 & & 1.09 & \\
\hline 1_40_a & 52.5 & \multirow{2}{*}{52.0} & 1.48 & \multirow{2}{*}{1.46} & 1.28 & \multirow{2}{*}{1.27} \\
\hline 1_40_b & 51.5 & & 1.45 & & 1.26 & \\
\hline 2_20_a & 51.4 & \multirow{2}{*}{55.2} & 1.45 & \multirow{2}{*}{1.55} & 1.25 & \multirow{2}{*}{1.30} \\
\hline 2_20_b & 58.9 & & 1.66 & & 1.35 & \\
\hline 2_40_a & 77.0 & \multirow{2}{*}{76.0} & 2.17 & \multirow{2}{*}{2.14} & 1.88 & \multirow{2}{*}{1.85} \\
\hline 2_40_b & 75.1 & & 2.11 & & 1.83 & \\
\hline 3_20_a & 84.1 & \multirow[t]{2}{*}{78.6} & 2.37 & \multirow[t]{2}{*}{2.22} & 2.05 & \multirow{2}{*}{1.92} \\
\hline 3_20_b & 73.2 & & 2.06 & & 1.78 & \\
\hline 3_40_a & 94.6 & \multirow{2}{*}{93.6} & 2.66 & \multirow{2}{*}{2.64} & 2.31 & \multirow{2}{*}{2.28} \\
\hline 3_40_b & 92.6 & & 2.61 & & 2.26 & \\
\hline
\end{tabular}

Los resultados muestran en primer lugar que el confinamiento con CFRP mejora la capacidad de carga axial en todos los casos.

El incremento relativo de resistencia que se consigue con el confinamiento aumenta con la cuantía de refuerzo y, para una cuantía dada se incrementa también con el radio de curvatura de las esquinas $R_{c}$.

Respecto a las probetas patrón sin reforzar, para el radio de curvatura de $20 \mathrm{~mm}$ el refuerzo con 1, 2 y 3 capas consigue incrementar la resistencia en un 21, 55 y $122 \%$ respectivamente (valores promedio de las dos probetas reforzadas con cada cuantía). Para el radio de curvatura de $40 \mathrm{~mm}$ los incrementos de resistencia que se consiguen son respectivamente: 46, 114 y $164 \%$. Es decir, se consigue una mejora muy notable de la resistencia al incrementar el radio de curvatura de 20 a $40 \mathrm{~mm}$. De hecho, en el caso de las probetas ensayadas, la 
mejora conseguida al aumentar $R_{c}$ de 20 a $40 \mathrm{~mm}$ equivale prácticamente a la que se consigue con una capa más de refuerzo. Tomando como referencia el valor de la resistencia del hormigón sin confinar obtenida de las probetas normalizadas $f_{c o}=41 \mathrm{MPa}$ (valor de referencia en los modelos de cálculo), en las probetas 1_20 (una capa de CFRP y $R_{c}=20 \mathrm{~mm}$ ) prácticamente no hay mejora de resistencia, mientras que bien aumentando el radio de redondeo a $40 \mathrm{~mm} o$ disponiendo una capa más de refuerzo se consiguen ya incrementos de resistencia cercanos al 30\% (probetas 1_40 y 2_20).

\subsubsection{Deformación axial}

En la Tabla 4.8 se indica la máxima deformación axial alcanzada en los ensayos $\varepsilon_{c c}$ (valor para cada probeta y promedio de las dos probetas de cada serie) y la relación entre $\varepsilon_{c c}$ y $\varepsilon_{c o}$, siendo $\varepsilon_{c o}$ la deformación en la probeta sin reforzar 0_a correspondiente a su tensión axial máxima $f_{c o}$.

Tabla 4.8 Resultados experimentales. Deformación axial última.

\begin{tabular}{|c|c|c|c|c|}
\hline Probeta & \multicolumn{2}{|c|}{$\varepsilon_{c c}$} & \multicolumn{2}{|c|}{$\varepsilon_{c d} \varepsilon_{c o}$} \\
\hline 0_a & 0.00214 & \multirow{2}{*}{0.0021} & \multirow{2}{*}{\multicolumn{2}{|c|}{ - }} \\
\hline 0_b & - & & & \\
\hline 1_20_a & 0.00808 & \multirow{2}{*}{0.0069} & 3.8 & \multirow{2}{*}{3.2} \\
\hline 1_20_b & 0.00575 & & 2.7 & \\
\hline 1_40_a & 0.01066 & \multirow{2}{*}{0.0091} & 5.0 & \multirow{2}{*}{4.3} \\
\hline 1_40_b & 0.00755 & & 3.5 & \\
\hline 2_20_a & 0.00826 & \multirow[t]{2}{*}{0.0139} & 3.9 & \multirow{2}{*}{6.5} \\
\hline 2_20_b & 0.01948 & & 9.1 & \\
\hline 2_40_a & 0.02114 & \multirow[t]{2}{*}{0.0197} & 9.9 & \multirow{2}{*}{9.2} \\
\hline 2_40_b & 0.01833 & & 8.6 & \\
\hline 3_20_a & 0.02089 & \multirow[t]{2}{*}{0.0182} & 9.8 & \multirow{2}{*}{8.5} \\
\hline 3_20_b & 0.01554 & & 7.3 & \\
\hline 3_40_a & 0.01353 & \multirow{2}{*}{0.0145} & 6.3 & \multirow{2}{*}{6.8} \\
\hline 3_40_b & 0.01551 & & 7.2 & \\
\hline
\end{tabular}


El refuerzo con FRP incrementa notablemente la deformación axial última de todas las probetas con respecto a las probetas sin reforzar. La deformación axial última $\varepsilon_{c c}$ en las probetas reforzadas con una capa oscila entre 2.7 y 5 veces el valor de $\varepsilon_{c o}$, en las probetas reforzadas con dos capas entre 3.9 y 9.9 veces $\varepsilon_{c o}$, y en las de tres capas entre 6.3 y 9.8 veces $\varepsilon_{\mathrm{co}}$. La deformación axial aumenta con el radio de curvatura para las menores cuantías, pero disminuye con la cuantía mayor (tres capas). Dado el número reducido de ensayos y la dispersión de los resultados no es posible establecer conclusiones generales en este sentido. La mayor dispersión en los resultados en los valores de deformación axial respecto a los de resistencia es habitual en los ensayos publicados en la literatura, y el ajuste de los valores de la deformación axial última con respecto a la dada en las formulaciones para el cálculo es peor.

\subsubsection{Deformación última efectiva}

En la Tabla 4.9 se dan, para todas las probetas ensayadas, los valores de deformación transversal última o deformación última efectiva, $\boldsymbol{\varepsilon}_{f u}$, es decir, la deformación de tracción medida en la fibra en el momento de la rotura de la camisa. Este valor es el promedio de las lecturas de las bandas extensométricas situadas en la sección central en las cuatro caras en el momento en que se produce el fallo de la probeta.

En todas las probetas la deformación última efectiva es muy inferior a la deformación de rotura $\left(\varepsilon_{f}=1.776 \%\right)$ obtenida en los ensayos de tracción de cupones planos realizados sobre los laminados FRP y descritos en el apartado 4.4. Este hecho se refleja en la mayoría de los estudios experimentales publicados, como se ha visto en el capítulo 2. En la Tabla 4.9 se muestra también la relación entre la deformación última efectiva y deformación última del material $\left(\varepsilon_{f u} / \varepsilon_{f}\right)$, lo que suele denominarse factor de eficiencia de la deformación $k_{\varepsilon}$. Se dan los valores de esta relación para cada probeta, que oscila entre 0.48 y 0.77 , y los valores medios de cada par de probetas iguales. Como valor medio de los doce ensayos se obtiene un factor de eficiencia de la deformación $k_{\varepsilon}=\varepsilon_{f u} / \varepsilon_{f}=0.60$. De los resultados no se desprende que la deformación última efectiva dependa de la cuantía de refuerzo. En los refuerzos con una y dos capas sí se observa que la deformación última efectiva aumenta con el radio de curvatura de las esquinas, pero sin embargo en los refuerzos con tres capas se obtuvieron valores medios similares. 
En la Tabla 4.9 se indica también el valor máximo medido por alguna de las bandas extensométricas $\varepsilon_{f m a ́ x}$ y la relación $\varepsilon_{f m a ́ x} / \varepsilon_{f}$. Al igual que se indicó en el programa experimental de la fase I, algunas bandas extensométricas en los momentos previos a la rotura miden valores superiores debido a concentraciones de tensiones locales. Si se consideran las deformaciones máximas medidas en alguna de las bandas $\varepsilon_{f m a ́ x}$, en vez del valor medio de las cuatro medidas $\varepsilon_{f u}$, el valor promedio $k_{\varepsilon}$ se elevaría a 0.72 .

Tabla 4.9 Resultados experimentales. Deformación última efectiva.

\begin{tabular}{|c|c|c|c|c|c|c|c|c|}
\hline Probeta & \multicolumn{2}{|c|}{$\varepsilon_{f u}$} & \multicolumn{2}{|c|}{$\varepsilon_{f u} / \varepsilon_{f}$} & \multicolumn{2}{|c|}{$\varepsilon_{f m a ́ x}$} & \multicolumn{2}{|c|}{$\varepsilon_{f \operatorname{máx}} / \varepsilon_{f}$} \\
\hline 1_20_a & -0.0100 & \multirow{2}{*}{-0.0097} & 0.56 & \multirow{2}{*}{0.55} & 0.0131 & \multirow{2}{*}{-0.0127} & 0.74 & \multirow{2}{*}{0.71} \\
\hline 1_20_b & -0.0094 & & 0.53 & & -0.013 & & 0.69 & \\
\hline 1_40_a & -0.0136 & \multirow{2}{*}{-0.0116} & 0.77 & \multirow{2}{*}{0.65} & -0.0161 & \multirow{2}{*}{-0.0144} & 0.91 & \multirow{2}{*}{0.81} \\
\hline 1_40_b & -0.0095 & & 0.54 & & -0.0127 & & 0.71 & \\
\hline 2_20_a & -0.0086 & \multirow{2}{*}{-0.0088} & 0.48 & \multirow{2}{*}{0.50} & -0.0101 & \multirow{2}{*}{-0.0104} & 0.57 & \multirow{2}{*}{0.59} \\
\hline 2_20_b & -0.0091 & & 0.51 & & -0.0108 & & 0.61 & \\
\hline 2_40_a & -0.0123 & \multirow[t]{2}{*}{-0.0119} & 0.69 & \multirow{2}{*}{0.67} & -0.0154 & \multirow{2}{*}{-0.0139} & 0.87 & \multirow{2}{*}{0.78} \\
\hline 2_40_b & -0.0115 & & 0.65 & & -0.0124 & & 0.70 & \\
\hline 3_20_a & -0.0132 & \multirow{2}{*}{-0.0109} & 0.74 & \multirow{2}{*}{0.61} & -0.0140 & \multirow{2}{*}{-0.0132} & 0.79 & \multirow{2}{*}{0.74} \\
\hline 3_20_b & -0.0086 & & 0.48 & & -0.0124 & & 0.70 & \\
\hline 3_40_a & -0.0112 & \multirow{2}{*}{-0.0110} & 0.63 & \multirow{2}{*}{0.62} & -0.0122 & \multirow{2}{*}{-0.0121} & 0.69 & \multirow{2}{*}{0.68} \\
\hline 3_40_b & -0.0109 & & 0.61 & & -0.0120 & & 0.68 & \\
\hline Valor medio & & & & 0.60 & & & & 0.72 \\
\hline
\end{tabular}

Como posibles causas del valor reducido de la deformación última efectiva se han señalado el estado triaxial de tensiones del FRP en las camisas, defectos de ejecución, la curvatura de las fibras y también deformación no homogénea y fisuración del hormigón. Dentro del ámbito de los parámetros de estos ensayos, y con las limitaciones derivadas del reducido número de ensayos, sí parece que el incremento del radio de redondeo de las esquinas incrementa la deformación última efectiva, para cuantías de refuerzo bajas y medias, aunque para cuantías altas no puedan establecerse conclusiones en este sentido. La deformación no homogénea de la sección de hormigón fisurada sí es una causa clara. 
Como se vio en el apartado 2.4.2.2, los valores de $k_{\varepsilon}$ en los ensayos publicados en la literatura presentan una gran dispersión, y se han publicado varios trabajos de revisión. Entre estos un reciente estudio de (Sadeghian and Fam, 2014) sobre una base de datos de 454 probetas cilíndricas, encuentra valores de $k_{\varepsilon}$ entre 1.22 y 0.12 , con un valor medio de $k_{\varepsilon}=0.67$. Otros autores (Harries and Carey, 2003, Lam and Teng, 2003b, Lam and Teng, 2004) encuentran también valores medios similares en ensayos propios y de la literatura, y con base en estas investigaciones sobre probetas de sección circular algunas guías internacionales han propuesto utilizar en el cálculo un valor de eficiencia de la deformación en torno a 0.55 o 0.6 .

El valor medio obtenido en el presente programa de ensayos $k_{\varepsilon}=0.60$ coincide con los valores propuestos en las guías, a pesar de tratarse de probetas de sección cuadrada. En la primera parte del programa experimental sobre probetas de sección cuadrada pero con hormigones de baja resistencia, presentado en el capítulo 5 , se obtuvieron valores de $k_{\varepsilon}=0.24$ para las probetas reforzadas con vidrio y $k_{\varepsilon}=0.32$ para las reforzadas con carbono. La razón para esta reducción podría estar relacionada con la baja resistencia del hormigón.

\subsubsection{Comportamiento tensión-deformación}

En la Figura 4.17 se muestran las curvas tensión axial-deformación axial y tensión axial-deformación transversal de todas las probetas ensayadas. Se observa en todas las probetas reforzadas el incremento de resistencia respecto a la probeta 0_a sin reforzar. En las probetas reforzadas con 2 y 3 capas de fibra de carbono la respuesta tensión-deformación tiene una forma aproximadamente bilineal con una segunda rama también ascendente, característica del hormigón confinado con FRP con un grado de confinamiento suficiente. No ocurre lo mismo en algunas de las probetas reforzadas con una sola capa. En las Figuras 4.18 a 4.20 se muestran de manera independiente las probetas reforzadas con una, dos y tres capas respectivamente.

En las probetas 1_20, reforzadas con una sola capa y con las esquinas redondeadas con un radio de curvatura de $20 \mathrm{~mm}$ (Figura 4.18), la segunda rama de las curvas no es ascendente. En las dos probetas de la serie 1_20 se supera ligeramente la resistencia de la probeta patrón, pero después se van incrementando las deformaciones axial y transversal sin que se incremente la carga (probeta 1_20_a) o incluso con pérdida de carga (1_20_b), lo que muestra 
que el grado de confinamiento aplicado es insuficiente para conseguir un incremento de resistencia.

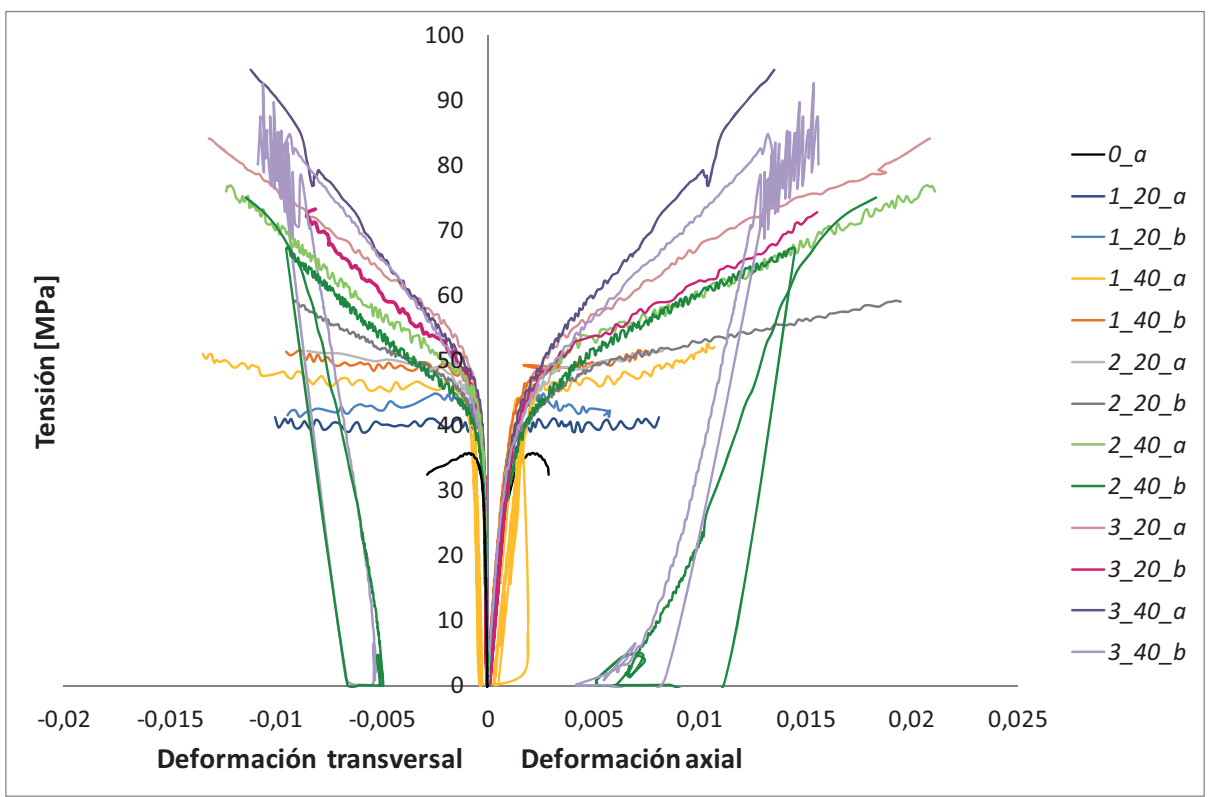

Figura 4.17 Comportamiento tensión-deformación de todas las probetas ensayadas

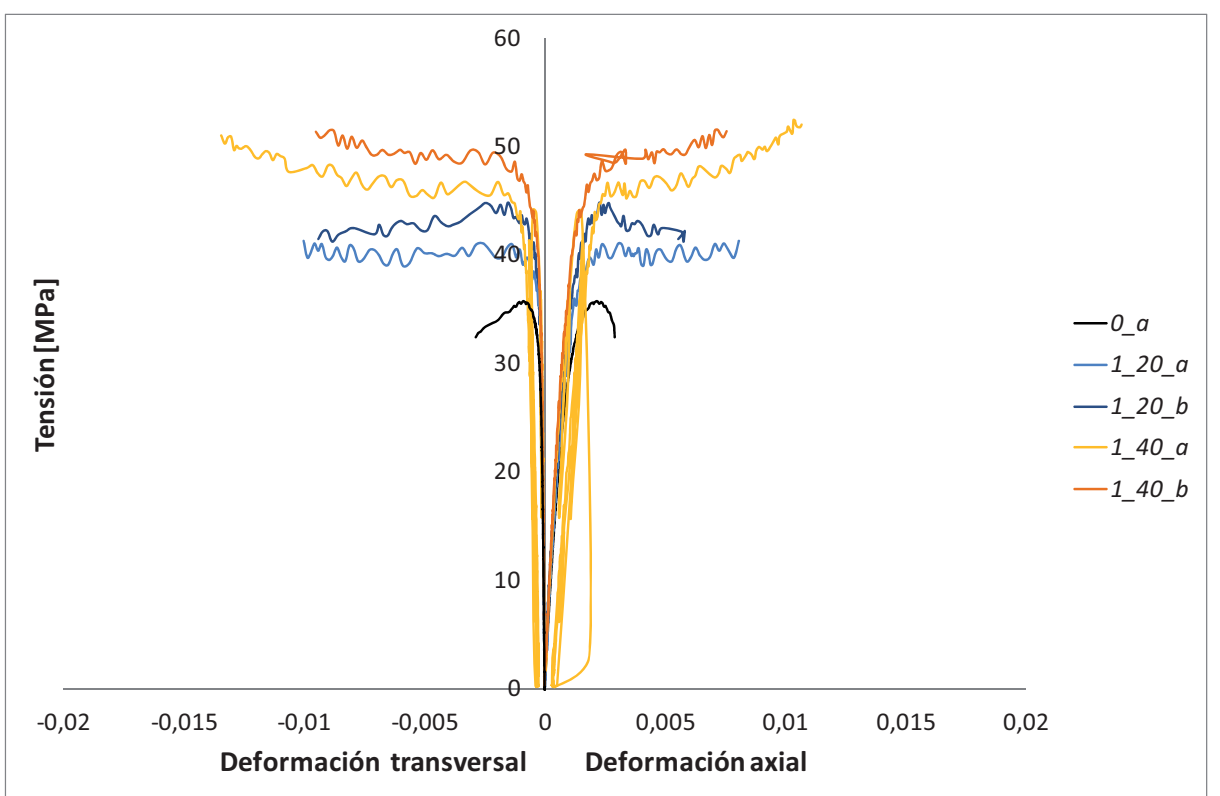

Figura 4.18 Comportamiento tensión-deformación de probetas reforzadas con una capa

En las probetas reforzadas con 1 capa pero con el radio de curvatura de $40 \mathrm{~mm}$ la segunda rama muestra una tendencia ascendente, y el incremento de resistencia respecto a la probeta patrón es mayor. Estos resultados muestran 
que ya se habría alcanzado el ratio de confinamiento mínimo para que el comportamiento sea monótono creciente.

En las probetas reforzadas con dos capas (Figura 4.19) la segunda rama es ascendente, y su pendiente es mayor en las probetas 2_40 que en las 2_20. Lo mismo ocurre en las reforzadas con tres capas (Figura 4.20). En estas figuras se observa, como ya se vio en el apartado 4.8.2 la importante mejora en el comportamiento que se consigue aumentando el radio de las esquinas para una cuantía de refuerzo dada.

Finalmente en las Figuras 4.21 y 4.22 se representan de manera separada las probetas con radio de redondeo 20 y $40 \mathrm{~mm}$ respectivamente, con el fin de apreciar el conocido incremento de la pendiente de la segunda rama de las curvas al aumentar la cuantía de refuerzo.

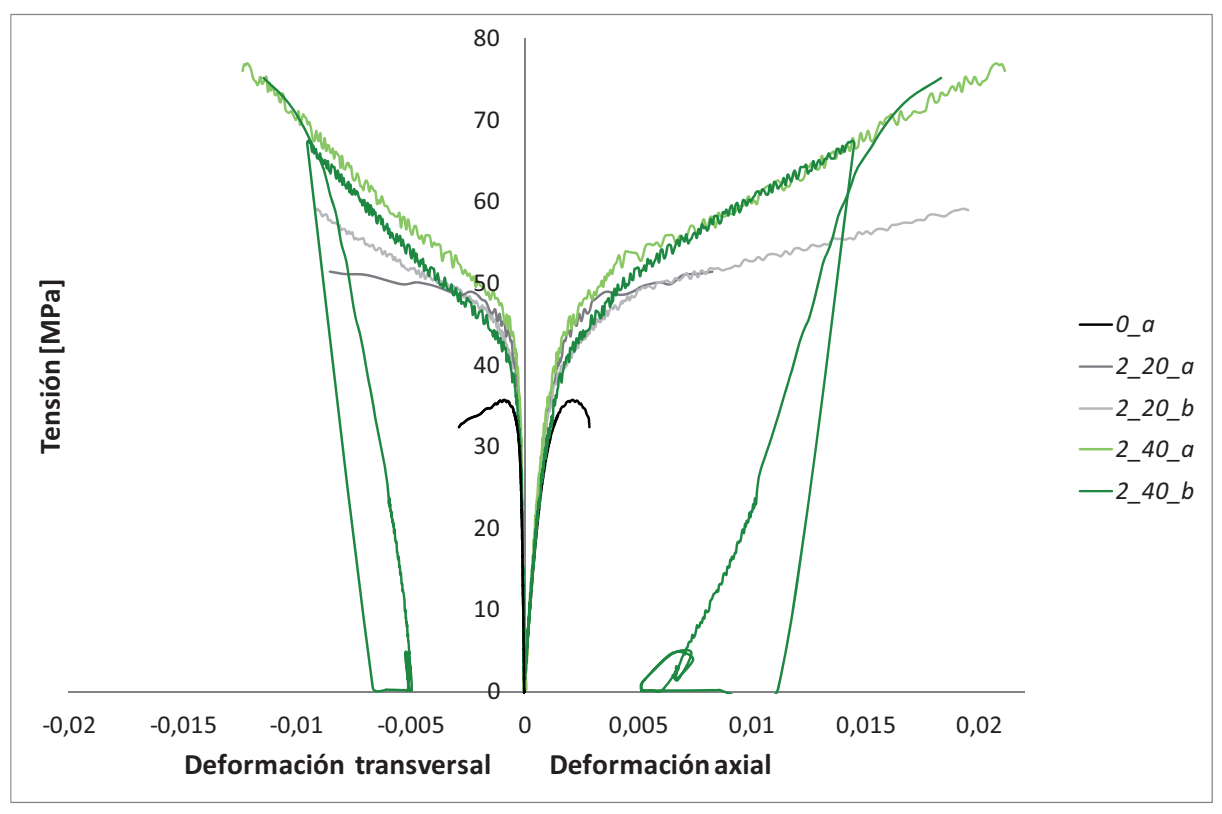

Figura 4.19 Comportamiento tensión-deformación de probetas reforzadas con dos capas 


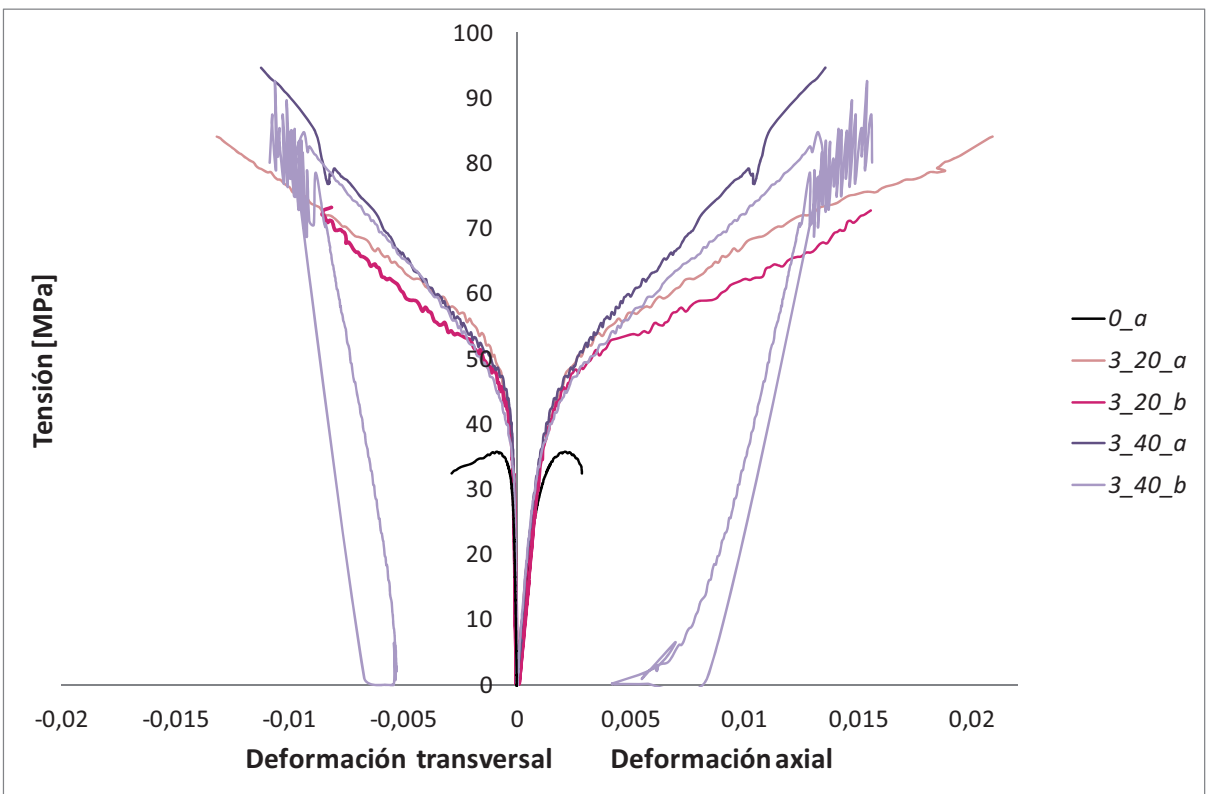

Figura 4.20 Comportamiento tensión-deformación de probetas reforzadas con tres capas

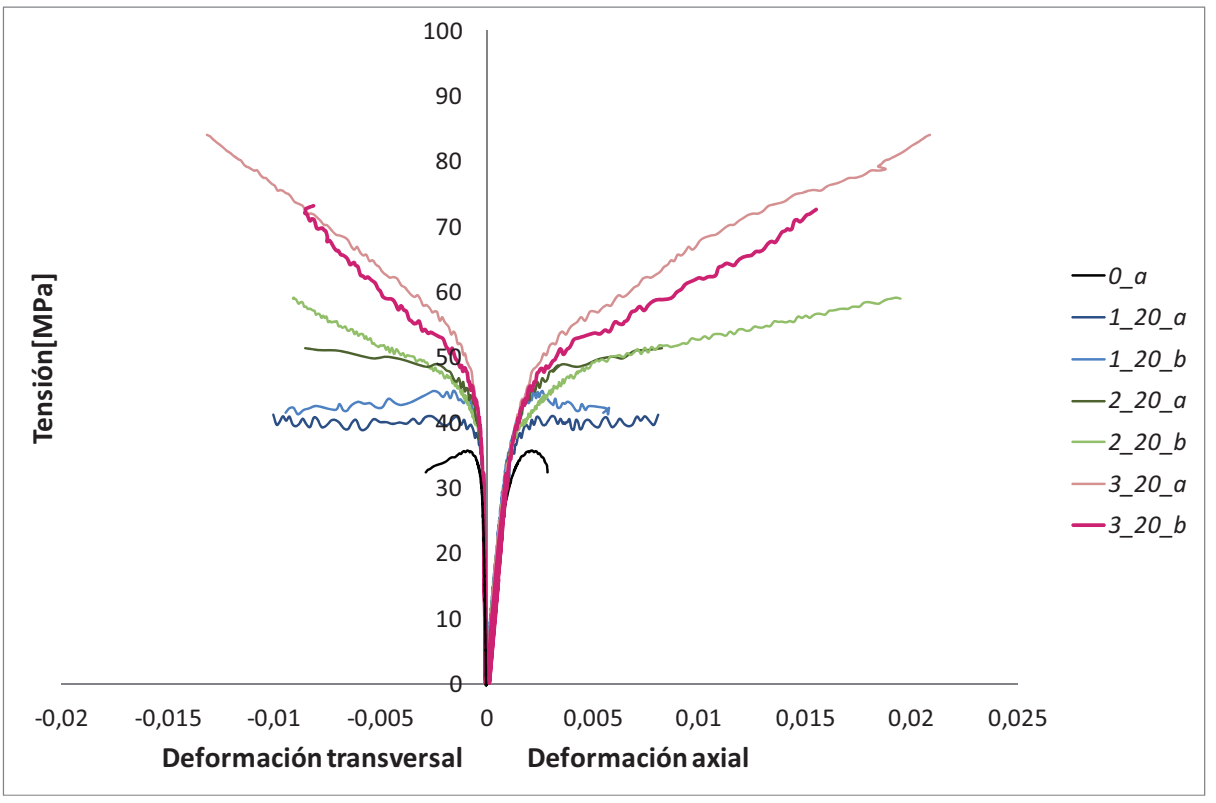

Figura 4.21 Comportamiento tensión-deformación de probetas con $R_{c}=20 \mathrm{~mm}$ 


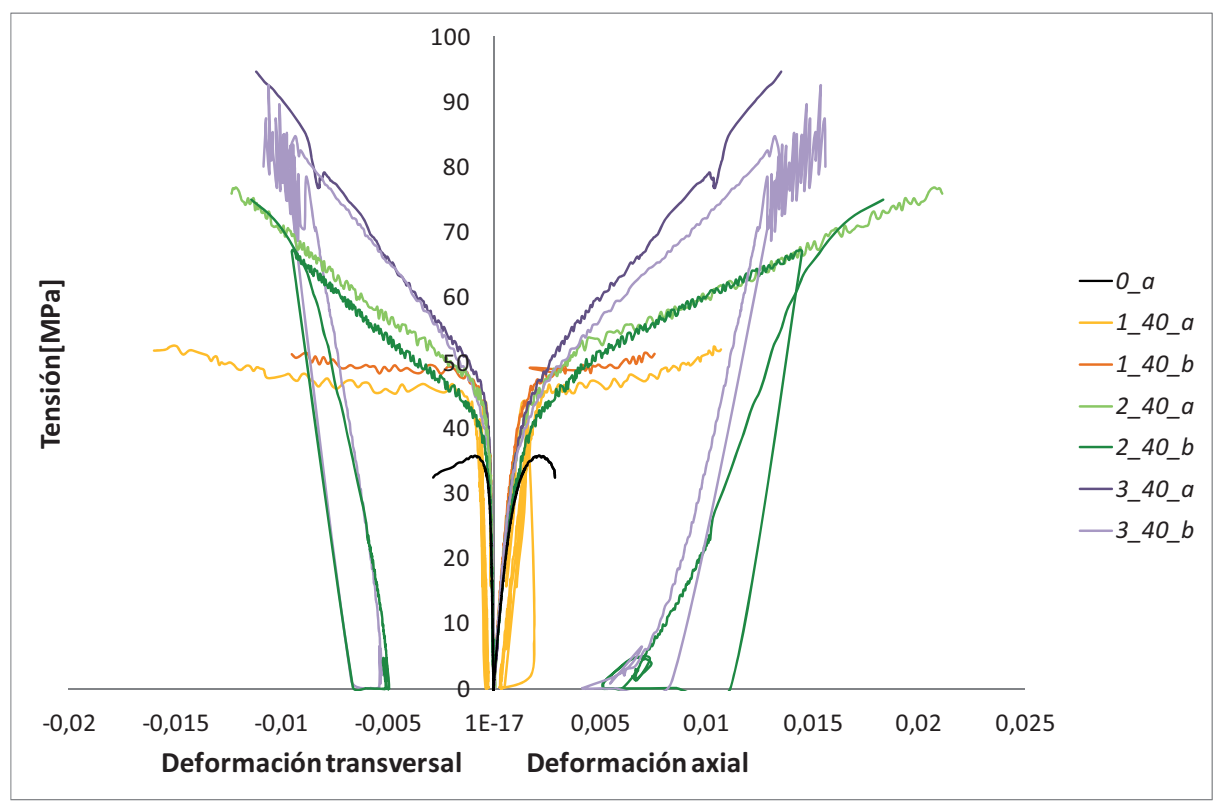

Figura 4.22 Comportamiento tensión-deformación de probetas con $R_{c}=40 \mathrm{~mm}$ 

CAPÍTULO 5

\section{ANÁLISIS DE LOS MODELOS DE CÁLCULO PROPUESTOS EN LAS GUÍAS}

\subsection{Introducción}

El confinamiento con un encamisado de FRP se ha convertido en un método habitual de refuerzo de pilares de hormigón armado en estructuras existentes como puentes o edificios. Numerosos estudios experimentales han demostrado que se trata de un modo eficaz de incrementar considerablemente la resistencia del hormigón. En los últimos años se están proponiendo también diferentes modelos teóricos y se han publicado en diversos países guías y recomendaciones con diversas ecuaciones para el cálculo.

En este capítulo se hace un análisis de los modelos propuestos en las principales guías y una comparación entre los resultados experimentales obtenidos en esta tesis y las predicciones teóricas.

Las guías de cálculo están basadas en modelos de confinamiento que a su vez se basan en resultados experimentales, con las consiguientes limitaciones. Entre estas limitaciones hay que considerar, además del escaso número de ensayos disponibles, el rango de parámetros utilizados en los ensayos, como por ejemplo la resistencia del hormigón, o el tamaño de los elementos ensayados. El objetivo es utilizar los resultados experimentales obtenidos en el presente trabajo, 
presentados en los capítulos 3 y 4 , para verificar la validez de las recomendaciones de cálculo en un rango más amplio de resistencias, incluyendo hormigón de baja resistencia.

Con el fin de comparar los distintos modelos aquí presentados se ha unificado la notación y, por tanto las expresiones dadas no coinciden exactamente con las de los documentos originales. Igualmente, para poder comparar los valores que se obtendrían de los modelos con los valores experimentales, se han hecho iguales a la unidad todos los coeficientes parciales y otros coeficientes que las guías incorporan con el fin de establecer la seguridad a largo plazo de las estructuras calculadas con cada uno de los modelos.

Evidentemente, si se utiliza cualquiera de los modelos para calcular un refuerzo, deberán tomarse para cada uno de esos coeficientes y los parámetros de los modelos los valores dados en cada guía, teniendo en cuenta que los formatos de seguridad de las distintas guías no tienen por qué ser coherentes entre sí, y por lo tanto, cada uno de estos valores deberá ser usado exclusivamente en la guía que lo define.

Los modelos existentes para el cálculo del refuerzo de pilares, incluidos los aquí presentados, son esencialmente empíricos y se admite que obtienen una seguridad adecuada cuando se usan de forma completa dentro de los casos usuales en estructuras.

\subsection{Recomendaciones y guías de cálculo}

Se han revisado los siguientes documentos:

- fib Bulletin 14 (fib, 2001): Externally bonded FRP reinforcement for RC structures

- $\mathrm{ACl}$ 440.2R-08 (ACl-440.2R-08, 2008): Guide for the design and construction of externally bonded FRP systems for strengthening concrete structures

- CNR-DT200 R1/2013 (CNR-DT200_R1, 2013): Guide for the Design and Construction of Externally Bonded FRP Systems for Strengthening Existing Structures

- Concrete Society TR55 (TR55, 2012): Design Guidance for strengthening concrete structures using fibre composite materials 


\subsection{1. fib Bulletin 14 (2001) (fib, 2001)}

Se trata de un documento técnico desarrollado por un grupo de trabajo de la Fédération Internationale du Béton (fib), que puede considerarse una combinación de guía de cálculo y recopilación del estado del arte. De las cuatro guías analizadas, es la más antigua, y hay que tener en cuenta que cuando se publicó, en el año 2001, los estudios experimentales y teóricos llevados a cabo eran bastante limitados. Las otras tres guías analizadas han ido publicando revisiones a medida que avanzaba el estado del conocimiento sobre el refuerzo de estructuras con FRP.

\subsubsection{Diagrama tensión-deformación y ratio de confinamiento mínimo}

En el fib Bulletin 14 se citan varios modelos de confinamiento que intentan tener en cuenta el comportamiento específico del FRP: Spoelstra y Monti (Spoelstra and Monti, 1999), Saafi et al. (Saafi et al., 1999) y Samaan et al. (Samaan et al., 1998).

Destacan el modelo de Spoelstra y Monti como el más versátil y exacto a pesar de su complejidad indicando que una mayor verificación experimental sería bienvenida. Dicho modelo, como se ha visto con más detalle en el apartado 2.4.3.1, está orientado al análisis, y parte del modelo de Mander (Mander et al., 1988) para hormigón confinado con acero, combinándolo con un modelo que expresa la deformación circunferencial en función de la deformación axial para tener en cuenta el comportamiento específico del FRP. Se obtiene así la curva tensión-deformación completa, que puede considerarse como una curva que cruza a una familia de curvas de Mander, cada una perteneciente al nivel de presión de confinamiento correspondiente a la deformación lateral en cada momento, mientras que la tensión y deformación últimas pueden obtenerse de la presión de confinamiento ejercida por la camisa en el momento último.

El fib Bulletin 14 indica que existen casos en los que, para pequeñas cantidades de refuerzo de FRP o baja eficiencia (secciones cuadradas o rectangulares, confinamiento parcial) el comportamiento tensión-deformación puede presentar una rama post-pico descendente, resultando que la presión de confinamiento produce un incremento de resistencia despreciable. No se indica explícitamente cuál sería el ratio de confinamiento mínimo para evitar este comportamiento. 


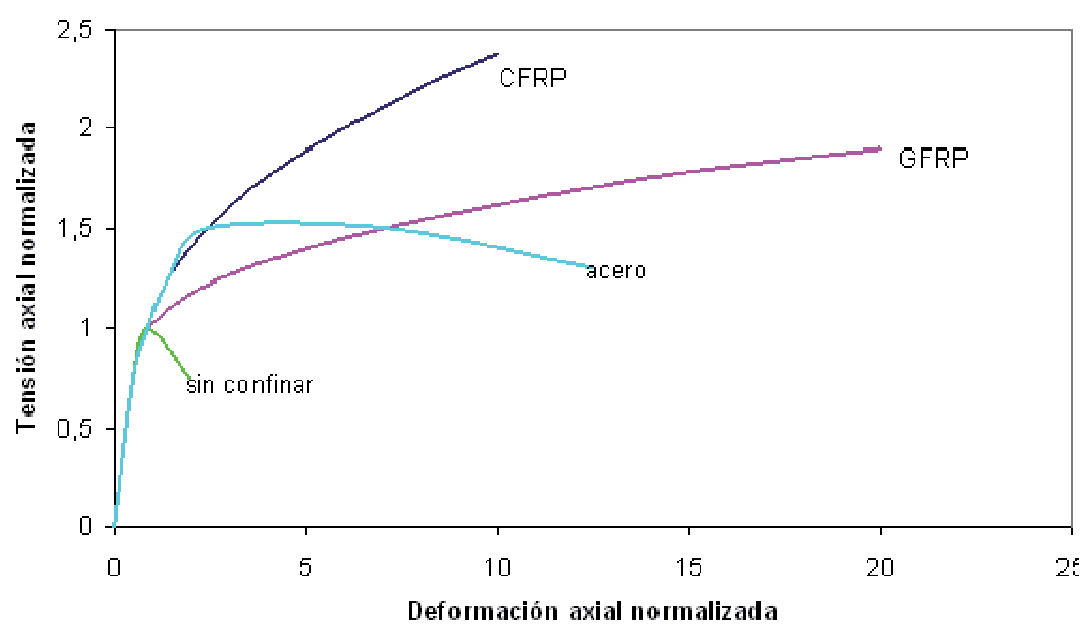

Figura 5.1 Diagrama tensión-deformación según modelo de Spoelstra y Monti

\subsubsection{Resistencia y deformación última}

Spoelstra y Monti proponen dos conjuntos de ecuaciones para el cálculo de la resistencia y deformación axial última: unas fórmulas "exactas" y unas fórmulas "aproximadas", como se ha visto en el apartado 2.4.3.1. Las primeras requieren el cálculo previo de los parámetros $f_{c c}$ y $\boldsymbol{\varepsilon}_{c c}$ de la curva tensión-deformación de Mander y el módulo secante de elasticidad en el momento último $E_{\text {sec,u. Las }}$ segundas son expresiones aproximadas, más adecuadas para el cálculo, basadas en un análisis de regresión de los resultados del modelo, y requieren únicamente el cálculo previo de la presión de confinamiento $f_{l}$.

La presión de confinamiento se obtiene a partir de la cuantía geométrica de refuerzo, y el módulo y la deformación última efectiva del FRP, según se vio en el apartado 2.4.2:

$$
f_{l}=\frac{1}{2} \rho_{f} E_{f} \varepsilon_{f u}
$$

En el análisis comparativo que se realiza a continuación se consideran únicamente las fórmulas aproximadas, según las cuales la tensión y deformación últimas del hormigón confinado $\left(f_{c c}, \varepsilon_{c c}\right)$ se obtienen a partir de los valores sin confinamiento $\left(f_{c o}, \varepsilon_{c o}\right)$, la presión de confinamiento $f_{l}$, la deformación última efectiva del FRP $\varepsilon_{f u}$ y el módulo del hormigón $E_{c}$ : 


$$
\begin{array}{r}
f_{c c}=f_{c o} \cdot\left(0,2+3 \sqrt{f_{l} / f_{c o}}\right) \\
\varepsilon_{c c}=\varepsilon_{c o} \cdot\left(2+1.25 \frac{E_{c}}{f_{c o}} \varepsilon_{f u} \sqrt{f_{l} / f_{c o}}\right)
\end{array}
$$

\subsubsection{Deformación última efectiva del FRP}

Además el fib 14 señala que la deformación de rotura de la camisa de FRP, basada en evidencias experimentales, es menor que la deformación última obtenida en ensayos a tracción del material. La guía indica que esta reducción es debida a varios factores como son la calidad de ejecución (fibras no alineadas perfectamente o preparación de la superficie no adecuada), el efecto de tamaño cuando se aplican varias capas, el efecto de aplicar el material en esquinas con reducidos radios de curvatura, y el estado combinado de tensiones a que se ve sometido el FRP. Debido a la falta de datos sobre estos efectos el documento no propone factores reductores apropiados pero dice que los valores utilizados en el cálculo deben estar justificados experimentalmente.

\subsubsection{Secciones rectangulares}

En cuanto al confinamiento de secciones cuadradas o rectangulares, se propone un coeficiente reductor $\alpha_{e}$ por el que ha de multiplicarse $f_{l}$ para obtener la presión de confinamiento efectiva. Este coeficiente es el basado en el efecto arco que considera que solamente el área de hormigón contenida por las cuatro parábolas de segundo grado que cortan a los lados a $45^{\circ}$ está plenamente confinada, mientras que en el resto de la sección el confinamiento es despreciable. $\alpha_{e}$ se obtiene como la relación entre el área confinada y el área total de hormigón (Figura 5.2):

$$
\alpha_{e}=\frac{A_{e}}{A_{c}}=1-\frac{b^{\prime 2}+d^{\prime 2}}{3 A_{g}\left(1-\rho_{s g}\right)}
$$

siendo $b y$ y $d^{\prime}$ la distancia entre dos esquinas redondeadas $\left(b^{\prime}=b-2 R_{c} ; d^{\prime}=d-2 R_{c}\right)$ y $\rho_{s g}$ la cuantía de acero longitudinal. Además de aumentar la efectividad del confinamiento, el redondeo de las esquinas de la sección antes de aplicar la fibra es necesario para evitar la rotura prematura de las mismas. Se indica un radio de 
redondeo mínimo de entre 15 y $25 \mathrm{~mm}$, dependiendo de las especificaciones dadas por el proveedor del FRP.

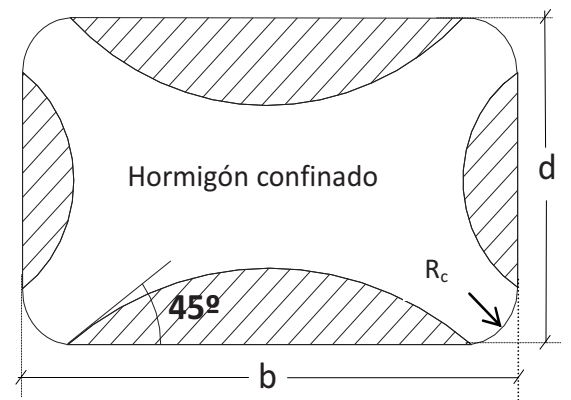

Figura 5.2 Área efectivamente confinada en secciones rectangulares

\subsection{2. $\mathrm{ACl} 440.2 \mathrm{R}-08$ (2008)(ACl-440.2R-08, 2008)}

El Comité 440 del American Concrete Institute ( $\mathrm{ACl}$ ) publicó la primera edición de la guía en el año 2002, y en el año 2008 una revisión del documento. En esta segunda edición se revisó el capítulo de confinamiento adoptándose con modificaciones mínimas el modelo orientado al cálculo propuesto por Lam y Teng publicado en el año 2003 (Lam and Teng, 2003b) y expuesto en el apartado 2.4.3.2.

En cuanto al tratamiento de las secciones rectangulares, proponen el modelo para secciones rectangulares de los mismos autores (Lam and Teng, 2003a). Cabe indicar que la edición del año 2002 de la guía no daba recomendaciones, indicando que las aplicaciones en secciones rectangulares debían evaluarse cuidadosamente ya que el confinamiento no se consideraba efectivo para incrementar la resistencia axial aunque sí para mejorar la ductilidad.

\subsubsection{Diagrama tensión-deformación y ratio de confinamiento mínimo}

Adopta el modelo de Lam y Teng (2003) en el cual la curva tensión-deformación está formada por dos partes: inicialmente una rama parabólica, similar al hormigón sin confinar, seguida de una línea recta cuya pendiente depende del nivel de confinamiento. La pendiente inicial de la rama parabólica es la misma que la del hormigón sin confinar. La parábola y la línea recta se encuentran con la misma pendiente, y la proyección de la línea recta corta al eje de la tensión axial en el valor correspondiente a la resistencia del hormigón sin confinar $f_{c o}$, como se ha mostrado en la Figura 2.31. 
Los valores de la tensión axial última $f_{c c}$ y la deformación axial de compresión última $\varepsilon_{c c}$ definen el punto final de la curva y la pendiente de la rama ascendente del modelo.

En cuanto al nivel mínimo de confinamiento que debe aplicarse, la guía indica un ratio mínimo de confinamiento $f_{l} / f_{c o}$ de 0.08 .

\subsubsection{Resistencia y deformación última}

La resistencia del hormigón confinado se calcula según la ecuación propuesta por Lam y Teng (2003) en la que el comité añade un coeficiente reductor adicional $\psi_{f}=0.95$.

$$
f_{c c}=f_{c o}+\psi_{f} 3.3 \kappa_{a} f_{l}
$$

Se indica también que la mejora de resistencia en elementos con una resistencia del hormigón sin confinar de $70 \mathrm{MPa}$ o superior no se ha verificado experimentalmente.

La máxima deformación de compresión en el hormigón confinado $\left(\varepsilon_{c c}\right)$ puede evaluarse mediante la ecuación [5.6], y en cualquier caso debe limitarse al valor de 0.01 para prevenir una fisuración excesiva del hormigón. En los casos en que este límite sea aplicable el valor correspondiente de $f_{c c}$ debería recalcularse utilizando la curva tensión-deformación.

$$
\frac{\varepsilon_{c c}}{\varepsilon_{c o}}=1.50+12 \kappa_{b} \frac{f_{l}}{f_{c o}}\left(\frac{\varepsilon_{f u}}{\varepsilon_{c o}}\right)^{0.45}
$$

La guía señala que bajo cargas de servicio debe evitarse la fisuración del hormigón limitando la tensión de compresión en el hormigón a $0.65 f_{c 0}$, y la tensión en la armadura de acero longitudinal a $0.60 f_{y}$.

\subsubsection{Deformación última efectiva del FRP}

La deformación última efectiva del FRP viene dada por:

$$
\varepsilon_{f u}=k_{\varepsilon} \varepsilon_{f}
$$

Donde $\varepsilon_{j}$ es la deformación de rotura del FRP y $k_{\varepsilon}$ es el coeficiente de eficiencia de la deformación, para el que la guía adopta un valor de 0.55 , que tiene en 
cuenta el fallo prematuro del FRP. Este comportamiento también puede estar relacionado con la concentración de tensiones en algunas zonas como consecuencia de la fisuración del hormigón.

En elementos sometidos a una combinación de compresión axial y momento flector, la deformación efectiva en el FRP debe limitarse además a un valor máximo de 0.004 para asegurar la integridad del hormigón frente a esfuerzo cortante.

\subsubsection{Secciones rectangulares}

$\kappa_{a}$ y $\kappa_{b}$ en las ecuaciones [5.5] y [5.6] son coeficientes relativos a la forma de la sección y son igual a 1 en el caso de secciones circulares, mientras que en cuadradas o rectangulares se obtienen en función de la fracción de área efectivamente confinada $A_{e} / A_{c}$ y de la relación entre los lados:

$$
\begin{aligned}
\kappa_{a} & =\left(\frac{d}{b}\right)^{2} \cdot \frac{A_{e}}{A_{c}} \\
\kappa_{b} & =\sqrt{\frac{b}{d}} \cdot \frac{A_{e}}{A_{c}}
\end{aligned}
$$

En el caso de secciones cuadradas el valor de ambos factores es igual a la relación entre el área efectivamente confinada y el área total de la sección de hormigón. Para calcularlo proponen una modificación al coeficiente comúnmente utilizado basado en que el área confinada es aquella encerrada por las parábolas que cortan a los lados con una pendiente de $45^{\circ}$. En su lugar se consideran las parábolas que cortan a los lados de la sección con una pendiente igual a la de la diagonal adyacente (Figura 2.32):

$$
\frac{A_{e}}{A_{C}}=\frac{1-\frac{\left[\left(\frac{d}{b}\right)\left(b-2 R_{c}\right)^{2}+\left(\frac{b}{d}\right)\left(d-2 R_{c}\right)^{2}\right]}{3 A_{g}}-\rho_{s g}}{1-\rho_{s g}}
$$

En secciones cuadradas o rectangulares el valor de $f_{l}$ se calcularía como la máxima presión de confinamiento ejercida por la camisa sobre una sección circular equivalente de diámetro igual a la diagonal de la sección (Figura 2.32).

La guía limita estas recomendaciones de cálculo en secciones rectangulares a los casos en que la relación de lados $b / d$ sea menor o igual a 2 , y que ninguno 
de los lados sea mayor de $900 \mathrm{~mm}$, a no ser que se demuestre su efectividad mediante ensayos.

\subsubsection{CNR-DT $200 \mathrm{R} 1 / 2013$}

Se trata también de la segunda edición de la guía elaborada en Italia por el Consiglio Nazionale delle Ricerche (CNR), aunque en el tema de confinamiento introduce pocas novedades respecto al documento inicial que publicó en el año 2004.

\subsubsection{Diagrama tensión-deformación y ratio de confinamiento mínimo}

Incluyen a igual que la guía de $\mathrm{ACl}$ el diagrama simplificado formado por un tramo parabólico y uno lineal (Figura 2.31).

Para que el confinamiento sea efectivo debe superarse un ratio de confinamiento mínimo que establece en $f_{l} / f_{c o}$ mayor de 0.05 , siendo $f_{l}$ la presión de confinamiento efectiva tal y como se define más adelante.

\subsubsection{Resistencia y deformación última}

El documento CNR-DT 200 R1/2013 propone calcular el incremento de resistencia del hormigón confinado mediante:

$$
\frac{f_{c c}}{f_{c o}}=1+2,6\left(\frac{f_{l}}{f_{c o}}\right)^{2 / 3}
$$

En la ecuación anterior $f_{l}$ es la presión de confinamiento efectiva, que es función de la forma de la sección transversal y de la configuración del refuerzo de FRP según la siguiente ecuación:

$$
f_{l}=k_{e f f} \frac{1}{2} \rho_{f} E_{f} \varepsilon_{f u}
$$

donde $k_{\text {eff }}$ es un coeficiente de eficiencia (menor o igual a 1) definido como la relación entre el volumen de hormigón efectivamente confinado y el volumen total de hormigón del elemento.

El coeficiente de eficiencia $k_{\text {eff }}$ viene dado por:

$$
k_{e f f}=\alpha_{e} k_{V} k_{\propto}
$$


Donde $\alpha_{e}$ es el factor de forma que depende de la sección transversal del elemento (ver apartado 5.2.3.4).

$k_{V}$ es el coeficiente que depende de la configuración vertical del FRP, siendo igual a 1 si el FRP envuelve al pilar de manera continua en toda su longitud, y para el caso de refuerzo discontinuo como el del esquema de la Figura 5.3 vendría dado por:

$$
k_{V}=\left(1-\frac{s^{\prime}}{2 d_{\min }}\right)^{2}
$$

Siendo $d_{\min }$ la dimensión menor de la sección transversal del pilar.

En el caso de refuerzo discontinuo, la distancia entre bandas de refuerzo debe cumplir la limitación $s^{\prime} \leq d_{\min } / 2$.

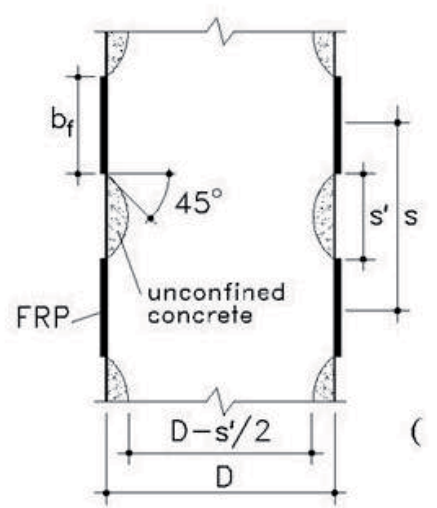

Figura 5.3 Vista en alzado de un elemento circular con refuerzo discontinuo con bandas de FRP

El coeficiente $k_{\alpha}$ es un coeficiente reductor para el caso de que el refuerzo se aplique en forma de espiral con un ángulo $\alpha_{f}$ respecto a la sección transversal del elemento y viene dado por:

$$
k_{\alpha}=\frac{1}{1+\left(\tan \alpha_{f}\right)^{2}}
$$

En cualquier caso el documento indica que un confinamiento adecuado se logra sólo disponiendo las fibras a $0^{\circ}$, y que si se dispone la fibra en espiral, su efectividad debe evaluarse cuidadosamente. 
Respecto a la deformación última la guía indica que en elementos sometidos a carga axial y momento flector la capacidad de carga axial se mejorará muy levemente pero sí habrá una mejora de la ductilidad, pudiéndose estimar la deformación axial última del hormigón confinado mediante:

$$
\varepsilon_{c c}=0,0035+0,015 \sqrt{\frac{f_{l}}{f_{c o}}}
$$

\subsubsection{Deformación última efectiva del FRP}

Para el cálculo de la resistencia según la ecuación [5.11], la presión de confinamiento efectiva $f_{l}$ debe calcularse suponiendo una deformación última efectiva del FRP dada por:

$$
\varepsilon_{f u}=\min \left\{\eta_{a} \cdot \frac{\varepsilon_{f}}{\gamma_{f}} ; 0,004\right\}
$$

En la ecuación [5.16] $f_{l}$ se calcula suponiendo una deformación última efectiva del FRP dada por:

$$
\varepsilon_{f u}=\eta_{a} \cdot \frac{\varepsilon_{f}}{\gamma_{f}} \leq 0.6 \cdot \varepsilon_{f}
$$

\section{Donde}

- $\eta_{a}$ es un coeficiente que depende del modo de aplicación y de la exposición del refuerzo, y para el caso habitual de refuerzos con carbono/epoxi es igual a 0,85.

- $\gamma_{f}$ es un coeficiente parcial que para el caso de confinamiento la guía establece en 1,10 .

La limitación de la deformación del FRP al 4 por mil se establece para evitar una fisuración excesiva en el hormigón, ya que si el núcleo de hormigón pierde su cohesión, dado que el encamisado de FRP es flexible, el pilar sería prácticamente incapaz de soportar esfuerzos transversales. Para los sistemas de refuerzo habituales con fibra de carbono resulta más limitante este valor de 0,004 . 


\subsubsection{Secciones rectangulares}

El tratamiento de las secciones rectangulares es similar al del fib Bulletin 14. Debe considerarse una presión de confinamiento efectiva que se obtiene multiplicando $f_{l}$ por un factor reductor de forma $\alpha_{e}$ basado en el efecto arco (ecuación [5.4]). La cuantía volumétrica de FRP a considerar en el cálculo de la presión de confinamiento en el caso de un pilar de sección rectangular de lados $b$ y $d$ envuelto en toda su longitud, vendrá dada por:

$$
\rho_{f}=\frac{2 t(b+d)}{b d}
$$

Debe realizarse el redondeo de las esquinas con un radio mínimo $R_{c m i n}=20 \mathrm{~mm}$, y en los casos en que la relación de lados $b / d$ sea mayor que 2 , o alguno de ellos sea mayor de $900 \mathrm{~mm}$, no se recomienda el refuerzo con materiales compuestos salvo que se asegure su efectividad mediante la disposición de las armaduras o con ensayos adecuados.

\subsubsection{Concrete Society TR55}

Se analiza a continuación la tercera edición de la guía TR55, publicada en el año 2012 por la Concrete Society en el Reino Unido. EI TR55 fue una de las primeras guías de cálculo disponibles, ya que su primera edición es del año 2000.

\subsubsection{Diagrama tensión-deformación y ratio de confinamiento mínimo}

Al igual que en la guías de $\mathrm{ACl}$ y $\mathrm{CNR}$, se propone el modelo tensión deformación de Lam y Teng debido a que es sencillo y representa el comportamiento observado en el hormigón confinado con FRP, habiendo sido verificado con datos experimentales.

Se indica que dicho modelo es válido sólo para un nivel mínimo de confinamiento, que definen a través de un ratio de rigidez adimensional $\rho_{k}$ :

$$
\rho_{k}=\frac{2 E_{f} t_{f}}{\left(f_{c o} / \varepsilon_{c o}\right) D} \geq 0,01
$$




\subsubsection{Resistencia y deformación última}

Para calcular la resistencia y deformación última del hormigón confinado en pilares circulares proponen unas ecuaciones basadas en un modelo más reciente de Teng (Teng et al., 2009).

Para pilares circulares en compresión centrada la resistencia se calcula según:

$$
\frac{f_{c c}}{f_{c o}}=1+5,25\left(\rho_{k}-0,01\right) \frac{\varepsilon_{f u}}{\varepsilon_{c o}} \quad \text { con } \quad \rho_{k} \geq 0,01
$$

La condición $\rho_{k} \geq 0,01$ establece un confinamiento mínimo para que en la curva tensión-deformación la segunda rama no sea descendente. Por tanto, cuando se cumple esta condición la tensión máxima se alcanza junto con la deformación de rotura. Cuando la rigidez del confinamiento es baja, para $\rho_{\kappa}<0,01$, la ecuación anterior no es válida para el cálculo.

Para calcular la deformación última de compresión proponen también una ecuación empírica desarrollada por Teng et al.:

$$
\frac{\varepsilon_{c c}}{\varepsilon_{c o}}=1.75+6.5 \rho_{k}^{0.8} \rho_{\varepsilon}^{1.45}
$$

El término 1,75 de la ecuación asegura que para el caso de que no haya confinamiento el valor de $\varepsilon_{\mathrm{cc}}$ converge a 0,0035 (este es el valor de la deformación última para el hormigón sin confinar según el EN 1992 (CEN, 2004) para hormigones de resistencia menor de $50 \mathrm{MPa}$ ). Esta ecuación se ajusta a los datos experimentales disponibles con una precisión razonable aunque generalmente hay una mayor dispersión en los resultados de ensayos que en el caso de la resistencia.

Sin embargo la guía llama la atención sobre el hecho de que para deformaciones de compresión del hormigón de aproximadamente 0.01 , el hormigón se habrá fisurado y perdido cohesión, por lo que podría producirse el fallo por cortante. Se recomienda por lo tanto que si la deformación última $\varepsilon_{c c}$ es mayor de 0.01, entonces la tensión de rotura $f_{c c}$ debería tomarse como el valor de $f_{c}$ correspondiente al valor de deformación $\varepsilon_{c}=0.01$ de la curva tensión deformación, en lugar de la tensión correspondiente a la tensión de rotura del FRP. 


\subsubsection{Deformación última efectiva del FRP}

La guía también indica que se ha demostrado que la deformación de rotura de la camisa de FRP es menor que la deformación obtenida en ensayos de tracción pura del FRP. Señala un número de posibles razones, como el estado biaxial de tensiones, la discontinuidad de tensiones en la zona de solape y concentraciones de tensiones debido a la fractura del hormigón. Proponen un valor del coeficiente de eficiencia de la deformación para secciones circulares del $60 \%$, a partir de las observaciones de resultados experimentales recopilados en Lam y Teng. Así, la deformación última efectiva se obtiene como

$$
\varepsilon_{f u}=0,6 \varepsilon_{f}
$$

Un aspecto importante es que, a diferencia de los documentos anteriores, el TR55 limita aún más el valor de deformación última efectiva a considerar en el cálculo de secciones rectangulares. Mientras que para secciones circulares propone un coeficiente de eficiencia de la deformación de 0.6 , para secciones rectangulares con las esquinas redondeadas este coeficiente disminuye al hacerlo la relación entre el radio de curvatura y el lado mayor de la sección. Suponiendo un coeficiente de 0.6 para secciones circulares $\left(2 R_{c} / b=1\right)$ y un valor mínimo de 0.14 cuando las esquinas no se redondean, proponen en secciones rectangulares obtener el coeficiente de eficiencia de la deformación mediante la siguiente expresión (Barrington, 2011), en la que $b$ es la longitud del lado mayor de la sección y $R_{c}$ el radio de redondeo de las esquinas:

$$
k_{\varepsilon}=0,46\left(\frac{2 R_{c}}{b}\right)+0,14
$$

\subsubsection{Secciones rectangulares}

El tratamiento de las secciones rectangulares en el TR55 difiere del resto de guías.

Por una parte limita aún más el valor de deformación última efectiva a considerar en el cálculo de secciones rectangulares, haciéndolo depender de la relación $2 R_{c} / b$, como se ha visto en el apartado anterior.

Por otra parte, más que definir explícitamente un área efectivamente confinada, como en otros modelos, supone una presión de confinamiento media obteniendo el siguiente factor de efectividad: 


$$
\alpha_{e}=\frac{R_{c}}{d}\left(1+\frac{d}{b}\right)
$$

Y propone calcular la resistencia en secciones rectangulares mediante:

$$
\frac{f_{c c}}{f_{c o}}=1+5.25\left(\alpha_{e} \rho_{k}-0.01\right) \frac{\varepsilon_{f u}}{\varepsilon_{c o}} \quad \text { con } \quad \rho_{k} \geq \frac{0.01}{k_{H}}
$$

siendo en este caso:

$$
\rho_{k}=\frac{E_{f} t}{\left(f_{c o} / \varepsilon_{c o}\right) R_{c}}
$$

Respecto a la deformación axial última recomiendan un valor máximo $\varepsilon_{c c, \max }=$ 0.01 , debido a la falta de modelos teóricos para predecir $\varepsilon_{c c}$ en pilares rectangulares. Señalan que este valor es inferior a los que se han obtenido en la práctica, pero es un límite que mantiene la integridad del hormigón.

Recomienda también limitar el uso de confinamiento con FRP en secciones rectangulares a los casos en que la relación entre los lados $b / d$ sea menor o igual que 1/1.5, y redondear las esquinas con un radio de curvatura mínimo de $20 \mathrm{~mm}$.

\subsubsection{Resumen comparativo de las guías}

Al comparar las 4 guías analizadas, se aprecia cierto consenso en el modelo tensión-deformación del hormigón confinado con FRP. Tres de las guías ( $\mathrm{ACl}$ CNR y TR55) proponen, siempre que exista un nivel de confinamiento suficiente, un modelo simplificado formado por un tramo parabólico y uno lineal, similar al modelo de Lam y Teng (Lam and Teng, 2003b).

Sin embargo, para el cálculo de la resistencia y deformación última del hormigón confinado con FRP, que son los parámetros más importantes desde el punto de vista del cálculo, todas las recomendaciones analizadas proponen ecuaciones distintas (Tabla 5.1). Estos dos parámetros $f_{c c}$ y $\varepsilon_{c c}$ definen además el punto último del diagrama tensión-deformación (Figura 2.31) y la pendiente de la rama lineal teniendo una importancia clave en el ajuste entre las curvas tensióndeformación experimentales y el modelo. 
Tabla 5.1 Ecuaciones para el cálculo de la resistencia y deformación última en las guías.

\begin{tabular}{|c|c|c|}
\hline Guía & Cálculo de $f_{c c}$ & Cálculo de $\varepsilon_{C C}$ \\
\hline fib Bulletin 14 & $f_{c c}=f_{c o} \cdot\left(0,2+3 \sqrt{f_{l} / f_{c o}}\right)$ & $\varepsilon_{c c}=\varepsilon_{c o} \cdot\left(2+1.25 \frac{E_{c}}{f_{c o}} \varepsilon_{f u} \sqrt{f_{l} / f_{c o}}\right)$ \\
\hline$A C l$ 440.2R-08 & $f_{c c}=f_{c o}+\psi_{f} 3.3 \kappa_{a} f_{l}$ & $\frac{\varepsilon_{c c}}{\varepsilon_{c o}}=1.50+12 \kappa_{b} \frac{f_{l}}{f_{c o}}\left(\frac{\varepsilon_{f u}}{\varepsilon_{c o}}\right)^{0.45}$ \\
\hline $\begin{array}{c}\text { CNR-DT } 200 \\
\quad R 1 / 2013\end{array}$ & $\frac{f_{c c}}{f_{c o}}=1+2.6 \cdot\left(\frac{f_{l}}{f_{c o}}\right)^{2 / 3}$ & $\varepsilon_{c c}=0,0035+0,015 \sqrt{\frac{f_{l}}{f_{c o}}}$ \\
\hline TR55 & $\begin{array}{l}\text { Circulares } \\
\qquad \frac{f_{c c}}{f_{c o}}=1+5,25\left(\rho_{k}-0,01\right) \frac{\varepsilon_{f u}}{\varepsilon_{c o}} \\
\text { Rectangulares } \\
\frac{f_{c c}}{f_{c o}}=1+5.25\left(\alpha_{e} \rho_{k}-0.01\right) \frac{\varepsilon_{f u}}{\varepsilon_{c o}}\end{array}$ & $\begin{array}{l}\text { Circulares } \\
\frac{\varepsilon_{c c}}{\varepsilon_{c o}}=1.75+6.5 \rho_{k}^{0.8} \rho_{\varepsilon}^{1.45} \\
\text { Rectangulares } \\
\qquad \varepsilon_{c c, \max }=0.01\end{array}$ \\
\hline
\end{tabular}

También difiere el tratamiento que se hace en las guías de los dos aspectos clave que determinan el comportamiento del hormigón confinado con FRP: la deformación última efectiva del FRP y el efecto de la forma de la sección.

El fib Bulletin 14, el documento más antiguo de los analizados (año 2001), ya llamaba la atención sobre el hecho comprobado experimentalmente de que las probetas confinadas con FRP rompían por rotura de la fibra, para un valor de tensión (o deformación) inferior al que se obtiene si ensayamos a tracción laminados de FRP. Sin embargo, debido a la falta de datos proponía justificar experimentalmente los valores utilizados en el cálculo. Basándose en una recopilación de datos experimentales llevada a cabo por Lam y Teng, en el documento de $\mathrm{ACl}$ sí se propone ya un valor para este coeficiente reductor de la deformación igual a 0,55. El CNR-DT 200/2004 limita la deformación última efectiva del FRP a un valor de 0.004, aunque la razón para esta limitación es evitar una fisuración excesiva en el hormigón. Finalmente el TR55, la recomendación más reciente, propone utilizar un coeficiente reductor de 0.6, también basado en los trabajos de Lam y Teng, pero sólo para secciones 
circulares. Para secciones rectangulares reduce aún más este coeficiente en función del radio de redondeo y del lado mayor de la sección, resultando valores en torno a 0,2 para los casos habituales

En resumen, las guías analizadas recomiendan para el cálculo del refuerzo considerar una deformación última en el FRP que oscila entre el 20 y el $60 \%$ de la deformación de rotura que se obtiene en ensayos de tracción del material. Llama la atención que a pesar de su importancia en el cálculo, es uno de los aspectos peor resueltos por los modelos, y en los que se hace necesario continuar la investigación.

Respecto al tratamiento de las secciones rectangulares, todas las recomendaciones señalan una reducción de la eficacia del confinamiento respecto a las circulares así como la necesidad de redondear las esquinas. Los documentos de la fib y la CNR proponen en el cálculo introducir un factor de forma $\alpha_{e}$ igual al que se utiliza en el caso de los cercos de acero basado en que sólo se supone confinada una parte de la sección (Figura 5.2). El ACl tiene un planteamiento similar, de manera que para secciones cuadradas el coeficiente es el mismo pero lo modifica ligeramente en secciones rectangulares (Figura 2.32). EI TR55 propone un factor de forma diferente, dado por la ecuación 5.24, y una limitación mayor de la deformación última efectiva (ecuación 5.23).

$\mathrm{ACl}$ y CNR limitan sus recomendaciones, salvo que se demuestre su efectividad, a secciones en los que el lado mayor no supere $900 \mathrm{~mm}$, y la relación entre los lados no sea mayor de 2. El TR55 limita la relación entre los lados a 1,5. En CNR y TR55 se indica un radio de redondeo mínimo de las esquinas de $20 \mathrm{~mm}$, mientras que en el fib se indica $15-25 \mathrm{~mm}$ sujeto a las especificaciones del fabricante del FRP.

Como se ha visto en el Capítulo 2, además de estas formulaciones incluidas en las recomendaciones de cálculo, se han publicado en los últimos años muchas otras, y aún siguen proponiéndose nuevos modelos. La mayor parte son ecuaciones basadas en resultados experimentales de probetas de sección circular por lo que en términos generales, cuando se comparan con una base de datos extensa recopilada de la literatura, se ajustan mejor los modelos más actuales. En este sentido pueden consultarse en la literatura algunos trabajos que comparan las predicciones de diferentes guías y modelos de cálculo con resultados experimentales de probetas circulares [(De Lorenzis and Tepfers, 2003, Chaallal, 2006). Estos estudios llaman la atención sobre la gran dispersión 
existente en los resultados experimentales, y encuentran un ajuste razonable de algunas formulaciones en la predicción de la resistencia. No ocurre lo mismo en la predicción de la deformación última del hormigón, donde las diferencias son mucho mayores.

Los resultados experimentales sobre secciones no circulares son bastante más escasos. A continuación se realiza una comparación entre los resultados experimentales propios, presentados en los capítulos 3 y 4 de esta tesis doctoral y las predicciones teóricas según las guías.

\subsection{Comparación con los resultados experimentales}

En la Tabla 5.2 se indican los valores de resistencia y deformación axial última obtenidos en los ensayos junto con las estimaciones según las guías de cálculo. Los valores experimentales son el promedio de las 2 o tres probetas ensayadas de cada tipo. Se incluyen las dos partes del programa experimental:

- la parte I, con hormigones de baja resistencia reforzados con carbono o vidrio. Estas probetas se designan con la letra C (carbono) o G (vidrio) seguida del valor de la resistencia $f_{c o}$ en MPa.

- la parte II, con hormigones de resistencia media $\left(f_{\mathrm{co}}=41 \mathrm{MPa}\right)$ reforzados con fibra de carbono. En esta fase las variables son el número de capas y el radio de redondeo de las esquinas. La nomenclatura de las probetas indica el número de capas de refuerzo seguido del radio de curvatura en $\mathrm{mm}$.

En el cálculo de las predicciones según las guías se han tenido en cuenta las siguientes consideraciones:

- El fib Bulletin 14 no da un valor para el coeficiente de eficiencia de la deformación $k_{\varepsilon}$, pero sí dice que el valor adoptado debe justificarse experimentalmente. Se ha adoptado $k_{\varepsilon}=0.6$, ya que es el valor más aceptado, obtenido por varios investigadores a partir de bases de datos de ensayos de la literatura.

- En la estimación de la resistencia según $\mathrm{ACl}$ (ecuación [5.5]) se ha tomado $\psi_{f}=1$. 
- La estimación de la deformación última según $\mathrm{ACl}$ se ha obtenido con la ecuación [5.6] sin tener en cuenta el valor máximo de $\varepsilon_{c c}=0.01$, ya que esta limitación se establece para prevenir una fisuración excesiva del hormigón.

- Por la misma razón en la estimación de la resistencia según CNR no se ha considerado la limitación de la deformación última efectiva al 4 \% y en su lugar se ha adoptado $\varepsilon_{f u}=0.6 \varepsilon_{f}$.

- La deformación última del hormigón confinado $\varepsilon_{C c}$ según CNR se ha estimado mediante la ecuación [5.16], aunque en la guía proponen esta ecuación para estimar la mejora de ductilidad en elementos sometidos a axil y flector.

- No se ha obtenido predicción de la deformación última $\varepsilon_{c c}$ mediante el TR55, ya que este documento únicamente da un valor máximo $\varepsilon_{C C}=0.01$ debido a la falta de modelos teóricos para predecir $\varepsilon_{c c}$ en pilares rectangulares.

En la Figura 5.4 se representan los valores experimentales y los estimados según las guías de la relación $f_{c c} / f_{c o}$. Se observa un mejor ajuste de las predicciones según $\mathrm{ACl}$ y fib con los resultados de los ensayos. Análogamente en la Figura 5.5 se muestran los valores experimentales y las estimaciones de la relación $\varepsilon_{c c} / \varepsilon_{c o}$, siendo en este caso bastante peor el ajuste de los resultados, como era esperable. Es conocida la dificultad de los modelos en la predicción de la deformación axial última del hormigón confinado así como la dispersión de los resultados experimentales existentes en la literatura.

Sin embargo, el rango de los parámetros no es adecuado para realizar una evaluación general de los modelos, y tampoco es el objeto de esta tesis doctoral. El programa experimental se ha diseñado con el objetivo de estudiar la influencia de determinadas variables que se consideran importantes en el comportamiento del hormigón confinado con FRP en secciones cuadradas, y lo que se pretende en este capítulo es analizar en qué medida los modelos recogen el efecto de dichas variables observado en los ensayos. En los siguientes subapartados se presenta una discusión de estos aspectos. 
Tabla 5.2 Ecuaciones para el cálculo de la resistencia y deformación última en las guías.

\begin{tabular}{|c|c|c|c|c|c|c|c|c|c|}
\hline \multirow{2}{*}{ Probeta } & \multicolumn{4}{|c|}{ Resistencia $f_{c c}$ [MPa] } & \multicolumn{3}{c|}{ Def. axial última $\varepsilon_{c c}$} \\
\cline { 2 - 9 } & $\begin{array}{c}\text { Experi- } \\
\text { mental }\end{array}$ & FIB & ACl & CNR & TR55 & $\begin{array}{c}\text { Experi- } \\
\text { mental }\end{array}$ & FIB & ACI & CNR \\
\hline C_8.8 & 21.7 & 22.6 & 20.6 & 25.5 & 28.1 & 0.0172 & 0.0379 & 0.0264 & 0.0154 \\
\hline C_13 & 23.2 & 28.0 & 24.8 & 32.0 & 31.9 & 0.0344 & 0.0269 & 0.0154 & 0.0133 \\
\hline C_16.3 & 31.4 & 31.7 & 28.1 & 36.8 & 34.8 & 0.0235 & 0.0223 & 0.0121 & 0.0122 \\
\hline C_16.5 & 28.4 & 31.9 & 28.3 & 37.1 & 35.0 & 0.0197 & 0.0221 & 0.0119 & 0.0122 \\
\hline C_16.7 & 29.6 & 32.1 & 28.5 & 37.4 & 35.1 & 0.0249 & 0.0219 & 0.0118 & 0.0121 \\
\hline C_17.5 & 25.8 & 32.9 & 29.3 & 38.5 & 35.9 & 0.0286 & 0.0210 & 0.0113 & 0.0119 \\
\hline C_26.4 & 41.3 & 36.0 & 34.9 & 45.8 & 38.5 & 0.0134 & 0.0123 & 0.0072 & 0.0093 \\
\hline G_8.8 & 20.8 & 21.6 & 19.4 & 24.4 & 24.9 & 0.0298 & 0.0767 & 0.0435 & 0.0148 \\
\hline G_13 & 20.3 & 26.7 & 23.6 & 30.8 & 28.0 & 0.0288 & 0.0532 & 0.0233 & 0.0128 \\
\hline G_16.5 & 24.6 & 30.5 & 27.1 & 35.8 & 30.6 & 0.0213 & 0.0428 & 0.0168 & 0.0117 \\
\hline G_16.7 & 25.3 & 30.7 & 27.3 & 36.0 & 30.8 & 0.0233 & 0.0423 & 0.0165 & 0.0117 \\
\hline G_17.5 & 24.6 & 31.5 & 28.1 & 37.1 & 31.4 & 0.0293 & 0.0406 & 0.0156 & 0.0115 \\
\hline 1_20 & 43.0 & 41 & 46.9 & 58.6 & 46.0 & 0.0069 & 0.0102 & 0.0064 & 0.0074 \\
\hline 1_40 & 52.0 & 45.0 & 48.9 & 62.3 & 48.3 & 0.0091 & 0.0111 & 0.0067 & 0.0080 \\
\hline 2_20 & 55.2 & 53.3 & 52.8 & 69.0 & 55.9 & 0.0139 & 0.0127 & 0.0072 & 0.0090 \\
\hline 2_40 & 76.0 & 60.2 & 56.7 & 74.9 & 62.9 & 0.0197 & 0.0140 & 0.0086 & 0.0098 \\
\hline 3_20 & 78.6 & 63.5 & 58.7 & 77.7 & 65.9 & 0.0182 & 0.0147 & 0.0085 & 0.0102 \\
\hline 3_40 & 93.6 & 71.9 & 64.6 & 85.4 & 77.6 & 0.0145 & 0.0163 & 0.0116 & 0.0113 \\
\hline
\end{tabular}




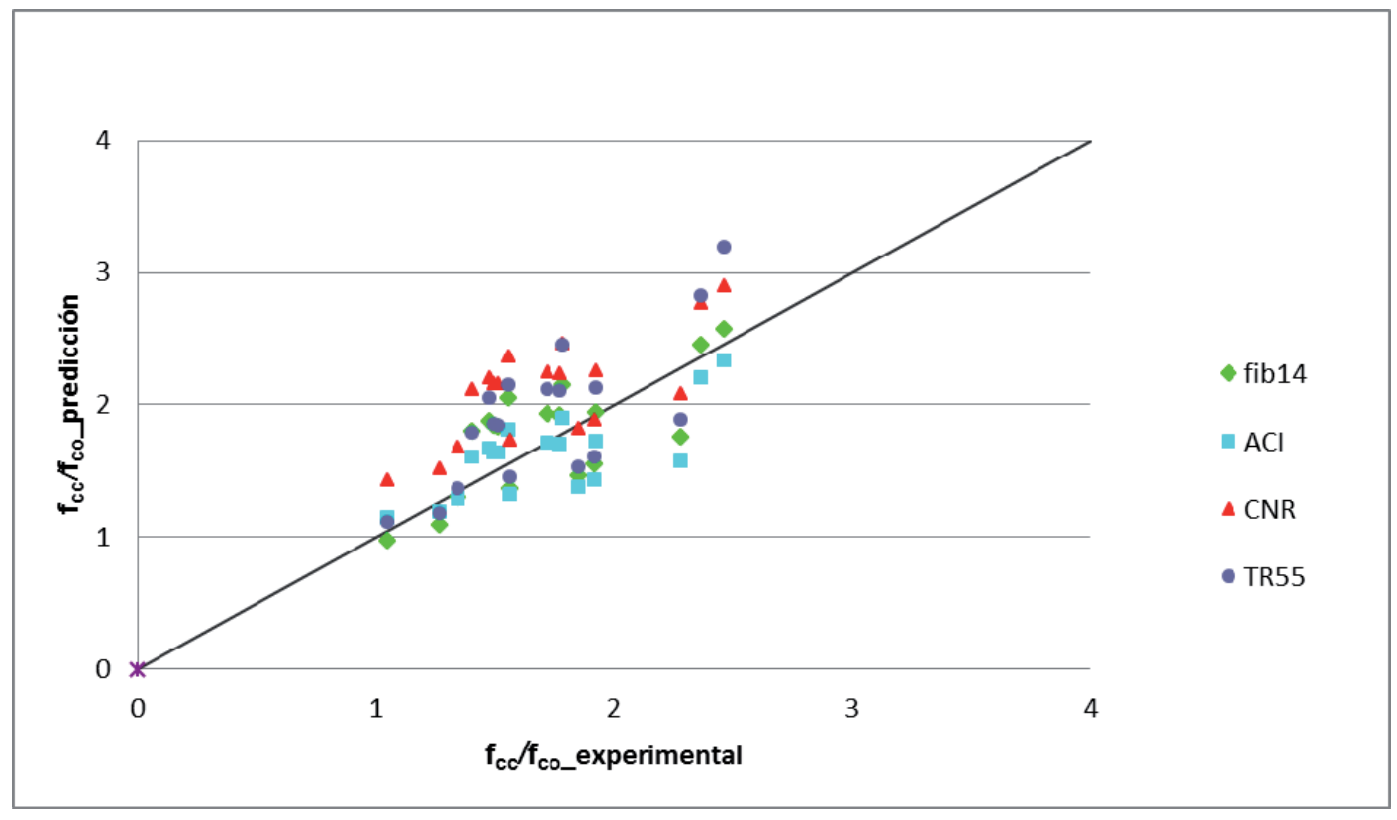

Figura 5.4 Comparación del incremento de resistencia experimental y las predicciones de las guías

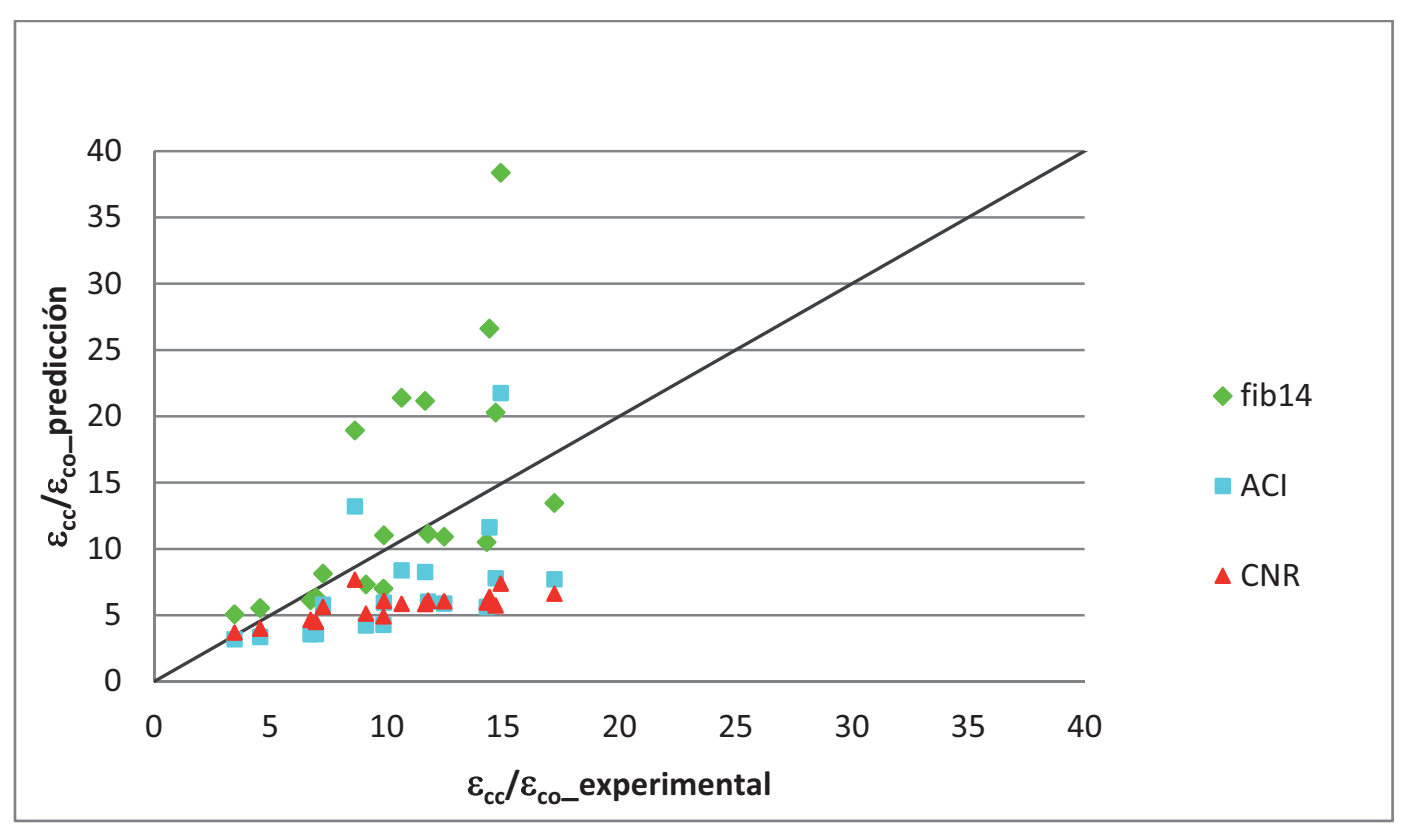

Figura 5.5 Comparación del incremento de deformación axial experimental y las predicciones de las guías 


\subsubsection{Hormigones de baja resistencia}

En un primer análisis de los datos de la Tabla 5.2 y la Figura 5.4 correspondientes a hormigones de resistencia baja se aprecia que el ajuste de las predicciones de resistencia $f_{c c}$ con el modelo de $\mathrm{ACl}$ es bueno, pero las demás guías sobreestiman el incremento de resistencia que puede conseguirse con el confinamiento; sobre todo en CNR y TR55 la diferencia entre las predicciones y los valores experimentales es muy grande.

Se observa sin embargo que la guía CNR también sobreestima en gran medida la resistencia en los hormigones de resistencia media, por lo que parece que no está relacionado con una carencia del modelo en la consideración de los hormigones de baja resistencia. En el cálculo de los valores de $f_{c c}$ según CNR no se ha considerado la limitación de la deformación última efectiva al 4 \%, por entender que esta limitación se establece para asegurar una mínima resistencia frente a esfuerzos transversales, pero incluyendo esta condición el ajuste con los resultados de hormigones de baja resistencia es bueno.

En el caso del fib 14 sí se observa que está sobreestimación no se da en el caso de resistencia media. Hay que decir que el coeficiente de eficiencia de la deformación obtenido en los ensayos con hormigones de resistencia baja (ver apartado 3.8 .4$)$ es muy reducido $\left(k_{\varepsilon}=0.33\right.$ en las probetas reforzadas con carbono y $k_{\varepsilon}=0.24$ en las reforzadas con vidrio), mientras que en el cálculo según el fib se ha considerado el valor más aceptado de $k_{\varepsilon}=0.6$. Esto explicaría los valores elevados de resistencia estimados por el fib (de hecho si se calcula con los valores de $k_{\varepsilon}$ experimentales se obtienen valores de resistencia inferiores a los obtenidos en los ensayos).

El TR55 sin embargo propone un valor de $k_{\varepsilon}=0.29$ en función del radio de redondeo de las esquinas que sí coincide con los valores de $k_{\varepsilon}$ experimentales ( 0.33 para las probetas reforzadas con carbono y 0.24 para las de vidrio), y a pesar de ello se sobreestima la resistencia en los hormigones de baja resistencia.

De la comparación con los resultados experimentales obtenidos en este trabajo recogidos en el capítulo 3 , y dentro del rango de los parámetros en él considerados, se desprende que las formulaciones propuesta en el TR55 no representa adecuadamente el efecto del confinamiento en pilares de resistencias 
bajas, en el rango de 10 a $25 \mathrm{MPa}$. La ecuación del fib el valor habitualmente aceptado de $k_{\varepsilon}=0.60$ también sobreestima la mejora de resistencia. Las formulaciones de $\mathrm{ACl}$ y CNR sí dan predicciones adecuadas.

Es importante llevar a cabo una mayor verificación experimental, ya que los resultados disponibles con hormigones de baja resistencia son muy limitados, y el desarrollo de los modelos se ha basado en ensayos con hormigones de resistencia media (30 a $50 \mathrm{MPa}$ ).

\subsubsection{Deformación última efectiva del FRP}

La propuesta más extendida es considerar en los modelos de cálculo una deformación última efectiva en el FRP de aproximadamente el $60 \%$ de la deformación de rotura obtenida en ensayos de tracción normalizados del material; es decir, considerar un coeficiente de eficiencia de la deformación $k_{\varepsilon}=0.60$, que es el promedio obtenido por varios investigadores a partir de bases de datos de ensayos de la literatura.

Este es el valor adoptado en el CNR, y también en el TR55, aunque en este último documento sólo para secciones circulares. La guía $\mathrm{ACl}$ propone para este coeficiente un valor de 0.55 , y la fib no propone ningún valor debido a la falta de datos fiables en el momento de su publicación.

TR55 es la única guía que propone un valor diferente de $k_{\varepsilon}$, más reducido, para las secciones rectangulares. $k_{\varepsilon}$ se obtiene en función de la relación entre el radio de curvatura de las esquinas $R_{c}$ y el lado corto de la sección (ecuación 5.23). En la primera parte del programa experimental, con $R_{c}=25 \mathrm{~mm}$, se obtiene $k_{\varepsilon}=0.29$, que es muy similar a los valores medios obtenidos en los ensayos $(0.33$ para carbono y 0.24 para vidrio).

Con el fin de confirmar esta relación entre la deformación última efectiva y el radio de redondeo de las esquinas, se ensayaron en la segunda parte del trabajo experimental probetas con $R_{c}=20$ y $40 \mathrm{~mm}$. A estos valores de radios de redondeo corresponden según TR55 $k_{\varepsilon}=0.26$ y 0.39 respectivamente. En los ensayos sí se observó que $k_{\varepsilon}$ aumenta con el radio de redondeo para cuantías bajas y medias de refuerzo (ver Tabla 4.9), pero sin embargo se obtuvieron valores superiores de $k_{\varepsilon}$, con un valor medio de $k_{\varepsilon}=0.60$, que precisamente coincide con el valor propuesto en CNR y TR55 para secciones circulares. 
De los resultados experimentales obtenidos en esta tesis doctoral se desprende que, si bien la deformación última efectiva depende del radio de curvatura de las esquinas, no es adecuado adoptar un valor de $k_{\varepsilon}$ en función únicamente del radio de redondeo y las dimensiones de la sección. En la primera parte del programa experimental se han obtenido valores muy reducidos de $k_{\varepsilon}$ que podrían también estar relacionados, por una parte con la baja resistencia del hormigón, y por otra parte con que se trata de probetas con armadura interna de acero. Aunque no se ha podido verificar con los ensayos, cabe la posibilidad de que el pandeo de las armaduras se inicie antes de la rotura de la camisa de FRP generando deformaciones locales elevadas y la rotura prematura del FRP.

\subsubsection{Forma de la sección. Efecto del radio de curvatura $\boldsymbol{R}_{c}$}

Los ensayos realizados muestran que con el confinamiento con FRP puede mejorarse notablemente la resistencia y ductilidad de pilares de sección cuadrada. El incremento de resistencia y deformación última es mayor cuanto menor es la resistencia del hormigón sin confinar, y los resultados manifiestan la importancia del radio de curvatura de las esquinas en el comportamiento del hormigón confinado.

Los modelos de cálculo incorporan el efecto del radio de curvatura $R_{c}$ con que se redondean las esquinas en secciones rectangulares a través del factor de forma $\alpha_{e}$, que habitualmente expresa la relación entre el área con confinamiento efectivo y el área total. El TR55 hace una propuesta diferente a través de un factor de efectividad $\alpha_{e}$ dado por la ecuación 5.24, y reduciendo el valor de la deformación última efectiva en función de $R_{c}$ como se ha visto en el apartado anterior. De hecho en la formulación del TR55 para obtener $f_{c c}$ en secciones rectangulares (ecuación 5.25) el valor de $R_{c}$ sólo interviene a través de la deformación última efectiva.

Al comparar en la Tabla 5.2 las predicciones de la resistencia $f_{c c}$ con los valores obtenidos en las probetas de la segunda parte del programa experimental, se observa que las predicciones de las guías sí reflejan la mejora de resistencia al aumentar el radio de curvatura de 20 a $40 \mathrm{~mm}$, aunque en menor medida que la obtenida en los ensayos.

Un aspecto relevante mostrado en los ensayos es como manteniendo la misma cuantía de refuerzo, el incremento del radio de redondeo $R_{c}$ produce un cambio en el comportamiento tensión-deformación. Así, en las probetas 1_20 (reforzadas con una capa de fibra y $R_{c}=20 \mathrm{~mm}$ ) la segunda rama de las curvas 
es horizontal o descendente, muestra de un nivel de confinamiento insuficiente, mientras en las 1_40 (una capa de fibra y $R_{c}=40 \mathrm{~mm}$ ) la segunda rama muestra ya una tendencia ascendente (ver Figura 4.18). Esto sugiere que el radio de curvatura es un parámetro a tener en cuenta al establecer un ratio de confinamiento mínimo.

\subsubsection{Diagrama tensión-deformación}

Existe bastante consenso en admitir el modelo tensión-deformación simplificado propuesto por Lam y Teng (Lam and Teng, 2003b) expuesto en el apartado 2.4.3.2 (ver Figura 31). Sin embargo el ajuste de este modelo a los resultados experimentales depende de que se haga una buena estimación de los valores de resistencia y deformación última del hormigón confinado, y mientras que en la resistencia el ajuste en general es razonable, no ocurre lo mismo en las formulaciones de cálculo de la deformación última.

Los valores de $\varepsilon_{c c}$ obtenidos en los ensayos son en general bastante mayores que los estimados con las formulaciones del CNR y ACl, y en el caso del fib el ajuste es mejor en las probetas reforzadas con carbono pero sin embargo en las de vidrio da valores mucho mayores que los experimentales.

Aunque los ensayos realizados abarcan un rango de parámetros muy limitado, los resultados sí permiten señalar ciertas líneas para la futura mejora de los modelos tensión-deformación:

- En primer lugar que una estimación adecuada de la deformación última efectiva del FRP es fundamental para determinar los valores de resistencia y deformación última.

- Los ensayos de probetas reforzadas con vidrio y carbono muestran el efecto de la rigidez del material confinante en la pendiente de la segunda rama de las curvas, a pesar de que el espesor de refuerzo de vidrio era mayor que el de carbono y la presión de confinamiento aplicada no era muy diferente. En este sentido puede que las formulaciones que obtienen $f_{c c}$ y $\varepsilon_{c c}$ sólo en función de la presión de confinamiento y el valor de $f_{c o}$ sean demasiado simplificadas. Parece más correcto incluir de manera separada la influencia de la rigidez del confinamiento y la deformación última, como se hace en la última versión del modelo de Teng (Teng et al., 2009) en el que se basa el TR55.

- En secciones cuadradas es necesario investigar el efecto del radio de redondeo en probetas de mayor tamaño, así como su efecto en el ratio 
de confinamiento mínimo que los modelos proponen para asegurar una mejora de resistencia y un diagrama tensión deformación sin rama descendente.

\subsubsection{Limitación de la deformación última del hormigón confinado}

Por último se analizan los resultados de los ensayos en relación con las recomendaciones de las guías para limitar en la práctica la deformación axial última del hormigón.

Como se ha indicado en este capítulo las guías del CNR y $\mathrm{ACl}$ recomiendan evitar una fisuración excesiva del hormigón, ya que aunque el FRP pueda encontrarse aún lejos de la rotura, la pérdida de cohesión del hormigón haría que el pilar fuera incapaz de soportar esfuerzos transversales.

Con este fin el CNR limita la deformación última efectiva del FRP $\varepsilon_{f u}$ (o lo que es lo mismo, la deformación lateral en el hormigón) a un valor de 0.004, mientras que $\mathrm{ACl}$ limita la deformación axial última del hormigón confinado $\varepsilon_{c c}$ a un valor máximo de 0.01 . Este valor de $\varepsilon_{c c m a ́ x}=0.01$ coincide con el recomendado en el TR55 debido a la falta de modelos teóricos para predecir $\varepsilon_{c c}$ en pilares rectangulares ya que es un límite que mantiene la integridad del hormigón.

Al observar las gráficas tensión deformación axial y lateral obtenidas en los ensayos con hormigones de resistencia media (41 MPa) reforzados con carbono, se aprecia que ambas limitaciones son coherentes. Sin embargo en los ensayos con hormigones de resistencia baja, con valores de deformación lateral menores de 0.004 se alcanzan valores de deformación axial muy superiores a 0.01 , y la rotura de las probetas se produce en muchos casos para valores de deformación lateral próximos a 0.004 , observándose que el hormigón completamente falto de cohesión.

La limitación que da la guía del CNR de $\varepsilon_{f u}=0.004$ no es suficiente para limitar la fisuración del hormigón en el caso de hormigones de baja resistencia (10-25 $\mathrm{MPa})$. 
CAPÍTULO 6

\section{CONCLUSIONES Y LÍNEAS FUTURAS DE INVESTIGACIÓN}

\subsection{Introducción}

En esta tesis, además de establecer el estado del arte sobre el refuerzo de pilares mediante confinamiento con materiales compuestos (FRP), se ha presentado un programa experimental propio realizado en dos fases y se han analizado los modelos propuestos en las guías de cálculo más importantes comparándolos con los resultados obtenidos. A continuación se presentan las conclusiones obtenidas en el trabajo y se proponen algunas líneas para continuar la investigación.

\subsection{Conclusiones del estudio experimental}

El programa experimental se ha desarrollado en dos partes, cuyos resultados se han presentado en los capítulos 3 y 4 :

- En la primera parte se han ensayado a compresión centrada 26 probetas prismáticas de sección cuadrada de hormigón armado reforzadas con FRP y 2 probetas patrón sin refuerzo externo. Se han empleado hormigones con valores de resistencia a compresión bajos (10 a $25 \mathrm{MPa}$ ) 
y se han reforzado con fibra de carbono y fibra de vidrio. Las esquinas de la sección se redondean con un radio de curvatura $R_{C}=25 \mathrm{~mm}$.

- En la segunda parte se han ensayado a compresión centrada 14 probetas prismáticas de hormigón de sección cuadrada de resistencia media (41 $\mathrm{MPa})$ : 2 probetas patrón de hormigón sin reforzar y 12 probetas de hormigón reforzadas con fibra de carbono. Las probetas no llevan armadura interna. Las variables son la cuantía de refuerzo (1, 2 y 3 capas de fibra) y el radio de curvatura $R_{c}$ con el que se redondean las esquinas (20 y $40 \mathrm{~mm}$ ).

A continuación se exponen las principales conclusiones derivadas de los resultados obtenidos en el programa experimental:

- Los resultados muestran que mediante el confinamiento con FRP puede incrementarse muy notablemente la resistencia y ductilidad de pilares de hormigón de sección cuadrada con las esquinas redondeadas.

- La mejora de propiedades es mayor cuanto menor es la resistencia del hormigón sin confinar y es superior en las probetas reforzadas con fibra de carbono que en las de vidrio.

- El incremento relativo de resistencia que se consigue con el confinamiento aumenta con la cuantía de refuerzo y, para una cuantía dada, se incrementa notablemente con el radio de curvatura de las esquinas $R_{c}$. En el caso de las probetas ensayadas, la mejora conseguida al aumentar $R_{c}$ de 20 a $40 \mathrm{~mm}$ equivale prácticamente a la que se consigue con una capa más de refuerzo.

- El fallo de las probetas se produce de manera repentina y explosiva por la rotura del encamisado de FRP, con frecuencia cerca de las esquinas de la sección. El fallo de las probetas reforzadas con vidrio y con distintas cuantías de carbono es similar, pero en los refuerzos de carbono hay menos señales de aviso previas a la rotura y al aumentar el número de capas de refuerzo la rotura es aún más violenta. No se observan diferencias en el modo de fallo de las probetas con distinto radio de redondeo de las esquinas. 
- El factor de eficiencia de la deformación $\left(k_{\varepsilon}=\varepsilon_{f u} / \varepsilon_{f}\right)$ obtenido en los ensayos con hormigones de resistencia media reforzados con carbono es $k_{\varepsilon}=0.60$, que coincide con el valor propuesto por algunos investigadores a partir de los resultados de la literatura. Dentro del ámbito de los parámetros estudiados, y con las limitaciones derivadas del reducido número de ensayos, se demuestra que el incremento del radio de redondeo de las esquinas incrementa la deformación última efectiva, para cuantías de refuerzo bajas y medias, aunque para cuantías altas no puedan establecerse conclusiones en este sentido.

- En los ensayos con hormigones de baja resistencia y $R_{c}=25 \mathrm{~mm}$ se han obtenido valores de $k_{\varepsilon}$ bastante menores: 0.24 en las probetas reforzadas con vidrio y 0.33 en las de carbono, apreciándose un valor más reducido para los hormigones de menor resistencia. Estos resultados apuntan a la influencia de otros factores además del radio de curvatura, como la baja resistencia del hormigón o el posible pandeo de la armadura interna.

- Las curvas tensión-deformación tienen una forma característica formada por dos tramos. En la primera parte el comportamiento es similar al del hormigón sin confinar y en la segunda parte la respuesta es también monótona creciente, aproximadamente lineal, con una mayor pendiente en los refuerzos de carbono que en los de vidrio. La pendiente aumenta al incrementarse la cuantía de refuerzo, y para la misma cuantía aumenta con el radio de las esquinas $R_{c}$. Únicamente en las probetas 1_20 (reforzadas con una sola capa y con $R_{c}=20 \mathrm{~mm}$ ) la segunda parte de las curvas es horizontal o descendente, muestra de un nivel de confinamiento insuficiente.

\subsection{Conclusiones derivadas de la comparación de los modelos de cálculo propuestos en las guías y los resultados experimentales}

Se han analizado los modelos de cálculo propuestos en las guías internacionales más relevantes (fib Bulletin 14, ACl 440.2R-08, CNR-DT200 R1/2013 y Concrete Society TR55). Se aprecia cierto consenso en el modelo tensión-deformación adoptado. Sin embargo, para el cálculo de la resistencia y deformación última del hormigón todas las recomendaciones proponen ecuaciones distintas. También 
difiere el tratamiento que se hace de los dos aspectos clave que determinan el comportamiento del hormigón confinado con FRP: la deformación última efectiva del FRP y el efecto de la forma de la sección.

De la comparación entre los resultados experimentales obtenidos en esta tesis y las predicciones teóricas se derivan las siguientes conclusiones:

- El modelo tensión-deformación propuesto por Lam y Teng (Lam and Teng, 2003b) es un modelo que las recomendaciones han adoptado por su sencillez, pero su ajuste a los resultados experimentales depende de que se haga una buena estimación de los valores de resistencia y deformación última del hormigón confinado. En este sentido, las formulaciones que predicen el incremento de resistencia y deformación en función únicamente de la presión de confinamiento y las propiedades del hormigón sin confinar son demasiado simplificadas. Parece más correcto incluir de manera separada la influencia de la rigidez del confinamiento y la deformación última, como se hace en la última versión del modelo de Teng (Teng et al., 2009) en el que se basa el TR55.

- Una estimación adecuada de la deformación última efectiva del FRP es fundamental para determinar los valores de resistencia y deformación última del hormigón. A pesar de su importancia este es uno de los aspectos peor resueltos por los modelos. De los resultados experimentales obtenidos en esta tesis doctoral se desprende que, si bien la deformación última efectiva depende del radio de curvatura de las esquinas, no es adecuado adoptar un valor de $k_{\varepsilon}$ en función únicamente del radio de redondeo y las dimensiones de la sección. Es necesario continuar investigando la influencia de otros factores, como la resistencia del hormigón o el posible pandeo de la armadura interna que puede generar deformaciones locales elevadas y la rotura prematura del FRP.

- Respecto al tratamiento de las secciones rectangulares, las predicciones de las guías reflejan la mejora de resistencia al aumentar el radio de curvatura, aunque en menor medida que la obtenida en los ensayos. La línea apuntada en el TR55 de limitar más la deformación última efectiva en secciones cuadradas parece acertada, aunque los resultados experimentales de esta tesis no confirman la formulación propuesta en dicha guía. El radio de curvatura es un parámetro que debería tenerse en cuenta al establecer un ratio de confinamiento mínimo. Se hace 
necesaria la experimentación con probetas de mayor tamaño para confirmar estos aspectos.

- Es importante llevar a cabo una mayor verificación experimental con hormigones de baja resistencia, ya que los resultados disponibles son muy limitados. De la comparación con los resultados experimentales obtenidos en la primera parte del programa experimental, y dentro del rango de los parámetros en él considerados, se desprende que la formulación propuesta en el TR55 no representa adecuadamente el efecto del confinamiento en hormigones de baja resistencia, en el rango de 10 a $25 \mathrm{MPa}$. La ecuación del fib con el valor habitualmente aceptado de $k_{\varepsilon}=0.60$ también sobreestima la mejora de resistencia. Las formulaciones de $\mathrm{ACl}$ y CNR sí dan predicciones adecuadas de los resultados de los ensayos.

- En aplicaciones prácticas deben evitarse valores elevados de deformación de compresión en el hormigón, ya que aunque el FRP se encuentre lejos de la rotura, el hormigón estará muy fisurado y el pilar sería incapaz de resistir esfuerzos transversales. Con este fin la guía $\mathrm{ACl}$ y el TR55 recomiendan un valor máximo de la deformación última del hormigón confinado $\varepsilon_{c c m a ́ x}=0.01$, mientras que el CNR limita la deformación última efectiva del FRP $\varepsilon_{f u}$ a un valor de 0.004. De los ensayos llevados a cabo en este trabajo se concluye que ambas limitaciones son coherentes en el caso de hormigones de resistencia media (40 $\mathrm{MPa}$ ) reforzados con fibra de carbono, pero sin embargo el valor límite que establece el CNR de $\varepsilon_{f u}=0.004$ no es suficiente para limitar la fisuración excesiva del hormigón en el caso de hormigones de baja resistencia (10-25 $\mathrm{MPa})$.

\subsection{Líneas futuras de investigación}

Los trabajos presentados en esta tesis doctoral han permitido ver las incertidumbres que aún persisten en el cálculo de refuerzo de pilares. A partir de los resultados obtenidos en este trabajo, se plantea el interés de las siguientes líneas de investigación:

- Realizar más estudios experimentales con el objetivo de lograr una estimación adecuada de la deformación última efectiva del FRP, 
investigando la influencia del radio de curvatura y de otros factores, como la resistencia del hormigón o el posible pandeo de la armadura interna que puede generar deformaciones locales elevadas y la rotura prematura del FRP.

- Extender la investigación realizada incluyendo pilares de sección rectangular.

- Incorporar en los estudios experimentales técnicas avanzadas de medida que capturen la distribución de tensiones no uniforme del hormigón.

- Desarrollar un modelo de cálculo que incorpore los resultados anteriores. En este sentido, a la vista del conocimiento logrado hasta el momento parece acertada la propuesta de la última revisión del TR55 de incluir de manera separada la influencia de la rigidez del confinamiento y la deformación última del FRP. También es valorable la limitación que hace esta guía de la deformación última efectiva en función del radio de curvatura, aunque los resultados experimentales de esta tesis no confirman la formulación incluida en el TR55 y apuntan a la concurrencia de otros factores que es necesario investigar e incluir en el modelo.

- Desarrollar un programa experimental sobre pilares cuadrados a escala real, e incluir el estudio de la excentricidad de la carga. Este programa debería servir para verificar los valores obtenidos en los ensayos realizados hasta la fecha en probetas a escala reducida y contrastarlos con los propuestos en las guías de cálculo. Los resultados disponibles a escala real son escasísimos debido a la falta de equipos con capacidad de carga suficiente. 


\section{BIBLIOGRAFÍA}

ACl-440.2R-08 2008. Guide for the design and construction of externally bonded FRP systems for strengthening concrete structures, American Concrete Institute, Farmington Hills, Michigan.

ACHE en prensa. Monografía M-29 Refuerzo de pilares, Grupo de Trabajo 5/7, Asociación Científico-Técnica del Hormigón Estructural.

AHMAD, S. M. \& SHAH, S. P. 1982. Stress-strain curves of concrete confined by spiral reinforcement , 79(6). Journal of the American Concrete Institute, 79, 484490.

AIRE, C. M. 2002. Estudio experimental del comportamiento del hormigón confinado sometido a compresión. Tesis Doctoral. Universidad Politécnica de Cataluña.

ASTM 2008a. Standard test method for apparent tensile strength of plastics or reinforced plastic pipe by split disk method, D 2290-08 Annual Book of ASTM Standards, Vol. 08.04. .

ASTM 2008b. Standard test method for tensile properties of polymer matrix composite materials, D3039/D3039M-08 Annual Book of ASTM Standards, Vol. 08.04 .

BALMER, G. G. 1949. Shearing strength of concrete under high triaxial stress Computation of Mohr's envelope as a curve, Structural Research Laboratory Report, SP-23, U.S. Buerau of Reclamation, Denver.

BARRINGTON, J., DICKSON, D., BISBY, LA AND STRATFORD, TJ. 2011. Strain development and hoop strain efficiency in FRP confined square columns. Proceedings of FRPRCS-10, Florida, USA.

BECQUE, J., PATNAIK, A. K. \& RIZKALLA, S. H. 2003. Analytical Models for Concrete Confined with FRP Tubes. Journal of Composites for Construction, 7, 31-38.

BERTHET, J. F., FERRIER, E. \& P., H. 2005. Compressive behavior of concrete externally confined by composite jackets. Part $A$ : experimental study. Construction and Building Materials, 19, 223-232.

BINICI, B. 2005. An analytical model for stress-strain behavior of confined concrete. Engineering Structures, 27, 1040-1051.

CALAVERA, J. 2005. Patología de estructuras de hormigón armado y pretensado, $2^{a}$ edición. 
CALLADINE, C. R. 1983. Theory of shell structures, Cambridge University Press, Cambridge, UK.

CEN 2004. EN 1992-1-1 - Eurocode 2: Design of concrete structures - Part 1-1: General rules and rules for buildings. Bruselas.

CNR-DT200_R1 2013. Guide for the Design and Construction of Externally Bonded FRP Systems for Strengthening Existing Structures, Advisory Committee on Technical Recommendations for Construction, Italy.

CONSIDĖRE, A. 1906. Résistance à la compression du beton armé et du beton fretté, Experimental researches on reinforced concrete, translated by L.S. Moisseiff. McGraw Publishing Co., New York.

CHAALLAL, O., HASSAN, M. AND LEBLANC, M. 2006. Circular Columns Confined with FRP: Experimental versus Predictions of Models and Guidelines. Journal of Composites for Construction, 10, 4-12.

CHEN, J. F., LI, S. Q. \& AI, J. 2009. Relationship between FRP fracture strains in flat coupon tests, split disk tests and FRP wrapped columns. APFIS 2009 The Second Official International Conference of International Institute for FRP in Construction for Asia-Pacific Region. Seúl, Korea.

DE LORENZIS, L. \& TEPFERS, R. A. A. 2003. Comparative Study of Models on Confinement of Concrete Cylinders with Fiber-Reinforced Polymer Composites. Journal of Composites for Construction, 7, 219-237.

DONG, C. X., KWAN, A. K. H. \& HO, J. C. M. 2015. Effects of confining stiffness and rupture strain on performance of FRP confined concrete. Engineering Structures, 97, 1-14.

ELSANADEDY, H. M., AL-SALLOUM, Y. A., ALSAYED, S. H. \& IQBAL, R. A. 2012. Experimental and numerical investigation of size effects in FRP-wrapped concrete columns. Construction and Building Materials, 29, 56-72.

FAM, A. Z. \& RIZKALLA, S. H. 2001. Confinement Model for Axially Loaded Concrete Confined by Circular Fiber-Reinforced Polymer Tubes,98(4), 451-461. ACI Structural Journal, 98, 451-461.

FARDIS, M. N. \& KHALILI, H. H. 1981. Concrete encased in fiberglass-reinforced plastic. Journal of the American Concrete Institute Proceedings, 78, 440-446.

FARDIS, M. N. \& KHALILI, H. H. 1982. FRP-Encased Concrete as a Structural Material. Magazine of Concrete Research, 34, 191-202.

FIB 2001. fib Bulletin 14, Externally bonded FRP reinforcement for RC structures. Fédération internationale du béton.

FIB 2006. Bulletin 35 Retrofitting of concrete structures by externally bonded FRPs with emphasis on seismic applications, fédération internationale du béton. 
GEHO-CEB 1994. Reparación y refuerzo de estructuras de hormigón. Guía FIP de buena práctica.

H.M. MOHAMED, R. M. 2010. Axial load capacity of concrete-filled FRP tube columns: experimental versus theoretical predictions. Journal of Composites for Construction, 14, 231-243.

HARRIES, K. A. \& CAREY, S. A. 2003. Shape and "gap" effects on the behavior of variably confined concrete. Cement and Concrete Research, 33, 881-890.

HARRIES, K. A. \& KHARELL, G. 2002. Behavior and modeling of concrete subject to variable confining pressure. ACI Materials Journal, 99, 180-189.

HULL, D. \& CLYNE, T. W. 1996. An Introduction to Composite Materials. Second edition.Cambridge University Press.

JIANG, T. \& TENG, J. G. 2007. Analysis-oriented stress-strain models for FRPconfined concrete. Engineering Structures, 29, 2968-2986.

KARAM, G. \& TABBARA, M. 2004. Corner Effects in CFRP-Wrapped Square Columns. Magazine of Concrete Reseach, 56, 461-464.

KENT, D. C. \& PARK, R. 1971. Flexural members with confined concrete, Proceedings. In: ASCE (ed.).

KURT, C. E. 1978. Concrete filled structural plastic columns. Journal of the Structural Division ASCE, 104, 55-63.

LAM, L. \& TENG, J. G. 2002. Strength Models for Fiber-Reinforced PlasticConfined Concrete. Journal of Structural Engineering, 128, 612-623.

LAM, L. \& TENG, J. G. 2003a. Design-Oriented Stress-Strain Model for FRPConfined Concrete in Rectangular Columns. Journal of Reinforced Plastics and Composites, 22, 1149-1186.

LAM, L. \& TENG, J. G. 2003b. Design-oriented stress-strain model for FRPconfined concrete. Construction and Building Materials, 17, 471-489.

LAM, L. \& TENG, J. G. 2004. Ultimate Condition of Fiber Reinforced PolymerConfined Concrete. Journal of Composites for Construction, 8, 539-548.

LAM, L., TENG, J. G., CHEUNG, C. H. \& XIAO, Y. 2006. FRP-confined concrete under axial cyclic compression. Cement and Concrete Composites, 28, 949-958.

LI, G. 2006. Experimental study of FRP confined concrete cylinders. Eng Struct, $28,1001-1008$.

MANDER, J. B., PRIESTLEY, M. J. N. \& PARK, R. 1988. Theoretical StressStrain Model for Confined Concrete , 114(8), 1804-1826. Journal of Structural Engineering, ASCE, 114, 1804-1826. 
MARQUES, S., MARQUES, D., LINS DA SILVA, J. \& CAVALCANTE, M. 2004. Model for Analysis of Short Columns of Concrete Confined by Fiber-Reinforced Polymer. Journal of Composites for Construction, 8, 332-340.

MATTHYS, S., TOUTANJI, H., AUDENAERT, K. \& TAERWE , L. 2005. Axial Load Behavior of Large-Scale Columns Confined with Fiber-Reinforced Polymer Composites. ACl Structural Journal, 102, 258-267.

MEIER, U. 1995. Strengthening of structures using carbon fibre/epoxy composites Construction and Building Materials, 9, 341-351.

MIRAVETE, A. 2000. Materiales Compuestos. Primera edición.

MIRMIRAN, A., SHAHAWY, M., SAMAAN, M., EL ECHARY, H., MASTRAPA, J. C. \& PICO, O. 1998. Effect of Column Parameters on FRP-Confined Concrete. Journal of Composites for Construction, 2, 175-185.

MIRMIRAN, S. \& SHAHAWY, M. 1996. A new concrete-filled hollow FRP composite column. Composites Part B: Engrg, 27B, 263-268.

MIYAUCHI, K., NISHIBAYASHI, S. \& INOUE, S. Estimation of strengthening effects with carbon fiber sheet for concrete column. Third International Symposium (FRPRCS-3) on Non-Metalic (FRP) Reinforcement for Concrete Structures, 1997 Sapporo. 217-224.

NEWMAN, K. \& NEWMAN, J. B. Failure theories and design criteria for plain concrete. International Engineering Materials Conference on Struture, Solid Mechanics and Engineering Design, 1969 Southampton. Wiley Interscience, New York, 963-995.

OZBAKKALOGLU, T. 2013. Compressive behavior of concrete-filled FRP tube columns: assessment of critical column parameters, Eng Struct, 51, 188-199.

PAN, J. L., XU, T. \& HU, Z. J. 2006. Experimental investigation of load carrying capacity of the slender reinforced concrete columns wrapped with FRP. Construction and Building Materials, 21, 1991-1996.

PANTAZOPOULOU, S. J. \& MILLS, R. H. 1995. Microstructural aspects of the mechanical response of plain concrete. ACI Materials Journal, 92, 605-616.

PARK, R., PRIESTLEY, M. J. N. \& GILL, W. D. 1982. Ductility of square-confined concrete columns, 108(4), 929-950. Journal of the Structural Division, ASC, 108, 929-950.

PESSIKI, S., HARRIES, K. A., KESTNER, J. T., SAUSE, R. \& RICLES, J. M. 2001. Axial Behavior of Reinforced Concrete Columns Confined with FRP Jackets. Journal of Composites for Construction, 5, 237-245.

PHAM, T. M. \& HADI, M. N. S. 2013. Strain Estimation of CFRP-Confined Concrete Columns Using Energy Approach. Journal of Composites for Construction, 17, 04013001 
PHAM, T. M. \& HADI, M. N. S. 2014. Stress Prediction Model for FRP Confined Rectangular Concrete Columns with Rounded Corners. Journal of Composites for Construction, 18, 04013019.

PHAM, T. M., HADI, M. N. S. \& YOUSSEF, J. 2015. Optimized FRP Wrapping Schemes for Circular Concrete Columns under Axial Compression. Journal of Composites for Construction, 04015015.

POPOVICS, S. 1973. Numerical approach to the complete stress-strain relation for concrete. Cement and Concrete Research, 3, 583-599.

RICHART, F. E., BRANDTZAEG, A. \& BROWN, R. L. 1928. A study of the failure of concrete under combined compressive stresses, Engineering Experiment Station Bulletin No. 185. University of Illinois, Urbana.

RICHART, F. E., BRANDTZAEG, A. \& BROWN, R. L. 1929. The failure of plain and spirally reinforced concrete in compression, Engineering Experiment Station Bulletin No. 190. University of Illinois, Urbana.

ROCHETTE, P. \& LABOSSIÈRE, P. 2000. Axial Testing of Rectangular Column Models Confined with Composites. Journal of Composites for Construction, 4, 129-136.

SAADATMANESH, H., EHSANI, M. R. \& LI, M. W. 1994. Stregth and Ductility of Concrete Columns Externally Reinforced with Fiber Composite Straps. ACl Structural Journal, 91, 434-447.

SAAFI, M., TOUTANJI, H. A. \& LI, Z. 1999. Behavior of Concrete Columns Confined with Fiber Reinforced Polymer Tubes. ACI Materials Journal, 96, 500509.

SAATCIOGLU, M. \& RAZVI, S. R. 1992. Strength and ductility of confined concrete. Journal of Structural Engineering, ASCE, 118, 1590-1607.

SADEGHIAN, P. \& FAM, A. 2014. A Rational Approach toward Strain Efficiency Factor of Fiber-Reinforced Polymer-Wrapped Concrete Columns. ACI Structural Journal, 111, 135-144.

SAMAAN, M., MIRMIRAN, A. \& SHAHAWY, M. 1998. Model of Concrete Confined by Fiber Composites. Journal of Structural Engineering, ASCE, 124, 1025-1031.

SHEIKH, S. A. \& UZUMERI, S. M. 1980. Strength and ductility of tied concrete columns ASCE. Journal of the Structural Division, ASCE, 106, 1079-1102.

SHEIKH, S. A. \& UZUMERI, S. M. 1982. Analytical Model for Concrete Confinement in Tied Columns. Journal of Structural Engineering, ASCE, 108, 2703-2722.

SPOELSTRA, M. \& MONTI, G. 1999. FRP-Confined Concrete Model. Journal of Composites for Construction, 3, 143-150. 
TALBOT, A. N. 1906. Tests of concrete and reinforced concrete columns, series of 1906, Engineering Experiment Station Bulletin No. 10, University of Illinois, Urbana, IL.

TENG, J., HUANG, Y., LAM, L. \& YE, L. 2007a. Theoretical Model for FiberReinforced Polymer-Confined Concrete. Journal of Composites for Construction, 11, 201-210.

TENG, J. G., JIANG, T., LAM, L. \& LUO, Y. Z. 2009. Refinement of a DesignOriented Stress-Strain Model for FRP-Confined Concrete. Journal of Composites for Construction, 13, 269-278.

TENG, J. G., LIN, G. \& YU, T. 2014. Analysis-Oriented Stress-Strain Model for Concrete under Combined FRP-Steel Confinement. Journal of Composites for Construction, 04014084, 1-14.

TENG, J. G., YU, T., WONG, Y. L. \& DONG, S. L. 2007b. Hybrid FRP-concretesteel tubular columns: Concept and behavior. Construction and Building Materials, 21, 846-854.

TOUTANJI, H., HAN, M., GILBERT, J. \& MATTHYS, S. 2010. Behavior of largescale rectangular columns confined with FRP composites. Journal of Composites for Construction, 14, 62-71.

TOUTANJI, H. A. 1999. Stress-Strain Characteristics of Concrete Columns Externally Confined with Advanced Fiber Composite Sheets. ACl Materials Journal, 96, 397-404.

TR55 2012. Technical Report Design guidance for strengthening concrete structures using fibre composite materials, 3rd edition, Concrete Society, UK.

UNE-EN-ISO 1997. 527-4 Plásticos. Determinación de las propiedades en tracción. Parte 4: Condiciones de ensayo para plásticos compuestos isotrópicos y ortotrópicos reforzados con fibras. .

VINCENT, T. \& OZBAKKALOGLU, T. 2013. Influence of fiber orientation and specimen end condition on axial compressive behavior of FRP-confined concrete. Construction and Building Materials, 47, 814-826.

WANG, L.-M. \& WU, Y.-F. 2008. Effect of corner radius on the performance of CFRP-confined square concrete columns: Test. Engineering Structures, 30, 493505.

WU, G., WU, Z. S. \& LÜ, Z. T. 2007. Design-oriented stress-strain model for concrete prisms confined with FRP composites. Construction and Building Materials, 21, 1107-1121.

WU, Y. \& WEI, Y. 2015. General Stress-Strain Model for Steel- and FRPConfined Concrete. Journal of Composites for Construction, 19, 04014069. 
WU, Y. F. \& WANG, L. M. 2009. Unified strength model for square and circular concrete columns confined by external jacket. Journal of Structural Engineering, $135,253-261$.

WU, Y. F. \& WEI, Y. Y. 2010. Effect of cross-sectional aspect ratio on the strength of CFRP-confined rectangular concrete columns. Engineering Structures, 32, 32-45.

WU, Y. F. \& ZHOU, Y. W. 2010. Unified strength model based on Hoek-Brown failure criterion for circular and square concrete columns confined by FRP. Journal of Composites for Construction, 14, 175-184.

XIAO, Q. G., TENG, J. G. \& YU, T. 2010. Behavior and modeling of confined high-strength concrete. Journal of Composites for Construction, 14, 249-259.

XIAO, Y. \& WU, H. 2000. Compressive Behavior of Concrete Confined by Carbon Fiber Composite Jackets. Journal of Materials in Civil Engineering, 12, 139-146.

XIAO, Y. \& WU, H. 2003. Compressive Behavior of Concrete Confined by Various Types of FRP Composite Jackets. Journal of Reinforced Plastics and Composites, 22.

YANG, X., NANNI, A. \& CHEN, G. Effect of corner radius on the performance of externally bonded FRP reinforcement. . In: TELFORD, T., ed. Proc., 5th Int. Conf. On Fibre-Reinforced Plastics for Reinforced Concrete Structures, 2001 London. 197-204.

YOUSSEF, M. N., FENG, M. Q. \& MOSALLAM, A. S. 2007. Stress-strain model for concrete confined by FRP composites. Composites Part B: Engineering, 38, 614-628. 


\section{ANEJO A}

\section{RESULTADOS EXPERIMENTALES}

\section{A.1 Introducción}

En este anejo se muestran las fotografías de la rotura y los diagramas cargadeformación axial y carga-deformación transversal de todas las probetas ensayadas que se presentan en esta Tesis Doctoral.

En el apartado A.2 se incluyen los resultados correspondientes a la Parte I del programa experimental, descrito en el capítulo 3, y en el apartado A.3 los de la Parte II, descrito en el capítulo 4. 


\section{A.2 Programa experimental. Parte I}

\section{A.2.1 Rotura de las probetas}
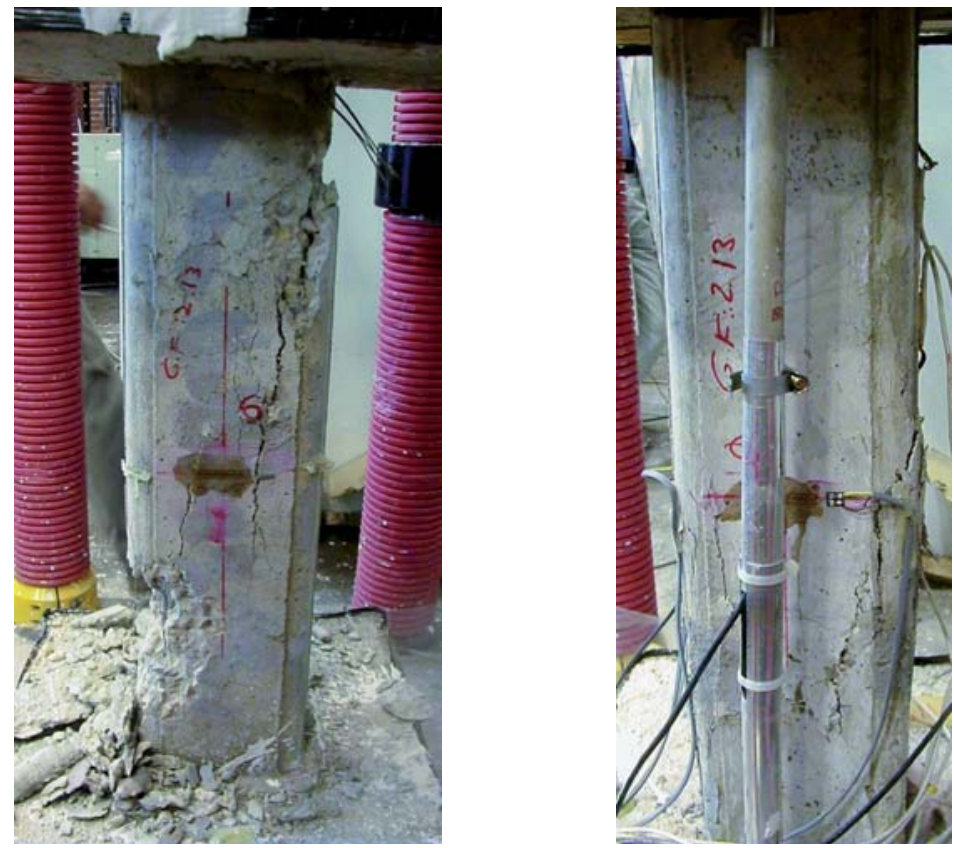

Figura A.1 Rotura de la probetas sin refuerzo (a y b)
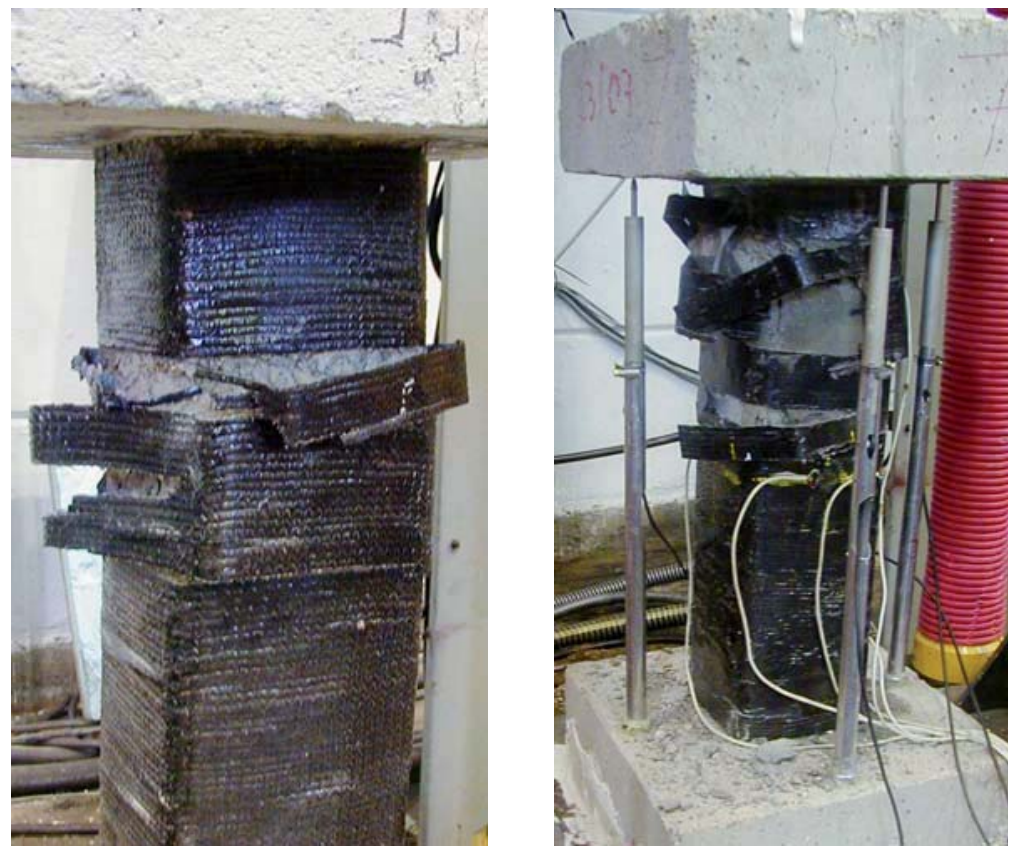

Figura A.2 Rotura de las probetas C_8.8_a y C_8.8_b 

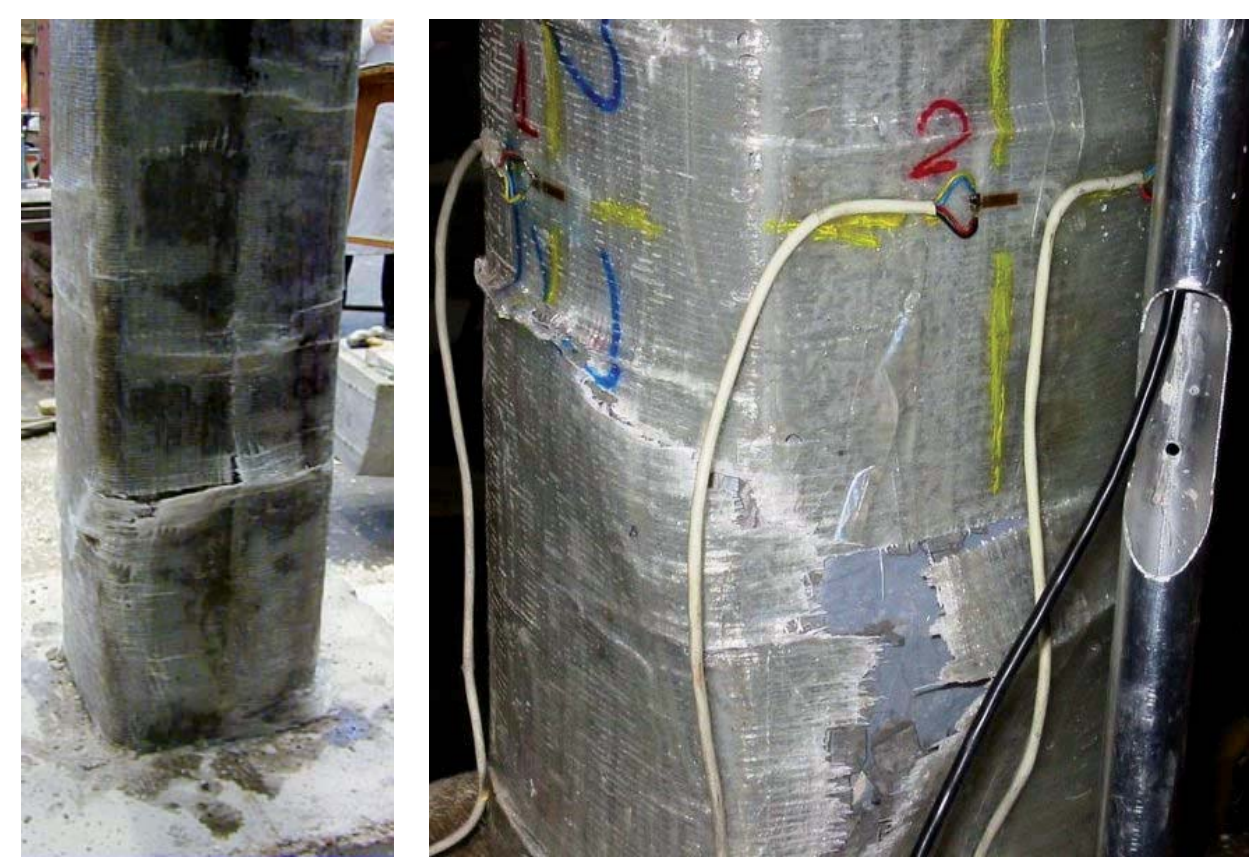

Figura A.3 Rotura de las probetas G_8.8_a y G_8.8_b
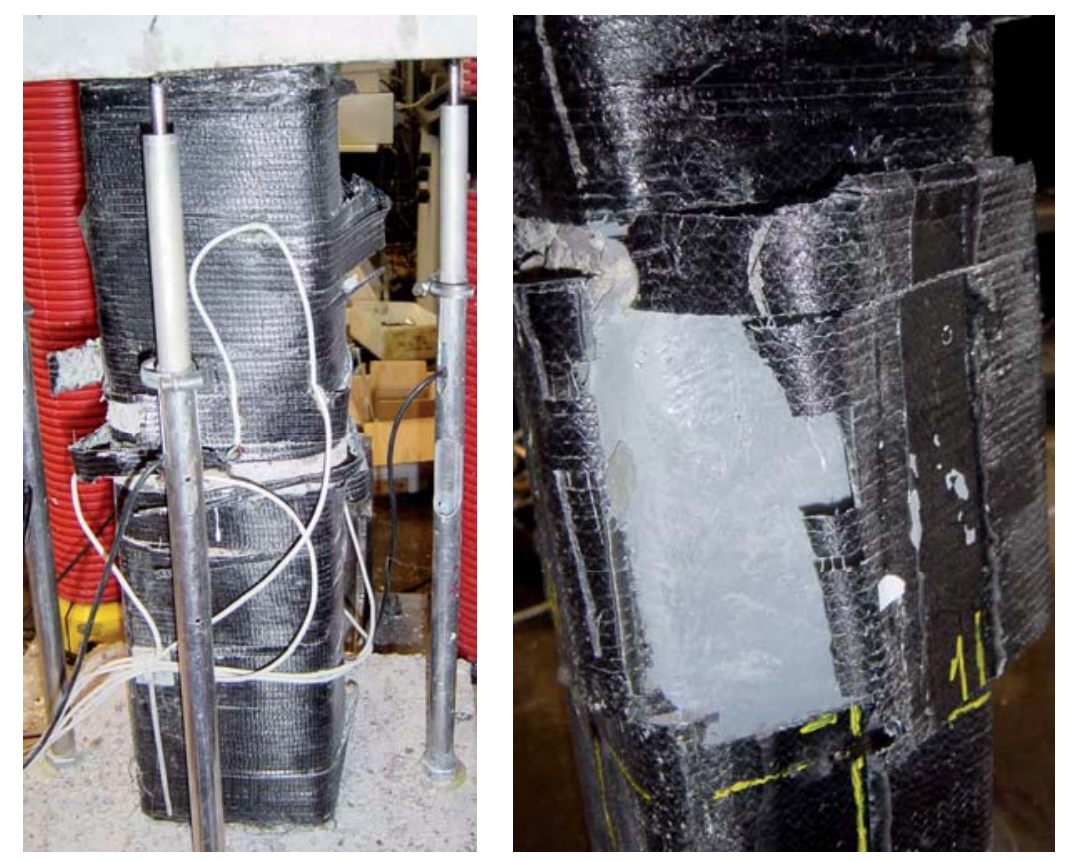

Figura A.4 Rotura de las probetas C_13_a y C_13_b 

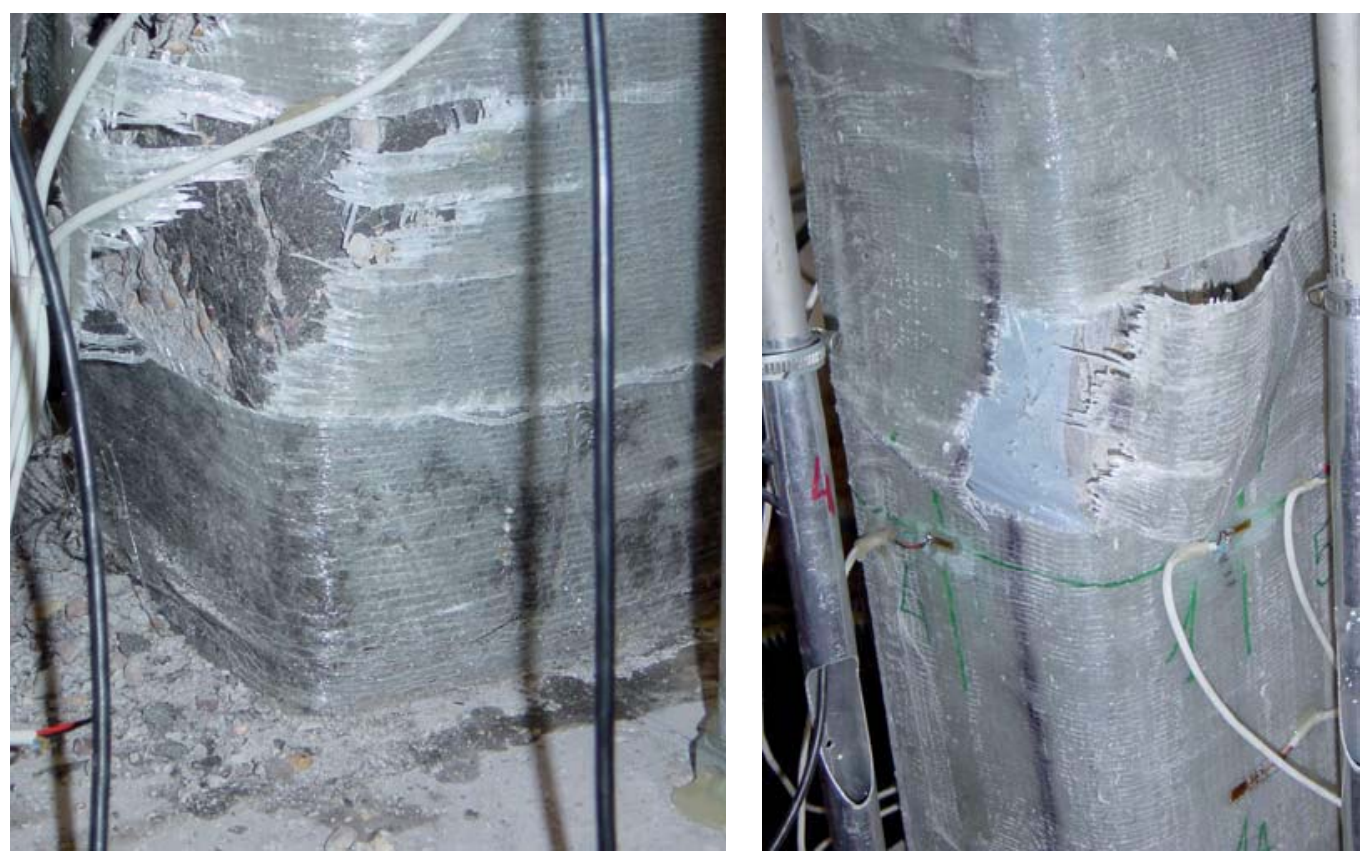

Figura A.5 Rotura de las probetas G_13_a y G_13_b
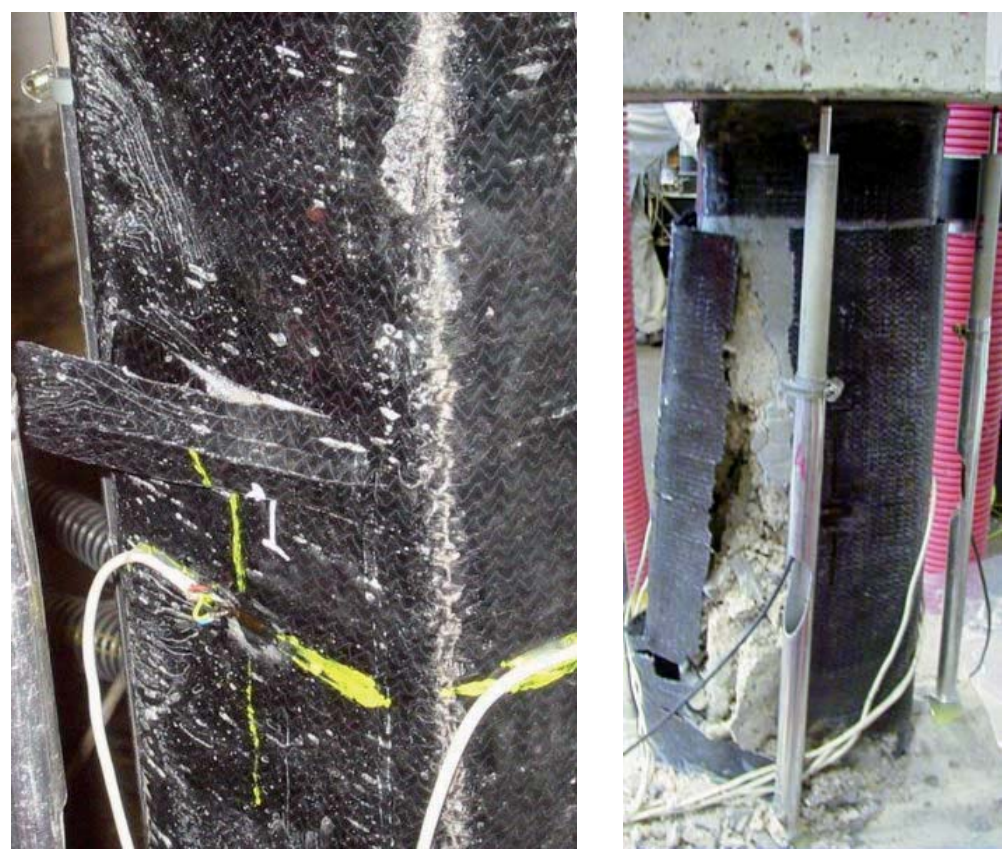

Figura A.6 Rotura de las probetas C_16.3_a y C_16.3_b 

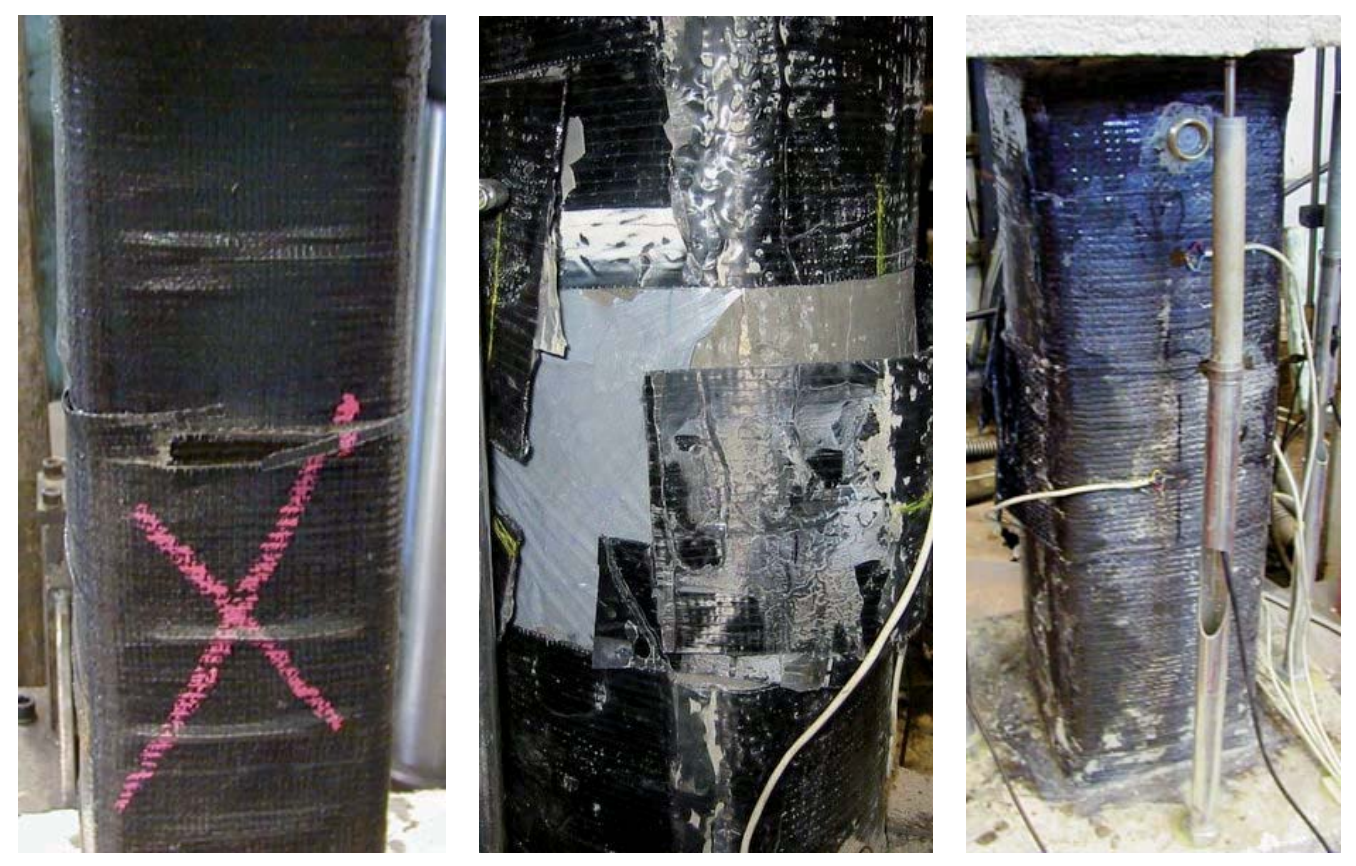

Figura A.7 Rotura de las probetas C_16.5_a, C_16.5_b Y C_16.5_c
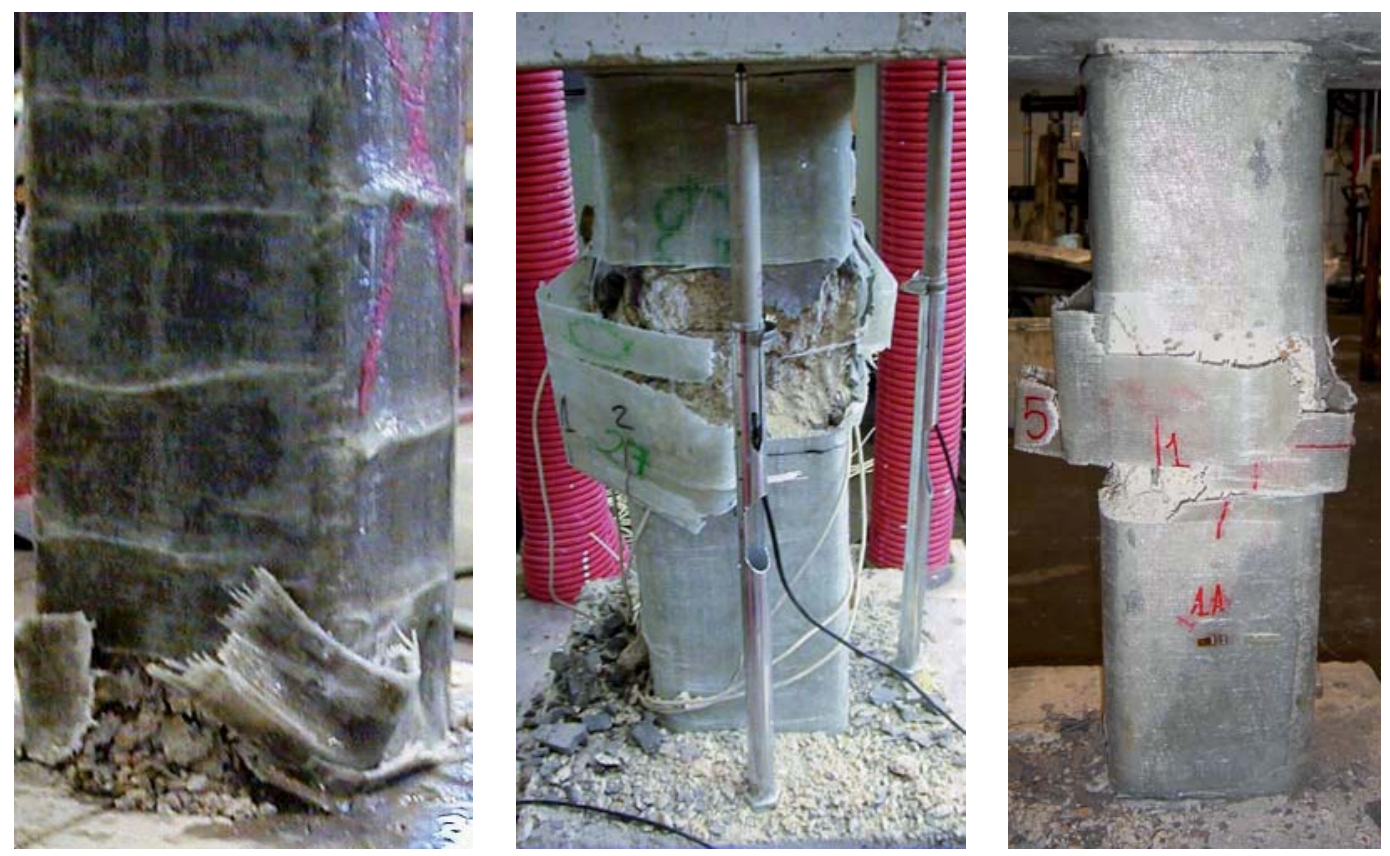

Figura A.8 Rotura de las probetas G_16.5_a, G_16.5_bYG_16.5_c 

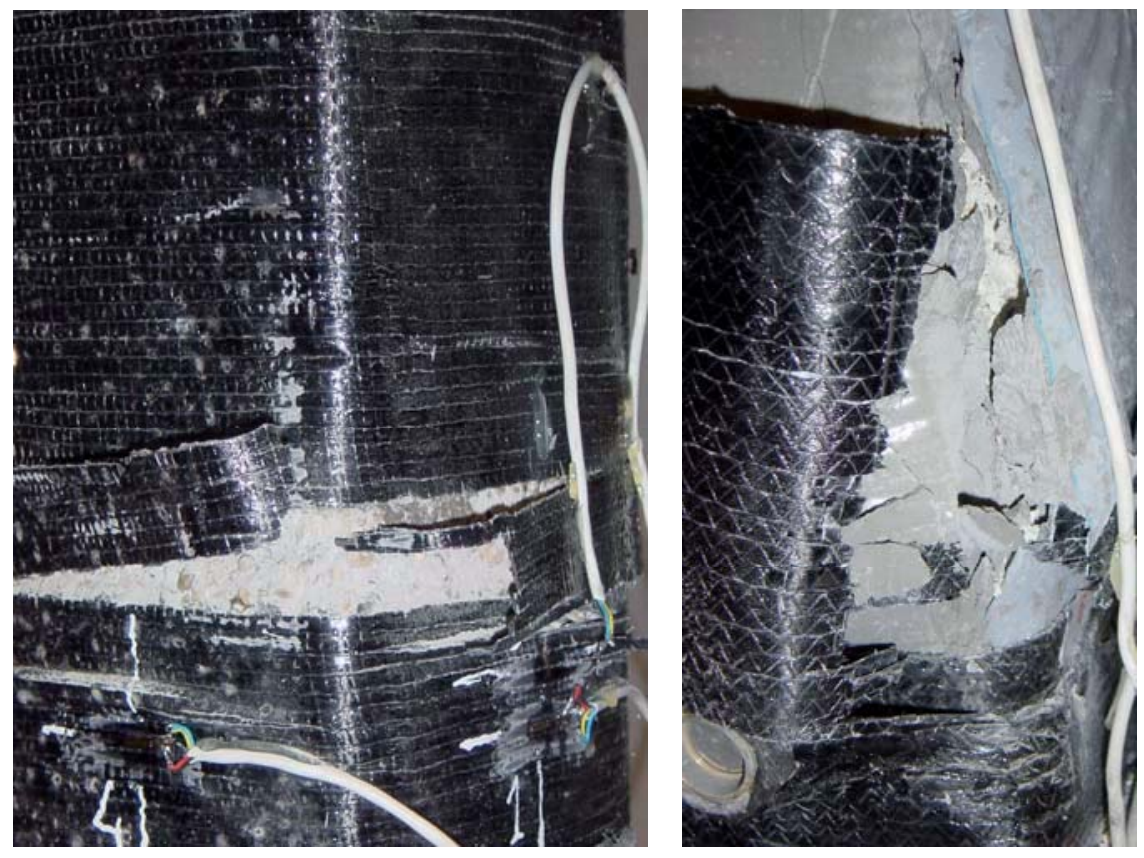

Figura A.9 Rotura de las probetas C_16.7_a y C_16.7_b
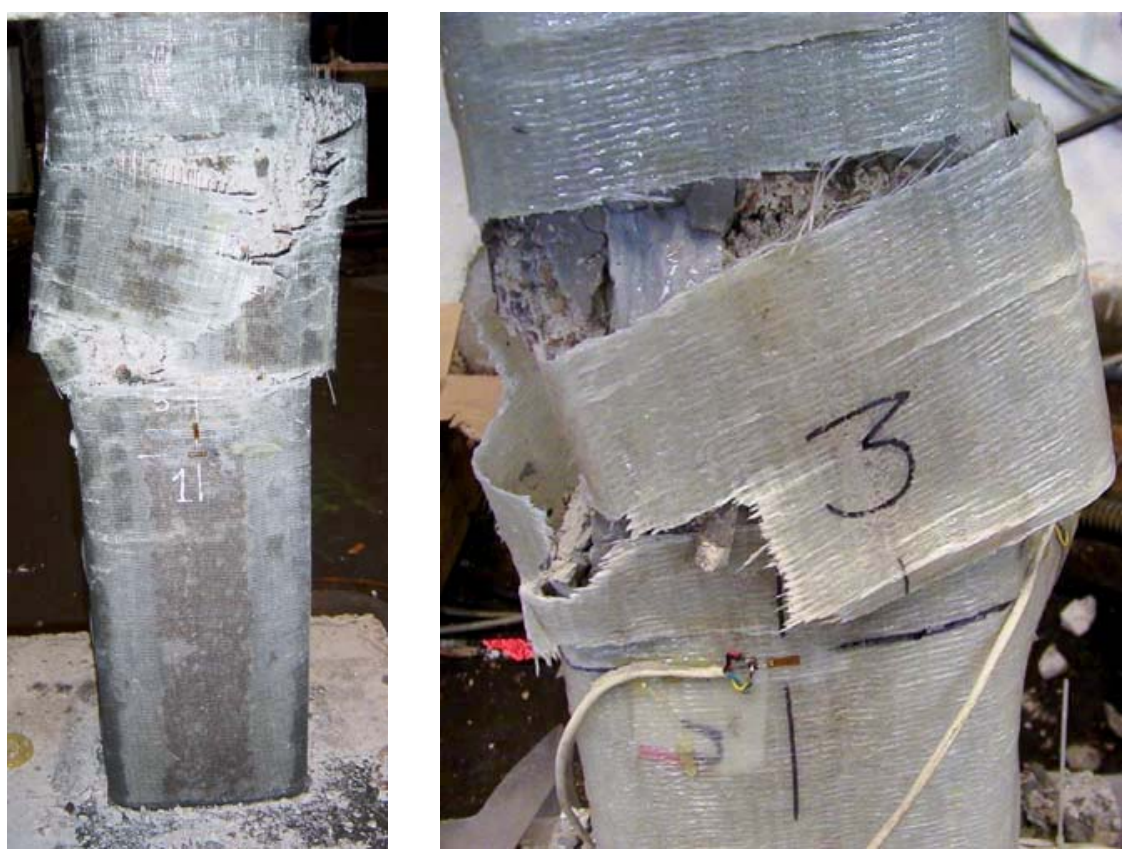

Figura A.10 Rotura de las probetas G_16.7_a y G_16.7_b 

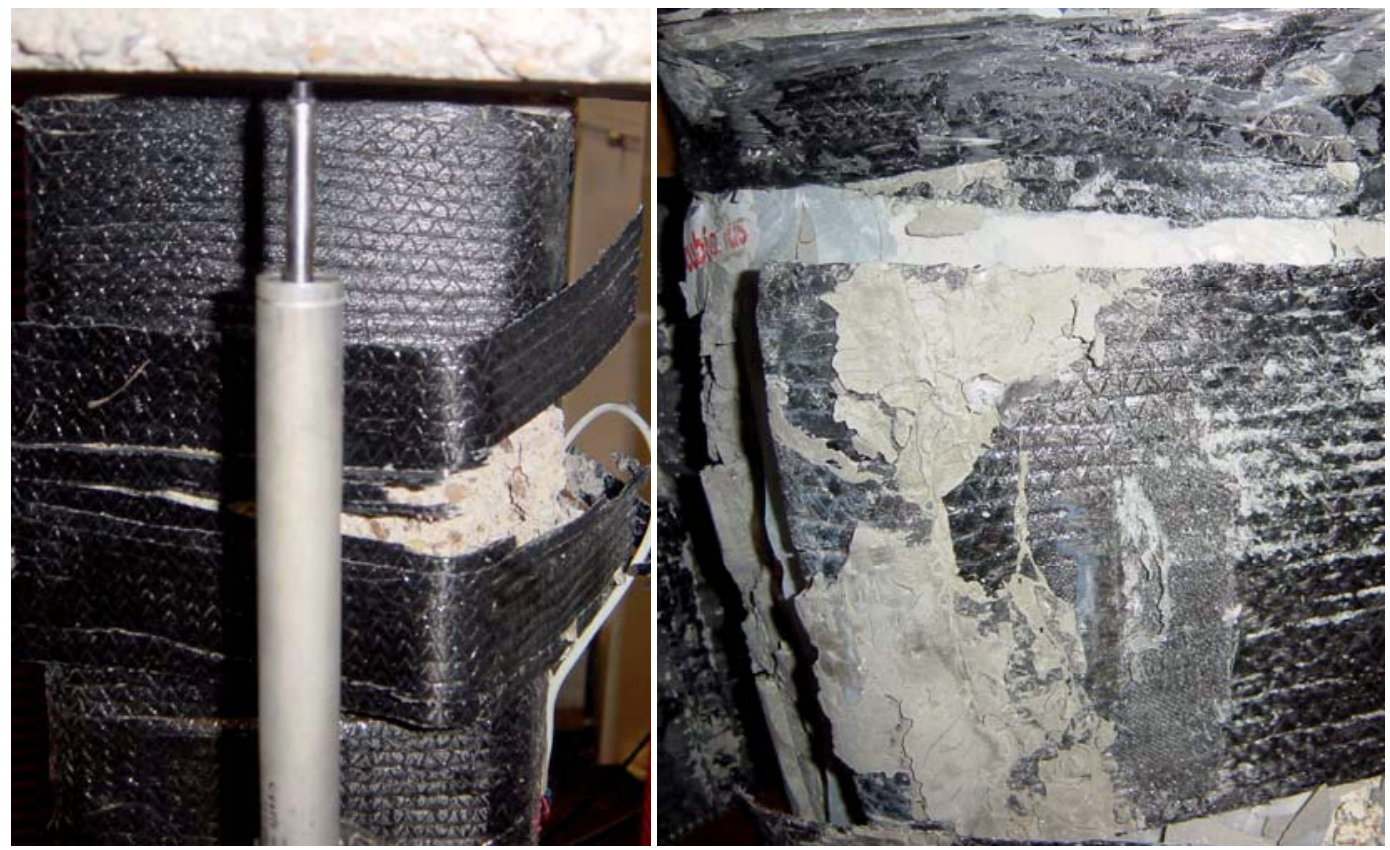

Figura A.11 Rotura de las probetas C_17.5_a y C_17.5_b
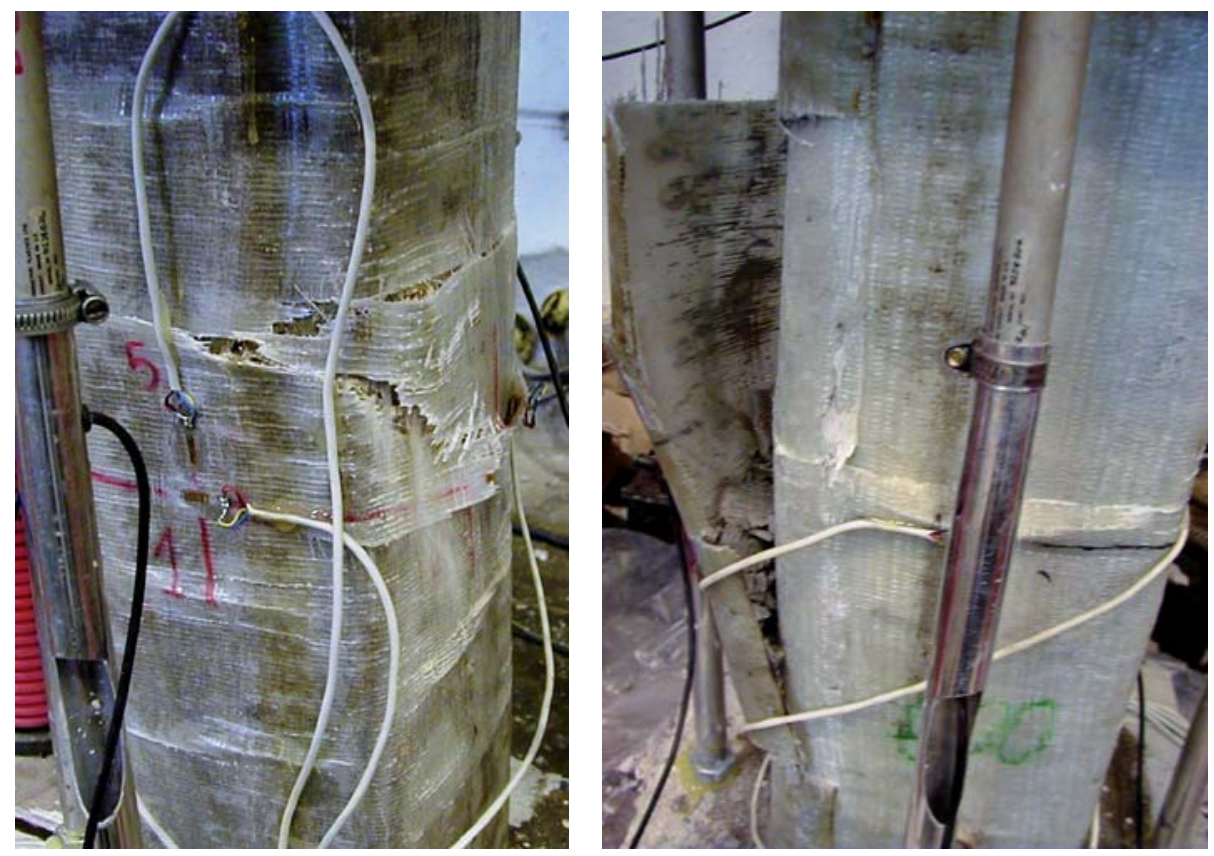

Figura A.12 Rotura de las probetas G_17.5_a y G_17.5_b 

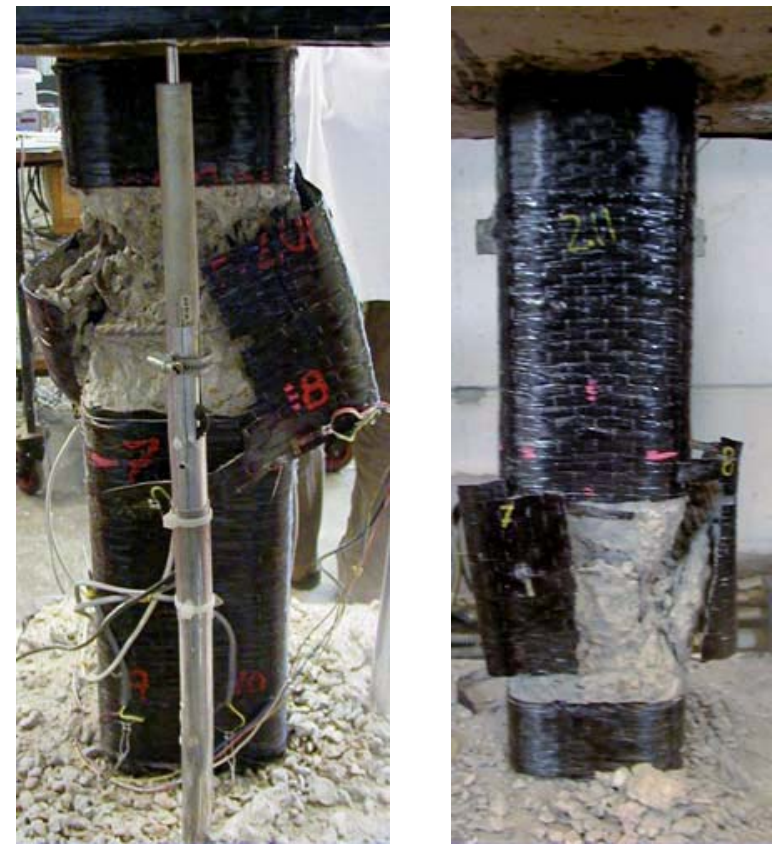

Figura A.13 Rotura de las probetas C_26.4_a y C_26.4_b

\section{A.2.2 Gráficos carga-deformación}

La deformación axial se ha medido con 4 captadores de desplazamiento (designados 1, 2, 3 y 4) situados entre los capiteles como se ha indicado en el apartado 3.6. La deformación lateral se ha medido en la sección central de las probetas con al menos 4 bandas extensométricas (B1, B2, B3 y B4) situadas en el centro de cada cara, y en algunas probetas con una banda adicional (B5) en la zona de la esquina.

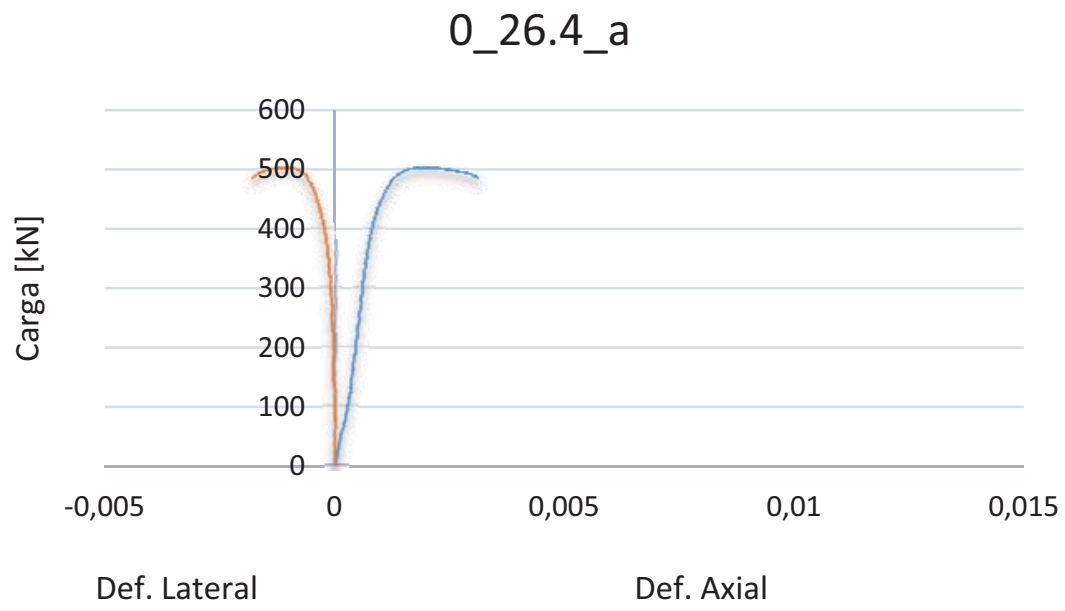

Figura A.14 Curvas carga-deformación en la probeta 0_26.4_a 


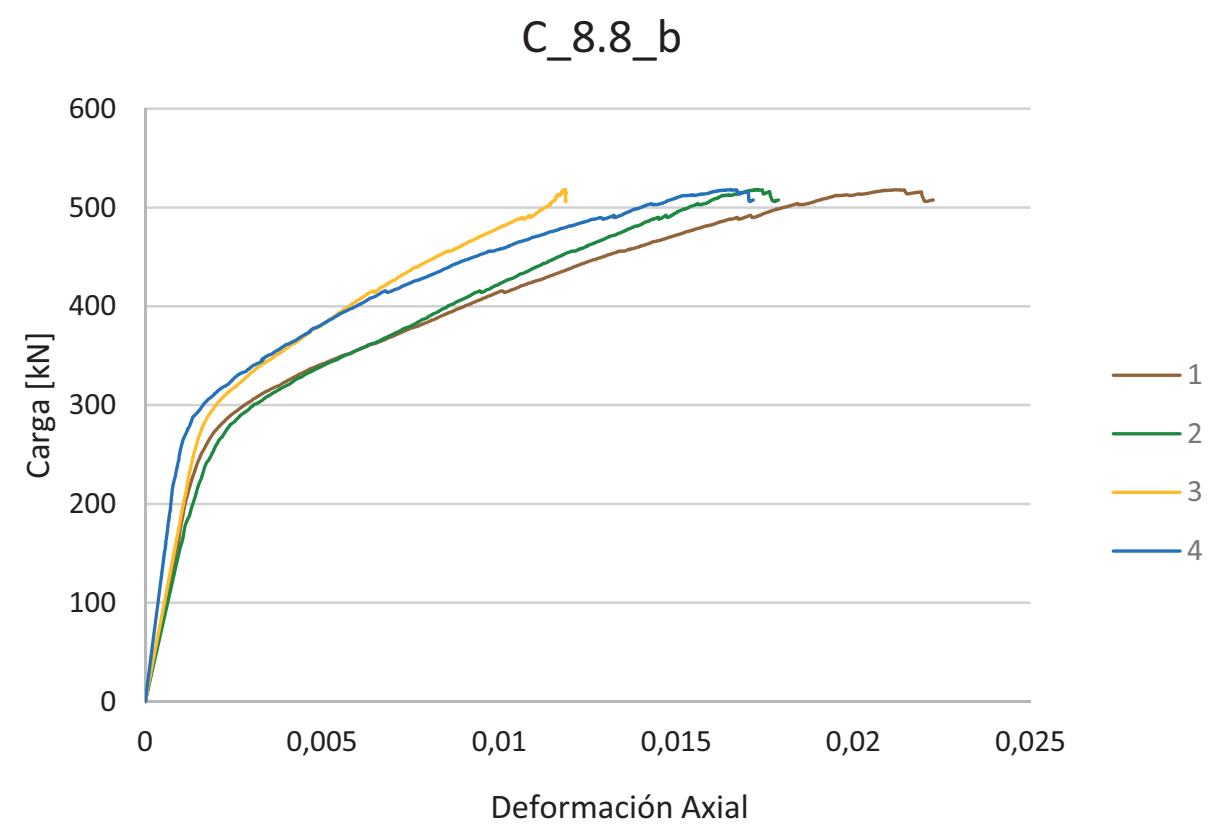

Figura A.15 Curvas carga-deformación axial en la probeta C_8.8_b

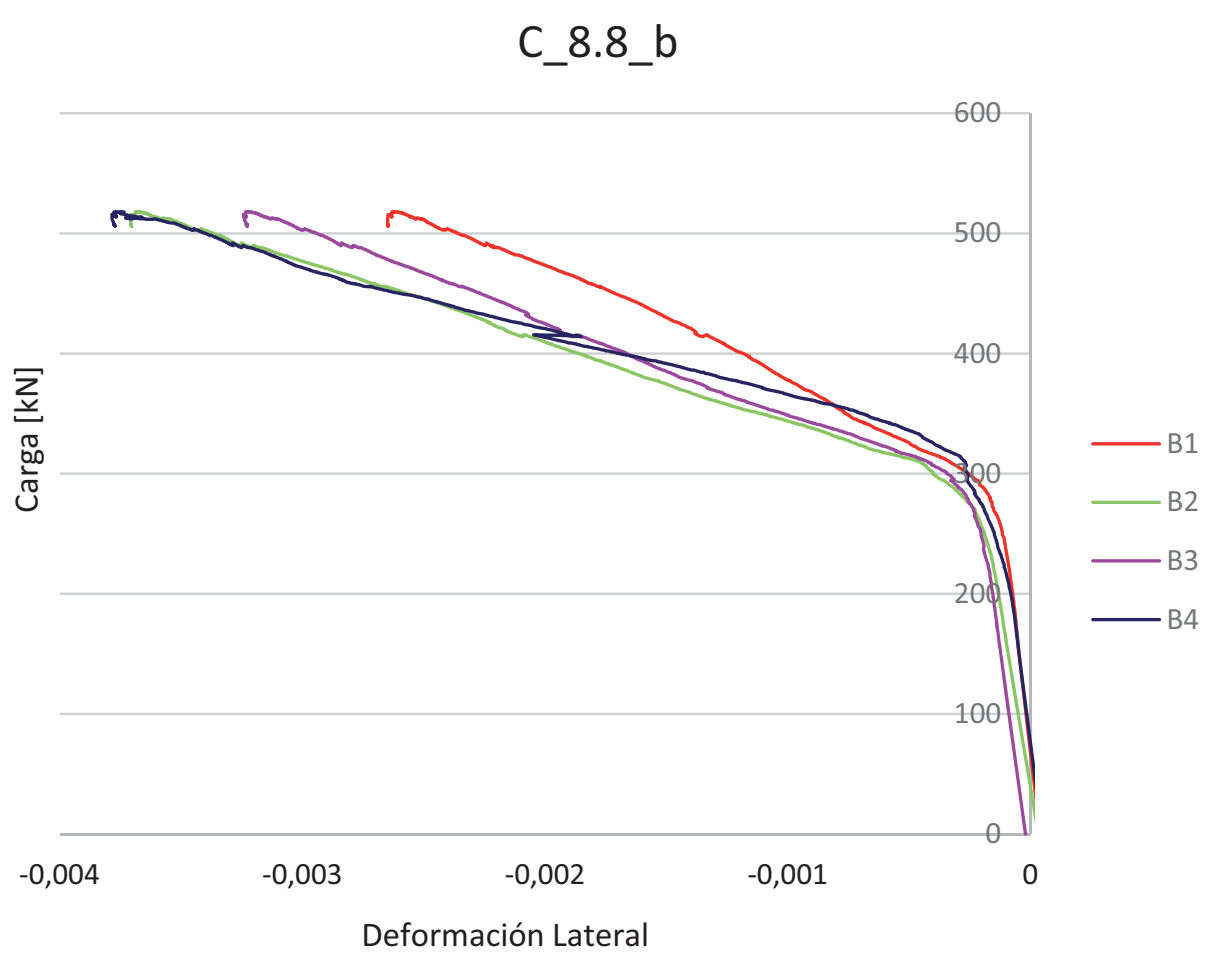

Figura A.16 Curvas carga-deformación lateral en la probeta C_8.8_b 


\section{G_8.8_b}

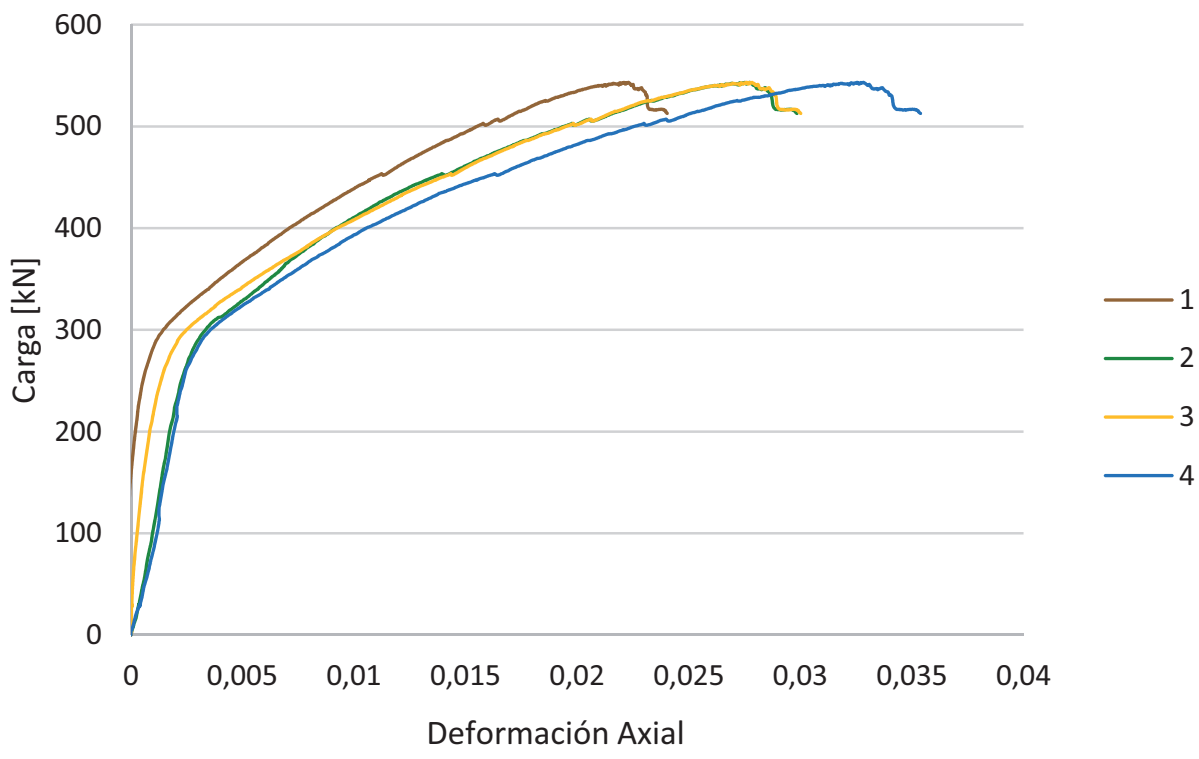

Figura A.17 Curvas carga-deformación axial en la probeta G_8.8_b

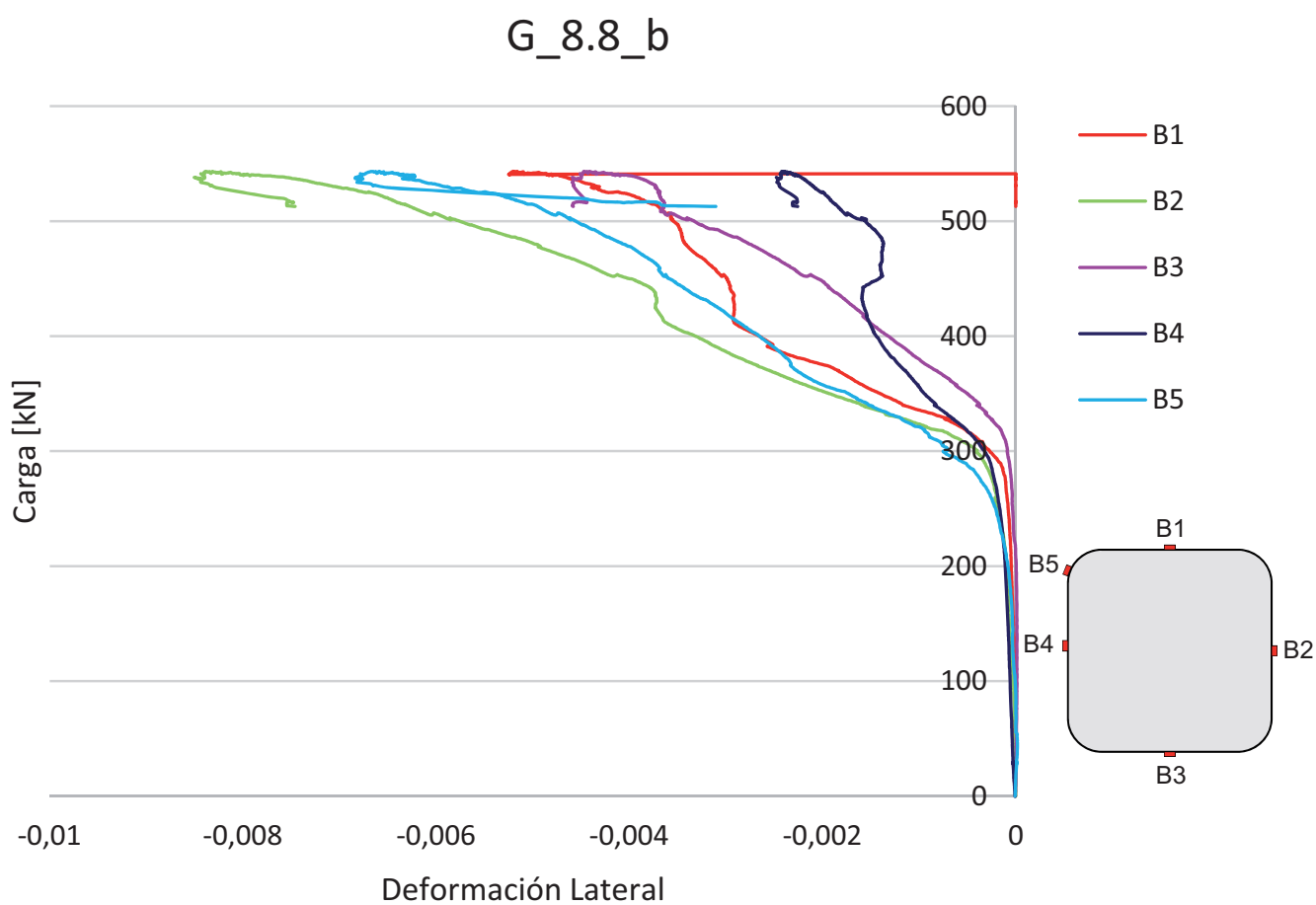

Figura A.18 Curvas carga-deformación lateral en la probeta G_8.8_b 


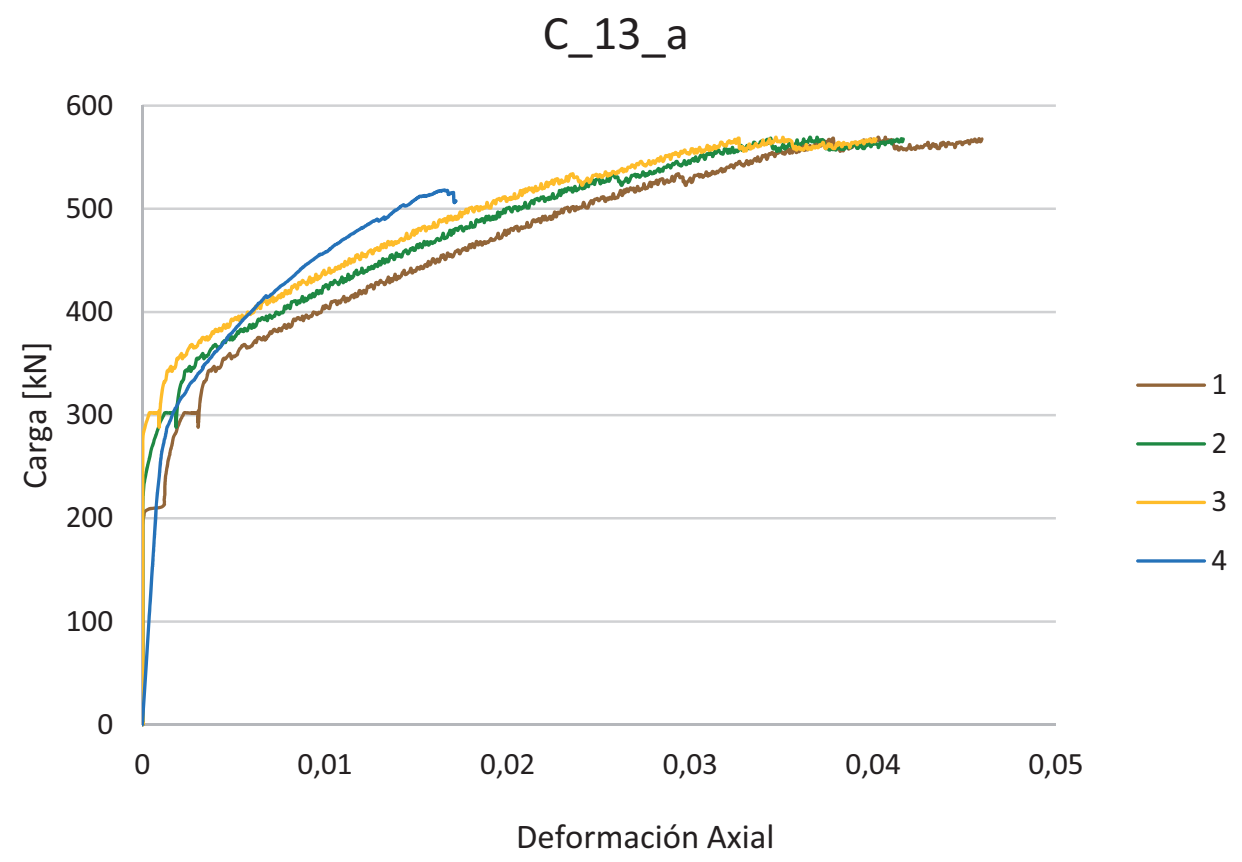

Figura A.19 Curvas carga-deformación axial en la probeta C_13_a

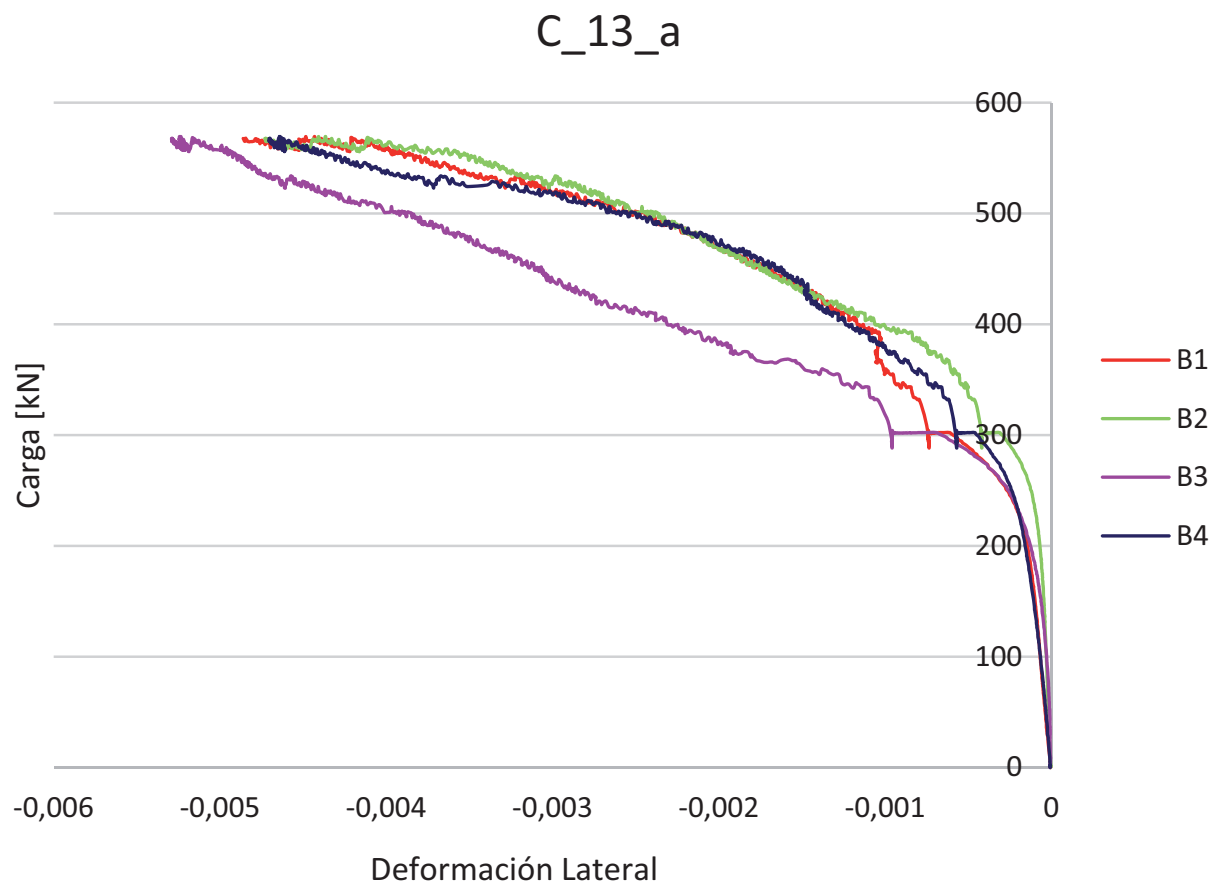

Figura A.20 Curvas carga-deformación lateral en la probeta C_13_a 


\section{C_13_b}

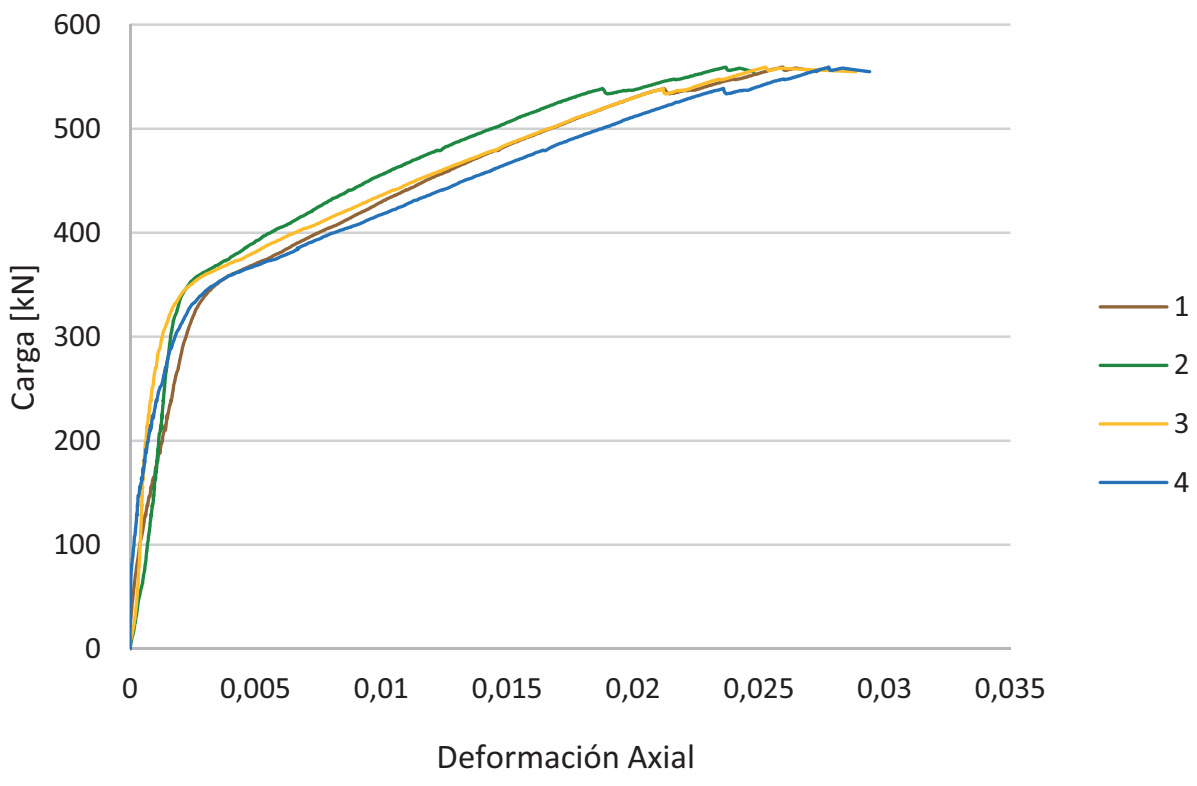

Figura A.21 Curvas carga-deformación axial en la probeta C_13_b

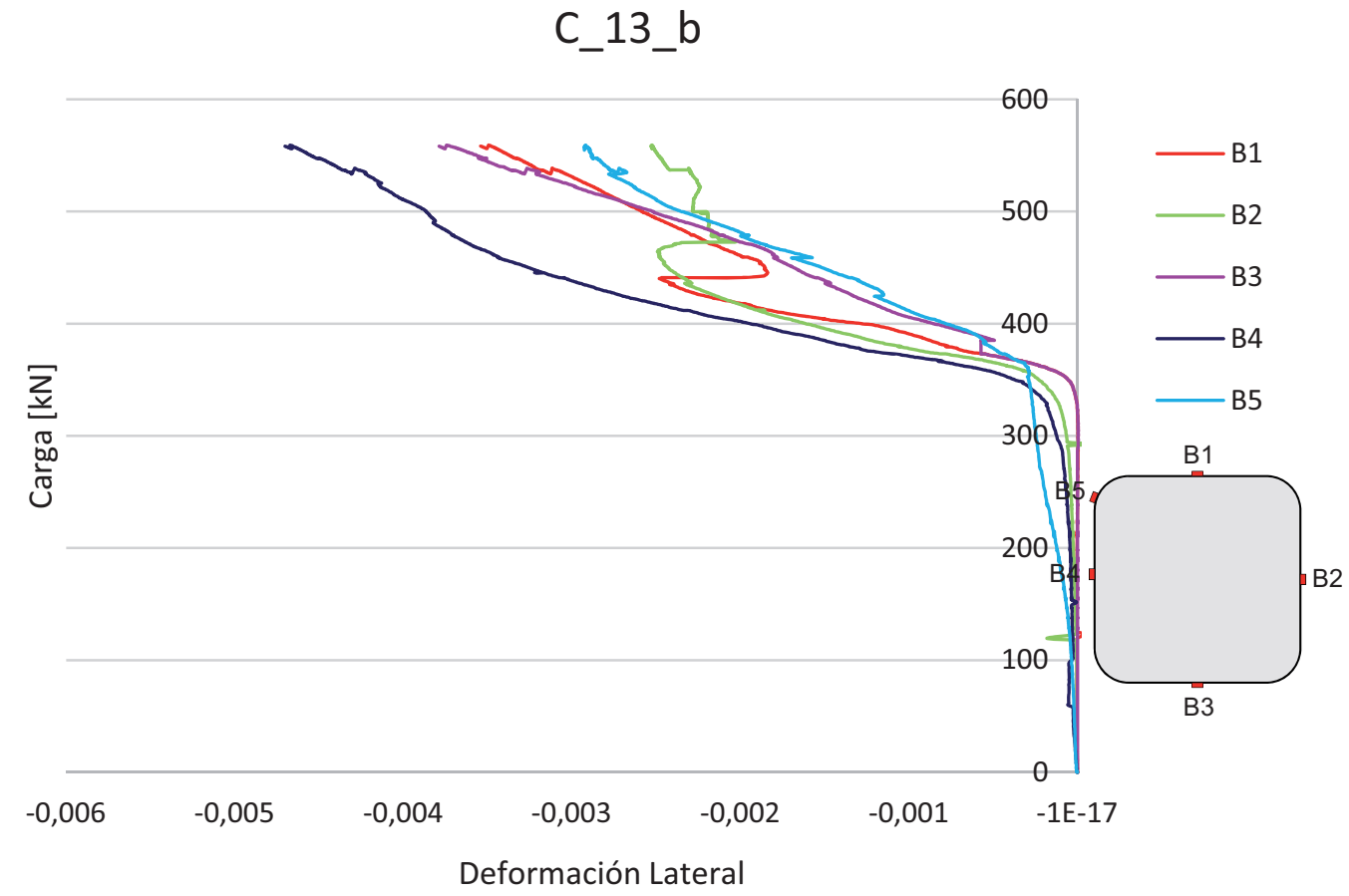

Figura A.22 Curvas carga-deformación lateral en la probeta C_13_b 


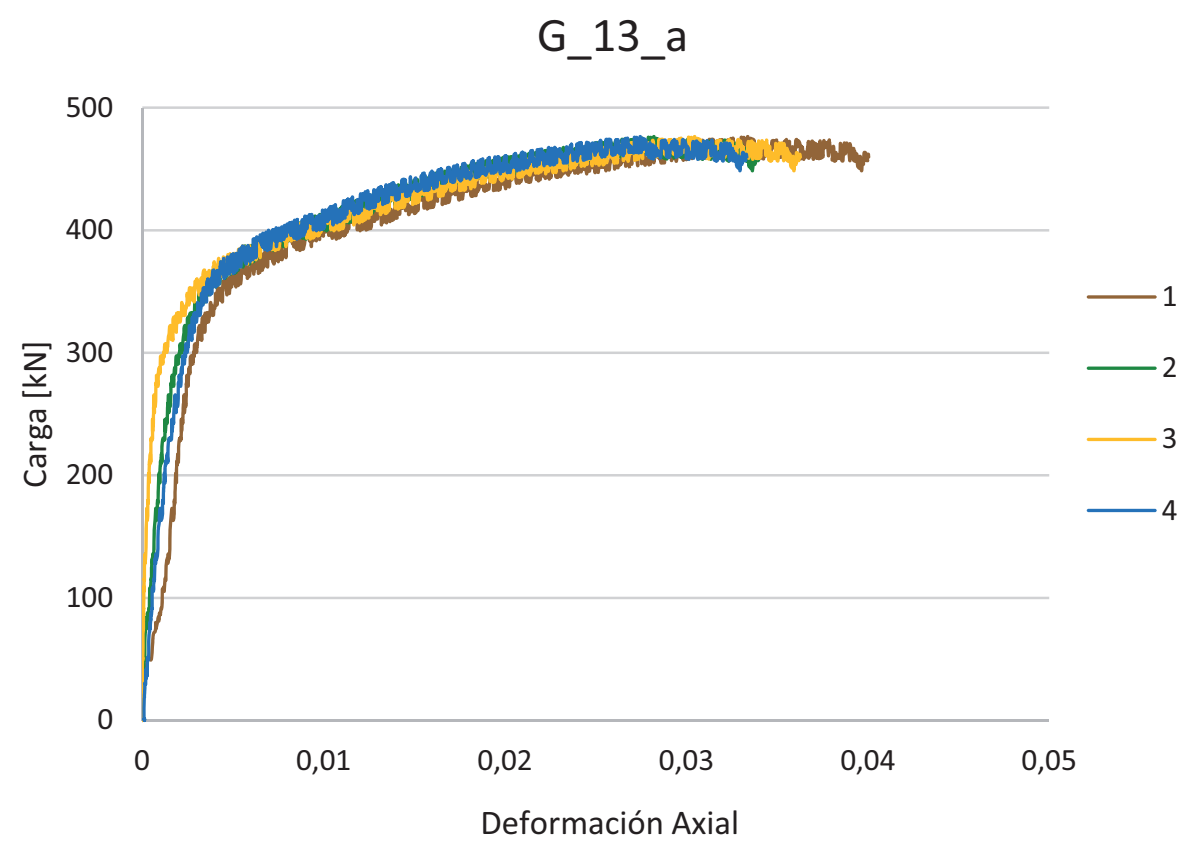

Figura A.23 Curvas carga-deformación axial en la probeta G_13_a

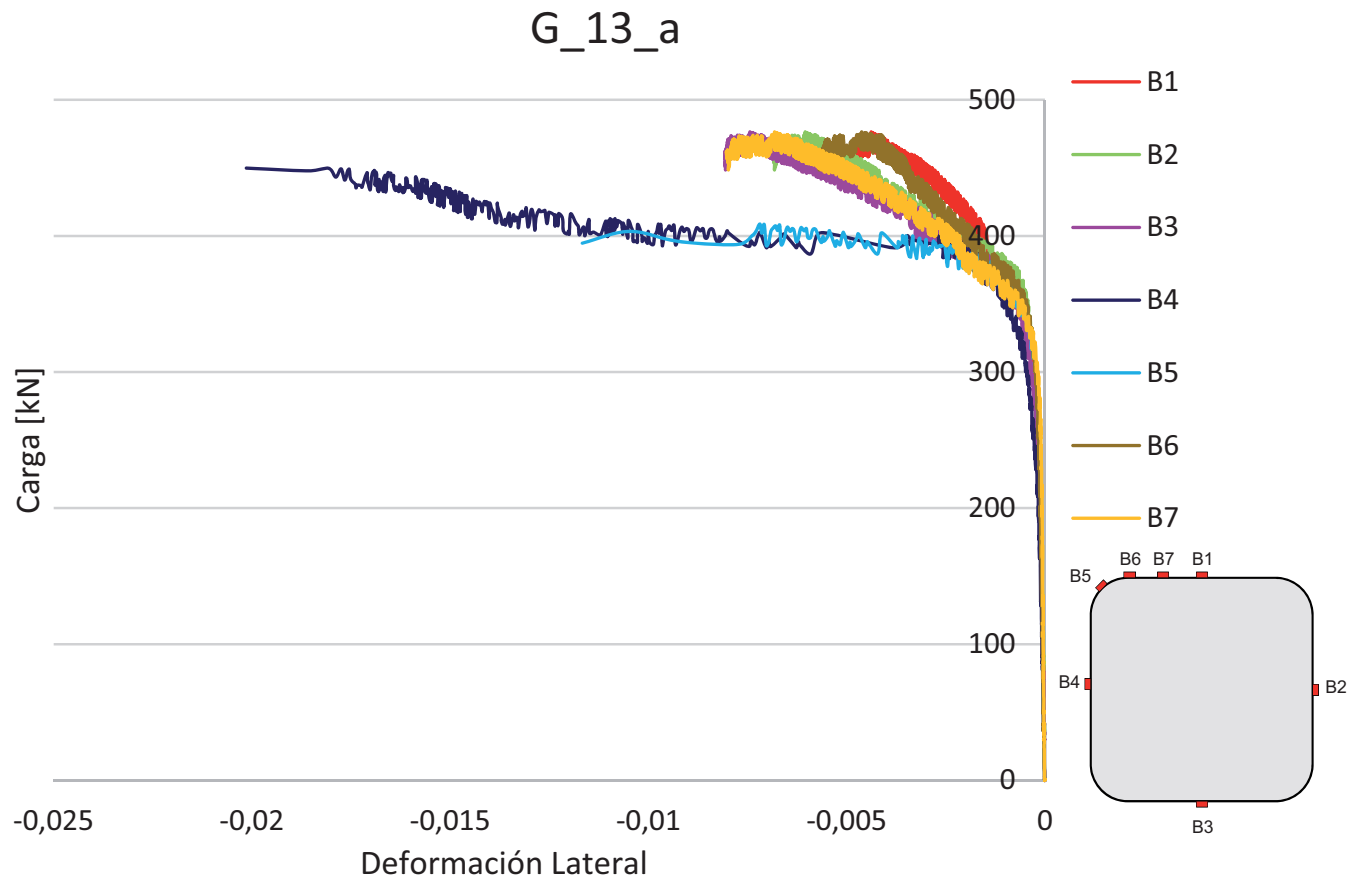

Figura A.24 Curvas carga-deformación lateral en la probeta G_13_a 
G_13_b

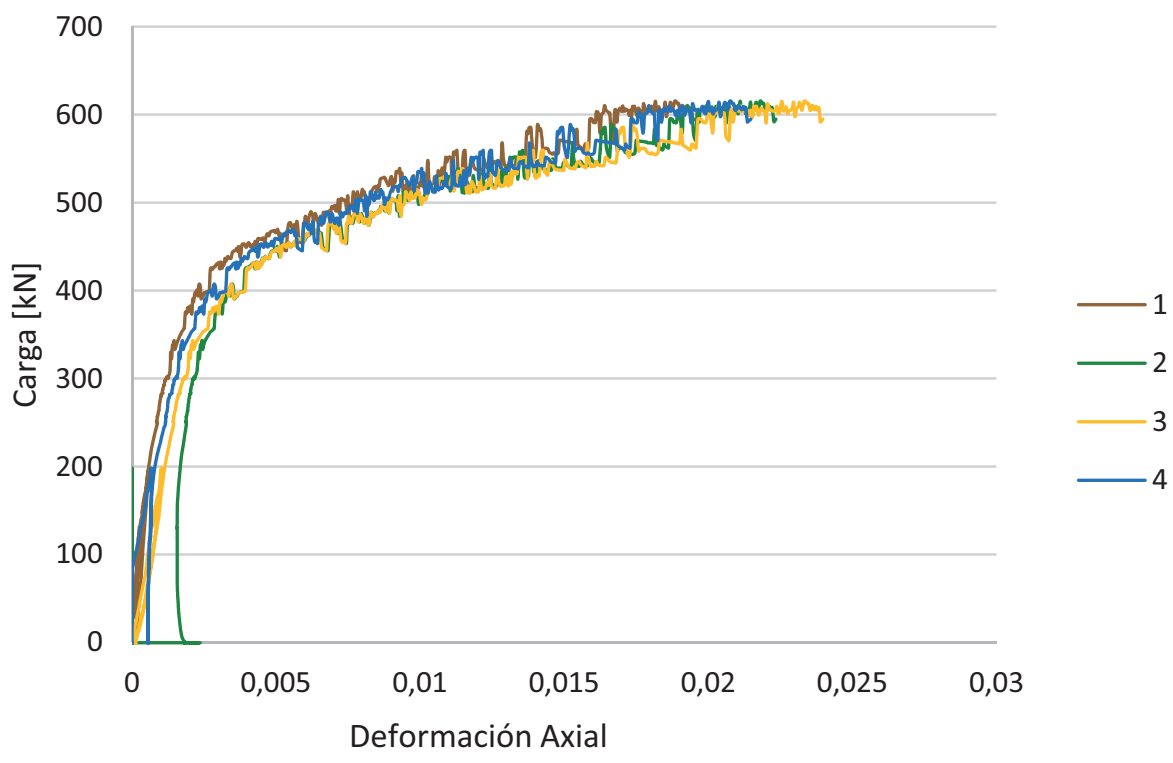

Figura A.25 Curvas carga-deformación axial en la probeta G_13_b

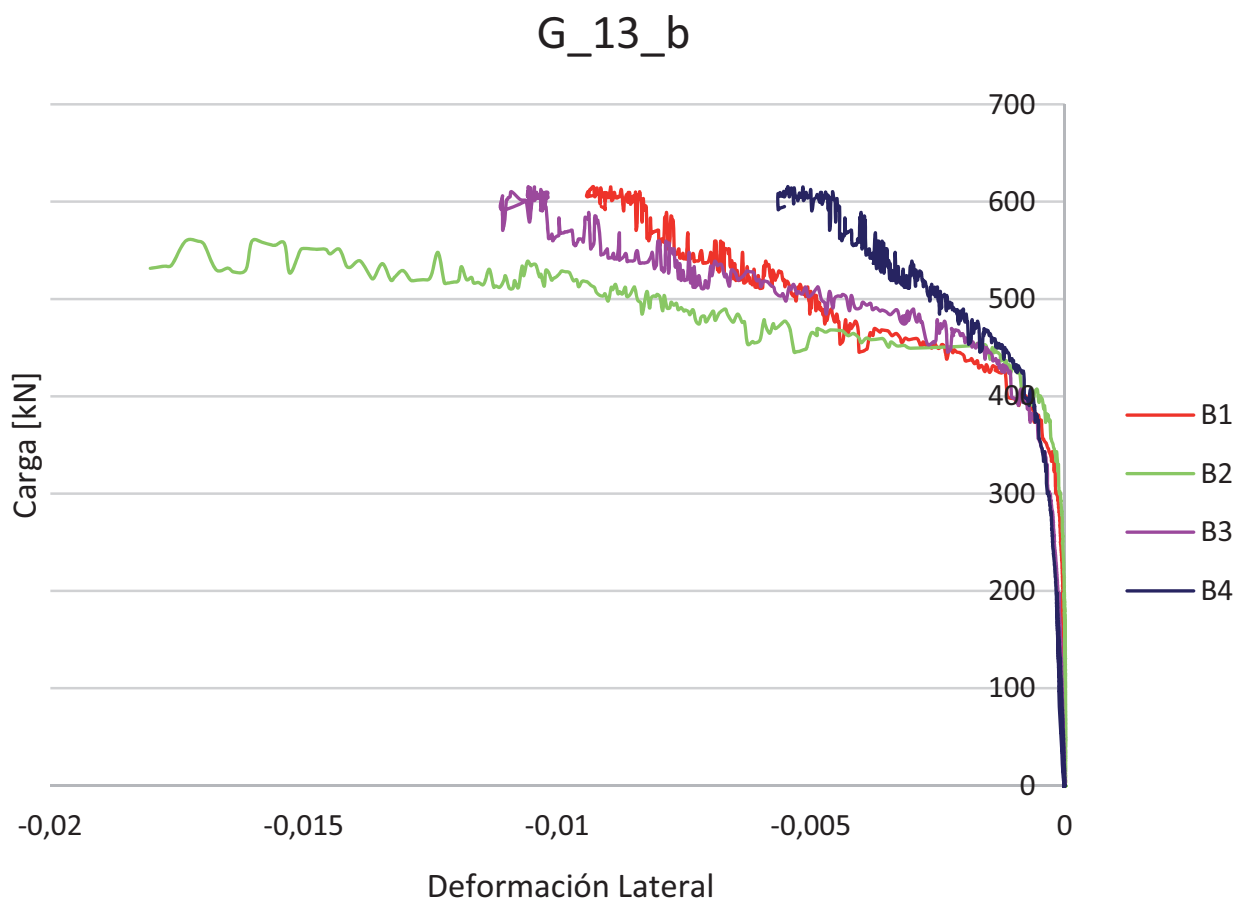

Figura A.26 Curvas carga-deformación lateral en la probeta G_13_b 


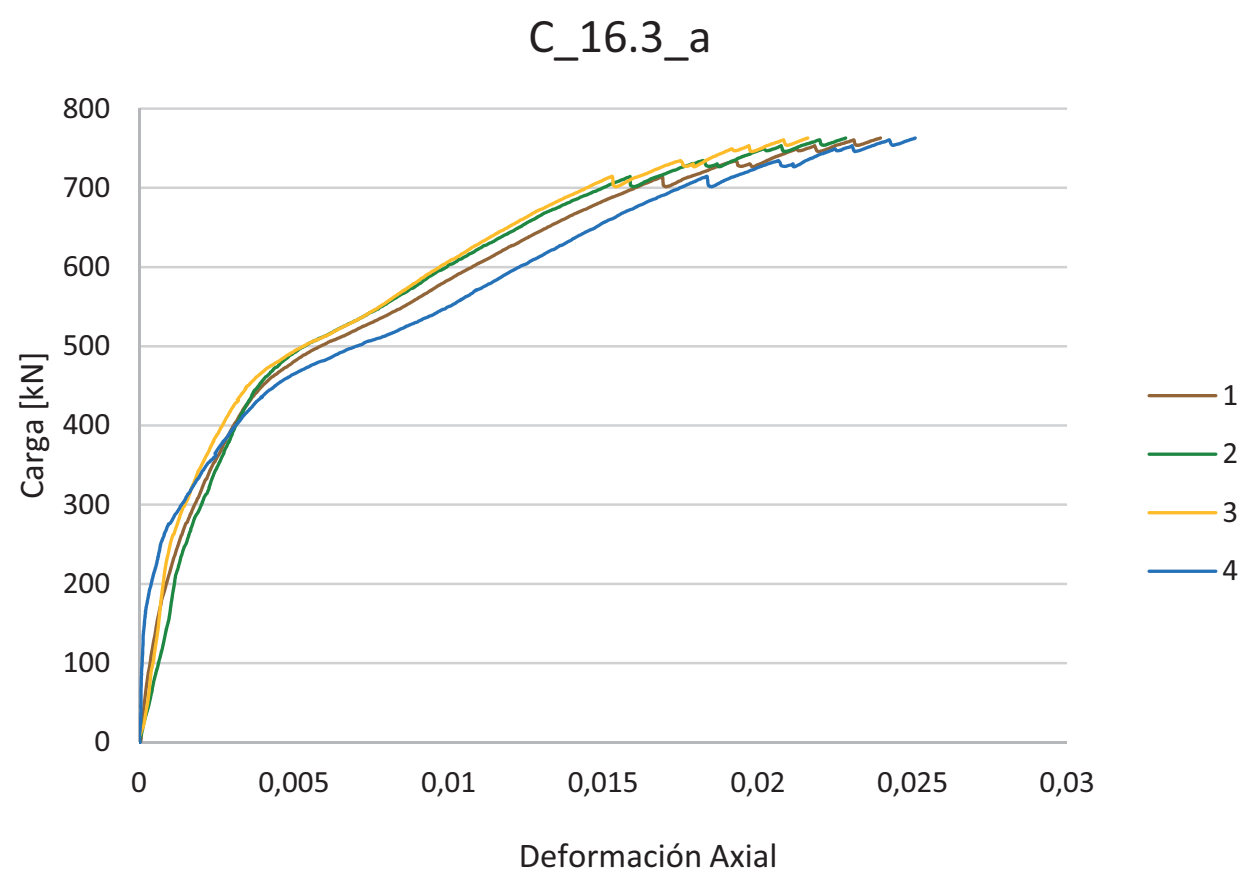

Figura A.27 Curvas carga-deformación axial en la probeta C_16.3_a

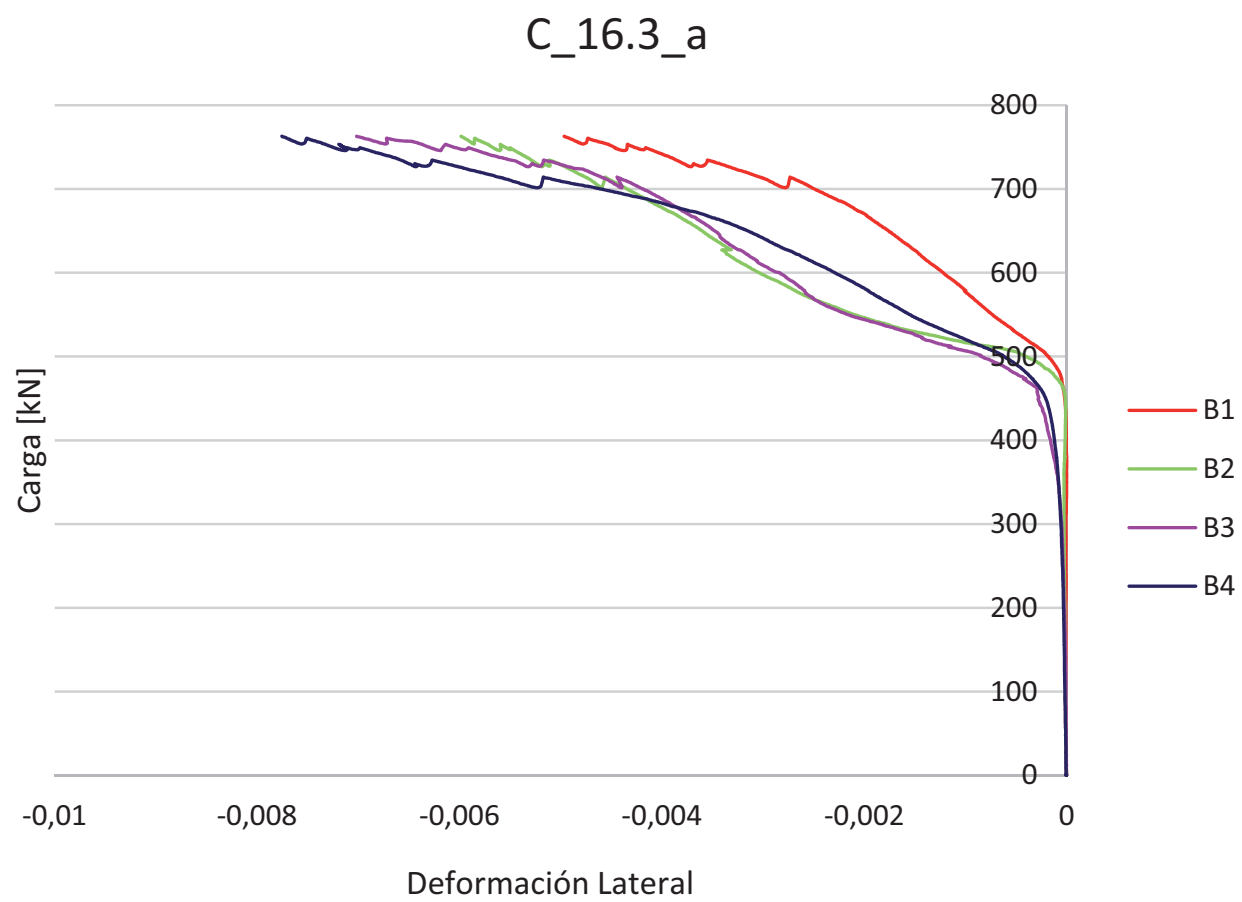

Figura A.28 Curvas carga-deformación lateral en la probeta C_16.3_a 


\section{C_16.3_b}

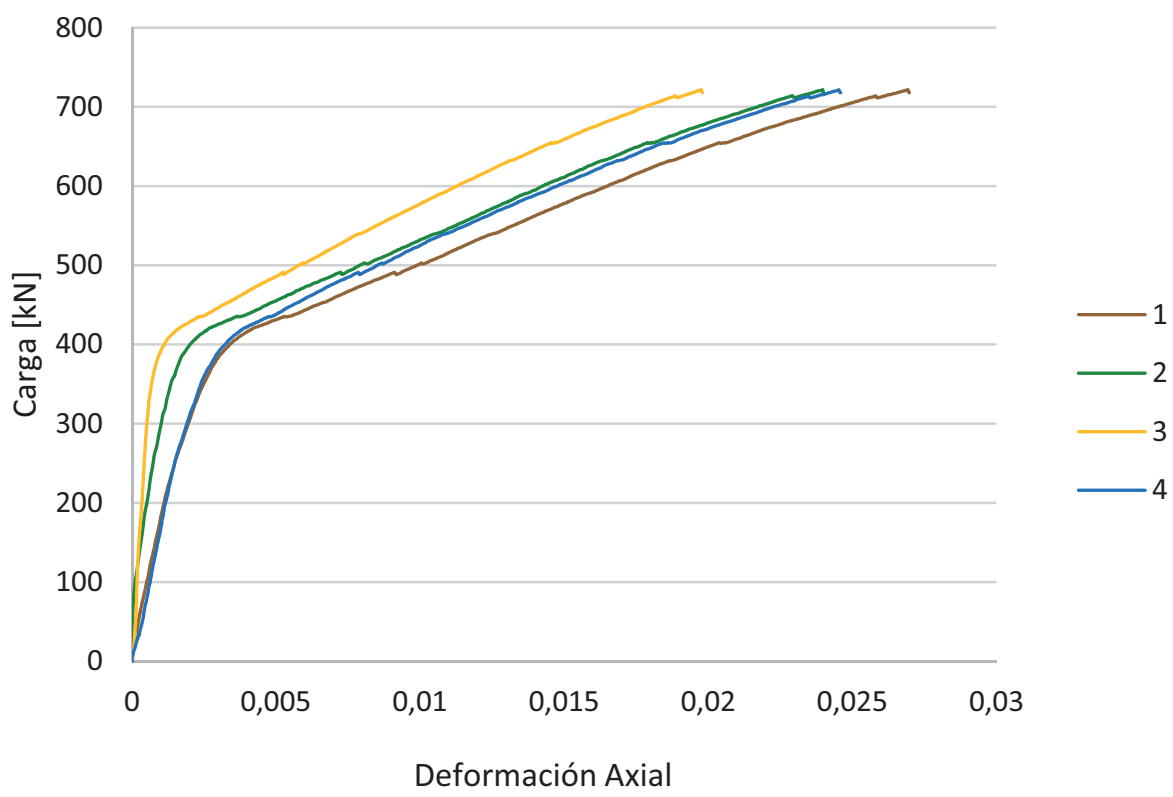

Figura A.29 Curvas carga-deformación axial en la probeta C_16.3_b

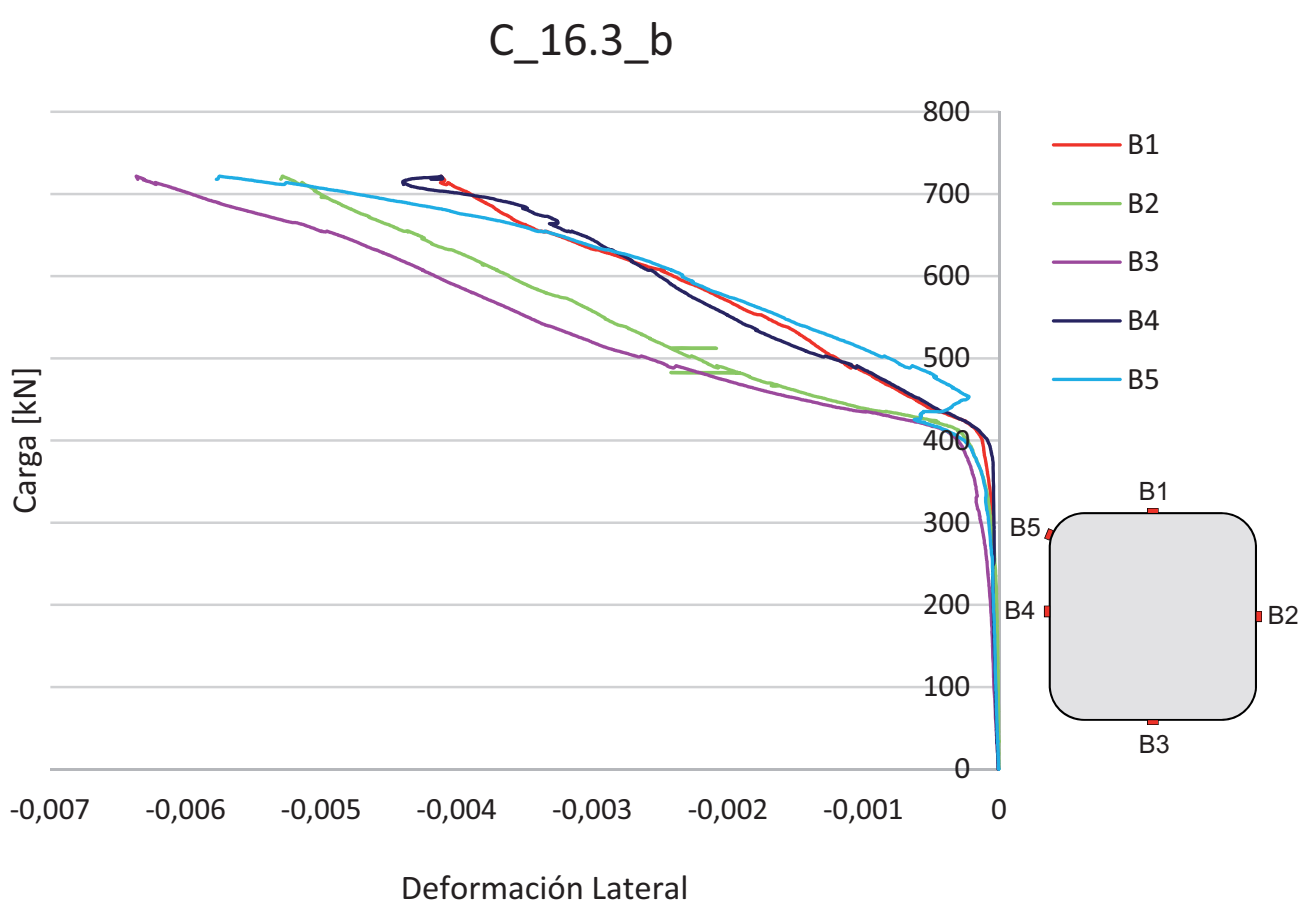

Figura A.30 Curvas carga-deformación lateral en la probeta C_16.3_b 


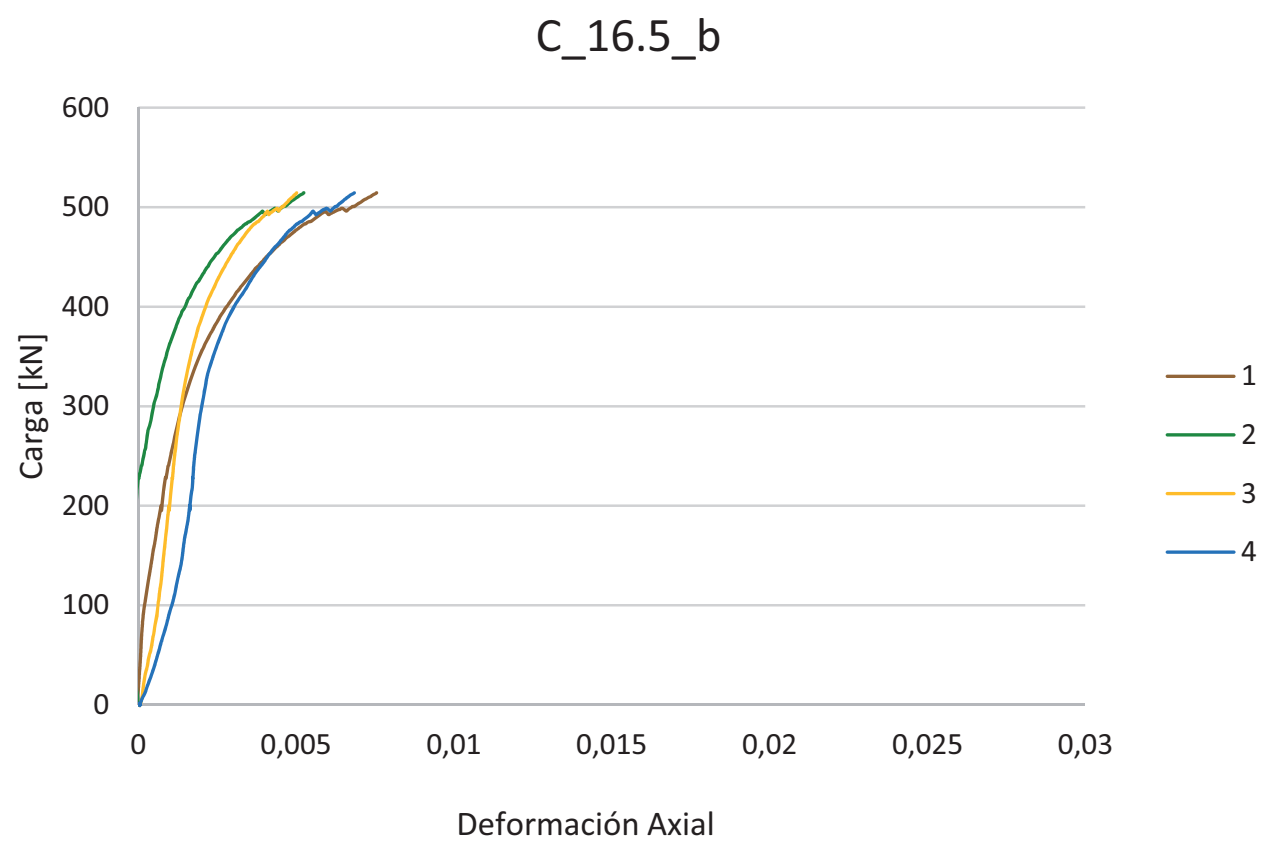

Figura A.31 Curvas carga-deformación axial en la probeta C_16.5_b

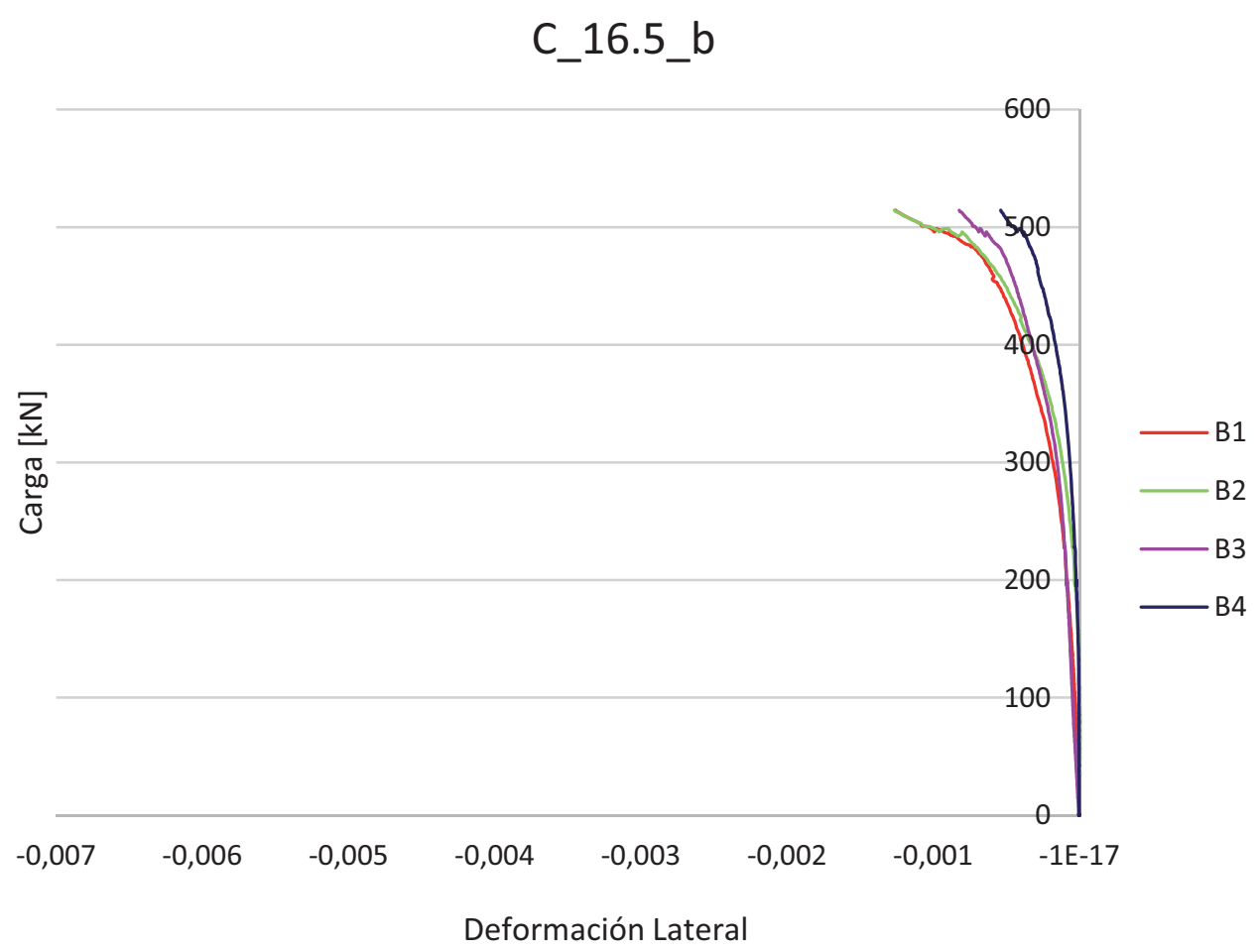

Figura A.32 Curvas carga-deformación lateral en la probeta $C \_16.5 \_b$ 


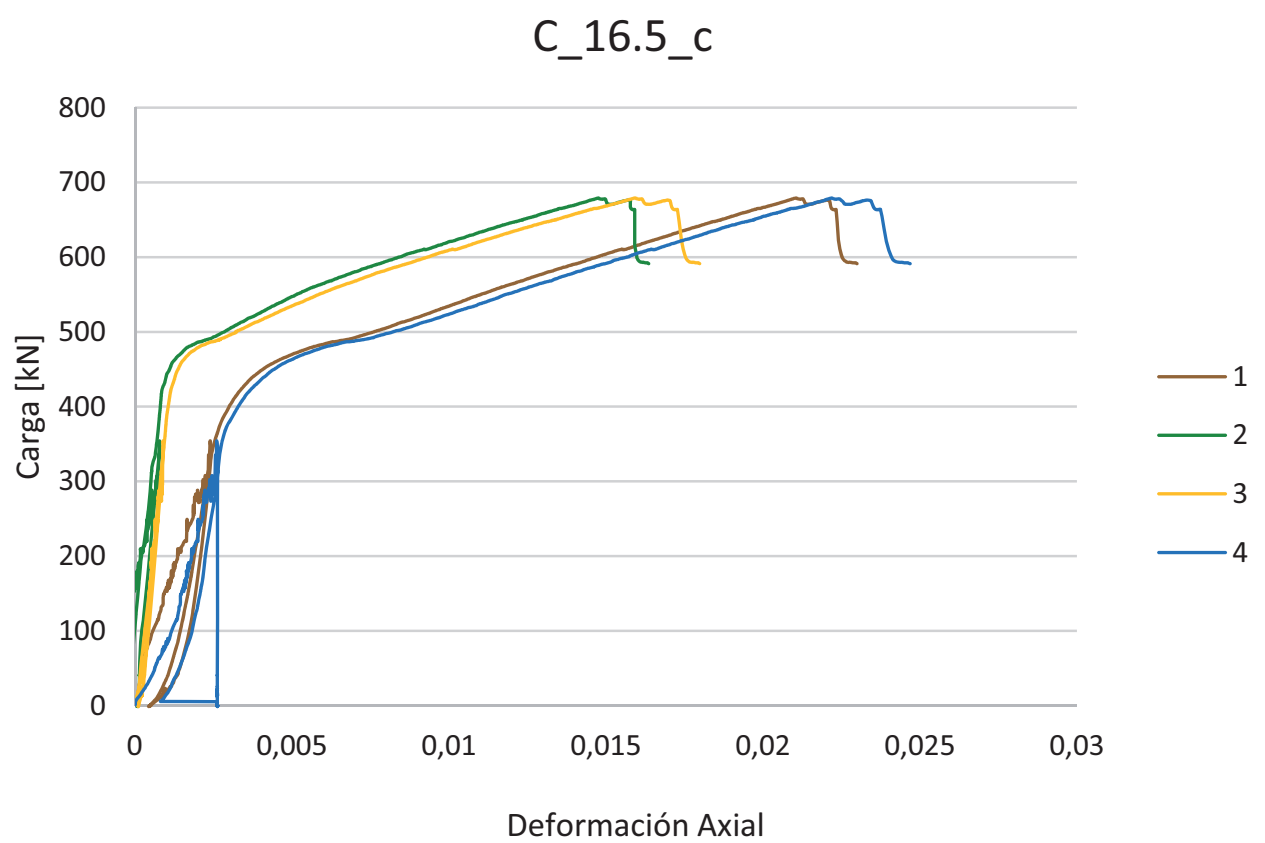

Figura A.33 Curvas carga-deformación axial en la probeta $C \_16.5 \_c$

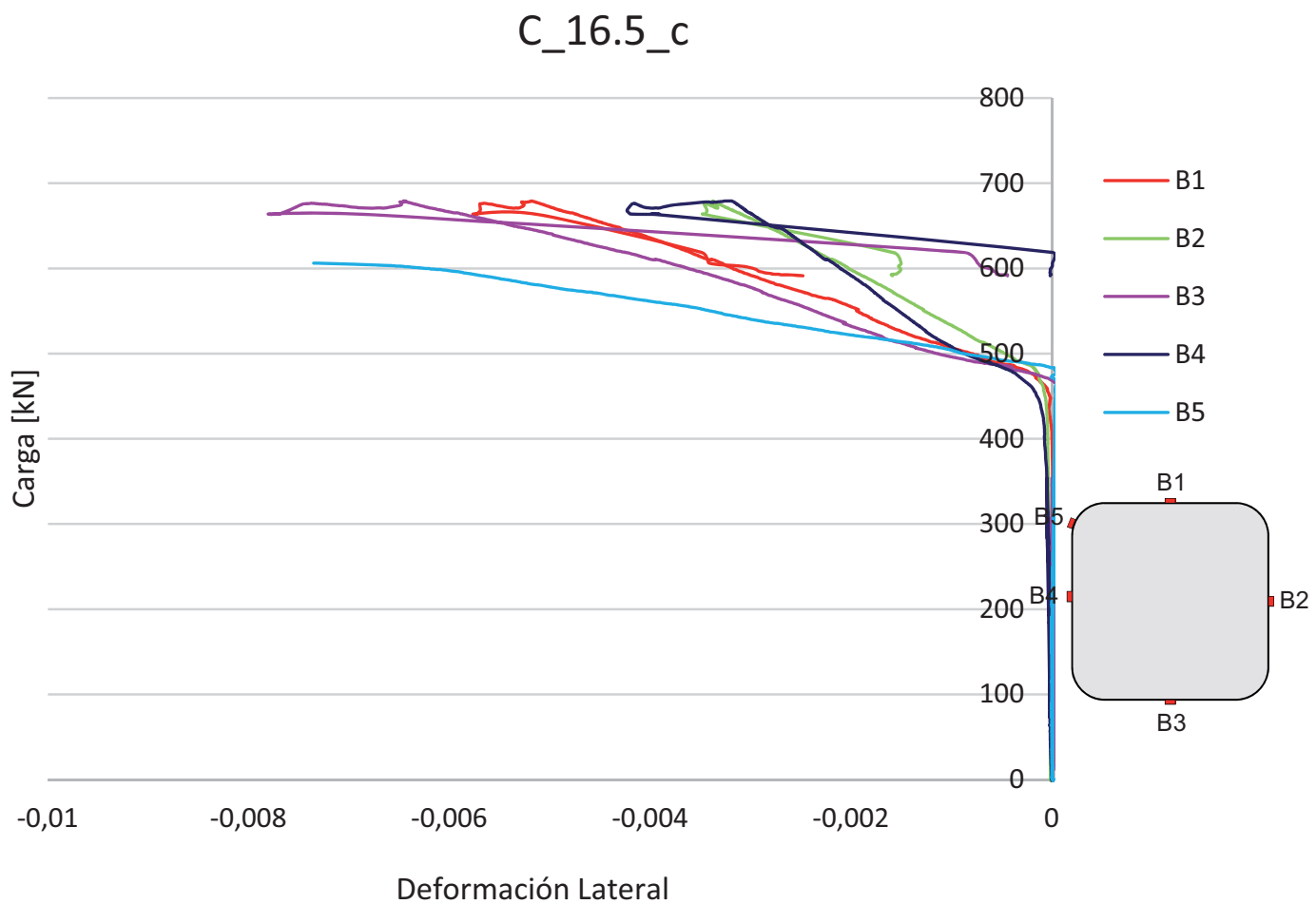

Figura A.34 Curvas carga-deformación lateral en la probeta C_16.5_c 


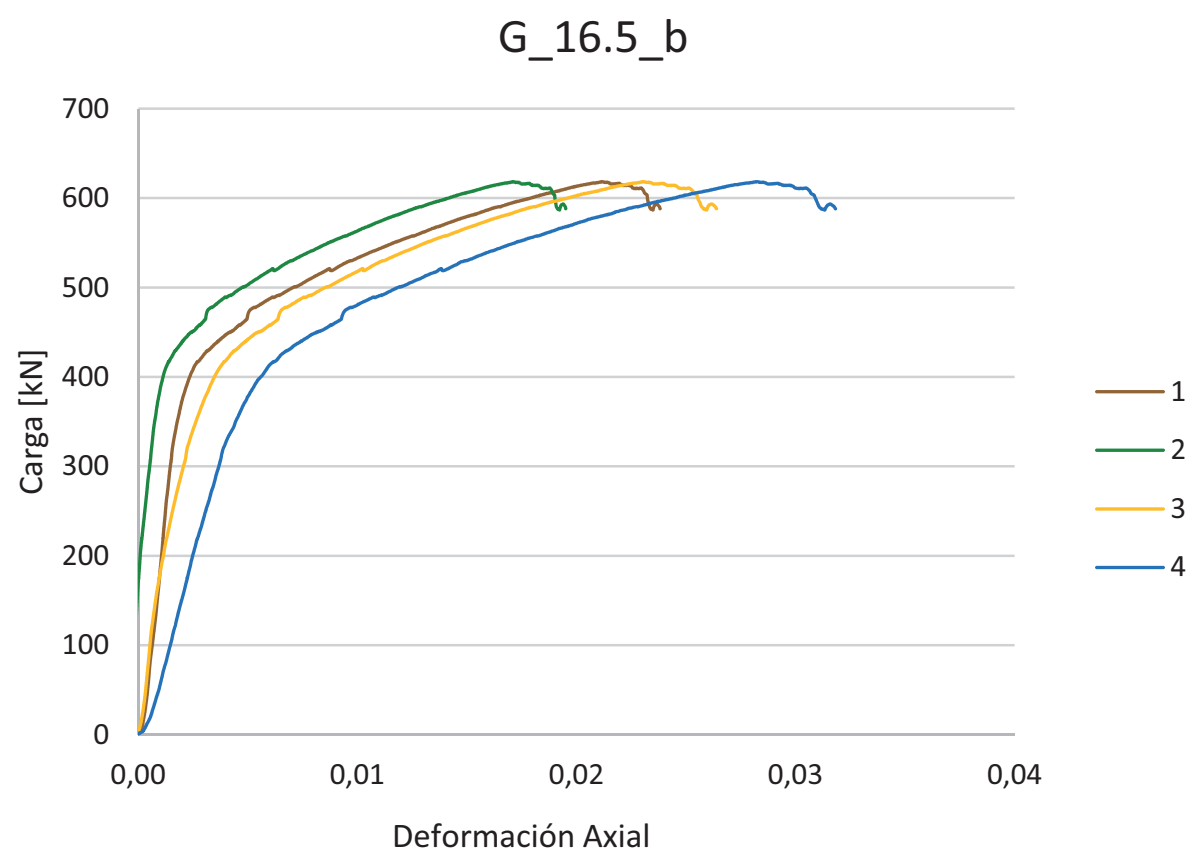

Figura A.35 Curvas carga-deformación axial en la probeta G_16.5_b

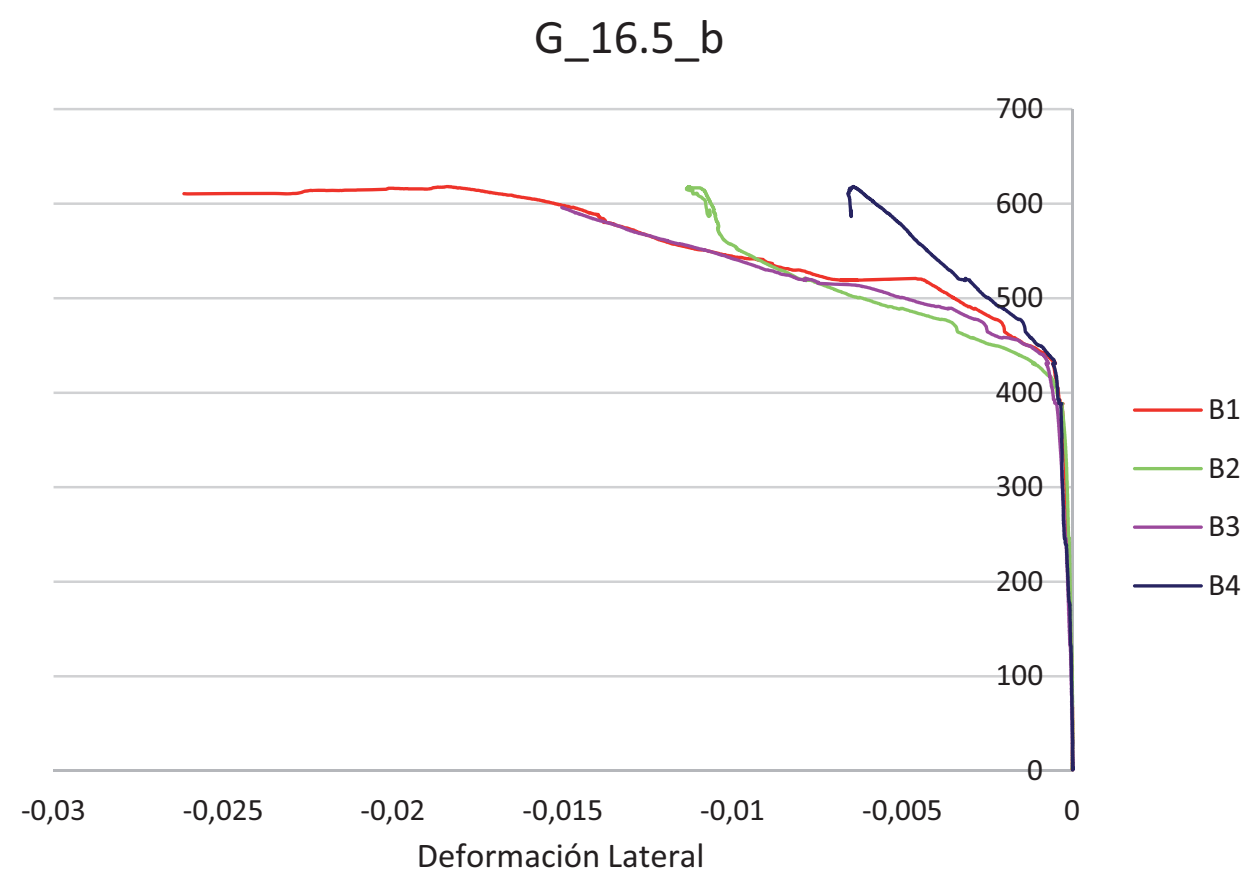

Figura A.36 Curvas carga-deformación lateral en la probeta G_16.5_b 


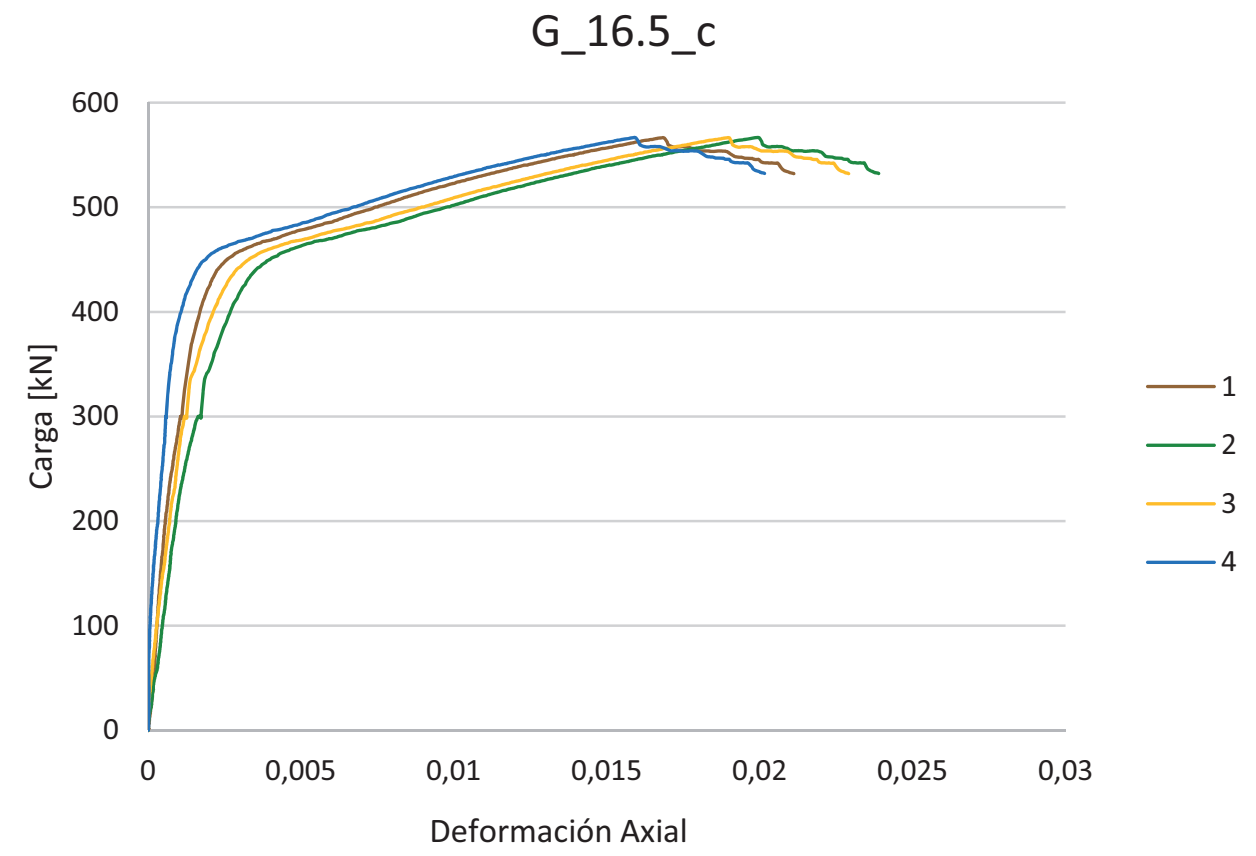

Figura A.37 Curvas carga-deformación axial en la probeta G_16.5_c

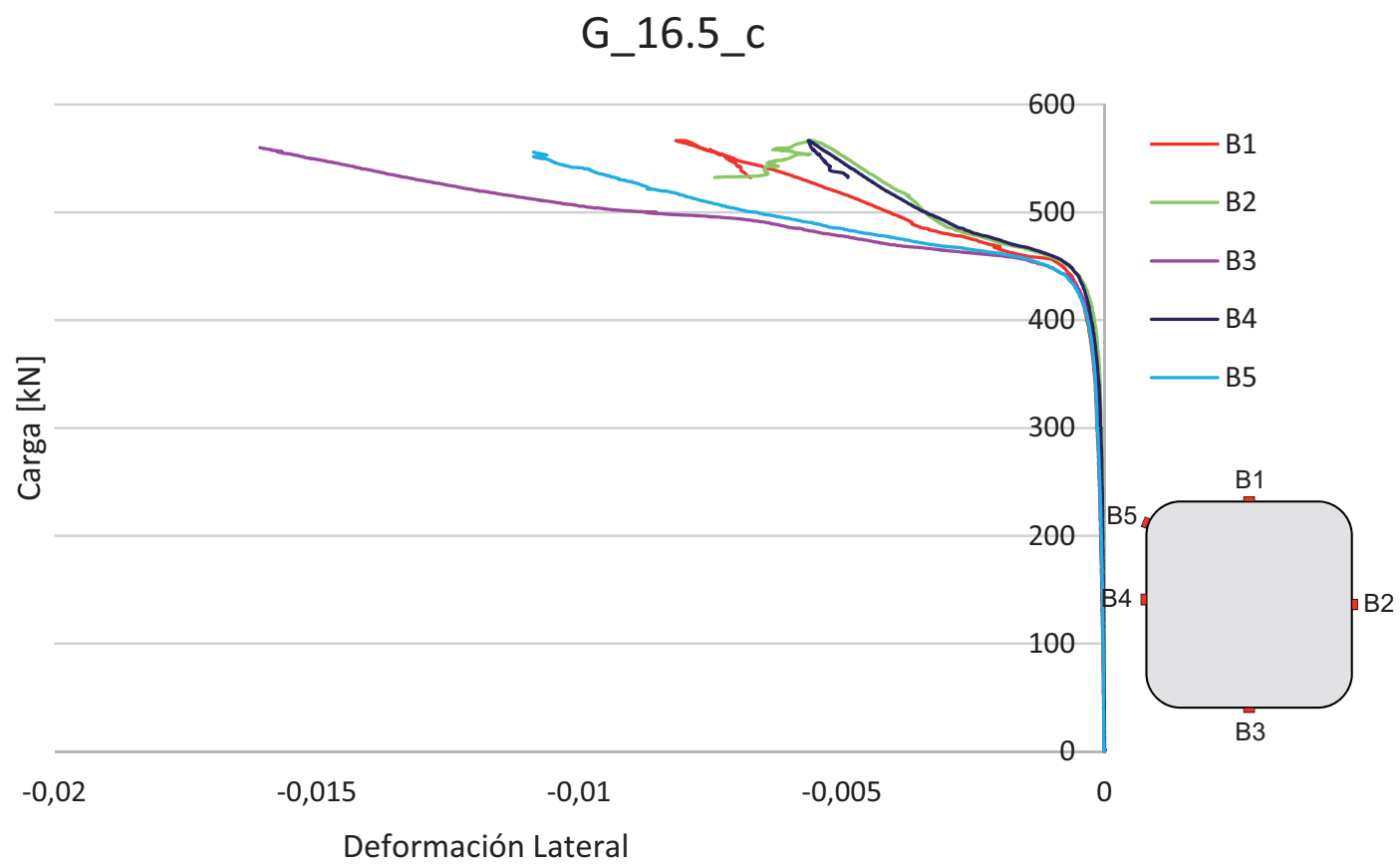

Figura A.38 Curvas carga-deformación lateral en la probeta G_16.5_c 


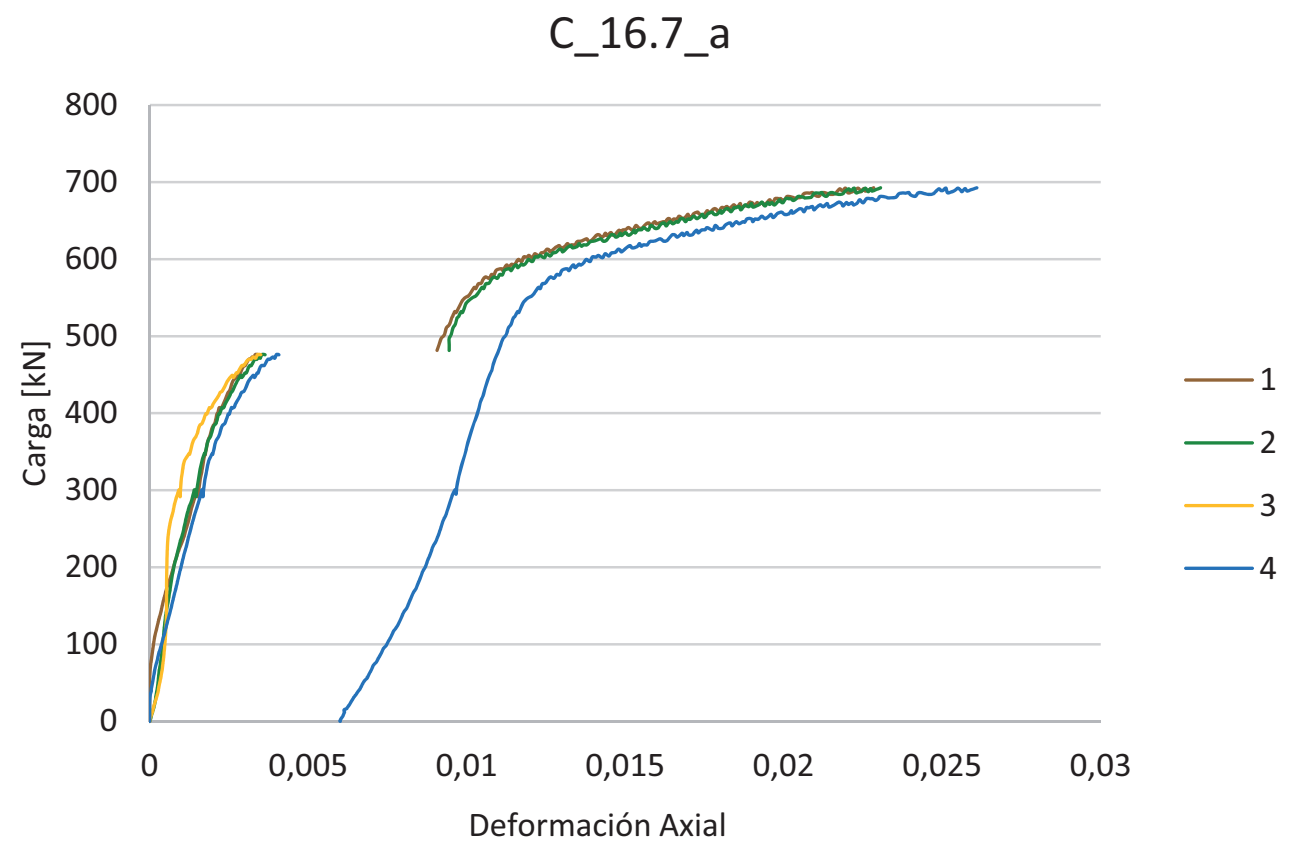

Figura A.39 Curvas carga-deformación axial en la probeta C_16.7_a

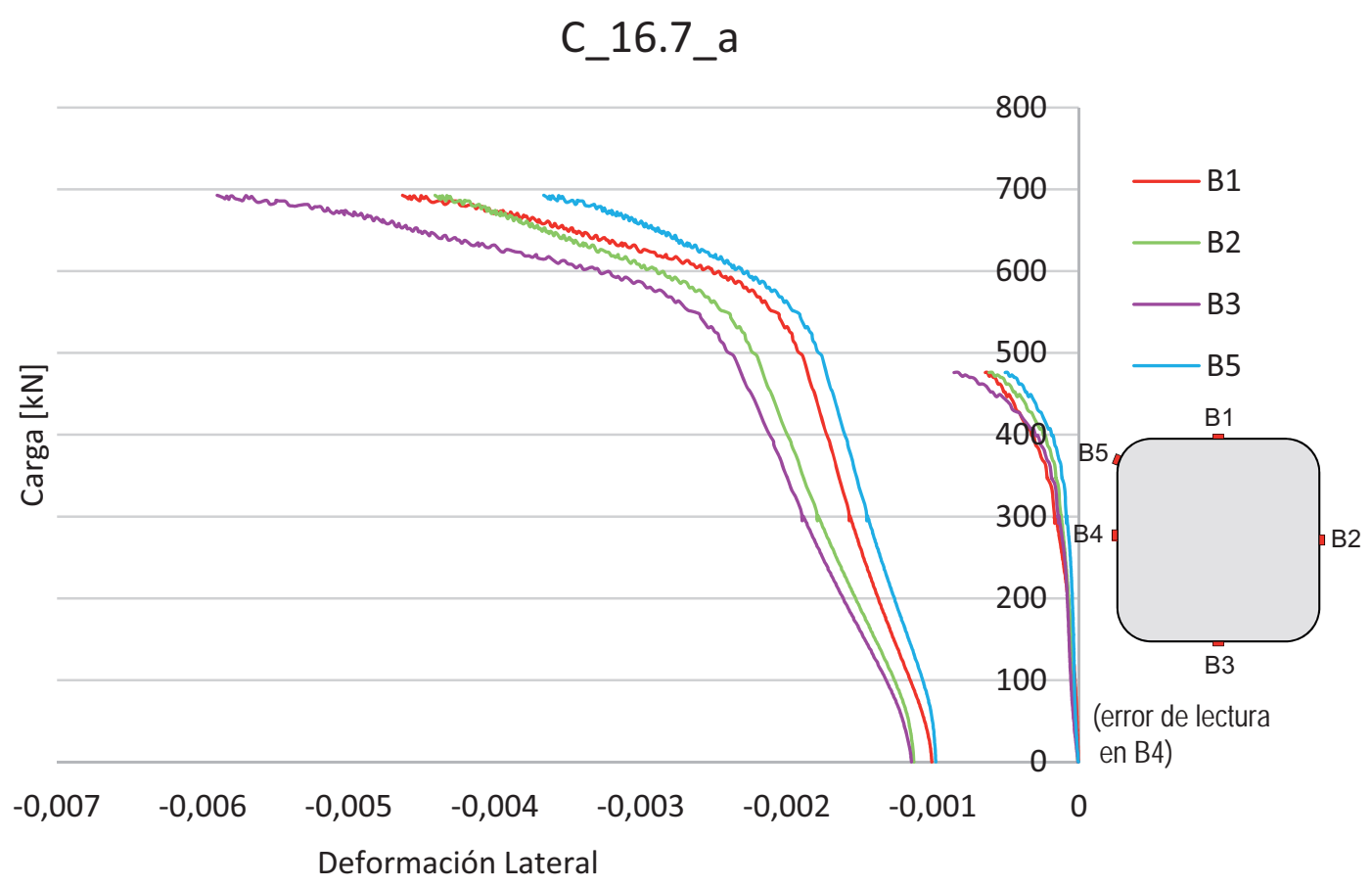

Figura A.40 Curvas carga-deformación lateral en la probeta C_16.7_a 


\section{C_16.7_b}

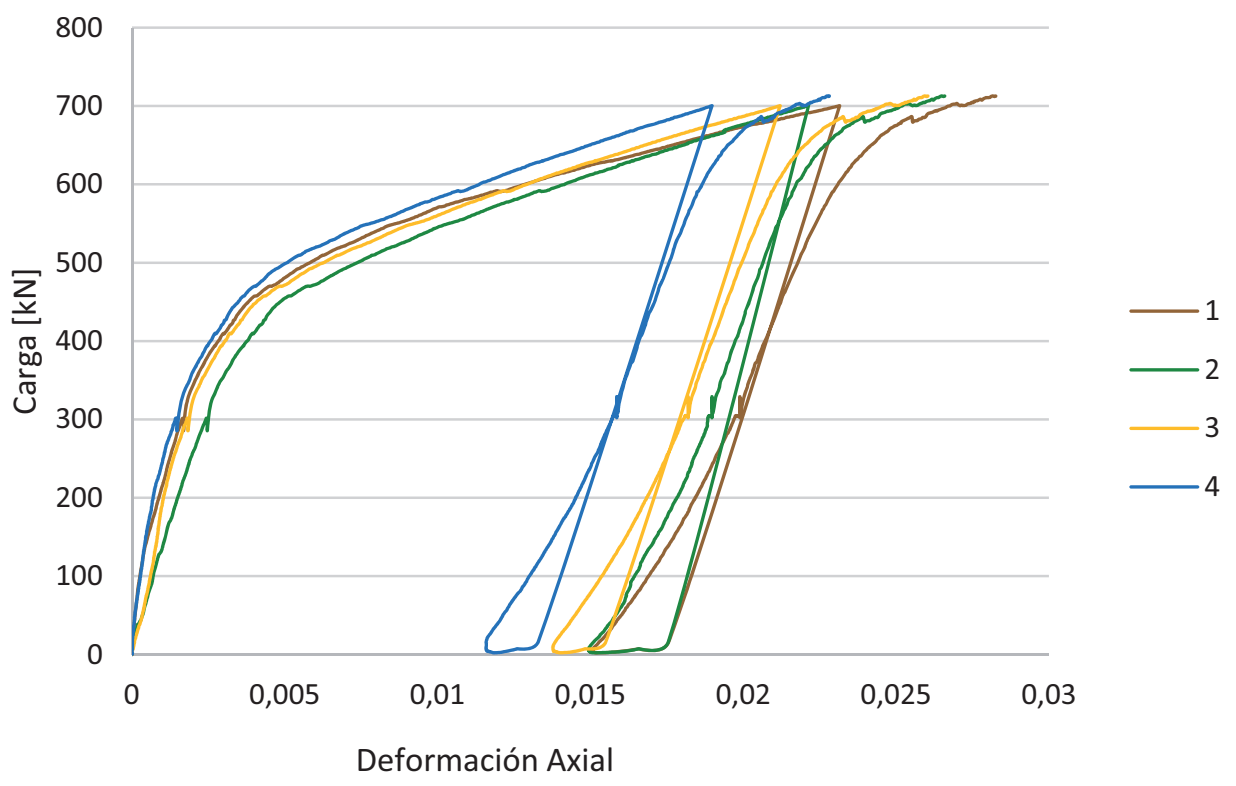

Figura A.41 Curvas carga-deformación axial en la probeta C_16.7_b

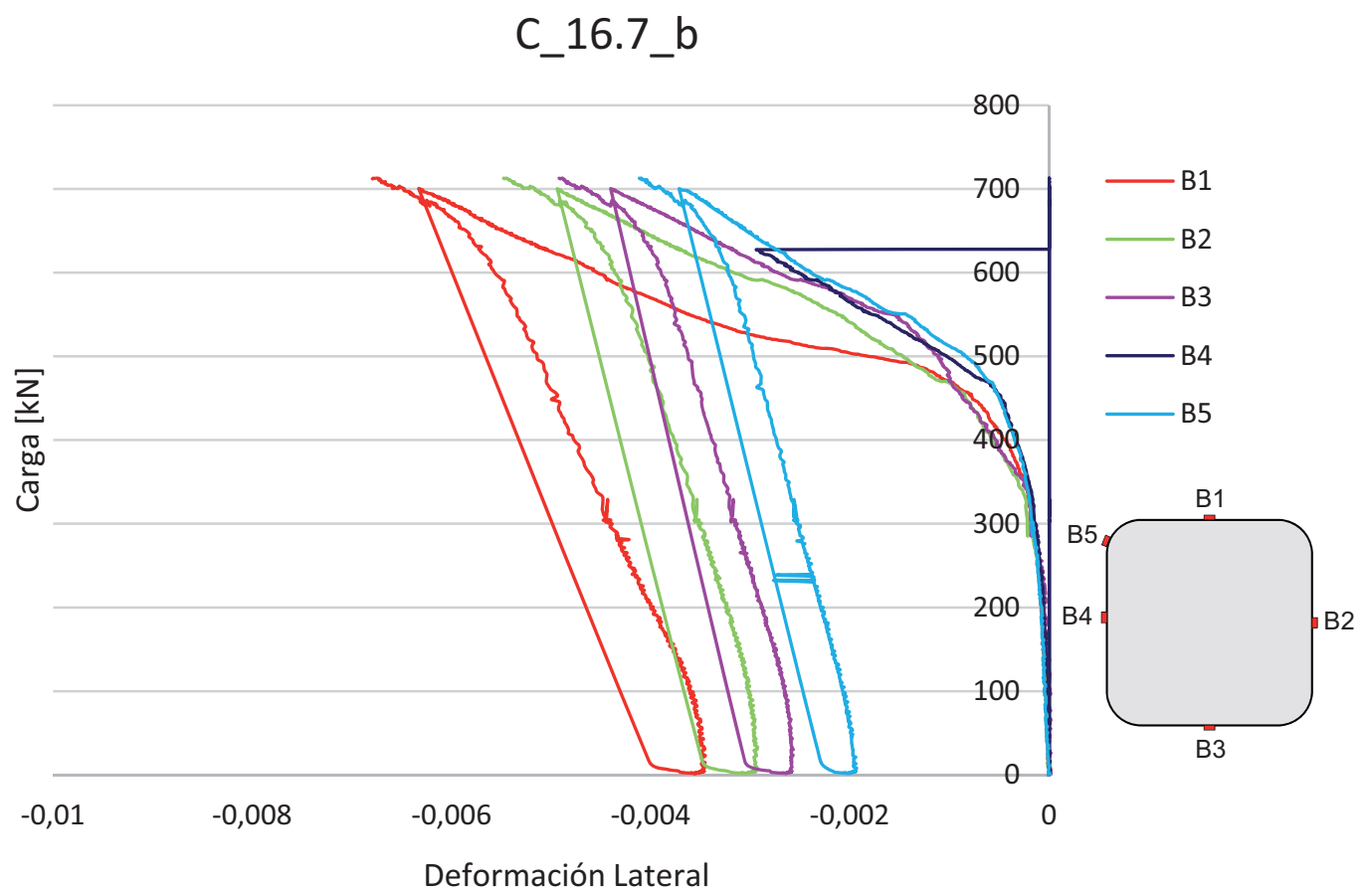

Figura A.42 Curvas carga-deformación lateral en la probeta C_16.7_b 


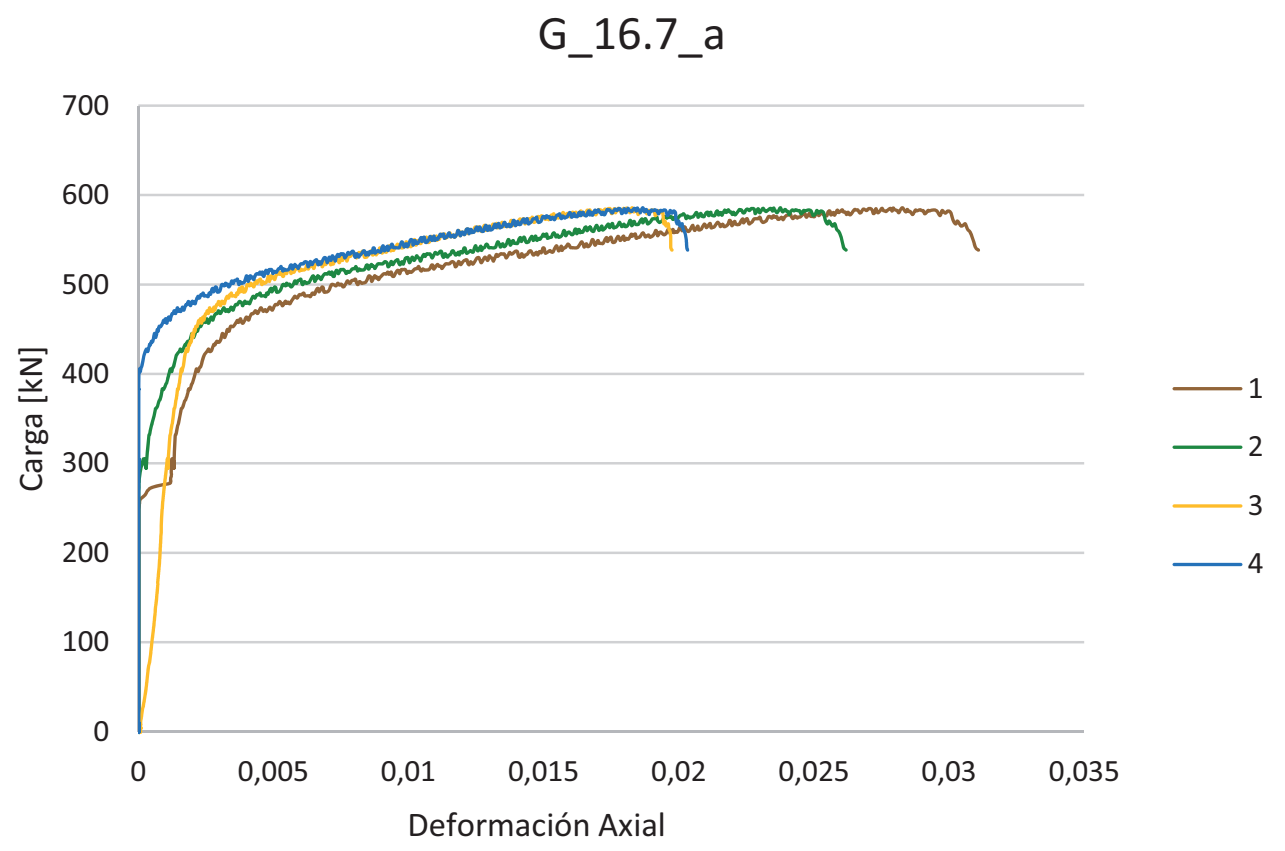

Figura A.43 Curvas carga-deformación axial en la probeta G_16.7_a

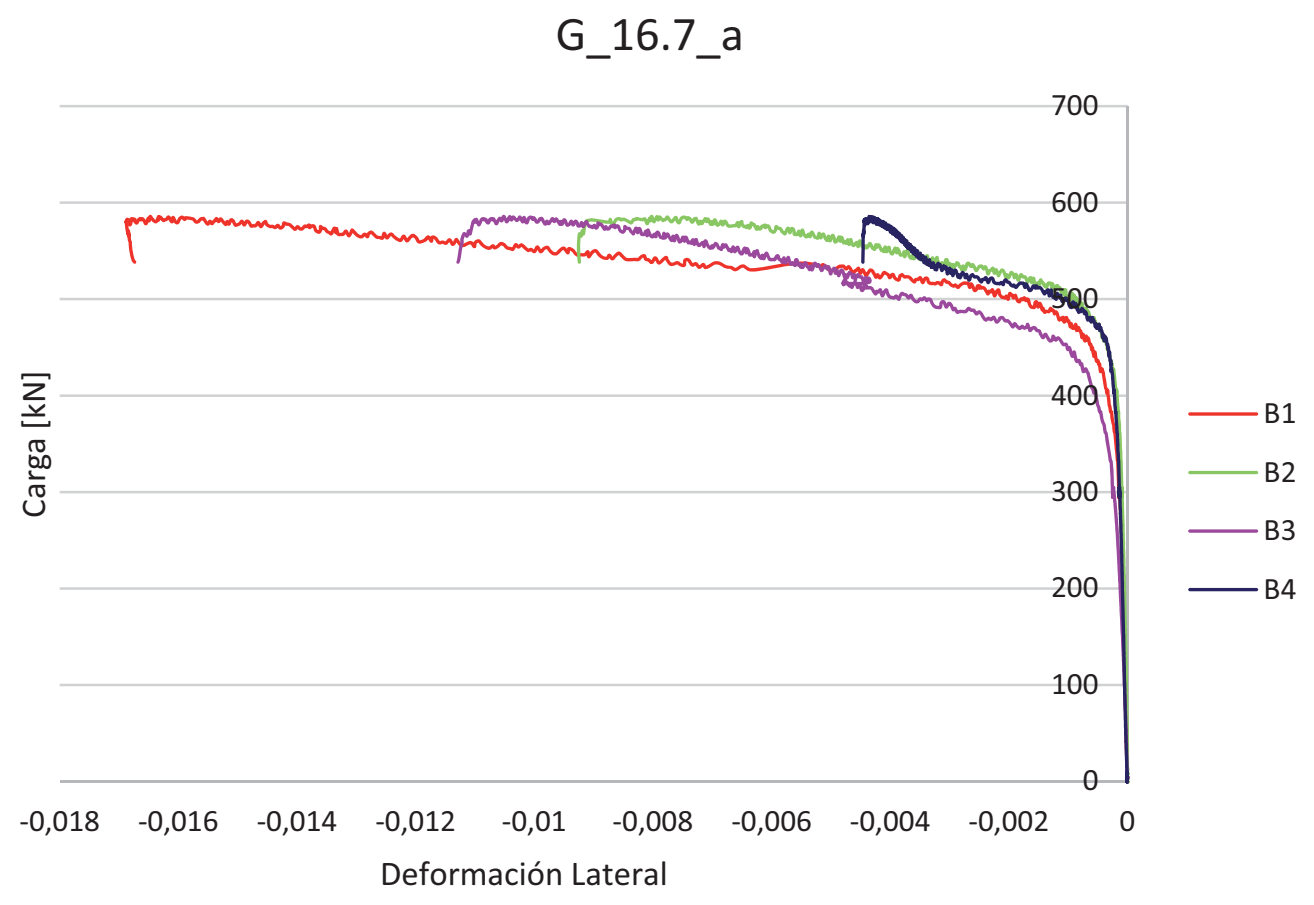

Figura A.44 Curvas carga-deformación lateral en la probeta G_16.7_a 


\section{G_16.7_b}

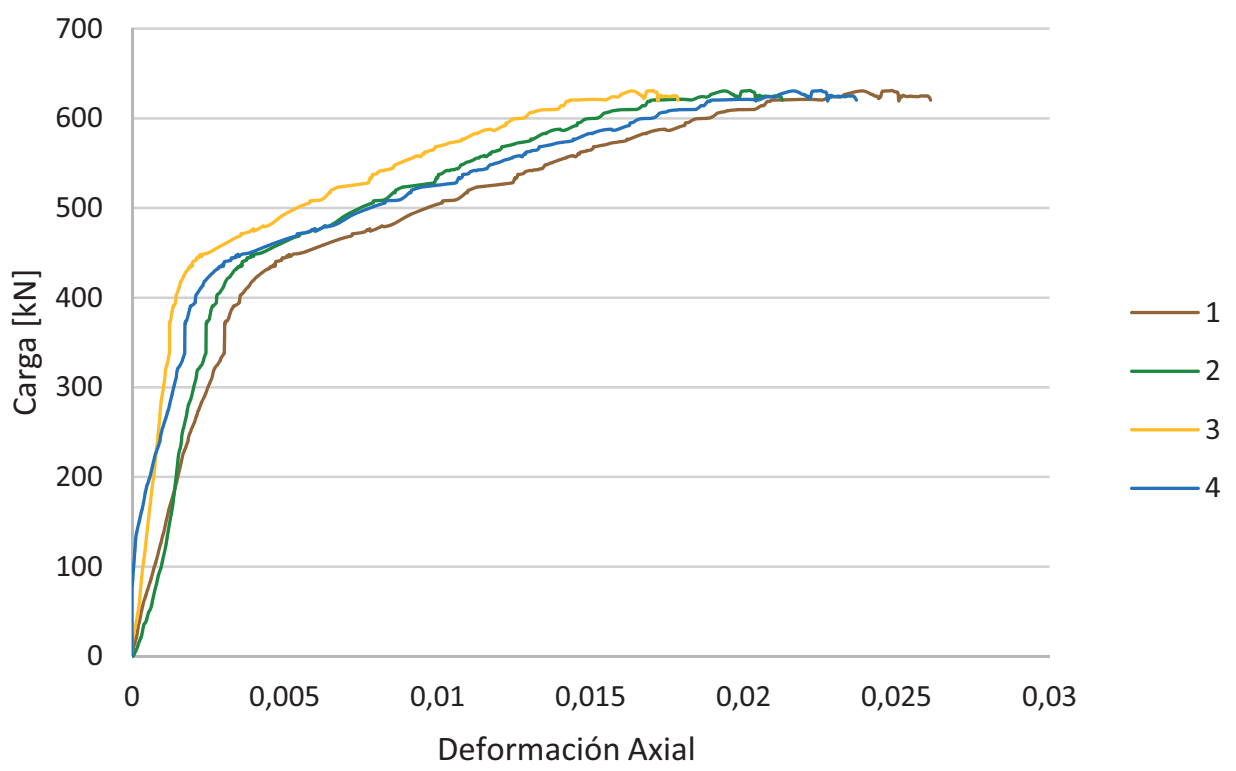

Figura A.45 Curvas carga-deformación axial en la probeta G_16.7_b

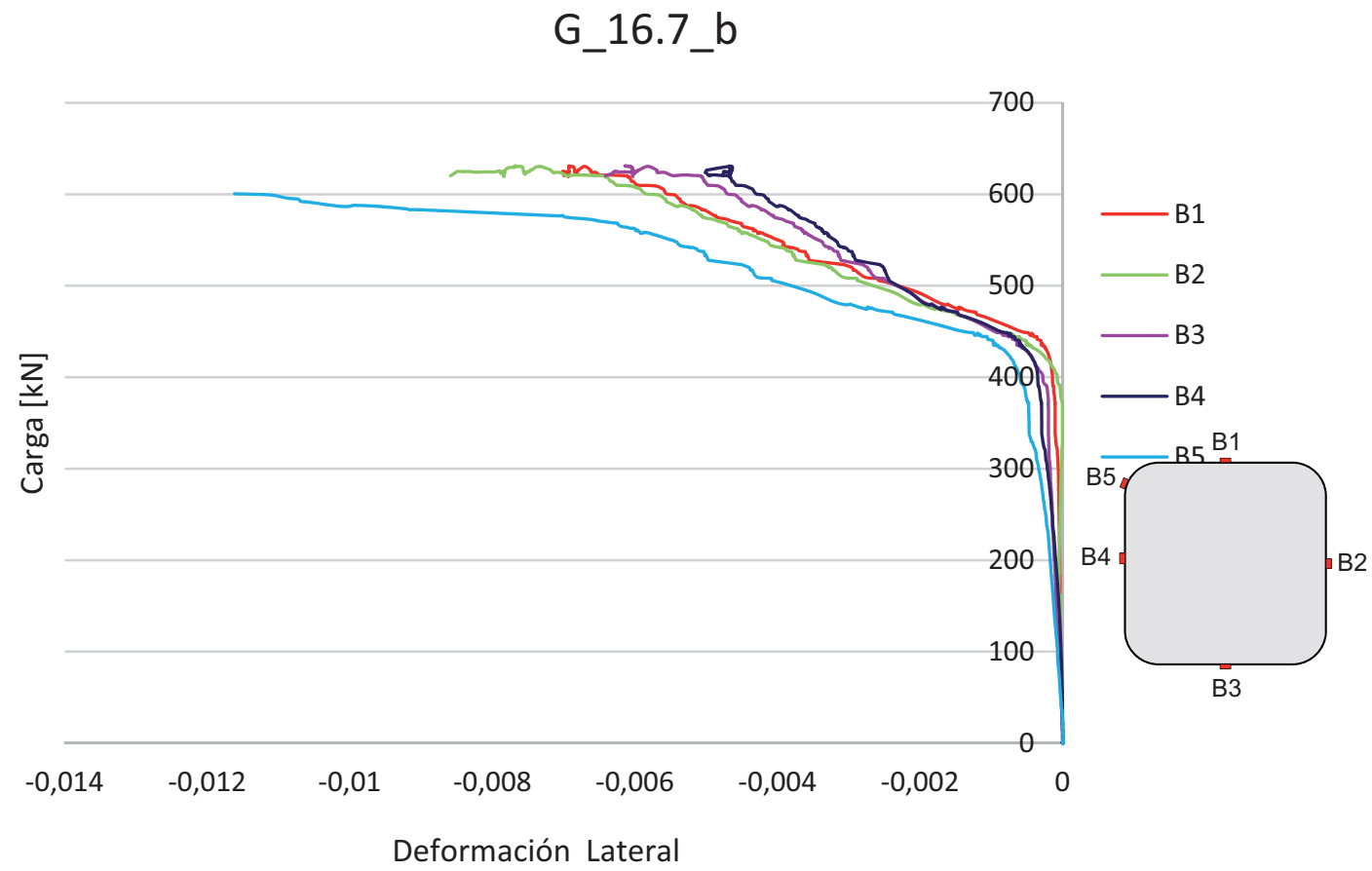

Figura A.46 Curvas carga-deformación lateral en la probeta G_16.7_b 
C_17.5_a

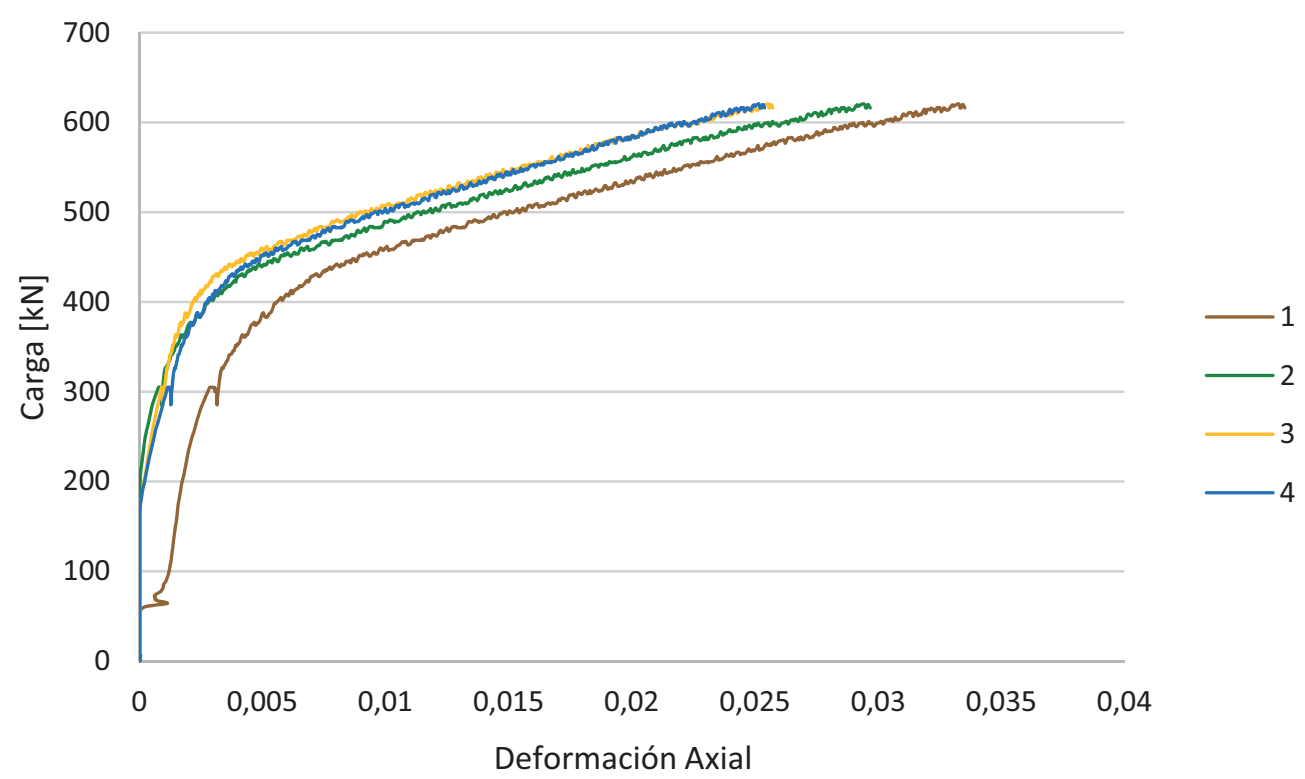

Figura A.47 Curvas carga-deformación axial en la probeta C_17.5_a

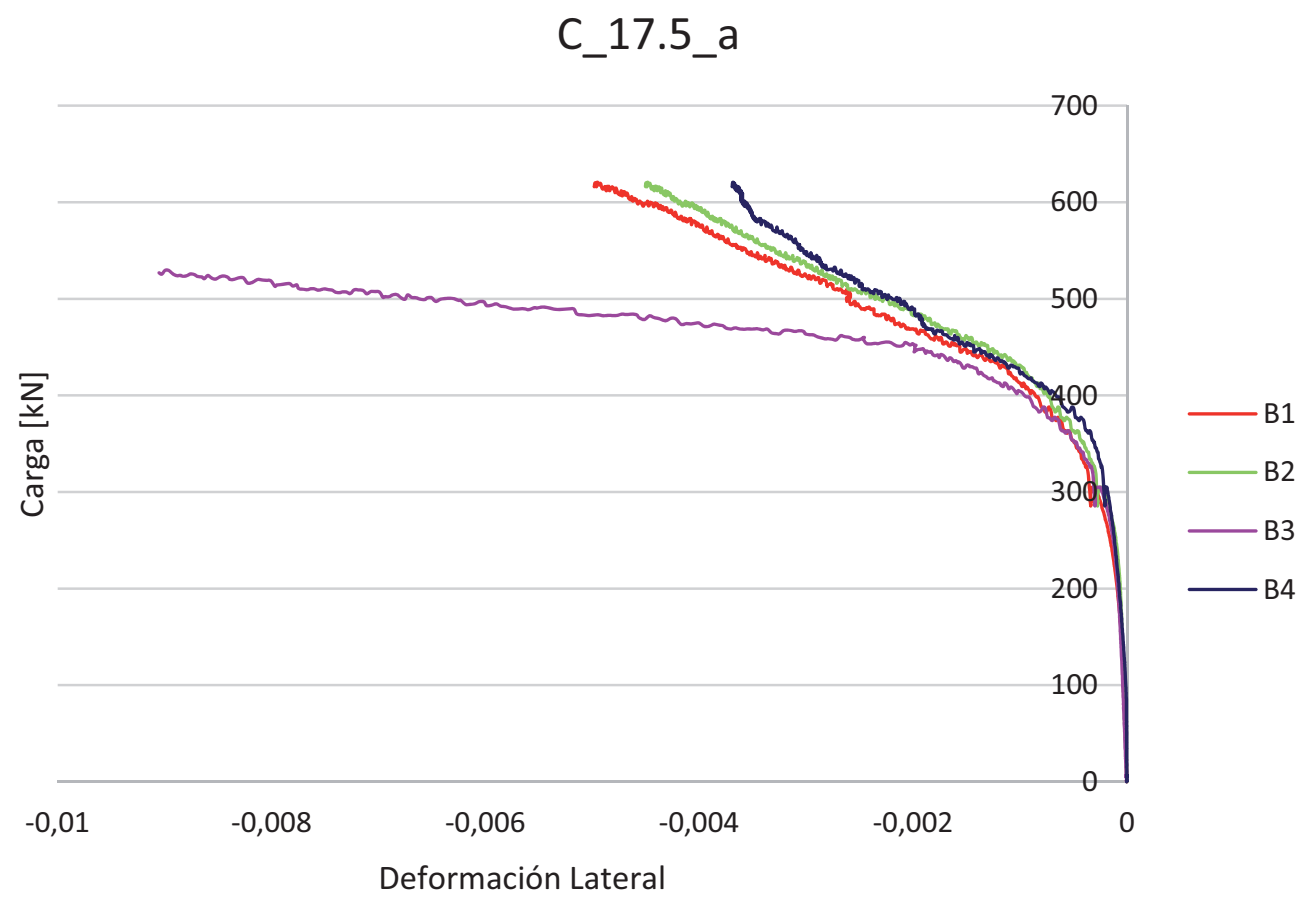

Figura A.48 Curvas carga-deformación lateral en la probeta C_17.5_a 


\section{C_17.5_b}

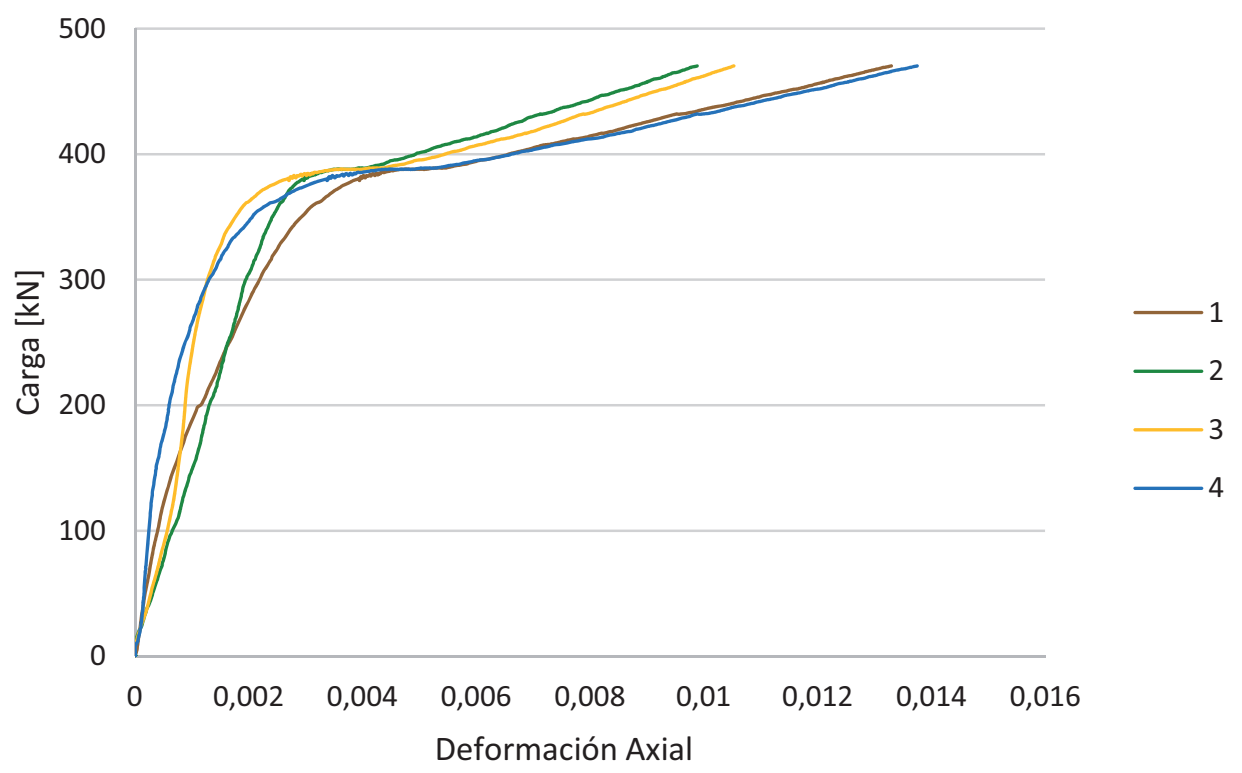

Figura A.49 Curvas carga-deformación axial en la probeta C_17.5_b

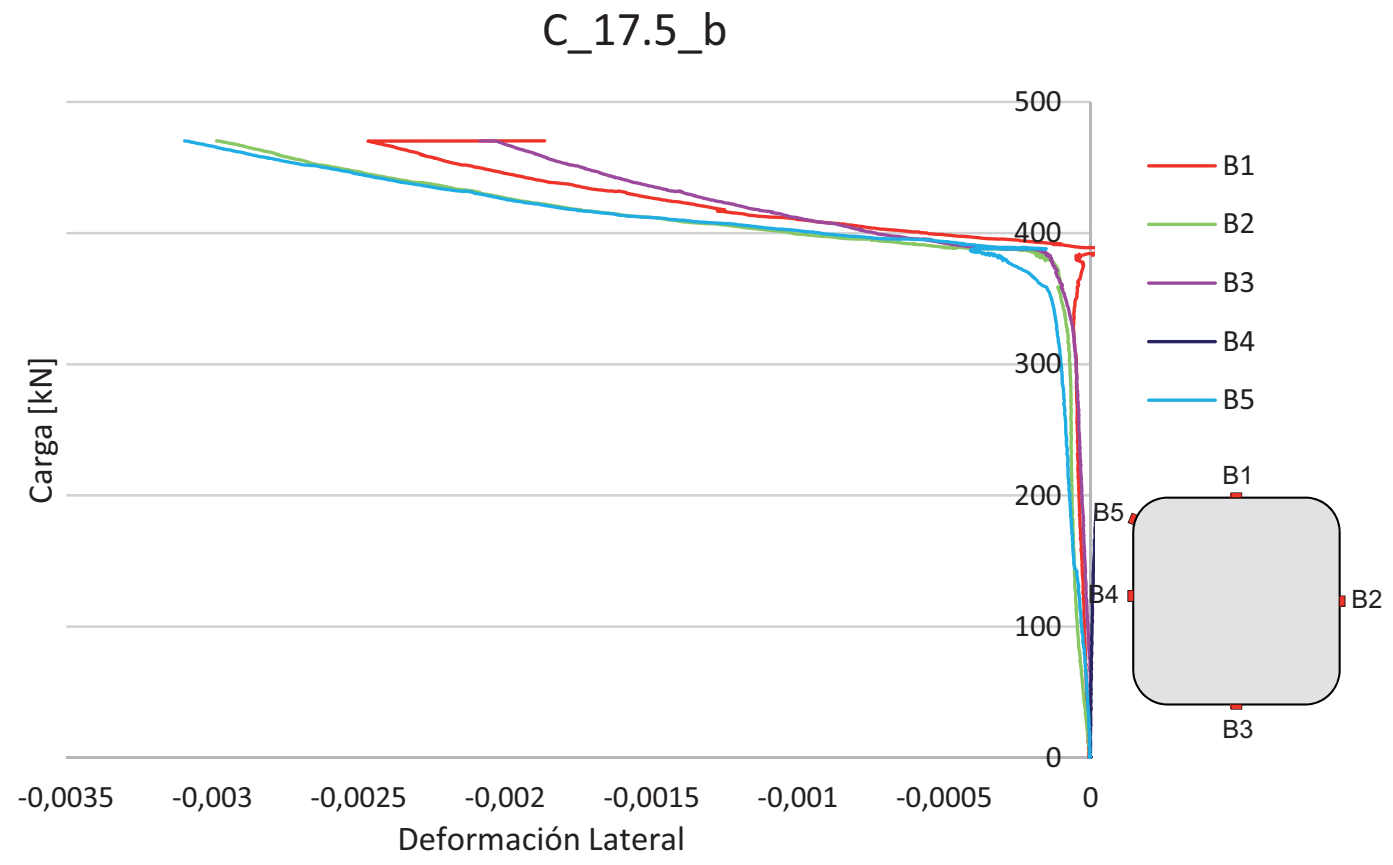

Figura A.50 Curvas carga-deformación lateral en la probeta $C \_17.5 \_b$ 


\section{G_17.5_a}

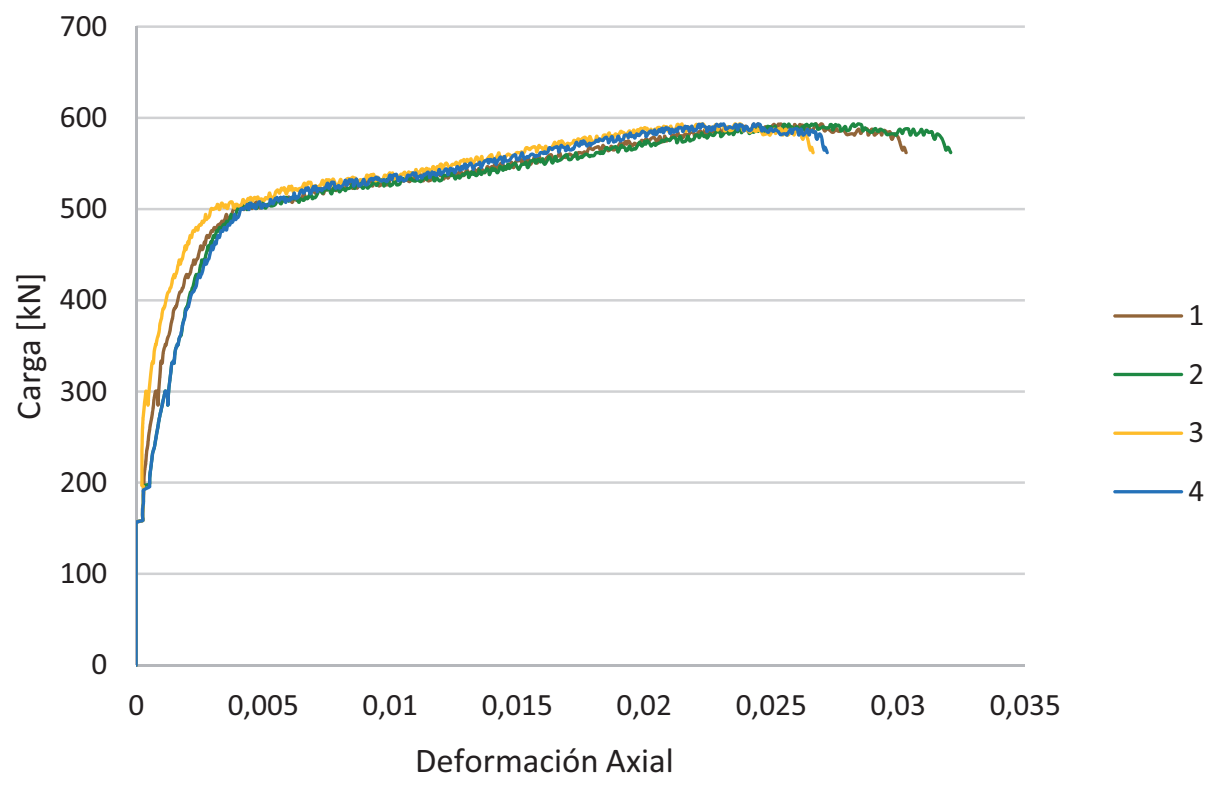

Figura A.51 Curvas carga-deformación axial en la probeta G_17.5_a

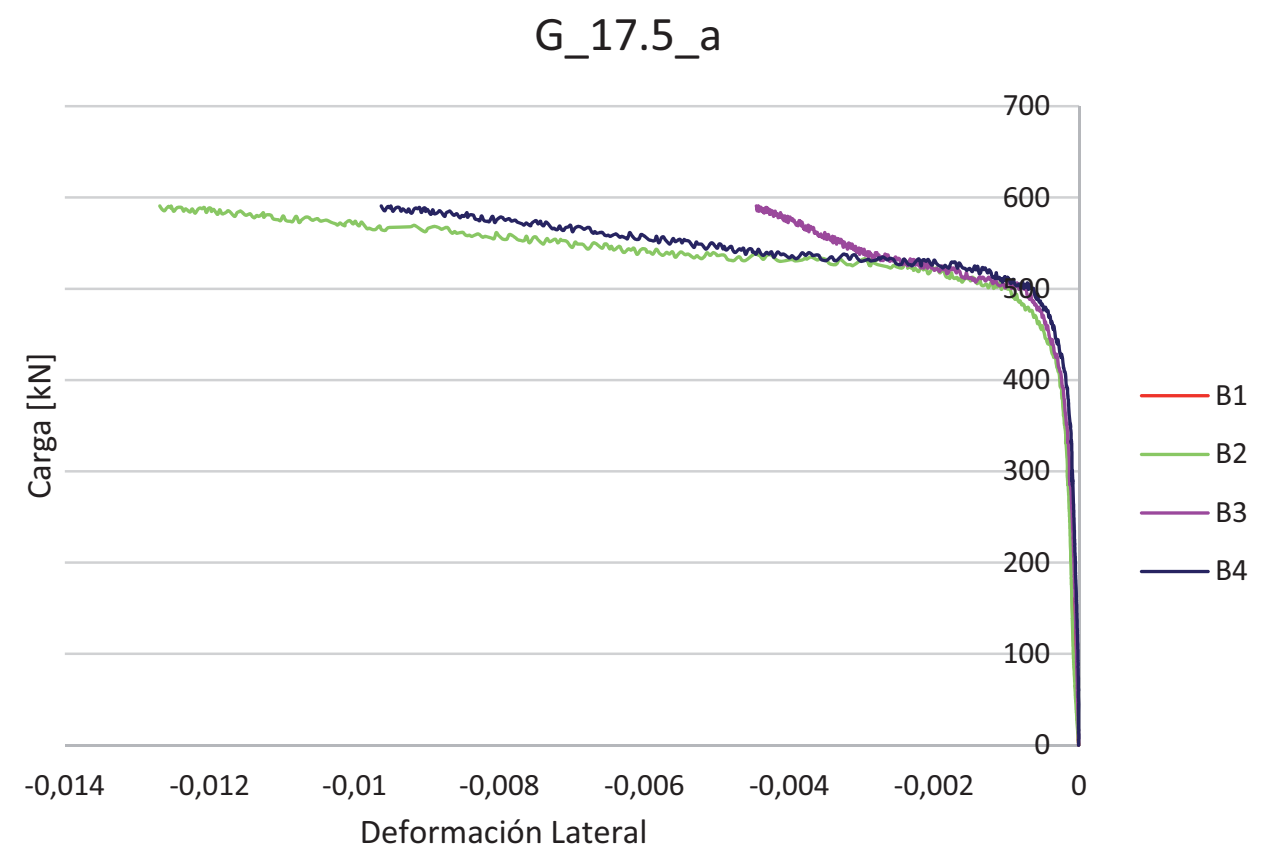

Figura A.52 Curvas carga-deformación lateral en la probeta G_17.5_a 


\section{G_17.5_b}

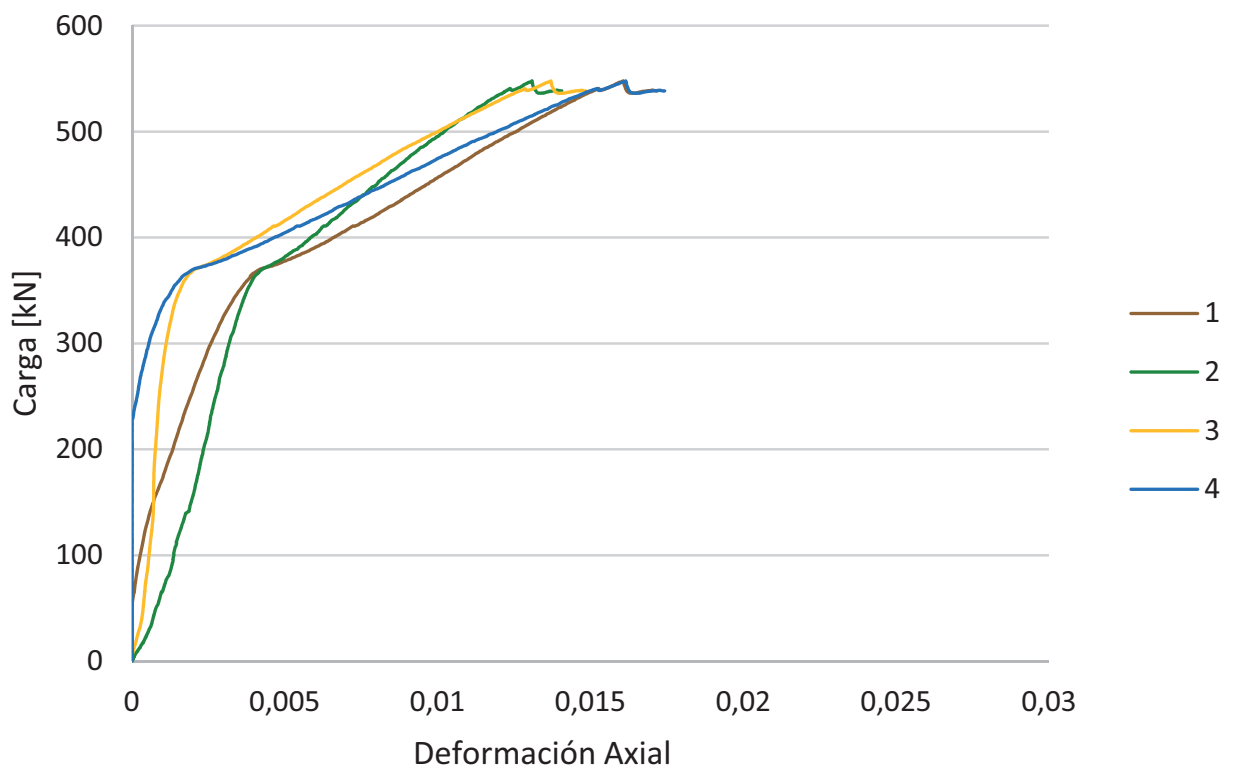

Figura A.53 Curvas carga-deformación axial en la probeta G_17.5_b

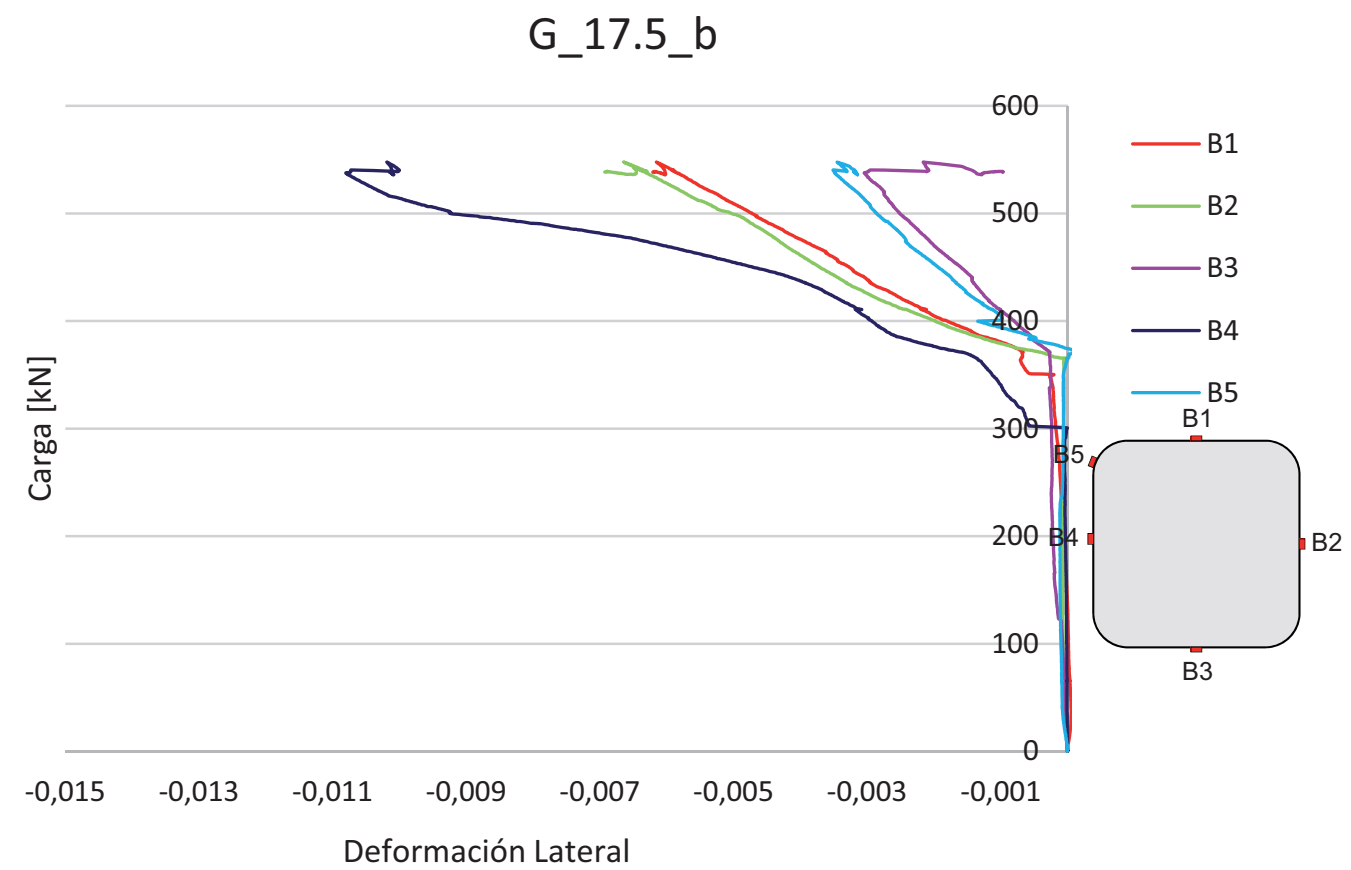

Figura A.54 Curvas carga-deformación lateral en la probeta G_17.5_b 


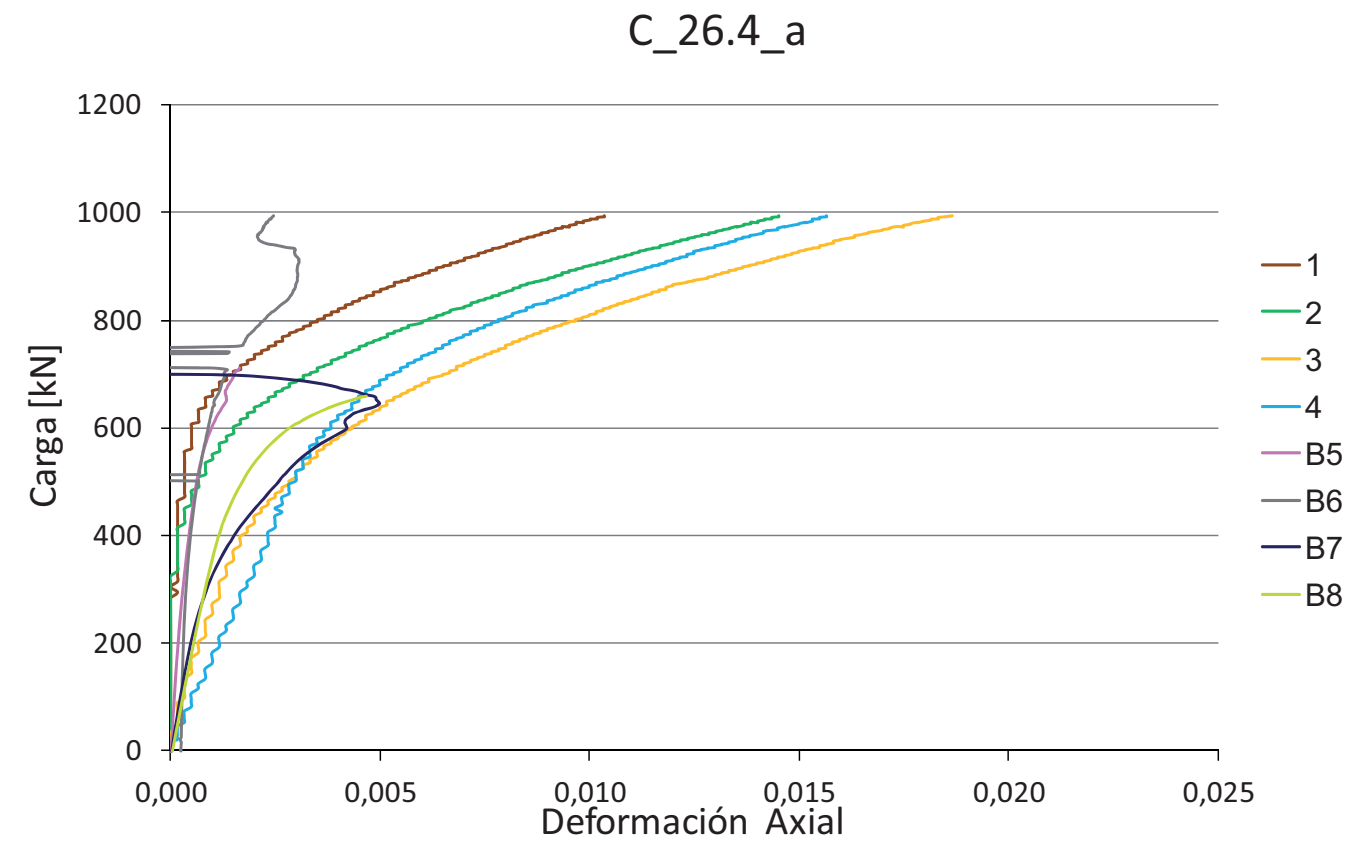

Figura A.55 Curvas carga-deformación axial en la probeta C_26.4_a

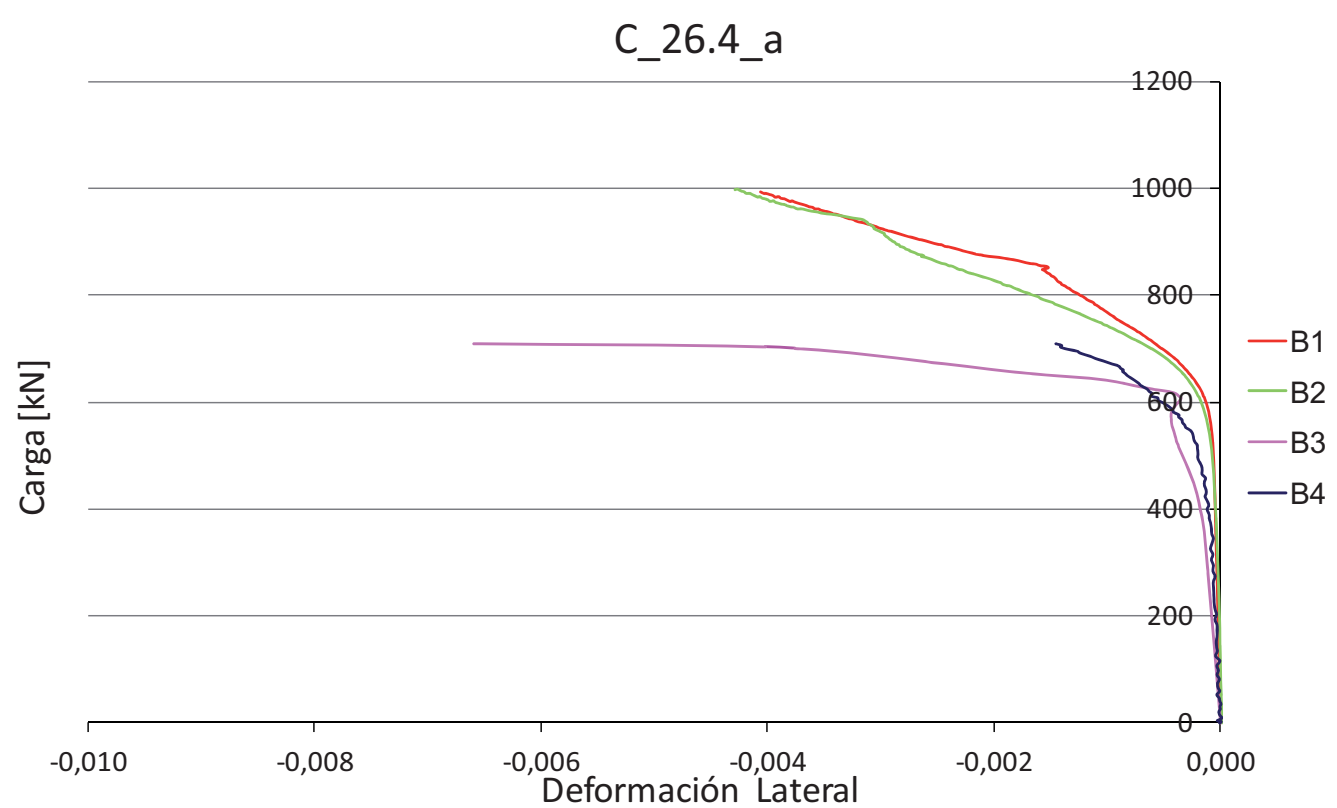

Figura A.56 Curvas carga-deformación lateral en la probeta C_26.4_a 


\section{C_26.4_a}

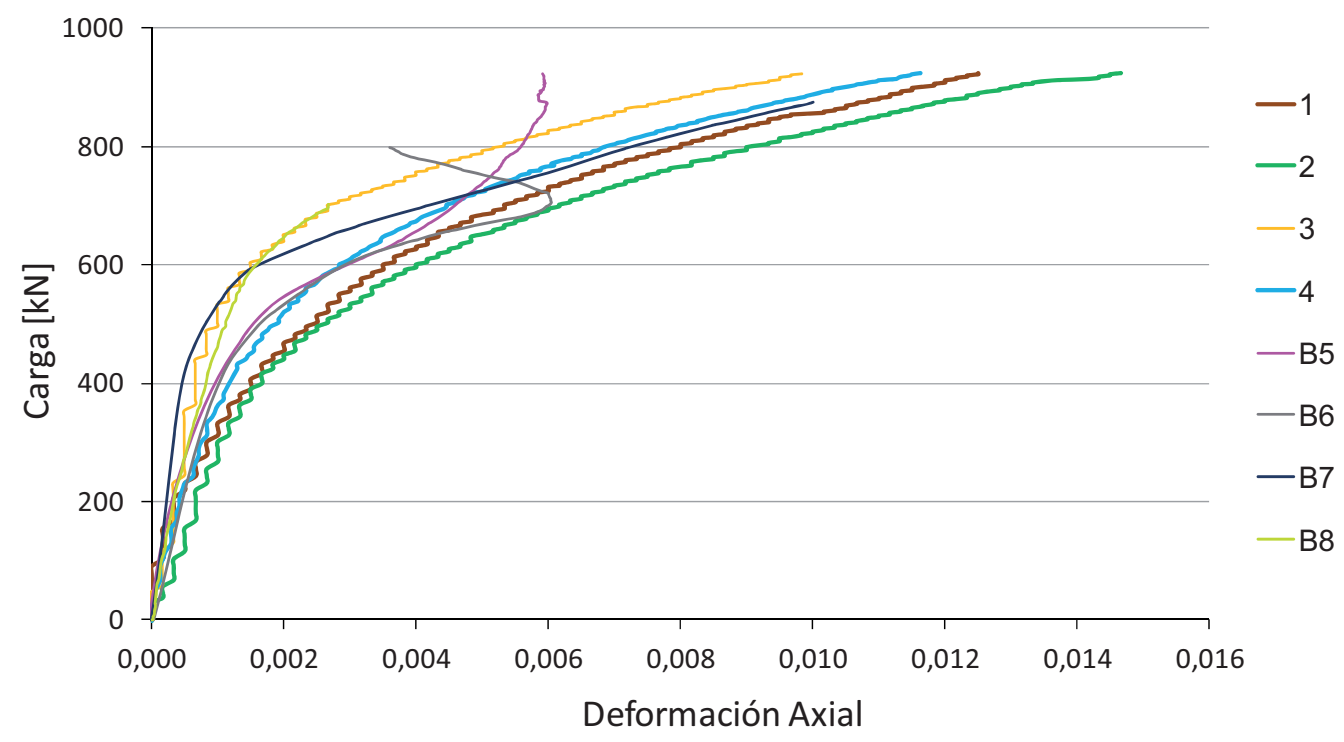

Figura A.57 Curvas carga-deformación axial en la probeta C_26.4_b

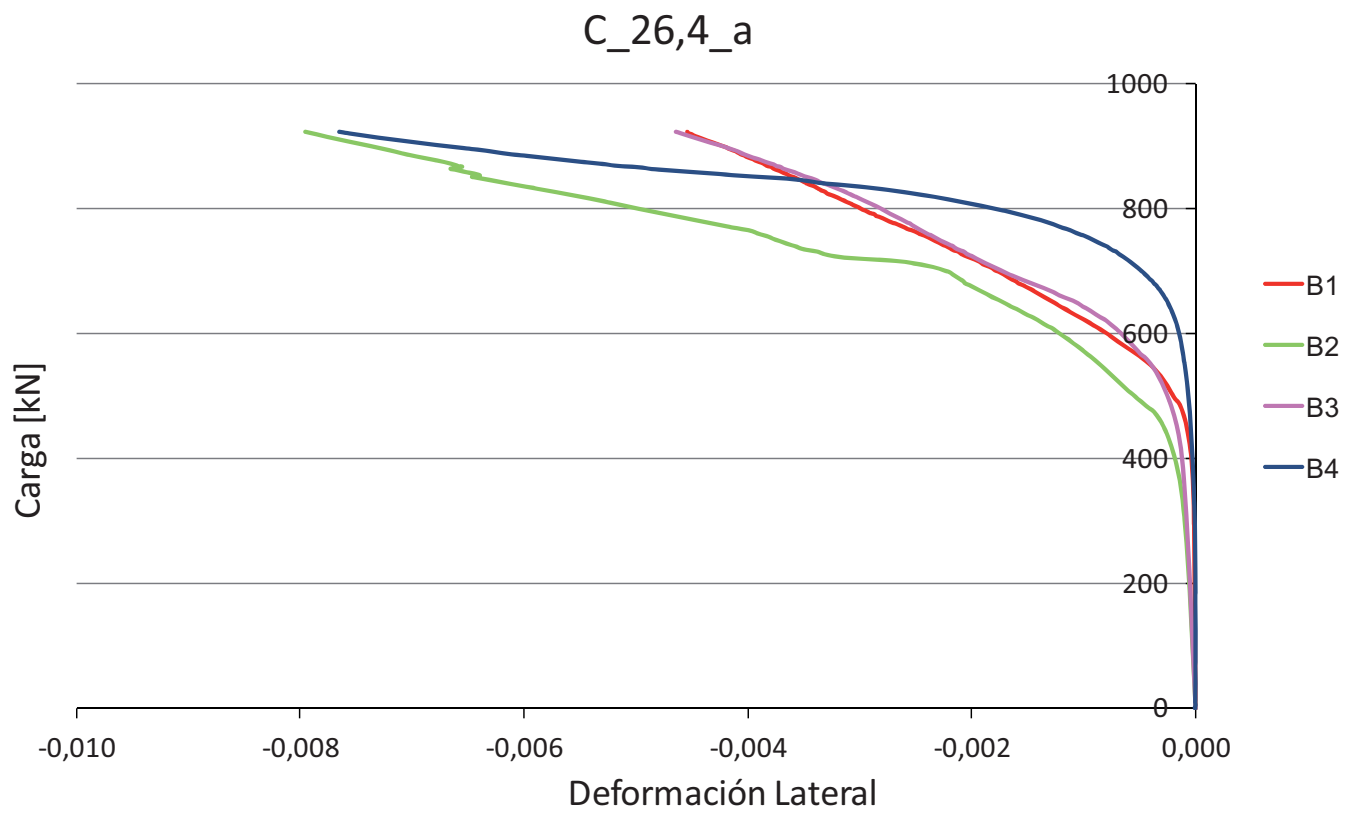

Figura A.58 Curvas carga-deformación lateral en la probeta C_26.4_b 


\section{A.3 Programa experimental. Fase II}

\section{A.3.1 Rotura de las probetas}
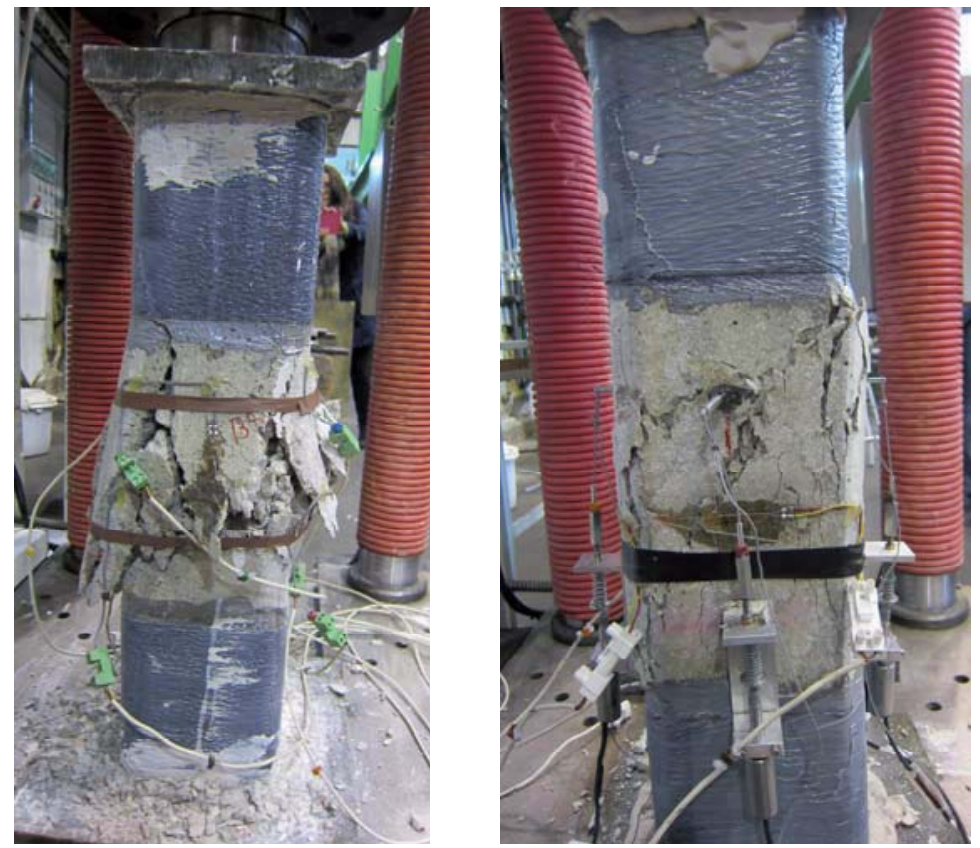

Figura A.59 Rotura de las probetas $0 \_a$ y $0 \_b$

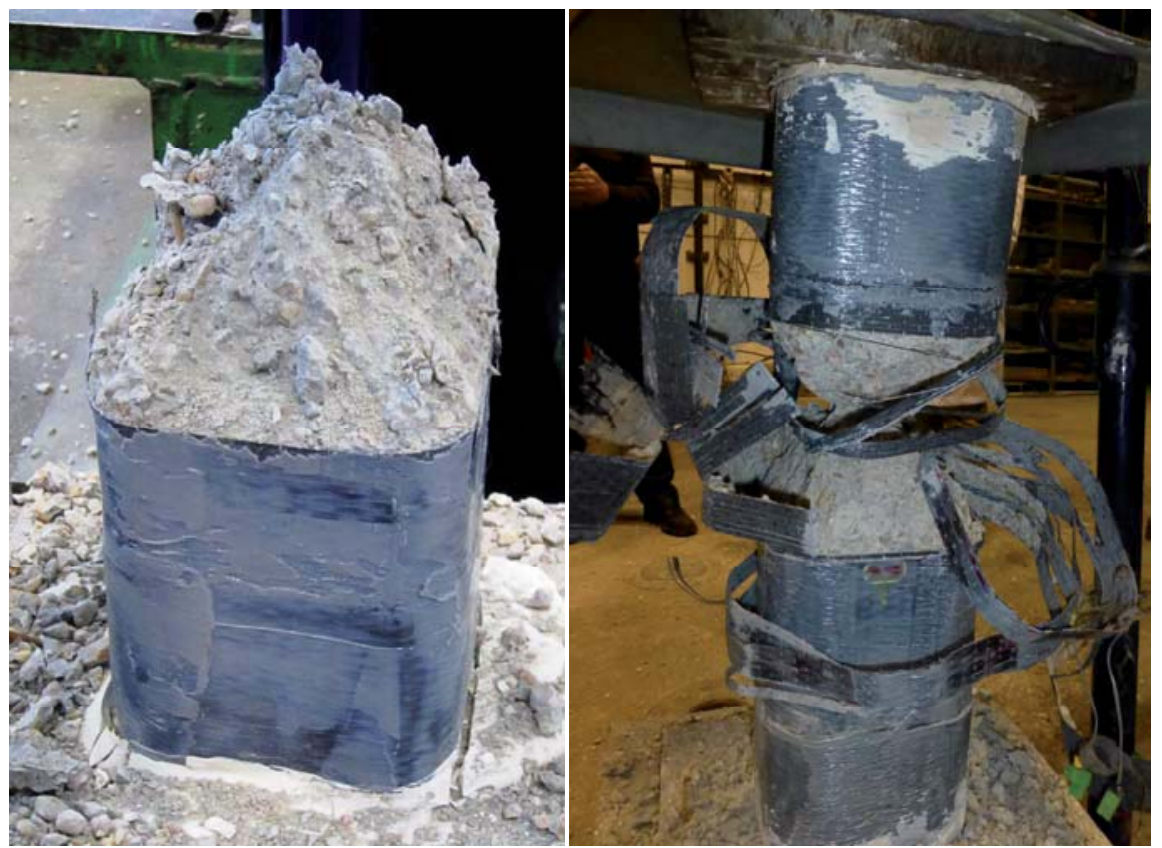

Figura A.60 Rotura de las probetas 1_20_a y 1_20_b 

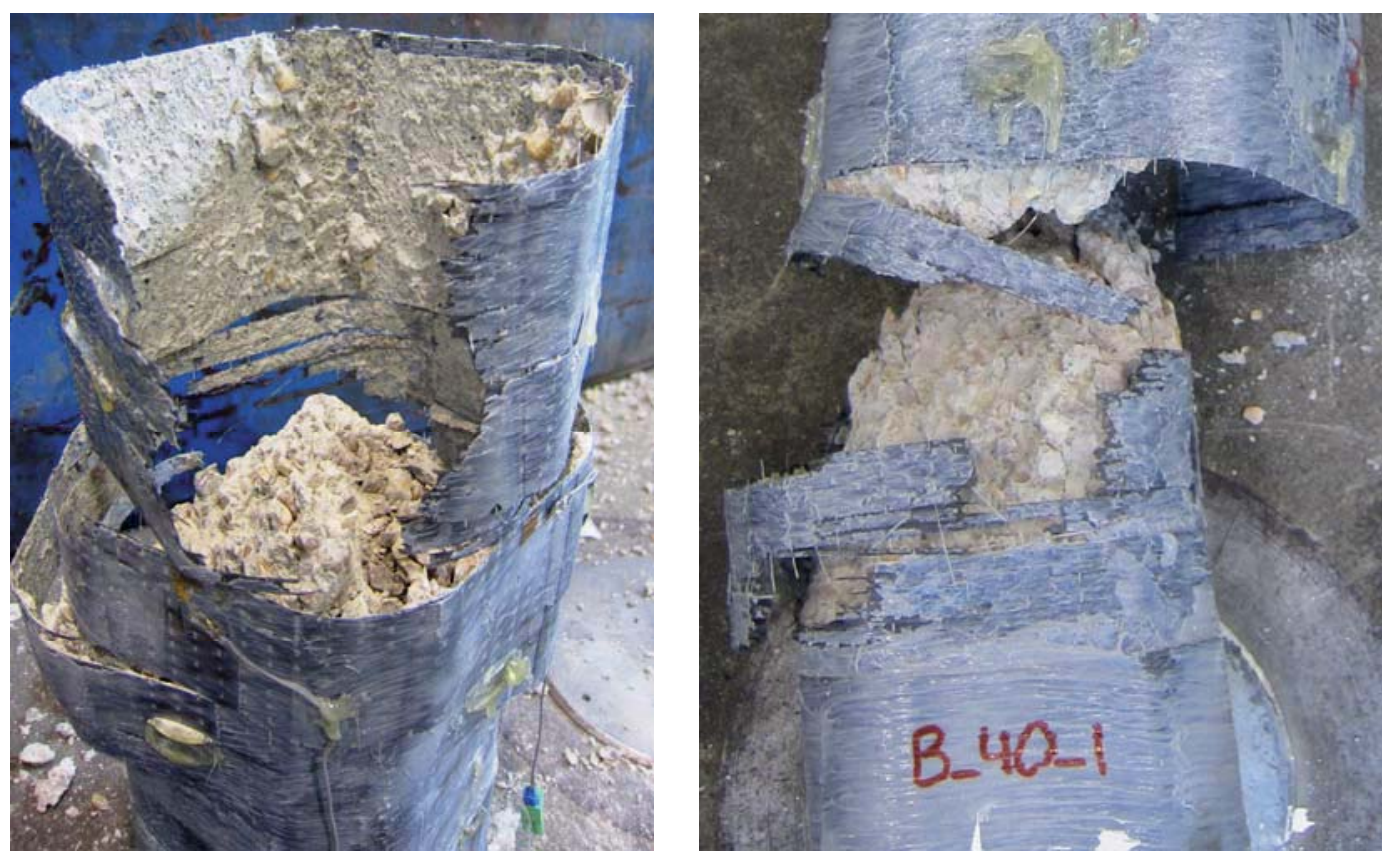

Figura A.61 Rotura de las probetas 1_40_a y 1_40_b
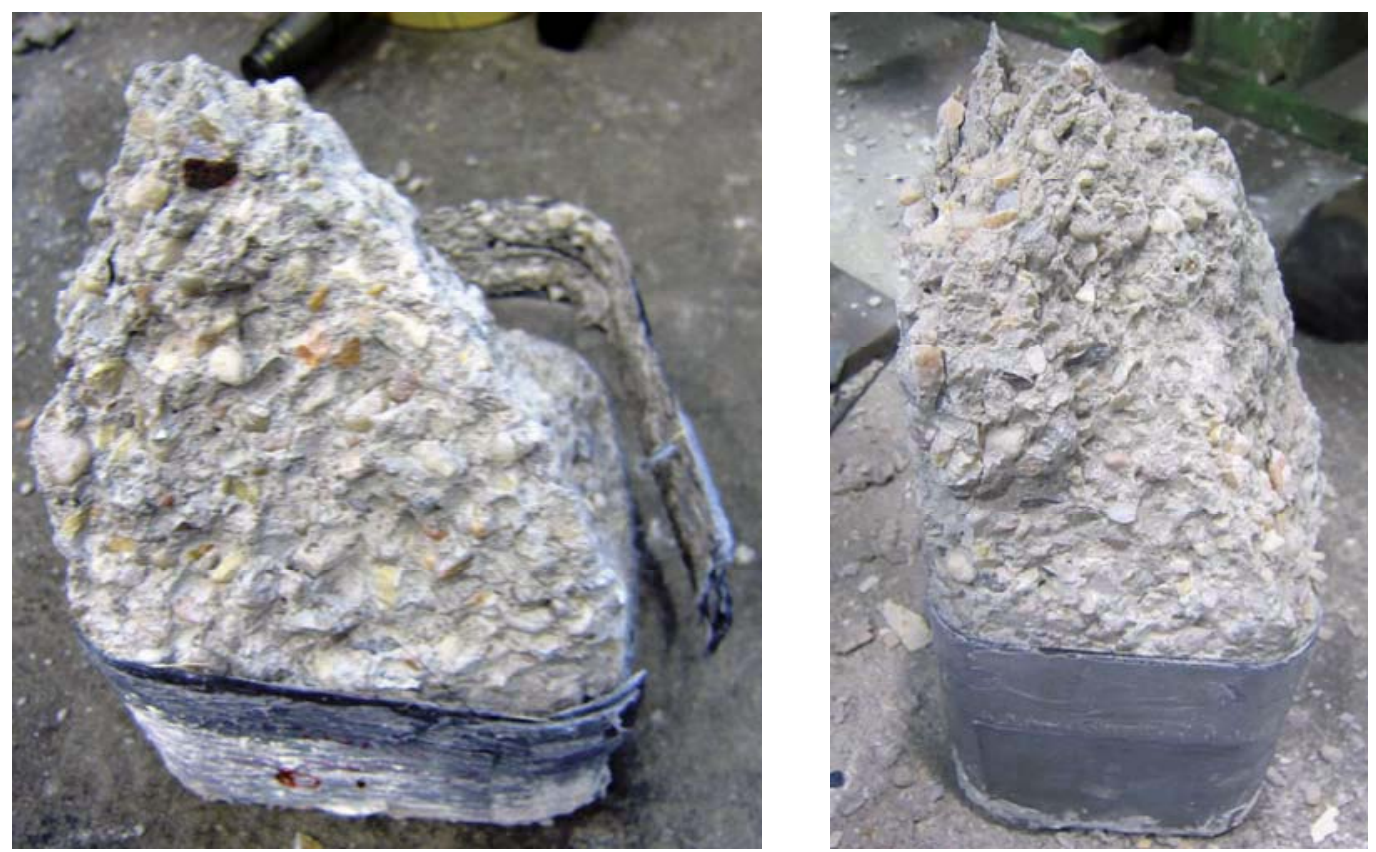

Figura A.62 Rotura de las probetas 2_20_a y 2_20_b 

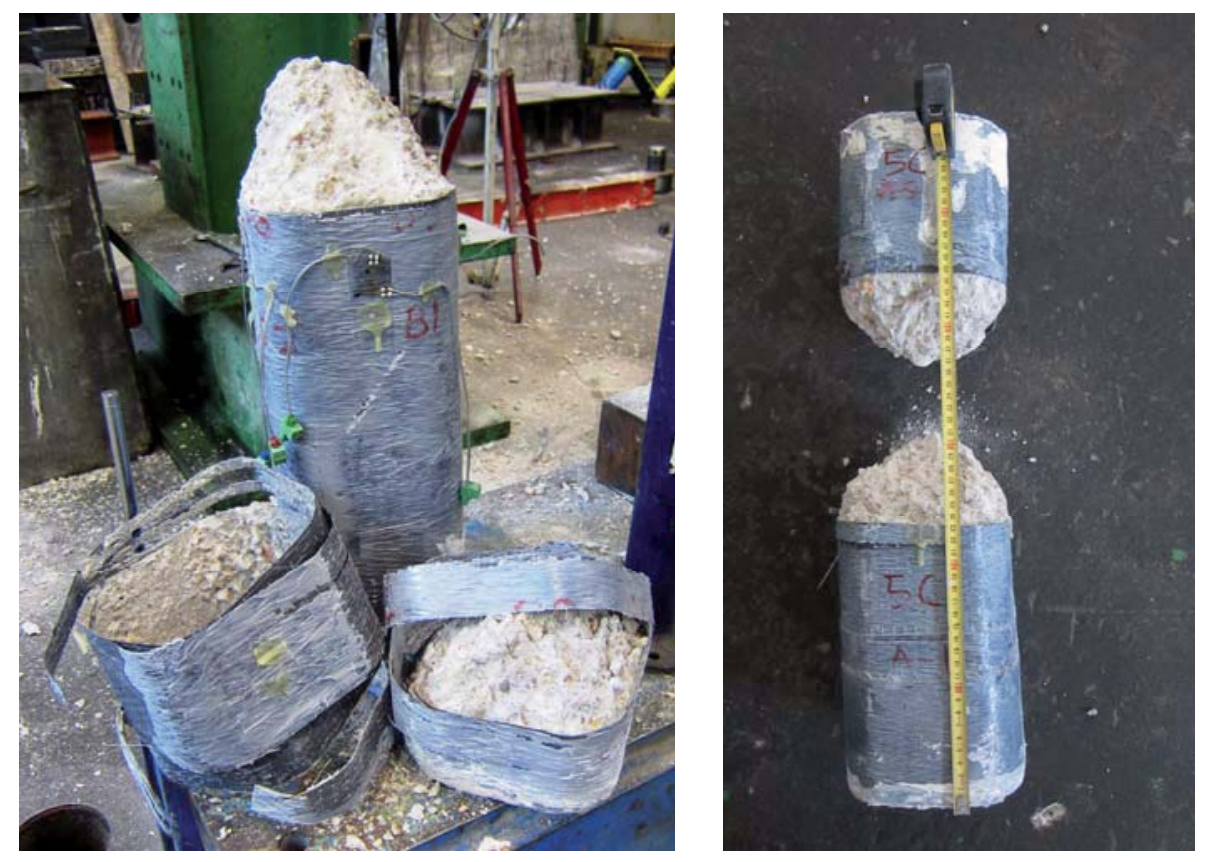

Figura A.63 Rotura de las probetas 2_40_a y 2_40_b
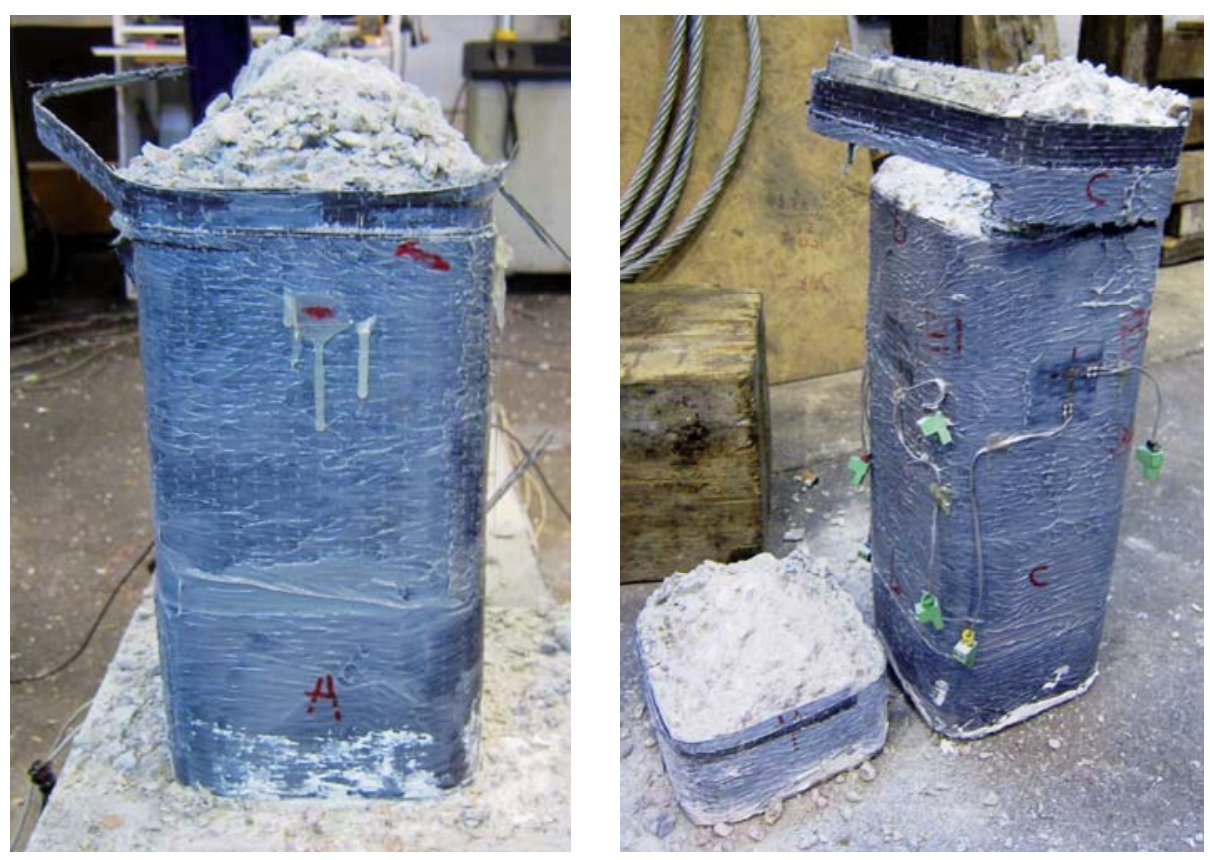

Figura A.64 Rotura de las probetas 3_20_a y 3_20_b 

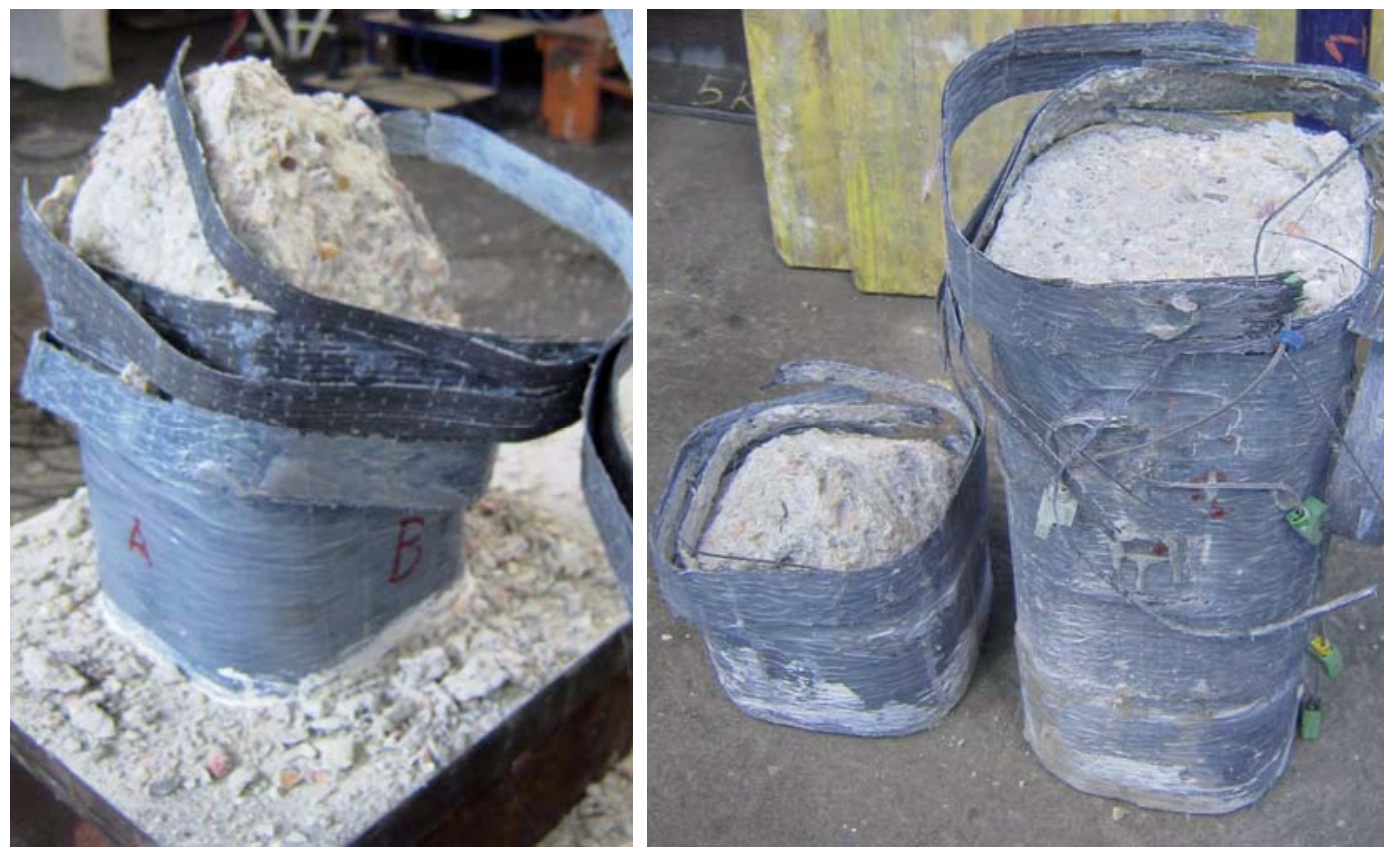

Figura A.65 Rotura de las probetas 3_40_a y 3_40_b 


\section{A.3.2 Gráficos carga-deformación}

La deformación lateral en la sección central de las probetas se ha medido con 4 bandas extensométricas (B1, B2, B3, B4) situadas en el centro de cada cara.

Para medir la deformación axial en la probeta 0_a se dispusieron 4 captadores de desplazamiento, uno en cada cara, pero solo se obtuvo medidas de uno de ellos. En la probeta 0_b se midió con 4 bandas extensométricas (B5, B6, B7, B8).

En las probetas reforzadas la deformación axial se ha medido con 4 captadores de desplazamiento (designados 1, 2, 3, 4) y 4 bandas extensométricas (B5, B6, B7, B8).

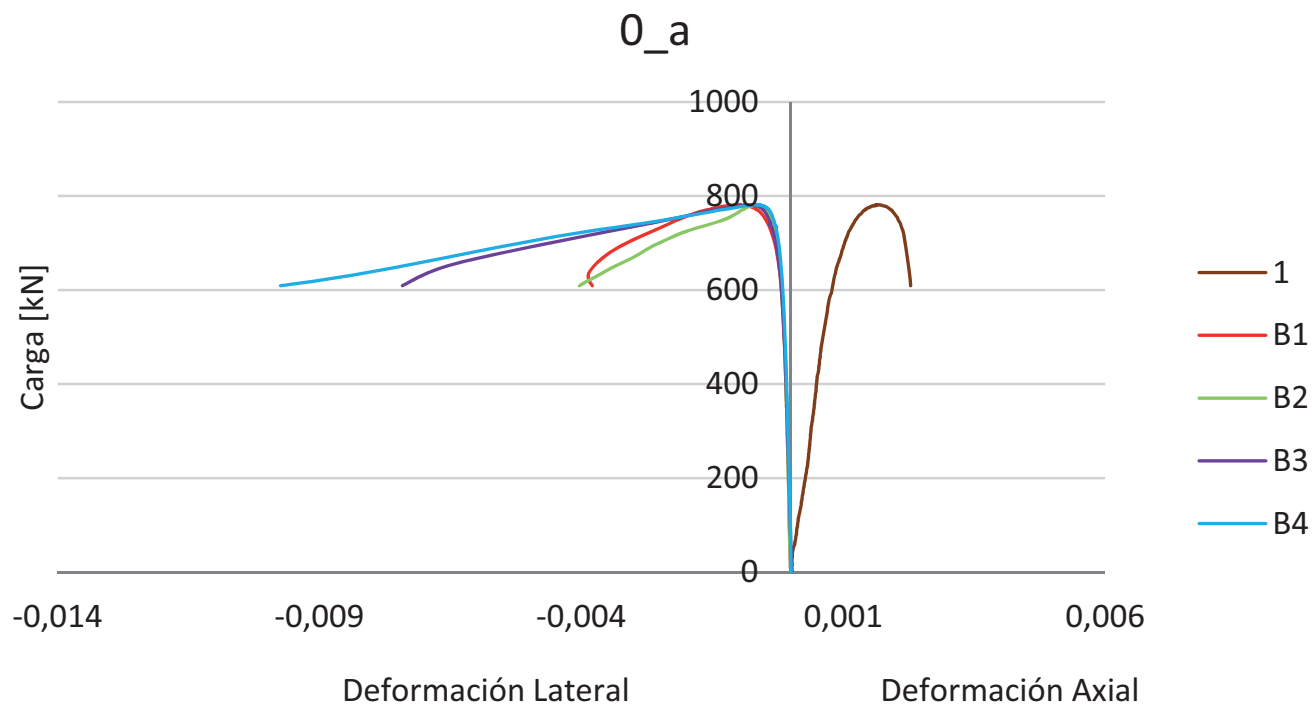

Figura A.66 Curvas carga-deformación en la probeta 0_a 
0_b

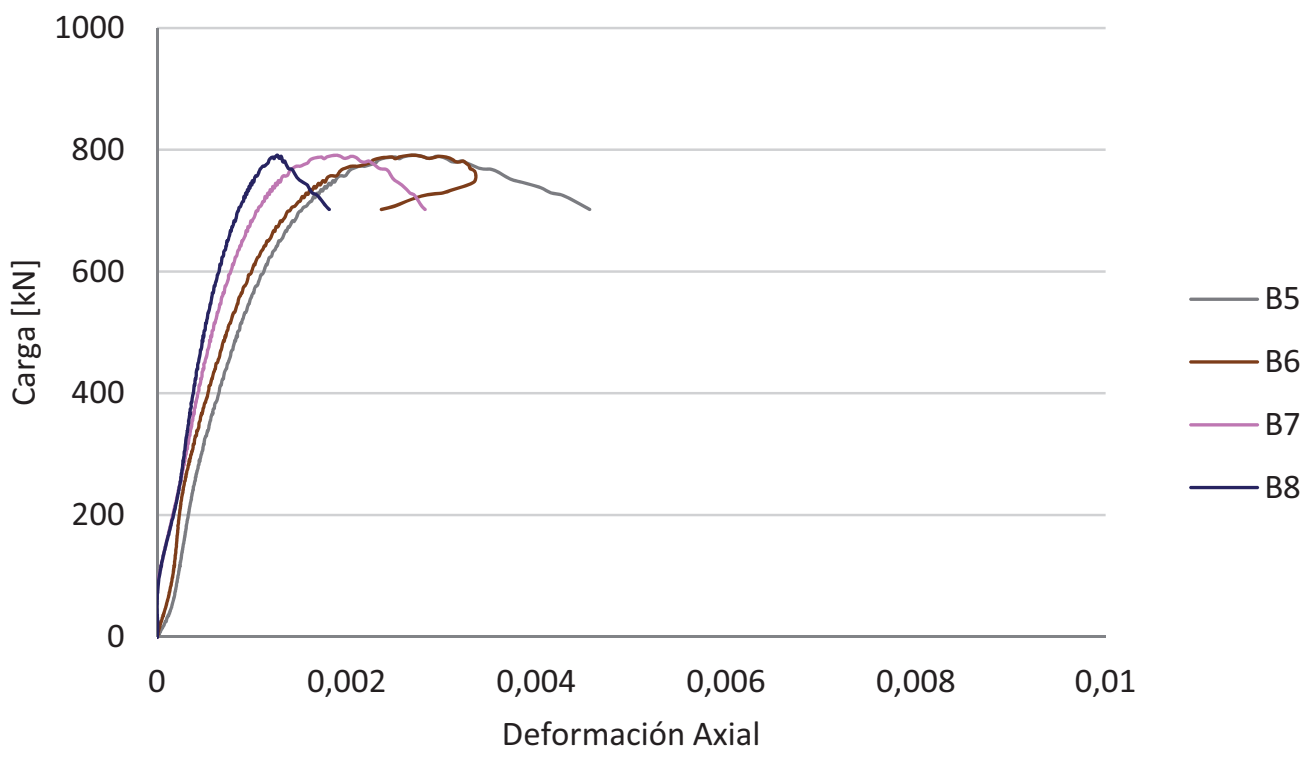

Figura A.67 Curvas carga-deformación axial en la probeta 0_b

0_b

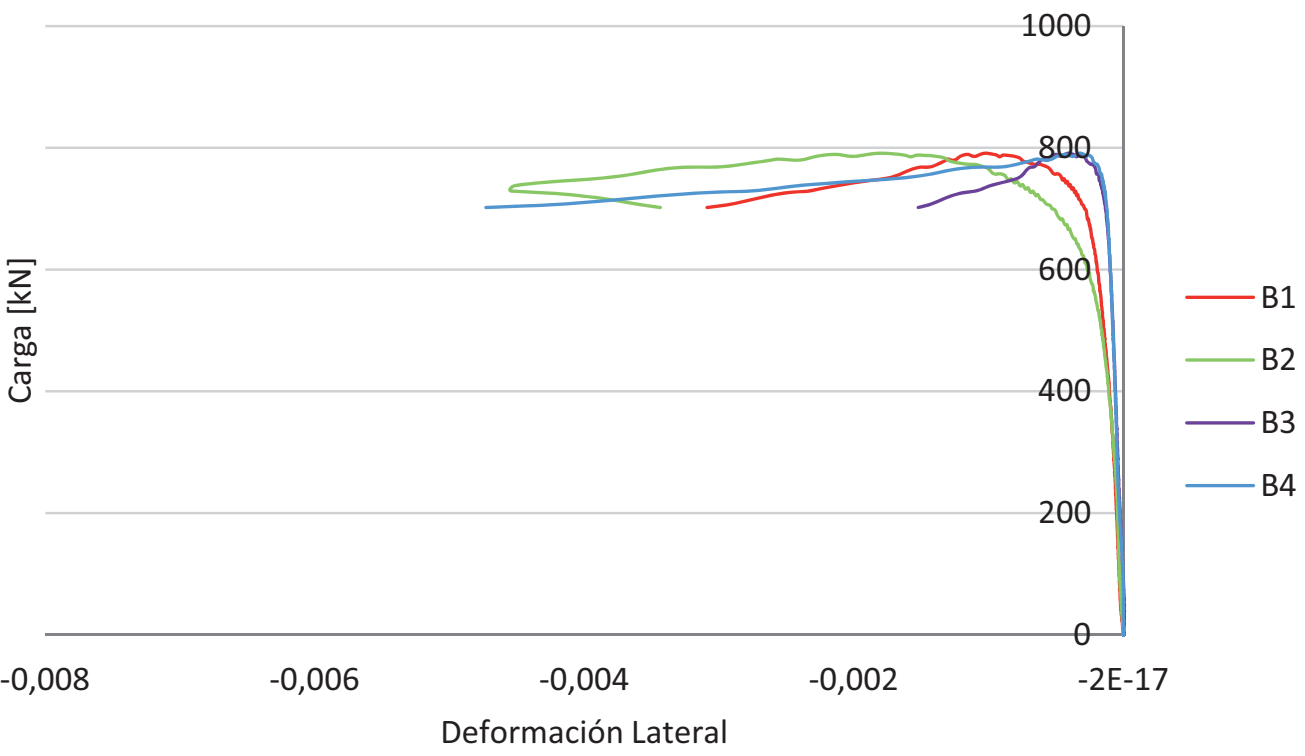

Figura A.68 Curvas carga-deformación lateral en la probeta 0_b 


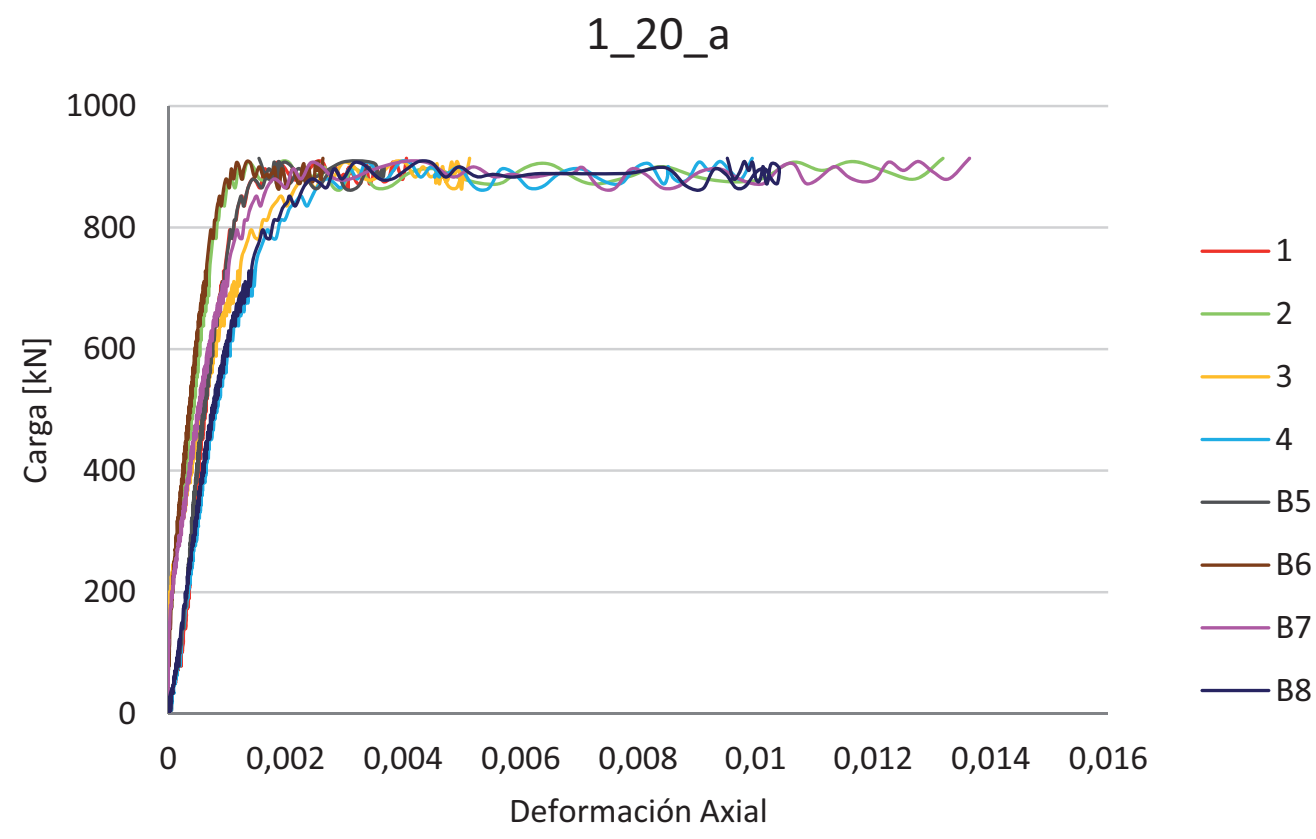

Figura A.69 Curvas carga-deformación axial en la probeta 1_20_a

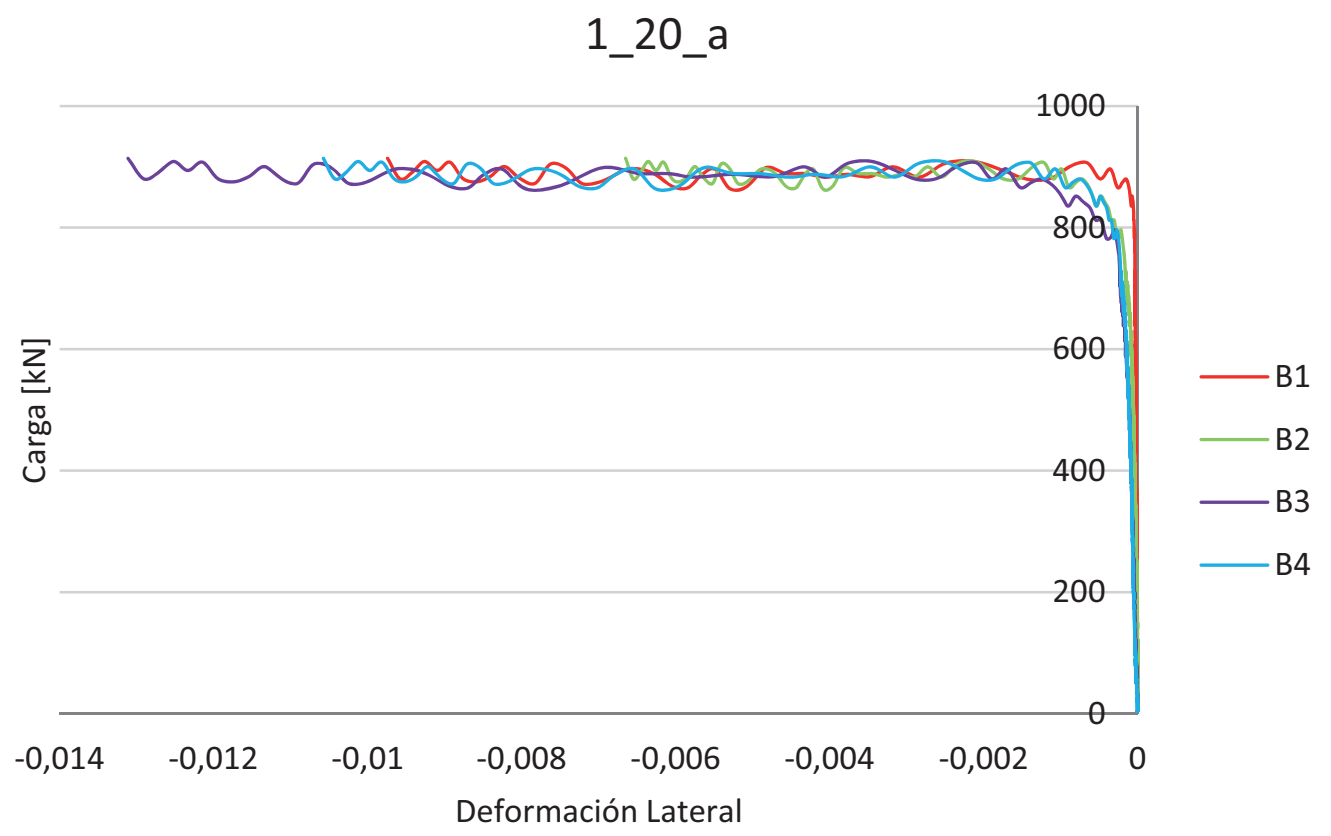

Figura A.70 Curvas carga-deformación lateral en la probeta 1_20_a 


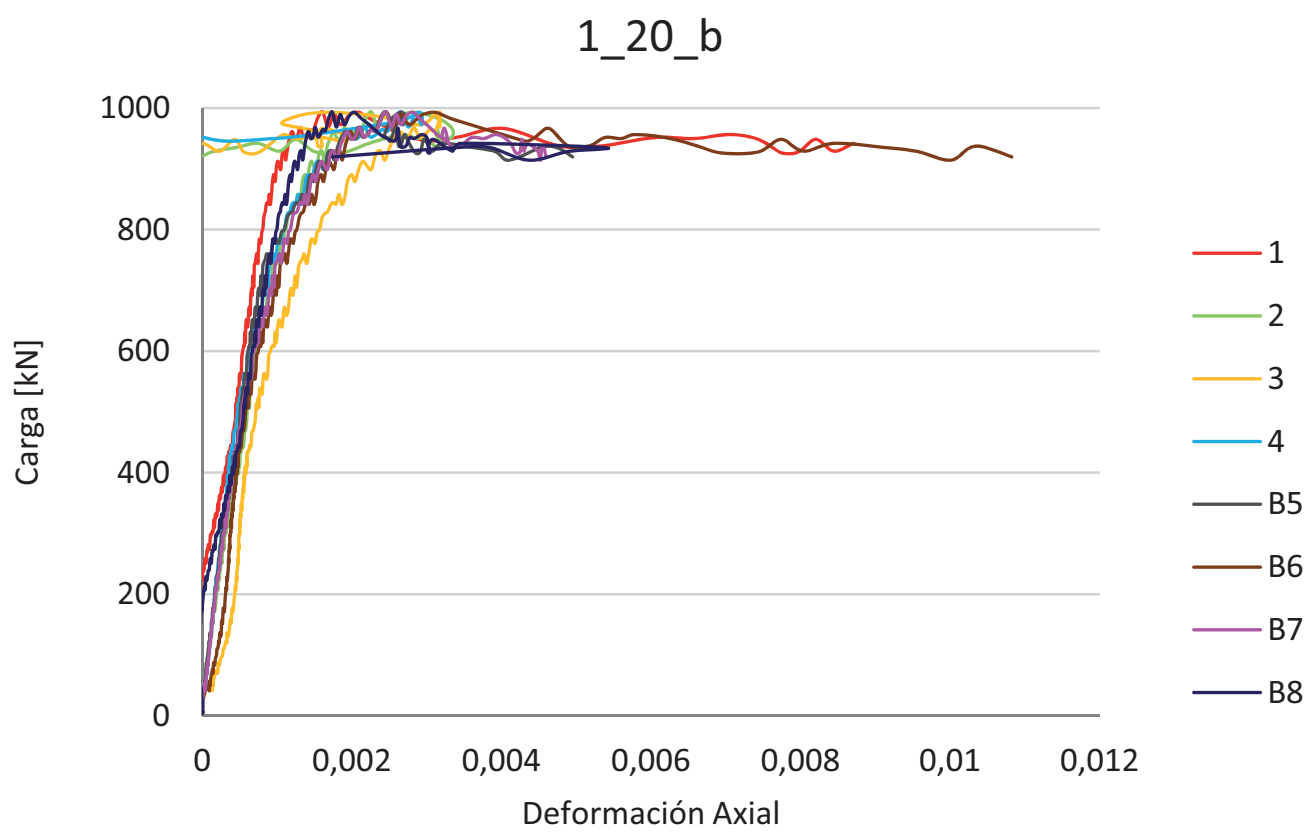

Figura A.71 Curvas carga-deformación axial en la probeta 1_20_b

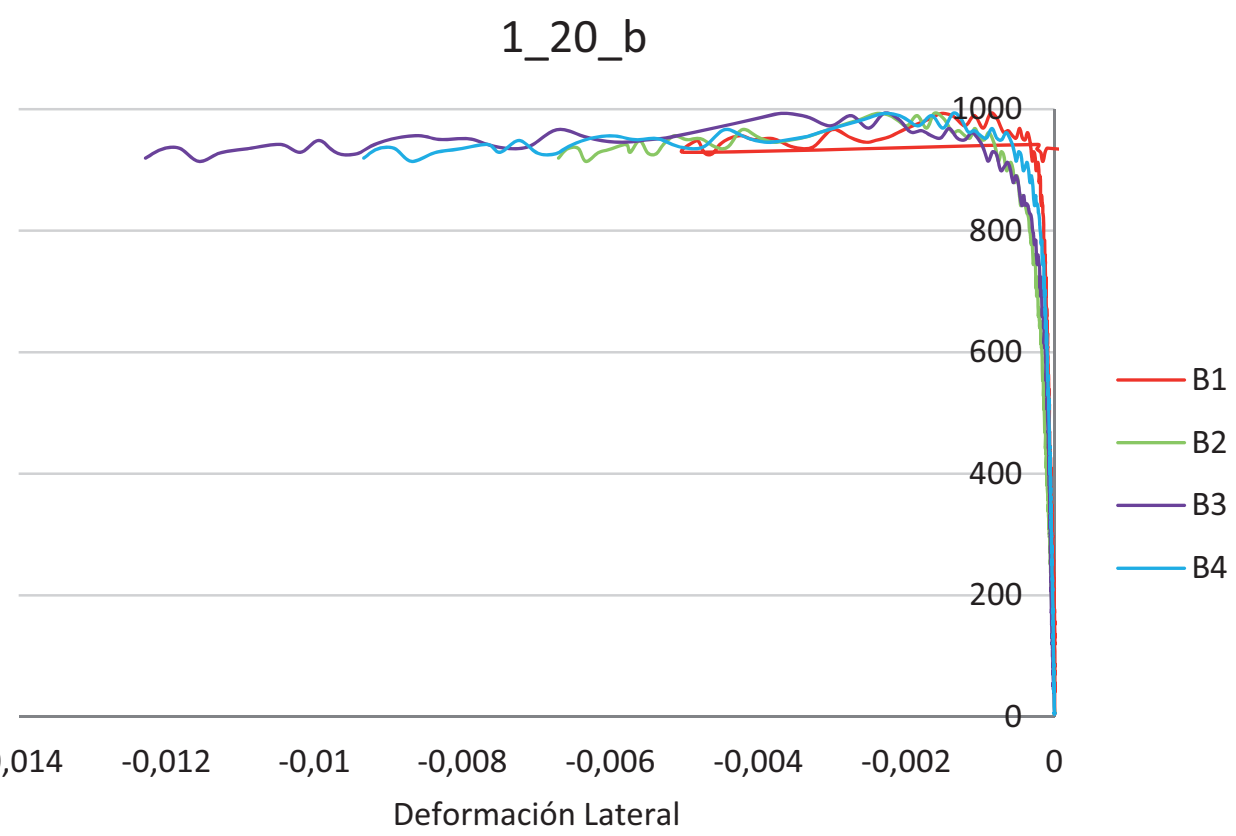

Figura A.72 Curvas carga-deformación lateral en la probeta 1_20_b 


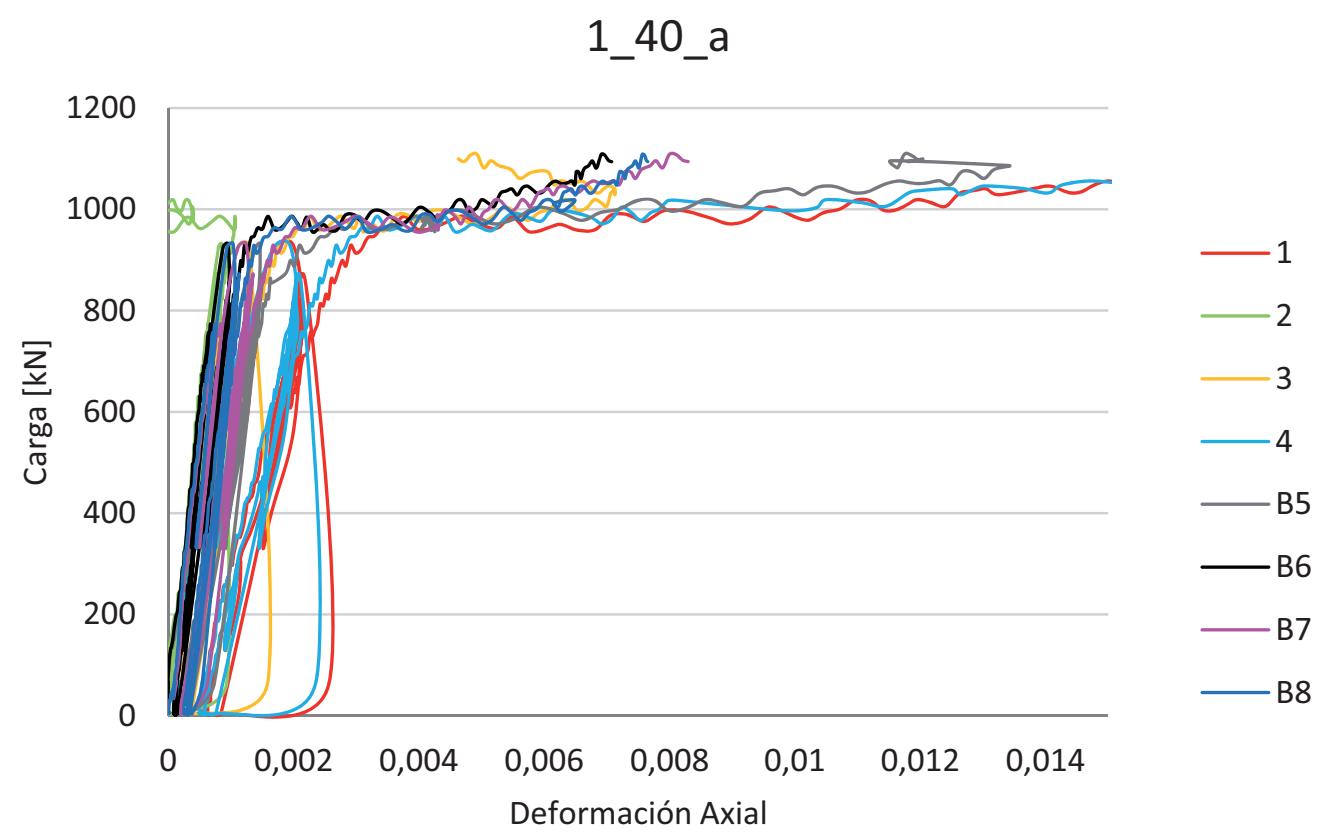

Figura A.73 Curvas carga-deformación axial en la probeta 1_40_a

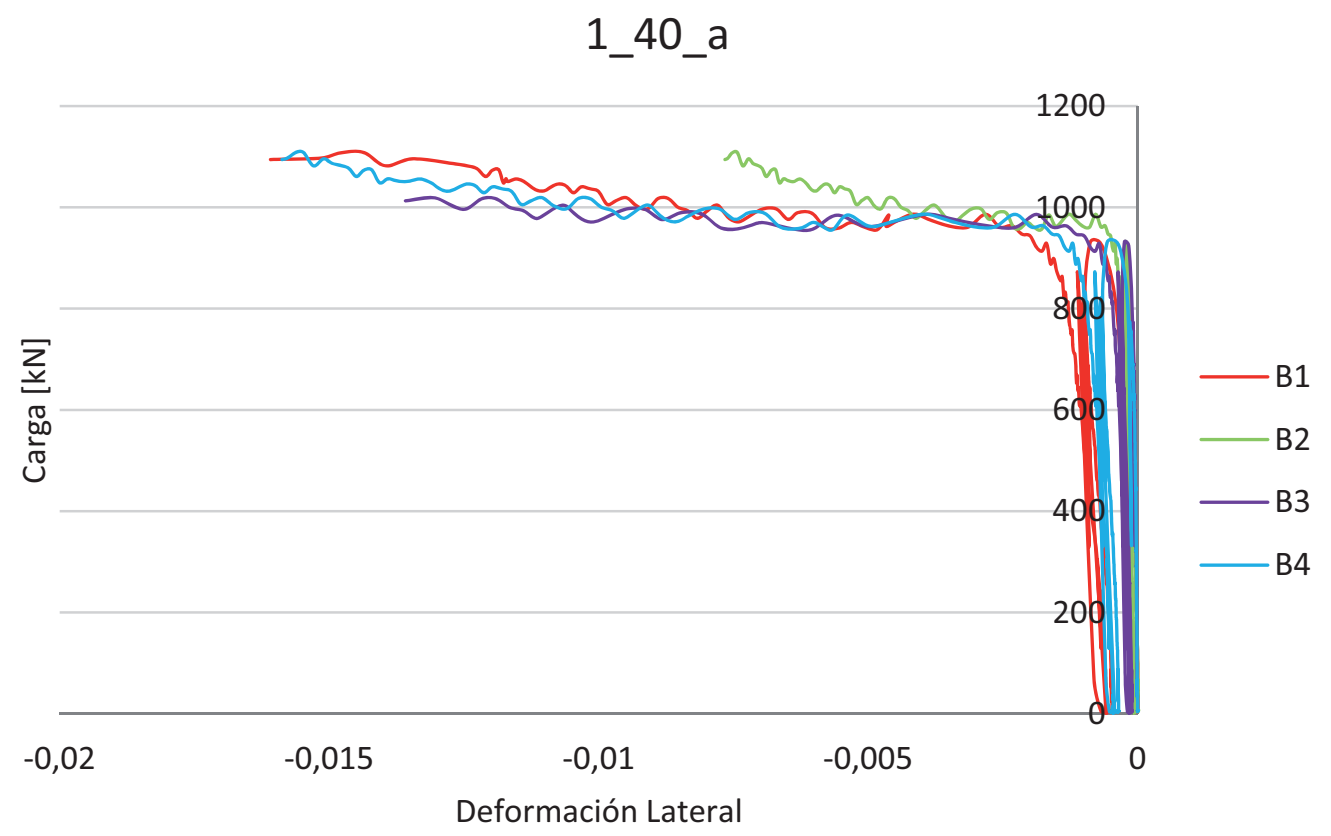

Figura A.74 Curvas carga-deformación lateral en la probeta 1_40_a 
$1 \_40 \_b$

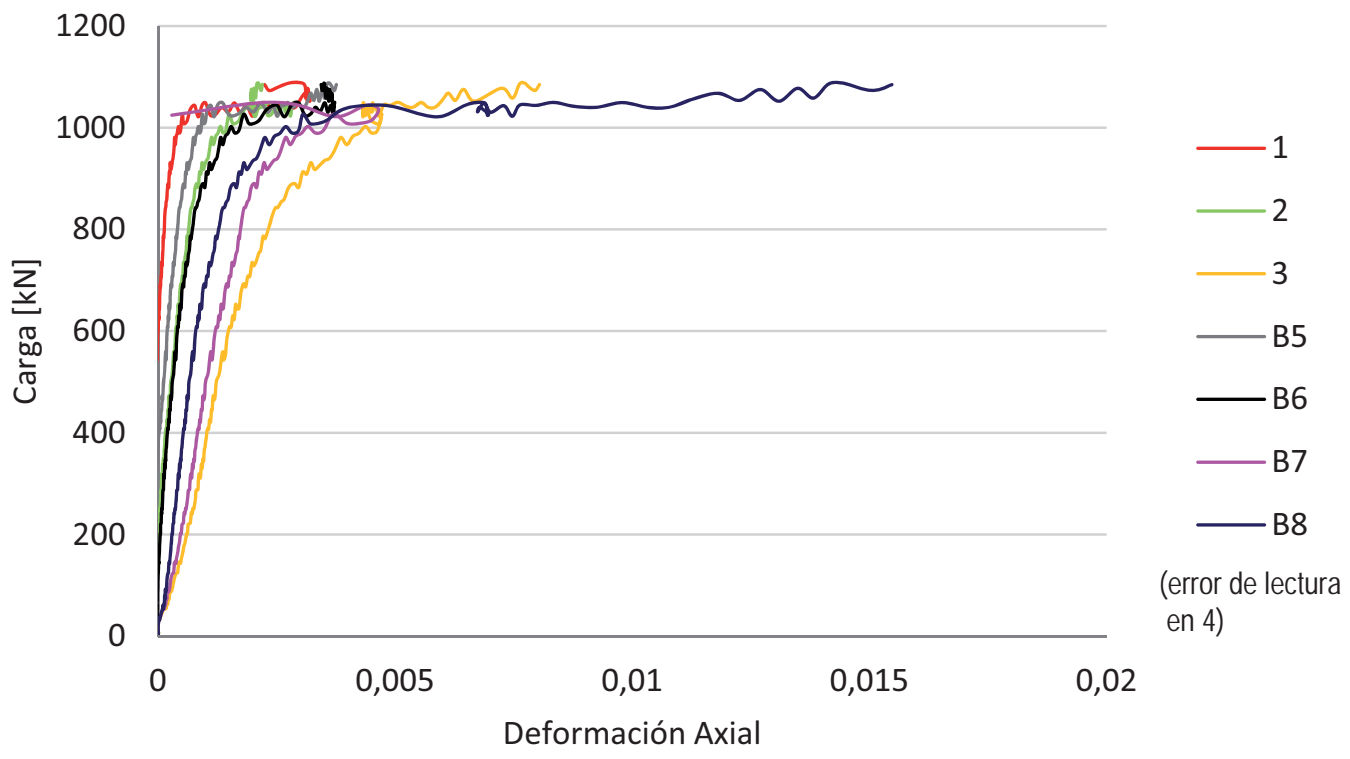

Figura A.75 Curvas carga-deformación axial en la probeta 1_40_b

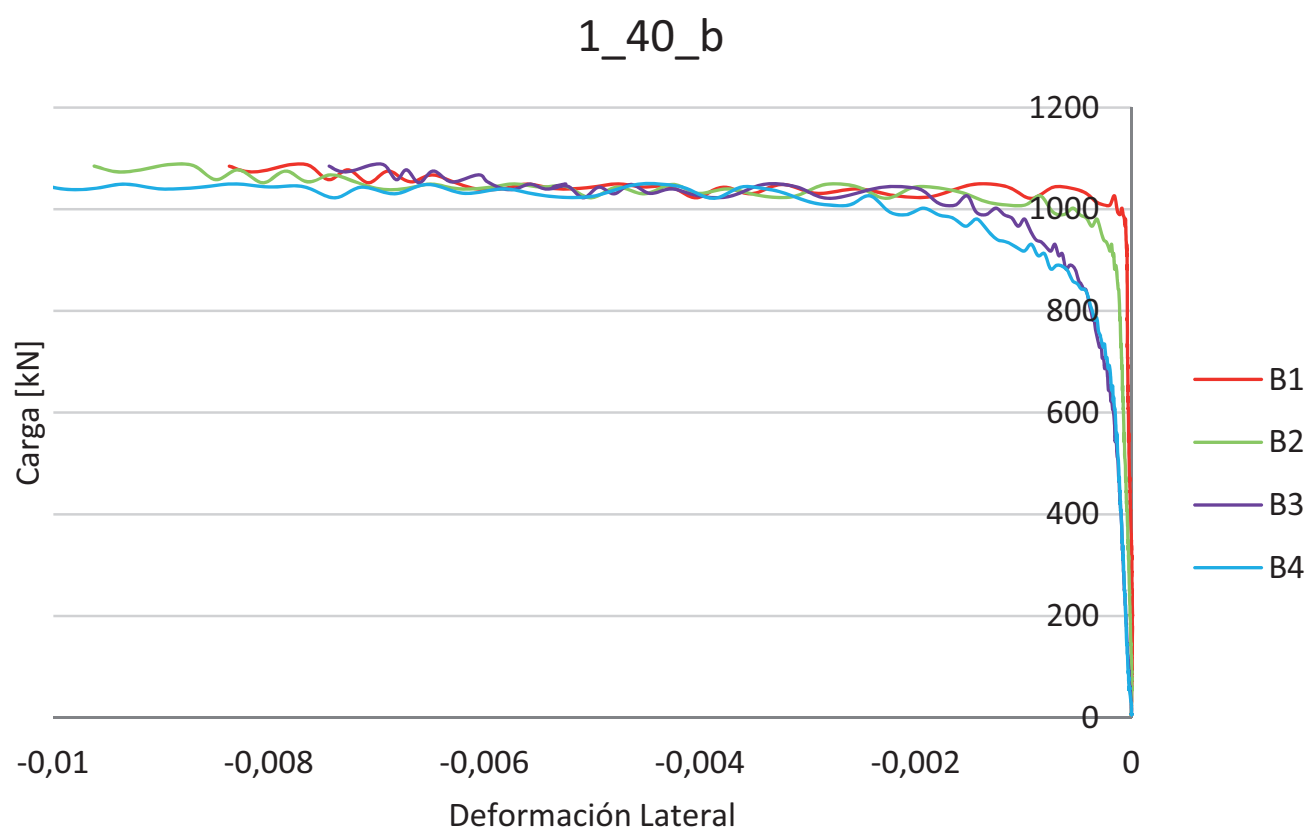

Figura A.76 Curvas carga-deformación lateral en la probeta 1_40_b 


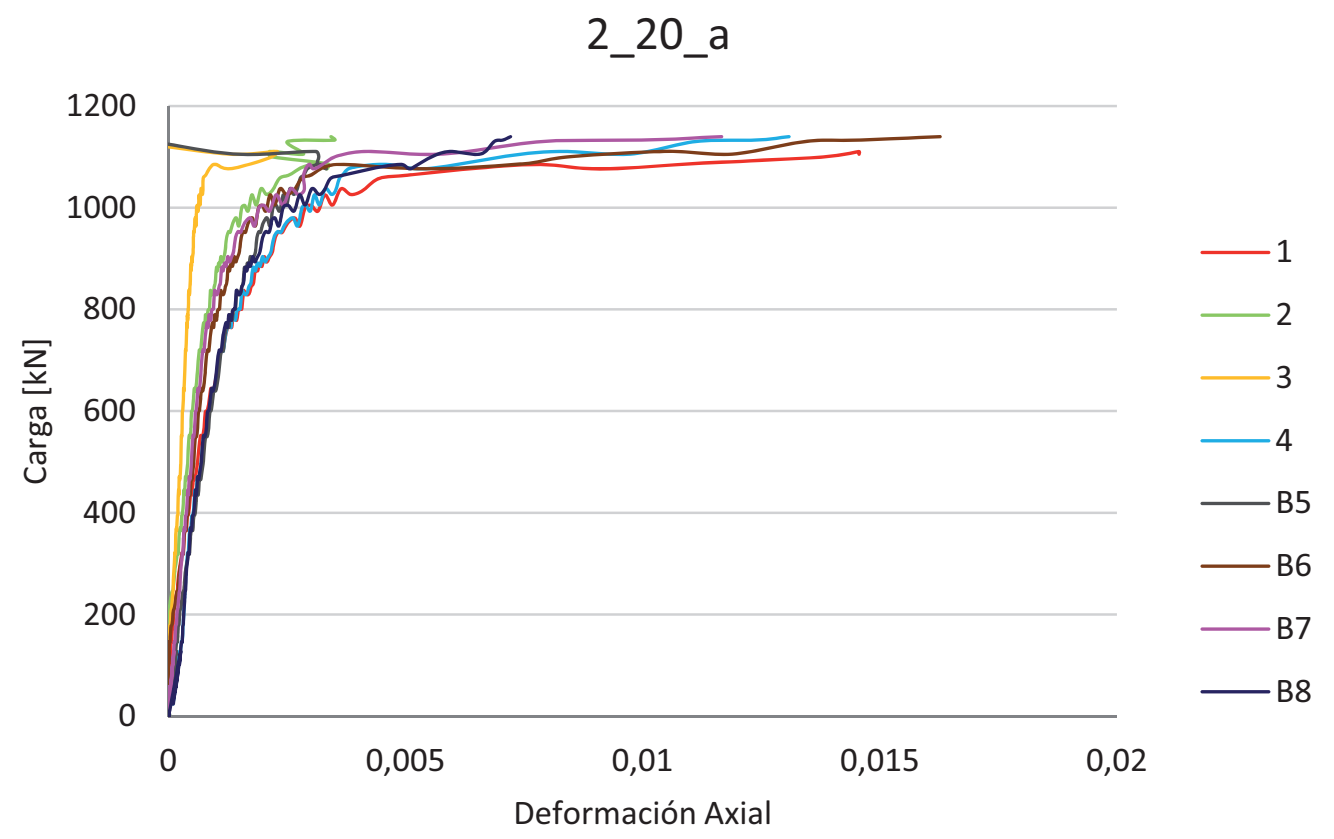

Figura A.77 Curvas carga-deformación axial en la probeta 2_20_a

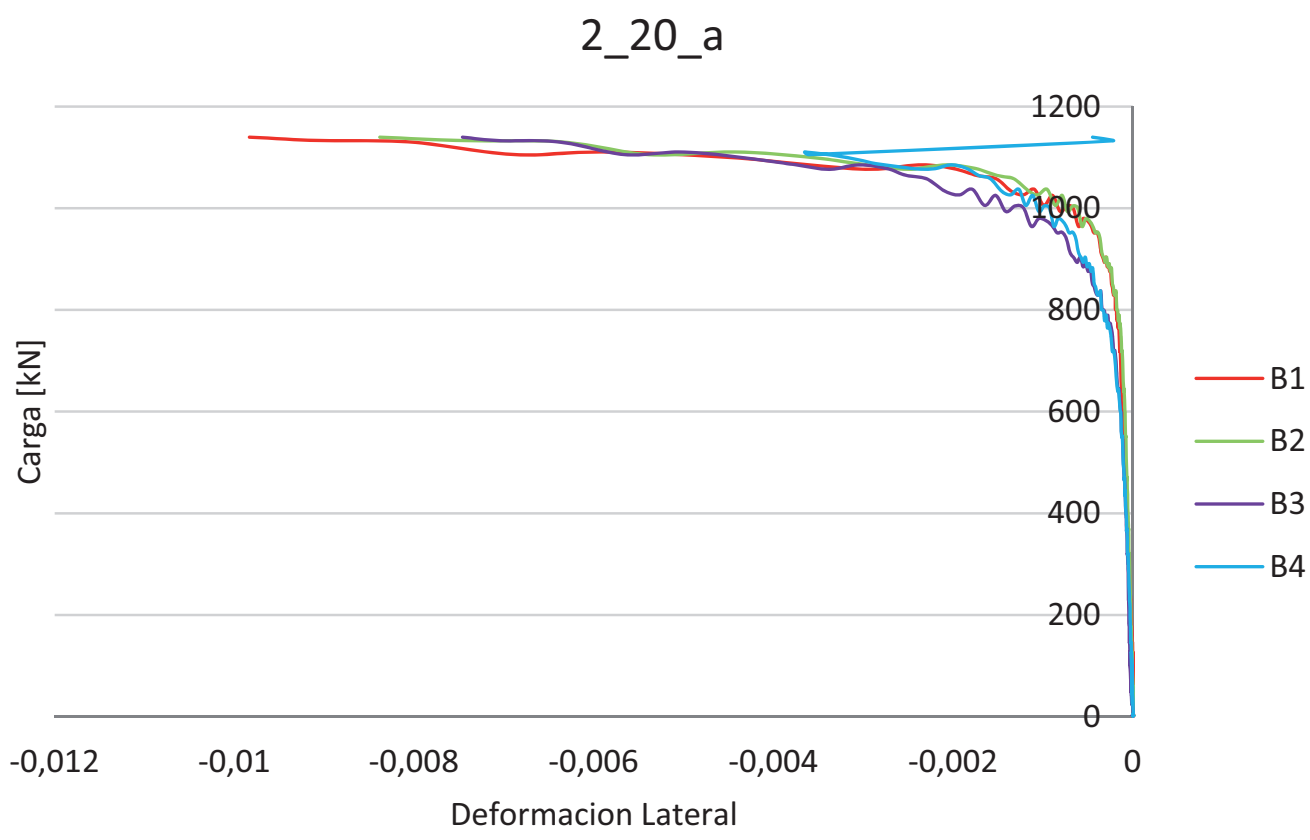

Figura A.78 Curvas carga-deformación lateral en la probeta 2_20_a 


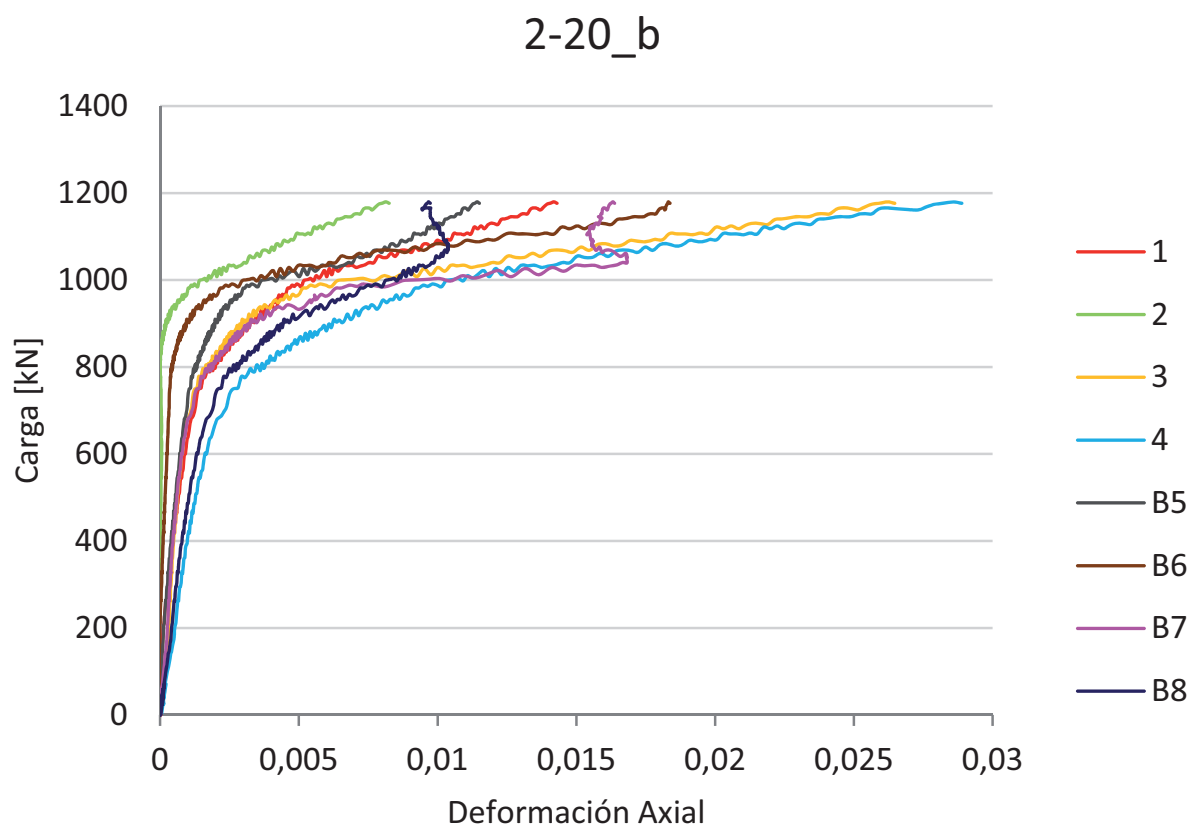

Figura A.79 Curvas carga-deformación axial en la probeta 2_20_b

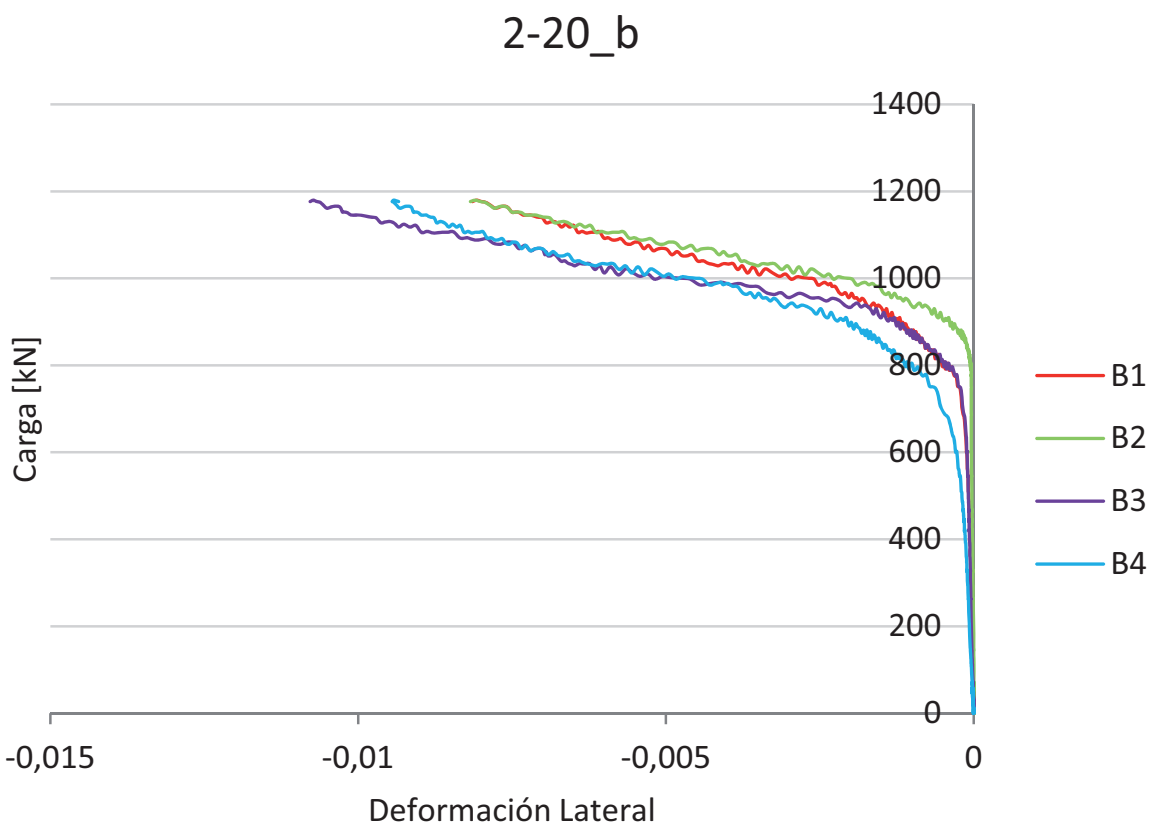

Figura A.80 Curvas carga-deformación lateral en la probeta 2_20_b 


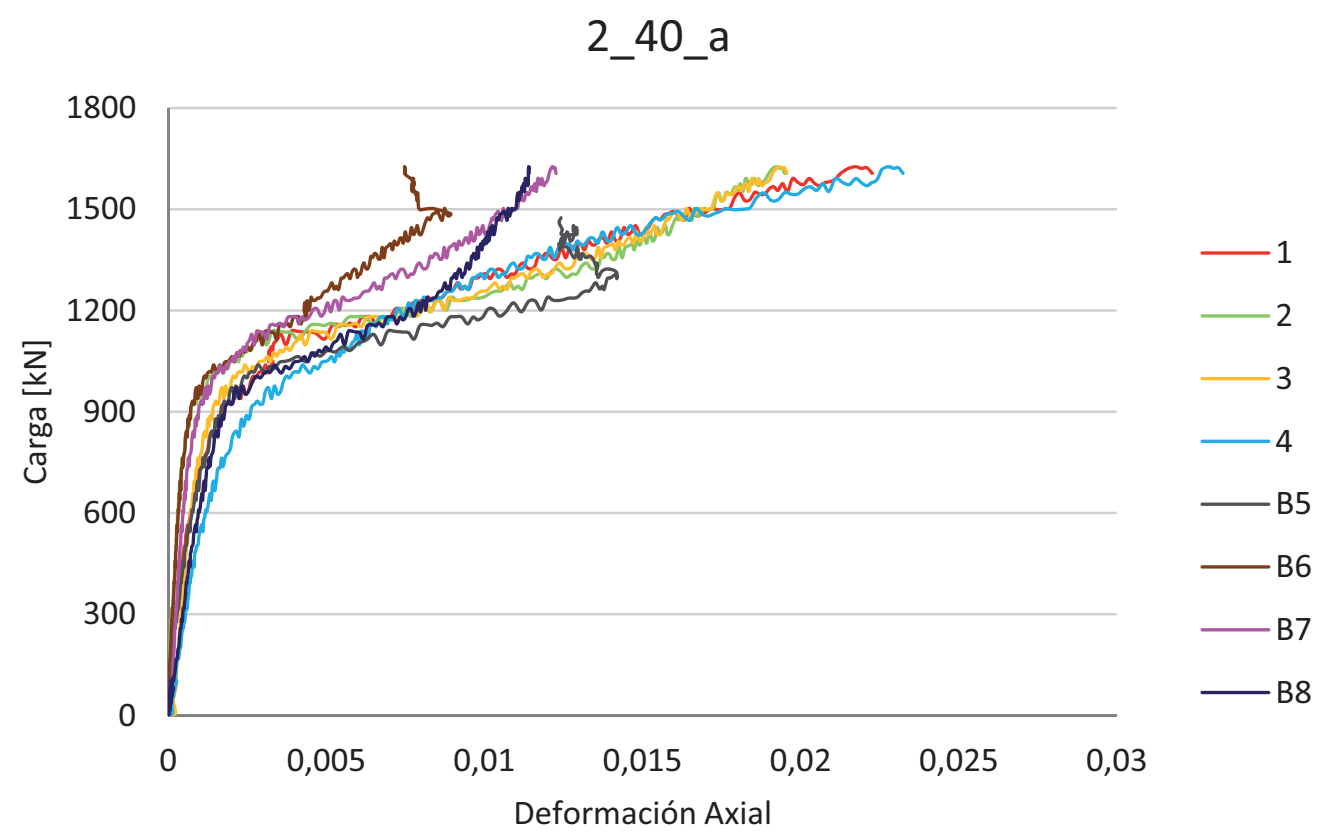

Figura A.81 Curvas carga-deformación axial en la probeta 2_40_a

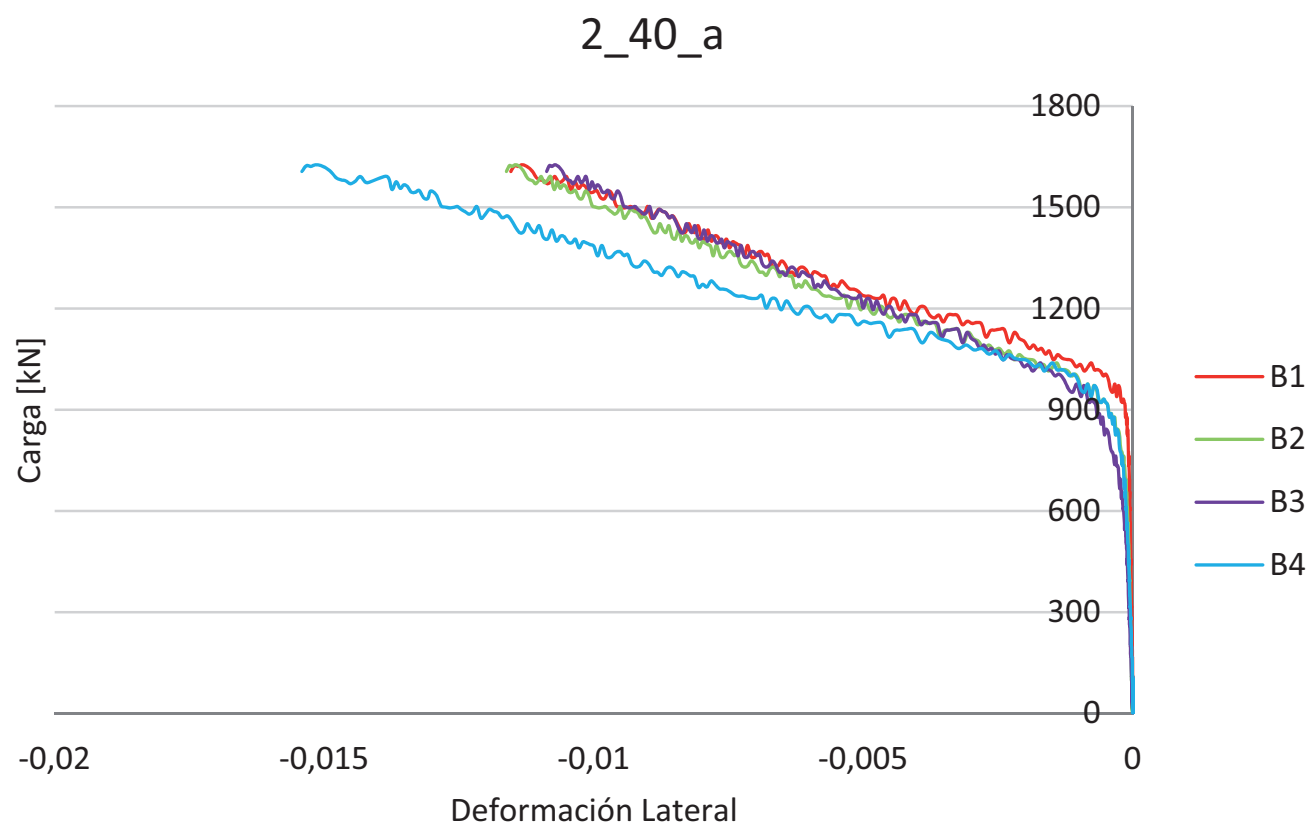

Figura A.82 Curvas carga-deformación lateral en la probeta 2_40_a 


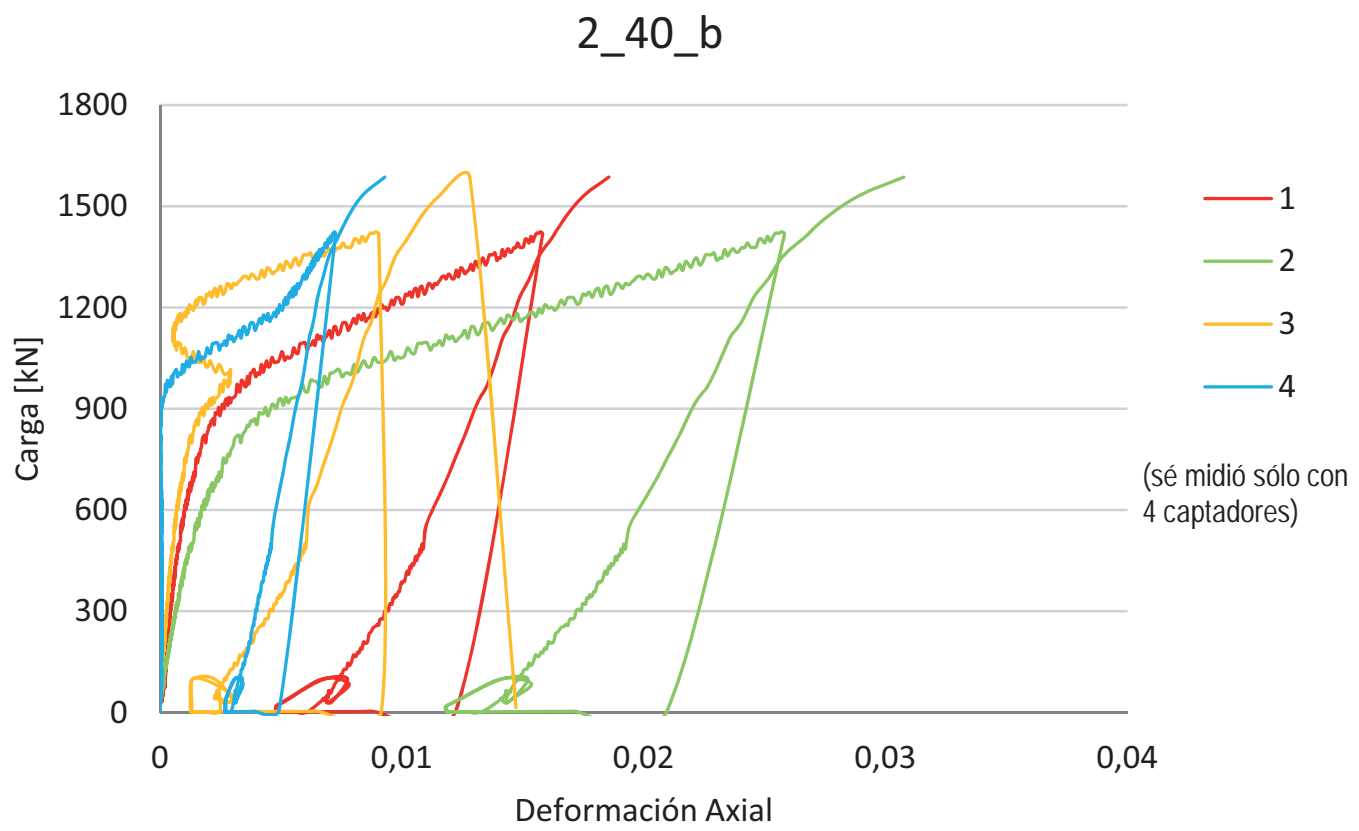

Figura A.83 Curvas carga-deformación axial en la probeta 2_40_b

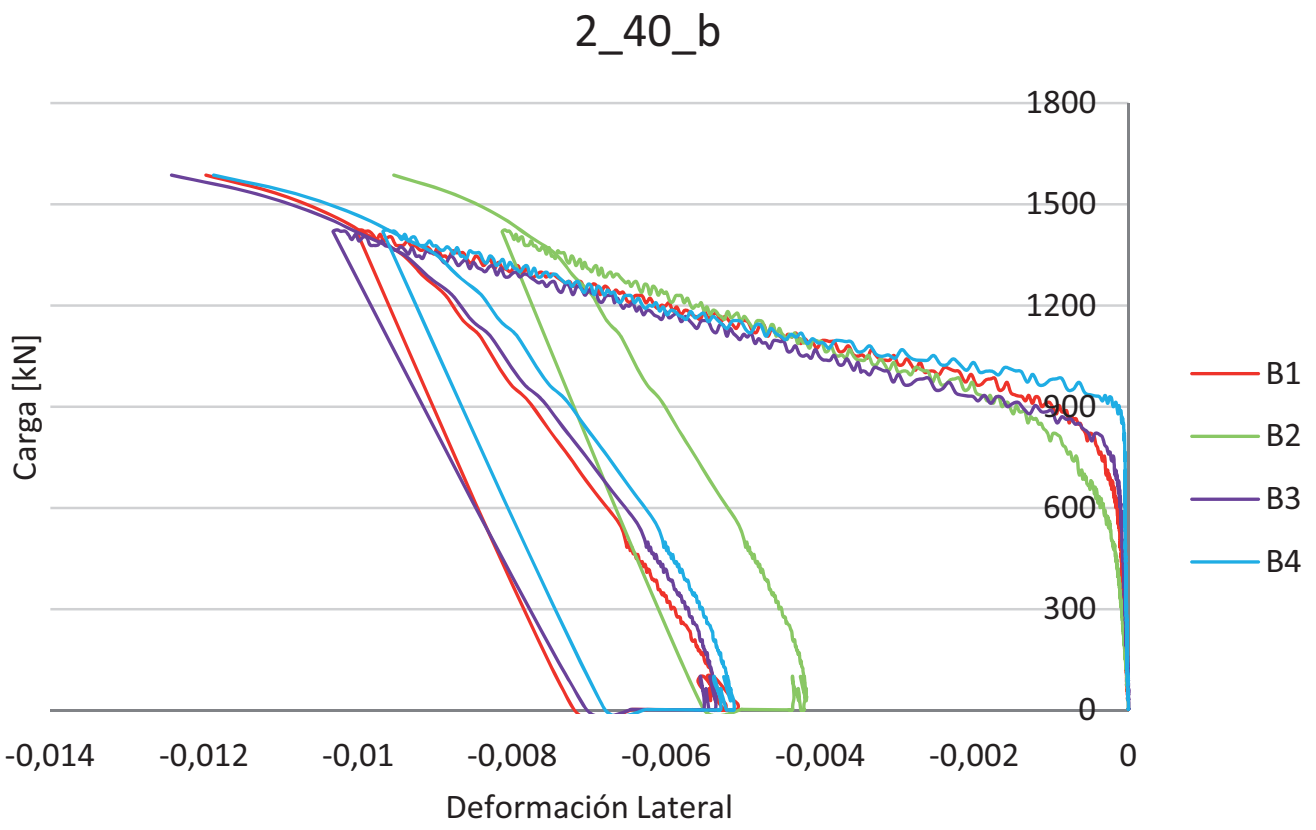

Figura A.84 Curvas carga-deformación lateral en la probeta 2_40_b 
3_20_a

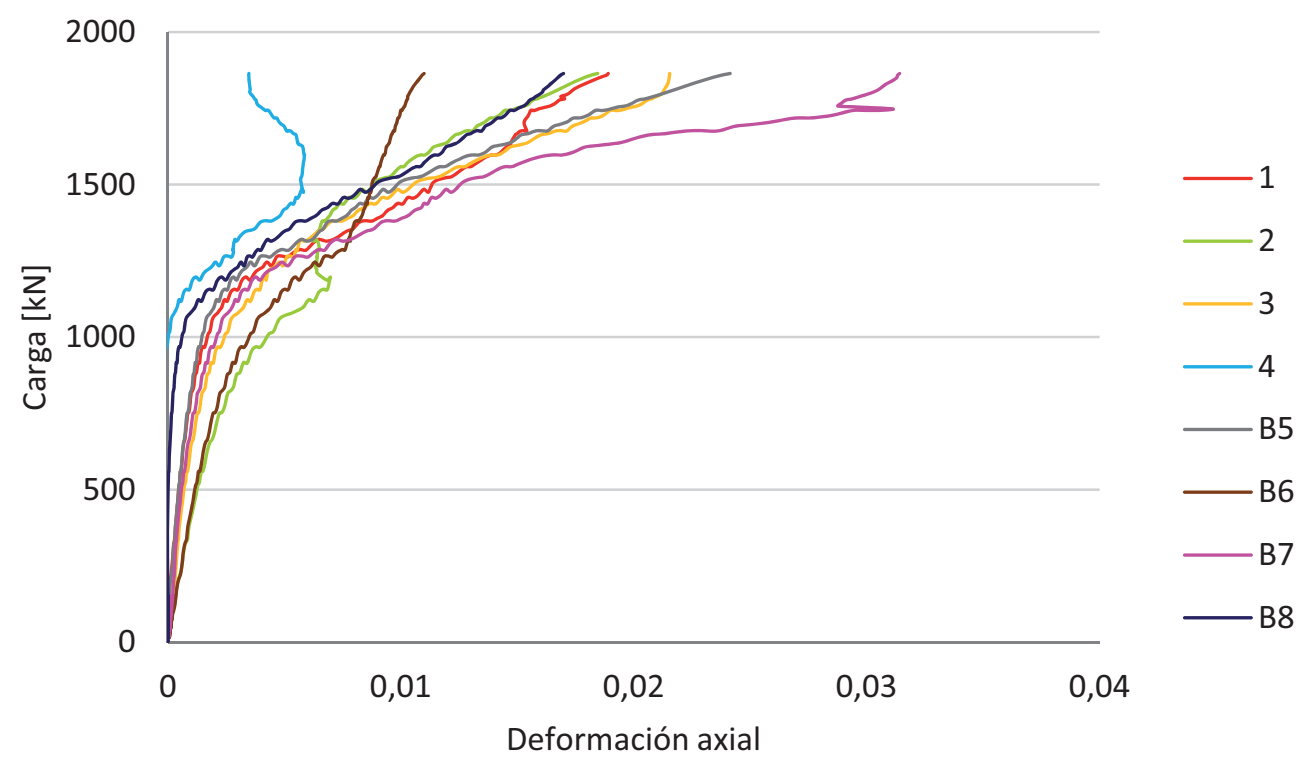

Figura A.85 Curvas carga-deformación axial en la probeta 3_20_a

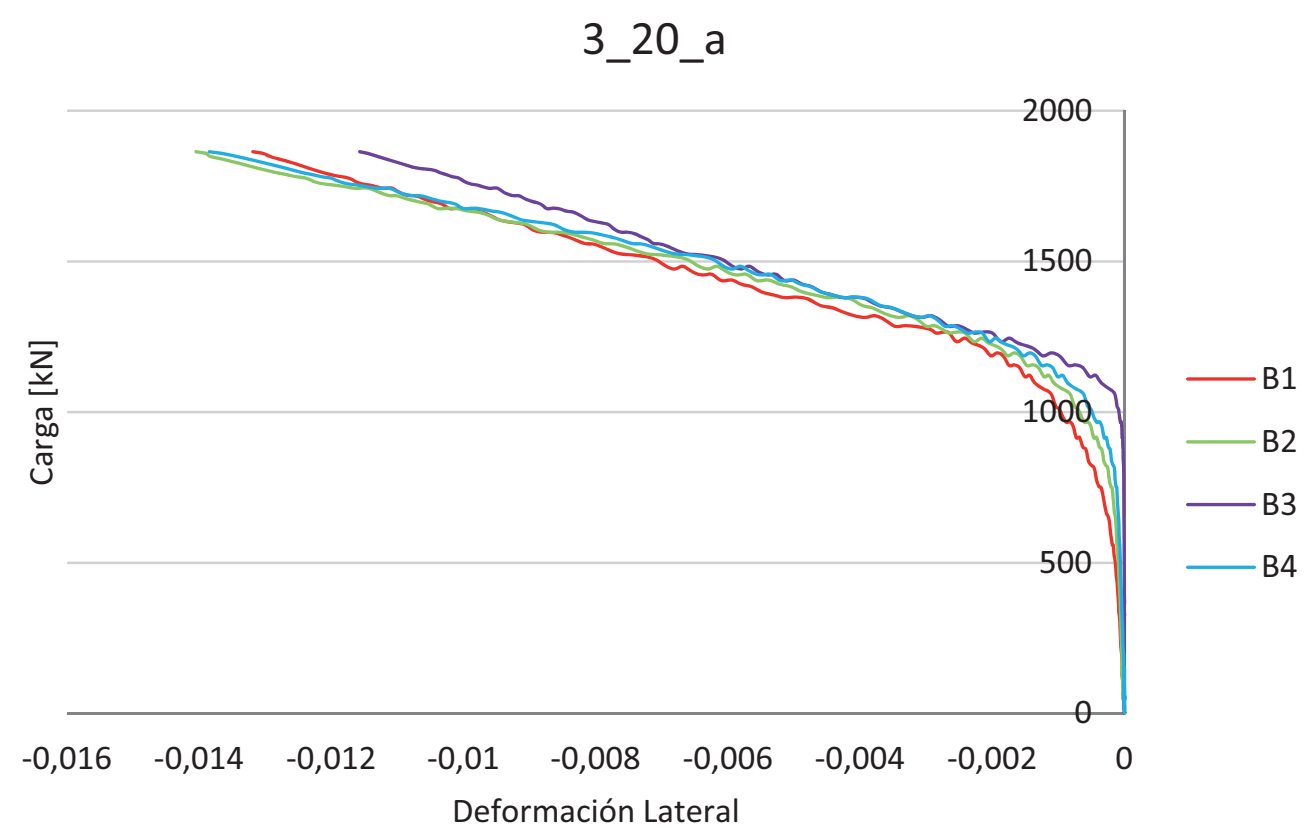

Figura A.86 Curvas carga-deformación lateral en la probeta 3_20_a 
3_20_b

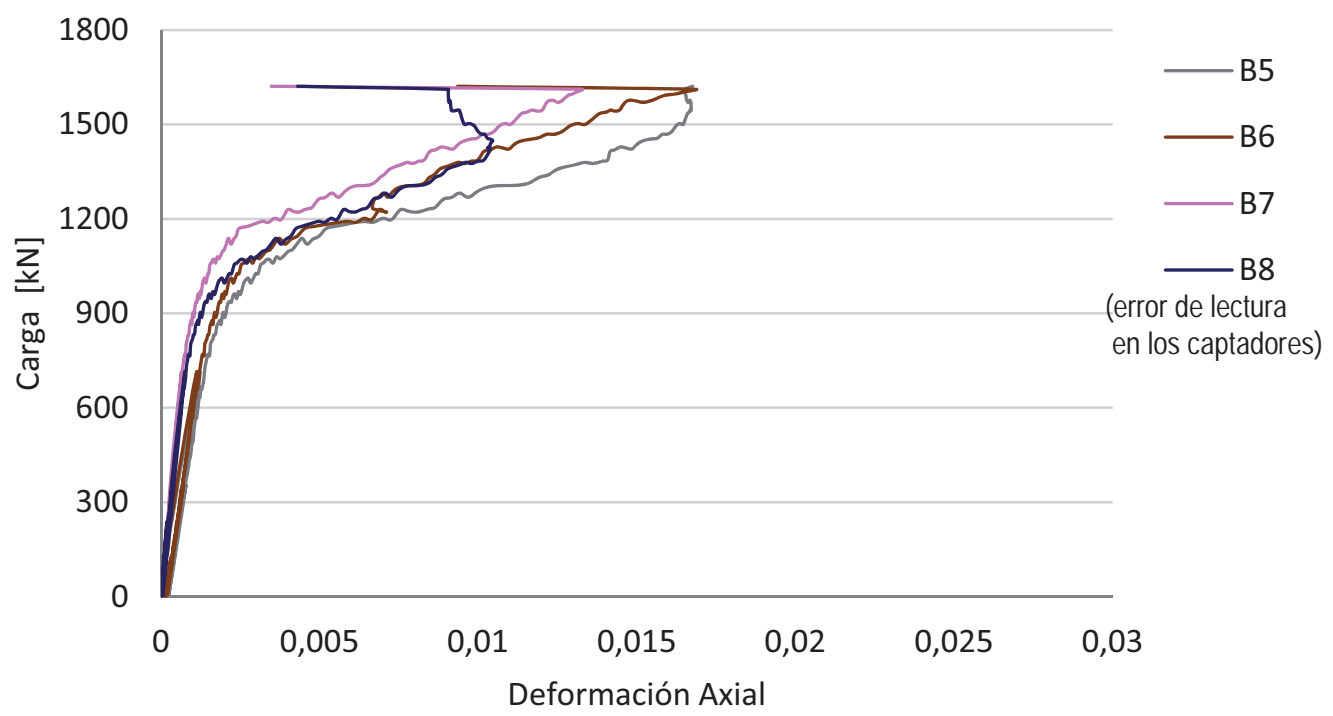

Figura A.87 Curvas carga-deformación axial en la probeta 3_20_b

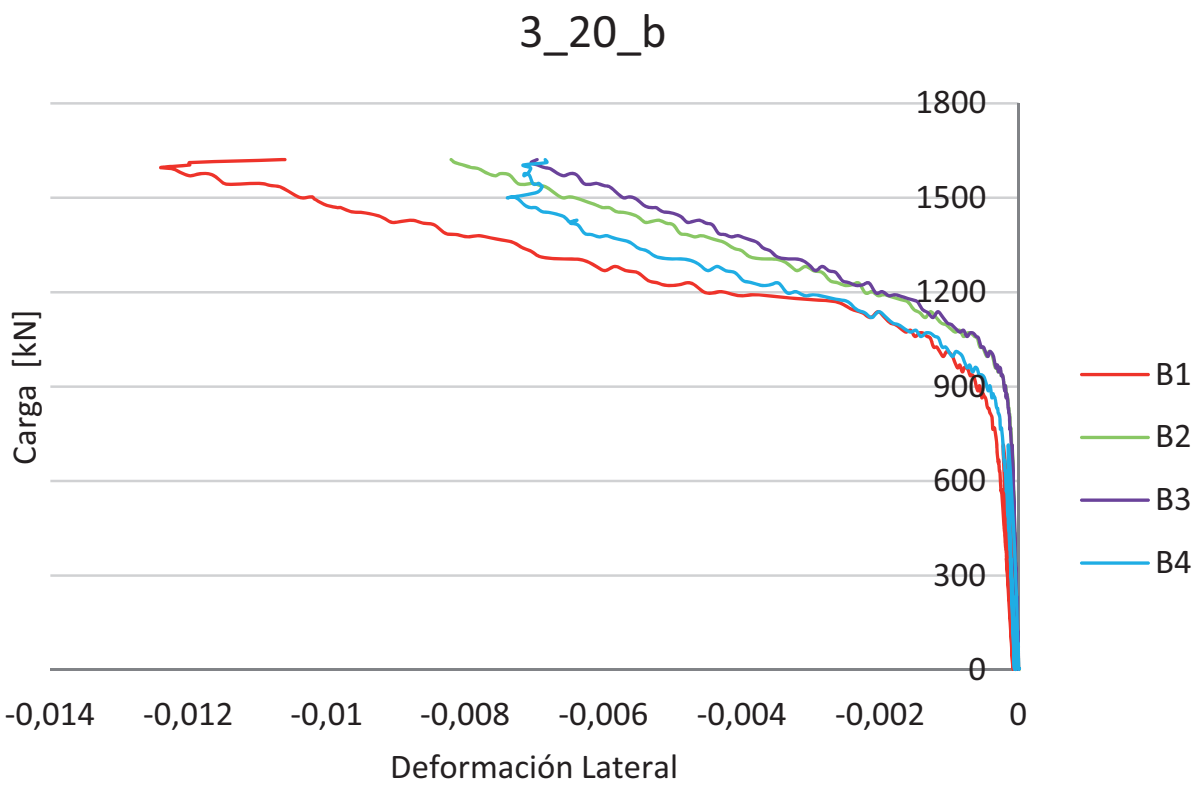

Figura A.88 Curvas carga-deformación lateral en la probeta 3_20_b 
3_40_a

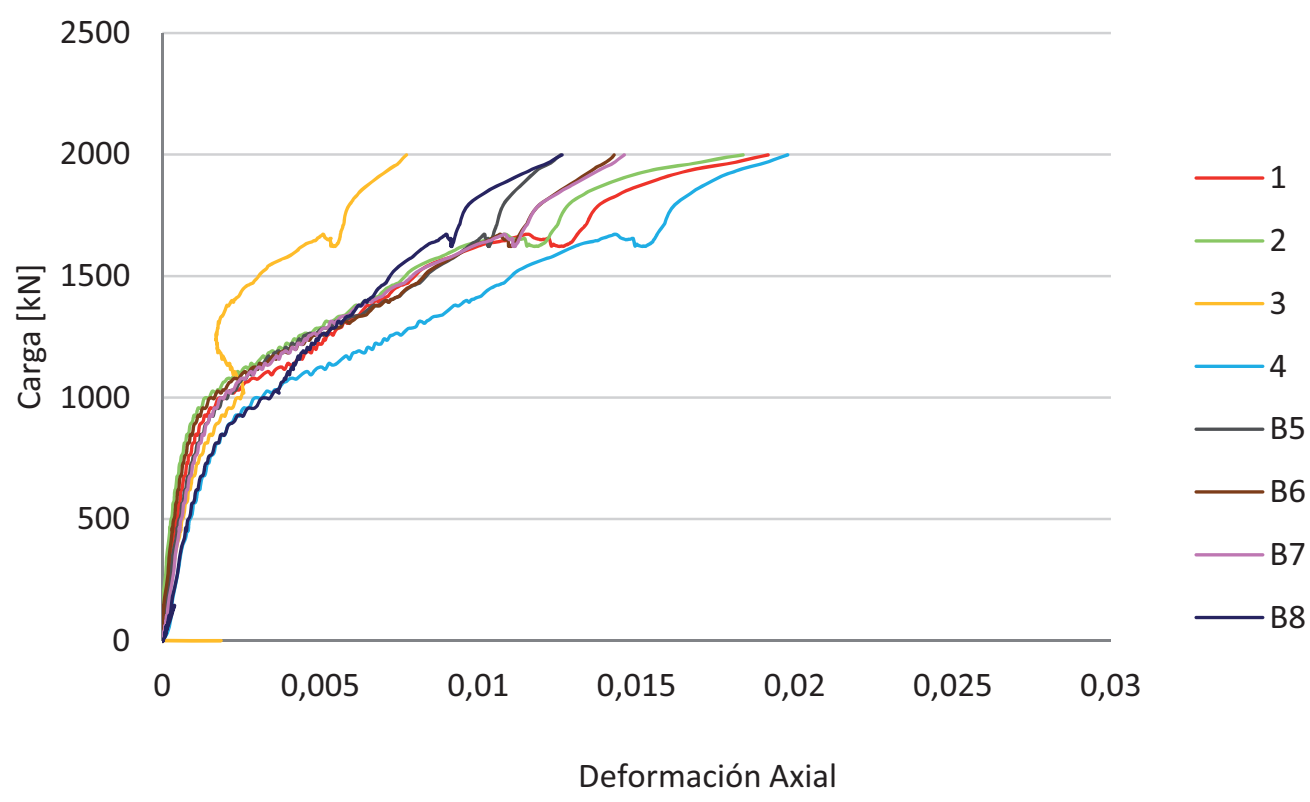

Figura A.89 Curvas carga-deformación axial en la probeta 3_40_a

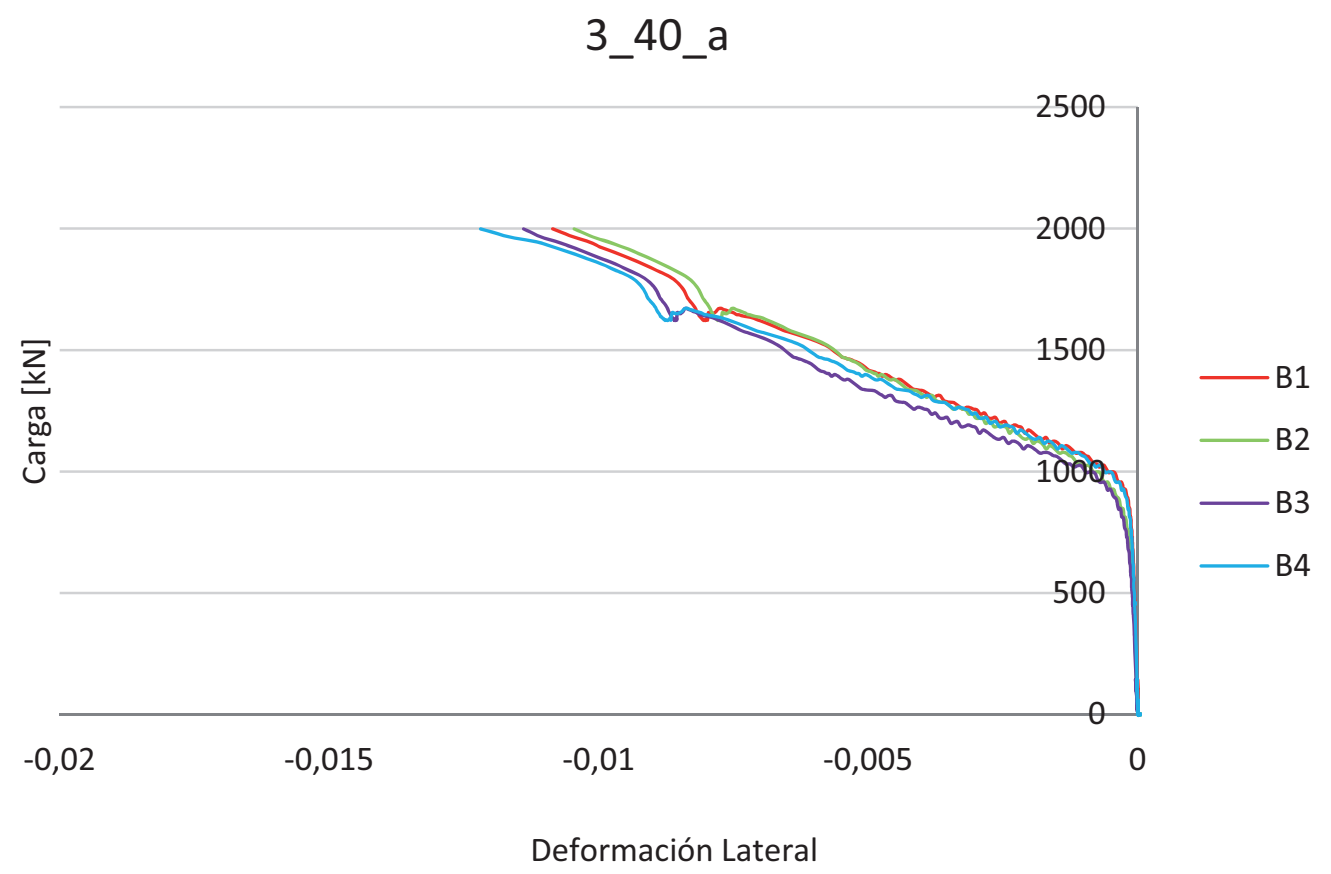

Figura A.90 Curvas carga-deformación lateral en la probeta 3_40_a 
3_40_b

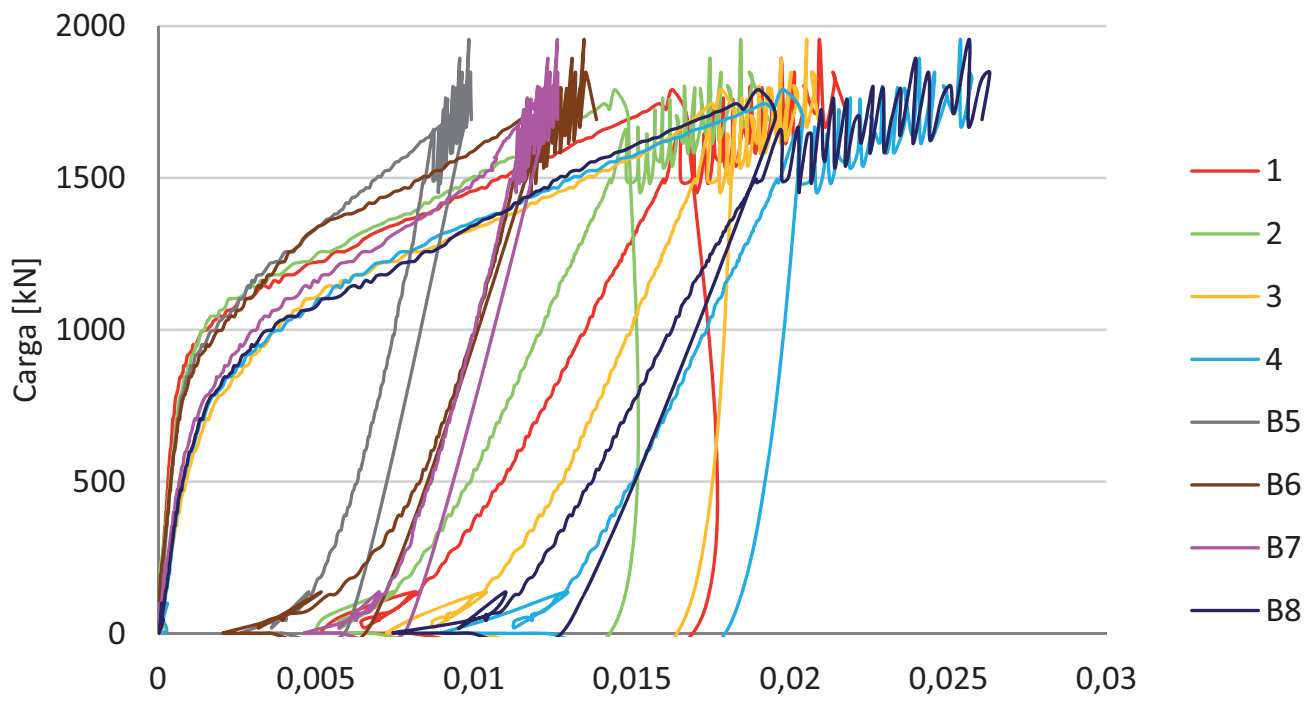

Deformación Axial

Figura A.91 Curvas carga-deformación axial en la probeta 3_40_b

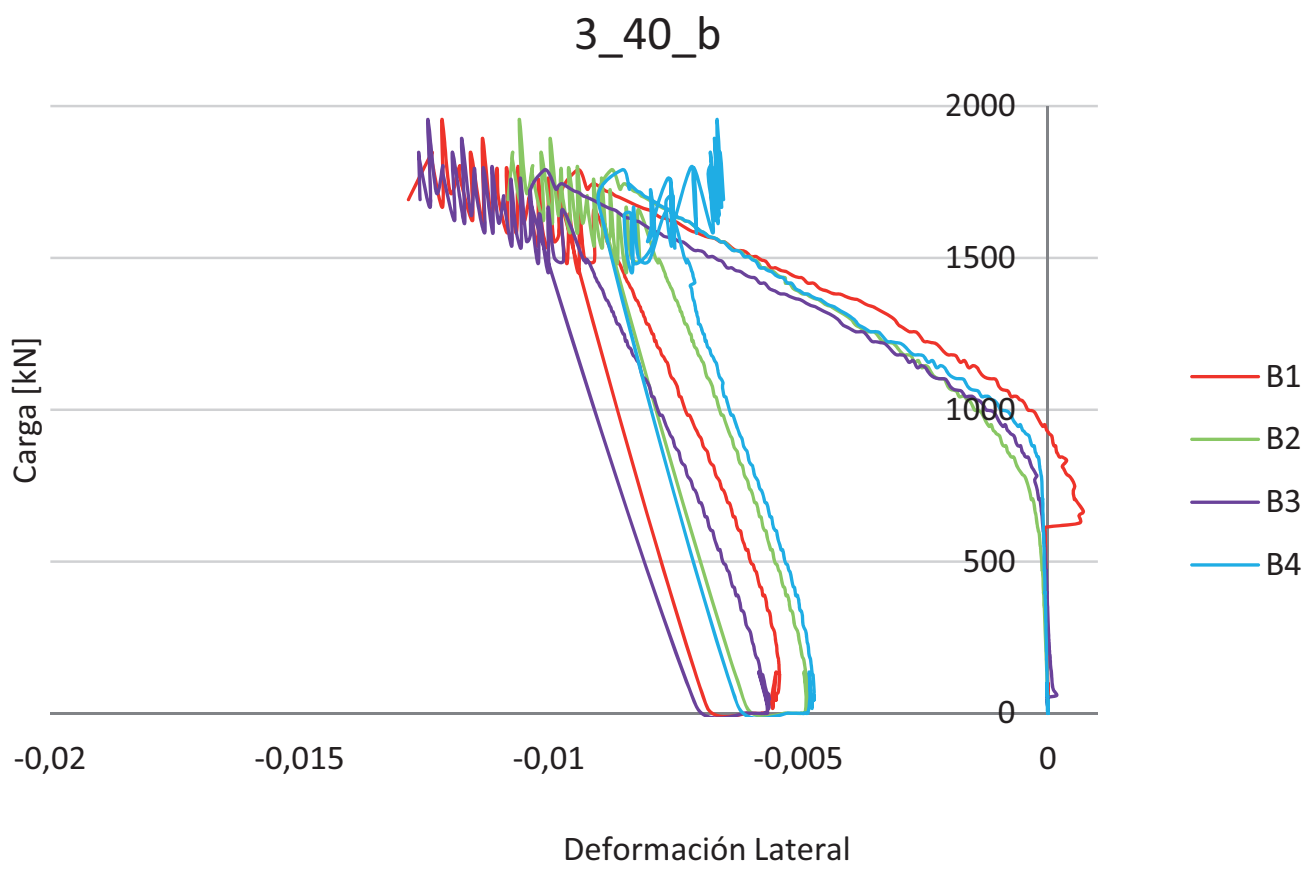

Figura A.92 Curvas carga-deformación lateral en la probeta 3_40_b 